\title{
THE MAORI POPULATION OF NEW ZEALAND
}

by

D.I. Pool

Thesis submitted for the Degree of Doctor of Philosophy at the Australian National University. 


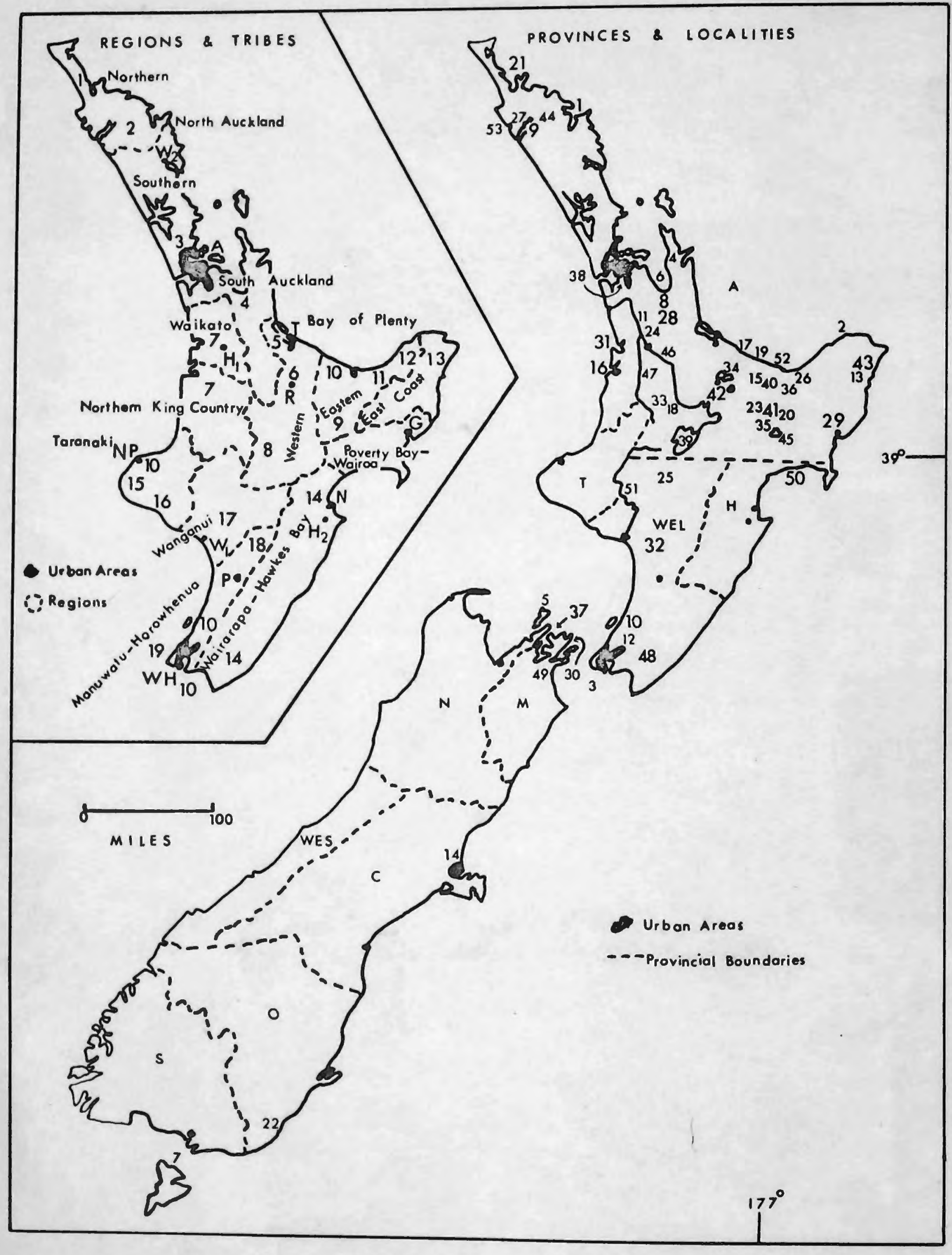

\section{NEW ZEALAND : LOCATION MAP}

TRIBES: 1.Rarawa;2.Ngapuhi; 3.Ngat1 Thatua;4.Ngati Maru;5.Ngaiterang1;6.Arawa;7.Ngat1 Maniapoto \& Waikato 8 . Ngati Tuwharetoa;9. Tuhoe or Urewera; 10. Ngatiawa; 11. Whaka tohea; 12 . Whanau-a-Apanui; 13. Ngati Porou; 14.Ngati Kahungunu; 15. Taranak1;16. Ngati Ruanui;17. Whanganui, but this name, used in nineteenth century censuses, is not strictly correct;18. Rang1 tane, Ngat1 Raukawa \& Muaupoko; 19. Ngati Toa. South Island: Ngaitahu, Ngatiawa \& others.

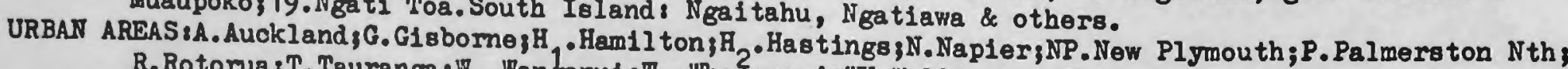
R. Rotorua; $T$. Tauranga; $\mathbb{N}_{1}$. Wanganui; $\mathbb{W}_{2}$. Whanga rei; $W_{H}$. Well ington-Hutt.

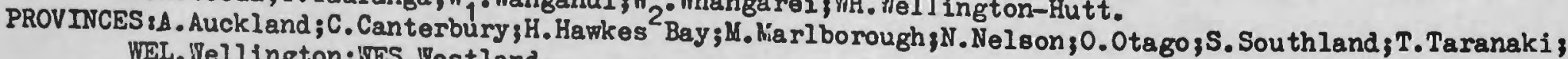
WEL. Nellington; IVES. Hifestland.

LOCALITIES:1. Bay of Is;2. Cape Runaway

7. Foveaux Strait;8. Hauraki Plains ; Cook Strait34.Coromandel Penin.35.D'Urville I.;6.Firth of Thames; 7. Foveaux Strait;8. Hauraki Plains;9.Hokianga Harb. Dist.;10. Horowhenua Dist.311.Huntly;12. Hutt Val.313.Jerusalem; 14. Ka iapoi; 15. Kaverau; 16. Kawhia Dist.; 17. Maketu; 18. Mangak 1no; 19. Ma ta ta; 25. Ohanea pohatu; 21. Nongonui (Mangonui alt. 8p.) ;22. Molyneux Bay ;23. Hurupa ra; 24. Ngaruawahia; Dist.; 32. Rangitikei Dist.; 33 Ra;28. Piako Dist.;29.Poverty Bay Dist.; 30.Q. Charlotte Sd.;31. Raglan Dist. 32. Rangitikei Dist. ; 33. Rangi toto Ra. 3 34. Rotorua Lakes; 35. Rua tahuna 36. Rua toki; 37. Sounds 42. Volcanic Plateaus 43. Taia 48. Hairarapa Dist. 349 . Wairau Plains 54 . Waihou; 45. Taikaremoana Lake;46. Waika to Riv. 47 . Wa1pa Riv.

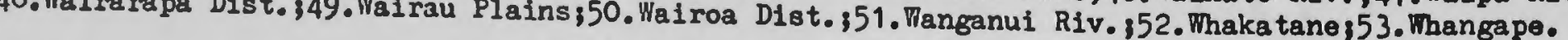


This thesis is my original work undertaken as a research scholar from 1961 to 1964 in the Demography Department, Institute of Advanced studies, Australian National University. 


\section{PREFACE}

Style

In this thesis, footnoting procedure is an adaptation of that used in the Journal of the Polynesian Soclety. The first reference to a book will be footnoted as follows: vol. 1, p.214. Thomson, A.S. (1859): The Story of N.Z, London. 2 vols. And, to a journal article: pp.22-23. Jacoby, E.G. (1958): 'A Fertility Analysis of N.Z. Marriage Cohorts', Pop. Stud, vol. XII, no.1, July. pp.18-39. But, in both cases, subsequent references to the same works will take the form: Thomson (1859): vol. II, pp.290-91; and, Jacoby (1958): p.21. This procedure will be resumed afresh at the beginning of each new chapter, while the full reference will be given in the bibliography.

In the footnotes a number of abbreviations is used:

A.J.H.R. : Appendices to the Journals of the House of Representatives of New Zealand. These are footnoted as follows: A.J.H.R. (Year): Paper, page. eg. A.J.H.R. (1922): H-3l, p.2. Where relevant, the subject is noted after the page no. eg. 'Report of a Commission..." Otherwise papers $G$ - are on Maori Affairs, and paper H-3I is the Health Dept. Report.

A.N.Z.A.A.S, : Australian and New Zealand Assoc. for the Advancement of science.

Aust, Med, Cone : Transactions of the Australasian Medical Congress. Formerly Intercolonial Medical Congress.

Census

: Dept. of Statistics, N.Z. Population Census..., Wellington. Footnoted: Census (Year): vol., p.

Demoge Year Book : United Nations, Demographic Year Book. Footnoted: Demog. Year Book (Year): p. J.P.S. : Journal of the Polynesian Soc. 
J.S.S.L.

M.J.A.

Med Stats.

M.M.F.Q.

N.Z.G.

N.Z.M.J.

P.P.

- Journal of the Statistical Soc, of London. (Later Roral Stat, Soc. Journ,)

: Medical Journ, of Australia.

: Dept. of Health, Report on the Medical Statistics of N.Z. for the year..., Wellington.

: Milbank Memorial Fund Quarterly

: N.Z. Geographer

: N.Z. Medical Journ.

: Parliamentary Papers (British). Footnoted: P.P. (Year): vol., p. Most references are to reports on N.Z. which take up the entire volume. Where this is not so, reference may also be given to the number of the paper.

Pop. Bulle.

: Population Bulletin of the United Nations

Pop. Mige \& Bldge: Dept. of Statistics, Report on Popee Stats.

Migration and Building Statisties of N.Z. for the year..., Wellington.

Pope stud.

: Population Studies

Thesis

: Unpublished M.A. (unless noted to the contrary) thesis, University of N.Z. or one of the now independent universities. The Library in which the thesis is located is noted as: (A.U.) Auckland Univ.; (V.U.) Victoria Univ. of Wellington; (C.U.) Canterbury Univ.; (O.U.) Otago Univ., including the Hocken Library.

T.N.Z.I.

Vit. Stats.
: Trans. \& Proceedings N.Z. Institute. (Recently, Royal Soc. of N.Z.)

: Dept. of Statistics, Report on the Vital Statistics of N.Z. for the yearee, Wellington.

: N.Z. Official Year Book, Wellington.

Maori and other non-English words are underlined in the text. This includes the names of Maori tribes, but not Maori 
or other non-English place-names, or the word 'Maori' itself. The definitions of Maori words are only approximate.

It is more correct in certain contexts to use the plural form 'Maori' rather than the plural 'Maoris'; in fact, it is incorrect to form the plural of any Maori word by adding the letter 's'. However, colloquially, plurals to Maori words are usually formed by adding ' $s$ ', and the term 'Maoris' is generally used in preference to 'Maori'. Colloquial usage will be followed here, except where other works are quoted.

Reference will be made to social surveys of several Maori communities. In a number of cases the authors of these surveys chose to give the communities fictitious names (eg. 'Paerau'). These names have been used here and no attempt has been made to pinpoint their exact locality.

Following census procedure, 'New Zealand' in this thesis, 'refers to what may be termed 'geographic New Zealand' and excludes the Cook Islands (with Niue Island) and Tokelau Is.' Western Samoa, now independent, will also be excluded throughout the thesis. These Polynesian Islands are administered separately from 'geographic New Zealand'. On the other hand, the census of 'geographic New Zealand' is a de facto enumeration and, thus, all persons residing in 'geographic New Zealand' on census night are included in the population of New Zealand analysed here.

In this thesis, as in colloquial parlance, Northland and North Auckland are synonomous.

Finally, unless noted to the contrary, tables present the results of calculations made by the writer from raw data tabulated in the publications of the N.Z. Depts. of Statistics and Health.

\section{Acknowledgements}

An analysis of Maori mortality trends occupies five of the fourteen chapters of this thesis. Therefore, I was particularly fortunate to have recourse to a number of 
admirable surveys. In particular, Dr Ian Prior of the Wellington Hospital Medical Unit, Dr H.B. Turbott, Director General of the Dept. of Health, Sir Douglas Robb, Surgeon and Chancellor of the University of Auckland and Mr R.J. Rose, Medical Statistics Branch, Dept. of Health, discussed aspects of Maori health with me, and gave me reprints and other material. I wish to thank them for their assistance. In addition, Mr. Rose granted me permission to quote from Rose (in Press).

I have discussed Maori problems with Dr Joan Metge, Dept. of Adult Education, University of Auckland, whose intimate knowledge of contemporary Maori life is based on extensive field-work. I make grateful acknowledgement of the considerable help she has given me, for allowing me to quote personal communications, and for making available a number of reports on Maori conferences organised by her department. I was also fortunate to be able to discuss aspects of Maori life with Dr J. Harre, now lecturer in Sociology, Otago University, Mr J. Booth, formerly Research Officer, Maori Affairs Dept. and now Secretary, N.Z. Maori Council, Dr G.M. Vaughan, Dept. of Psychology, Victoria University, and Mr P.W. Hohepa, at present a Ph.D. student at the University of Indiana. Moreover, Mr Hohepa has kindly granted me permission to quote from his M.A. thesis, in accordance with the rules of the University of Auckland Library. The chance visit to Canberra of Dr J.H. Robb gave me the opportunity to reacquaint myself with the survey work carried out by the School of Social Science, Victoria University. I would also like to thank Dr H. Mol, Dept. of Sociology, A.N.U. for criticizing the rough draft of Chapter One.

The Registrar-General, and Mr R.E. Mustchin and other officers of the Dept. of Statistics have answered requests for information and unpublished data and I wish to thank them for their cooperation.

When analysing nineteenth century material I obtained information from Dr G. Lewthwaite, Dept. of Geography, San 
Fernando Valley State College, Dr M.P.K. Sorrenson, Dept. of History, University of Auckland, and Mr H. Miller, Victoria University Library, and I wish to record my thanks to these persons.

During discussions members of the Demography Dept. made many valuable suggestions. In particular, I wish to thank Dr N. McArthur who gave me much advice, especially on aspects of mortality, which was all the more relevant because of her knowledge of Polymesian population trends; and Mr K.G. Basavarajappa with whom I discussed statistical problems on a number of occasions. But the person to whom I am most indebted is Professor W.D. Borrie, who supervised this work.

In Chapter One the social history of the Maoris and contemporary patterns of race relations are surveyed as an introduction to the thesis. This is not intended to be a definitive analysis; indeed, there are many persons better equipped than I am to analyse these two subjects. Some of these persons have been thanked already, but it is impossible to mention every person from whom I have absorbed, consciously or unconsciously, views and ideas on Maori social history and contemporary patterns of race relations. I thank these people, but must add that the blame for any misinterpretation is mine alone.

The library staffs of municipal, university, government departmental and museum libraries in Canberra, Sydney, Auckland, Wellington, Christchurch and Dunedin gave me considerable assistance in locating various publications, and above all the staffs of the Alexander Turnbull, Menzies and Dept. of statistics (Canberra) Iibraries must be thanked. Finally, I would like to thank Miss Theo and Mesdames Smith, Speight and Hall who typed this manuscript; and Mrs. Freiberg who photocopied some of the tables. 


\section{PRECIS}

This thesis is concerned with the growth of the Maori population since 1769. The primary aim is to discuss the two major determinants of trends - mortality and fertility.

Maori population trends can only be viewed in terms of European contact, New Zealand's subsequent social history, and as one aspect of contemporary pattern of race relations, all of which are surveged briefly in Chapter One.

Before commencing the demographic analysis in detail, Chapter Two discusses the sources and scope of Maori population data. Chapters one and Two form the introductory section, Part A.

Part $B$ is concerned with the demographic history of the Maoris from 1769 to 1921. Thus, Chapter Three analyses the quality of the available data. Chapter Four studies mortality in the period by reviewing the circumstantial evidence relating to prevalent diseases. From this review and from a few crucial items of direct evidence an interpretation is made of the levels and trends of mortality. A similar plan is followed for the study of fertility in Chapter Five. Chapter Six in Part B summarises first the decline of the Maori population from 1769 and then its subsequent increase until 1921.

Part $C$ deals with the period of rapid increase since 1922. Chapter Seven answers two questions relating to the basic structure of the population: is it 'closed' and is it 'quasi-stable'? Then the internal accuracy of censuses and intercensal anomalies are analysed and some adjustments are made, mainly to vital data of the period 1926-35. Chapter Seven concludes with a discussion of life-table construction.

Chapters Eight to Eleven deal with mortality since 1922. Chapter Eight shows that a rapid mortality transition has occurred only since World War II. This mortality transition 
is studied in greater detail in the two following Chapters, which cover causes of death and infant mortality. The study of mortality is concluded in Chapter Eleven, which determines the extent of Maori and non-Maori mortality differentials and reviews a number of factors which may bring about these differences. Finally, several possible causes of post-war Maori mortality declines are analysed.

Chapter Twelve studies the levels of fertility since 1922 and suggests some causes of high levels. It concludes with an analysis of regional differentials and discusses the possible implications of these differences.

Chapter Thirteen is concerned with population growth and some interrelated social and economic factors, such as rural-urban migration and its consequences.

Chapter Fourteen examines the implications of present growth patterns by examining three projected patterns of population growth over the next fifteen years based on the following assumptions:

(a) that present levels of mortality and fertility remain constant;

(b) that mortality declines but fertility levels remain unchanged; and

(c) that both mortality and fertility decline. 


\section{TABLE OF CONTENTS}

Page

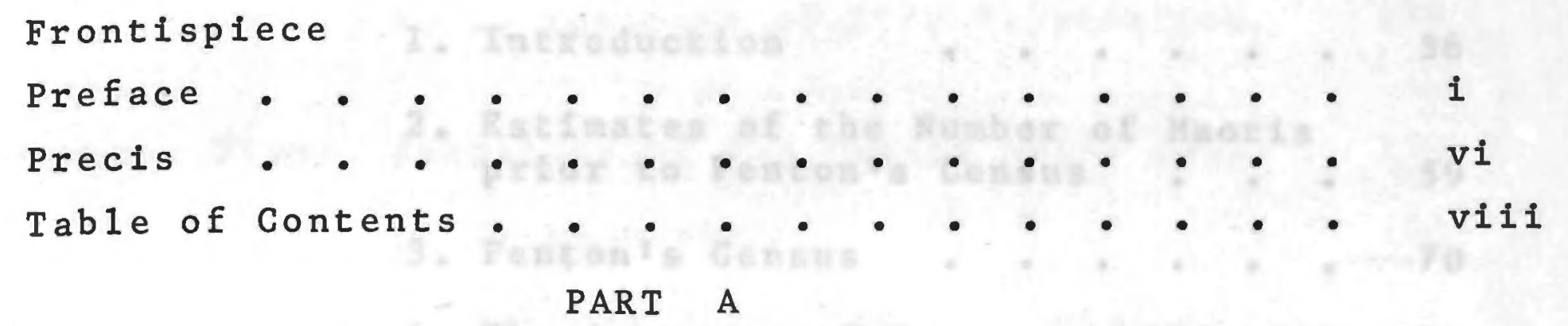

Chapter One: Introduction . . . . . . . . 1

1. The Maoris •.. • • . . • . 2

2. European Contact • • • • • 3

3. The Period 1840-70 • . . . 5

4. The Period 1870-1910 . . 8

5. The Period 1910-40 . . . . 11

6. Race Relations Since World War II 15

7. The Role of the Present Study - . 29

Chapter Two: The Sources and Scope of Maori

Population Data •. . . . . 30

1. Introduction . . . . 30

2. Estimates and Census Enumerations:
Early Estimates
- . - 30

Fenton's Census • • • • 32

Censuses 1874-1921 . . . 32

Censuses 1926-61 • . . . 35

3. Vital Data: Prior to $1913 \ldots 42$

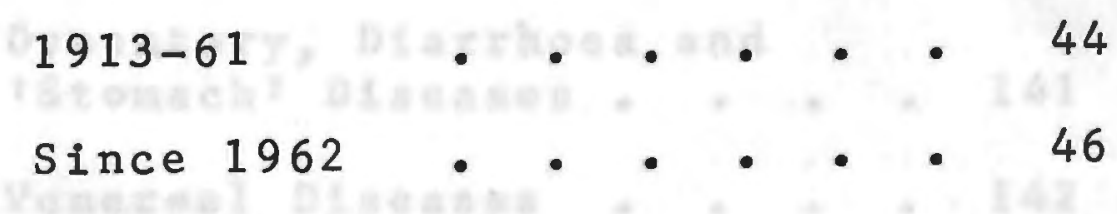

4. Some Problems relating to the Definition of 'Maori'Employed in Census and Vital Statistics . . 47

5. Marriage Statistics • • . • 53

6. Division of the Thesis into Two
Sections 
The Maori Population Until 1921

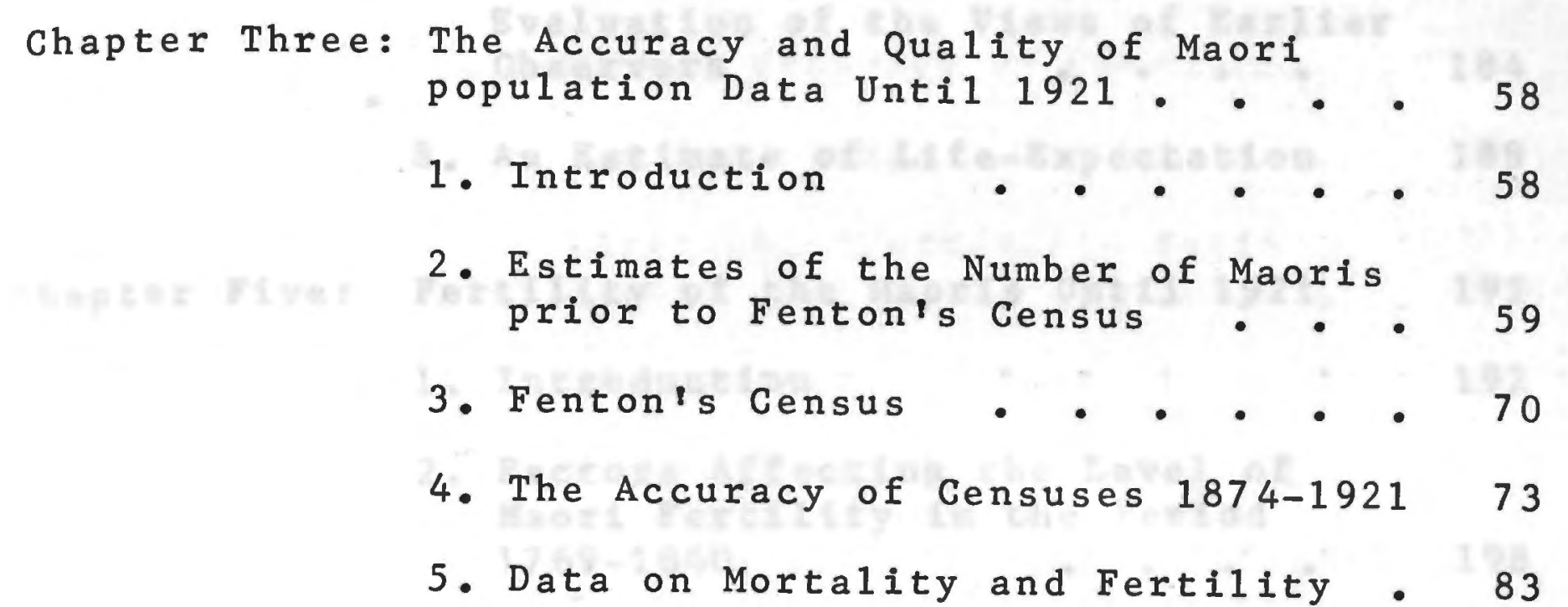

Chapter Four: Maori Mortality Until 1921 • • $\quad 86$

1. Introduction . . . . 86

The Data on Mortality . $\quad 86$

2. Maori Health prior to 1769 - 95

3. Epidemics and Warfare - . 100

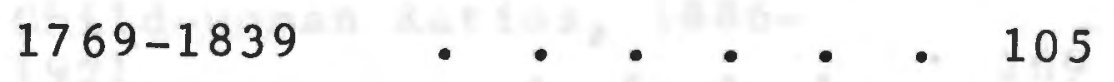

$1840-59 \quad$ • $\quad$ •

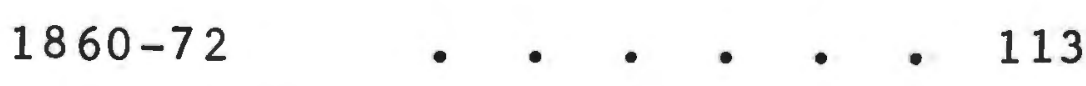

$1873-1911 \quad$ • $\quad$ • $\quad$ - 115

1912-21 • • • • • 125

4. Non-Epidemic Mortality . . . 137

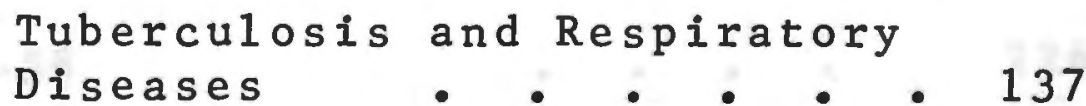

Scrofulous Diseases • . . 140

Skin Diseases • . . . . 140

Dysentery, Diarrhoea and

istomachi Diseases. . . . 141

Venereal Diseases • • . 142

Two Surveys of Morbidity • $\quad 147$

5. Foetal, Infant and Childhood

Mortality . . . . . . 152

Foetal Mortality . . . . 153

Infant Mortality • • • . 158

Induced Abortion and

Infanticide . . . . . 162 
6. Preventive Measures . . . 169

7. Reconstruction and Interpretation Factors related to the High Mortality of Maoris: an Evaluation of the Views of Earlier Observers

8. An Estimate of Life-Expectation

Chapter Five: Fertility of the Maoris Until 1921

1. Introduction

2. Factors Affecting the Level of Maori Fertility in the Period $1769-1840$

3. Factors Affecting the Levels of Maori Fertility, 1840-1921.

Factors Favouring High 1 eve $1 \mathrm{~s}$

-. .

Factors not favouring High levels . . . .

4. Levels of Fertility . . . . 208

Child-woman Ratios, $1886-$ 1921

5. Conclusion

Chapter Six: The Patterns of Growth of the Maori Population, 1769-1921

1. Introduction

2. Growth Patterns: 1769-1840.

3. $1840-58$

4. $1858-74$

5. 1874-1921

6. Summary

\section{PART $\mathrm{C}$}

Chapter Seven: Methodological Problems and the Accuracy of Population Data . . 234

1. Introduction • • • 234

Tests used in this Chapter 235

2. Basic Structure of the Maori Population: A 'Closed' Population 
Inter-ethnic Migration' . . 238

A 'Quasi-stable' Population • 251

3. Internal Accuracy of Censuses:

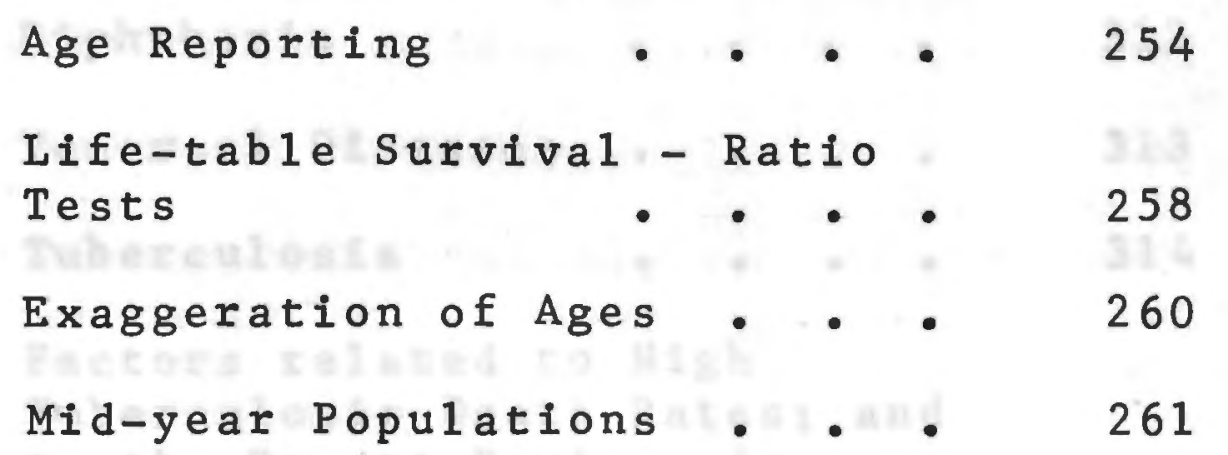

4. Anomalies in Intercensal Periods: Notification and Registration of Vital Events

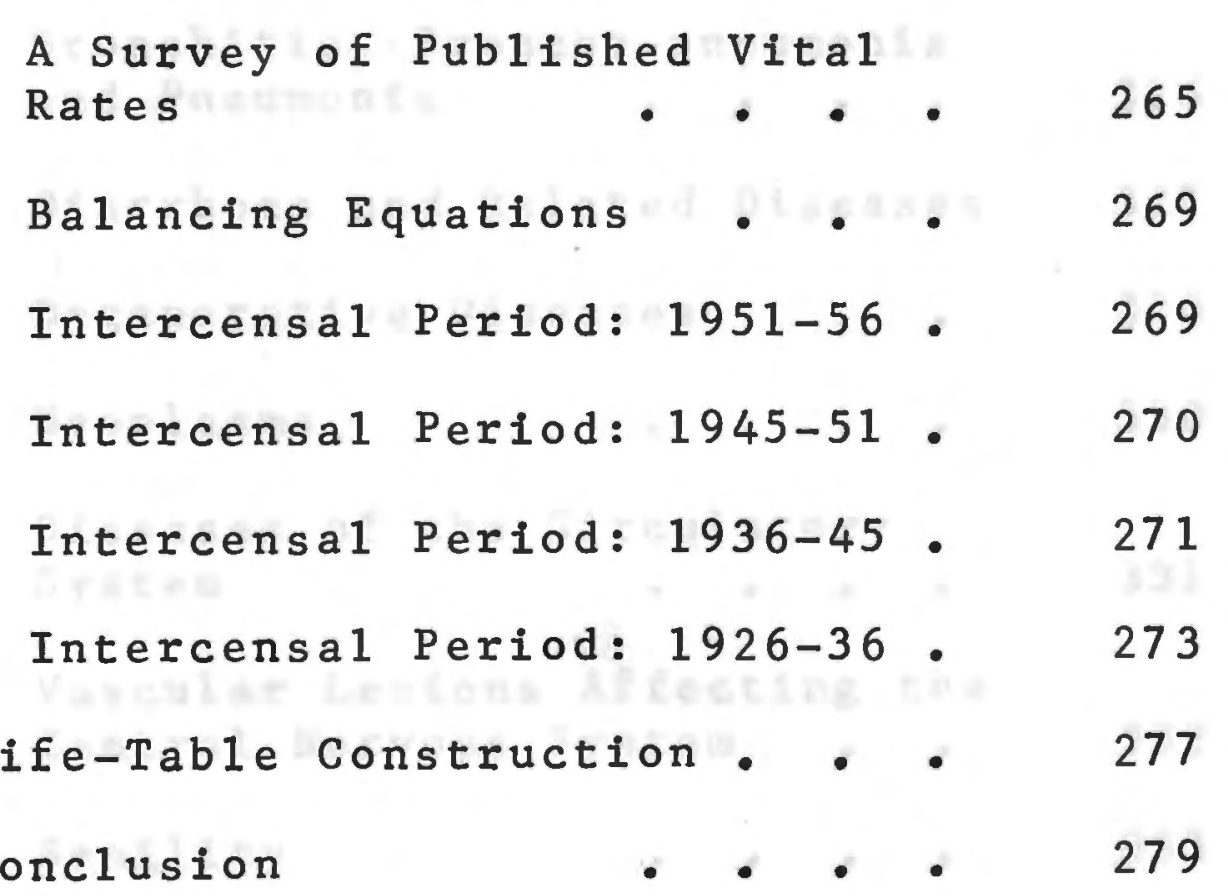

Chapter Eight: Maori Mortality Trends Since 1922: Part I, General Trends . . . 281

1. Introduction . . . 281

2. Accuracy of Data - . - 282

3. Crude Death Rates • . . 284

4. Age-Specific Death Rates • • 288

5. Life-Tables

Chapter Nine: Maori Mortality... 1922: Part II, Deaths by Cause • . . 302

1. Introduction - . . 302

2. Accuracy of the Certification of
Causes of Death
- . -

3. A Study of Certain Causes of Death 310 Measles _. . . 310 


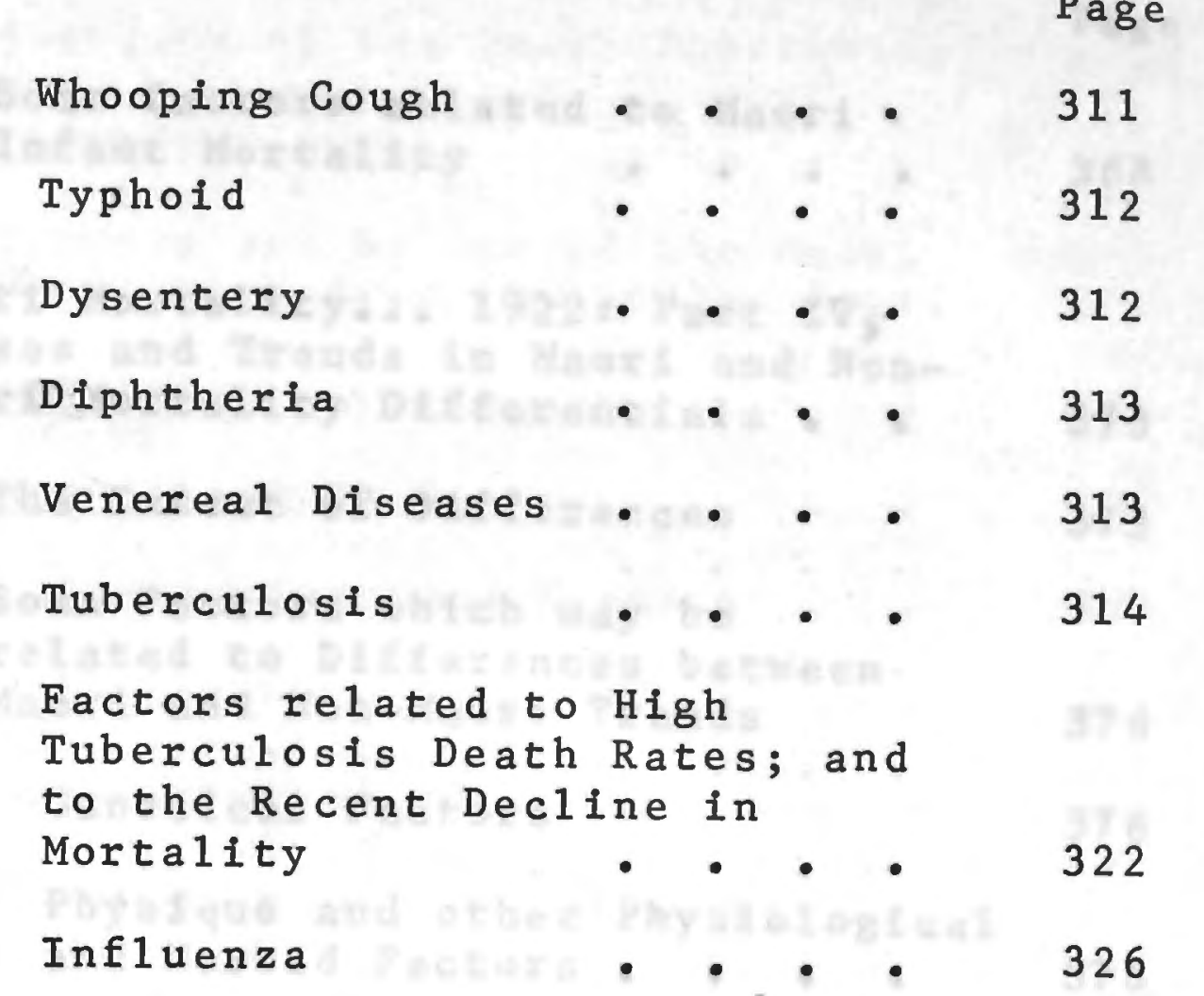

Bronchitis, Broncho-pneumonia and Pneumonia $\quad$ • $\quad$ • . $\quad 326$

Diarrhoea and Related Diseases 327

Degenerative Diseases • • • 330

Neoplasms $\quad$ - $\quad$ - 330

Diseases of the Circulatory

System $\quad$ • . . 331

Vascular Lesions Affecting the

Central Nervous System . . 332

Senility $\quad$ • $\quad$ - 333

Maternal Mortality .. . . 333

Accidents, Homicide and Suicide 335

4. Deaths by cause: Summary and
Conclusions

Chapter Ten: Maori Mortality... 1922: Part III, Infant Mortality • . . 344

1. Accuracy of Data - • . 344

Registration at Infant Age-
Groups

Certification of Causes of Death •. • $\quad 355$

2. Infant Death Rates for A11
Causes of Death $\quad$. . 357

3. Infant Death Rates for $A 11$ Causes of Death at Each Quinquennia . . .

4. Causes of Infant Deaths . . 366 
5. Some factors related to Maori

Chapter Eleven: Maori Mortality... 1922: Part IV, Causes and Trends in Maori and NonMaori Mortality Differentials •

1. The Extent of Differences

2. Some Factors which may be related to Differences between Maori and Non-Maori Trends

Genetical Factors

Physique and other Physiological and Morbid Factors . . . 378

Diet and Nutrition • • • 379

Housing

Sanitation

- $\bullet$ -

Social Factors and Attitudes 381

Economic Factors • • • . 382

3. Factors Causing a Decline in Maori Mortality, 1945 to the present

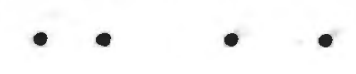

4. Conclusion

Chapter Twelve: Maori Fertility Since 1922 • • 392

1. Introduction - • • 392

2. Levels of Fertility - - • $\quad 395$

3. Factors Related to High Levels of Fertility

4. Differential Fertility - • . 415

5. Conclusion - • • • 421

Ghapter

Thirteen:
Social and Economic Factors Interrelated with Population Growth 1926 to the Present

1. Introduction - $\bullet$ -

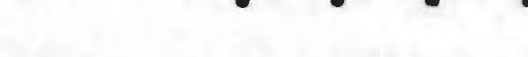

2. Rural - Urban Migration and Its Consequences - - .

3. Social and Economic Conditions of the Maoris, 1956 
2. Projections by Age of the Maori Population from 1961-1976: No.1.
Results
3. Projection No.2. . . . 458 Assumptions and Methods . $\quad 459$ 
Appendix A: Table Showing the Percentage Belonging

to Various 'Religious Professions',

Maoris and Non-Maoris, $1956 \ldots \ldots \ldots \ldots$ i

Appendix B: Non-Maoris Crude \& Infant Death Rates, and numbers of Deaths from Certain

Infectious Diseases, $1872-1921 \ldots \ldots \ldots \ldots$

Appendix B: Note on the Areal Breakdown of N.Z.

Census Statistics

Appendix C: Counties included in Rural Regions,

1956

vi

Appendix D: Highest Annual Rates of Increase in the Period 1953-56

Bibliography ix

Part I: New Zealand $\ldots \ldots \ldots \ldots \ldots \ldots \ldots$ ix

(1) Published N.Z. Official ....... ix

(2) Published non-Official Books and Articles $\ldots \ldots \ldots \ldots \ldots \ldots \ldots \ldots \ldots$ x

(3) Unpub1ished .................... xvi

(4) Newspapers ................ xvi

Part II: General ................. xvii 
2.1. Census Data on Maoris, $1857 / 58-1921$

2.2. Census data on Maoris, 1926-56

2.3. Classification of various Component Populations in the 1956 Census of N.Z.

2.4. The Years for which Various Tabulations of published vital registration data are available relating to Maoris, 1913-61

2.5. The classification of a birth by 'race' on the basis of the iraces' of its parents

3.1. Estimates of the Maori population from 1769 to $1857-58$

3.2. The number of Maoris enumerated at each Census from 1857-58 to 1921

3.3. The percentage of the population with ages partly not specified, and not specified at a11, 1886, 1891, 1896, 1901 \& 1921

3.4. Numbers for each 5-year age-group, for various cohorts, at the censuses of 1886-1921

3.5. Percentage distribution of decennial agegroups, at the censuses of 1886-1926

4.1. Epidemics occurring among Maoris between $1769 \& 1921$.

4.2. Effect of vaccinations: Smallpox epidemic among Maoris, North1and, May \& June, 1913

4.3. Epidemic of influenza, Oct.-Dec. 1918: Maori age-specific death rates (per 10,000)

4.4. Table... showing the comparative frequency of certain classes of diseases among the inhabitants of a 1 arge town in England and the natives of New Zealand?

4.5. The average annual incidence of disease per 1,000 of the Maori population for 6 years, $1901-07$

5.1. Estimated General fertility and crude birth rates in 1901, assuming various conception and foetal mortality rates

5.2. Child-woman ratios, 1886-1921

5.3. Expected child-woman ratios, 1901

5.4. Children aged $0-14$, per 1,000 aged $15+$ years

7.1. Numbers belonging to each component of the Maori-descent population at various censuses 
7.2. Estimated changes in the size of components of the Maori-descent population in excess of changes 1 ikely to have resulted from natural disease

7.3. Percentage distribution of ages, censuses of $1921-56$

7.4. Stable \& mid-year populations at 1956

7.5. Age-ratio, Sex-ratio and joint scores

7.6. Surviva1 ratio Tests: difference between expected ${ }_{n}{ }^{P}$ and enumerated ${ }_{n}{ }^{P} x$

7.7. Maori centenarians, 1926-56

7.8. Preference for each unit digit of age recorded by males and females, 1945, 1951, 1956

7.9. Published vital rates (both sexes) 1926-56

7.10. Results of balancing equations: differences between enumerated and estimated Maori populations, working back from year

7.11. Date of occurrence of births (both sexes) registered in $1936,1941,1946$ and 1951

8.1. Crude death rates, 1921-61 (rates per 1,000)

8.2. Age-specific death rates, Maoris, 1921-56 (rates per 10,000 mid-year population)

8.3. Comparison between deaths recorded in 1956 and those expected had 1945 age-specific rates still occurred in 1956

8.4. Life-expectations at various ages: the Maori, non-Maori and other populations

8.5. Life expectations at various ages, Maoris, around the censuses of 1926-56

8.6. Probability of Surviving from exact age $x$ to exact age $x+n$ around the censuses of $1926-56$

9.1. Type of certification of causes of death, 1925-56 (a11 causes)

9.2. Certification of certain causes of death at census years

9.3. Crude death rates: ill-defined causes of death

9.4. Unsatisfactorily defined causes of death

9.5. Age-specific death rates: ill-defined causes of death 
9.6. Crude death rates: certain infectious diseases

9.7. 1938: Age-specific death rates for certain diseases

9.8. Age-specific death rates: Whooping Cough

9.9. Age-specific death rates: tuberculosis, $1921-56$

9.10. Crude death rates: certain respiratory diseases

9.11. Age-specific death rates: influenza

9.12. Age-specific death rates: bronchitis, bronchopneumonia and pneumonia

9.13. Crude death rates: diarrhoea

9.14. Age-specific death rates: diarrhoea and related diseases

9.15. Crude death rates: certain degenerative diseases

9.16. Age-specific death rates: neoplasms

9.17. Age-specific death rates: diseases of the circulatory system

9.18. Age-specific death rates: vascular lesions affecting the central nervous system

9.19. Age-specific death rates: senility

9.20. Crude death rates: maternal mortality

9.21. Crude death rates all accidents, suicide and self-inflicted injury, and homicide

9.22. Age-specific death rates accidents, suicide and homicide

9.23. Crude death rates: grouped causes of death

9.24. 1945-56: the percentage of the decline in the total crude death rate arising from declines in the crude death rates of various groups of diseases

9.25. Age-specific death rates: grouped causes of death

10.1. The average number of deaths at each day of Age, for each Infant Age-group

10.2. Infant death rates: ill-defined and notstated causes of death

10.3. Infant death rates: 1925-59 
No.

10.4. Infant death rates for various quinquennia

10.5. Post-neo-natal deaths as a percentage of total deaths

10.6. Total infant death rates: grouped causes of death, 1925-59

10.7. Infant death rates: grouped causes of death for various infant age-groups

11.1. Sti11-birth rates, Maoris and non-Maoris, 1942-59

11.2. Non-Maoris, infant mortality, 1901-50

374.

11.3. Age-specific death rates, Maoris and nonMaoris, 1954-58

374

12.1. Estimated and published crude birth rates, $1926-61$

12.2. General fertility rates, 1926-61

12.3. Child-woman ratios, 1926-56

12.4. Children ever-born alive to currently married women, 1945

12.5. Maori estimated age-specific fertility rates 1956, compared with rates for the Hutterites

12.6. Estimated net-reproduction and estimated general fertility rates compared with replacement indices and general fertility rates calculated from published data, 1936 and 1945

12.7. Proportions in various marital-status groups, 1926-56 (females only)

12.8. Numbers and proportions of females marrying at various ages, and the median age at marriage for males and females, 1948-51

12.9. Rura1 - urban variations in child-woman ratios, 1926-56

12.10. Rural - urban variations in general fertility rates, 1956 and 1961

12.11. Child-woman ratios, Auckland Urban Area, 1956

12.12. Rural-urban variations in marital status, females, 1926-45 (Age-group 15t)

12.13. Proportions at each age-group, urban and rural females, 1926-56. 
13.1. Annual intercensal rates of growth (\%s)

13.2. Proportionate Change in the rural-urban distribution of the Maori population

13.3. Regional differences in Increases and Decreases of the Maori population, 1956-61

13.4. Rura1-urban migration, 1956-61

13.5. Percentage of the Maori work-force belonging to each industrial division, 1945 and 1956

13.6. Percentage of the Employed Maori and NonMaori populations in various industrial divisions (1956)

13.7. Percentage of workers in Agriculture, etc. belonging to various status groups, Maori and non-Maori, 1956

13.8. Percentage of Maoris and Non-Maoris in various occupation divisions (1956)

13.9. Percentage distribution of incomes earned by workers in each industrial division, Maoris and Non-Maoris, 1956

13.10. Proportion of the work-force at various agegroups, 1956

13.11. Percentages of State Secondary School Leavers (1960): (a) by years of attendance at secondary School; and, (b) by Attainments

13.12. Percentages of the Maori Households with certain amenities

14.1. Projection No.1 of the Maori Population by Age, from 1961 to 1976

14.2 Projection No. 2 of the Maori Population by Age, from 1966 to 1976

14.3. Projection No. 3 of the Maori Population by Age, from 1966 to 1976 
Appendix B: Non-Maori deaths, numbers and rates, $1872-1921$

\section{LIST OF FIGURES}

Frontispiece

Fig. 7.1
New Zealand Location Map.

Age and Sex Pyramids, 1926 and 1956

7.2 .

Graphs showing the Numbers at each single year of age, censuses of $1926-56$

8.1 .

Death rates from all causes, for quinquennial age-groups, 1936-56

9.1.

9.2 .

10.1
Tuberculosis age-specific death rates, 1941 and 1956

Tuberculosis: Cohort mortality

Maori and non-Maori Populations, 1955-59: The Average number of Deaths at each day of age, per infant age-group, per 100,000 1 ive-births 


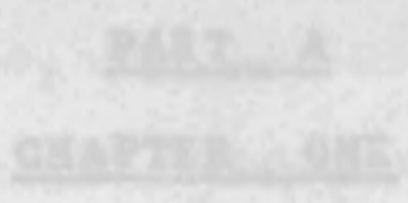

Introdistebon

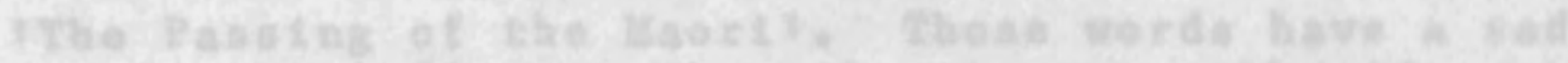

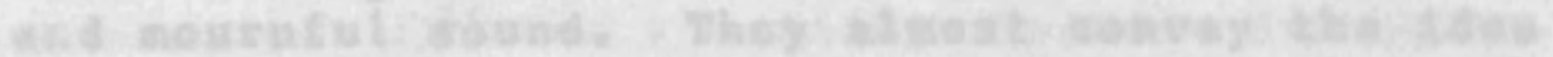

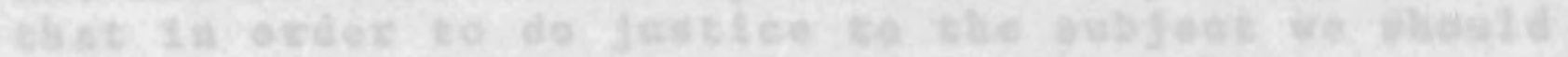

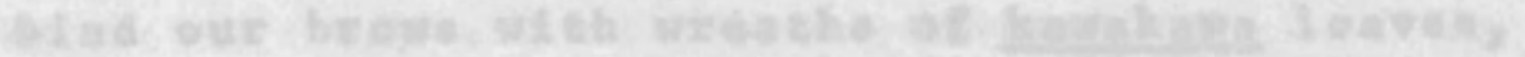

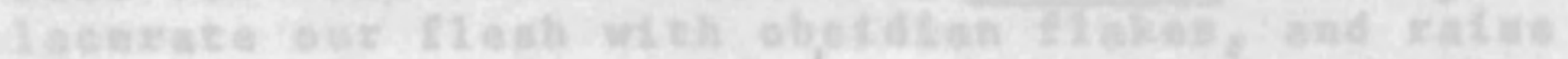

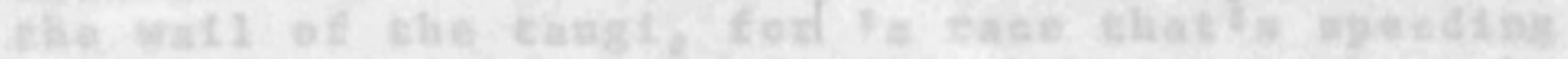

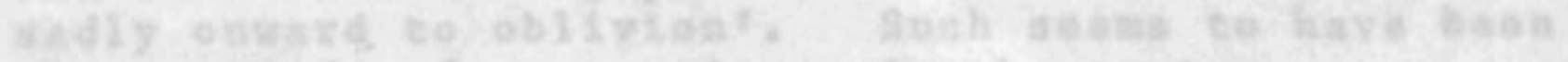

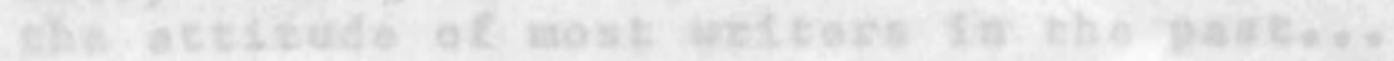

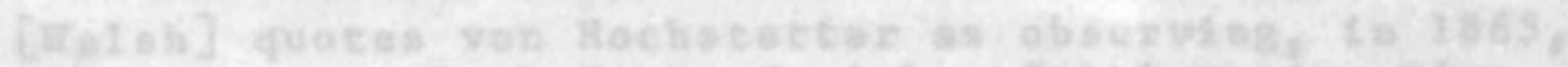

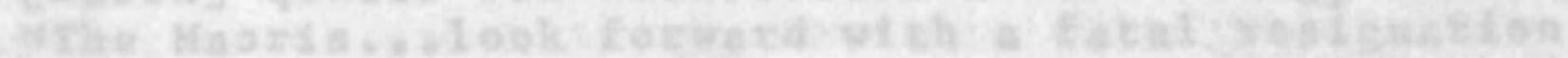

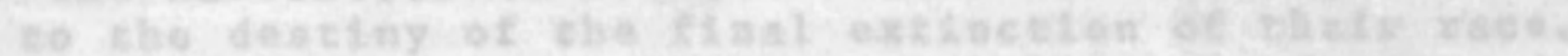

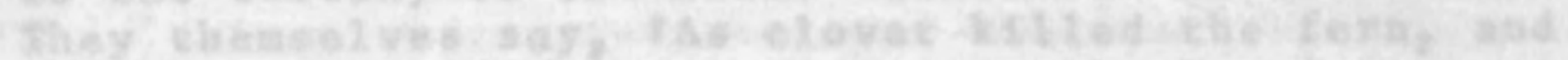

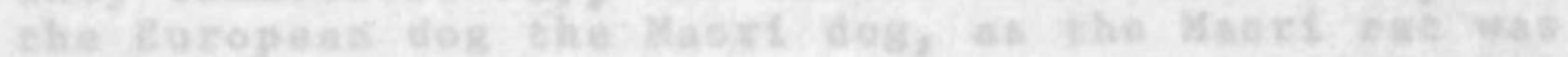

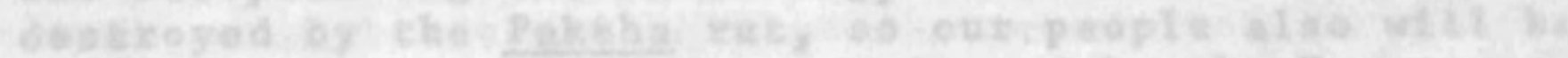

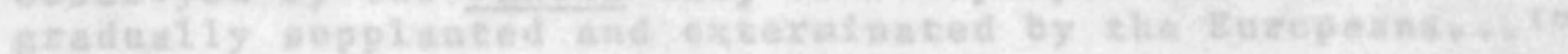

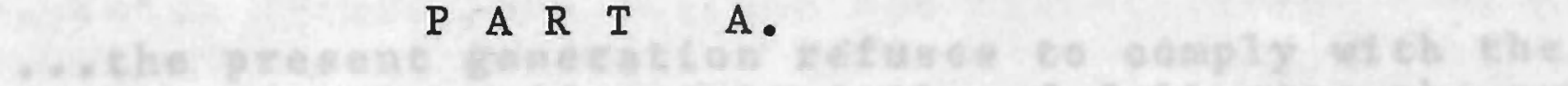

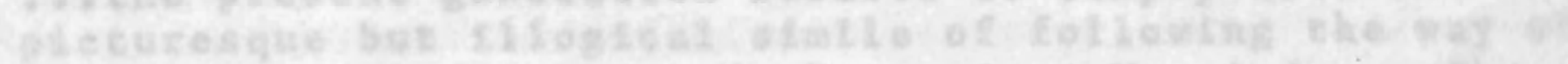

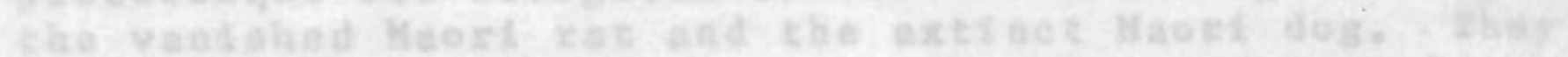
Introduction

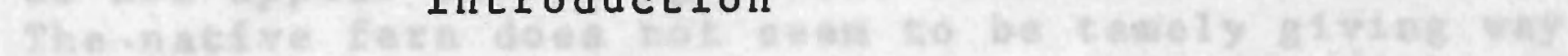

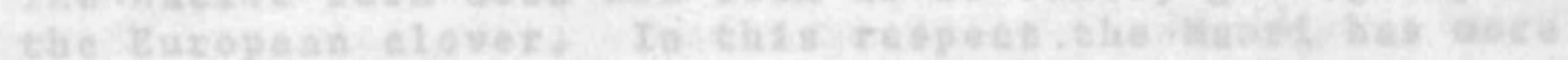

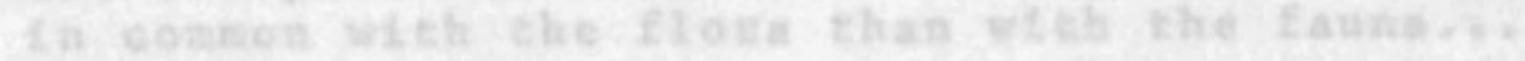

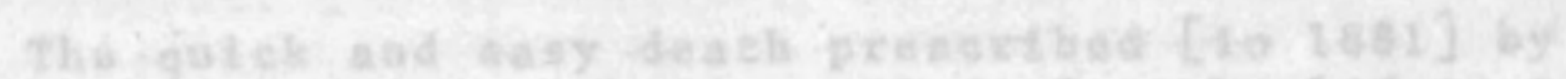

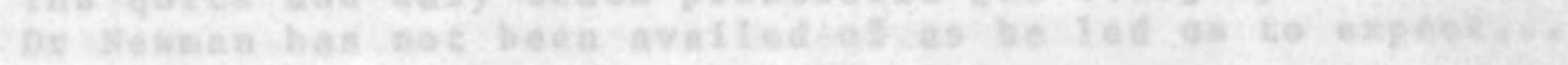

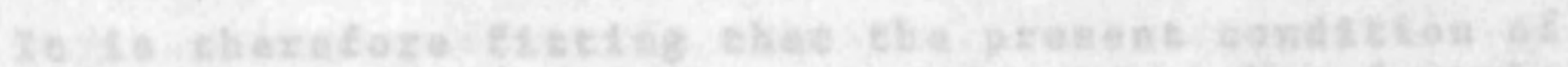

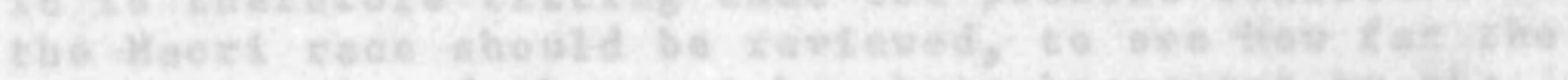

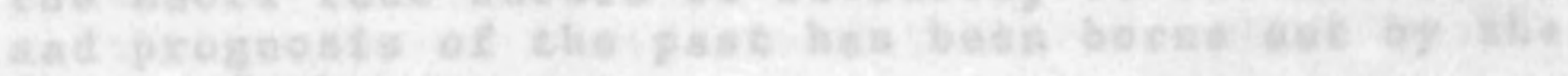

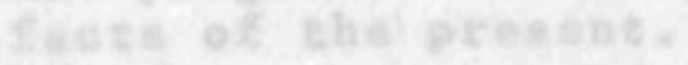

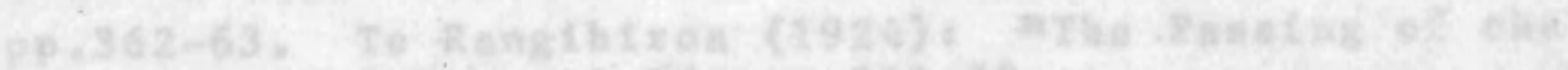

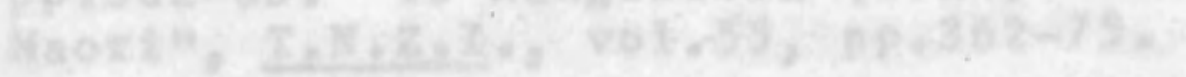

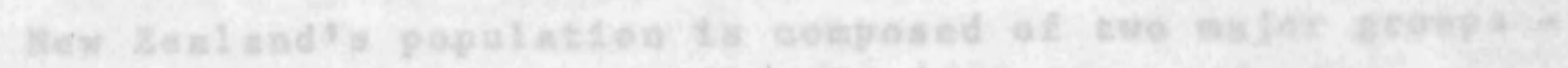

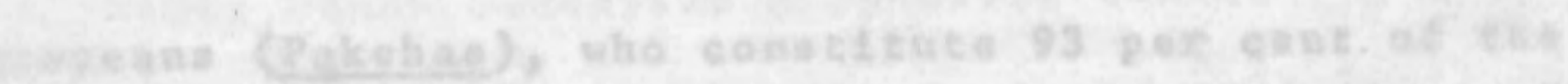

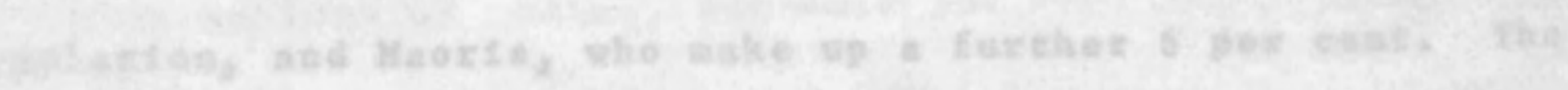

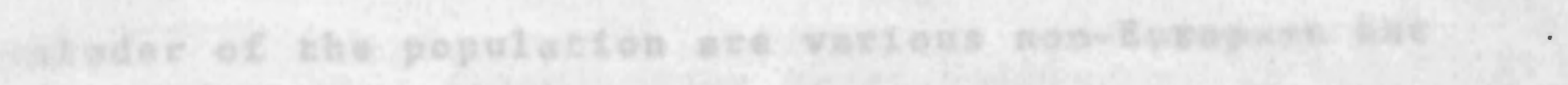

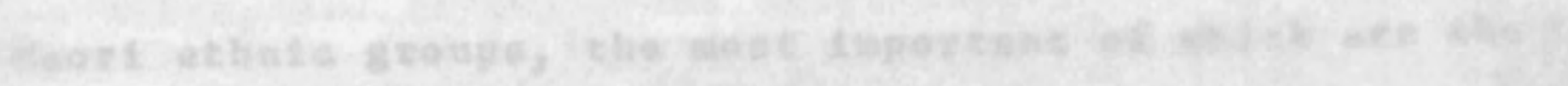

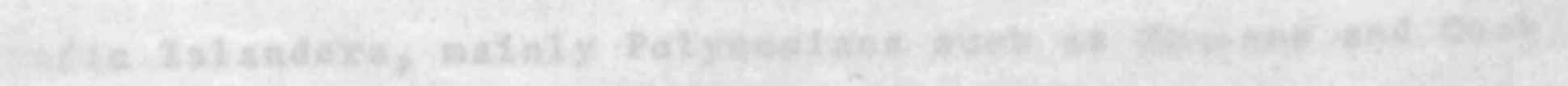

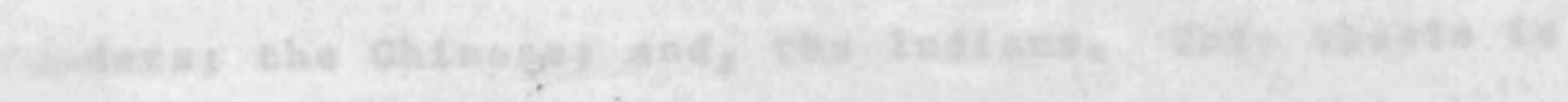

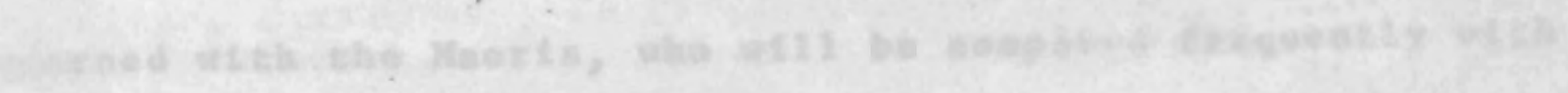




\section{CHAPTER ONE}

\section{Introduction}

The Pasing of the Maori'. These words have a sad and mournful sound. They almost convey the idea that in order to do justice to the subject we should bind our brows with wreaths of kawakawa leaves, lacerate our flesh with obsidian flakes, and raise the wail of the tangi, for 'a race that's speeding sadly onward to oblivion'. Such seems to have been the attitude of most writers in the past...

[Wa1sh] quotes von Hochstetter as observing, in 1865, "The Maoris...10ok forward with a fatal resignation to the destiny of the final extinction of their race. They themselves say, tAs clover killed the fern, and the European dog the Maori dog, as the Maori rat was destroyed by the Pakeha rat, so our people also will be gradually supplanted and exterminated by the Europeans...."

...the present generation refuses to comply with the picturesque but illogical simile of following the way of the vanished Maori rat and the extinct Maori dog. They do not appear to belong to the same class of mammal. The native fern does not seem to be tamely giving way to the European clover. In this respect the Maori has more in common with the flora than with the fauna...

The quick and easy death prescribed [in 1881] by Dr Newman has not been availed of as he led us to expect...

It is therefore fitting that the present condition of the Maori race should be reviewed, to see how far the sad prognosis of the past has been borne out by the facts of the present.

pp.362-63. Te Rangihiroa (1924): "The Pasing of the Maori", T.N.Z.I., vo1.55, p..362-75.

New Zealand's population is composed of two major groups Europeans (Pakehas), who constitute 93 per cent of the population, and Maoris, who make up a further 6 per cent. The remainder of the population are various non-European but non-Maori ethnic groups, the most important of which are the Pacific Islanders, mainly Polynesians such as Samoans and Cook Islanders; the Chinese; and, the Indians. This thesis is concerned with the Maoris, who will be compared frequently with 
the non-Maori population. The 1 atter group is composed of both the Europeans, and the non-Europeans mentioned above, including the Pacific Islanders. Thus, "Cook Island Maoris" are counted here as non-Maoris. In this chapter Maori-European relations will be analysed, as this factor is of major importance, but for the remaining chapters Europeans will not be separated from the other non-Maoris.

\section{The Maoris}

The Polynesians migrated from the South East Asian mainland at some time in pre-history, and settled in the Central South Pacific. ${ }^{1}$ From there, they voyaged thousands of miles across this vast ocean to settle in what is termed the Polynesian Triangle - Hawail, New Zealand and Easter Island - within the boundaries of which the majority live today. The Maoris came to New Zealand in the period about 950-1350A.D., but whether by accident or design is a point still in dispute among Pacific ethnologists and historians. In traditional accounts, it is claimed that a ifleet' of vast ocean-going canoes reached New Zealand, Aotearoa, from the ancestral homeland, Hawaiki. Thus, at the time of European contact, loosely-knit groups of tribes claimed descent from the particular canoe (whaka) which had reached their region. For example, the tribes of the Tainui canoe included the Waikato and Ngati Maniapoto, which were famed later as the major tribes in the King Movement. At the time of European contact, there was a large number of tribes, each occupying a specific territory, and with complex systems of social, economic and political organisation,

$\overline{1}$

See Metge, A.J.(1960): "The Maori Settlement of N.z.", in McLintock, A.H. (ed.): Descriptive Atlas of N.Z., Wellington. pp.1-3; Golson, J.(1961): "The Polynesian Settlement of N.Z.", in Sinclair, Keith (ed.): Distance Looks Our Way: The Effects of Remoteness on N.Z., Auckland. pp.15-26; Chapt.1. Wright, Harrison M. (1959): N.Z.1769-1840: Early Years of Gontact, Cambridge, Mass.; and, Te Rangihiroa (1952): The Coming of the Maori, Wellington. 
and land inheritance. The major viable unit was the hapu (sub-tribe), which normally occupied either a village (kainga) or fortified settlement (pa). The population at this time, variously estimated at between 100,000 and 500,000 , resided chiefly in northern Northland; around the Tamaki isthmus, the Firth of Thames and the Bay of Plenty; on the northern East Coast as far south as Hawkes Bay; along the Waikato and Waipa Rivers and around Lake Taupo in the centre of the North Island; and along the Taranaki coast. There were also scattered settlements in the Wellington Province and in the South, Stewart and Chatham Islands, but the bulk of the population lived north of the 39 th parallel. In this northern region, the kumara (sweet potato) was the basic food, being supplemented by other cultivated crops - taro, yam and gourd gathering of foods such as berries and fern roots, fishing and fowling. The cultivated crops were tropical and reached their southernmost limits in northern New Zealand. Alone among these crops, kumara was grown in a few favoured localities south of the $39 \mathrm{th}$ parallel. There were no land mammals other than the highly prized dog and the rat, both of which seem to have been introduced by the Maoris, and the bat which had no economic significance. Clothing was made from flax, or from dog fur and feathers.

Warfare was highly developed. Inter-tribal wars seem to have been an endemic disease, resulting in the building of the fortified hillside pa. Nevertheless, these wars do not seem to have caused the devastation of later wars.

\section{European Contact}

Other than the brief and tragic encounter between Maoris and the Dutch navigator, Abel Tasman, in 1642, European contact did not take place until Captain Cook's memorable 
voyages between 1769 and the late 1770 s. $^{2}$ In Cook's first

voyage British sovereignty was claimed over New Zealand, which was not ratified until 1840. From Cook's time until 1814, when the first mission station was established in the Bay of Islands by the Rev. Samuel Marsden for the Church Missionary Society, New Zealand was visited by French, English and even Spanish explorers. From the 1790s traders, sealers and whalers of various nationalities were sailing its coasts. By repute, it was cook who introduced the pig, while about this time maize and potatoes were brought in. All of these effected considerable changes in Maori diet, and were diffused rapidly to all parts of the country. Muskets and other trade goods were exchanged for flax, timber and even tattooed heads.

\section{2}

The social history which follows is not intended to be definitive, nor are the sources of the assertions, data etc. documented in detailed footnotes. The major sources are: Sinclair, Keith (1959): A History of N.Z., Hammondsworth, London; and, 01 iver, W.H. (1960): The Story of N.Z., London. For particular periods: Wright (1959); Miller, John (1958): Early Victorian N.Z.: A Study in Racial Tension \& Social Attitudes, 1839-52, London; Sinclair, Keith (1957): The Origins of the Maori Wars, Wellington; Sorrenson, M. P.K. (1956): Tand Purchase Methods \& Their Effect on the Maori Pop., 1865$1901^{1}$, J.P.S., vo1.65, no.3, Sept. pp.183-99, which is based on Sorrenson, M.P.K. (1955): The Purchase of Maori Lands, Thesis (A.U.). It is probably rather significant that nothing of general importance has been written (then or since) about the Maoris in the period 1900-25. The period 1925-51 is covered in Metge, A. Joan (1951): The Distribution \& Character of the Maori Pop. of the Auckland Province, Thesis (A.U.); and, Metge, A. Joan (1952): The Maori Pop. of Norther N.Z.', N.Z.G., vo1.8, no.2, Oct. pp.104-24. Since the war there have been a number of surveys which will be referred to specifically. Two general books on Maoris are: Firth, Raymond (1959): Economics of the N.2. Maori, Wellington; and, Sutherland, I.L.G. (ed.) (1940): The Maori People Today, Christchurch. For a wide coverage of the field of Race Relations see Harre, John (1963): "The Background to Race Relations in N.Z." Race, vol.v, no.1, July. pp.3-25. A clear and sympathetic analysis of the recent period is in Pearson, Bill (1962): "N.Z. Since the War: 7. The Maori People", Landfa11, vol.16, no.2, pp.148-80, June. Although Pearson is not a social scientist he speaks with objectivity and authority, plus a considerable degree of insight. 
From the early 1800 s, the Maori way of life changed rapidly. It has been claimed that there was depopulation through the ravages of disease; many tribes migrated to localities where flax could be gathered and exchanged, in particular, for muskets; there was an amazing demand for teachers; the Maoris even participated in the religious controversies resulting from the confrontation between Anglican Church Missionary Society clerics, Methodist Missionaries, and later Catholic Preachers. Not least of al1, there was an intensification of warfare. In the north, the warriors of Hongi Hika ravaged the neighbouring regions during the 1820s. He had visited England and, whilst there, was feted by society. When passing through sydney on his way home, he exchanged the many presents he had received for muskets, and then set out to conquer northern New Zealand. In the south, in the $1820 \mathrm{~s}$ and $1830 \mathrm{~s}$, Te Rauparaha decimated the Cook Strait and South Island tribes, while elsewhere Pomare, Te Waharoa, Te Wherowhero and other chiefs conducted campaigns. Meanwhile, in Hongi Hika's own area, the Bay of Islands, European contact increased. The newcomers were an oddly assorted collection of missionaries, escaped convicts, ships deserters and traders of every nationality, whose numbers were compounded by temporary visitors from re-victualling ships. The 'grog-shops', prostitution and vice of Kororareka, the major frontier settlement' in the Bay of Islands, became renowned. However, some of the missionaries, whose journals are the main source of eyewitness accounts of the period, may have over-emphasised some of the more sordid aspects of life in Kororareka.

\section{The Period 1840-70}

In 1840 , by the Treaty of Waitangi signed between the British Crown and certain Maori chiefs, New Zealand became a 
part of the Colony of New South Wales, under whose control it remained for but a few years before becoming a separate colony. This move, reluctantly undertaken by Great Britain, brought in its train organised settlement in a number of regions, most importantly, as far as Maori interests are concerned, in the Auckland, New Plymouth (Taranaki), Wanganui and Wellington areas. Unlike some other colonies, New Zealand was annexed at a period when humanitarian interests were very strong in Whitehall. Thus, for the next two decades, there were clashes between the wishes of these humanitarians and the more materialistic demands of many of the settlers. In particular, there were violent debates revolving around the original decision that the Grown should hold pre-emptive rights over 1 and, and that there should be no direct transactions between Maoris and private concerns. This decision frustrated the settlers, particularly those in the North Island, who attacked it in the colony's legislative assemblies and caused the Crown to change its attitude considerably, and disconcertingly, in this period. Moreover, Maori 1 and was held communally, so that purchasers had to obtain the consent of all owners, usually the entire hapu. This procedure greatly obstructed land alienation, for often one group would agree to sell land, but others would not. Therefore, the settlers made constant demands that 1 and tenure be individualised and the rate of alienation accelerated.

Between 1840 and 1859 there were four isolated outbreaks of fighting - three small 'wars' in the North Island, and the 'Wairau Massacrel of some European officials in the South. However, in general, relationships were not unduly strained, largely because of three factors. Firstly, the bulk of Maoris did not come into close contact with the settlers. Secondly, Sir George Grey, the Governor from 1845-54, was a 
remarkable man who terminated the hostilities mentioned above, gained the respect of the Maoris and even sought to

'amalgamate' the two groups. But, because of his authoritarian control, there was no means of maintaining his methods after his departure. Thirdly, there was the forebearance of the Maoris in the face of constant demands by the settlers that they relinquish their 1 and, and even that they should be exterminated. Moreover, while in theory they could vote, in practice the laws were so complex that only a few Maoris were able to enrol. These were Maoris who were willing to sell their land to the crown for $6 \mathrm{~d}$ or $1 /$ - an acre and purchase it back at $10 /$ - or $\$ 1$, in order to become freeholders. However, in certain areas the Maoris were thriving - they owned most of the North Island's coastal shipping and traded wheat and potatoes as far afield as sydney. In the ififties, matters came to a head because of the political frustrations of the Maoris and the growing realisation that European settlement was accelerating. In 1858, the censuses revealed that the Maories were outnumbered. Moreover, there was the competition over land between the settlers, who looked upon land purely in economic terms, and the Maoris, for whom 1 and had magico-religious and sociopolitical as well as economic significance. The materialism of the Europeans was compounded by the fact that 1 andpurchasers began to use unethical and 111 egal methods. Thus, a number of tribes formed the 'King Movement', which aimed at unifying the Maoris politically and at stemming the alienation of land, but which, initially, was not avowedly anti-European. Meanwhile, in Taranaki, hostility was developing between Wiremu Kingi, who had refused to join the King Movement, and the settlers. The major cause of dissension was the ownership of a block of land at Waitara, some ten miles from the New Plymouth settlement. The exact 
events in Taranaki are very complex, but it seems that Wiremu Kingi had genuine claims, and that, by declaring martial law in 1860 , the Grown acted rashly. The Government provoked the Maoris into open warfare, either purposely, or at least without due consideration of Maori rights.

The outcome of the 'Taranaki War' was disastrous. Wiremu Kingi linked with the 'King's' tribes of the Waikato and King Country and, ultimately, the fighting spread to the Waikato, the Bay of Plenty and elsewhere. When hostilities appeared to be drawing to a close, a militant millenarian cult - the $\underline{\mathrm{Hau} H a u}$ - arose, and the war continued spasmodically until 1872. In the latter stages there were skirmishes between the $\underline{\mathrm{Hau} \mathrm{Hau}}$ and government forces. A Ifriendly: Maori, Te Kooti, who had been wrongly imprisoned on the Chatham Islands, escaped and led a guerilla group in the Urewera country. The Ringatu faith, to which some 4 per cent of Maoris still belong, was developed by Te Kooti by fusing together aspects of Christianity, his own role as a charismatic leader, and some elements of Maori traditional magico-religious belief.

It has been necessary to discuss the period 1840-70 in fairly full detail, because many of the subsequent aspects of Maori social history have their roots in this period.

\section{The Period 1870-1910}

From 1870 to 1900 , the Maoris were subjected to the humiliation of losing their lands. Land belonging to defeated tribes living near European settlements was confiscated in Taranaki, the Waikato, the Bay of Plenty and on the East Coast. The more cynical observer would claim, with some justification, that land was confiscated regardless of the allegiance of its owners. By contrast, other defeated tribes, notably the Ngati Maniapoto, Ngati Tuwharetoa and the 
Tuhoe, were able to cordon themselves off from European contact, and thus land alienation, until the 1880 s and even the 1890 s. The 'friendly' tribes' 1 and was not confiscated, but much was alienated, and had been even while they were fighting on the side of the Crown. The whole history of 1 and purchasing is sordid in the extreme. Unethical methods were used to gain the approval of the owners, and the land courts, set up in the $1860 \mathrm{~s}$, degenerated into an instrument by which 1 and could be forcibly taken from the Maoris. In the $1880 \mathrm{~s}$, buyers, chiefly government officials, moved into the Taupo and King Country regions. Methods of 1 and purchasing had become more regular by this time, so that the accompanying disorganisation was 1 ess severe. By 1892 , the Maoris retained only the most hilly and uncultivated third of the North Island. Between about 1895 and 1900 , buyers moved into the Urewera country - the Tuhoe stronghold.

The alienation did not occur without some protest from the Maoris. In 1867 , their legitimate political ambitions were profitably capitalised on by the wise, if rather 1 ate, move of extending the franchise to them. The electorates allotted to them have come down to this day, so that, for the 1 ast century, Maoris have held four seats in Parliament. Furthermore, there were Maori members of the Legislative Council from 1872 until this upper house was abolished. Their representatives continually attacked 1 and purchasing methods. For example, the most notable nineteenth century Maori representative, the Hon. Sir James Carrol1, a self-educated man who was 1 ater an acting prime-minister, in his minority opinion included in the Report of the 1891 Rees, Carrol1, Mackay Commission, had this to say: ${ }^{3}$ iBut is it not a somewhat melancholy reflection that, during all the years the New Zealand 
Parliament has been legislating upon Native-1and matters no single bona fide attempt has been made to induce the natives to become thoroughly useful settlers in the true sense of the word.'

A more novel attempt to prevent alienation was the passive resistance movement led by the prophet Te Whiti. Returning after the war to confiscated 1 and in Taranaki, Te Whiti and his followers set up a mode1 vil1age, and obstructed a11 attempts at surveying and settling the area from 1865 to the early $1880 \mathrm{~s}$ and beyond. The measures taken by the government and the settlers to defeat this movement provide one of the saddest, if rather Gilbertian, episodes in New Zealand's history. U1timately, the movement was not very successful, but one sideline was that some difficulty was experienced, so it was claimed, in taking censuses in that part of Taranaki.

Some previous observers have claimed that contact and then the wars of the 'sixties caused the Maori population to tose hope', and thus, to decline in numbers. The commentators who noted the 'despairt of the Maoris in the late nineteenth century refer also to the 'Maori Renaissance' in the 1890 s and the early 1900s. If an ethnic minority deserves praise for finding its own salvation in a plural society, it is the Maori; and, if a date must be set for the commencement of this rehabilitation, it is the 1890s. In that period, inspired by Carrol1 and others, one of the most remarkable school-1eaving lcohorts' ever to enter adult life met at their school, Te Aute College, a Church of England residential secondary school for Maoris. Among the most renowned were Maui Pomare, Apirana Ngata, and Peter Buck. At these meetings, the Maori situation was discussed, plans were formulated for its alleviation, and the Young Maori Party was formed. Pomare entered an American medical school, and, when the Department of Public Health was formed in 1900, he was recalled to take charge of matters pertaining to Maori hygéine. There, he was joined by Buck, who had also graduated in 
medicine. The impact on Maori health by the campaigns conducted by these men is discussed 1 ater, but, as one historian has said, the primary problem in Maori revival was the conquest of disease'. 4 About 1910 , these two entered politics, whereupon Carroll christened Buck 'Te Rangihiroa'. Later, Sir Maui Pomare became a cabinet minister, retiring from public life in the 1920s. Te Rangihiroa headed the Health Department's Division of Maori Health in the 1920s, but resigned from this duty and was replaced by Dr El1ison (Erihana), another Young Maori Party member. At that stage, Te Rangihiroa went overseas to become a world-famous ethnologist, and later died in Hawaii.

\section{The Period $1910-40$}

Between 1910 and 1938 still more 1 and was alienated, so that by 1939 , as is true today, the Maoris held only 4,000,000 acres out of a total of $66,000,000$. But 777,000 acres of this remaining Maori 1 and are not suitable for farm development, while another 750,000 acres are 1 eased to Europeans. 5

Meanwhile two important events were occurring. The first was the rise, in the 1920s, of another millenarian cult whose leader Ratana, from which it takes its name, was a faith healer. Ratana still has many adherents, as does the American religion, the Church of Jesus Christ of the Latter Day Saints (Mormons) (See Appendix A). Later, Ratana's interests spread to politics and, in the 1930s, the movement became associated with the Labour Party. From the electoral defeat of Ngata until, but probably excluding, the election of 1963, al1 Maori M.P.s have been elders of this religion. The support of Labour by Ratana, and 1 ater by Maoris in general, had significant results. The first Labour government, from 1935 to 1949 , greatly extended

\section{$\overline{4}$}

01 iver (1960): p.260. 5 P.47. Hunn, J.K. (1961): Report on Dept. of Maori Affairs, We 11 ington. 
expenditure on Maori welfare, housing and education, while ensuring that Maoris received equality of treatment in all social welfare legislation which they administered and/or introduced.

Secondly, in 1929, with prompting from Sir Apirana Ngata, who had graduated in 1 aw and who had been appointed Native Minister in 1928, a Native Land Act was passed, which allowed the use of government funds for Maori land development schemes. Moreover, in the $1920 \mathrm{~s}$, commissions had investigated Maori 1 and claims, some of the unfair features of confiscation had been redeemed and compensatory payments made. In the early $1930 \mathrm{~s}$, the progress of these land schemes was watched over by Ngata, who also initiated 'incorporation' and 'consolidation'. The first involved the management of unfragmented 1 and blocks as corporate companies. The second was the combining of fragmented, and thus uneconomic, blocks of land, particularly where small blocks could not be used because of multiple ownership. His schemes were most successful among his own tribesmen, the Ngati Porou of the East Coast, while Ngata himself seems to have been determined to achieve results with scant regard for bureaucratic niceties. This was justified, in part, because the Maori problems required rapid attention but, unfortunately, these two factors led to the discrediting of the department's work by a Royal Commission in 1934. $\mathrm{Ngata}$ resigned because this was an indirect indictment of his work, while the press advocated that a Maori should never again be given a portfolio, 'and certainly not Native Minister'. 6 The Labour Government increased expenditure on the 1 and schemes,

6 Harre (1963): p.9, quoting N.Z. Herald, Ist Nov. 1934. 
revitalising those which had been curtailed by the slump, and thus the area 'broken-in' was extended from 253,000 acres in 1939 , to 559,000 in 1946 .

Until the war, Ngata and most observers had predicted that the future of the Maoris was on the 1 and, but, since then, views have changed, for the number of maoris who can be settled on the 1 and is 1 imited. Hunn, formerly secretary of the Department of Maori Affairs, has estimated that if all the idle Maori 1 and were developed and settled, it would not provide more than 4,000 farms at most. By that time, the Maori population may be half a millions. 7 It is obvious that the future of the Maoris does not 1 ie in farming to any considerable extent, and thus the major issues of race relations have swung away from this sphere.

In these earlier years and even recently, the contentious issues over 1 and have taken the following forms. Firstly, Maori land is inherited both through the female and through the male lines, so that an individual receives both his mother's and his father's rights to certain properties. By the act of individualising titles, and because of the rapid increase in the Maori population, multiple ownership of even the smallest block can be extreme. As there is a tendency for individuals to retain their claims, the block must be 1 arge enough for any user to make sufficient profit to pay dividends to the many owners. Besides this, a potential user must first obtain consent from all these people, who may reside anywhere in New Zealand or overseas, and may belong to any tribe. Thus, much Maori land has been forced to remain idle, although, as suggested above, the amount may be less than is popularly believed. Secondly, the Maoris have resumed much of the 1 and rented on 1 ong-term leases to Europeans. This 1 and

$\overline{7}$

Hunn (1961): p.29. 
has sometimes become unused for the reason noted above.

Another reason is that some European lessees, determined to make a profit in the period of the lease, mismanaged and overgrazed their leaseholds, so that the Maoris have often been forced to return these properties to second-growth bush. This is sometimes misinterpreted as laziness or inefficiency - the losses incurred by the Maori owners are compared with the profits made by the former lessees, and an unfavourable concept of 'Maori farming' is formed.

These problems have declined in significance as the crucial area of contact between European and Maori has swung from the country to the city. But, an allied factor has been the decreasing importance of the sheep-breeding industry of much of the North Island's dissected hill country, in which a large proportion of Maori land is located, and which formerly was the ireservoirt from which the lowland farms drew their stock for fattening. The causes of this decline have been changes in market demands, the soil erosion and other factors which are a legacy of past mismanagement, and the increased efficiency of 1 owland farms, which now breed their own stock for fattening. Both Maori and European farmers have been affected by these changes, which have brought about declines in the acreage under grass particularly in these areas which are marginal both agriculturally and economically. Thus, one cause of friction has decreased because there is less desire by Europeans to retain leaseholds.

Throughout the first four decades of this century, Maoris had lived in isolated rural areas, where their accelerating growth rate went largely unnoticed. There was a comparative 1 ack of contact between Maori and European,

friction being restricted mainly to 1 and issues, and relations were unstrained and untested. The major point of demographic interest in this period is that the Maoris seem 
to have recouped, in part, their losses of the nineteenth

century. The ground was being prepared for the demographic transition of the last two decades.

\section{Race Relations since World War II}

In every sense, population trends are the basic elements in the post-war patterns of race relations. These trends have been the product of a mortality transition, which has resulted in extremely high rates of growth; and, rapid urbanisation, which has been accompanied by a change in the occupational structure of the Maori work-force. But, as these demographic factors are merely a part of the complex matrix of race relations, it is necessary to nominate the other factors.

Today, there are few legislative or administrative discriminations between Maori and European, and most legislation of this kind either protects or favours Maoris. Furthermore, in statutes there is no single definition of Maori, so that each act which distinguishes Maoris from nonMaoris applies, at least in theory, to a different group. For example, the Ngarimu Scholarship may go to any person 'descended from a Maorit, while for a birth to be recorded as Maori, the infant must be thalf-caste or more'. In turn, this definition differs slightly from that in the census, and so on.

Superficially, the most discriminatory procedure is the retention of Maori schools and separate Maori electorates. Persons who are Maori must enrol in Maori electorates; persons who are 'less than half-Maori' must enrol in a general electorate. Persons who are 'half-Maori' and 'half non-Maori' can make a choice, which can be changed from election to election. Thus, Sir James Carrol1, who was half-Maori, represented, at different periods, both Maori and general seats. Officials have no means of checking or enforcing 
enrolment in Maori or non-Maori electorates. At present there is no evidence that Maoris wish their separate representation to be abolished, for in this way they are guaranteed a direct voice in the nation's affairs. Moreover, neither of the two main political parties give any indication of wishing to change this situation. Labour could lose four fairly safe seats, while several secure National ('Right-Wing') rural seats, in which there are large Maori populations, could become marginal. Instead, the major demands for a reform have come from the 'Right-Wingt press, which has depicted the Maoris as capricious and irresponsible Labour voters. 8 In fact, their continued support of Labour, which, as was noted, has given considerable thought to Maori welfare, is an indication of both reliability and responsibility. Nevertheless, if separate representation is retained, there is a need to extend the number of Maori seats. 9

Maori schools are located only in areas in which the majority of people are Maori. Their curricula are substantially the same as those of other schools, except that Maori 1 anguage, arts and crafts are taught. Any child may attend these schools, while today over 70 per cent of Maori children attend the normal schools. There is only one locality known to the present writer where the two schools exist side by side. This special case has provoked widespread criticism, as have many other features of race $\overline{8}$

See Part IV.Thompson, R.H.T. (1953-55): 'Maori Affairs \& the N.Z. Press', J.P.S. I, vol.62, no.4, Dec. 1953, pp.366-83; II, vol.63, no.1, Mar. 1954, pp.1-16; III, vol.63, no.3, Sept-Dec. 1954, pp.216-27; and IV, vo1.64, no.1, Mar. 1955, pp.22-34. (In 4 parts). Since Thompson wrote one important change has been the cessation of 'race-labelling' in reports of criminal court proceedings. 9

pp.8-10. Jackson, Keith (1962): 'The Electoral Framework', in Chapman, R.M. et al: N.Z. Politics in Action: The 1960 General Election, London. 
relations in this district, where many of the Maoris work on market gardens.

The situation might have remained static, with conditions as they were in 1940 , with Maoris enjoying virtually the same privileges as European non-Maoris, with comparatively 1ittle contact of an abrasive sort between the groups, and with European New Zealanders maintaining that prejudice was absent. However, the high rate of population growth, coupled with an increasing shortage of 1 and and work in rural areas, has resulted in the rapid urbanisation of Maoris in the post-war period. Rural-urban migration has brought Maoris into close contact with non-Maoris, and this has created many problems. The concentration of Maoris into unskilled jobs, and the relative absence of Maoris from tertiary industry and from employment as highly-skilled operatives in manufacturing could result from discrimination. But, it is difficult to decide whether this is the reason, or whether the causes are the low average level of Maori educational attainment, or a desire by Maoris to seek employment where they know there will be other Maori workers. For example, there is every reason to believe that there is active discouragement of Maoris seeking employment in privately owned retalling, banking and insurance firms. 10 These employers will often excuse their action on the grounds that their clients would not like to be served by a Maori. But this may be a rationalisation based on the commonly held prejudice that Maoris cannot be 'trusted with money', or that they will extend credit haphazardly to 'countless relatives'. By contrast, the absence of Maoris

$\overline{10}$

This and other views expressed here have been gained by the present writer from reading, from field-work in Maori communities, from a short spell teaching in a Maori school, and from discussions with Maori students and others conducting social research projects on Maori people. 
from the professions - the clergy, nursing and teaching being exceptions - can be taken as an indication of the lack of education of many Maoris. A few have entered every profession, and there is no code prohibiting Maoris from membership in any professional body. For example, there is at least one Maori professor, numerous medical practitioners, and the last High Commissioner in Malaya was a Maori. In the field of popular entertainment, many of the performers are Maori. There appears to be no discrimination against Maoris in trade unions, for a number of high-ranking union officials have been Maori, and wage demands and awards are the same for both Maoris and nonMaoris. Finally, the government does not employany discriminatory policy when making appointments.

Socially, the situation is much more diversified. Moreover, there are probably regional differences in the patterns of race relations resulting from differing proportions of Maoris in each area, past events, the present economic and social conditions of the Maoris, degree and type of contact, etc. Thus, in a paper delivered by Ritchie, a psychologist whose main work has been in rural communities and in the Wellington urban area, a favourable view was presented of Maori-European relations. ${ }^{11}$ But, in Wellington, Maoris make up a smaller proportion of the population than they do, for example, in the Auckland urban area. Probably, there are more Maoris, at all levels, in middle-class occupations in Wellington, in particular in government services. In Auckland the problems of Maori-European relations were compounded by the fact that some 4,600 Pacific Island Polynesians resided in the urban area in 1956 (this number must be 1 arger now). At that

$\overline{11}$

Ritchie, J.E. in a symposium Polynesian Pops. of N.Z. \& the South Pacific', Section F, A.N.Z.A.A.S., Canberra., Canberra. 20 th Jan. 1964. Dr Ritchie prefaced this paper by the qualification that his comments referred only to Wellington and a rural community in the centre of the North Island. 
date, they constituted a large proportion of the total membership of their group in New Zealand -73 per cent of all Niueans in New Zealand lived in the Auckland urban area, as did 61 per cent of the Samoans, 64 per cent of Tongans and 47 per cent of Cook Islanders. They are congregated in the central city districts, as are many of the Maoris, and are competing for the same unskilled jobs. 12

Furthermore, there are probably rural-urban differences in the patterns of race relations. In rural areas Maoris can readily keep contact with Europeans to a minimum, and, if discriminated against, they can regain confidence within the protected enclaves of their own rural society with whose institutions they are thoroughly familiar. In the city, even if Maoris live and work among other Maoris, they cannot avoid contact completely. There are, it might be added, no 'ghettoes', nor 'Maori zones', nor 'Island belts' in any New Zealand city. There is some tendency for each of these Polynesian groups to congregate, but Maoris do so to a lesser degree than the Pacific Islanders. ${ }^{13}$ The city Maori stands a greater chance than his rural kinsmen of meeting discrimination, and, if it occurs, there are fewer means available to him by which he may regain confidence. On the other hand, if migration is at all selective, it might be supposed that the migrants are those who already have the greatest self-confidence.

\footnotetext{
12 passim. Poo1, Ian (1961): 'Maoris in Auckland: A Pop. Study', J.P.S., vo1.70, no.1, Mar. pp.43-66. 13

Pool (1961): pp.57-58. Some 50\% of urban Maoris live in Auckland, as do high proportions of all Pacific Islanders, rural and urban (see above; if urban cook be shown for them taken alone a similar concentration couldook Islanders). Thus, there are several 'rural groupingsckland experience, which generalisations can be made from has observed in the are supported by whatington and Hutt urban areas.
} 
The attitudes of European New Zealanders to Maoris seem to take six common forms:

1. There is overt prejudice; a dislike of Maoris, perhaps based on one unhappy experience upon which an antagonistic attitude is based. It may take the form of a rationalisation that Maoris are inferior, cannot achieve higher educational goals, etc.

2. Such patronising expressions as: 'Our Maoris...',

A fine, proud race...', The Maoris are a very superior type of coloured race...', After a11, some Maoris are quite intelligent...' are heard quite frequent1y.

3. Europeans often maintain an unfavourable stereotype. The individual Maori must show that it does not apply to him before he is admitted to full equality. 01iver has said:

This, essential1y, is an unfair demand- no one would ask a fellow European to prove beyond doubt that he was not shiftless but it accurately indicates the kind of effort the Maori must make. He must prevent himself from becoming the kind of person too many of his European fellow-countrymen already assume him to be. He must prevent himself, above all else, from becoming a dark-skinned city slum dweller, a worker without ski11.14

4. There is a peculiar attitude composed of paradoxes. Thus, some persons will condemn Maoris for being thriftless, 'happy-go-1ucky', 'shiftless' and for '1ivingoff their relations', but envy them their slack of worries and tensions', their lability to shrug off any cares' and their assurance that if they ever go broke, they'11 be looked after', and so on. So often people will say: IIf the worst comes to the worst, Maoris can always return to the mat'. This phrase, which refers to the fact that, 
traditionally, Maoris slept on flax mats, contains

elements of both envy and malice. It is wrong to assume

that Maoris have no worries, for even the small Maori

rural communities are as full of tensions and factions

as any other village. Furthermore, the privations

suffered by Maoris during the depression of the 1930 s

controvert the view that they always have economic

security.

5. There are the persons who claim they are

unprejudiced, but avoid close contact with Maoris. A not dissimilar view is expressed by the man who will

drink with a Maori workmate, but will 'draw the line'

at taking him home for a meal.

6. Finally, there are probably some Europeans who are

not prejudiced, or else are apathetic to the whole

question.

Given that there is no discriminatory legislation, the major discriminations applied against the Maoris will be at this inter-personal level. For example, it may occur with respect to hotel accommodation, lodgings, retail credit and all but the statutory forms of car insurance. In Hilliardis novel, Netta Samuels, a young Maori girl who has migrated to Wellington, swiftly learns about lodgings: "Trouble is, about rooms', Myra said, "other girls, Pakeha girls, they do all right, but you and me don't get on so good. There's only a few places take Maoris, and they're all rough places". "Thompson notes that newspaper advertisements of vacant lodgings often contain such phrases as Europeans only', while he quotes a survey which suggests that a minority of hotels discriminate against Maoris. 15

P.74. Hilliard, Noel (1960): Maori Girl, London. A sympathetic novel about the problems facing urbanising Maoris; and, p.32. Thompson, Richard (1963): Race Relations in N.Z.: A Review of the Literature, National Council of Churches, Christchurch. 
By contrast, there is a highly favourable, almost

sentimental attitude based on their achievements, towards

Maoris in sport and as soldiers in both wars. Latterly,

Maori girls have been winning beauty contests, from the

district level up to the national.

One of the most interesting sample tests of the ethnic

attitudes of New Zealand children has been carried out by

Vaughan, a psychologist, whose results show: ${ }^{16}$

1. The development of ethnic attitudes in Maori and

Pakeha [subjects] is curvilinearly related to age...'

2. Neither degree of ethnic awareness nor nature of

ethnic attitudes are significantly related to

differences in socio-economic status among Pakeha

subjects...

3. Own-race preference in older Pakeha children is

less marked than that reported in White American

children...

Elsewhere, using two samples of children at schools chosen in 'working-class' areas in Christchurch, where there are few Maoris, and Auckland, where there are many, Vaughan and Thompson have shown that 'prejudice may be reduced by equal status contact 17

The most important field of inter-personal race relations is that of inter-marriage and miscegenation. Four truisms can be made, but, at present, there are virtually no supporting data. 18

16

Abstract. Vaughan, G.M. (1962): Ethnic Awareness \& Attitudes: A Developmental Study of Maori \& Pakeha Children in N.Z., Thesis $(\mathrm{Ph} \cdot \mathrm{D})(\mathrm{V}, \mathrm{U}$.$) .$

17

P.704. Vaughan, G.M. \& Thompson, R.H.T. (1961): 'N.Z.

Children's Attitudes Towards Maoris', Journ. of Abnormal \& Social Psychology, vo1.62, no.3, pp.701-4. 18

Harre (see fn.2) has recently completed a research project on this subject, but his results were not available at the time of writing this thesis. 
Firstly, a very considerable degree of miscegenation has occurred. Today, in spite of the censuses' reports on the proportions of the Maoris who claim to be 'ful1-blooded', it seems that a significant proportion of Maoris may have some non-Maori forebears. The corollary to this is that a sense of 'belonging' is a more significant criterion than 'degree of b1ood', by which to distinguish between the two groups for social research. This, in fact, is the 'man in the street's' criterion, along with the more obvious, if less meaningful, factor of colour or appearance. Ritchie has described what he terms IMaoriness': In New Zealand today there is little sense in using a physical or racial definition of who is and who is not Maori... Being Maori means that in addition to knowledge of and participation in, the patterns of non-Maori New Zealand life, the person who acknowledges his Maoriness acts in terms of another whole set of purposes and intentions and possibilities 19

Secondly, many European families, at least those in the North Island and of several generations' residence in New Zealand, have either Maori forebears or else Maori relationsin-1aw. While some persons, Maori and non-Maori, may attempt to hide their background, there is nothing in New Zealand akin to the 'passing' of Negroes in the United States, and Europeans of all social classes may admit to having Maori forebears. Terms such as a 'Touch of the tar brush' are in use in New Zealand, but social position and religion are probably more important criteria of marriageability than a trace of Maori blood?. Thirdly, miscegenation is still occurring outside the bounds of legal marriage, while legal ceremonies between Maoris and non-Maoris are a frequent event, occurring at all social

19 p.45. Ritchie, James E. (1963): The Making of a Maori, We11ington. 
1eve1s. Fourth1y, inter-marriage often brings about disunity among families, but a compromise may develop whereby the Maori relation-in-1aw is no longer regarded as Maori, even though severe general prejudices against Maoris may be retained.

Government spokesmen often claim that racial prejudice

does not occur in their country. It is probably true that prejudice is less severe than in other plural societies. Most importantly, the official view is that Maoris and non-Maoris should be integrated', while there is opposition to 'assimilation' and, of course, to 'segregation'. The official attitude is To combine (not fuse) the Maori and Pakeha elements to form one nation wherein Maori culture remains distinct. This is taken as being different from 'Assimilation: To become absorbed, blended, amalgamated, with complete loss of Maori culture? ${ }^{20}$ Geddes has written that the concept of integration implicitly accepts two propositions:

The first proposition is that for a long time to come Maoris, because of differences in physical appearance and differences in culture, will remain a distinctive section of the New Zealand population. The second proposition is that changes in the lifeways bringing greater economic and social equality, similarity and possible identity with the European supposing for the moment all three to be desirable will be adopted more easily by a people proud of their ethnic associations and fortified by group membership than by a people disrupted and ashamed.21

By contrast, he continues, assimilation would rob [the Maoris] of contentment while they still lack the capacity and means to 1 ive happily on the European pattern', while 'public emphasis upon assimilation...can increase the sense of superiority held by the European group and thus make the culturally different person less acceptable to them'.

20 Hunn (1961): p.15. See also Booth, J.M.\&Hunn, J.K. (1962): Integration of Maori \& Pakeha, Special Studies by Dept. of Maori Affairs, Wellington. 21

this and following quotes see p.220 \& passim. Gedds, W.R. (1961): 'Maori \& Aborigine: A Comparison of Attitudes \& Policies', Aust. Journ. of Science, vol.24, no.5, Nov. pp.217-25. 
Most writers argue that there must be equality of economic and social opportunity, but Maori and non-Maori must have the right to associate freely in groups of their own choosing. Although these groups probably will be defined along ethnic lines, their boundaries, according to Geddes, 'need be only partial and flexible' and they will contribute to the improvement of Maori living conditions. Moreover, the view that all Maoris desire to participate primarily in the Maori culture is fallacious, for some individual Maoris are already outside the boundaries of 'a distinctively Maori culture which ever will be undergoing modification'.

Thompson observes that flexibility, akin to that advocated by Geddes, is a reality in contemporary New Zealand:

A feature of Maori-Pakeha relations is their fluid quality. There is mobility between these groups. Maoris can to a large extent move across and be regarded as Pakehas, and part-Maoris can be fully accepted as members of the Maori community... This is an untidy situation from an administrative point of view, but so long as relationships do not set into prematurely fixed forms, so long will the society be able to regain its equilibrium with relative ease in the face of rapid social change. ${ }^{22}$

obviously this 'fluid quality' and 'untidy situation' creates a problem for officials charged with the collection of census and vital statistics relating specifically to either population.

Underlying the official view on race relations are two implicit beliefs of New Zealanders:

1. The ideology of equality has been a persistent theme in New Zealand's history.... and appears to extend beyond the issues of race relations to an equalitarianism which regards all social inequalities as unjustifiablel. This carries a disadvantage, so Thompson claims, for there seems to be a deep distrust 
of non-conformity, an inability to visualize a plura society in which the 'otherness' of a different cultural group is accepted as a matter of course. ${ }^{23}$

2. New Zealanders accept almost without questioning the creed that race relations are on a satisfactory plane.

The constant emphasis of the 1 ack of prejudice in New Zeal and has created, so an American critic, Ausldbel, claims, a complacency in New Zealanders, as well as a tendency to overlook or rationalise their own extreme prejudices. ${ }^{24}$ His view, which is correct in essence, if rather severely stated, overlooks two other factors:

1. While individuals may be prejudiced, these same persons will be appalled by such acts on the part of institutions, or even by evidence of prejudice in other individuals. Their whole process of incidental learning has taught them to be repulsed by overt discrimination. 2. Community pressures and attitudes are weighted against discriminatory acts carried out by individuals or bodies.

By analogy, people take cuttings from a botanical reserve, but may describe such behaviour in other individuals as criminal. If vandals create wanton destruction, they will join with the community as a whole in prescribing drastic punishments for the offenders.

Even while Ausubel was writing, New Zealand's racial attitudes were being 1 aid bare by two significant events.

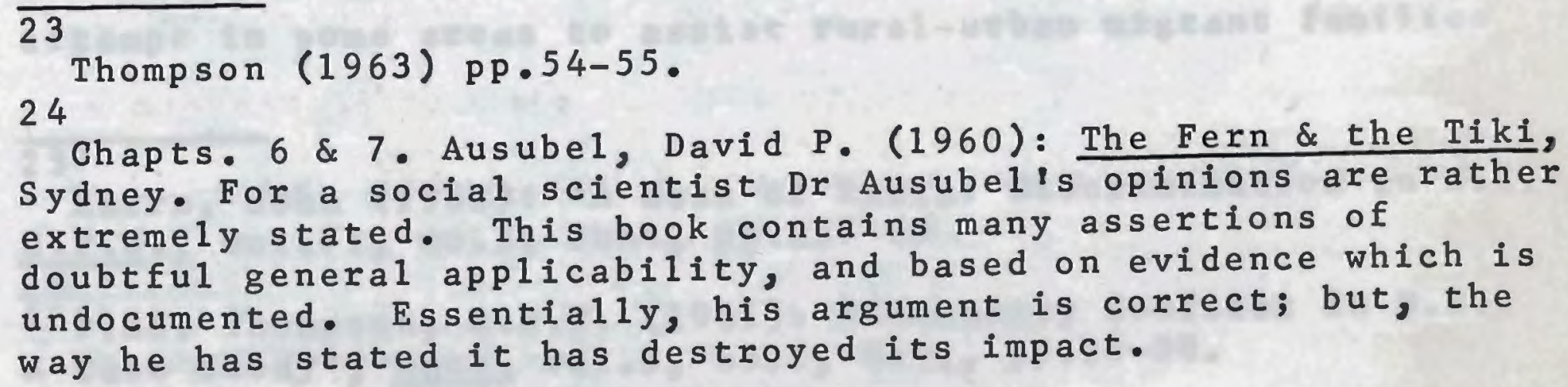
Sydney. For a social scientist Dr Ausubelis opinions are rather extremely stated. This book contains many assertions of doubtful general applicability, and based on evidence which is undocumented. Essentially, his argument is correct; but, the way he has stated it has destroyed its impact. 
Firstly, a Maori medical practitioner, the brother of the High Commissioner in Malaya, was refused service in a hote1. 25

This nationally publicised event created a considerable stir in the press, and demonstrated that discriminations did occur.

This caused surprise to many Europeans, while government officials were forced to clarify the legal position.

Secondly, the decision of the Rugby Football Union - this

is the major national sport - to send an 'all-white' team to

South Africa in 1960 caused a tremendous controversy. Students, trade unionists, clergy and citizens from all walks of life, religious denominations, and political parties, led by a number of distinguished persons, protested against the Union. The team went, but,

The All Black [the name given to New Zealand rugby union representatives] controversy provided the opportunity for a much needed reassessment of the idealised Maori-European relations... The Rugby Union's decision provided the opportunity to reaffirm the belief that there should be no colour bar in the Dominion. The strength and persistence of the affirmation surprised rugby officials, the party leaders and the country as a whole... The controversy demonstrated that the customary protestations of racial equality have a surprising vitality. 26

There is every hope that race-relations may improve. A pointer to this is the more mature attitude evident in New Zealanders after the rethinking involved during the two events discussed above. There are more and more Maoris taking up responsible professional positions. Today, urban European children are likely to have Maoris as teachers as well as playmates. Members of various service organisations are attempting to meet Maoris and to help them. There is an attempt in some areas to assist rural-urban migrant families

$\overline{2} \overline{5}$

Harre, John (1962): AA Case of Racial Discrimination in N.Z.', $\frac{J}{2} \cdot$ P.S., vol.71, no.2, June, pp.257-60

$\frac{\pi}{2} 6$

P.38. Thompson, R.H.T. (1961): 'Community Conflict in N.Z.:

A Case Study', Race, vol.3, no.1, Nov., pp.28-38. 
to establish themselves in their new surroundings, to obtain retail credit and to accumulate savings and property. Finally, there seems to be a gain in confidence on the part of the Maoris.

\section{On the debit side, much Maori housing is still sub-} standard; 1ife-expectation and standards of health remain below those of non-Maoris; and, economically, Maoris are still at a disadvantage. Pearson has described the position most succinctly: The most striking feature of the Maori situation seventeen years after the end of the war is the continued existence, within the welfare state, of rural enclaves of material poverty and, in city and country, spiritual insecurity'. 27

Little has been said here about Maori attitudes, important as these may be. For example, Maori rural-urban migrants, who are changing their social milieu as well as their place of residence, must be forced to make considerable personal adjustments. Instead, it has been presumed that Maoris, although wishing to maintain certain distinct ways of life (see above), should also have the right and opportunity to participate fully in the economy of their country. This is an expert economy based on pastoral and other rural industries which are highly-capitalised and mechanised. Yet, because of mechanisation, rural labour requirements are minimal, and 60 per cent of non-Maori New Zealanders are urban dwellers. Thus, the bias here has been toward an analysis of the attitudes of the non-Maori majority into whose styles of living the Maoris are being drawn at an accelerating pace.

27 Pearson (1962): p.148. 
A study can now be made of the demographic causes of the transition in the Maori way of 1 ife and the related consequences, within the framework of the general pattern of race relations outlined above. It can be seen that a detailed review of Maori demographic trends could hardly come at a more significant period in New Zealand's social history; a period in which the whole delicate fabric of race relations is being severely tested.

This study has wider implications. The high fertility, the high but declining mortality of the Maoris, and their rapid urbanisation are similar to patterns which are occurring widely throughout the non-Western portions of the world. Generally, there is the advantage that Maori population data are of a higher quality than those for populations in many of the 'under-developed nations. Thus, as Borrie has said: 'an admirable laboratory for the study of an emergent population exists amongst the Maoris and New Zealand. 128

The major difference is that these trends are occurring to one segment of a plural society. Plural societies exist in many other countries, but in the 'under-developed' nations there is seldom such a difference in living standard between the majority and minority populations. Herein lies a critical implication - can the Maoris, in view of current demographic trends, reach the same high standards of living as their fellow countrymen, an opportunity which is denied by national economic circumstances to many other emergent populations? 28.
P.249. Borrie, W.D. (1959): The Maori Pop.: A Microcosm of Anthropology in the South Seas, New P1ymouth, N.Z. pp.247-62. 


\section{Introduction}

This chapter is concerned with the range of demographic data available for Maoris, ${ }^{1}$ but not with their quality - a subject which will be raised in 1 ater chapters. In the present chapter topics to be discussed are: When did attempts to enumerate the Maori population as a whole supersede mere estimates of its size? What data on Maoris were tabulated at each census? Which persons were enumerated as Maoris or nonMaoris? What 'vital data' are available prior to the introduction of the registration of Maori births and deaths? When did vital registration commence for Maoris? Which persons were included on Maori or non-Maori registers? What information was tabulated in the Maori vital register? What data are available on marriages, marital status, etc.?

\section{Estimates and Census Enumerations: Early Estimates}

Prior to 1857-58 there were no full-scale attempts to enumerate the Maori population. There were 'censuses' of some small areas, although these were often really estimates based upon a detailed knowledge of the district, rather than on enumeration by means of a head count. In a few areas some officials and missionaries, particularly the latter, took actual counts, and even attempted to differentiate adults from children, and to tabulate tribes, hapu, etc.

1

There is a reliable and comprehensive bibliography of N.Z. Statistical Sources, which discusses their compilation and, in general terms, their scope. See Dept. of Statistics (1961): Statistical Publications, 1840-1960, Wellington. 
These early estimates fall into three chronological groups:

1. From 1769 to c.1830 there were very few estimates;

in fact, the only ones known to the present writer are Cook's (1769-74), Forster's (c.1773: Forster was on Cook's second voyage), and Nicholas' (1817)

2. From c.1830 to c.1840 non-Maori settlement was concentrated in the north of the North Island, around the Bay of Islands where there were many Maoris, and in the South of the South Island. The southern group of non-Maoris was engaged mainly in industries such as sealing, and was not concerned with the well-being of the few Maoris in the area. In the north the situation was different and the missionaries, as well as some traders, visiting ships' officers, etc. made estimates of the size of the Maori population. A number of these men, such as the trader Polack, published long accounts of life in early New Zealand. But, the most important source is the Report of the Select Committee of the House of Lords, ${ }^{2}$ which assembles the evidence of a wide range of visitors and settlers on the numbers and the well-being of the Maoris, as well as other subjects. Thus, there are a number of estimates of the Maori population for the $1830^{\prime} \mathrm{s}$, although some may emanate from one or two unacknowledged sources.

3. From 1840 to $1857 / 58$ there were more small scale detailed estimates, as well as a number of estimates of the size of the total Maori population. These estimates differ in two regards from their predecessors: (a) often they were based on widespread travel; and (b) 
the more detailed give some indication of the

geographical distribution of the Maori population.

\section{Fenton's Census}

In 1857-58, Francis Dart Fenton made the first attempt to enumerate the entire Maori population. Other than being purely a head count, Fenton's census differentiated between adults and minors in certain regions. The range of data collected by Fenton is shown in Table 2.1 .

Censuses Between 1874 and 1921

In 1867 , the size of the Maori population was estimated for North Island districts, and in 1868 there was a census of South Island Maoris.

The censuses of 1874-1921 are distinguished from 1 ater censuses by three features: 1. throughout the period concerned the Maori census included Maoris plus thalf-castes living as Maoris', but excluded 'half-castes living as Europeans from 1874-1921; 2. the officials, usually district officers of the Native Department, rather than Maori interviewees, filled in the questionnaires; 3 . the census enumeration took place over more than one night.

The range of data tabulated at these early censuses is given in Table 2.1. From the 1886 census onwards, it is possible to determine age and sex structure and to calculate child-woman ratios, both for the total Maori population and also for regions (and tribes until 1901). In general, detailed data - age by county or tribe - are not available for two groups, 'half-castes 1 iving as Europeans', and 'Maori wives'. At most censuses between 1874 and 1921 total numbers are the only data available for the first group, which was composed of persons arbitrarily differentiated, according to the individual enumerator's whim, from thalf-castes living 


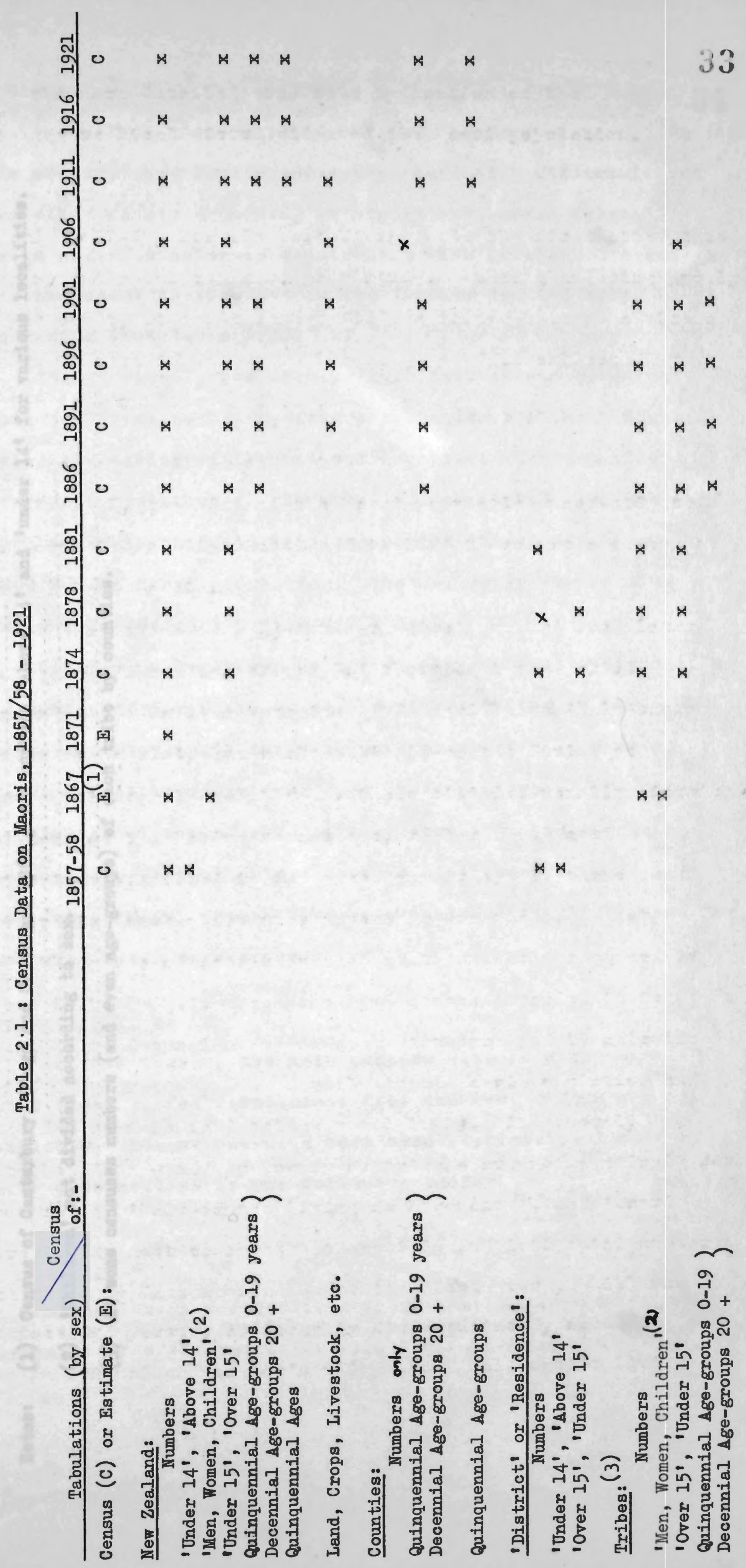




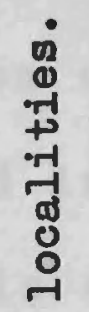

:

㔛

广

ఫ్్ㅀㅇ

ฐ

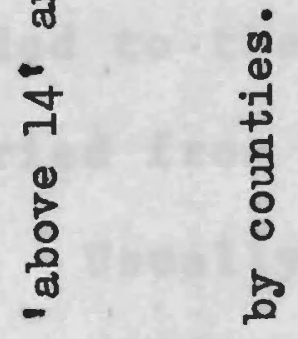

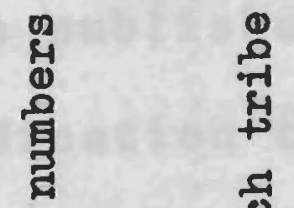

क्ष

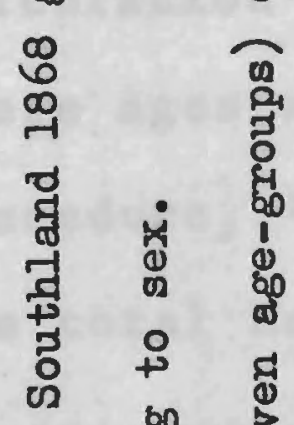

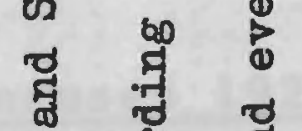

के :

0 व

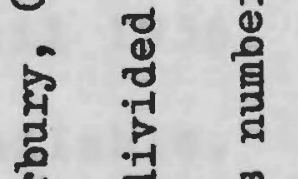

है

ฮี व

냉 뎡

热

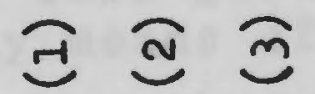

$\ddot{0}$
$\stackrel{0}{ \pm}$
$\stackrel{+}{0}$
$\stackrel{0}{*}$ 
as Maoris: 3 Thus, this group has had to be excluded from the detailed calculations carried out here on Maori census data for this period. However, because they have been differentiated from other Maoris according to highly subjective criteria, and in order to maintain consistency with subsequent censuses, this component is included in the figures for the total Maori population (see Table 3.2 ).

Maori wives', presumably 'full Maoris' who lived with their non-Maori husbands, were enumerated with their husbands during the taking of the non-Maori census. Subsequently, information relating to the wives was extracted from the nonMaori schedules and the total number of 'Maori wives' was added to the Maori population. The number of Maori wives? varied from 196 to 379 (see Table 3.2).

Usually no breakdown by age or geographical distribution was published for these women. Moreover, there is no indication that their children were enumerated as Maoris, so Maori wives' were excluded from the denominator during the calculation of child-woman ratios, even in those instances where ages were available. However, following census procedure, Maori wives' have been included in the figures for the total Maori population.

\section{Gensuses 1926-61}

In this thesis, the main concern will be with censuses until 1956, as few tabulations from the 1961 census are yet available. Recent censuses have been distinguished from their predecessors by the following facts:

3 more detailed data From the census reports it appears non-Maori census, without any means of differentiation from the remaining non-Maoris. 
1. Household heads have been responsible for the enumeration. This procedure had been adopted for the South Island Maoris, a small proportion of the total, at the 1916 census.

2. Questions asked have been similar to those asked of non-Maoris, while since 1951 the same schedule has been employed for both populations. 3. The range of data collected has been greatly extended, as can be seen by comparing Table 2.2 . with Table 2.1, and the census has included a variety of questions about socio-economics, as well as more narrowly demographic variables.

4. The census has been taken on the one night.

5. The differentiation between the two types of 'half caste', those 'living as Europeans' and those living as Maoris', has been abandoned, while minor illogicalities regarding persons 'part Maori' and part other non-European 'blood' have been gradually, but not completely, eliminated. The changes in the census definition of Maori in this period require further description.

As was noted above, throughout the nineteenth century and until, and including, the 1921 census, the Ienumeration covered Maoris and half-castes 1 iving as Maoris ${ }^{4}$ The 1921 census described the problem of half-castes:

The half-caste population consists of those who 1 ive as members of Maori tribes together with others living with and counted as Europeans in the census. It has proved a matter of some difficulty to ascertain the number of half-castes living as Maoris. There has been no definite rule to guide collectors in deciding when a half-caste should be classified as 1 iving as a Maori...5

4

Census (1921): Appendix A, p.1.

Census (1921): Appendix A, p.2. 


\section{Census of: \\ Tabulations (by sex for personal details). \\ 1. New Zealand:} 1926 1936 1945 $1951 \quad 1956(1)$

(a) Demographic

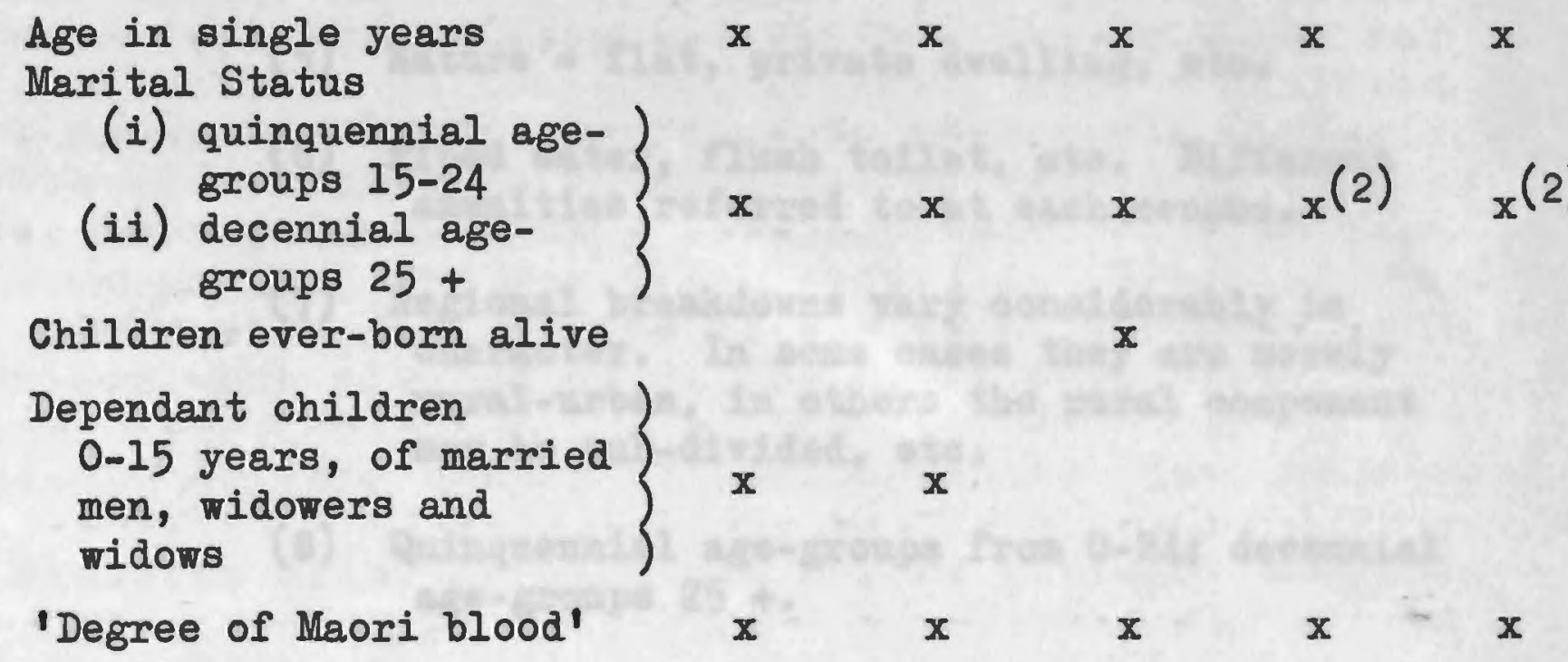

(b) Socio-Economic (3)

Religion
Specific Occupation
Occupational Status
(i.e. Managers,
wage or salary earner,
etc.)

$\begin{array}{llll}\mathbf{x} & \mathbf{x} & \mathbf{x} & \mathbf{x} \\ \mathbf{x} & \mathbf{x} & \mathbf{x} & \mathbf{x} \\ & & \mathbf{x} & \mathbf{x} \\ & & \mathbf{x} & \mathbf{x} \\ & & \mathbf{x} & \mathbf{x} \\ \mathbf{x}(4) & & \mathbf{x} & \mathbf{x}\end{array}$

War Service

(c) Household Schedule

$\begin{array}{llllll}\begin{array}{l}\text { Nature(5) and Tenure } \\ \text { of dwellings }\end{array} & \mathbf{x} & \mathbf{x} & \mathbf{x} & \mathbf{x} & \mathbf{x} \\ \begin{array}{l}\text { Occupants of dwellings } \\ \text { Rooms of dwellings }\end{array} & \mathbf{x} & \mathbf{x} & \mathbf{x} & \mathbf{x} & \mathbf{x} \\ \text { Amenities of dwellings(6) } & & & \mathbf{x} & \mathbf{x} & \mathbf{x} \\ \end{array}$

2. Data from which Regional Breakdowns may be obtained: (7)

$\begin{array}{llllll}\text { Age-groups (8) } & \mathbf{x} & \mathbf{x} & \mathbf{x} & \mathbf{x} & \mathbf{x} \\ \text { Marital Status } & \mathbf{x} & \mathbf{x} & \mathbf{x} & & \\ \text { 'Degree of Maori Blood'(9) } & \mathbf{x} & \mathbf{x} & \mathbf{x} & \mathbf{x} & \mathbf{x} \\ \text { Selected household data } & \mathbf{x} & \mathbf{x} & \mathbf{x} & \mathbf{x} & \mathbf{x}\end{array}$
Notes: (1) At the time of completion of this thesis the only
1961 census data available on Maoris were 'Distribution and Location' (Census (1961): Vol.1)

'Race' (Vol.v'I) and certain tabulations made available to the writer by the Department of Statistics to whom grateful acknowledgement is made.

(2) In 1956, quinquennial age-groups 25 +. In 1951 and $1956,16-19,20-24$, etc. 
(3) In 1956, and other years, these variables are of ten cross-tabulated together and with other variables. Inter censal comparisons difficult to make because classifications vary so much.

(4) Income data refer only to Maoris belonging to households enumerated on the general (i.e. nonMaori) schedules. Over $90 \%$ of Maori households were enumerated on the Maori schedules.

(5) Nature = flat, private dwelling, etc.

(6) Piped water, flush toilet, etc. Different amenities referred to at each census.

(7) Regional breakdowns vary considerably in character. In some cases they are merely rural-urban, in others the rural component may be sub-divided, etc.

(8) Quinquennial age-groups from 0-24; decennial age-groups $25+$.

(9) Urban areas only in 1951 and 1956. 
At the census of 1926 a number of administrative changes

were made including the first change in the definition of

Maoris :

The former practice in regard to European-Maoris of mixed-blood was to include them with the European or with the Maori population according to which race was nearer in point of blood. Thus quarter-castes were treated as Europeans and three-quarter-castes as Maoris... Half-castes, however, were classified European or Maori according to their mode of 1 iving. The classification of half-castes according to mode of 1 iving was becoming 1 ess satisfactory with each enumeration, and was discontinued in 1926, for which enumeration al1 persons of the Maori-European halfblood were classed among the Maori population. 6

The result of this change of definition is that detailed data from censuses prior to 1926 can not be strictly compared with those from 1926 on. 7

Two other definitions used at the 1926 census should be noted. The first, 1 ater to be changed, was that:

No known cases of descent from Maori and any non-

European race were classed with the Maori population, as it was considered preferable that these cases should be included with the race-alien division as was done for mixed-bloods of European and alien races. The distinction is perhaps a little finely drawn in the case of Maori-Polynesians, in view of the fact that Maoris are a division of the Polynesian race; but it is preferable to keep such instances apart.8 Secondly, the 'European' population was taken as the 'population exclusive of Maoris'. Thus, the term 'European', as used in the census, is synonymous with 'non-Maori'. It is felt by the present writer that the term 'non-Maori' is preferable to tEuropean', or the widely-used, colloquial term 'pakeha', which often refers solely to Europeans, in the usual

Census (1926): vo1.XIV, p.2.

7 Census (1926): vol.XIV, Table 1, gives the number of TMari Wives', 'half-castes 1 iving as Maoris' and 'half-castes living as Europeans' back to Fenton's census. This means that there is direct comparability solely for total numbers. 8

Census (1926): vol.XIV, p.3. The 'Race-alien' population included (see fn.14) al1 non-Maori non-Europeans, such as Indians, Chinese and Pacific Island Polynesians, as well as Syrians and Lebanese. 
sense of that word. 9 Therefore, non-Maori will be used here except when quoting another work.

No further changes were made until 1951, when MaoriOther Polynesians' (i.e. Tother Polynesians' are Pacific Islanders, such as Samoans and Cook Islanders) were included with the Maori population for the first time, 'whatever the degree of Maori blood'. 10 Thus, in 1951, the Census

Department noted that: For census purposes the Maori population includes all Maoris of full blood, all MaoriEuropean ha1f-castes, a11 Maori-Europeans who are nearer to Maori in blood than to European, and Maori-other Polynesians" 11

The Maori-other Polynesian' population numbered 263 in 1945, when it was classified as 'European', and 374 in 1951, when it was classified as Maori. As their numbers are so very small and as the majority of Polynesians entered New Zealand only after the war of $1939-45,12$ the inclusion of Maori-other Polynesians' in 1951, and their exclusion earlier from the Maori population, does not introduce any serious bias in terms of comparative analysis between censuses.

The most recent change was in 1956 when the census department noted then that: 13

For census purposes the Maori population includes all Maoris of full-blood, all persons with half or more Maori blood and all mixtures of Maoris with lother Polynesians'. Until 1956 all persons of mixed Maori

9 Census (1926): vo1.I, p.1. There is a considerable amount of
confusion caused by the Dept. of Statistics dual use of the word European. Generally, as a definition, they mean non-Maori and include Asians and other non-Maori non-Europeans in this category. Sometimes, as in a few quotations here, they use the term in its normal sense. 10

$$
\begin{aligned}
& 10 \text { Census (1956): vol. VII, p.6. } \\
& 11^{\text {Census }}(1951) \text { : vol.VI, p. } 4 . \\
& 12^{\text {Census }} \text { (1956): vol.VII, p.6. } \\
& 13^{\text {Census }} \text { (1956): vol.VIII, p.5. }
\end{aligned}
$$


and Other Races 14 blood were classified with the nonMaori population, but in 1956 those with half or more Maori blood were classified, logically, with the

Maori population; they numbered 820 in 1956 .

This statement is interpreted in Table 2.3.

Most of the persons included in the category lother Ethnic Groups', defined in footnote 14 , belong to long-established Chinese, Indian and Lebanese communities. Thus, throughout the period from 1921 to 1951, some persons classified as 'Europeans' would, by the 1956 definition, be classified as Maoris. Probably, they did not exceed 600 at any census. This estimate of 600 is arrived at for 1951 , by determining the proportion of the total Maori and 'other ethnic groups' 'Mixed bloods' included in the Maori census in 1956, then allotting a similar proportion to the 1951 census.

In summary the most important change in definition occurred at the 1926 census, being significant enough to complicate comparisons between pre-1926 Maori populations and the Maori population from this date onwards. However, the ages and other data published prior to 1926 can be compared with those collected for the period 1926 onward in order to see broad trends, but such a comparison must be taken as an approximation.

14

In Census (1956): vol.VII, p.1 and elsewhere the Dept. of Statistics includes all non-Europeans (except Maoris) in the category lother Races', which replaces the term 'Race Aliens' referred to in fn.8. But, the Department is bedevilled by its own definition, for Maori-other Polynesians' form a special case although they are included in the general category 'Other Races'. 1) All 'Maori-Other Polynesians' are included in the Maori Census, while for the tother Ethnic Groups included in the category lother Races inclusion in the Maori Census is limited to those 'mixed bloods' who are thalf or more Maori'. 2) The definition applying to 'other Polynesians: was introduced in 1951, while the definition applying to tother Ethnic Groups ' was not introduced until 1956. Thus reference will be made here to Maoris and nonMaoris, the latter being sub-divided into Europeans, 0 ther Polynesians' and 'Other Ethnic Groups'. This 1 ast category includes all non-Polynesian (i.e. Maori + lother Polynesian') non-Europeans. 
Tab1e 2.3.

Classification of Various Component Populations

in the 1956 Census of New Zealand

Included in the Maori

"Ful1" Maori
Included in the non-Maori Population

"Full" tEuropean (1)

"Full other Polynesian"(2)

"Ful1" sother ethnic group : (3)

"Mixed-bloods half or more Maori"

\section{Most other "Mixed-bloods"}

e.g.

e.g.

$3 / 4$ European - 1/4 Maori

$1 / 2$ Maori - 1/2 European'

$3 / 4$ Maori - $1 / 4$ sother Ethnic Group' $3 / 4$ IOther Ethnic Group $1 / 4$ Maori

$1 / 2$ Maori - 1/2 IOther Ethnic Group?

$3 / 4$ Maori - 1/4 "Other Polynesian"

$1 / 2$ Maori - 1/2 "Other Polynesian"

- - - - _ - _ - - - - - - - - - - - - - - - - - "Al1 mixtures of Maoris with Other Polynesians"

e.g.

$1 / 4$ Maori - 3/4 "Other Polynesian"

$1 / 16$ Maori - 15/16 "Other Polynesian"

Notes: (1) European in normal sense

(2) Included by the Dept. of Statistics with lother Ethnic Groups" in their category "Other Races". This procedure leads to confusion (see footnote 14).

(3) This term, the writer's, is used to avoid the confusion brought about by the term "Other Races". This group is composed mainly of Asians.

\section{Vital Data: Prior to 1913}

Until 1913, there was no systematic attempt to obtain vital data relating to Maoris. Maoris were exempted from vital registration, but could register if they desired. However, the 
published records do not go back beyond 1913. Even if the data had been published there would be no means of determining, for the purpose of calculating vital rates, an appropriate denominator which could be related to those Maoris who had chosen to register vital events. To obtain an indication of possible levels of mortality and fertility prior to 1913, it is necessary to turn to the accounts of missionaries, administrators and others. Until the $1860 \mathrm{~s}$, these sources are dispersed through many books, articles, reports, etc. However, in 1868 , data on prevalent diseases, population growth, etc. were given in the 'Reports on the Social and Political state of the Natives in Various Districts at the Time of Arrival of Sir G.F. Bowen", in Appendices to the Journal of the House of Representatives. The publication of similar annual reports of district officers continued from then until the early 1890s, while the publication of census enumerators ${ }^{\prime}$ reports, which contain some information, ceased only in 1916.

Generally, numerical data relating to morbidity or mortality consists merely of crude estimates, or else of a more detailed count of a selected locality. The major exceptions are morbidity statistics collected from several hospitals by Dr A.S. Thomson in the $1850 \mathrm{~s}$, and data based on cases attended by officials of the Department of Health from 1901 to 1907. Data on fertility are even more unsatisfactory, for this demographic process portrays fewer dramatic highlights than does, for example, epidemic mortality. However, the calculation of child-woman ratios mentioned above when 1 ate nineteenth century censuses were discussed, does permit some speculation about the levels of crude birth rates at that time. 
On April 1st 1913, the Births and Deaths Registration Amendment Act (1912) came into force. Similar acts in 1924 and 1951 incorporated the existing legislation which was changed only in 1961. By these acts Maori births and deaths were to be registered, a Maori' being defined as a person possessing 'half or more Maori blood', and non-Maori and Maori vital data were to be recorded on separate registers. Registration procedure was as follows: The informant gave the registrar details of the birth or death to be registered, including the 'degree of Maori blood', if any, of each parent. By adding together the fractions of 'Maori blood of both parents and dividing by two, the registrar determined whether the birth or death was to be registered as Maori or non-Maori. Once a birth or death was qualified for registration as Maori, different details were reported: 1. Degree of Maori blood' was recorded only for those births or deaths included on the Maori register. For non-Maoris there was no indication at all whether the child of the deceased person was of part-Maori descent. 2. Fewer facts about Maori births or deaths were recorded than for non-Maori. The range of Maori vital data published in this period is presented in Table 2.4 .

In the period 1913-19 only deaths and births were recorded, and it is possible that there was severe underregistration. No other detailed information about Maori morbidity and mortality is available, even in Department of Health reports, except for data relating to the 1913 smallpox epidemic and the 1918-19 influenza pandemic. From 1920 , statistics on deaths/age/cause permit a detailed analysis of mortality to be carried out. By contrast, any analysis of fertility in the period $1913-61$ is restricted to 


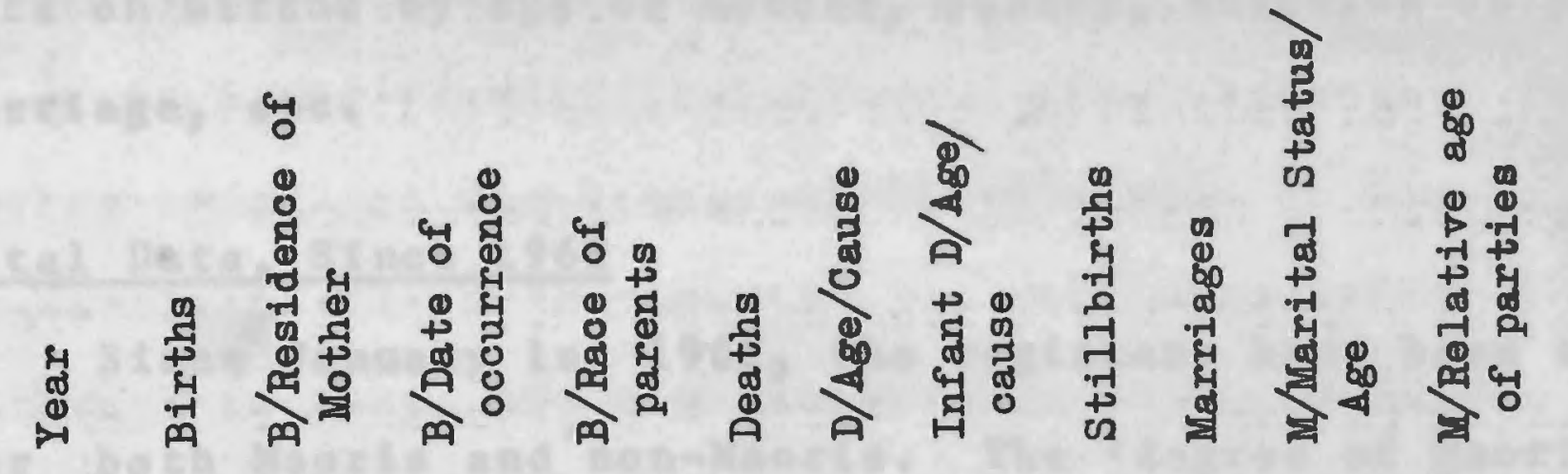

$1913 x$

$1914 \mathrm{x} x$

$1915 x$

$1916 \mathrm{x}$

$1917 x$

$1918 \mathrm{x}$

$1919 x$

$1920 \mathrm{x}$

$1921 \mathrm{x}$

$1922 x$

$1923 x$

$1924 x$

$1925 \mathrm{x}$

$1926 \mathrm{x}$

$1927 \mathrm{x}$

$1928 \mathrm{x}$

$1929 x$

$1930 \mathrm{x}$

$1931 x$

$1932 x$

$1933 x$

$1934 \mathrm{x}$

$1935 x$

$1936 \mathrm{x}$

$1937 x$

$1938 \mathrm{x}$

$1939 x$

$1940 x$

$1941 x$

$1942 x$

$1943 x$

$1944 \mathrm{x}$

$1945 x$

$1946 \mathrm{x}$

$1947 x$

$1948 \mathrm{x}$

$1949 \mathrm{x}$

$1950 \mathrm{x}$

$1951 \mathrm{x}$

$1952 x$

$1953 x$

$1954 \mathrm{x}$

$1955 \mathrm{x}$

$1956 x$

1957
1958

$\begin{array}{ll}1958 & x \\ 1959 & x\end{array}$

$1960(2)_{x}^{x}$

$\mathrm{x}$

$x$

$\mathrm{x}$

$\mathbf{x}$

$\mathrm{x}$

$x \quad x \quad x$

$x \quad x$

$x \quad x$

$x \quad x$

$x \quad x$

$x \quad x \quad x$

$x \quad x \quad x$

$x \quad x \quad x$

$x \quad x \quad x$

$x \quad x \quad x$

$\begin{array}{lll}\mathbf{x} & \mathbf{x} & \mathbf{x}\end{array}$

$x \quad x$

$\boldsymbol{x}$ x $\mathrm{x}$ x

$x$ x $x$ x

x $x$ x $x$

$x \quad x \quad x$

x $x$ x

x $x$ x $x$

$x \quad x \quad x$

$x \quad x \quad x \quad x$

x $x$ x $x$

$x \quad x \quad x$

x $x$ x $x$

$\begin{array}{lllll}\mathbf{x} & \mathbf{x} & \mathbf{x} & \mathbf{x}\end{array}$

$\begin{array}{lllll}x & x & x & x\end{array}$

$\begin{array}{lllll}x & x & x & x & x\end{array}$

$x \quad x \quad x \quad x \quad x$

$\begin{array}{lllll}x & x & x & x\end{array}$

$\begin{array}{lllll}x & x & x & x & x\end{array}$

$\begin{array}{lllll}x & x & x & x\end{array}$

$\begin{array}{lllll}x & x & x & x\end{array}$

$x \quad x \quad x \quad x$

$x \quad x$

$\begin{array}{ll}\mathbf{x} & \mathbf{x} \\ \mathbf{x} & \mathbf{x}\end{array}$

$\begin{array}{lllllll}\mathbf{x} & \mathbf{x} & \mathbf{x} & \mathbf{x} & \mathbf{x} & \mathbf{x} & \mathbf{x} \\ \mathbf{x} & \mathbf{x} & \mathbf{x} & \mathbf{x} & \mathbf{x} & \mathbf{x} & \mathbf{x}\end{array}$

$x=$ Years for which data were collected.

Notes: (1) Not all data have been published for 1962-64 so this table ends at 1961.

(2) In 1961 data on births, deaths and stillbirths by statistical areas (regions formed by combining adjacent administrative units) were published. 
the calculation of general fertility rates, for there are no data on births by age or mother, parity, duration of parents marriage, etc.

\section{Vital Data, Since 1962}

Since January 1 st 1962 , the registers have been the same for both Maoris and non-Maoris. The 'degree of Maori blood' of each parent of a deceased person or newly born child must be reported by the informant. This means that the questions asked of both Maoris and non-Maoris are now the same, and, presumably, the published Maori vital statistics could be broadened in scope.

The vital statistics collected since this administrative change were published in Report on the Vital Statistics of New Zealand for the Years 1962 and 1963. In spite of the wider range of questions now asked, the scope of the data published on Maoris remains unaltered. For example, there are still no data on births by age of mother. The major change has been in the tabulating of non-Maori data, which are now combined with the Maori to give Total Population' figures. The only data for which separate figures can be obtained for non-Maoris and this has to be done indirectly by the process: 'Total' minus Maori = non-Maori - are those for which separate data are published on Maoris. These Maori data are: deaths by age (deaths/age/cause will be tabulated in Report on the Medical Statistics of New Zealand which is not yet published for 1962); deaths and births by 'races' of parents; deaths, births and still births by statistical areas (regions made up of adjoining local government units); births by date of occurrence; and, births by normal residence of the mother. Ex-nuptial birth rates provide the most extreme example of the effect of combining data on Maoris and non-Maoris without also providing separate tabulations. Ex-nuptial births 
have risen from $5.0(1958), 5.1(1959), 5.3(1960$ and $5.8(1961)$

per cent of the non-Maori live-births to $8.1(1962)$ and $8.8(1963)$

per cent of the 'Total' live-births. The researcher studying secular trends in the levels of illegitemacy in New Zealand for non-Maoris (data on Maoris were not collected before 1962) will be forced to close off his analysis at 1961 , unless he is prepared to make estimates.

The detail of classification of 'race remains the same, so in theory there should be no changes in vital trends which commenced before 1962. However, the crude birth rates of Maoris show a slight decline coinciding with the change in procedure, but there were marked decreases in infant and crude death rates in 1962 and 1963 without any indication of sudden improvements in public health. This may mean that vital events which previously would have been recorded in the Maori register are now being recorded as non-Maori. 15

\section{Some Problems relating to the Definition of Maori" \\ Employed in Census and Vital Statistics}

In the nineteenth and early twentieth centuries population data and accounts of missionaries, etc. refer to a Maori population which would have been easily distinguished from the non-Maori. The two problematical groups are thalf-castes and Maori Wives', for there are no records regarding the criteria by which officials classified individuals.

\section{5}

See pp.7 and 12. Dept. of Statistics (1963): Monthly Abstract of Stats., Oct., Wellington. They note that since the change some difficulty has been experienced in ascertaining whether deceased persons are Maori or not, and that some 'understatement' has occurred. This carries the implication that the previous procedure was different in practice if not in theory. Vital rates in the period 1958-63 were:

rates in the period $\begin{gathered}1958-63 \\
\text { Year }\end{gathered}$
\begin{tabular}{lrrrrrrr} 
Crude birth rate & 1958 & 1959 & 1960 & 1961 & 1962 & 1963 \\
\hline Crude death rate & 46.24 & 46.28 & 46.41 & 46.41 & 43.84 & 44.81 \\
\hline Infant death rate & 54.37 & 54.42 & 44.50 & 49.68 & 38.75 & 32.61 \\
\hline
\end{tabular}


The closer contact between Maoris and non-Maoris in the twentieth century has raised many other problems. Chief among these is 'category-jumping' from the Maori to the non-Maori census and vice versa, a subject which will be discussed in Chapter 7. The present section is concerned with the more basic questions: (a) Is there likely to be any difference between the census Maori population or persons who have been recorded on Maori vital registers, and that group of New Zealanders which is composed of persons who consider themselves to be Maoris? (b) If so, is it preferable to use the ifullblood' population as recorded in the census? (c) What is the result of differences between census and vital registration definitions of Maorit? This last point will be discussed for three periods: 1913-25, 1926-61, since 1961.

It is impossible to give conclusive answers to any of these questions. In the first case, the writer feels, from personal experience, that most persons who are of Maori descent, and whose association is with Maoris, will choose to call themselves 'Maori' for census and other purposes. 16 In theory, this should not occur with vital registrations because the registrar makes the choice on the basis of the 'races' of the parents of the deceased person or newly born infant. Yet, it is possible that the'races' of parents are misreported. Many of these persons recorded as 'Maoril in the census, etc. may be Iless than half Maori', yet feel that they are Maoris socially. However, this does not allow for genuine mixed marriages between persons who feel that they are non-

$\overline{1} 6$

cf. p.6. Beaglehole, Ernest \& Beaglehole, Pear1 (1946): Some Modern Maoris, Christchurch. They state: Our own knowledge of the Kowhai [a fictitious name for a real community] Maori population... suggests that those who filled in census schedules [1936], either through ignorance or pride, exaggerated a great deal the amount of Maori blood in their veins.' 


$$
\begin{aligned}
& M=\text { Birth registered as Meori } \\
& \mathrm{E}=\text { Birth registered as non-Maori }
\end{aligned}
$$

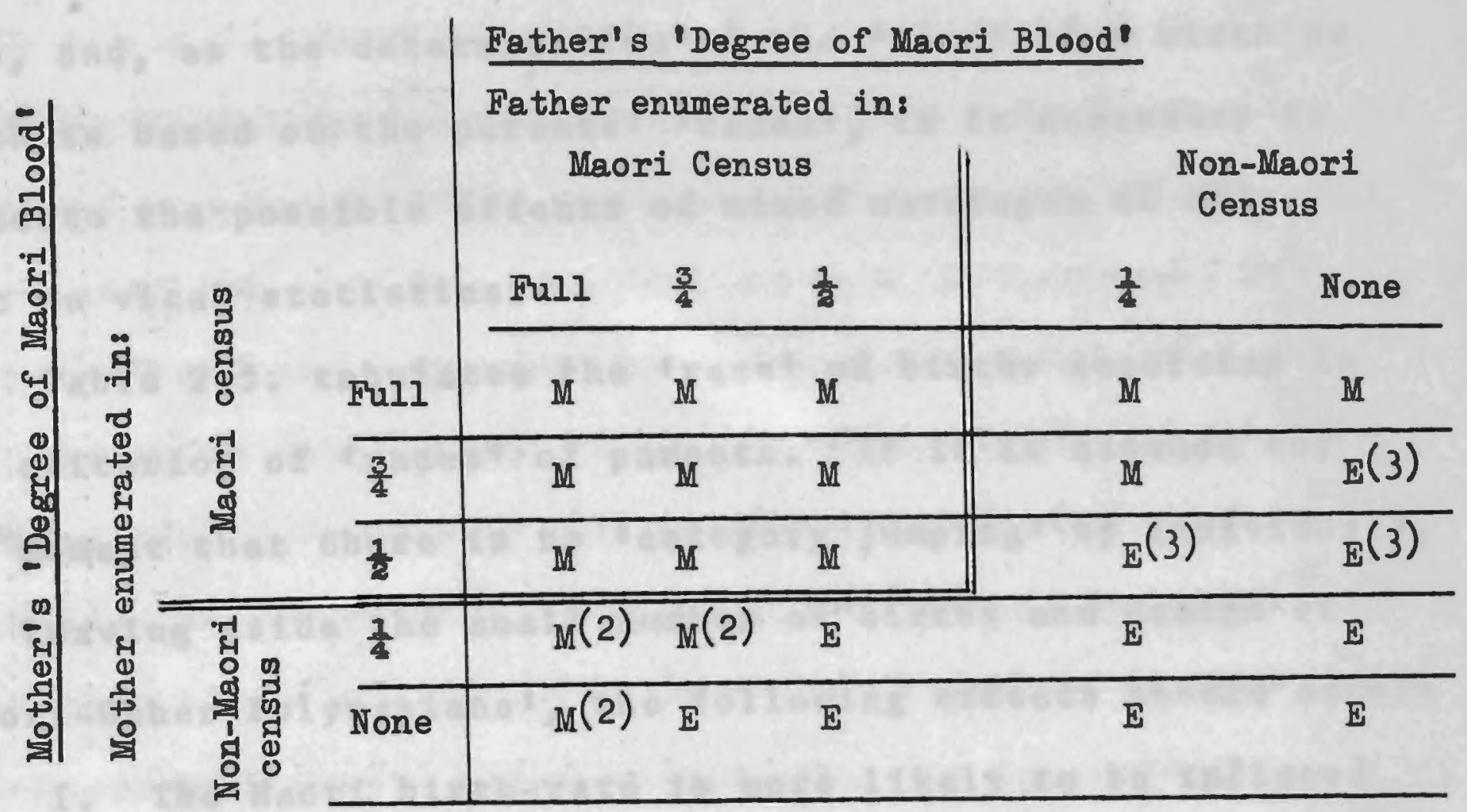

Notes: (1) The same classification applies to deaths.

(2) This birth is registered as Maori, but the mother is a non-Maori. The denominator for the Maori G.F.R. (G.F.R. = Frrth $15-49$ ) will be depleted, and thus the Maori G.F.R. will be inflated.

(3) Non-Maori G.F.R. inflated(i.e. birth registered as non-Maori, mother Maori). 
Maori, whose spouses consider themselves to be Maori, who 50 continue to mix in both communities and who are recorded strictly according to definition as Maoris or non-Maoris in census and vital statistics. This group may be growing in size, and, as the determination of the 'racel of a birth or death is based on the parents' Iraces', it is necessary to indicate the possible effects of mixed marriages of this sort on vital statistics.

Table 2.5. tabulates the racel of births according to the criterion of 'races' of parents. If it is assumed for the moment that there is no 'category jumping' by individuals, and leaving aside the small number of births and deaths of Maori-other Polynesians', the following effects should occur:

1. The Maori birth-rate is more likely to be inflated than the non-Maori, for all births thalf or more Maoris are recorded as Maori, although one parent may be enumerated as non-Maori in the census.

2. The same inflation of the Maori crude death rate should occur, for 'race of parents' is also the criterion used in death registration. However, this factor may be of importance only for infant and childhood deaths, as the parents of elderly deceased persons are not likely to be alive themselves to be recorded in the census.

3. Inflation of general fertility rates of either population will resuit only when the child's irace', is different, by virtue of the admixture of the father's tblood', from that of its mother.

In all probability, the census Maori population is composed of the Maori social and cultural group. Thus, it may include some persons tless than half-Maorit, and exclude others who, though more than ihalf Maori', do not teel that 
they are Maoris. There is no way of ensuring that people record their 'race' correctly. 17 Nor is this desirable except from an administrative point of view, for the census definition is arbitrarily based on biological characteristics, while the data obtained will be used most commonly for studying social groups; for studying those who feel they are Maori or non-Maori. This problem of definition, which is of importance for official purposes as well as research, has been analysed and published by the present writer. 18

Question (b), raised above, is more directly answerable. Data on 'ful1: Maoris do not cover a wide enough range of phenomena to be of much value in a demographic survey. Moreover, there are probably many 'ful1: Maoris who have some non-Maori ancestry - known or unknown. Te Rangihiroa gives evidence on this subject from two samples derived firstly, from his direct questioning of 814 Maori soldiers in 1919 , and secondly, from returns on 4,000 Maori school children furnished by their teachers in the early 1920s. If his two samples are representative, then the reporting of 'race' in subsequent censuses has been completely unreliable. 52 per cent of the soldiers and 50 per cent of the children were

P.116. Metge, Joan (1964): A New Maori Migration, L.S.E. Monographs in Soc. Anthrop., no.27, London. She says: Statistics relating to the degrees of Maori blood are most difficult to collect and assess. My own experience indicated that few Maoris worked out their proportion of Maori to non-Maori forebears in any detail; whether they declared themselves as full, half-, or quarter- Maori depended largely on subjective criteria." 18

Pool, Ian (1963): 'When is a Maori a "Maori"? A Viewpoint on the definitions of the Word Maori'. J.P.S., vol.72, No.3, sept. pp.2-6-10. In this article it is argued that the present definitions cause confusion and unnecessary controversy. An alternative definition is suggested, based on the individual's affinity to some cultural group'. $(p .209)$. 
Ifu11-Maori?. By comparison, over 60 per cent of Maoris claimed to be 'ful1-Maori' at each of the censuses between 1926 and 1956.19

Most importantly, a study relating to iful1' Maoris alone would refer to a biologically defined section of a cultural group, and thus would exclude a considerable proportion of the group. This is not logical, because, as Firth and others have noted, 'A person of mixed blood, provided that he is prepared to accept his Maori ancestry and share with some degree of approval in Maori institutions, is reckoned without question as a Maori for a 11 social purposes! 20

Question (c) concerned the differences between census and vital statistics data. Because of the changes in the census definition of Maoris, census data, the denominator in vital rates, should refer to a different population from that referred to in vital statistics.

1. Prior to the 1926 census al1 'half-castes were

included in Maori vital data, whereas a section of the 'half-caste' population was excluded from the Maori census. The vital rates, such as age-specific death rates, calculated for the period 1925-27 are not affected by this differentiation as the mid-year population is derived from the 1926 census at which this anomaly was eliminated. 2. From 1926-61 there are minor differences arising from the changes in the definition relating to persons 'part Maori' and part-other non-European 'blood'. Until 1951,

\section{9}

pp.373-74. Te Rangihiroa (1924): The Passing of the Maori', T.N.Z.I., vol.55, pp.362-75. The percentage of If 11, Maoriswas: 71.3 at the 1926 census; 67.8 in $1936 ; 62.1$ in $1941 ; 66.5$ in 1951 ; and 64.5 in 1956. 20

p.472. Firth, Raymond (1959): Economics of the N.Z.
- Wollington. See also p.8. Hohepa, P.W. (1961): Maori, Wellington. See also p.8. Hohepa, Phesis (A.U.). 
the small number of persons 'half or more Maorit and part'other Polynesian" should have been included in Maori vital, but not census data. From 1951 persons iess than half Maori' and more than half-lother Polynesian' ought to have been included in the census Maori population, but not the vital data. The 1956 census was the first at which persons thalf or more Maoril and part-'other ethnic group', as defined in footnote 14, were included in the Maori population, while throughout the period they should have been included in Maori vital data.

3. Since 1962 the differences should have been similar to those examined above for the period about 1956. That is, census and vital data employ the same definition of Maori except for the inclusion in the Maori census of the persons Iless than half Maori' and 'more than half other Polynesian'. In summary, it is postulated that the major difference between vital and census data was in the period prior to the 1926 census. As deaths by age have been published since 1920 , it is worthwhile calculating age-specific death rates for the period 1920-22 in order to investigate secular trends from 1920-56. However, it must be borne in mind that the numerators and denominators (derived from the 1921 census) use different definitions of 'Maori' for these rates.

\section{Marriage Statistics}

Quantitative data on Maori marriages may be determined from two sources: the census, and marriage registrations. Data on the marital statuses of Maoris have been collected at every census in the period 1926-56 (see Table 2.2.). The question asked has remained the same throughout, except that the census schedules used since 1951, the same as those distributed to non-Maoris, have contained special instructions to persons under 16 years of age. This is 
because 16 years has been the minimum legal age of marriage in New Zealand since 1933. In 1956 the census question was: istate whether "never married", "married", "legally separated", "widowed" or "divorced". If under 16 years of age, write N.A.' No instructions were given regarding the meaning of the terms, so that interpretation was left in the hands of persons filling the schedules, and thus it is possible that persons in de facto unions were reported as 'married'.

As is shown in Table 2.4, the total number of Maori marriages registered annually was published from 1920 until 1951 , but details such as age at time of marriage were published only for the period 1948-51. No data have been published on Maori marriages since 1952 when the Maori Purposes Act terminated both the publication of separate marriage data and the separate marriage registration procedures for Maoris and non-Maoris.

For the period 1920-51, published data refer to the combined totals of two categories of what may be termed 'registered marriages'. Firstly, the marriage laws applying to non-Maories applied to Maoris when either partner in a wedding was non-Maori, or when Maoris desired to be married under this general law. Secondly, by the terms of the Maori Land Act (1909), when both partners were Maoris, weddings performed before an ordained minister were to be registered. Such a marriage ceremony did not have to fulfil the requirements of the act pertaining to non-Maoris, a though bigamous marriages were illegal. This second procedure has not been followed since 1952. other categories of marriages are unregistered and have virtually no de jure status, although they may be long established de facto unions. For purposes of land inheritance, Unions 'contracted according to Maori custom? 
were given some standing prior to 1951 , provided that neither partner was a spouse in a 'registered marriage'. In addition, there are temporary liaisons and de facto unions in which one partner is already married.

Information about marriages which are not registered is restricted to the accounts of anthropologists and other field workers, who usually combine de jure and de facto unions, except those which are obviously temporary liaisons, when they analyse marriage, marital stability, etc. Thus, the data published by field workers relate to a different group of 'married' persons from those whose marriages are reported in registration statistics, but may be similar to the census tabulation 'married'.

Except at the 1951 census for age-group 16-20, it is not possible to investigate the composition of the census category 'married'; to investigate whether it includes persons in de facto unions and temporary 1 iaisons as well as Iregistered marriages'. Such an analysis would require data on age at marriage, as well as cross-tabulations relating to deaths/age/marital status/duration of marriage. Data relating to age at marriage are available only for the period 1948-51, while the 1951 census has tabulations on marital status at ages 16-19, 20, 21-24, 25-29, 30-34, etc. For females, the numbers at the appropriate ages whose marriages were registered during each year 1948-51 were added to the number estimated to have married at 16 years in 1946 and 16 and 17 years in 1947.21 This calculation gave an

21 by calculating the percentage of the total married Estimated by calculating 1948 and 1951 and allotting the same at ages 16 and 17 and 1947. As the census was in 1 ate April percentage to 1946 and 1947 . As the be taken back to April 1946. Expected $M_{16-20}^{1951}=1 / 6 M_{20}^{1951}+1 / 3 M_{16-19}^{1951}+1 / 3 M_{20}^{1950}+M_{16-19}^{1950}+1 / 3 M_{19}^{1949}$ $+M_{16-18}^{1949} \ldots 1 / 3 M_{17}^{1947}+M_{16}^{1947}+1 / 3 M_{16}^{1946}$ where, M=marriages. It was presumed that there was an equal where, M=marriages. It was presumbut a year running from May
distribution of marriages throughout a
lst to April 31 st, and that the average age at marriage was $\mathrm{x}+1 / 2$ years. 
expected number of 657 'married' females aged $16-20$ at the time of the 1951 census, yet 1,241 females aged 16-20 enumerated themselves as 'married', 'widowed', and 'divorced or legally separated'. Thus, the expected figure was only 53 per cent of the census figure, and, if all dissolutions and remarriages (a small number at this age) could have been taken into account, the expected number 'married' may have been slightly smaller.

In view of the substantial differences between expected and enumerated marriages at ages $16-20$ revealed for the 1951 census it appears that the census enumeration covers de facto unions as well as 'registered marriages', thus making the census enumeration in accord with field studies but not with registration data. However, such a case must remain unproven for other age groups and other times because age-group 16-20 may not be typical, and the pattern in 1951 may not have been representative of a wide period. Moreover, it is obvious that such an analysis cannot be carried out for older agegroups because: (a) registrations occurring before 1948 would have to be estimated for a significant proportion of the marriages and patterns may have altered; and, (b) patterns of marriage duration, dissolution, remarriage, etc. would also be more complex.

\section{Division of the Thesis into Two Sections}

The 1921 census provides a useful date at which to divide this thesis in to two parts. In Part B the Maori population will be studied until 1921, while Part C will deal with the period since 1921. Until 1921, the census enumeration employed a different definition of IMaori' from that used subsequently. Moreover, until 1921 much of the analysis is restricted to the interpretation of crude estimates of total numbers (in the early part of the period 
1769-1921) and of unquantified descriptions of morbidity, mortality and fertility. Since 1921, census enumeration procedures have been different, while the publication of quantitative data, particularly those relating to deaths, enables vital trends to be studied in some detail.

Vital registration commenced in 1913, so that this date could also be taken as an arbitrary breaking point. However, the range of data was narrow until 1920. Since 1920 , the range has been increased as far as deaths are concerned. In order to show secular trends in mortality over as long a period as possible age-specific death rates have been calculated for the period 1920-22, but have been included in Part $C$ of the thesis, rather than Part B. 
P A R T B.

$1769-1921$. 


\section{The Maori Population until 1921}

Ciest un fait curieux de constater que les événements démographiques et leurs conséquences sociales entrent très lentement dans

1'historiographie, quoique beaucoup d'historiens éminents soient sourcieux de combler cette lacune. La cause en est plus que connue parmi les statisticiens, elle résulte de $1^{\prime}$ existence relativement récente de 1 a démographie comme discipline indépendante et de celle du régime des statistiques officielles démographiques ou économiques.

Les difficultés sont encore plus nombreuses quand on veut pousser les recherches scientifiques, historiques ou bien démographiques plus loin dans le passe, ciest-a-dire à l'époque précédant 1 a statistique scientifique et officielle. Dans cette époque métastatistique il est particulièrement difficile d'évaluer les effets démographiques quantitatifs des grandes épidémies du moyen-âge et du capitalisme naissant, malgré le fait que les anciens auteurs - et plus specialement le premier représentant conscient de la démographie comme discipline autonome:

Sussmilch - nous affirment que le rôle négatif des grandes épidémies a été presque égal à celui des grandes guerres et famines de $1^{\text {thistoire. }}$

p.373. Horvath, R. (1962): 'Quelques Données Inconnues sur la Mortalité de la Peste de Debrecen/1739-40/ et celle du Choléra en Hongrie/ $1831,1866,1872-73 / .1$ Bu11. de 1 Inst. Int. de Stat., vol.XXXIX, no.4, pp.373-79.

\section{CHAPTER THREE}

The Accuracy and Quality of Maori Population

Data until 1921.

\section{Introduction:}

The range of data in the period 1769-1921 is very limited, although there was an improvement during the more recent years. For much of the period the researcher is faced with the problem of inferring population trends from descriptive accounts which vary in quality and scope. Even when the initial question of the quality of data is under consideration, 
few explicit tests can be made. Instead, the accuracy and value of each account, estimate and census must be implied from what is known about the method by which the data were collected and the experience of the writers or enumerators. When second-hand reports are reviewed an analysis must be made of the criteria on which their authors based conclusions. In this chapter the quality of data will be analysed, more in terms of the criterion of the mode of collection or estimation than the feasibility of the results. The quality of early estimates, Fenton's census, subsequent censuses and data on mortality and fertility will be reviewed in that order.

\section{Estimates of the Number of Maoris prior to Fenton's}

\section{Census.}

In 1769 Captain James Cook made the first estimate of the size of the Maori population. His figure of 100,000 , which is presented in Table 3.1 , along with others made in the period 1769-1857/58, was based on one criterion - the population density of the coastal settlements he visited, or observed from his ships. Subsequent observers have argued about the validity of this estimate by asking the four following questions:

(1) Was Cook's estimate in agreement with Forster's, made at the same time, and did Nicholas" estimate in 1817 agree with their estimates?

(2) How reliable were Cook's estimates of other Polynesian populations, and thus how much faith can be placed on his judgement?

(3) Were there large Maori Settlements in areas unseen by Cook?

(4) Assuming that the estimates of the $1830 \mathrm{~s}$ and $1840 \mathrm{~s}$ were relatively reliable, what inferences about Maori population 
growth or decline can be drawn from contemporary knowledge of the events occurring between 1769 and 1830-40, and thus of the veracity of cook's estimate?

To these questions must be added a fifth: to what degree was cook's judgement influenced by his observations of population distribution in other Polynesian groups, particularly of the 'high' volcanic islands where settlement tended to hug the coastal lowlands, and where the hilly interiors were unsettled? The answer to this last question can only be conjectured. It is possible that cook, on the basis of his Tahitian experience - he sailed directly from Tahiti to New Zealand - was misled into believing that the majority of Polynesians were coast dwellers. ${ }^{1}$

The other questions can be answered more explicitly. Forster, who visited New Zealand with Cook during his second voyage of $1772-75$, took the view that Cook underestimated the size of the Maori population. He states: $1 .$. according to the accounts we had from cook, and from what we saw in a few places, as we passed by,... [New Zealand] is... in some spots very populous, therefore allowing 100,000 souls to both islands we rather think our estimate to fall short of the true population. ${ }^{2}$ In 1817 , Nicholas made an estimate, based on his brief visit in 1 ate 1814 and early 1815 mainly to the Bay of Islands, which assumed that there was a population density of one person to every 70 to 80 acres. By this reasoning, he felt Forster's estimate 'to be fully equal to

1 (1964) Man and Land in Early pp.28-30. Lewthwaite, Gord vo1.5, no.1. pp.11-34. Lewthwaite Tahiti?, Pacific Viewpoint, says (p.30): "Whatever the the population [of Tahiti] inhabitants dwelt on the lowlands...' distribution. Virtually all inhabi

pp.224-25. Forster, John Reinold (1778): Obser During a Voyage round the World, 1772-5, London. 
the number of inhabitants, yet I will suppose them at prestent one hundred and fifty thousand. ${ }^{3}$

Gook's estimates of the sizes of other Polynesian populations were not notably reliable. Lewthwaite, citing the South Island official Shortland, notes that "Cook seems to have over-estimated the population of Hawaii by onequarter at least. $8^{4}$ Elsewhere, Lewthwaite shows that Cook's estimate of the population of Tahiti was too high, and may have been far wide of the mark - 204,000, as against the 16,050 estimated in a detailed survey in 1797. An estimate of the population of Tahiti would have been far easier to make than one of New Zealand, because of the 'coastal concentration and regularity of settlement. $s^{5}$

The question of the distribution of population in 1769 is very important. Lewthwaite, writing in 1950, shows that Cook believed that the interior and the west coast of the North Island from Cape Maria van Diemen in the far north to Taranaki were uninhabited. Lewthwaite then brings forward archaeological and other evidence to show that there was relatively dense settlement in parts of the interior notably in the Waikato - and even immediately inland from the West Coast of the North Island. He concluded that lat least half the population lived in districts unknown to him [Captain Cook]! 6 In 1924, Te Rangihiroa had put forward the same argument and had suggested that the frequent fortifications in many areas, seen and unseen by cook, could have been built and manned only by a population perhaps four

Vo1.2, p.299. Nicholas, J.L. (1817): Narrative of a Voyage to N.Z. Performed in the Years 1814 \& 1815 , London. 2 vols.

P.45. Lewthwaite, Gordon (1950): The Pop. of Aotearoa: Its Number \& Dist., N.Z.G., vol.VI, no.1. pp.35-52.

5 Lewthwaite (1964): pp.28-30. On the first voyage, Cook and his men probably spent more time ashore in Tahiti - they had been sent there to make astronomical observations - than in New Zeal and. 6 .

Lewthwaite (1950): pp.36-39\&44. 
to ten times larger than the Maori population enumerated at the Census of 1921; by a population numbering 200,000 to $500,000 .^{7}$

In 1949 , Cumberland took the extreme view that New Zealand's natural resources, in association with the neolithic technology of the Maoris, could have been capable of supporting a population even in excess of $1,000,000$ in the eighteenth century, and that much evidence of settlement may be disguised by subsequent regeneration of forest. 8 A rather more conservative estimate is that of Wright, a recent historian, who notes that, because of conquest and migration, adjacent fortresses and other village sites may have been occupied at different dates. 9 The most conservative view is that of Skinner who, in 1933, pointed out that Cook'saw little of the South Island, and only the thickly populated districts of the North... 10

The fourth procedure is to survey events between 1769 and 1840 and to decide whether these occurrences imply an increase or decrease of the population, and thus whether Cook's estimate is reliable. This method is probably the most valid, in view of the cursory manner in which Cook's estimate was made, and the inherent problems involved in the interpretation of archaeological evidence. Lewthwaite reviews the evidence of epidemics, warfare, etc, and concludes that the population declined by half, from over

pp.363-64. Te Rangihiroa (1924): The Passing of the Maoris, T.N.Z.I. vol. 55, pp.362-75.

pp.416-17. Cumberland, K.B. (1949): Aotearoa Maori: N.Z. about 17808, Geog.Rev., vol.39, No.3, July.pp.401-24. 9

pp.11-12. Wright, Harrison (1959): New Zealand 1769-1840: Early Years of Contact, Cambridge, Mass. 10

p.19. Skinner, H.D. (1933): The Maoris', in Cambridge History of the British Empire, vol. VII, Part II, Cambridge. p p. 8-21. 
200,000 to just over 100,000 between 1769 and 1840.11 Wright puts forward similar evidence, but accepts a lower rate of decline - from between 175,000 and 200,000 in 1769 to between 100,000 and 150,000 , 'say 125,000 ', in 1840.12 By contrast, Skinner asserts that: 'Early contact with European resulted in the acquisition of new food plants, followed in some, perhaps in all, districts by an increase in population.' As evidence he cites only an increase in population in otago and Canterbury about 1800 , following the introduction of the potato. In combination with his evidence on the settlements observed by Cook (see above), this is an indication, he claims, that Cook's figure of 100,000 was an overestimate. ${ }^{13}$ Skinner's conclusion is interesting, but is influenced by his knowledge of South Island conditions. Traditional agriculture, dependent particularly on the sub-tropical sweet potato, appears to have been of marginal importance in the South Island, while hunting had been of limited significance since pre-historic periods when the large flightless bird, the Moa, had become extinct. Thus, the South Island regions were not densely settled and were the most likely to have been affected by the introduction of new crops, particularly those suited to temperate conditions. Further discussion of this point will be postponed until Chapters IV and $V$ when the evidence relating to events occurring between 1769 and 1840 will be reviewed and interpreted. In Chapter VI a study of feasible growth, or decline, rates will be made in the light of this evidence.

When working back to 1769 , the authors mentioned above have implied that the estimates of c.1840 are more reliable

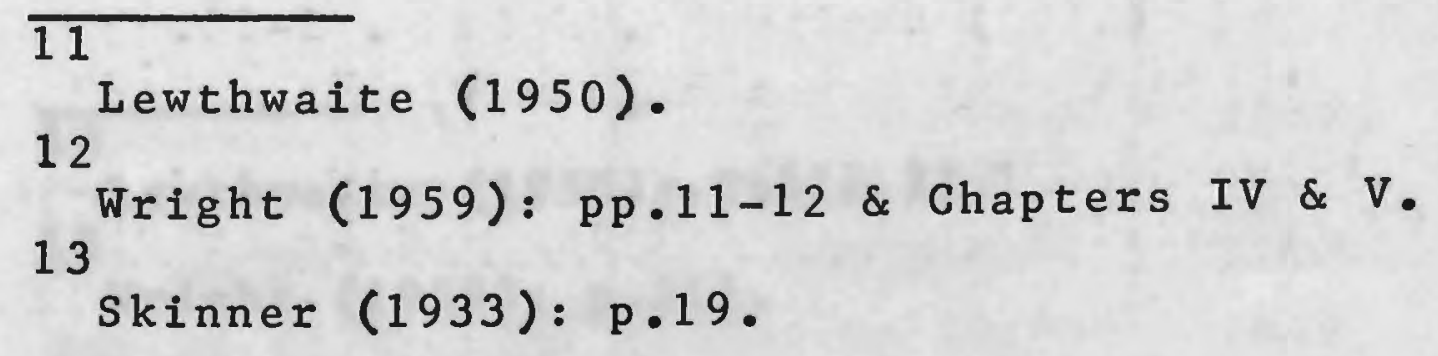


than Cook's. Lewthwaite took the precaution of comparing a wide range of these estimates, and also contrasts the patterns of geographical distribution of three estimates giving this degree of detail - those of Williams, Hamlin and Dieffenbach. ${ }^{14}$

Table 3.1 presents the estimates made about 1840 . The House of Lords Inquiry in 1837-38 included estimates from a number of observers whose experience can be gauged from the cross-examinations. This evidence suggests that Rev. Coatest, Rev. Hinds ${ }^{2}$ and Polackis estimates are probably based on reasonable premises. Coates and Hinds had probably not been to New Zealand, but Coates merely read a letter from the Rev. W. Williams, while Hinds quoted mission records. Williams had travelled widely and his 1 etter gives regional estimates, plus other details such as a crude idea of population concentrations, or the mission stations around which varioussized populations were found. He does not seem to give figures for Rotorua, Urewera and Taupo districts. The Rev. Beacham, Secretary of the Wesleyan Methodist Missionary Society, who had not visited New Zealand but who quoted from his mission's record, supported Williams' estimate of the population around the Wesleyan mission station in the Hokianga district. It is difficult to determine whether or not the Mission records quoted by Hinds are, in fact, Williams: estimate. Polack was a widely-travelled trader who claimed to speak Maori, who had spent six years in New Zealand and who wrote books about the country. Therefore Polack's experience seems to have been fairly broad, although the historian Wright thought that Polack's descriptions were 's 1ightly suspect. 15

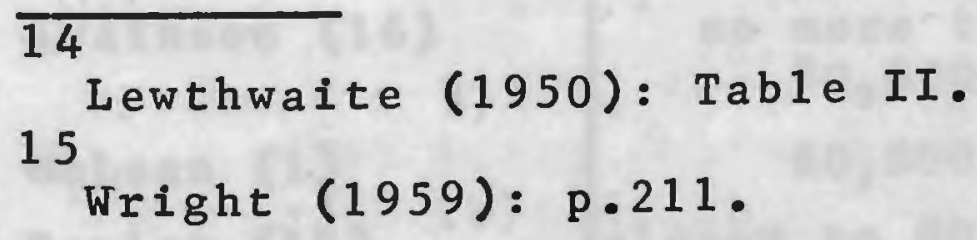


Table 3.1 : Estimates of the Maori Population from 1769 to

\section{$\underline{1857-58}$}

\begin{tabular}{|c|c|c|c|}
\hline Source & Number & $\begin{array}{l}\text { Year for } \\
\text { which the } \\
\text { estimate } \\
\text { was made }\end{array}$ & Notes \\
\hline Cook (1) & 100,000 & $1769-74$ & \\
\hline Forster (2) & 100,000 & 1773 & 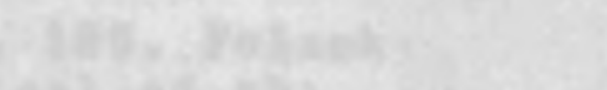 \\
\hline Nicholas (3) & 150,000 & $1814-15$ & 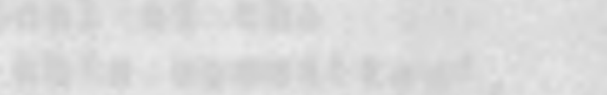 \\
\hline Hinds (4) & 105,000 & $1830 \mathrm{~s}$ & $\begin{array}{l}\text { Quoting Church } \\
\text { Missionary Society } \\
\text { records }\end{array}$ \\
\hline Baring (4) & $\begin{array}{c}\text { not above } \\
150,000\end{array}$ & $1830 \mathrm{~s}$ & 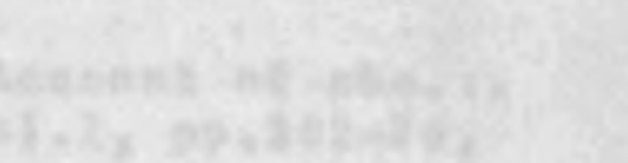 \\
\hline Bannister $(5)$ & 180,000 & $1830 \mathrm{~s}$ & $\begin{array}{l}\text { Quoting Rev. W. } \\
\text { Gate. North I. }\end{array}$ \\
\hline Coates (4) & 106,000 & 1834 & $\begin{array}{l}\text { Quoting Rev. W. } \\
\text { Williams. North I. }\end{array}$ \\
\hline Terry (6) & 150,000 & c. 1840 & 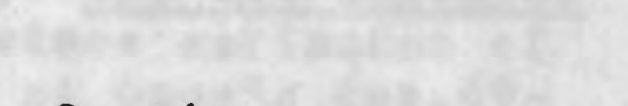 \\
\hline $\begin{array}{l}\text { Fox (7) } \\
N \cdot Z \cdot C o y \cdot R \text { eport (1) }\end{array}$ & $\begin{array}{c}109,000-120,000 \\
100,000\end{array}$ & 1840 & $\begin{array}{l}\text { Quoting } \\
\text { Missionaries }\end{array}$ \\
\hline 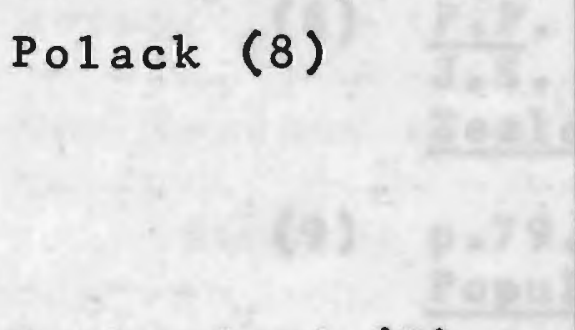 & $\begin{array}{l}\text { does not exceed } \\
130,000\end{array}$ & $61969\}$ & $\begin{array}{l}\text { Also a witness to } \\
\text { the House of Lords } \\
\text { Committee, see } \\
\text { note (4) below }\end{array}$ \\
\hline $\begin{array}{l}\text { Rutherford }(9) \\
\text { Crawford (10) }\end{array}$ & $\begin{array}{r}2,800 \\
100,000\end{array}$ & $\begin{array}{l}1840 \\
1840\end{array}$ & South I. \\
\hline Ham 1 in $(11)$ & 120,000 & c.1840 & $\begin{array}{l}\text { Quoting Missionary } \\
\text { records. North I. }\end{array}$ \\
\hline Wilkes (12) & $140,000-180,000$ & c. 1840 & 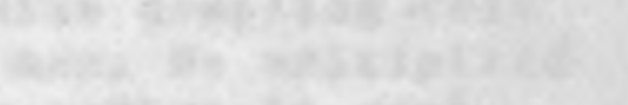 \\
\hline Dieffenbach (13) & 114,890 & $1839-41$ & 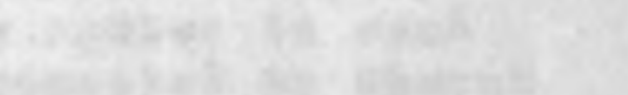 \\
\hline Ha1swe11 (14) & 107,219 & 1841 & 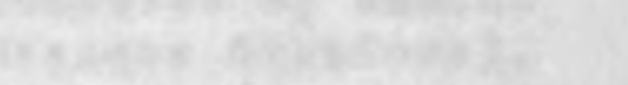 \\
\hline Shortland (15) & 1,923 & 1844 & South I. \\
\hline Fox (7) & 1 ess than 90,000 & 1846 & $\begin{array}{l}\text { Quoting One of the } \\
\text { eldest and most } \\
\text { intelligent } \\
\text { missionaries...' }\end{array}$ \\
\hline Fitzroy $(7)$ & 80,000 & 1846 & \\
\hline Grey (1) & 120,000 & 1849 & Governor, 1845-54. \\
\hline Fox (7) & 70,000 & 1850 & $\begin{array}{l}\text { Quoting An intell- } \\
\text { igent and well- } \\
\text { informed Wesleyan } \\
\text { missionary... }\end{array}$ \\
\hline Swainson (16) & $\begin{array}{c}\text { no more than } \\
70,000\end{array}$ & $1850 \mathrm{~s}$ & See also fn.16. \\
\hline McLean (1) & 60,000 & 1853 & \\
\hline Taylor (17) & $\mid \begin{array}{c}\text { closer to } 80,000 \\
\text { than } 100,000\end{array}$ & 1855 & \\
\hline $\begin{array}{l}\text { Fenton } \\
\text { (census) (18) }\end{array}$ & 56,049 & $1857-58$ & \\
\hline
\end{tabular}


Notes: (1) Table I. Lewthwaite, G.R. (1950): The Pop. oYU Aotearoa: Its Number and Distribution', N.Z.G. Vo1.VI, No.1, Pp.35-52.

(2) p.225. Forster, John Reinold (1778): Observations made during a Voyage Round the World, 1772-75, London.

(3) Vo1.2, P.299. Nicholas, J.L. (1817): Narrative of a Voyage to N.Z. Performed in the Years 1814 \& 1815, London. 2 vols.

(4) P.P. (1837-38): XXI, Pp.129, 151, 180. Polack (p.239, see below) was very critical of the experience of other witnesses to this committee (he was one himself). Terry (p.177, see below) criticised Williams estimate, claiming that Williams missed certain tribes.

(5) p.364. Bannister, Saxe (1838): Account of the... Population of N.Z.', J.S.S.L., vol.I, PP.362-76.

(6) p.177. Terry, Charles (1842): N.Z,, Its Advantages \& Prospects..., London

(7) pp.51-52. Fox, Sir William (1851): The Six Colonies of N.Z., London. Fox analyses various estimates of the period. He is most critical of Grey's (pp.4952), particularly his estimate of 25,000 in the South Island.

(8) P.P. (1837-38): XXI p.86; and, vol.II, p.91. Polack, J.S. (1840): Manners and Customs of the New Zealanders, London, 2 vols. P.79. Rutherford, D.W. $(1940)$
Population, Thesis, (0.U.).

(10) P.P. (1844): vo1.XIII, P.168.

(11) p.73. Hamlin, J. (1915): 'Estimate of the Maori Population of the North Island circa $1840^{\circ}$, J.P.S., vol.24, June, pp.72-74. (Rev. Hamlin compiled this from Mission records on fighting men. He multiplied fighting men by 3 to give him the number in each tribe. The Mission records were compiled by Church Missionary Society and Wesleyan Mission Stations).

(12) Vol.2, pp.416-17. Wilkes, C. (1845): Narrative of the U.S. Exploring Edpedition During the years 1838 to 1842 , Philadelphia.

(13) Vo1.2, p.83. Dieffenbach, E. (1843): Travels in N.Z., London. 2 vols.

(14) Despatch dated Nov.11, 1841 in Appendix G. No.46. N.Z. Coy. (1844): 12th Annual Report of Directors, London, 26th April. Published in P.P. (1844): XIII.

(15) Letter of Edward Shortland, 18 th March 1844 , to Chief Protector of Aborigines in P.P. (1846): XXX, $337, \mathrm{p} .156$.

(16) p.12. Swainson, William (1859): N.Z.\& Its Colonization, London. 
(17) p.258. Taylor, Rev. Richard (1855): Te Ika a Maui, London.

(18) Main Table. Fenton, F.D. (1859): Observations on..., Auckland.

Montefiore, another witness, said: 'I have heard many say it [the Maori population] was $1,000,000$; I have heard others say 500,000 ; but I think that it is impossible to state the fact... With but four months experience, spent entirely on the West Coast between Kawhia and Wellington, it is obvious that he could not be expected to make a reliable estimate, as he himself admitted. The Hon. Baring M.P. was the 'originator' of the New Zealand Association, which was pressing for colonization and settlement. It appears from his use of the term 'we' that he was quoting from records compiled by the association, presumably from persons with New Zealand experience.

Nothing is known about Rev. Gate who was quoted by Bannister. Terry visited New Zealand for about a year, wrote a book and was interested in land problems, but his general experience cannot be gauged. Crawford stayed in New Zealand for a year or more and gave witness at another enquiry in 1844. Hamlin appears to have fairly detailed knowledge of population distribution, again compiled from mission records, in combination with personal experience. By contrast, Wilkes merely paid a brief visit and saw little more than the Bay of Is lands, so his figure is probably based on hearsay. Presumably, the more reliable estimates are based on travel through most of New Zealand. Moreover, by the early $1840 \mathrm{~s}$, pockets of non-Maori settlements were located throughout New Zealand, and thus it was possible for quite detailed estimates to be made of small areas. For example, 
about 1840 the Wellington and South Island areas were covered more closely than most, by Dieffenbach and Swainson (?), and by Short 1 and respectively.

About 1840 for the North Island as a whole, Dieffenbach's estimate is probably the most reliable, because he had

travelled over most areas except possibly the East Coast. As a basis for comparison he had relatively complete data on the We 11 ington area. 16

Déffenbach carefully 1 isted tribes, settlements, subtribes, etc., and most importantly, he described the method he used to calculate his estimates. As he travelled, he determined the number of fighting men in each tribe. Then he calculated the total population by assuming that there were two children per family, and that the ratio of warriors to total population was $1: 4$. For example, The Waikato tribes can collectively bring 6,000 men into the field, and the whole population amounts at 1 east to 24,000 if not more;... Then he feels that some qualification is necessary, for he continues, rbut in these interior tribes the average number of

16

Vol.II, passim. Dieffenbach, E. (1843): Travels in N.Z., London. 2 vols. It seems that he did not make estimates for Banks Peninsula, Otago and the Southern King Country. His more detailed estimate of the area around Cook strait can be compared with one compiled by Swainson (?). The 2 enumerations are relatively similar:

\section{District}

Ne1son-Marlborough

We 11 ington-Porirua-Mana $I$. Manawatu-Horowhenua-Kapiti I. Wanganui-Patea

Taranaki

\section{Total Cook Strait Region}

Sources: Dieffenbach (1843): Vol.I., p.195; and, [Swainson] published in Supplementary Information Relative to N.Z., Comprising Dispatches \& Journals of the Company's officers of the First Expedition...., London, 1840. Reviewed in N.Z. Journal (1841): vol.1, p.183. 
two children to a family is scarcely sufficiently high.' Again, referring to the Ngati Tuwharetoa of the Taupo region (nga-tetuaretoa), he says: There are about 800 men capable of bearing arms, and 3,200 souls.?

He did not make any extravagant claims about the accuracy of his estimate, summarising its reliability in these words:

In this census I do not pretend anything like accuracy; but I have visited nearly all the tribes myself, and if, as I think is the case, the data which I obtained of the number of fighting men and the average of the rest of the population are to be relied on, my estimate is entitled to some credit.

This 'census' cannot be accepted as wholly reliable, but at least it is possible, with one major exception, to determine likely sources of error. Unfortunately, this exception is basic: how did he obtain data on numbers of fighting men? Obviously, he cannot have counted all the warriors himself, and few observers, whether chiefs or other persons could be classified as reliable informants. Presumably, the other data on family size and the ratio of warriors to total population was based on his own observations in various regions; and there seems no reason to accept the view that Dieffenbach, a surgeon and field naturalist, was an incompetent observer.

Dieffenbach's estimate approximates the majority of estimates of this time. For example, it is relatively close to Halswel1's. Halswell, the Commissioner for Native Reserves, was widely travelled, and may have had access to official documents. Moreover, allowing for differing boundaries, names, etc., there is some accord between the regional distributions given by Dieffenbach, Hamlin and Williams. In each case, Northland, Waikato-King Country, Bay of Plenty and the East Coast are allotted large populations, while the Firth of Thames and the southern regions are given smaller numbers. 17

17 Lewthwaite (1950): Table II; and Dieffenbach (1843): Vo1.II, pp. $72-83$. 
The estimates of the 1 ate $1840 \mathrm{~s}$ and early $1850 \mathrm{~s}$ suggest that a decline of the population was occurring. These estimates were made by colonial officials or legislators who, presumably, could refer to the reports of district officials, missionaries and others, and to the growing number of detailed estimates and actual head-counts of small areas. The exception was Taylor, a minister of religion, who had been in New Zealand for a long period and who appears to have taken 'censuses' in the Wanganui region. However, it is doubtful whether Taylor's personal experience would have equalled that of McLean. 18

3. Fenton's Census. 19

Fenton's census in 1857-58 revealed a Maori population of 56,049 , as is shown in Table 3.2. The non-Maori population, enumerated by a separate census in 1858 , was now 59,413 and thus, if census figures were accurate, exceeded the Maori. Fenton's census was a commendable undertaking for he tried to ensure that all regions were carefully enumerated. However, this was not possible, and estimates had to be made for several quite important areas. Six of the eleven enumerators, including Fenton himself, reported that they ran into difficulties when conducting the count.

Because of suspicion on the part of the natives, the enumeration was unsystematic in the East Coast and Bay of Plenty regions which, presumably, contained large Maori populations. In Taranaki, as might have been expected in a region on the verge of war, the enumerators also ran into hostility.

18

McLean's wide range of experience in the period 1840-53 is detailed on pp.55-58. Sinclair, Keith (1957): The Origins of the Maori Wars, Wellington.

19 is based on the introductory pages to This discussion is basedrations on the State of the Aboriginal Population of N.Z., Auckland. 
Elsewhere, Fenton claims, enumerations were relatively reliable, an assertion supported, in the case of the Waikato, Whanganui (Wanganui) and Taupo areas, by comparison with earlier counts by missionaries and others.

Fenton himself conducted the Waikato census. This was a wise decision in view of the state of ferment in the region at that time, for Fenton was well known to the Maoris of that area. Fenton stated that the Waikato enumeration was accurate, although he does admit that he missed one tribe (hapu?). Yet, John Gorst, who was 1 iving in the Waikato district at the time of Fenton's census, wrote that Fenton had been implored upon to take the census as a duty additional to his normal work as a magistrate. Moreover, Gorst was sure that many Maoris had avoided the taking of the census. 20

Even if enumeration had been straightforward, this census could not be accepted as accurate by modern standards. The census was conducted over a 12 month period, while the figures for Nelson were derived from the provincial census of 1855 .

Fenton has summarised the quality of his census:

From the foregoing remarks a favourable estimate of the value of the census may be formed. Still it is evident that elements of uncertainty must exist in information, obtained for the most part in a somewhat cursory manner, from people to whom thought is often an exertion, and who have little idea of the age of even the younger branches of their own families.

The total numbers, males and females may, I believe, be received without distrust. Those given for the Province of Canterbury are absolutely accurate; those for Nelson and Otago a close approximation. The statistics of the Provinces of the North Island are also presented as trustworthy, with the exception of those for some portions of Auckland, in which the numbers are merely estimates, and are stated as such. 21

20 pp.76-79. Gorst, John (1959, reprint): The Maori King, Hamilton, N.Z.

21 Fenton (1859): pp.1-2. 
It is obvious that the figures for some regions are unreliable, being collected unsystematically, or else being merely estimates. In other regions under-enumeration occurred even when the census takers were reasonably systematic and thorough. Thus, Pearce has estimated, by procedure to be discussed below, that at least 3,600 Maoris were not enumerated at Fenton's census. Three problems arise here:

(1) Was Fenton's census likely to be more reliable than the estimates of the period 1840-57?

(2) From 1840 until Fenton's census, the Maori population appears to have declined very rapid1y - from 114,890 (Dieffenbach's estimate) to 56,049 (Fenton's census). Was such a decline feasible?

Was Fenton's census as accurate as those of the $1870 \mathrm{~s}$, and thus, was the reported rate of decline between 1857-58 and 1874 a reliable indication of trends in the period? Unless there is evidence to the contrary, a systematic census must be accepted as more reliable than estimates. It appears that Fenton took every reasonable step to ensure accuracy, reporting those areas where the standards of accuracy were unsatisfactory, and thus his census is probably a more reliable indication of the number of Maoris at the midnineteenth century than any of the preceeding estimates. The problem of the apparent rapid decline between 1840 and 1857-58 will be discussed in Chapter VI after an analysis is made of possible mortality and fertility trends in the period. However, it is obvious that the relative reliability of Fenton's census, and thus of the estimates about 1840 , must be taken into account when the question of growth or decline between 1760 and 1840 is discussed. When studying population trends during the early years of contact, Wright and Lewthwaite have accepted as satisfactory the estimates about 
1840. Yet, if the decline between 1840 and 1857-58 was not feasible, the validity of estimates such as Dieffenbach's must be challenged and the trends of the period 1769-1840 reinterpreted.

\section{The Accuracy of Censuses: 1874-1921}

The size of the Maori population as recorded at each census in this period, plus details relating to components is given in Table 3.2. It is not possible to test the accuracy of these censuses by standard methods, because there are no vital data. However, a qualitative assessment can be made from the comments of observers and particularly from the enumerators reports, which were published in the Appendices to the Journal of the House of Representatives and in the census volumes. 22

In an attempt to overcome the problem of relying on the subjective assessments of enumerators, Pearce studied every census from Fenton's to that of 1896. She examined the differences between the numbers recorded in the census and that recorded in any other source, for each district in each region. She then gave a new series of totals for these censuses, based on adjustments to the original data. For every census, other than those of 1886 and 1891 , her adjusted figure was larger than the enumerated population. Her estimates were as follows:

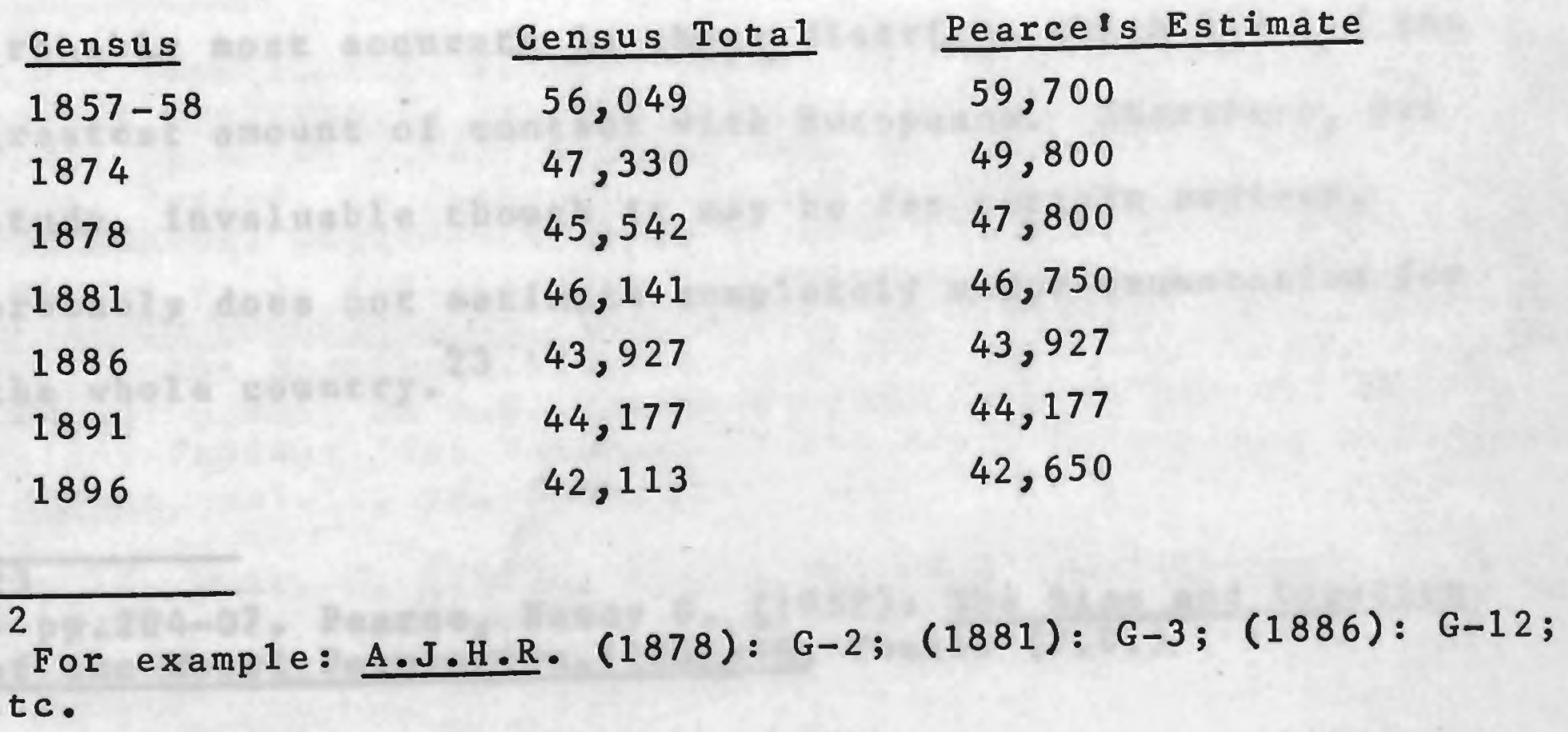


Tab1e 3.2 : The Number of Maoris Enumerated at each Census

\section{from $1857-58$ to 1921}

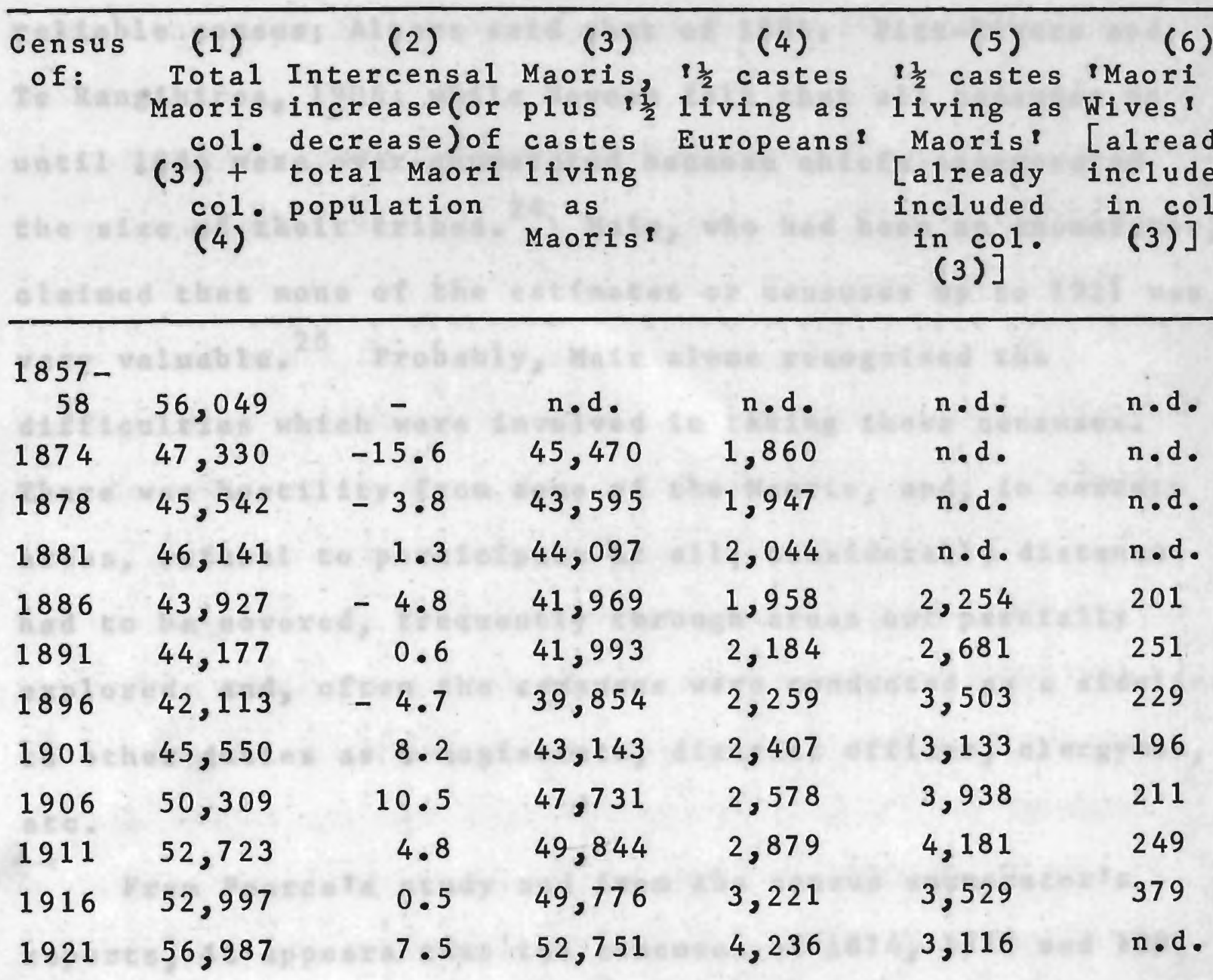

Note: $\quad$ n.d. $=$ no data

Sources: cols.(1)\&(6): Census (1956): vol.vIII, p.8

remaining cols. Census (1926): vol.XIV, Tables I \& II.

Like the census data, the alternative sources are probably most accurate in those districts which had had the greatest amount of contact with Europeans. Therefore, her study, invaluable though it may be for certain regions, probably does not estimate completely under-enumeration for the whole country. 23

23

pp.204-07. Pearce, Nancy G. (1952): The Size and Location of the Maori Population, 1857-96, Thesis (V.U.) 
Although other writers have noted the census which they felt was the first accurate enumeration, their assessments are probably subjective. Ngata asserted that 1886 was a reliable census; Alpers said that of 1881; Pitt-Rivers and Te Rangihiroa, 1906; while Newman felt that all censuses up until 1884 were over-enumerated because chiefs exaggerated the size of their tribes. ${ }^{24}$ Mair, who had been an enumerator, claimed that none of the estimates or censuses up to 1921 was very valuable. ${ }^{25}$ Probably, Mair alone recognised the difficulties which were involved in taking these censuses. There was hostility from some of the Maoris, and, in certain areas, refusal to participate at a11; considerable distances had to be covered, frequently through areas but partially explored; and, often the censuses were conducted as a sideline to other duties as a magistrate, district officer, clergyman, etc.

From Pearce's study and from the census enumerator's reports, it appears that the censuses of 1874,1878 and 1881 were under-enumerated. Pearce gives no adjusted figure for 1886 and 1891 , and thus the enumeration at these two censuses may have been more accurate than at preceding censuses. There was an increase in population in the period 1886-91, followed by a decrease in the period 1891-96 (Table 3.2), which might indicate that the censuses of 1881 and 1896 were less reliable

24

P.9. Ngata, A.T. (1899): Maori Pop. Stats.', Report of the 3rd N.Z.; Pp.8-14; p.145. Alpers, Hon. Theritten 28 years Wellington. pp.144-51. Alper's paper had (1923): Report of the before; p.11. Pitt-Rivers, G. (convenor) (1923) : Research Committee on Vital Stats. of Primitive Ranin; Te Rangihiroa Wellington Meeting A.N.Z.A.A.S. Hocken Liscusion p.58. Buller, (1924): p.365; Dr A.K. Newman during discussion p. N.Z. Journal of Walter $(1884)$ : The Decrease 25

p.15. Mair, G. (1923): Reminiscences \& Maori Stories, Auckland. He felt they were lentirely approximatel, and criticised the fact that they were taken over long periods. 
than those in intervening years. Moreover, the enumerators $\mathrm{z} u$ stated that there was fairly severe under-enumeration at the 1896 census in certain regions. 26 However, fluctuations in growth may also be explained, in part, by the occurrence of epidemics.

In 1901 , there was less recognition of possible deficits by enumerators. In 1911, it was felt that the enumeration was the most thorough up till that time. By contrast, in 1916, The enumerators for the North Island - Taranaki and particularly Waikato districts - report that some difficulty was experienced in obtaining information owing to the fear that the statistics were being used for the purposes of recruiting . $^{27}$ In 1921, no enumerators' reports were published.

From the census of 1886 age data were published. In societies in which births are not significant social events (death was of greater significance to Maoris), or in which education is obtained by only a small proportion of the population, the reporting of ages is likely to be unreliable, even assuming that all sections of the population - infants, children, young adults, etc. - are fully enumerated. These two factors were probably important determinants of the accuracy of age-reporting by nineteenth century Maoris. Agereporting should have improved in the twentieth century in response to the increase in basic education and, perhaps, by the adoption of non-Maori ceremonies, notably birthday celebrations.

The accuracy of age-reporting cannot be tested by standard methods because there are no comparable data or single-year age-distributions. The censuses of 1911,1916 and 1921 could be tested by the use of reverse survival

\footnotetext{
26 A.J.H.R. (1896): H-13B, passim

Census (1916): Appendix A, p.x.
} 
ratios from the 1926 census, except that such a procedure would raise more problems than it would solve. Most importantly the questions of the effects of the change in definition between 1921 and 1926, and the absence of troops (1916) would have to be raised.

Two methods have been used to investigate the accuracy of census age-distributions. A general clue is provided by data published at the censuses from 1886 to 1901, and again in 1921, which tabulated the numbers whose ages were not specified and, more importantly, not specified but within some general age-group (e.g. $0-14$ and $15+$ ). A decline in the proportions so reported should indicate improving standards of age-reporting. However, it is possible that such a decline also could result from the increased determination on the part of census enumerators to obtain detailed information on ages. Thus, interviewees could have been directed by district officials to be specific, or the interviewer might have put down a specific age, when, in fact, the interviewee himself was vague about his correct age.

In Table 3.3. the proportions not stating their ages, referring, of course, on $1 y$ to those persons who were enumerated, are shown for the censuses of 1886-1901 and 1921. These data suggest that age-reporting in 1891 and 1896 was more accurate than in 1886. Moreover, in this detail, 1896 does not appear to be a poorer census than that of 1891 , and may have been better than 1901. By 1921, there was a considerable improvement, particularly at age-group 0-14. Probably, the improvement resulted more from the increased education of Maoris and similar factors, than from the enforcement by officials of unrealistic levels of accuracy. A second method by which irregularities in the agedistribution may be investigated is to compare the numbers recorded for various cohorts at each census. In Table 3.4., 
Table 3.3 : The Percentage of the Population with Ages

$$
\begin{aligned}
& \text { 'Partly Not Specified', and 'Not Specified At Al1', } \\
& 1886,1891,1896 \text { and } 190181921
\end{aligned}
$$

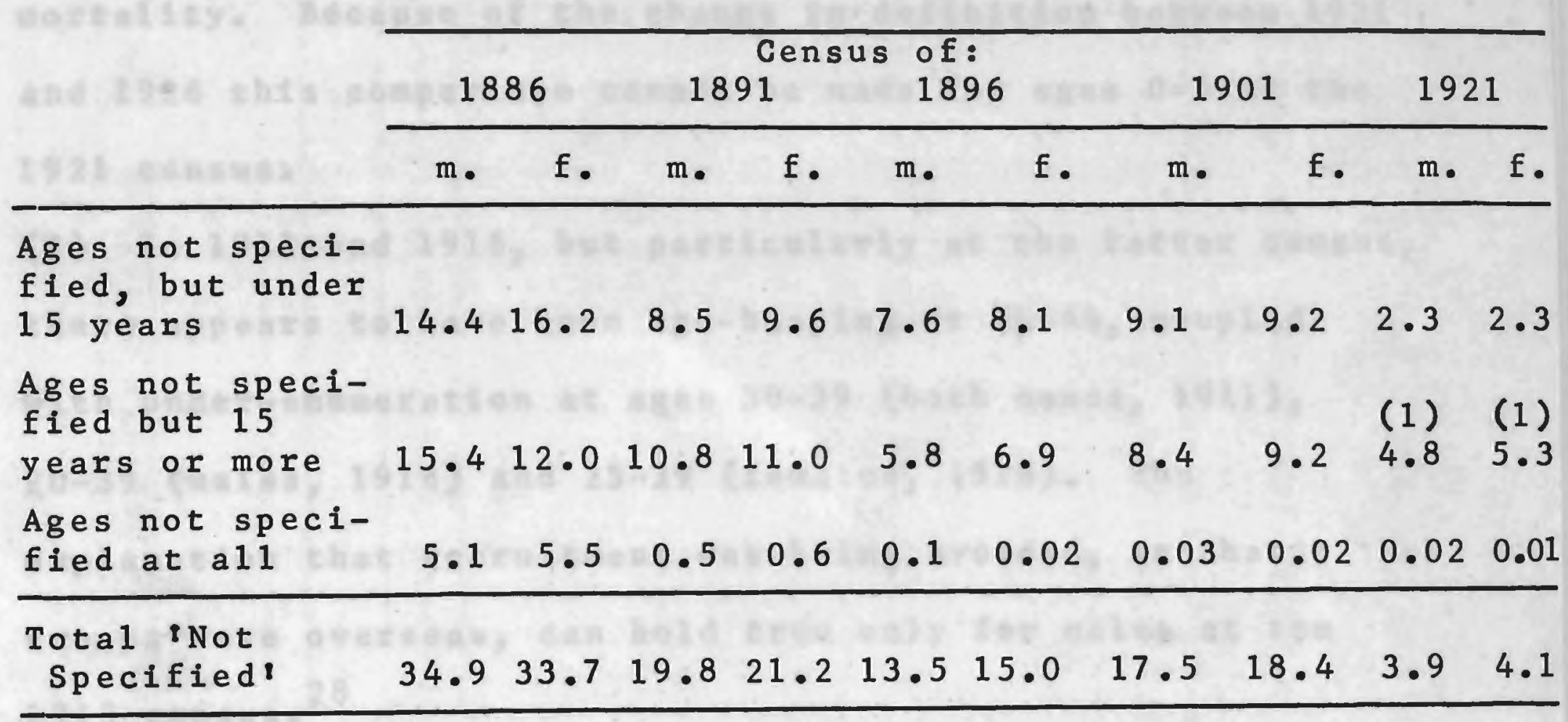

Note: (1) In 1921, these were further subdivided thus:

\begin{tabular}{lrr} 
Age group & m. & f. \\
\hline $15-44$ & 2.7 & 2.7 \\
\hline $45+$ & 9.4 & 12.0 \\
\hline
\end{tabular}

the numbers at each quinquennial age-group, where such data are available, are given for each cohort born between 1837-41 and 1917-21, as recorded at the censuses of 1886-1921. Ages not specified, but below 15 years have been distributed pro rata to age-groups $0-4,5-9$ and 10-14; ages not specified, but 15 years or more, have been distributed pro rata to each agegroup 15-19 to $70+(15-19$ to 40-44; and 45-49 to $70+$ in 1921 . See Note (1), Table 3.3); and ages not specified at all have been distributed pro rata to all age-groups. By comparing the numbers thus adjusted for unspecified categories at each census, the following anomalies can be noted:

(1) Ages $0-4$ are poorly enumerated at every census except, possibly, 1911. For example, in 1901, 5,399 infants 0-4 were enumerated, yet in 1911 this same cohort numbered 5,968. It might be noted that such an increment could not be due to 
immigration. Moreover, the level of implied enumeration

defects at ages $0-4$ in 1901 would have been shown to be even greater if some account could have been taken of intercensal mortality. Because of the change in definition between 1921 and 1926 this comparison cannot be made for ages $0-4$ at the

1921 census.

(2) In 1911 and 1916, but particularly at the 1 atter census, there appears to have been age-heaping at 40-44, coupled with under-enumeration at ages 30-39 (both sexes, 1911), 20-39 (males, 1916) and 25-39 (females, 1916). The explanation that recruitment was being avoided, or that troops were overseas, can hold true only for males at the 1915 census. 28

(3) There is a considerable decline between the censuses of 1911 and 1921, ignoring the 1916 census, for all cohorts born between 1882-86 and 1902-06 (i.e. persons 15-39 at the 1921 census). In particular, this may result from high agespecific mortality in 1918 .

These observations are based only on the available quinquennial age-groups. In order to determine whether the age-reporting irregularities remained consistent from $1886-$ 1921 , it is necessary to turn to the percentage distribution of decennial age-groups adjusted to include not specified ages. These distributions are shown in Table 3.5. 1926 is included on this table for purposes of comparison. The major points are these:

(1) At the early censuses the proportions at ages $0-9$ and 10-19 are closer than at most later censuses. The increase

See Census (1945): Appendix B, Table 17, which gives data on ar service collected at that census. 1,180 males and 9 females still 1 iving in 1945 reported that they had served overseas in W.W. I. The total number overseas may have been far higher than this. 


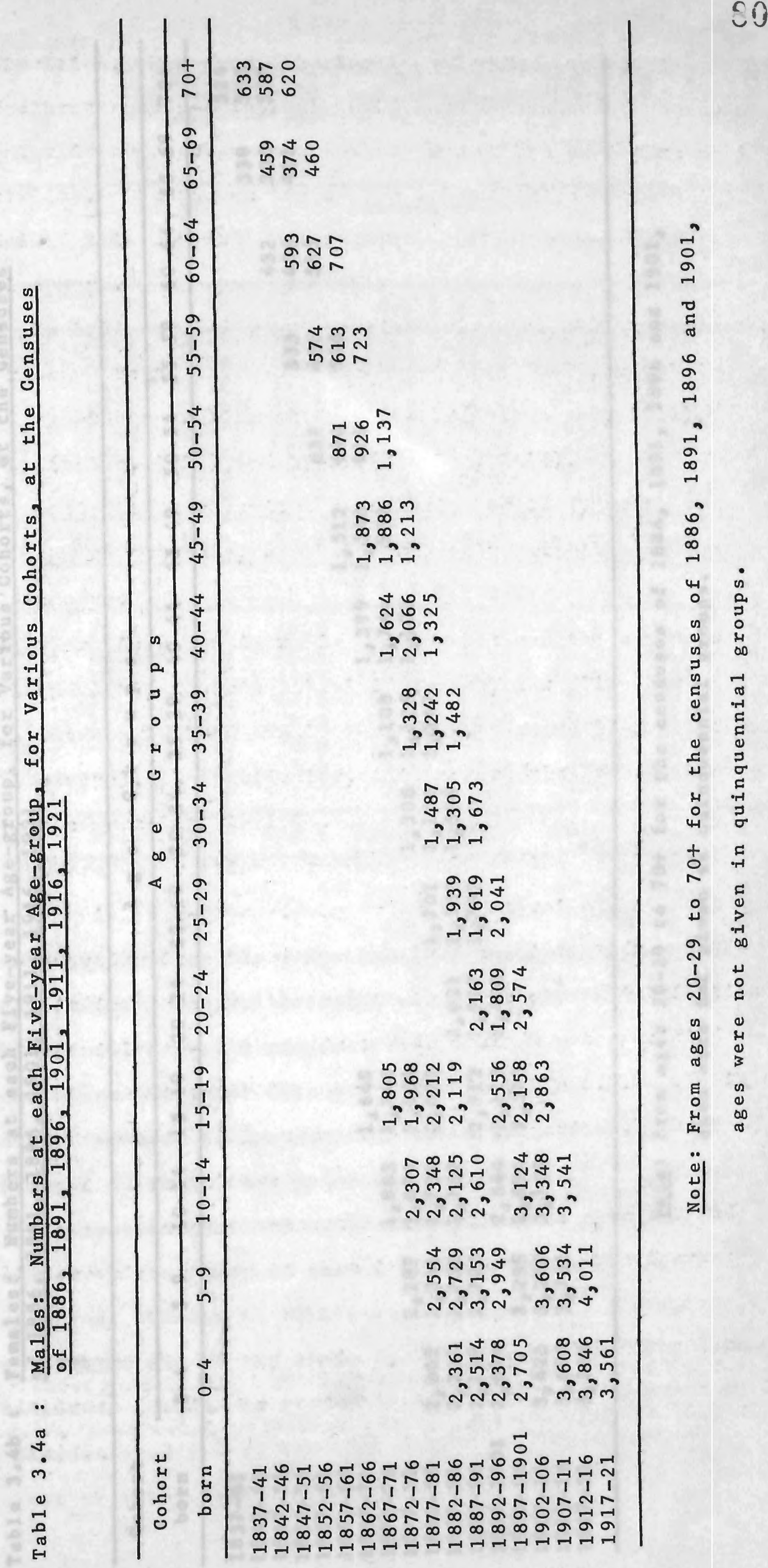




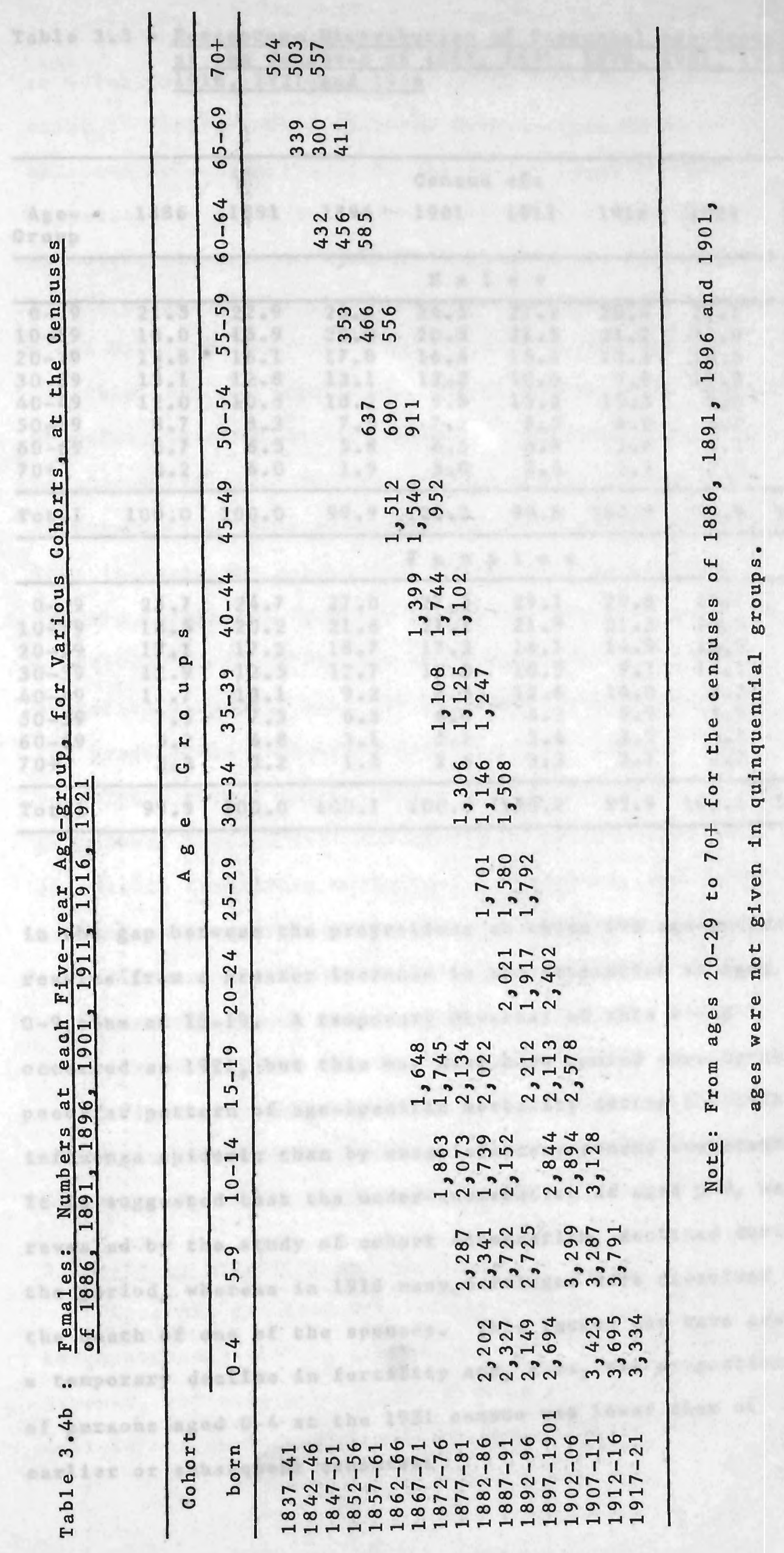


Table 3.5 : Percentage Distribution of Decennial Age-Groups, at the Censuses of $1886,1891,1896,1901,1911$, 1916,1921 and 1926

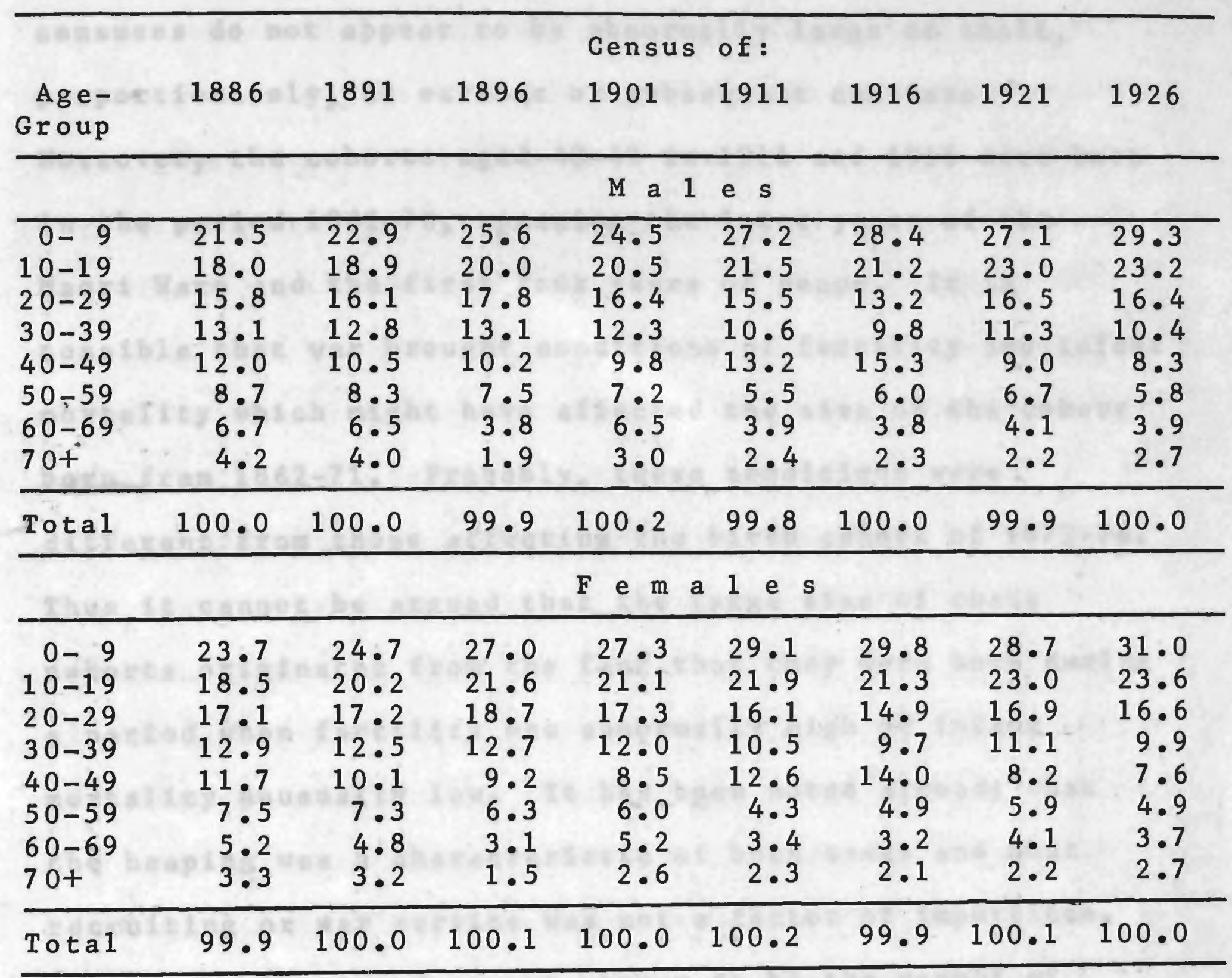

in the gap between the proprotions at these two age-groups results from a greater increase in the proportion at ages 0-9 than at 10-19. A temporary eversal of this trend occurred at 1921 , but this may have been caused more by the peculiar pattern of age-specific mortality during the 1918 influenza epidemic than by unsatisfactory census enumeration. It is suggested that the under-enumeration at ages $0-4$, as revealed by the study of cohort enumeration, declined during the period, whereas in 1918 many marriages were dissolved by the death of one of the spouses. This factor may have caused a temporary decline in fertility and, thus, the proportion of persons aged $0-4$ at the 1921 census was lower than at earlier or subsequent censuses. 
(2) The censuses of 1911 and 1916 were the only enumerations at which the proportion at ages 40-49 exceeded the percentage at 20-29 (1916) and 30-39. The cohorts aged 40-49 at these censuses do not appear to be abnormally large or small, proportionately, at earlier or subsequent censuses. Moreover, the cohorts aged 40-49 in 1911 and 1916 were born in the period $1862-76$, spanning the 1 ater years of the Maori Wars and the first four years of peace. It is possible that war brought conditions of fertility and infant mortality which might have affected the size of the cohort born from 1862-71. Probably, these conditions were different from those affecting the birth cohort of 1872-76. Thus, it cannot be argued that the large size of these cohorts originates from the fact that they were born during a period when fertility was abnormally high or infant mortality unusually low. It has been noted already that the heaping was a characteristic of both sexes and that recruiting or war service was not a factor of importance. Therefore, heaping does not appear to be the result of changes in fertility, mortality, war service, etc. The heaping may result from the fact that the censuses of 1911 and 1916 were the first at which ages were published in quinquennial groups, at all ages $20+$. Yet, any tendency for persons $30-39$ to be reported as $40-49$, 1401 being a round figure, is not evident in earlier or later distributions. Therefore this heaping appears to be a peculiarity, as yet unexplained, of the enumeration of these two censuses alone.

\section{Data on Mortality and Fertility}

Specific problems relating to data assembled on each of these subjects will be discussed in the relevant chapters. However, the same observers commented on both topics, as well as the more general subject of population growth, and 
thus some broad points regarding the quality of these data should be made here.

(1) The basic problem is that there was no vital registration until 1913. As noted earlier, it is necessary to turn to eye-witness accounts. Sometimes in these reports, figures are quoted relating to a particular vital event, but in general, the reports are unsupported by numerical evidence. (2) There is seldom any indication of the methods by which the data were assembled, or even whether the writer himself collected the information. For example, when numerical data are presented, it is difficult to determine whether the figures are based on counts, careful estimates, or whether they are merely rhetorical statements derived from current hearsay.

(3) Usually, details such as the time, place, causes, trends and immediate effects of vital events are vague. (4) Until the mid-1860s, there is no systematic geographical coverage in these reports. Moreover, until then it is difficult to assemble comparable accounts from different regions; in a particular decade there may be only two or three observers each reporting, at different times, on one area which he knows well.

(5) These reporters were, of course, unsophisticated by present-day standards of demographic practice. Thus, many of their conclusions, and even some evidence they put forward, cannot be accepted uncritically. Furthermore, in liew of other data the reports of untrained persons must be referred to, even in fields for which there was some professional training at that time - studies of prevalent diseases being a case in point.

(6) There is a tendency to concentrate on the more bizarre aspects of Maori life, and to overlook the more common- 
place but perhaps more significant. This bias is particularly marked when they discuss the underlying causes of population growth or decline.

In summary, the data until 1921 may be characterised as unreliable. Cook's estimate of the size of the Maori population (the starting point of any serious analysis of trends) is no more than the guess of a mariner who observed some coastal settlements. Even the 1 ater estimates must be accepted, at the most, as enlightened conjectures. Fenton's census is better placed for there is some indication of likely sources of error. Subsequent censuses probably improved in quality, while in the detail of age-reporting 1921 seems to be a better census than those of the late nineteenth century. The feasibility of the growth rates implied by those estimates and censuses can be tested only after the intervening vital events are analysed. In turn, this analysis depends on data which, in terms of mode of collection, are unsystematic, subjective assessments. 


\section{Maori Mortality Trends Until 1921}

\section{Introduction}

This chapter will review the data on mortality in the period 1769-1921; describe in brief Maori health in the preEuropean period; analyse the nature, course and possible effects of epidemics; describe non-epidemic mortality; analyse infant and foetal mortality; and, study preventive measures in the period. In section 7 and 8 an attempt will be made to reconstruct and interpret Maori mortality trends in the nineteenth century by integrating both the evidence reviewed in the remainder of the chapter, and principles derived from some general studies of mortality.

\section{The Data on Mortality}

With the virtual exception of data collected in the last few years, the period $1769-1913$ is distinguished by the lack of quantitative records, which means that the researcher must turn to written accounts, both in government and nongovernment publications. From 1840 these are mainly eyewitness accounts. Sources for the period prior to 1769 , are second hand accounts written by later scholars who derived their material either from Maori traditions or the journals of early explorers. This is tride also for a significant proportion of the sources relating to the period 1769-1840. However, even eye-witnesses may not have been reliable rapporters, as many were untrained medically, or had but brief contact with Maoris.

It is very difficult to assess the relative significance of any disease or epidemic in this period. Even when figures are quoted, there is seldom any indication of the means by which the data were assembled, or the size of the population 
at risk. Moreover, the reports are often vague about the time, the place, the intensity, and the spread of disease. For example, on what criteria could Dr Thomson have based his assertion that the wide-spread 1854 measles epidemic caused 4,000 deaths in the North Island? He could not have seen all these cases himself, nor were other possible reporters so evenly spaced that Thomson could build up a composite and reliable estimate from their accounts. Instead, this appears to have been a crude estimate based on Thomson's observations in one region, p1us, perhaps, some additional information from observers in a few other areas. Yet, it is probable that Thomson was more experienced and informed than most of his contemporaries, for he collected and presented data in a more systematic manner. He, alone among nineteenth century writers, actually collected the morbidity statistics of hospitals to which Maoris were admitted.

Mortality data for the period prior to 1840 are even more generalised - an epidemic 'rages', but the disease, the magnitude of the epidemic and its date are often unstated. The exceptions are attempts to assess the numbers who were killed, or who had died during the wars of the 1820 s and $1830 \mathrm{~s}$, and the more specific accounts of epidemics occurring around mission stations. From 1840 to the mid-1860s, there is an improvement, although the tendency is still to state that there were 'numerous deaths'. From the mid-1860s, reports of district administrators and government appointed medical officers sometimes give fairly specific details about the region, date, disease and even the magnitude of epidemics. For example, there is a report that 20 children died from 'low fever' in an epidemic at Waihou in 1879. Until the mid-1860s, there was no systematic coverage in these accounts; each account usually refers merely to 
the region seen by the writer. From the mid-1860s, there are annual reports from each district, by which means an estimate can be made of the spread of various diseases. For example, about 1875 , reports of measles, came in from all over the North Island, whereas most reports of typhoid in any one year were restricted to a single district, or to widely scattered areas. In the case of typhoid, it is apparent that outbreaks, however severe they might be, were essentially localised occurrences. This does not seem to apply invariably to other acute infectious diseases. For these other diseases, a report of an outbreak in one district does not necessarily imply that the spread was restricted, for there may have been no qualified observers in other districts.

In this regard the investigation must rely upon the general consideration: what factors might have contributed to the spread or containment of a particular epidemic? For example, close communal living and lack of medical care could be significant within particular communities, while migratory movements and military campaigns could have resulted in the spread of disease to neighbouring and distant areas. Generally, the data from which this study of mortality is derived do not relate to mortality specifically as distinct from morbidity or prevalent diseases. Usually, the writers note that a specific disease occurred or was widespread, sometimes adding that the disease had caused a number of deaths. Just as frequently, the occurrence of a particular disease is mentioned merely as one of a list of causes of depopulation. Thus, this study of mortality is mainly derived by inference from what may be determined about the relative frequency of various diseases.

Very few of the commentators prior to 1921 had the time or opportunity to study Maori disease patterns in detail so their accounts do not deal with a representative range of 
prevalent diseases. They tended to concentrate either on outbreaks of acute contagious diseases, resulting in the sudden increases in levels of morbidity and mortality known as epidemics, or else warfare. In other words, the more spectacular causes of mortality and morbidity came to their notice more readily than other causes. Consequently, not only is this study based on references to diseases, but it must, perforce, be weighted strongly towards epidemic mortality.

Epidemics may be associated with the introduction of new and more virulent strains of endemic disorders, with the introduction of new diseases or diseases which have not occurred for a long period, or with breakdowns of public health standards or unusual congregations of population which allow endemic diseases to spread more rapidly than under normal circumstances. From the reports of early writers, it is difficult to determine which of these factors may have operated in the spread of diseases, or, indeed, whether the so-called 'outbreaks' or 'epidemics' caused incidence rates in excess of the 'normal'. Moreover, circumstantial evidence must be relied on when inferring that various diseases were introduced or reintroduced to a population which had no clearly developed patterns of immunity. Generally, deductions can be made only about those diseases which have proven regimes of immunity. The epidemics occurring between 1769 and 1921 are 1 isted in Table 4.1. The analysis of these epidemics is complicated further by five facts:

(1) Often it is difficult to establish the periodicity of of epidemics, particularly those of the early nineteenth century, because reported dates are vague, or different reporters give conflicting evidence. A rough relationship in time can be shown between epidemics elsewhere and some 
of the epidemics occurring in N.Z. When an epidemic is

widespread in the South-West Pacific, this relationship may

allow the date and other characteristics of the outbreak among

the Maori to be verified. Moreover, some lead may be obtained from non-Maori vital registrations. In 1855, registration of non-Maori vital events was introduced, while from 1872 deaths by cause were registered. From 1872, the appearance of epidemics among non-Maoris can be checked by noting abnormally high mortality from various diseases. In turn, the appearance of epidemics among non-Maoris is a check on the timing of epidemics reported for the Maori population.

Appendix $B$, gives the total numbers of non-Maoris who died from measles, influenza, scarlet fever and diphtheria in each year during the period 1772-1921. As typhoid tends to be restricted in occurrence to certain regions, there is not the marked variation in the number of typhoid deaths which is found among the other causes. Mortality from phthisis, cancer and other chronic diseases not included in Appendex $B$, was even less prone to sudden increases and decreases, while there were too few deaths from other epidemic diseases for them to be considered here. It might be noted that with the exception of influenza, absolute numbers of deaths declined, while the size of the non-Maori population rose rapidly.

(2) Early writers tended to emphasise the epidemics of 'common' diseases such as influenza and measles, probably because they were perplexed about the peculiar virulence of these 'mild' diseases when outbreaks occurred among the Maoris.

The reports of district officials later in the century also tend to be selective. It was their duty to report on the most important events in their district, so that any one of such topics as crime, agriculture, 
political agitation and health was emphasised at the expenš of others. When discussing health, they might mention the mortality of adults giving details about 'chiefs' of tribes and sub-tribes who had died, or about mortality arising from violence or extraordinary accidents - the few deaths caused by bee-stings were analysed in detail by a number of these officials.

Throughout the period infant and childhood epidemic mortality was reported upon specifically only when its causes were particularly noteworthy, or, in a few cases, when reporters had collected some data on deaths and were surprised at the results. For example, during the 1875 measles epidemic many officials noted that the outbreak was 'mild', for few Maoris 'succumbed' to the disease 'except for children'. In their defence it must be remembered that levels of infant mortality were still high in nineteenth century Great Britain and, thus these British observers were prone, it appears, to dismiss infant mortality as unworthy of detailed interest.

(3) In the 1 ate nineteenth century, typhoid, 'fever', 'enteric fever' and 'low fever' were the most frequently reported diseases, and officials may have underated the importance of other diseases. The emphasising of typhoid at this time - the other fevers are also probably typhoid is understandable because its epidemiology had been established quite early and public health programmes in Europe and elsewhere were attempting to prevent its occurrence. Outbreaks of typhoid were likely to be of short duration, but were severe enough to be brought to the notice of district officials. Generally, they were restriced in spread to particular regions, and, sometimes, could be traced directly back to some source, such as 
insanitary water supplies, etc. Outbreaks of other diseases were reported only when they were as severe as this in a particular region, or if the officials recognised that an epidemic was spreading from region to region, whereupon this disease would be emphasized at the expense of others. After 1900 , data cover cases attended by Health Dept. personnel and may be more representative. However, these officials would have attended cases in areas where outbreaks were most severe, so that some bias may have been introduced. (4) The first reference to a particular disease cannot be taken as evidence that a disease had not been introduced previously. However, circumstantial evidence can sometimes be used as a guide in such cases.

(5) During an epidemic the particular disease concerned may not have been the direct cause of all the reported deaths. Some deaths may result from sequelae or complications of the epidemic disease, while the infectious disease may cause the sudden deaths of persons having long-standing chronic disorders. The separation of primary from secondary causes of death is difficult even in populations which have an established routine of certification of causes; among other populations no such check can be made.

The state of medical knowledge is another factor which affected the interpretation of various events by observers in this period. The declines in mortality in the 'West' resulted, in part, from steps taken to combat infectious diseases. These preventive measures arose, in turn, from a greater understanding of epidemiology, and particularly from the formulation of the 'germ-theory' of disease after about 1850. This resulted from Panum's 1846 study of a measles epidemic in the Faroe Islands, among an isolated, European population, where he recognised that the spread 
of infection could be attributed to 'contagium' rather than to a 'miasmatic origin'; from Snow's work on cholera; from Budd's paper, in 1856, which stated that typhoid was an sessentially contagious disorder'; and, of course, from Pasteur's great work, Lister's use of antiseptics, and Koch's bacteriological research, mainly between 1867 and $1882 .^{1}$ Until these factors were studied, there could be no advances in the study of immunology. Thus, early writers had little understanding of immunity and were justifiably perplexed when they observed severe epidemics of what were considered Imild complaints.

Previously, the 'miasma' theory had held sway over the theory of contagion'. In the first half of the nineteenth century, steps had been taken to prevent 'miasma', by such measures as the reduction of filth, putrid matter and overcrowding, and the increase of ventilation. All these were recognised as sources of 'miasma'. The measures described above probably prevented some 'contagion' fortuitously, and in spite of the state of theoretical knowledge. 'Miasmatic' origins of disease were sometimes claimed in early New Zealand material. Some statements, such as those on the over-crowding and dirtiness of wharepuni (houses) and whare-runanga (meeting-houses), seem reasonable, although germs rather than stench would have caused the spread of infection. Again, a 'miasmatic' origin of disease was seen in the Maoris use of rotten maize as a food. Another attributed cause of disease was often natural calamity, which was noted for the Maoris as 1 ate as $1855^{2}$

1 Chapts.XII \& XIV. Winslow, Charles-Edward Amory (1944): The Conquest of Epidemic Diseases, Princeton.

pp.255-56. Taylor, Rev. Richard (1855): Te Ika a Maui, London. 
In the nineteenth century, diagnostic rationale changed as the knowledge of the characteristics of various diseases improved. Thus, in reading earlier material, account must be taken of these changes. Three cases are of direct importance. Firstly, the differences between typhus and typhoid were not recognised until 1849. Epidemic typhus, which is caused by a louse-borne organism of the genus rickettsiae, can be identified by a characteristic rash termed 'mulberry rash'. Typhoid is caused by bacilli, which spread because of insanitary conditions, and which infect the bowels and the intestines. ${ }^{3}$ secondly, until the 1839 treatise of Phillipe Record, gonorrhoea was thought to be the same disease as syphilis. 4 Thirdly, measles and whooping cough, although previously recognised, were not taken as extremely important until the mid-nineteenth century, when registration of deaths in Great Britain emphasised their significance. 5 Thus, it is not surprising that early writers expressed some astonishment at the rapid spread of ${ }^{\prime}$ childhood' ailments among Maoris.

Bubonic plague, malaria, yellow fever, cholera and smallpox are five infectious diseases which do not seem to have caused the mortality in New Zealand that they caused elsewhere. If they had occurred among Maoris, they could

$\overline{3}$

pp.35-38. Paul, Hugh (1952): The Control of Communicable Diseases, London. Typhoid is also called 'enteric fever Possibly, both typhoid and typhus occurred in this early period, although there is no record of typhus, with one possible exception (see Dr Rawson's comments about an outbreak in Nov. 1862, Section 3, and fn.72). After about 1860 , it seems that epidemics termed typhoid would not be an incorrect diagnosis of typhus. For a description of these diseases see Thompson, William A.R. (1961): Black's Medical Dictionary, London.

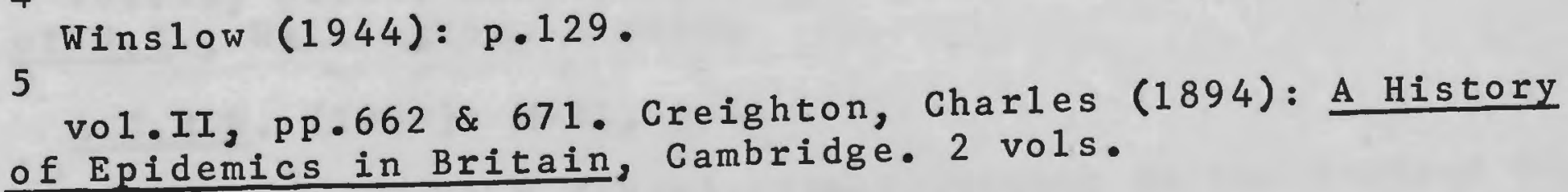


have been readily recognised, and would have been reported. A smallpox epidemic did occur right at the end of the period, but, although important overseas, the other diseases do not seem to have occurred among Maoris at all. For example, there were widespread epidemics of plague in Asia in the $1870 \mathrm{~s}$ and the $1890 \mathrm{~s}$, when important advances were made in the epidemiology of the disease, ${ }^{6}$ while cholera was prevalent in mid-nineteenth century in Britain. ${ }^{7}$

\section{Maori Health prior to 1769}

In 1773, the Maori people were described by Cook's astronomer as istrong made (sic) healthy people... 8 As New Zealand was so isolated, it seems that few of the more common diseases were endemic, none of the great 'apocalyptic' pestilences had swept the country and even the common 'childhood' epidemic diseases did not occur. 9

Dr Thomson, writing in 1854, gives the first quantified analysis of Maori physique. He measured Maoris, then compared his sample with English soldiers in New Zealand, with oxford and Edinburgh students, and with surveys in Belgium, England and France. He concluded: That they are taller than the natives of Belgium or the temperate countries of Europe, but not so tall as the English... That they are about equal in weight to the natives of Great Britain, and heavier than those of Belgium?. 10

Few observers agree as to the diseases endemic in preEuropean New Zealand. The most commonly accepted is some

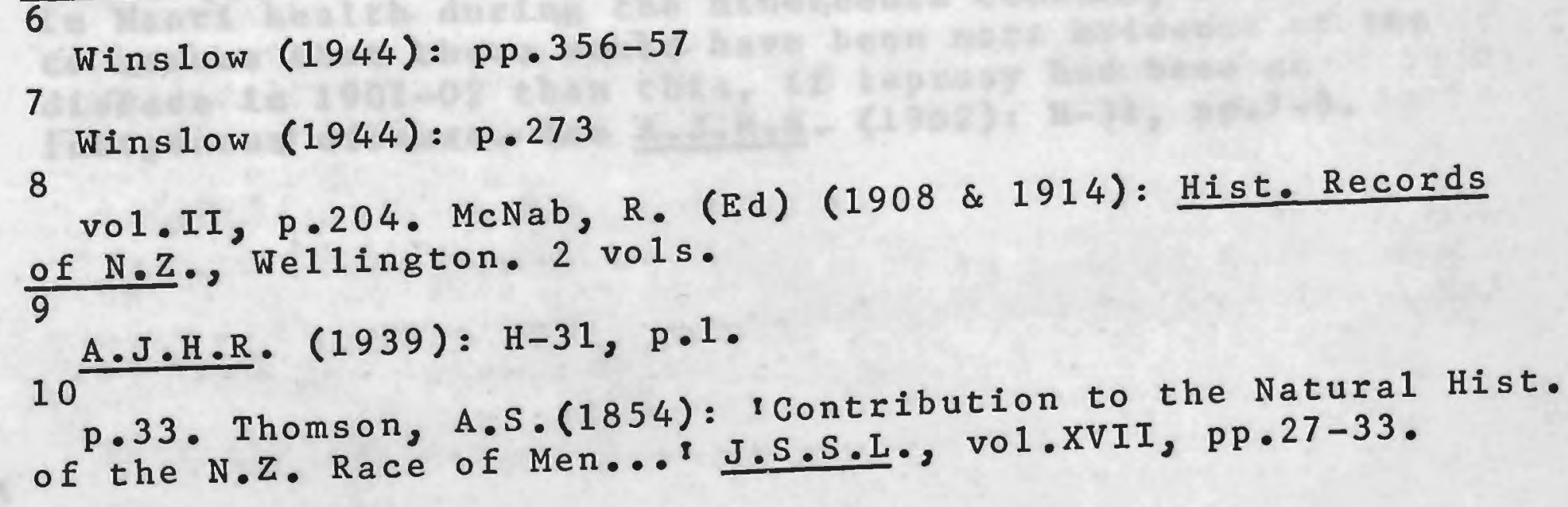


form of leprosy. 11 Thomson, from whose work some of these observations may derive, noted that Lepra gangrenosa (ngere ngere or tu whenua) occurred occasionally at the time he wrote $(1850 \mathrm{~s})$. He thought it might have been prevalent twenty years before, and implied, but did not explicitly state, that it was pre-European. 12 An answer to the weight of opinion that leprosy was indigenous, is Dr Alfred Ginder's belief, derived from Maori tradition, that the disease first appeared on this island at Hauraki sometime during the latter half of the seventeenth century'. He suggests that a marooned leper from a whaler could have introduced the disease, but this historian Sinclair notes that the first whaler visited New Zealand only in 1792 , over a century later. ${ }^{13}$ Recently, Robb has suggested another and perhaps more plausible alternative. 14 :A kwashiorkor-like state of malnutrition is

11

P.209. Wilson, D. Macdonald (1934) iHist. of N.Z.: Notes of Medical Interest ${ }^{2}$, N.Z.M.J., vo1.33, pp.102-10\& 205-16; p.279. MacMillan, David (1946): By-ways of Hist.\& Medicine, Christchurch; p.408. Te Rangihiroa (1952): The Coming of the Maori, Wellington; p.118. Goldie, W.H. (1899): Polynesian Medical Researches, M.D. Thesis(?), Edin. Mss. Auckland. Pub. Lib.; and, P.62. Goldie, W.H. (1904): 'Maori Medical Lore', T.N.Z.I., vol.37. pp.1-130. Elsdon Best, the ethnologist, supplied notes to Goldie for the last article. 12

vo1.I, Pp.217-18. Thomson, A.S. (1859): The Story of N.Z., London. 2 vols. 13

A.J.H.R. (1890): G-5, P.3; cf. P.34. Sinclair, Keith (1959): A History of N.Z., London. 14

p.8 (reprint). Robb, Douglas (1960): Maori \& European Differential Incidence of Surgical \& Other Diseases", N.Z.M.J., vol.59, no.334, June. pp.271-79. In 1901-02 a survey of forty or fifty Maoris, who were alleged to be suffering from leprosy, revealed only one possible case, the remainder being tuberculosis or syphilis. In view of the lack of improvements in Maori health during the nineteenth century, it is reasonable to assume that there would have been more evidence of the disease in 1901-02 than this, if leprosy had been an indigenous disease. See A.J.H.R. (1902): H-31, pp.7-8. 
seen occasionally in Maori children and the Maori "leprosy" of the nineteenth century writers may actually have been kwashiorkor'.

Skin diseases, such as 'itch', boils and ring-worm, 15 were claimed to be indigenous diseases of some importance. Tuberculosis is noted as an indigenous disease (termed mate kohi) by Dr Pomare, ${ }^{16}$ (as ngahe) by Dr Matthew Scott of Wairoa, ${ }^{17}$ and by McMillan and Colenso. ${ }^{18}$

Living conditions are considered to be important variables in the incidence of tuberculosis, including such factors as over-crowing and poor sanitation. ${ }^{19}$ If tuberculosis were endemic, its incidence could have been increased by the general social and 'political' disorganisation after Cook's time, which must have undermined the normal functioning of village hygiene; by the change in housing sites from hillsides to swampy valleys; and, perhaps by the oft-stated change in the dress to the less sanitary blanket and other non-Maori clothes. However, the reported high incidence of the disease in the nineteenth century seems more likely to have been due to the normal lack of immunity among primitive groups at first contact with the disease. In such cases the disease tends to run a rapid course... resembling far more the acute type of disease met with in infancy than the localized, slowly spreading, ulcerative type of phthisis common in adults of civilised countries'.

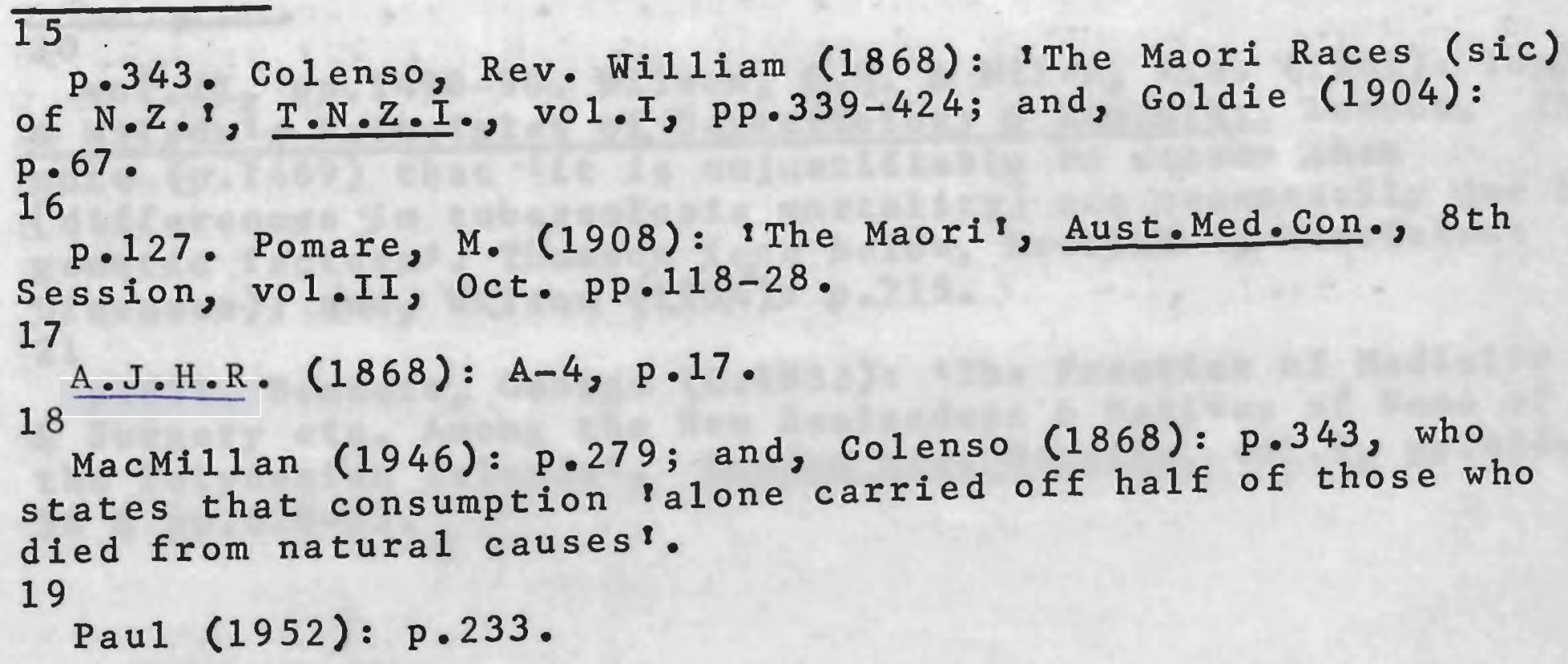


This factor, combined with a change in the style of living, could have caused an extremely high mortality. Thus, it can be argued quite strongly that tuberculosis was not an indigenous disease. Such a claim was made by the nineteenth century observer Thomson, while Wilson, a recent writer, has argued: 'it is seen that in 1814 tuberculosis was unknown, and 20 years 1 ater was common, and by the ififties was the curse of the races.20

It has also been suggested that influenza was indigenous or arose from natural causes. About 1832 , Dr Bennett said: 'I can find no proof why [influenza in the "Polynesian Islands"] should be considered of foreign introduction when epidemics are known to prevail without any cause but atmospherical vicissitudes'. 21 Bennett may have been right, in part, for there are two or more different influenza viruses each of which can change in character, and either of these may have been present in New Zealand. Epidemics would generally have been restricted to winter months, which is probably a reason for the claim that the causes of influenza were 'atmospherical vicissitudes'. On the other hand the reported severity of early influenza epidemics suggests that the Maoris had a lack of immunity to the particular viruses involved, and thus that these viruses were introduced. Such a claim cannot be held strongly, for one attack of influenza bestows only temporary immunity from

vo1.II, pp.1498-90. Wilson, G.S. \& Miles, A.A. (1961): Topley \& Wilson's Principles of Bacteriology \& Immunity, London. They note (p.1489) that lit is unjustifiable to assume that [differences in tuberculosis mortality] are necessarily due to genetic factors'. Thomson (see below, Section 4, Scrofulous Diseases); and, Wilson (1934): p.215. 21

P.631. Bennett, George (C.1832): The Practice of Medicine \& Surgery etc. Among the New Zealanders \& Natives of Some of the Polynesian Islands', London Med. Gazette, vol.9, pp.434$38 \& \mathrm{pP} \cdot 628-33$. 
that virus alone, and not necessarily for all influenza viruses. Any discussion of influenza is limited to a description of a particular epidemic because of the complexity of these patterns of immunity. 22

The absence of many of the common infectious diseases meant that the stage was truly set for the entrance of epidemics. However, it cannot be said that the Maoris lived a completely idyllic life with very low mortality. Warfare occurred quite frequently, and it is certain that infant and maternal mortality would have been at relatively high levels. The Maoris had comparatively little knowledge of medicine, although Pomare notes that they could perform cauterization, tonsillectomy and even caesarean sections. Furthermore, he states that there were many health measures in the pa (villages). Among these were the sweeping of rubbish, the proper construction of latrines, the use of springs for the water supply, a series of rules surrounding births, deaths and burials, which were enforced by tapu, and the fact that pa were usually on well-drained heights. He even suggests that the weak were strangled at birth. ${ }^{23}$

The view of Dr Bennett and the Rev. Taylor, that there was 1 ittle disease in this period, is perhaps too optimistic. ${ }^{24}$ Yet, their view may be more correct than the dismal picture painted by Dr Dieffenbach. 25

22

This commentary on influenza is from chapt.XX. Burnet, Frank Macfarlane (1953): Natural History of Infectious Diseases, Cambidge. He notes that the influenza virus was not isolated until 1933, and thus some of its immunological and epidemiological characteristics even during recent epidemics (e.g. 1918-19) are not fully catalogued or analysed. 23

Pomare (1908): pp.120-21.

24 Bennett (C.1832): p.434; and, Taylor (1855): p.254. 25 vo1.II, p.16. Dieffenbach, Ernest (1843): Travels in N.Z., London. 2 vols. 
A persistent idea is that a European ship introduced venereal disease or influenza prior to, or at the same time as Cook's voyages of about 1770 . Dieffenbach heard of a 1 egend among East Coast tribes that there was an epidemic prior to Cook, possibly in the Northern parts of the North Island. He said: Iits victims were so numerous that they could not bury them, but threw them into the sea... the disease is a bad form of influenza...26 Dr Thomson states that Maori tradition notes a visit to the North Island about 1740 of a European vesse1, commanded by someone named Rongotute. 27 This shadowy evidence is the first indication of the European introduction of disease. Whether or not a ship arrived before Cook's will remain a mystery. However this much is certain - Cook's men, and subsequent voyagers and settlers, introduced a wide range of diseases.

\section{Epidemics and Warfare}

The spread and nature of epidemics until 1921 is shown in Table 4.1, which also notes until the 1 ate 1860 s whether the source is primary or secondary. From then on sources are primary. On the assumption that common epidemic diseases were not found in New Zealand before European contact, the impact of influenza, measles, mumps, whooping cough, typhoid and other fevers can be suggested.

\footnotetext{
26

Dieffenbach (1843): vo1.II, pp.13-14 27

Thomson (1859): vol.I, p.229. See also pp.59-60. Smith, S. Percy (1910): The Maori Wars of the 19th Century, Christchurch. It is uncertain from Smith's account whether he is referring to a ship, after the time of Cook, captained by a Scotsman, or to a Ngapuhi tradition about a ship Rongotute. See also Wilson (1934): p.206 which is probably from one of the above sources. One other claim, that a man stivers visited and introduced the potato (taewa) is dison of the Maori to the Williams, Rev. H.W.
} 
Table 4.1: Epidemics Occurring Among Maoris Between c. 1769 and 1921

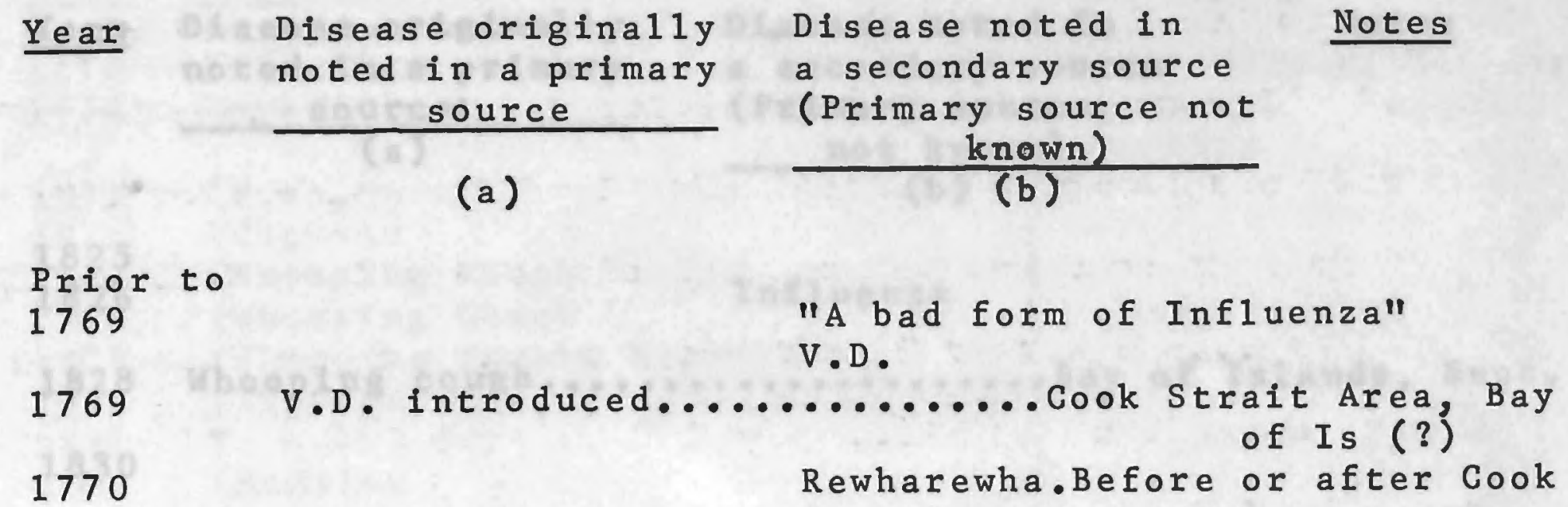

1775

1780

Te Rewharewha

$1780-90$

1785

1790

(Rewharewha........ (Cook Strait Area (Influenza (About 1790

1795

Dysentery.......... ( [Rewa rewa $]$

(Mercury Bay Area

1800

Dysentery....... Started in the North Influenza...... (North of the South (Island. Early $19 \mathrm{th}$ (Century

1805

1810

"2nd Gt.Epidemic"... (Original source (Mission Regis(ter, (1817).

$\begin{aligned} & \text { Rewharewha... } \text { (1815-20, South of } \mathrm{Nth} \\ & \text { (Island }\end{aligned}$ 
Table 4.1: (contd.) Epidemics Occurring Among Maoris Between c. 1769 and 1921

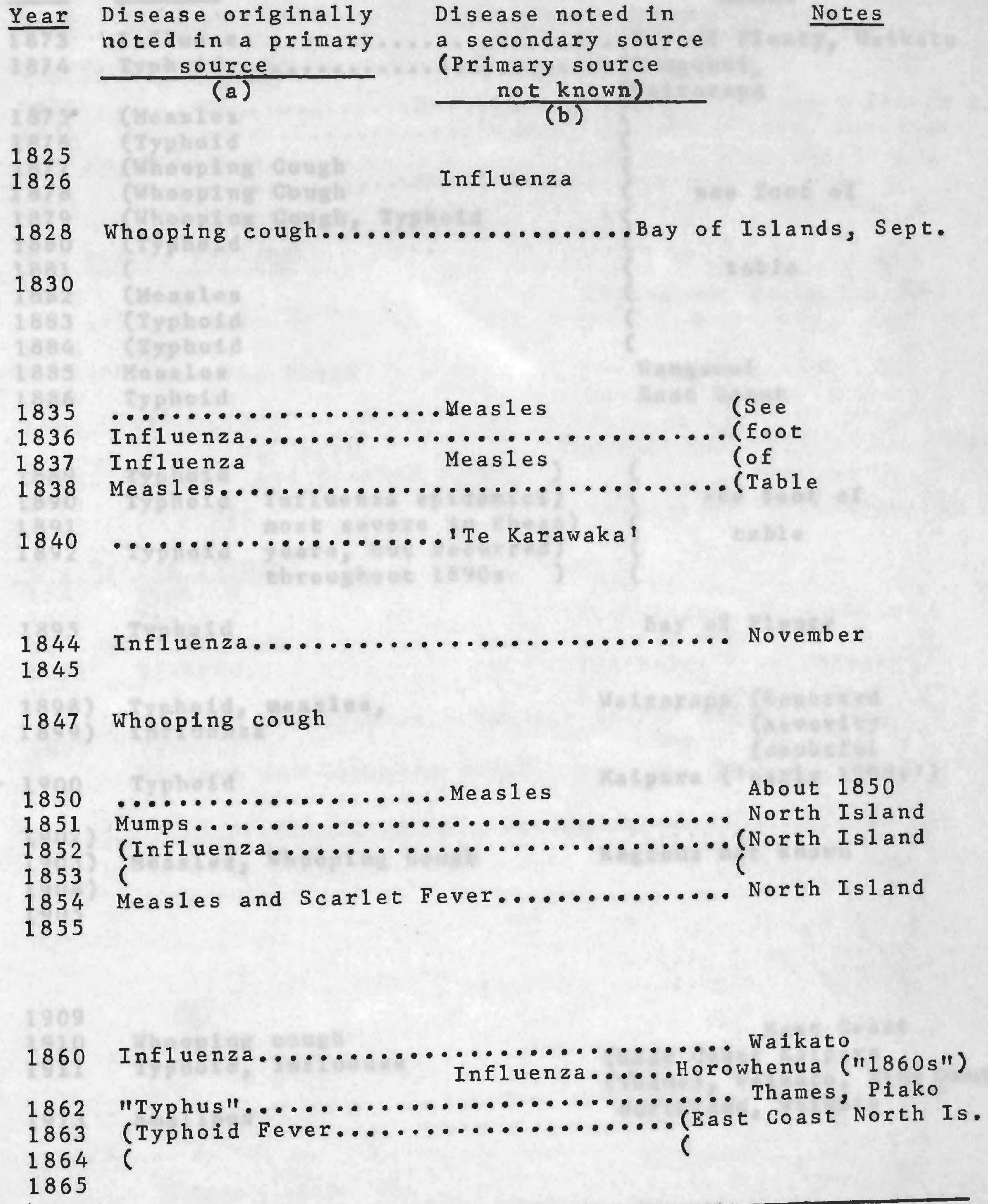

Compilation Notes: (a) Fever, low fever, etc. termed typhoid
here;
(b) From 1868 all sources are primary


Table 4.1: (contd.) Epidemics Occurring Among Maoris Between c.1769 and 1921

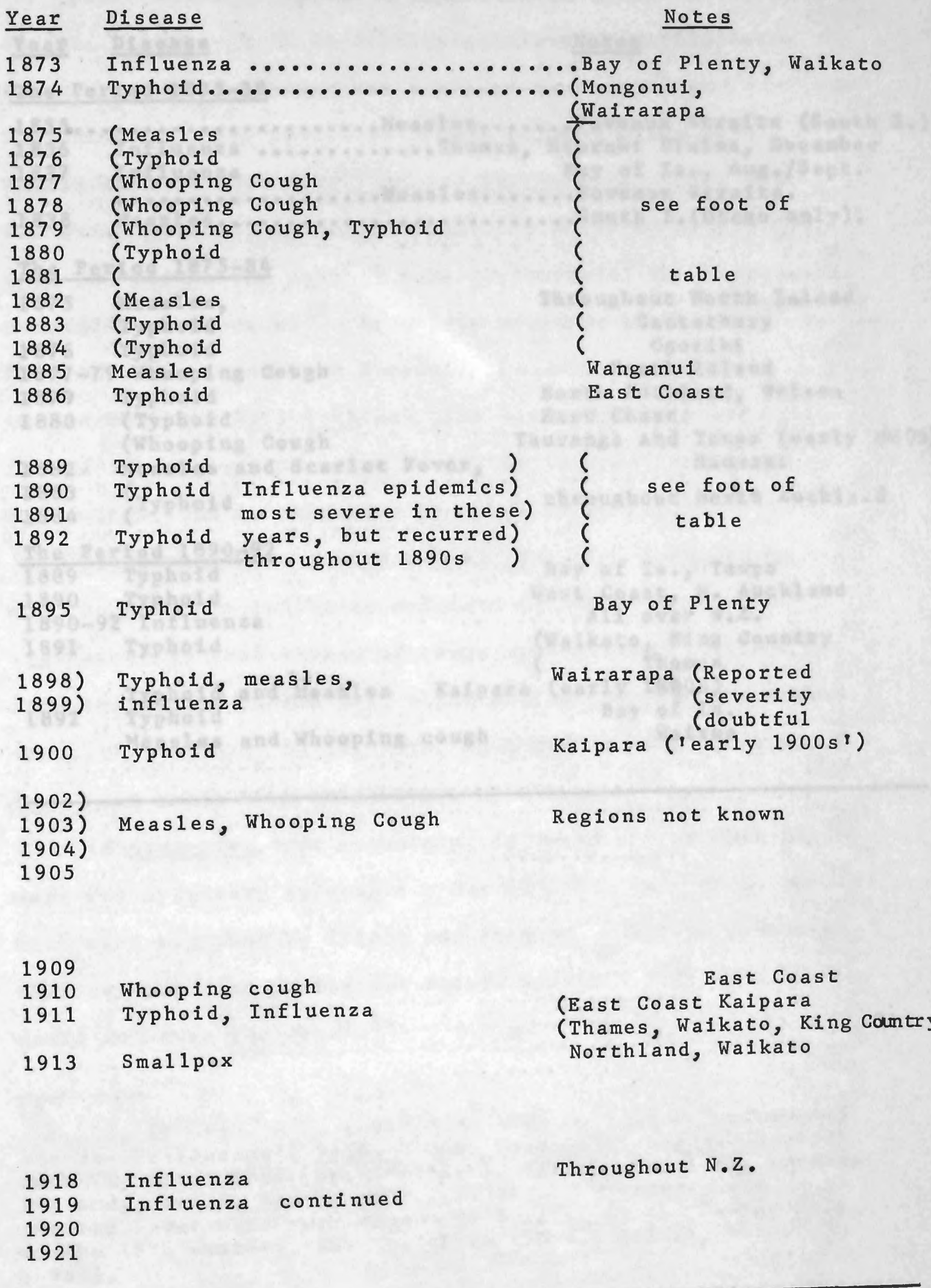


Table 4.1: (Contd.) Epidemics Occurring Among Maoris Between c. 1769 and 1921

Year Disease Notes

The Period 1835-38

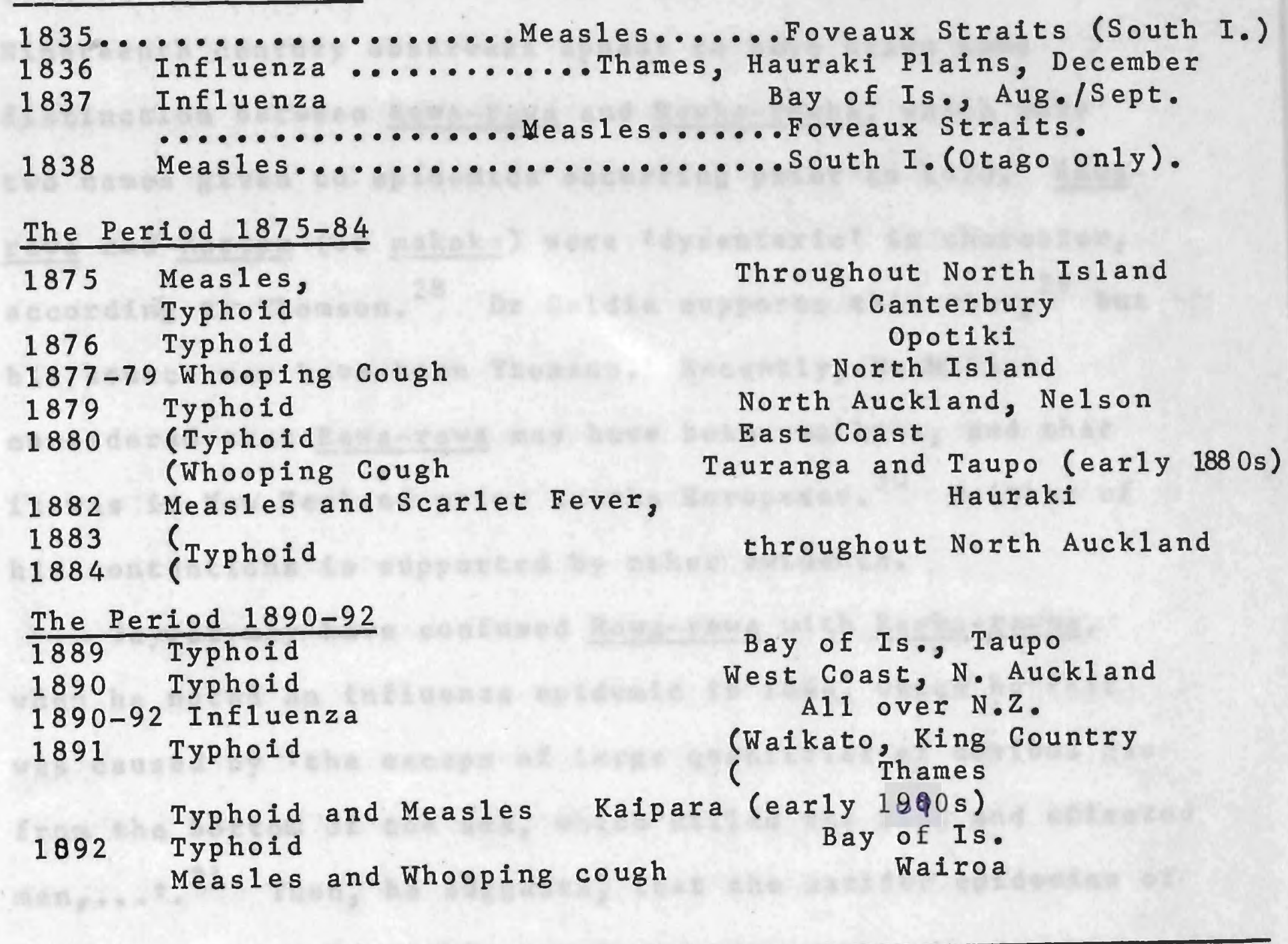


From Cook's time, the evidence about epidemics is more explicit, although it is still impossible to verify dates, and the types of disease are not easy to recognise. Nineteenth century observers appear to have drawn some distinction between Rewa-rewa and Rewha-rewha, which were two names given to epidemics occurring prior to 1820 . Rewarewa and Maripa (or makoko) were 'dysenteric' in character, according to Thomson. 28 Dr Goldie supports this view, ${ }^{29}$ but his source may have been Thomson. Recently, MacMillan considered that Rewa-rewa may have been smallpox, and that it was in New Zealand prior to the Europeans. 30 Neither of his contentions is supported by other evidence.

\section{Taylor may have confused Rewa-rewa with Rewha-rewha,} when he noted an influenza epidemic in 1844 , which he felt was caused by the escape of large quantities of noxious gas from the bottom of the sea, which killed the fish and affected men,.... 31 Then, he suggests, that the earlier epidemics of Rewa-rewa arose from this cause.

If Rewa-rewa were dysentery, it would appear that there were two dysentery epidemics - one in 1795; another in 1800. Both were reported by Goldie and Thomson. Thomson mentions that so many died during the second epidemic that ithe living could not bury the deadi. 32

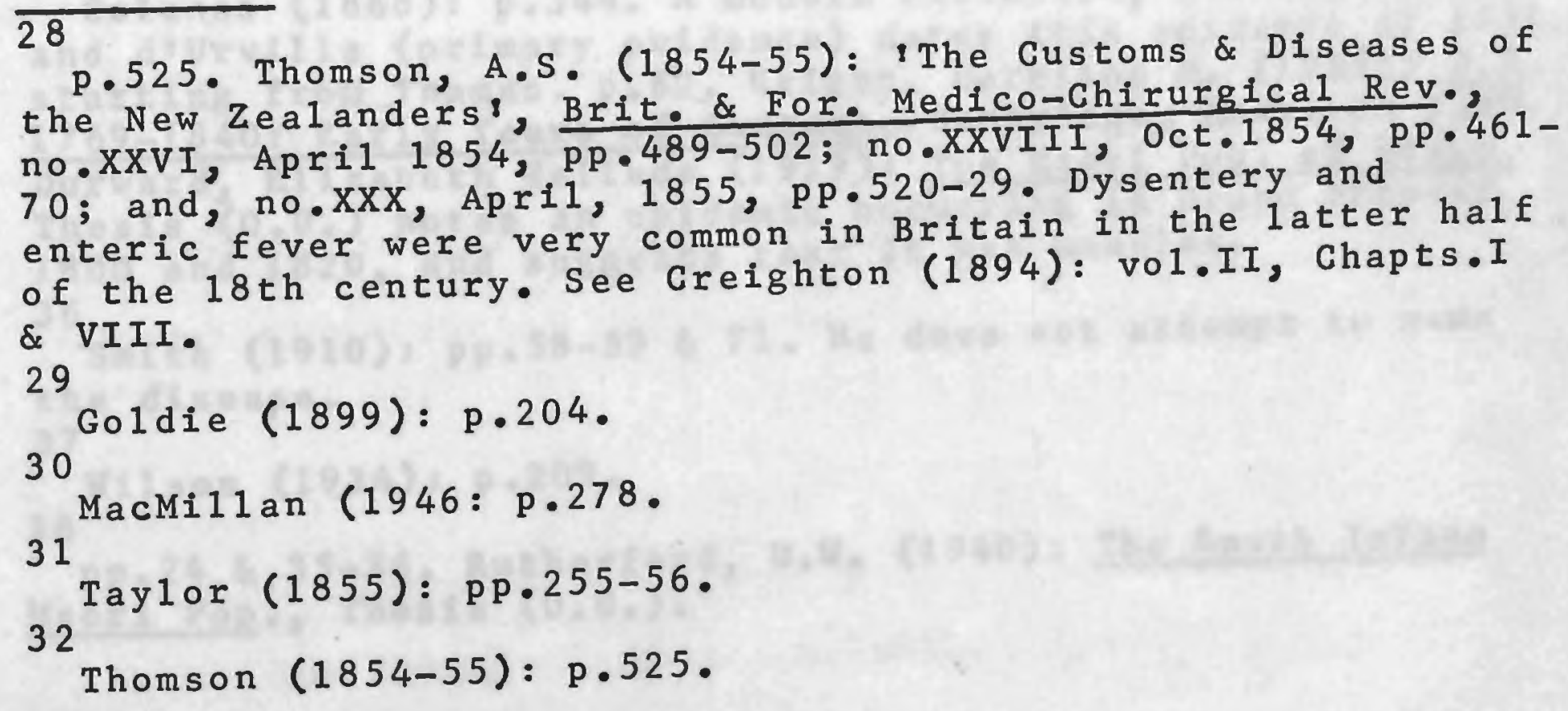


According to Goldie the other epidemic disease, Rewharewha, might have been influenza, ${ }^{33}$ while Mair and Smith do not define it. ${ }^{34}$ If Mair's date of a Rewha-rewha epidemic in 1780-90 and Smith's date of 1790 ( \pm 10 years) are compared with Goldie's date of 1790 , there is some correlation. Thus, Rewha-rewha first occurred, it seems, about 1780-90. Then it occurred again, by Colenso's account, about 1815, when it idestroyed nearly $3 / 5$ ths of the people in the southern parts of the Northern Island; in some villages and sub-tribes leaving only one or two individuals ${ }^{35}$ He dates this epidemic as occurring forty-fifty years before he wrote his account (1863). Possibly, it could have been the so-called 'second great epidemic', of about 1810 , noted by Percy Smith, the ethnologist, and dated from a note in the Mission Register of 1817. 36 Macdonald Wilson, a recent writer, states that Rewharewha occurred either before, or after, Cook's time. ${ }^{37}$

Finally, an influenza epidemic, noted by Rutherford, in the north of the South Island in the early nineteenth century, ${ }^{38}$

Goldie (1899): p.204. Epidemic influenza probably occurred frequently and severely in this period. Epidemics of the 'common cold? would have been even more frequent, following the arrival of each new ship. The 'stranger's cold' is a common phenomenon. See Burnet (1953): pp.231-32. 34

p.14. Mair, G. (1923): Reminiscences \& Maori Stories, Auckland; and, Smith (1910): pp.59-60. 35

Colenso (1868): p.344. A modern historian, quoting colenso and diurville (primary evidence) dates this epidemic at 1820 , starting from Thames. p.62. Wright, Harrison M. (1959): N.Z. 1769-1840: Ear1y Years of Contact, Cambridge, Mass. on p.60. Durward, Elizabeth Wallace (1929): The Maori Pop. of Otago, Thesis ( $\left.0 . U_{.}\right)$notes an epidemic occurring in Otago between 1800 and 1820 , and suggests that it was measles. 36

Smith (1910): pp.58-59\&71. He does not attempt to name the disease.

37

Wils on (1934): p.209.

38 pp.24\&35-36. Rutherford, D.W. (1940): The South Island Maori Pop., Thesis (0.U.). 
could have coincided with the Rewa-rewa (dysentery) efidemic noted by Thomson, or with the Rewha-rewha mentioned by Smith and Colenso, for Colenso specified that Rewha-rewha swept the south of the North Island.

The important factors to note about this early period prior to the early 1820 s are these. Firstly, epidemics, before or after Cook, made such obvious inroads that contemporary observers, or Maori traditions, recorded their occurrence. Secondly, the association of contact with the introduction of disease in these accounts must have been caused by more than superstition or prejudice. If the diseases had been endemic and the incidence quite normal, such a detail would have been overlooked. Thirdly, Wright has shown that, at 1 east in the north, where the majority of the Maoris resided, there were comparatively few visiting ships or contacts between Maoris and non-Maoris until the $1820 \mathrm{~s}^{39}$ Thus, if the crews of visiting ships introduced infectious diseases, there is every likelihood that epidemics would have been at widely-spaced intervals and that they would have been severe. The Maoris would not have had the opportunity to build up the type of immunity which would have developed if contact, and thus epidemics, had been frequent (see section 7). However, this is not to imply that every early crew introduced common infectious diseases. Two very recent observers have reported that there were influenza epidemics after the visit of the ship Coromandel, in 1826.40 The source of this observation is not known to the present writer, nor is the epidemic mentioned by Wright, a major historian of the period.

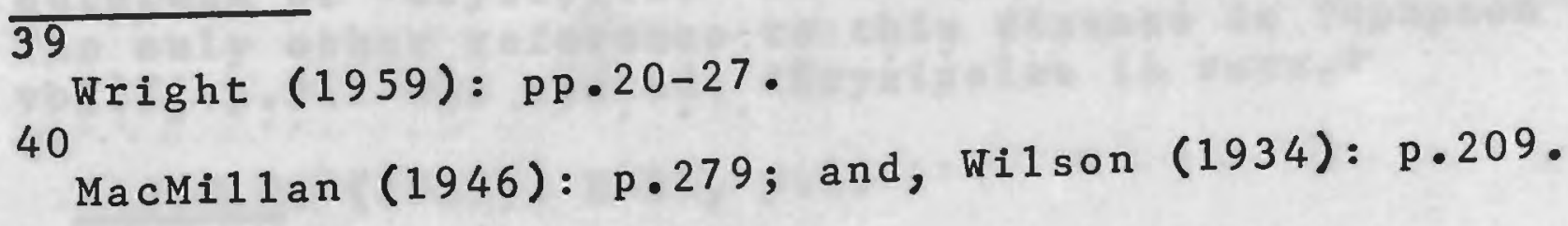


Wright has noted, from manuscript sources, that a

whooping cough epidemic occurred in 1828 , and that an

influenza epidemic, in 1 ate 1837 , spread through the Bay of

Is 1 ands, and perhaps elsewhere, being one of a series

occurring every Spring and Autumn...'. These outbreaks

were not Irestricted in their effects to any particular

section of the [North] island. 41 Thus, a mission surgeon

said of this August 1837 influenza epidemic: Influenza was

then [on his arrival in the Bay of Islands] prevailing in

that part of the Island to a great extent and affecting the

natives most seriously'. 42 Further south , a serious

epidemic of influenza, first noted at Thames in December,

1837, raged inland and along the Bay of P1enty ${ }^{1}$. Thames is a

coastal locality which was frequently visited by ships in

the nineteenth century, and thus this outbreak could have

been a continuation of an epidemic which originated in

Sydney in October $1836 .^{43}$

In 1835 and 1837 , a measles epidemic occurred in the

Foveaux Straits area of the South Island. 44 In 1838 , an

41

Wright (1959): pp.63-64. He says (p.63): ear1y epidemics

Imay have involved dysentery, diphtheria, streptococcal

infections, influenza or other diseases ${ }^{2}$. He notes an

epidemic of a streptococcus-like infection' in 1838. It is

not known how he derives this last fact, or that about

diphtheria (see below, Section 4, Two surveys of morbidity). Burnet (1953): p.278 has noted important influenza epidemics in Britain in 1833 and 1837 .

42

Reported by Coates, Sec. Church Missionary Society, from a letter, in P.P. (1837-38): XXI, p.199. See also Goldie $(1899)$ : P.206.

43

p.376. Melvin, L.W. (1962): 'Te Waharoa of the Ngatihaua', J.P.S., vol.71, No.4, Dec. pp.361-78. The original source was the unpublished journale of a missionary. For information on the Sydney influenza epidemic see p.371. information on the Sydney influenza of Influenza... in Gt. Britain from 1510 to 1837 , London. An 1837 epidemic in Gt. Britain had originated in Sydney. Melvin also notes an outbreak of ierysipelas in the same region, July 1838. The only other reference to this disease is Thompson (1859): vol.I, p.217 who stated: IErysipelas is rare.' 44

A.J.H.R. (1939): H-31, p.1. 
epidemic of measles occurred in the South Island, ${ }^{45}$ probably in Canterbury and Otago alone, for Rutherford says 'The epidemics which raged in the South after 1835 do not appear to have affected the Northern tribes settled about the shores of Cook Strait. ${ }^{46}$ About this time there was also an epidemic termed Te Karawaka by Mair, who gives no further details. 47

\section{Some coastal tribes, notably the Bay of Islands}

Ngapuhi, obtained fire-arms before their neighbours and took advantage of the situation by attacking any tribes against which they nursed grievances. This widespread warfare probably caused high mortality in the early nineteenth century, yet some earlier observers maintained that the introduction of the musket had made Maori warfare more efficient and, therefore, decreased casualties. The Rev. colenso stood out explicitly against them: "Nothing is more erroneous than to suppose that the introduction of fire-arms made their wars less sanguinary'. However, Wright has suggested that by the 1 ate 1830 s the ownership of fire-arms was more evenly spread, and thus iNew Zealand returned slowly to a balance of arms such as it had enjoyed before European weapons were introduced. ${ }^{48}$

Estimates of mortality vary. Colenso claims that more than 60,000 were killed, or perished as a result of wars

45 P.P. (1846): XXX, 337, p.154. This is almost a primary P.P. (1846): XXX, 337, p.154. This Bel, Thos. W. (1890): "Medical Notes on N.Z.', N.Z.M.J., vol. III (original series). pp.67-83\&pp.129-145. 46 Rutherford (1940): p.42; and, Durward (1929): pp.58-9, especially at Molyneux Bay. 47

Mair (1923): p.15, who thinks it is significant that early epidemics spread from the north, i.e. from the area of greatest contact. 48 Colenso (1868): p.414; Wright (1959): p.101. 
between 1822 and $1837 .^{49}$ Mair states that Hongi Hika's wars and raids resulted in 40,000 deaths, ${ }^{50}$ while smith thinks 80,000 died in the first third of the nineteenth century. 51 Other writers note depopulation and the intensification of warfare. Rutherford discusses the occupation of Nelson by Northern tribes, the massacre of the Canterbury Rangitane and Ngaitahu in the $1820 \mathrm{~s}$, and warfare in Canterbury and Marlborough in the early nineteenth century. ${ }^{52}$ An anonymous writer notes that 1,572 persons were killed in the Chatham Islands by the Atiawa conquest in $1838,{ }^{53}$ which must have been a fairly large proportion of the population of these islands. Finally, the Rev. Buller thought that 30,000 were killed between 1820 and $1840 .^{54}$

The historian Wright has analysed Hongi's battles in detail using mission reports. He concludes that: 'In five years he had killed upwards of 5,000 Maoris in battle and brought back countless prisoners to be killed at leisure.' Wright thought that 30,000 to 40,000 deaths was a Ireasonable' estimate of the 'deaths through war' in the $1820 \mathrm{~s}$ and $1830 \mathrm{~s}$ throughout the whole of New Zealand. 55 Recently, Vayda has questioned some of the estimates. Accounts of thousands being killed in old-time fight are

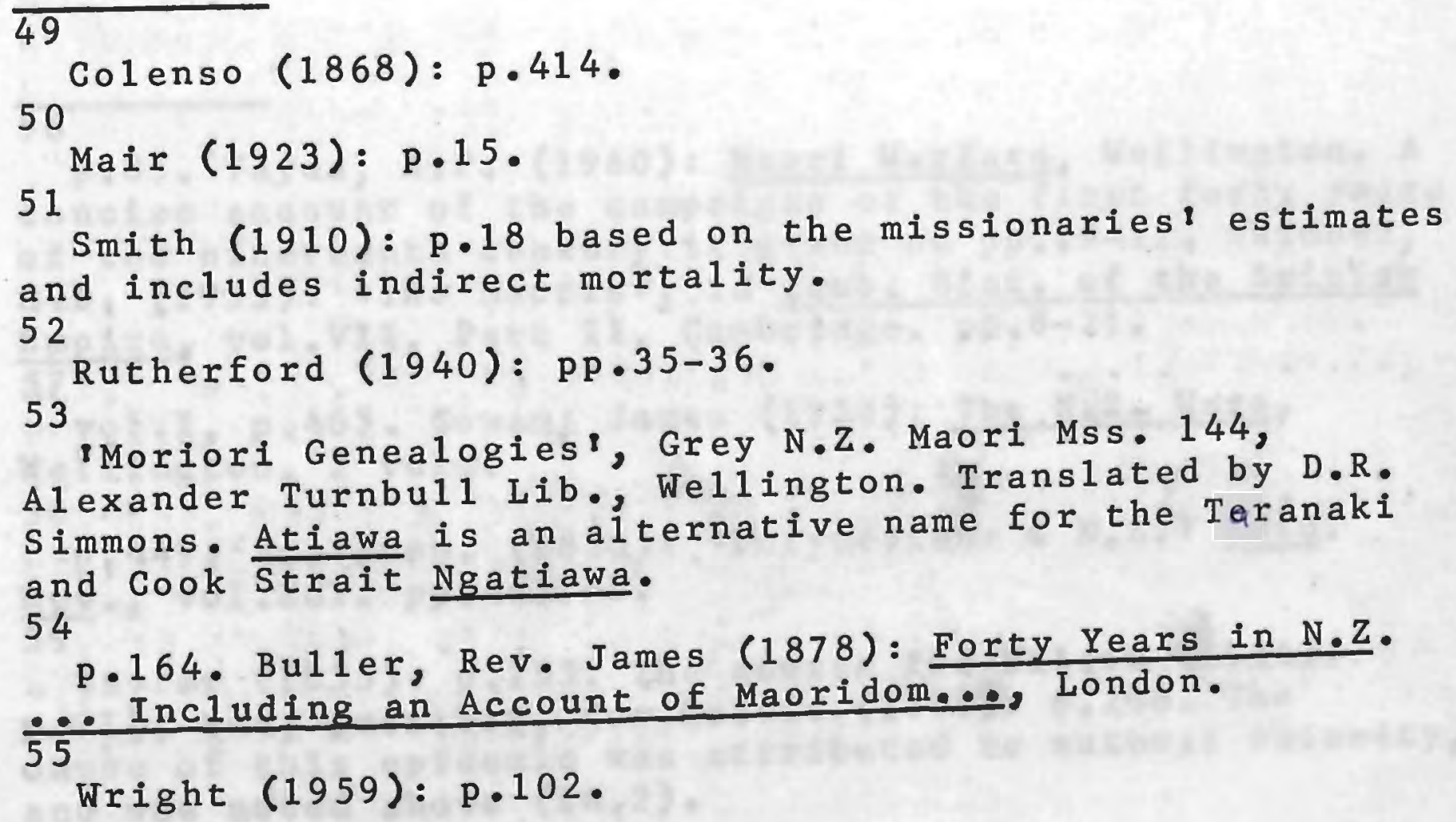


obvious exaggerations, but it is difficult to judge the accuracy of less extravagant estimates. $0^{56}$

\section{Epidemics and Wars, $1840-59$}

By contrast with the preceding two decades, the wars of this period were virtually restricted to localised skirmishes - one in Northland (1845), one in the Hutt area (1846), and one in Wanganui (1847). Cowan gives the total number of Maoris killed in these three 'wars' as 109, and wounded as 158.57 Cowan's evidence is carefully compiled and tabulated, but there is no account of the indirect effects of warfare. For example, it is reported that, in this period, the Maoris of the Wanganui area 'suffered greatly from the privations of war, including scarcity of provisions 58 Moreover, Cowan admits that he may not have a full list of deaths and casualties. However, these were very small wars by any reckoning.

Four epidemics were observed first-hand during this period, three being reported on by Dr A.S. Thomson, a medical practitioner; and the other by the Rev. Taylor. The first was influenza in 1844, which, according to Taylor, was the first appearance of the disease. ${ }^{59}$ Thomson notes

\footnotetext{
56

p.85. Vayda, A.P. (1960): Maori Warfare, Wellington. A concise account of the campaigns of the first forty years of the nineteenth century is given on pp.19-21. Skinner, H.D. (1933): "The Maoris', in Camb. Hist. of the British Empire, vol.VII, Part II, Cambridge.pp.8-21. 57 vol.I, p.465. Gowan, James (1955): The N.Z. Wars, Wellington. 2 vols. 58

p.449, fn. anon. (1850): BPolynesians \& N.Z.' Edin. Rev., vol.XCI. pp.443-71.

Taylor (1855): p.255. The source for Wilson (1934): p.211; and, possibly, for Goldie (1899): p.206. The cause of this epidemic was attributed to natural calamity, and was noted above ( $f n .2)$.
} 
epidemics of whooping cough (1847), 60 mumps $(1851), 61$ and measles and scarlet fever (1854). ${ }^{62}$ He claims that the measles epidemic caused 4,000 deaths in the North Island. 63 If it is assumed that the population numbered 60,000-70,000 at this time (see Swainson's and McLean's estimates, Table 3.1), the epidemic crude death rate would have been 57-67 per 1,000. This is not an impossibly high figure, for the epidemic affected all age-groups. Thus, the Rev. Hadfield, in a letter quoted by the historian John Miller, referring to what he had seen at first-hand in the Wellington area, made a most interesting comment about this epidemic. He said: 'In Europe, where children get these complaints, we have no notion of the wretchedness of an epidemic of this kind attacking young and old and prostrating all before it ${ }^{6} 64$ A further, second-hand report, probably referring to the same epidemic (one 'about 1850'), said that, in the Wairoa area, measles 'carried off great numbers of the aged and infirm and young children'. ${ }^{65}$ While there is a suggestion of age-selectivity here, the term 'infirm' may refer purely to those who died, and were thus, presumed to be weak. Hadfield's report of high mortality among all age-groups

60

Thomson (1854-55): p.525. 61 62

Thomson $(1854-55): p .525$.

Thomson (1859): vol.I, p.212; and, p.16. Sinclair, Keith (1957): The Origins of the Maori Wars, Wellington. 63

cf. Bell (1890); p.144 states that this epidemic caused 5, 000 deaths. nb. Paul (1952): p.111 states that one attack normally gives 1 ife-long immunity. 64

p.106. Miller, John (1958): Early Victorian N.Z.: A Study of Racial Tension \& Social Attitudes, 1839-52, London. According to Sinclair (1957): p.219, 'Hadfield was an expert on Maori affairs,...? 65

A.J.H.R. (1868):A-4, p.18. Report by Dr Matthew Scott, Native Medical Officer since 1862. He also notes the annual occurrence of influenza. 
points to a complete 1 ack of immunity to measles. Thus,

this epidemic was probably the first to attack the main body of Maoris. The 1838 measles epidemic, noted above, must have been restricted to the South Island.

There was one other epidemic in this period. A

severe influenza epidemic occurred in 1852-53, during which the greatest mortality was among the 'old and the young '.66

\section{Epidemics and Wars, $1860-72$}

In the period 1860-72, the attention of most observers was focussed on the wars which raged in the Waikato, Taranaki, Bay of Plenty, East Coast, Wairoa, Taupo and Urewera areas. By Cowan's account, over 2,000 'hostiles Maoris were definitely killed, plus others unknown. In addition, about 200 'friendly' Maoris were killed, and over 400 were wounded. 67 Colenso estimated, in 1863 , that at least 1,000 Maoris had been killed since 1860 . This would include only the Waikato and Taranaki phases of the wars. ${ }^{6}$ Pearce states that the Waikato war indirectly reduced the [Waikato and King Country] Maori in number'. ${ }^{69}$ This, of course, was just one of several districts where warfare caused depopulation, shifts of population, direct mortality, and social disorganisation.

66

Goldie (1899): p.206; and, p.193. Also, Price, A. Grenfell (1957): Moving Frontiers \& Changing Landscapes in the Pacific \& its Continents', 23rd A.N.Z.A.A.S. Jan., Dunedin. pp.96-103. His source may be Year Book (1919): pp.167-68, quoting: iobservations on the Climate of N.Z.', N.Z. Gazette, 23 rd Dec., 1853. Thomson (1854-55): p.525, al so notes that influenza occurred in the period $1840-54$, but gives no date. There was a pandemic of influenza about 1847-48. See Burnet $(1953):$ p.278.

67 68

Cowan (1955): vol.I, p.466\& vol.II, p.553. Colenso (1868): p.414.

69.52. Pearce, Nancy G. (1952): The Size and Location of the Maori Pop., 1857-96, Thesis (V.U.). 
During the 1860 s, epidemics of influenza were noted

for the Horowhenua region, and the rebellious Waikato districts. 70 A contemporary correspondent described the Waikato epidemic in these terms: 'Auckland may slumber undisturbedly for some while to come, for Waikato is laid up with the influenza. Nearly all, - men, women, and children are attacked... ["The oldest inhabitant"]... during his whole residence among them, is unable to recollect such general prostration'. 71 obviously, warfare had had disastrous side-effects.

It was noted above (footnote 3) that, by the $1860 \mathrm{~s}$, some differentiation could be made between typhoid and typhus. An epidemic described as 'typhus' occurred in the Thames and Piako districts in November 1862. It is difficult to tell from Dr Rawson's brief description whether the disease was typhoid or typhus. 72 If it were typhus, it would have been the only epidemic of that disease known, by the present writer, to have occurred among the Maoris.

In 1868 , Dr Scott reported that measles thave again visited Wairoa and as a marked contrast to former times, but one Maori child fell victim, though many were affected.$^{73}$ This reference raises a number of questions. Was the epidemic restricted to Wairoa? Were the other epidemics to which he refers also restricted in spread? Were the iformer times' recent, or was he referring to the 1854 epidemic? Had Wairoa adults gained immunity or were the 'many affected' both adults and children?

70

p.93. McDona1d, R.A. (1929): Te Hekenga: Reminiscences of Early Horowhenua, $\mathrm{Palm}$. Nth., N. ' (Te Wherowhero), the p.16. This epidemic killed Potatau (Te Wh first Maori King.

71

$73^{\text {Southern Cross }}$ (1862): Dec. 30th, P. 4 .

A.J.H.R. (1868): A-4, p.18. 
After the cessation of hostilities in 1872, many hapu (sub-tribes) were uprooted from their previous villages. Land alienation occurred rapidly, and thus there was increased contact with Europeans. It is likely that many Maoris were living in most unhygienic locations, for there were a series of typhoid and 'low fever' epidemics in various regions. These were punctuated by the widespread and cyclic epidemics of measles, whooping cough and 1 a grippe'. The sources for this period are eye-witness accounts of Native Department officials, district officers, census enumerators, and, sometimes, native medical officers and other medical practitioners.

\section{Typhoid outbreaks occurred repeatedly from 1860}

onwards. Probab1y, they had been frequent earlier but were not reported. Unfortunately, nomenclature is rather vague. Sometimes, the disease was called typhoid or enteric fever, while at other times writers refer to 'low fever', which may have been typhoid, or any one of a number of diseases. One nineteenth century medical practitioner, A.K. Newman, included 'low fever' and other diseases such as 'colonial', 'swamp', 'bilious' and 'gastric' fever, diarrhoea and dysentery under the category of typhoid. 74 But, for the purposes of this analysis, typhoid has been separated from 'fever' and 'low fever'.

The first definite outbreaks of typhoid known to the present writer, had occurred before the end of the wars, in 1863-64. In the Wairoa district, Dr Scott stated that typhoid had killed 100 adults, mainly old men, and had 
idecimated some hapus $^{8} .^{75}$ In 1868 , Nesbitt noted that 'epidemic fever was raging on the East Coast, and decimating the inhabitants: 76 Typhoid epidemics of this regional character occurred in Mongonui (North Auckland) late in $1874 ;^{77}$ Wairarapa $(1874) ;{ }^{78}$ Opotiki (1876); ${ }^{79}$ Mongonui, again, in $1874 ;^{80}$ on the East Coast, once more, in 1886, or early in $1887 ;^{81}$ and in the Bay of Islands and Taupo districts (1889). 82 The next regional typhoid epidemic occurred on the West Coast of Northland, between Hokianga and Whangape, in 1890 , 'but steps were successfully taken to prevent its spread. ${ }^{83}$ It is not known what these steps were, apart from quarantining the villages, which were in an isolated location anyway. During the years of high influenza morbidity (see below) outbreaks of typhoid also occurred, as in 1891 in the Waikato, King Country and Thames districts; South of Gisborne in the early 1890s; in 1892 on the East Coast; ${ }^{84}$ possibly in the Wairarapa in the $1890 \mathrm{~s}$, in conjunction with measles as well as influenza 'which carried off... great numbers $;^{85}$ in the early 1900 s in the Northern Kaipara area; and again in 1911 in the

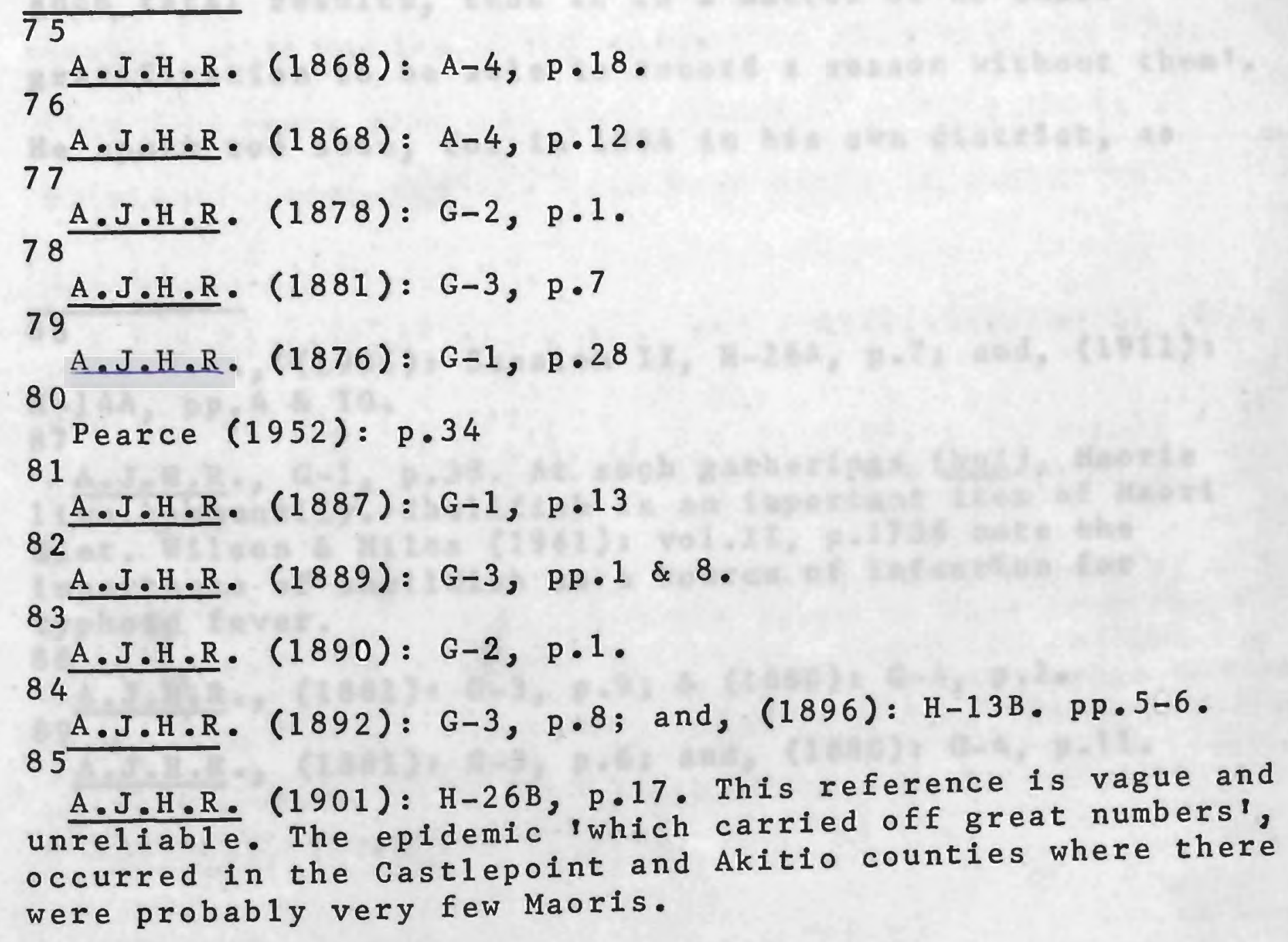
unreliable. The epidemic 'which carried off great numbers', occurred in the Castlepoint and Akitio counties where there were probably very few Maoris. 
Northern Kaipara, where 23 cases and 6 deaths were

reported, and on the East Coast. 86 Referring to the East

Coast outbreak, an eye-witness reported 'At Jerusalem it originated at a house through need of sanitary precautions, and I regret to say several deaths have resulted through its ravages?.

An outbreak of 'fever' or 'low fever', originated at a gathering in Canterbury in April 1875, and nearly every Maori in Kalapoi, near Christchurch, became infected. 87 In 1879,20 children died from this cause at Waihou, Northland, and there were a further 23 deaths at Little River, Province of Nelson. 88 In the same year, 'enteric fever' appeared on the East Coast, in conjunction with whooping cough, and 75150 deaths were reported, with the qualification tbut perhaps 100 would not exceed the actual 10 ss $^{1} .89$ In 1879

there were more typhoid deaths than normally among nonMaoris. (Appendix $B_{p}$ ).

Outbreaks of fever were so frequent that, in 1883 , the Mangonui Residential Magistrate said: 'Fevers of various types have been so constantly recurring of late years, with such fatal results, that it is a matter of no small gratification to be able to record a season without them'. He spoke too soon, for in 1884 in his own district, as

\footnotetext{
86 A.J.H.R., (1906): Session II, H-26A, p.7; and, (1911): $\mathrm{H}-14 \mathrm{~A}, \mathrm{PP} .4 \& 10$.

87 1 ive communal1y. Shelifish is an important item of Maori diet. Wilson \& Miles (1961): vol.II, p.1738 note the importance of shellfish as a source of infection for typhoid fever.

88 89

A.J.H.R., $(1881): G-3$, P.9; \& $(1880): G-4$, p.2. A.J.H.R., (1881): G-3, p.6; and, (1880): G-4, p.11.
} 
throughout North Auckland, epidemics of 'fever' caused 'very numerous deaths (sic)', and the Native Medical officer had 75 cases. 90

'Low fever' outbreaks also occurred during the influenza epidemic of the $1890 \mathrm{~s}$. Thus, in the early $1890 \mathrm{~s}$ there was a 'low fever' epidemic in the Eastern Kaipara area; in 1892 an outbreak occurred in Russe11; and, an epidemic was reported in the winter of 1895 in the Bay of Plenty. The disease reappeared in North Auckland in the late $1890 \mathrm{~s}$, while in 1911 , an outbreak 40 miles north of Opotiki, probably coinciding with the 1911 East Coast typhoid epidemic (fn.86), caused 18 deaths. 91

Measles broke out in Northland early in 1875 .

References were made to mortality from this cause in Mongonui, Bay of Islands, and in Hokianga, where Native schools had to be closed and where the 'measles visited every settlement - in fact every house;...,92 The epidemic then occurred in the South Auckland district, where 1 ack of proper care by parents aided the disease in causing a high mortality rate. Whooping cough [referring to the 1877-78 epidemic; see below] and measles have caused many deaths among native children, many of whom would not have died if proper care had been taken ${ }^{93}$ While this observer's comments may have been true, it should be

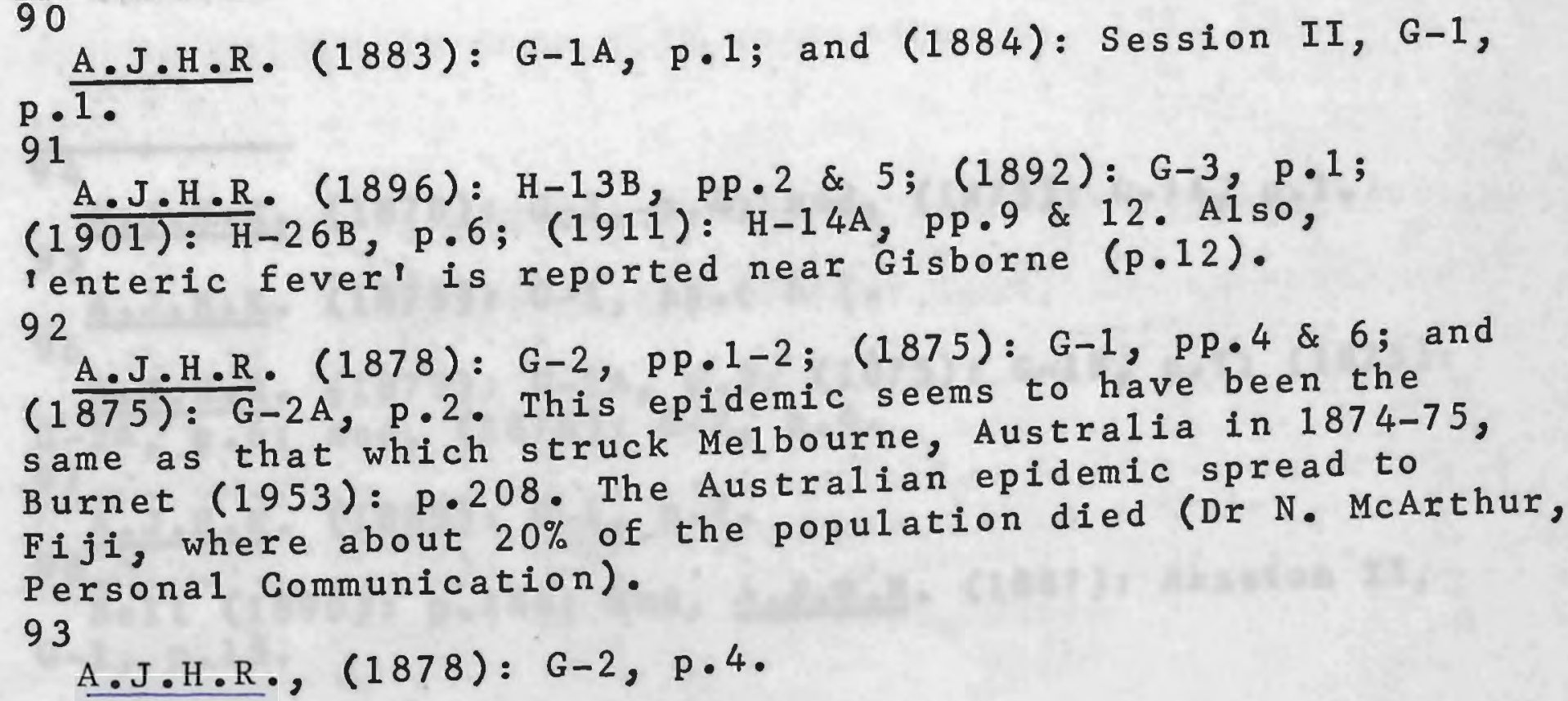


remembered that, because of the 1854 measles epidemic, persons over about twenty years of age should have had immunity. Thus, the mortality would have been age-selective. In 1875-76, the same epidemic of imeasles found a good many victims 1 in the Waikato. 94 By April to May 1875 , the disease had found its way to the Raglan area. It appears that there might have been a recent, earlier epidemic in the neighbouring Kawhia area for the outbreak struck, but no deaths were reported. 95 To the east of the Waikato, it seems to have reached as far as Thames, where school attendance dropped to 50 per cent, and the Bay of Plenty where attendance also declined sharply. 96 This epidemic also occurred among non-Maoris, causing 289 deaths and raising the infant death rate to 125.8 per 1,000 1ive births. (Appendix $B_{l}$ ).

In 1882 , it was reported that the Hauraki Plains had had an outbreak of measles, which was accompanied by scarlet fever. 97 other than Thomson's report of an epidemic in 1854, this is the only reference to scarlet fever prior to 1900 . About 1885 , another regional epidemic of measles in Wanganui 'killed thirty to forty per cent of the children attacked'. Perhaps, the high fatality rate resulted from the congregating of Maoris for a 1 and-court sitting. 98 The reported age-selective mortality is normal in a population which has suffered one

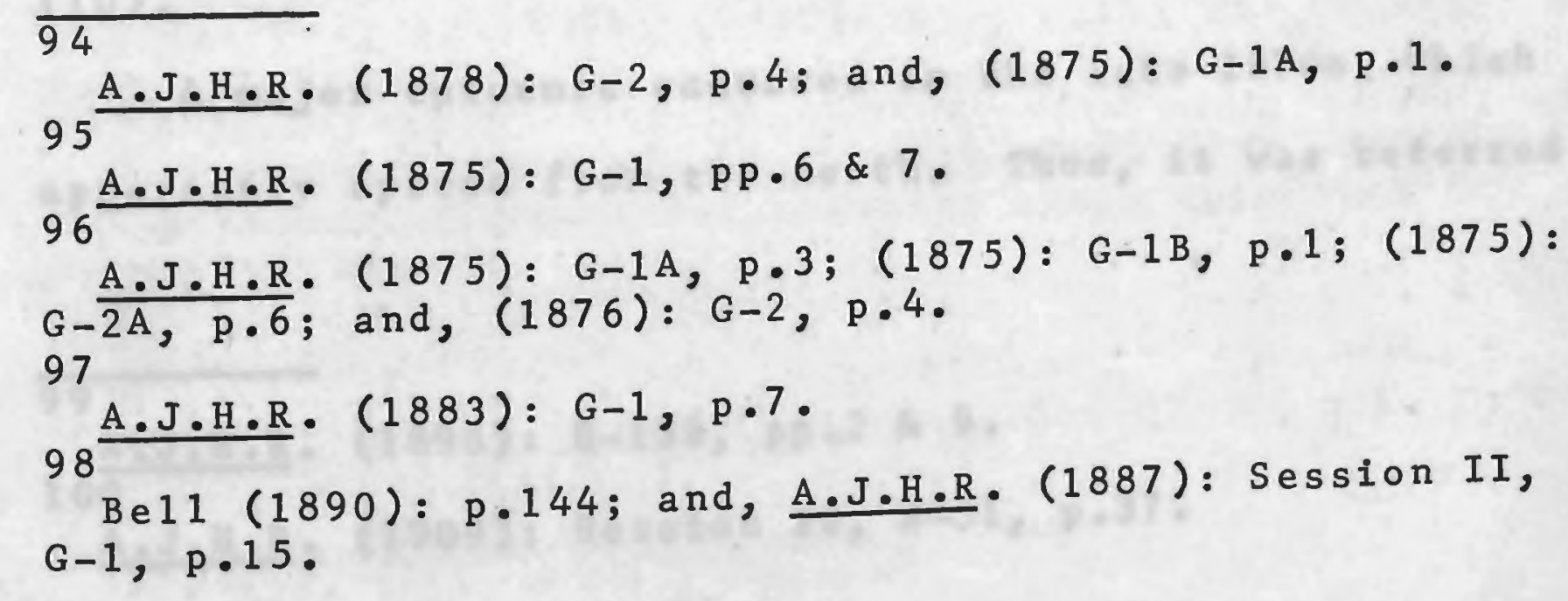


other previous, but recent, measles epidemic. However, there is no report that the 1875 measles epidemic reached Wanganui, although persons aged 30 or more would have gained immunity from the 1854 epidemic.

Measles were reported in the Eastern Kaipara area in the early 1890s, and in Wairoa in 1892.99 Among non-Maoris prior to 1922 , the number of deaths from measles in 1893 was exceeded only by the number from influenza in 1918 , and thus it is surprising that there are not further references to measles among Maoris in the early 1890 s. However, some reported mortality from influenza in the 1890 s may have been caused, primarily, by measles.

In 1903, high numbers of deaths from measles were recorded for the non-Maori population. Among Maoris in 1903-04, 196 cases of measles were handled by Dr Pomare and his assistants, and this epidemic comprised 69 per cent of the measles cases reported for the years 1901-07. 100 However, this may not represent the entire morbidity from measles during this period - how many Maori infants suffering from measles were not brought to a practitioner?

Higher than normal numbers of whooping cough deaths were recorded for non-Maoris in the following years:(1) 1873, (2) $1877-79$, (3) $1883-84$, (4) $1886-87$, (5) $1891-$ 92 , (6) $1894-95$, (7) 1899, (8) $1903-04$, (9) 1907, (10) 1910. For Maoris, reports of epidemics can be correlated approximately in time with outbreaks (2), (3), (5), (8) and (10).

A major epidemic occurred in the late $1870 \mathrm{~s}$, which apparently spread from the north. Thus, it was referred

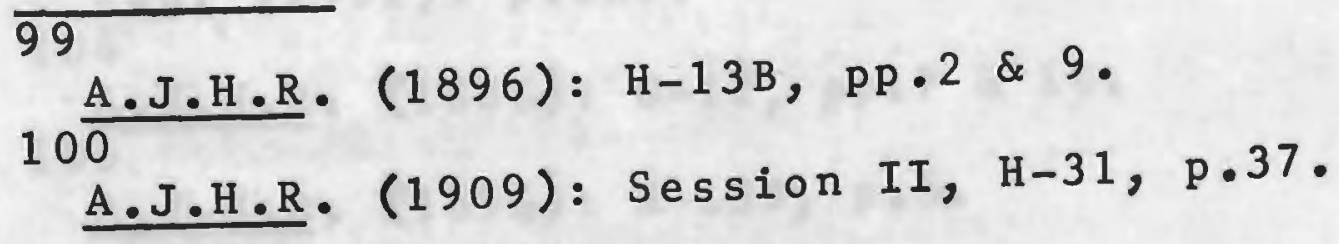


to first in the Hokianga district in September 1877, then again in 1878; it reached the Waikato, and, in April and May 1878 , it was recorded in the Raglan area; in 1878 it was also noted in the Tauranga-Maketu district, where it was reported to have given rise to a high infant death rate; and, finally, it had spread to the Ngati-Porou tribe of the East Coast by August and September 1879 where, once again, it affected mainly children. 101 There are two important factors. Firstly, at this time whooping cough mortality was high in England, as well as among Maori and non-Maori New Zealanders. 102 Secondly, one attack usually gives 1 ifelong immunity, 103 so that the epidemic would have affected those under 30 years, the previous reported epidemic being in 1847 . In 1847 , those over 20 years of age should have had immunity from the 1828 epidemic.

In the early $1880 \mathrm{~s}$ an outbreak occurred in Tauranga and in Taupo, where it was reported the children in this district have suffered greatly from an epidemic of whooping cough, which proved fatal in many cases? 104 This ageselectivity could have resulted from the fact that older persons had already been infected a few years previously about 1877-78. Whooping cough was reported in the area south of Gisborne in the early 1890 s. $^{105}$ A further epidemic occurred in 1903-04, during which medical officers attended 277 of

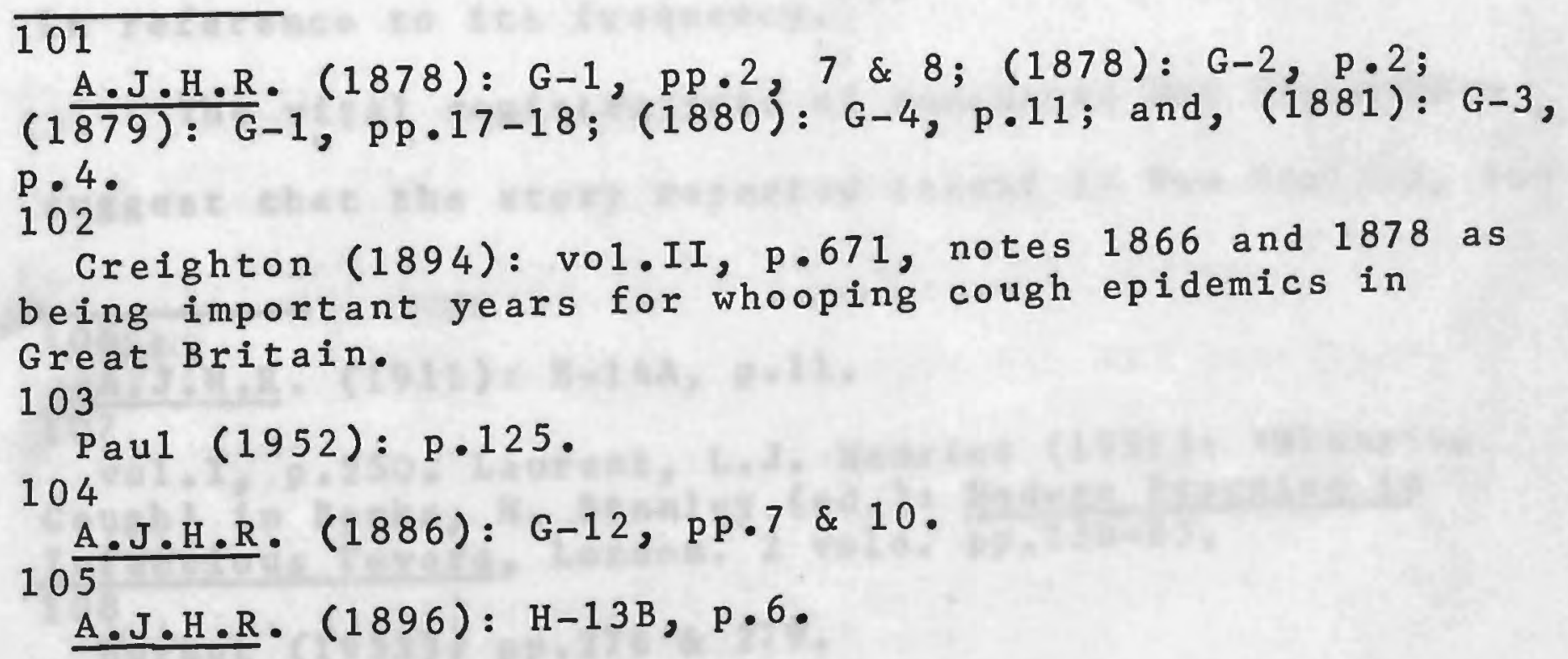


the 360 cases reported for the period 1901-07. Finally, in 1910-11 whooping cough was reported on the East coast by a census enumerator who made this rather pathetic comment: The birth-rate is good, and but for the high percentage of infant mortality during the last year when the whooping cough carried off so many little ones, the census would have shown a larger increase? 106

There is a possibility that some whooping cough mortality in the 1890 s was mistakenly attributed to the prevalent influenza outbreak. Whooping cough has been defined as 'an acute specific infectious disease characterised by catarrh of the respiratory tract and bouts of paroxysmal coughing 107 In the non-Maori registrations influenza and catarrh were tabulated together during this period.

The history of influenza in Great Britain in the nineteenth and twentieth centuries is intriguing. There were frequent epidemics until the late 1840 s. Then 'From 1848-1889 there was a rather extraordinary absence of influenza from England... no epidemics are on record... The year 1890 initiated a period of activity of influenza in England...', which culminated, after years of fluctuating rates, in the great pandemic of 1918-19. The epidemics of the 1890 s were often given the French name for influenza 'la grippe' (approximately, 'disease a la mode' in reference to its frequency. 108

The vital registrations of non-Maori New Zealanders suggest that the story repeated itself in New Zealand, for 106 $10 \frac{\text { A.J.H.R. }}{7} \cdot(1911): H-14 \mathrm{~A}, \mathrm{p} .11$. vo1.I, p.250. Laurent, L.J. Maurice (1951): twhooping Cough in Banks, H. Stanley (ed.): Modern Practice in Infectious Fevers, London. 2 vols. pp.250-85. 108

Burnet (1953): pp.276\&279. 
in the period 1872-89, the annual number of non-Maori influenza deaths was never above 17 , and went as 1 ow as 3 . Then in 1889 there were 70 deaths, while from 1890-1917 the number varied from the lowest figure of 38 (1917) to a maximum of 233 (1894). In the years 1918-21, the number of deaths was extremely high: 5,516 (1918); 346 (1919); 480 (1920); and 105 (1921) (See Appendix B). A study of the 1918 influenza epidemic among Maoris will be postponed until the next section.

Among Maoris in the period 1873-1911 the same pattern is evident. There were outbreaks in the 1840 s and early 1850 s (see above) which, allowing for the delay of 6-12 months during which Northern Hemisphere epidemics are transplanted, probably coincided with the terminating point of early nineteenth century period of high influenza mortality in Great Britain. Subsequently, there were only two other epidemics until 1889-90. In the 1860 s an epidemic had occurred in the Horowhenua and Waikato regions (see above, Epidemics and Wars 1860-72), and in 1873 a mild epidemic was reported in the Bay of Plenty and Waikato districts. 109

In the early $1890 \mathrm{~s}$, an epidemic of influenza appears to have spread right throughout the Maori population. Thus, referring to all Native schools Pope, the school inspector, wrote in his 1891 report: The health of the Natives during the year was not so good as usual (sic). Epidemics of influenza visited a considerable number of the Schools, and in many cases the disease and its sequelae caused a temporary but serious falling off in attendancel. Influenza was first mentioned in the Mongonui, Waikato and Thames districts, and the northern King Country where it was 
considered to be a mild epidemic. In the King country 24 mortality was greatest in the only remaining large

settlement, the pa of Tawhiao, the Maori King. In 1891, the outbreak was reported also in Wanganui, where it was not considered serious, in the Sounds, and at DiUrville Island, where it was seen as 'the prevailing cause of death...'; and, in Canterbury where it was claimed to have caused the deaths of non-Maoris, but not of Maoris. 110 No general trends can be drawn from the reference to DiUrville Island, as the Maoris on that island were few in number and isolated. Because of isolation an epidemic may have been more severe there than elsewhere.

The outbreak occurred in the early 1890 s in the East Coast where it was ifatal to a very large number of natives, the majority being youths and children...'; in the Poverty Bay-Wairoa region; and, in the Wairarapa where the report states 'no epidemic has visited the district, unless influenza be termed one. Directly or indirectly most of their deaths can be traced to it.' In 1892 and 1895 the epidemic recurred in the Waikato and Hauraki regions. In the latter year influenza was 'somewhat prevalent', and was the cause of 'some deaths', especially amorigst the old and very young people. 111 In the late 1890 s in North Auckland and Hawkes Bay, influenza, 'chronic cough' and bronchitis were seen as the 'principal ailments among the natives', particularly among the 'very young'. Also it was reported that in Wanganui and the Manawatu There appears to have been no particular epidemic with the exception of influenza: 112

$\overline{1} 10$

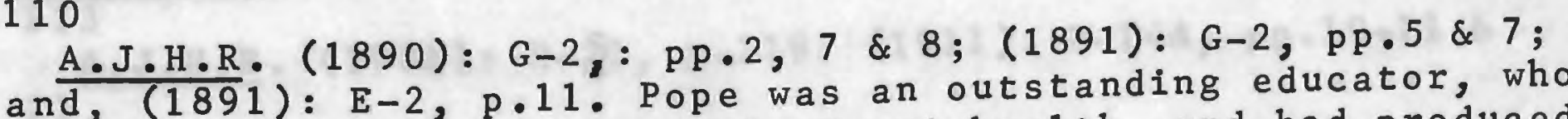
was also vitally interested in Maori health, and had produced a booklet on this subject.

111

$11 \frac{\text { A.J.H.R. }}{2} \cdot(1892): G-3, p p .2 \& 8$; and $(1896): H-13 B, p p \cdot 4-6 \& 9$. A.J.H.R. (1901): H-26B, pp.6, $14 \& 16$. 
In 1908, Pomare termed influenza a 'prevalent disease', wh 12 in 1911, it was noted in the Thames, Northern King Country and Wairarapa districts. 113

Apart from noting the prevalence of the disease in the two decades 1890-1911, these accounts give some indication of the age-selectivity of influenza. Apparently, deaths were most common among the very young and very old. The comments of these observers are in accord with the figures quoted by Burnet, who contrasts the age-incidence of this pandemic with that of the 1918-19 pandemic. Thus, in the 1890 s 15 per cent of the deaths occurred among people aged $0-4,5$ per cent at each decennial age-group 5-14 to 35-44, and 65 per cent to those aged $45+.114$ This age-selectivity is important both in the understanding of mortality per se and the interpretation of child-woman ratios calculated from 1896 and 1901 census data. Moreover, in view of the fact that early observers often may have overlooked infant deaths, mortality and morbidity from influenza may have been higher during this period than is suggested by the evidence quoted here. However, one fact is certain - neither the Maoris nor the non-Maori population remained immune from infection during the influenza pandemic of the $1890 \mathrm{~s} .115$

\section{Epidemics 1912-21}

In the decade 1912-21 the common diseases - typhoid and the childhood ailments - broke out frequently and were regular causes of morbidity and mortality, but observers were more impressed by the smallpox and influenza epidemics

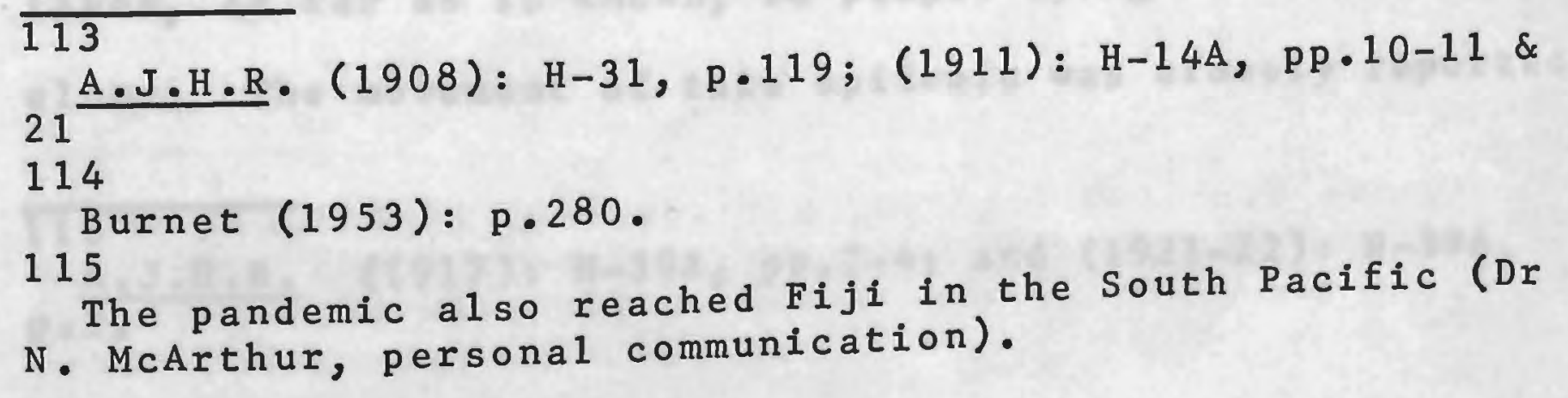


of the period. Thus, in 1917, the census enumerators for North Auckland, South Auckland, Waikato and King Country said that, since the smallpox epidemic, there had been 'no noticeable outbreaks of disease, but at the same time there have been continual cases of fever and other ailments ... Further south and east, where smallpox had not occurred, the reports were a little different: There have been the usual outbreaks of enteric, typhoid and measles, and the usual number of deaths from those diseases'; 'No epidemics of any kind have been reported...'; 'No serious illnesses have been reported...'; and, even the extremely suspicious claim that 'no epidemics or diseases have been reported'. Only in Taranaki was it reported that typhoid had 'carried off some young children,...' In 1921-22, the reports refer only to the 1918-19 influenza pandemic, except for a reference to whooping cough in the Bay of Plenty. 116 It is necessary to study these two major epidemics in detail.

In 1913, a Mormon missionary disembarked from the ship the Zealandia at Auckland and attended 'a large Maori gathering in a remote village [near Wangarei, Northland] at some distance from medical advice [where] people were crowded together in the same sleeping rooms so that the condition of close contact was present. On their dispersal to their various villages the same conditions were present'. The Mormon elder had smallpox, and so, the dispersal of people all over Northland and to the Waikato, yet another epidemic spread among the Maoris. This one claimed thirty 1 ives, as far as is known, 16 people dying in Northland alone. The movement of this epidemic was closely reported

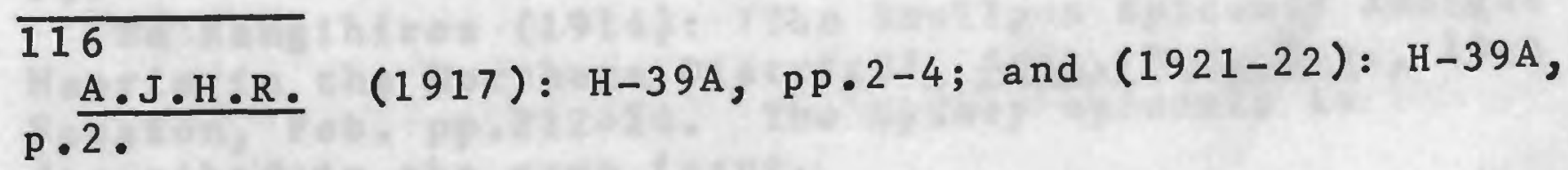


by Te Rangihiroa (Dr P.H. Buck), who assisted in combatting it. It illustrates three important points.

Firstly, the community style of living, the lack of hygiene and the isolation of Maori communities accelerated the spread of this epidemic. At this late juncture, isolation, and thus distance frommedical care, was a disadvantage, although, earlier, isolation may have been an advantage, when communities closer to European settlements seem to have been most affected by epidemics. Because of these factors, this epidemic caused the deaths of 30 people, whereas, the same outbreak spreading from the Zealandia caused only one death in Sydney. Secondly, it was contact with Europeans which initially introduced epidemics to the Maoris. Once introduced, typhoid and other diseases kept reappearing. Thirdly, it was not until this late stage that efficient preventive measures were undertaken. In this case, teams of public vaccinators spread through Northland. The Maoris co-operated and, when the disease spread, the vaccinators had been ahead of it, and the epidemic was checked. However, Te Rangihiroa does note that some persons above 45 years, who had been vaccinated by missionaries years before, were protected. The effect of the preventive measures for this epidemic is summarised in Table 4.2. 117 The influenza pandemic of 1918-19 was the most important outbreak of disease in twentieth century New zealand. It came in two major waves, an early mild wave in August-September 1918, followed by an extremely severe outbreak in october-December. This is shown by the record of the number of Maori deaths from respiratory diseases

\section{7}

Te Rangihiroa (1914): The Smallpox Epidemic Amongst Maoris in the Northern District', Aust. Med. Con., 10th Session, Feb. pp.212-24. The Sydney epidemic is described in the same issue. 
Table 4.2 : Effect of Vaccinations: Smallpox Epidemic Among Maoris, Northland; May and June 1913

$(N=882$, of whom 483 became infected)

\begin{tabular}{|c|c|c|c|c|c|c|}
\hline \multirow[b]{2}{*}{ Stál wovitat } & \multicolumn{3}{|c|}{ Vaccinated } & \multicolumn{3}{|c|}{ Unvaccinated } \\
\hline & $\begin{array}{r}\text { Total No. } \\
(1)\end{array}$ & $\begin{array}{c}\text { Sma11pox } \\
\text { Cases } \\
(2)\end{array}$ & $\begin{array}{l}\% \\
\frac{(2)}{(1)}\end{array}$ & $\begin{array}{c}\text { Total No. } \\
\text { (1) }\end{array}$ & $\begin{array}{c}\text { Smallpox } \\
\text { Cases } \\
\text { (2) }\end{array}$ & $\begin{array}{l}\% \\
\frac{(2)}{(1)}\end{array}$ \\
\hline Males & 178 & 16 & 9.0 & 302 & 248 & 82.1 \\
\hline Females & 138 & 7 & 5.1 & 264 & 212 & 80.3 \\
\hline Source: & \multicolumn{6}{|c|}{$\begin{array}{l}\text { p.213. Te Rangihiroa (1914): The Smallpox } \\
\text { Epidemic Amongst Maoris in The Northern } \\
\text { District? } \\
\text { Feb. pp.212-24. Med. Con., loth Session, }\end{array}$} \\
\hline
\end{tabular}

during each month of the period August 1917 to December 1918, which is tabulated below. This table, along with most of the following comment, was obtained from Dr Makgill's report on the pandemic in New Zealand. 118

The Number of Registered Maori Deaths from Respiratory Diseases During each Month from August 1917 to December 1918

\begin{tabular}{l|cccc||ccccccccccccc}
\hline Month: & A & S & $\frac{1917}{0}$ & N & D & J & F & M & A & M & $\frac{1918}{J}$ & J & A & S & 0 & N & D \\
\hline $\begin{array}{l}\text { No. of } \\
\text { deaths: }\end{array}$ & 12 & 13 & 14 & 7 & 6 & 3 & 3 & 5 & 4 & 7 & 6 & 7 & 8 & 29 & 10 & 200 & 950 \\
\hline
\end{tabular}

Moreover, Maori medical officers in the Wellington Province handled the following cases during each of the last six months of 1918 :

$\overline{118}$

A.J.H.R. (1919): Appendix A. Apparently, Makgill had access to registration records which were unpublished, for this is the only indication that causes of death were certified at this time. 


\begin{tabular}{lcccccc}
\hline \multicolumn{1}{c}{ Month } & July & Aug. & Sept. & Oct. & Nov. & Dec. \\
\hline $\begin{array}{l}\text { A1 forms of } \\
\text { respiratory and } \\
\text { catarrha1 diseases }\end{array}$ & 20 & 49 & 70 & 90 & 260 & 33 \\
\hline $\begin{array}{l}\text { Influenza } \\
\text { Deaths from influenza } \\
\text { (among these cases) }\end{array}$ & 15 & 41 & 63 & 83 & 250 & 24 \\
\hline
\end{tabular}

According to Makgill, The mortality due to the first wave [August-September], though abnormal for New Zealand, was not alarming; but the virulence of the second wave was far in excess of anything which has hitherto been experienced with influenzat.

Makgili's comments refer mainly to the second wave, an emphasis which will be retained here, but the reports of the first wave contain two interesting points.

(1) This wave was restricted mainly to the East coast and Poverty Bay - Wairoa regions.

(2) In these regions Maoris infected in the first wave appeared to have gained some immunity from attack during the second wave and thus, on the East coast, the first wave was more fatal than the second. During the second wave the medical officers who made these reports may have taken extra precautions in their districts, for this situation is contrary to the general evidence that an attack during the first wave did not bestow any immunity from attack during the second way. 119

The second wave of October-December 1918 first 'manifested itself' in New Zealand among 'Native Troops' (apparently Maoris and Pacific Islanders) quartered at 
Narrow Neck camp in Auckland. 120 To calculate Maori crude death rates from influenza during this wave, Makgill obtained the number of registered Maori deaths from respiratory diseases in the last quarter of 1918 . These numbered 1,160 (see Table in text above). He compared these figures with those collected for the last quarter of 1917 when there were 27 deaths from this cause. Then he subtracted the 1917 figure - actually, he subtracted 30 deaths - from the total deaths arising from respiratory causes in October-December 1918. He assumed that, by this calculation, he had estimated the number of influenza deaths during the second wave alone, and that he had excluded the 'normal' number of deaths from respiratory causes. Thus he estimated that 1,130 Maoris died from influenza during the pandemic. This figure gives an epidemic crude death rate of 22.6 per 1,000 for Maoris, as against 4.5 per 1,000 among the non-Maoris. A rate of 20 per 1,000 is reported also for Western Samoa, so the Maori rate does not appear to be an over-estimate. 121

Makgil1's data may contain two sources of error. Some influenza deaths may not have been reported, but this may be counterbalanced by the possibility that deaths from other causes are included in his influenza death rate. However, it is obvious that mortality was extremely severe during this epidemic, even allowing for unreliable sources of data.

120

A.J.H.R. (1919): H-31A, pp.26\&28. 'Report of the Influenza Commission'. This report is concerned, primarily, with the introduction of the epidemic to New Zealand, and the adequacy of the public health services. 121

A.J.H.R. (1919): H-31C, p.4, 'Report of the Samoan Epidemic Commission?. In India rates varied from 4 to 60 per 1,000; while in South Africa, Bantus had rates of 27 per 1,000. See Burnet (1953): p.280. 
Makgill estimated the total number of Maori influenza deaths, but did not give details such as deaths by age. Because of the high death rate it is important to extend the analysis here to the calculation of age-specific rates.

This was carried out as follows:

(1) The population at the census of October $15 \mathrm{th}, 1916$ was brought forward to October 15th, 1918, which was approximately the end of the second week of the 13 week period of the second wave. The estimated population at October 15 th was distributed by age according to the 1916 distribution.

(2) Maori deaths for the main wave were distributed by age on the basis of the non-Maori age-distribution of deaths. This could be carried out with a fair degree of confidence as one universal characteristic of the 1918-19 influenza pandemic was its age-incidence. 122

From these age-distributions, age-specific rates were calculated. As will be shown, the study of the age-specific mortality during the epidemic is relevant not only to the analysis of mortality per se, but also to the study of fertility and the age-structure.

The age-incidence of deaths, given in Table 4.3, differed considerably from that of the 1890 s pandemic. In 1918-19, mortality was highest at ages 20-44 (males) and 25-39 (females). High death rates were also recorded at a11 older ages and at ages $0-4$ and 15-19. Another factor is that males were affected more seriously than females, the males crude death rate being 27.7 per 1,000 , and the

122 Ministry of Health (U.K.) (1920): IReport on the Pandemic of Influenza, 1918-19:, Reports on Public Hea1th and Medical Subjects, No.4, London. e.g. see Some (p.363); Shiraz, Persia (p.381); \& London (p.37). 
Tab1e 4.3 : Pandemic of Influenza, October-December 1918: Maori Age-Specific Death Rates (per 10,000).

Rates

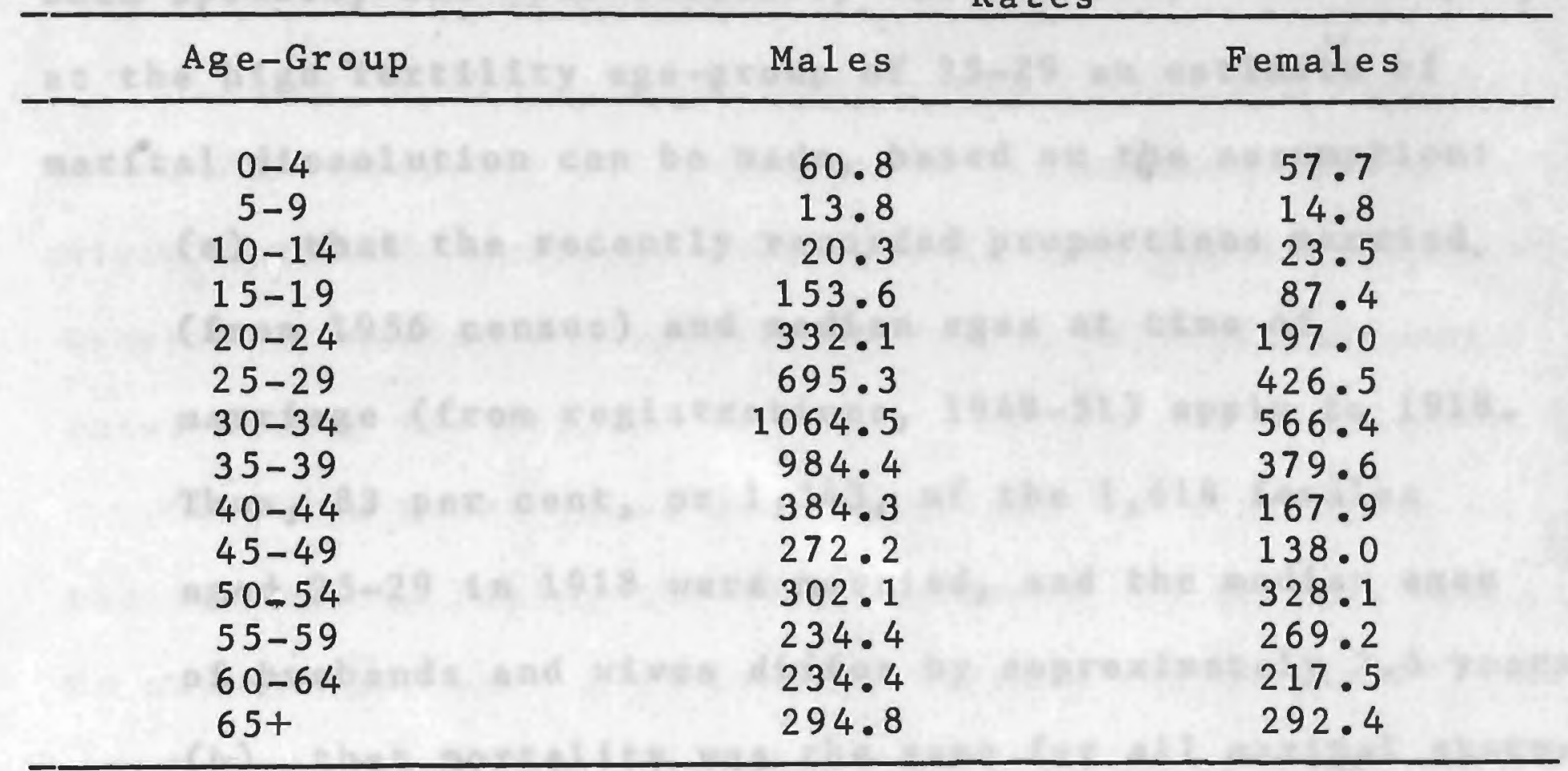

female 16.3. The immediately obvious result would have been the diminishment of some cohorts. For example, the male agegroup 30-39 in 1918 was reduced by almost 10 per cent. However, as was noted before (Chapter 3, Section 4), at the 1916 census there may have been some irregularities in the age-distribution, which probably affected age-specific rates by inflating those at 20-39 years, and reducing those at ages 40-49. At subsequent censuses age-reporting was not always satisfactory, while the cohorts most affected by high age-specific death rates constituted increasingly smaller proportions of the total population. Together these factors obscure the effect of the high age-specific mortality during the 1918 epidemic, in a manner which would not have occurred had the population been enumerated more accurately. By contrast, the child-woman ratio at the 1921 census (Table 5.2) does show the effect of the mortality at ages $0-4$ and 20-44 during this epidemic. The causes are as follows: First $1 y$, the number aged $0-4$ at the 1921 census, the survivors of births in the period 1916-21, was abnormal1y small because of high infant and early childhood mortality 
during the pandemic. Secondly, and perhaps more importantly, marriages would have been dissolved by the death of one or both spouses, and thus fertility was reduced. For example, at the high fertility age-group of 25-29 an estimate of marital dissolution can be made, based on the assumption:

(a) that the recently recorded proportions married (from 1956 census) and median ages at time of marriage (from registrations, 1948-51) app1y to 1918 . Thus, 83 per cent, or 1,343, of the 1,618 females aged 25-29 in 1918 were married, and the median ages of husbands and wives differ by approximately 2.5 years; (b) that mortality was the same for all marital status groups; and,

(c) that females 25-29 were married only to males 25-29 or 30-34. Thus, 50 per cent of the 1,343 females were married to males $30-34$, and 50 per cent to males 25-29.

4 per cent of females aged 25-29 would have died as a result of influenza, while this is true for 7 per cent of the males aged 25-29 and 10 per cent of those aged 30-34. Thus, in 4 per cent of the marriages concerned the wife would have died, in 8.5 per cent the husband would have died, while in 0.34 per cent $\left(\frac{40}{1,000} \times \frac{85}{1,000}\right)$ of unions both husband and wife would have died. It is estimated that 12.15 per cent of the marriages were dissolved at this age-group. This estimate is calculated as follows:

$\%$ Marriages dissolved $=\left(q_{m} \times q_{f}\right)+\left(p_{m} \times q_{f}\right)+\left(p_{f} \times q_{m}\right)$ where, $p=$ probability of surviving, and $q$ = probability of failing to survive.

The proportion dissolved of marriages of females aged $30-34$ would have been even higher. 
The study of the 1918-19 pandemic raises five general issues relevant to the study of earlier epidemics for which there were few detailed data.

(1) As in 1918, Maori child-woman ratios may have been reduced temporarily following epidemics because of the dissolution of marriages (which would have resulted in a temporary decline in fertility), and/or high infant mortality rates during the epidemics.

(2) The Maori crude death rate was 4-5 times that of the non-Maoris during the 1918 pandemic. Is it reasonable to assume that such a disparity, perhaps not as marked, was a feature of earlier epidemics occurring among both populations?

(3) There is evidence that in 1918 Maoris were more susceptible than non-Maoris to infection, and that once infected their cases were more likely to prove fatal. This is suggested by data assembled from both Makgill's Report and the Report of the Influenza Commission, and presented in the table below. Was this disparity unique to the 1918 pandemic?

It might be noted that both the non-Maoris and the Maoris represented in the data presented in this table were under medical care, while it could be assumed that both groups of troops were under similar conditions of congregation. 
Incidence and Fatality Rates (\%s) of Maoris and NonMaoris during the 1918 Pandemic

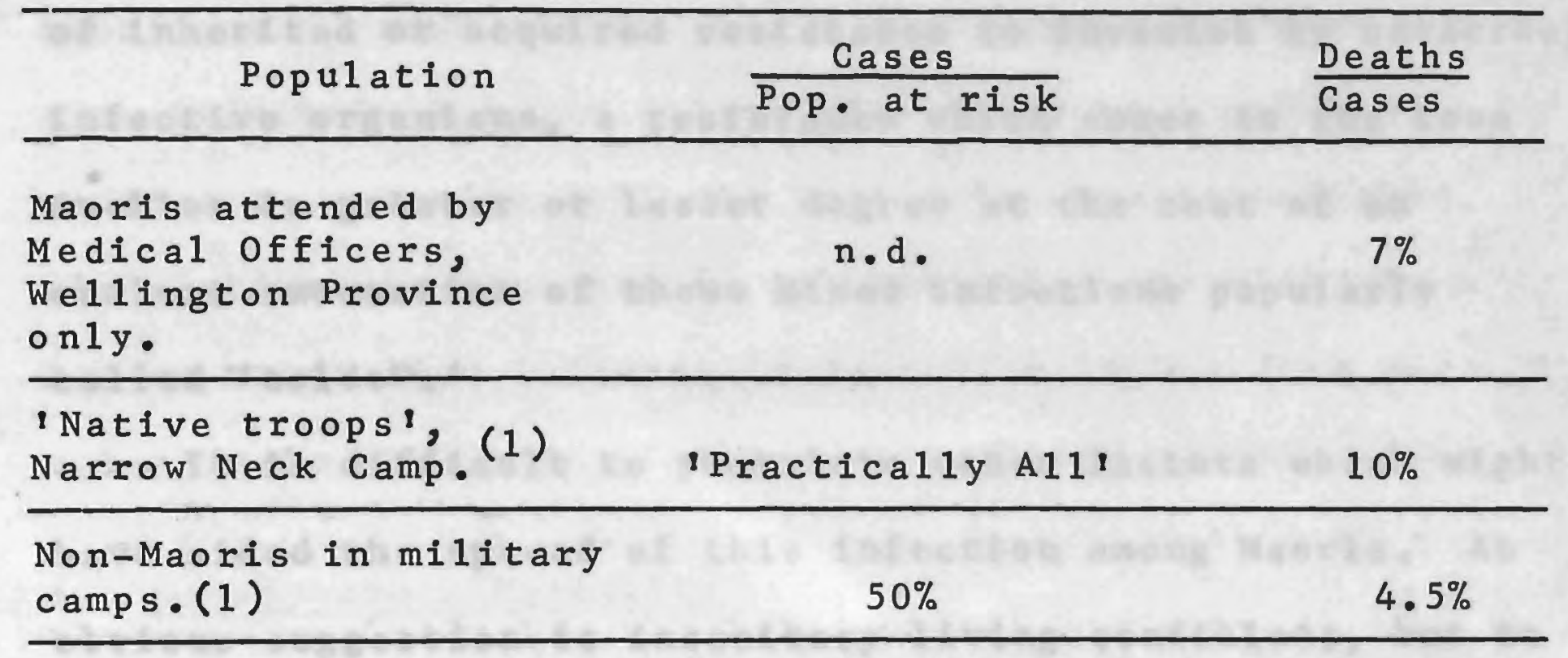

Note: (1) These troops were at the most susceptible age/sex group - males, 20-44 years. Data relating to troops were obtained by Makgill and the Influenza Commission from army medical officers.

(4) There is further evidence to suggest that at this pandemic Maori moftrality was higher than non-Maori because of 1 ack of medical care, 1 ack of immunity to influenza and other factors. The 24 Maori influenza deaths attended in october-December by medical officers constituted only 25 per cent of the total registered deaths from influenza occurring in the Wellington Province during the pandemic. If these data are representative it would appear that only a small proportion of Maoris could obtain medical care. Moreover, it is reported that in some districts sick bays were set up where teachers nursed the sick, often 'witbout medical assistance ... However, if was claimed that there was an attempt to 'quarantine' some districts. 123

The higher crude death, incidence and case fatality rates of Maoris indicate that they had lower levels of 
immunity than non-Maoris. Makgill suggests this reason:

IPresumably this suceptibility [of Maoris] is due to lack of inherited or acquired resistance to invasion by catarrhal infective organisms, a resistance which comes to the town dweller in greater or lesser degree at the cost of an endless succession of those mixed infections popularly ca11ed "colds"."

It is difficult to postulate other factors which might have aided the spread of this infection among Maoris. An obvious suggestion is insanitary 1 iving conditions, but in England The epidemic fell alike on "the sanitarily just and unjust". 124 However, it is probable that a close communal Iife may have increased the spread. On this point no comparison can be made between the incidence and fatality rates of the general, and perhaps more dispersed population (Wellington Province Maoris attended by medical officers) and the camp population because the latter consisted entirely of persons at the most susceptible ages. The 1918 -19 pandemic was a most peculiar phenomenon with a number of characteristics which still perplex epidemiologists, 125 so that generalisations from this one event must be made with considerable caution. Yet, it seems from this evidence that an epidemic among Maoris could spread more virulently than among non-Maoris, and that the lack of adequate medical care and immunity were factors of some significance.

(5) These data give some indication of the possible levels of deathrates for years in which widespread epidemics occurred. The crude death rate (a11 causes) for

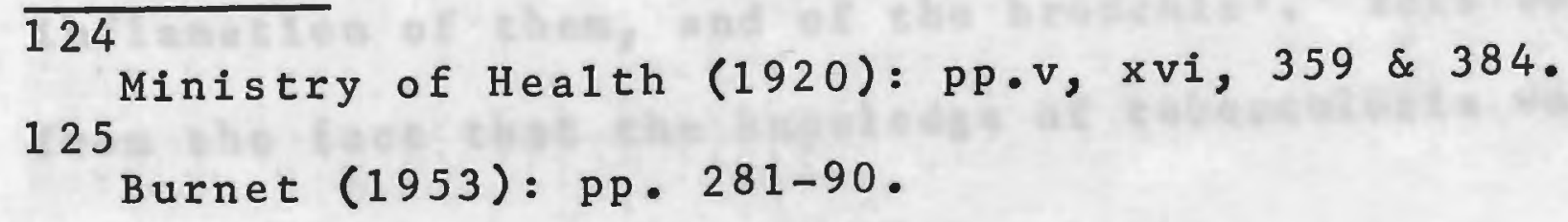


1918 was 40 per 1,000. Excluding influenza deaths, the crude death rate was 17.4 per 1,000 , as against 16.4 (1916); 15.5 (1917); and, 20.3 (1919). This last figure may have included late registrations, or deaths from 1 ater waves of the pandemic. Assuming that the data were equally reliable, it appears that in the year of the pandemic, mortality from causes other than influenza exceeded mortality from all causes in years in which there were no widespread epidemics.

\section{Non-Epidemic Mortality}

The problems inherent in the study of epidemics are more acute when non-epidemicmortality is analysed. All that can be done is to gather together the references to diseases which various observers made. This task is made more difficult by the wide range of terms, often vague, used for individual diseases, and the tendency merely to name the occurrence of a disease without indicating its frequency or effect. The diseases referred to most frequently are discussed here, and the question is posed: is there sufficient evidence to suggest that morbidity from these diseases was widespread? If so, does this imply that nonepidemic mortality was at high levels?

\section{Tuberculosis and Respiratory Diseases}

Chief among the non-epidemic conditions were the communicable diseases phthisis, or consumption, the related 'scrofulous' diseases, and the respiratory diseases such as pneumonia. It is often impossible to distinguish in early accounts between phthisis, 'bronchial affections', consumption, 'pulmonary complaints', "lung diseases' and a ' cough' resulting from itubercules of the lung... and inflamation of them, and of the bronchial. This results from the fact that the knowledge of tuberculosis was not 
firmly based until the isolation of the tubercle bacillus, in 1882, by Koch. 126 By the early 1900s, there was a surer recognition of tubercular diseases. Therefore, for this account, no distinction will be made between most of these diseases, the presumption being that they were tubercular or respiratory. However, scrofulous diseases, which may be tubercular, but which were often reported separately by early writers, are discussed in a separate section.

The frequency of pulmonary complaints, pneumonia and consumption in New Zealand was first reported to the Bigge's Commission on N.S.W. in the early 1820 s by Dr Fairfowl, who noted the 1 ast as a most prevalent disease, and by Ensign McCrae. In 1827 , Earle stated that these diseases were the 'scourge of the young;...' They were observed again in 1833-34 by a Dr Watkins who travelled 'a little' in Northland. Their importance was noted in the $1830 \mathrm{~s}$ by Polack, in 1841 by Dieffenbach, and in 1842 by Terry. 127 Throughout the 1840 s various observers claimed that these diseases were prevalent. 128 This claim was repeated in the 1850 s by

\footnotetext{
126

Winslow (1944): p.309. 127

Sections of the Report of the Bigge's Commission on N.S.W. relevant to N.Z. in McNab (1908\& 1914): vol.I, pp.541\& \&55; p.193. Earle, Augustus (1909): A Narrative of 9 Months Residence in N.Z., 1827, Wel1ington; Dr Watkins in P.P. $(1837-38): X X I, P .13$; vol.II, p.92. Manners \& Customs of Terry $(1842):$ p.178. 128

Shortland in P.P. (1846): XXX, 337, p.154; Molesworth, in P.P. (1844): XII I, p.186; Appendix G. no.46.N.Z. Coy (1844): $\overline{12 t h}$ Report of the Directors, 26th April, London; p.280. Martin, S.M.D. (1845): N.Z., London.
} 
Dr Fitzgerald, the Wellington Medical Officer, by Fox and by Dr Thomson. 129

The officers in native districts reported the occurrence ot tubercular diseases in particular, and resiratory disorders in general, in 1878, in Whangarei, Waikato, East Coast, Taranaki (where it icontinues to be their deadly enemy'), and Nelson; again, in 1881, in Thames and New P1ymouth; and, in 1891, in the Waikato. In 1885, Dr Ginders observed it in Rotorua. In 1890 , Bell noted that phthisis was the most common disease of Maoris, and was extremely prevalent during the sitting of 1 and courts when conditions were unhygienic. Thus, these diseases were definitely widespread, and in the second half of the nineteenth century, it seems that phthisis at least was accepted as universal among Maoris. By the early 1900 s, Pomare and others not only recognised the significance of phthisis, but, with surer knowledge, attempted to remove its causes (see Section 6). Yet, in 1911, it could still be reported: 'And then they always have consumption...130

In Section 2, it was argued that tuberculosis had been introduced, or at least that a new and more virulent strain was introduced. Perhaps after its initial impact some of its early virulence was lost. Thus, while tuberculosis was a recognised killer at the end of the century, its impact appears to have been less spectacular than earlier.

Many of the causes for the reported high incidence of respiratory diseases were recognised at a fairly early period.

Fitzgerald is quoted in anon. Polynesians \& N.Z.' (1850): p.466, which states that this disease had an 'almost universal prevalence?. See also, p.55. Fox, Sir William (1851): The Six Colonies of N.Z., London; and, Thomson $(1854-55):$ p.464.

130

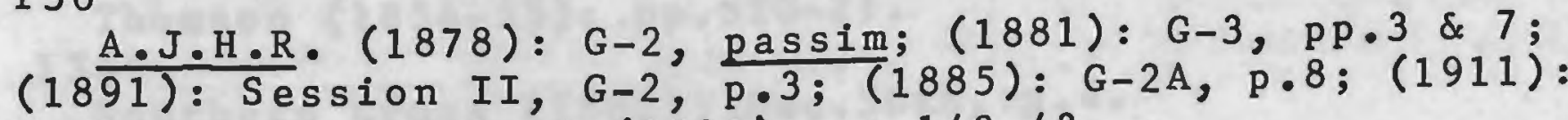
$\mathrm{H}-14 \mathrm{~A}, \mathrm{p} .9$; and Be11 (1890): pp.142-43. 
But, most observers preferred to direct their comments towards aspects of Maori behaviour and dress. Exposure to the open air, particularly after sitting around fires in their 'own smal1', low and 'excessively dirty houses' was a cause discussed by Earle, Martin, Polack, Terry and Thomson; while Terry and Thomson also noted the importance of poor diet. 131

\section{$\underline{\text { Scrofulous Diseases }}$}

The causes for scrofulous diseases, which are probably related to tuberculosis, are attributed to nineteenth century observers to the same factors that were noted above for tuberculosis. Only Thomson and Taylor noted explicitly that these diseases had been introduced. 132

The prevalence of scrofula is commented on by many observers. For example, Thomson claimed that up to 20 per cent of the adults in some districts suffered from these diseases. 133 Dr Rawson stated that lit prevails to a fearful extent. Most of the natives show evidence of its ravages past or present'.134

\section{Skin Diseases}

Scabies, boils, 'itch' and other skin diseases are referred to constantly. It is questionable whether they caused high mortality, but their frequency indicates a low standard of hygiene and personal cleanliness. The most common is a disease variously called wai-ake-ake, wai-haki-

\section{1}

Earle (1909): p.194; Martin (1845): p.280; Terry (1842): p.178; Polack (1840): p.92; and, Thomson (1854-55): p.464. 132

Taylor (1855): P.255; Thomson (1859): vol.II, p.289 said that scrofula had appeared among them at the beginning of the century... [and had increased]... the prevalence of pulmonary consumption'.

133

Thomson (1854-55): pp.520-21.

134

Southern Cross (1862): Dec.30th, P.4. 
haki, 'a sort of scrofulous scabies', 'almost universal amongst the children', and ake-ake, a parasitic skin disease 'peculiar to the race'.135

\section{Dysentery, Diarrhoea and 'Stomach Diseases'}

In the review of epidemics presented in section 3 (above), dysentery and related diseases were seldom mentioned specifically. The early epidemics termed Rewarewa might have been dysentery, but these are the only records of epidemics of these diseases. The 1 ack of references to dysentery epidemics is not prima facie evidence that there were no severe outbreaks. For example, epidemics vaguely 1 abelled 'fever' and ' $10 w$ fever' may have been misdiagnoses of bacillic dysentery. The frequent references to typhoid suggest that sanitation was unsatisfactory, and dysentery outbreaks can occur readily when sewerage disposal is inefficient or water supplies are unclean. Furthermore, infantile dysentery (colloquially termed 'summer diarrhoea') is still prevalent in mid-twentieth century Australia. ${ }^{136}$ Is it not probable that this disease was more prevalent in nineteenth and early twentieth century New Zeal and than in the Australia of today?

Acuttal epidemics of dysentery and related diseases were not frequently reported, but their general prevalence was noted prior to 1840 by four observers, three of whom were medical practitioners. More importantly, in the early 1900 s the Health Department reports frequently refer to these diseases. This suggests that their prevalence in the intervening years may have been overlooked by most

N.Z.Coy. (1844): Appendix G. No.46; anon. 'Polynesians \& N.Z.' (1840): p.466.A.J.H.R., (1891): Session II, G-2, p. 3 ; and, $(1885):$ G-2A, P.8. 136

Burnet (1953): pp.224-25. 
observers, the exceptions being Drs Thomson (in the 1850s)

and Bell (1890), both of whom report that such diseases

were common.

Diarrhoea also went unmentioned in most accounts.

However, its importance can be gauged from data collected

by Thomson and Pomare (see Commentary to Tables $4.4 \& 4.5$ ),

while Dr Scott of Wairoa reported the occurrence of

'diarrhoea, gastric derangements (sic), \&c., among the

children now and then,....137

\section{Venereal Diseases}

The study of the incidence of venereal diseases has implications more for the fields of foetal mortality and fertility than for adult mortality. The task here is to decide: (a) Were the diseases widespread enough to affect fertility levels in the period 1769-1921? And, (b) was

the disease introduced or indigenous?

Forster, who accompanied Cook on his second voyage, tried to suggest that veneral diseases were indigenous:
When we came to Queen Charlotte's Sound, in New- Zeeland in 1773 , we had been out at sea for at lease five months; none of our sailors had any symptoms of this disease which could hardly lie dormant for such a length of time; ...yet, when we went out of Queen Charlotte's Sound, a midshipman on board the Adventure discovered that he had been infected by one of the New- Zeeland females.138

Probably, the 'New-Zeeland female' who infected Forster's errant midshipman had, in turn, been infected following

\footnotetext{
137

A.J.H.R. (1868): A-4, p.18.

p.490. Forster, John Reinold (1778): Observations made during a Voyage Around the World, 1772-75. London Wilson (1934): p.207 says that veneral diseases were prevalent in Queen Charlotte Sd. in 1777 , but had lost some of their virulence. Also Dr Matthew Scott, Wairoa, stated that while syphilis (toka-toka) is an original Maori disease?, it had died out in his district then resumed when whaling commenced. A.J.H.R. (1868): A-4, p p.17-18.
} 
intercourse between Maori women and Cook's seamen on the first voyage (1769). In fact, the evidence to suggest that Cook's sailors introduced venereal diseases is rather substantial. William Bayly, who visited New Zealand on Cook's second voyage, gave evidence that venereal diseases were probably introduced by the men of the Endeavour on Cook's first expedition, in 1769.139 The fact that Forster visited Queen Charlotte Sound in the Resolution, in 1773, and reported venereal diseases, after the Endeavour had called at Queen Charlotte Sound during Cook's previous voyage, further supports this view. The nineteenth century observer, Thomson was sure that Cook's men had introduced venereal diseases. 140

In the period 1769-1840 the journals of Major Cruise on H.M.S. Dromedary show that the venereal diseases were introduced by its crew to the Bay of Islands in 1820.141 Dr Bennett noted that venereal diseases occurred and that they had been introduced by European contact. 142 Dr Fairfowl and Ensign McCrae observed cases in the Bay of Is 1 ands in the early 1820s. Polack notes the widespread incidence of these diseases in the 1830 s and admits, obliquely, that they may have been introduced, while Dr Watkins claimed that there is not one in fifty of the

\section{9} 140

Bayly in McNab (1908\& 1914): volII, p.204.

Thomson (1854-55): pp.468-69. The claim by Roux that, during a visit to the Bay of Is. in June, 1772 by the French ship 'Le Mascarin', several of the sailors received venereal diseases from Maori women may be further evidence that Cook's or subsequent ships introduced venereal diseases. See Roux' Journal, in $\mathrm{McNab}$ (1908\& \& 1914): vol.II, p.401. 141

pp.153-54. Cruise, Maj. Richard A. (1921): Journal of a Ten Month Visit of H.M.S. Dromedary to Northern N.Z. in 1820, Auckland. 142

Bennett $(c .1832): p .438$. 
women without the venereal disease... [Bay of Islands]: 143

It could be fairly claimed that these observers were prejudiced by conditions they noted in areas of close contact. So, perhaps, could Dr Dieffenbach, who stated that venereal diseases were common on both coasts of the North Island. 144 By contrast, the author of one article published in 1850 and relating mainly to the Wellington area, quoting his source as 'medical men', claimed that syphilis may have been common once, but was uncommon at the time he wrote. He was sure that the disease was indigenous, and any claim by Maoris that syphilis was a 'European [i.e. introduced] disease' was merely an example of the tendency for all people to give these affections (sic) names charging them on some other nation. 145

The majority of writers quoted above acknowledge that venereal diseases were introduced and that by the 1830 s they were fairly widespread, at least in areas of close culture contact with non-Maoris. The apparent ease with which these diseases were introduced in the early period may have resulted from the prostitution, miscegenation, pre-marital intercourse and promiscuity reported by nineteenth century writers. For example, it was frequently claimed that the services of female slaves, and perhaps other women, were exchanged for trade-goods. During the 1820 s and 1830 s the Bay of Islands Ngapuhi and other coastal tribes, which had obtained muskets, campaigned against hinterland tribes, even those in isolated areas,

\section{3}

McNab (1908\& 1914): vol.II, pp.541\&555; Polack (1840): vo1.II, p.98; Watkins in P.P. $(1837-38)$ : XXI, p.19. Also Dr Tawell notes its occurrence in the Hokianga Districts (p.121). 144

145 Anon. Polynesians \& N.z.' (1850): p.468, fn. 
and ravaged and enslaved their victims. If the victorious warriors were infected, it is probable that they would have introduced venereal diseases to the conquered tribes, $\mathbb{t}$ hus, these diseases may have been spread to areas which had had little or no contact with non-Maoris.

Once introduced venereal diseases remained widespread in incidence. Te Rangihiroa asserted that ivenereal diseases that were introduced by the crews of early traders and whalers had they dying fires revived by the soldiers of the 'sixties'. I have learned... that seventeen Maori women captured by white troops [during the $1860 \mathrm{~s}$ ]... on their 1 iberation spread the disease among their own people'.146 There is further evidence to support Te Rangihiroa's views about the last third of the nineteenth century. In 1868 , Parris, the Taranaki Residential Magistrate, was sure that they had imuch to do with the diminished number of children born, and with the diseased condition of many of the children which (sic) are born'. 147 In 1881, and 1885 Dr Moir of the Bay of Plenty said The influence of syphilis in the affections (sic) of children I find more extensive than formerly...' Were it not for syphilis the natives of this district would be very healthy?.148 Dr Ginders observed the diseases in Rotorua, but felt that they were less common than generally thought, although Dr Bell found that Gonorrhoea is very common... its extension to the fallopian tubes is doubtless a frequent cause of sterility 149

146 p.367. Te Rangihiroa (1924): The Passing of the Maori', T.N.Z.I., vo 1.55 , pp.362-75.

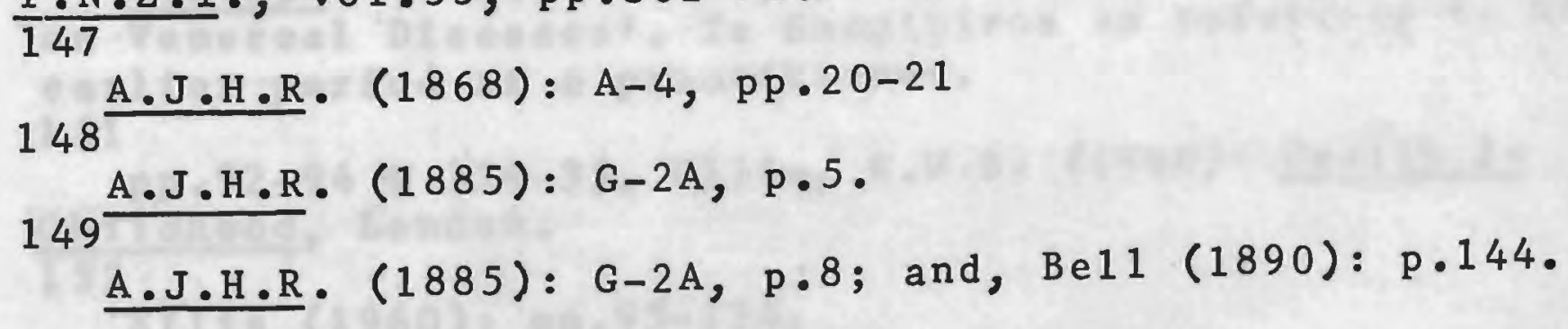


Te Rangihiroa, himself, gives the most reliable direct evidence of the prevalence of venereal diseases in the late nineteenth century. Referring to cases he had seen in the early 1900s, he said: 'Sterility, with histories of repeated miscarriages,... most of the old men - hemiplegias, and paraplegias, and subsequent general paralysis of the insane gave an old history of syphilis: 150 Again, the frequent reports of opthalmia are an indication that gonorrhoea was a widespread disease, and the commonly noted 'eye diseases' could be due to interstitial keratitis, which commonly occurs between 5 and 15 years as a result of congenital syphilis. ${ }^{151}$

Given the fairly widespread occurrence of this disease, its effect must have been important. Direct mortality of adults would not have been great, but there would have been a high morbidity rate resulting from infection during adulthood; or, reaching back further, to infection with congenital syphilis during the foetal period, or with gonorrhoea as the foetus is being expelled. 152

The most important factor is that gonorrhoea is recognised as a cause of sterility in women, and that infection with syphilis often 'gives rise to a succession of still-births', in addition to causing spontaneous abortion - usually between the 20 th and 28 th weeks of gestation. Thus, these diseases have the dual effect of lowering conception rates and increasing pregnancy wastage. For example, a recent study of a Micronesian population has 
shown that ${ }^{a}$ decline in venereal disease infection rates was accompanied by a sudden increase in fertility. 153

\section{Two Surveys of Morbidity}

The first survey of Maori morbidity was made in the 1850 s by Thomson, as a sideline to his duties as a military surgeon, and to his work writing the first history of New Zealand, plus a number of articles primarily on statistical subjects. He compared his results with those obtained from a similar survey in England, as is shown in Table 4.4. The English Infirmary is Sheffield General, while the Maori returns are compiled from a report of Maoris treated in Golonial Hospitals. Obviously, not too much significance can be placed on Thomson's data, and his remarks about particular diseases have been noted already. But, this was the first, and on1y quantitative survey until Dr Pomare started to collect data on Maori health, in the early 1900 s. Pomare's reports discuss Maori health problems and include detailed statements by district inspectors, and by Dr Buck (Te Rangihiroa) when he joined the department. To recapitulate their comments would be unnecessary as they are easily obtainable in the Department of Public Health Reports. However, of greater importance are the data they collected on cases they treated, a summary of which is shown in $\mathrm{Tab} 1 \mathrm{e} 4.5$

Pomare does not mention 'rheumatic affections' specifically, the most important disease noted by Thomson, so that no accurate comparison can be made between the two surveys. But, tuberculosis and respiratory diseases,

Pau1 (1952): pp.264-65; Vo1.1, P.16.U.N. (1954): Foetal Infant \& Early Childhood Mortality, Pop. Studies, no.13, N.Y. 2 vols; and Lessa, William A. \& Myers, George C (1962): Population Dynamics of an Atoll Community', Pop. Stud. vol.XV, No.3, March. pp.244-57. 
Table 4.4: Table...Showing the Comparative Frequency of Certain Classes of Diseases Among the Inhabitants of a Large Town in England and the Natives in New Zealand ${ }^{\text {? }}$.

\section{- Classes of Diseases?}

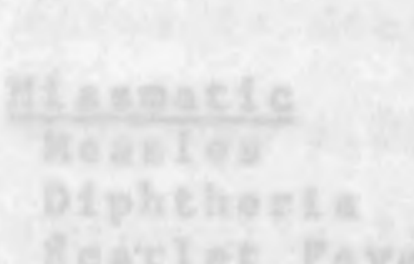

Rheumatic Affections (sic)

Venereal

Abcesses and U1 cers

$$
2,195
$$$$
1,952
$$$$
703
$$$$
1,173
$$

Scrofula

Eruptive Fevers

A11 other diseases

$\frac{4,908}{19,866}$

Wounds and
Injuries

Diseases of

Diseases of

the

$801 \quad 18$

210

81

190

$$
-
$$

304

$$
2
$$

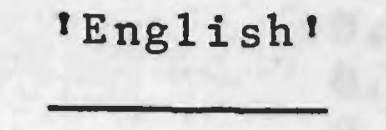

20

100

Proportion among each race; out of 1000 cases there were among the?

71

119

New Zealanders' (Maoris)

\section{4}

169

52

5

23

119

191

4

Source: vol.II, p.323. Thomson, A.S. (1859): The Story of N.Z., London. 2 vols. 
Table $4.5: \frac{\text { The Average Annual Incidence }(1) \text { of Disease }}{\frac{\text { per } 1,000 \text { of the Maori Population for six }}{\text { years, } 1901-07}}$

Disease $\quad \begin{gathered}\text { Total cases } \\ 1901-07\end{gathered}$

Average Annual Incidence per 1,000 of the total Maori Population (estimated to equal 55,000).

Miasmatic

Measles

Diphtheria

Scarlet Fever

Typhoid

Whooping cough

Diarrhoeal

Constitutional

\section{Phthisis}

Other tubercular diseases

Cancer

Local Diseases

\section{Respiratory System}

Bronchitic

Pneumonic

P1eurisy
0.86
0.00
0.09
0.54
1.09
3.37
1.75
0.71
0.10

1,114

580

236

Digestive System

Acute inflammatory diseases

Table compiled by Pomare

Source: A.J.H.R. (1909): Session II, H-31, p.37.

Notes: (1) These are incidence rates, but refer only to those persons who were treated by Dept. of Health officials.

probably equivalent to Thomson's categories, 'Diseases of the Lung' and 'Scrofula', remain important up until the time of Pomare. Pomare thought that the Maori tuberculosis morbidity rate was above that of 'the whole population', but no direct comparisons could be made with non-Maori data. Bronchitis and pneumonia together are the most important group of diseases in Pomare's table. Their annual rates remained consistent for the six year period covered in Table 4.5. If Pomare's data are representative, it appears 
that:

(a) Combined, these two diseases were the most important causes of non-epidemic morbidity throughout the period, and their rates may have exceeded epidemic morbidity rates in most years. Thus, together they show a rate of 8.60 per 1,000 on Pomare's table, while the rate for Miasmatic Diseases', spanning a period which included outbreaks of both measles and whooping cough, was only 2.58 . This conclusion accords with that of Dr Scott of Wairoa in the 1860s: 'Pleurisy, pneumonia, affections of the bronchia, influenza, and opthalmia being usually prevalent at certain seasons of the year, with diarrhoea, gastric derangements (sic), etc., among the children now and then,...1154

(b) Early writers may have given these diseases names which make them hard to identify. Some such terms were noted at the beginning of Section 4. Moreover, bronchitis and pneumonia are often sequelae and complications of epidemic diseases, and thus may have been reported under the name of the epidemic disease.

Thompson's category, Diseases of the Stomach and Bowels', probably approximates to Pomare's 'Diarrhoea' and 'Acute Inflammatory Diseases'. These are second in order of importance on Pomare's Table, together giving a rate of 5.6 per 1,000. Pomare attributed their importance to 'peculiarities of Maori diet...'

Although typhoid is not a major cause of morbidity on Pomare's table, he thought that the Maori morbidity rate was above that of the whole population'. Probably, even Pomare's data are far from complete, although measures taken to prevent typhoid outbreaks would ensure that a majority of cases were reported.

154

A.J.H.R. $(1868): A-4$, p.18. 
In Pomare's table diphtheria and scarlet fever are shown to be insignificant causes of morbidity. Pomare noted that diphtheria was 'practically unknown', although some cases may have been misdiagnosed as 'tonsilitis and other diseases, while 'scarlet fever appears to be also a rare disease amongst the Maoris'.155 It is possible that the low incidence of these diseases in the early 1900 s was a continuation of nineteenth century trends, for in the evidence on epidemics reviewed above scarlet fever is mentioned only twice, and diphtheria or 'croup' not at all. However, Thomson reported that 'croup' was a prevalent cause of infant mortality. 156 In the early nineteenth century, when Thomson would have received his training, diphtheria went unmentioned unless it was severe, in which case it was termed 'croup'.

The apparent absence of diphtheria and scarlet fever among Maoris is perplexing, particularly prior to 1900. There were spasmodic epidemics of both diseases among nonMaoris (see Appendix $B_{1}$ ), while high diphtheria mortality was a world-wide occurrence in 1858-59, including the nearby Australian Colonies. 157 In the case of diphtheria there may have been diagnostic problems, and thus Thomson and other observers may have overlooked its incidence and effects. Scarlet fever outbreaks may also have been misdiagnosed, or considered unworthy of further mention. However, this does suggest that neither diphtheria nor scarlet fever was

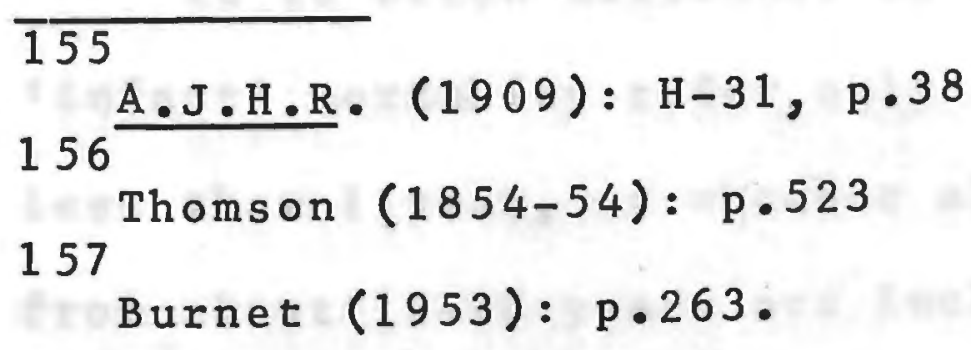


sufficiently widespread, at least in the late nineteenth century, to have attracted the attention of a number of district officials.

These data of Pomare and Thomson are crude, and the comparisons are unsatisfactory. But, presuming that both surveys were relatively representative, it does seem that there were few major changes in patterns of Maori morbidity between the two surveys. Respiratory and tubercular diseases held a prominent place, as did infectious diseases, diarrhoea and other diseases of the digestive system.

Neither of these tables give any accurate indication of the level and patterns of morbidity operating at the time when the data were assembled. Pomare's data are probably more reliable in terms of representation and the diagnosis of disease. However, it cannot be assumed that the total morbidity rate of 20 per 1,000 calculated by Pomare is a fair estimate of the level of morbidity at the turn of the century, for the denominator is the total Maori population, while the numerator is composed of cases handled by the Department of Health.

\section{Foeta1, Infant and Childhood Mortality}

In Sections $3 \& 4$ references were made to high epidemic morbidity among 'the young', and to the frequency of certain diseases which, once patterns of immunity were established, would have been more likely to cause higher mortality among children than among adults. The present section deals with data relating specifically to foetal and infant mortality.

It is often difficult to determine whether reports of infant mortality refer only to deaths among persons aged less than 1 year, or whether all persons below some age from about 12-18 years are included under this term. In a 
few accounts there appears to be a distinction between

'infants' and 'adults', presumably between those aged 0-14 and those aged $15+$ years, but elsewhere no such differentiation can be inferred. Thus, unless the context suggests otherwise, it has been assumed that the term 'infant' refers to persons 0-11 months, or that it covers, at the most, young children (i.e. those aged, say, 0-4 years). Although most of the references will be to foetal and infant mortality, the ambiguity associated with the term infant has dictated that this section be headed 'Foetal, Infant and Childhood Mortality'. Foetal mortality will be dealt with first, then infant mortality and, finally, induced abortion and infanticide. Induced abortion is, of course, a cause of foetal mortality, while infanticide is a cause of infant mortality, so logically, the two events should be separated. However, in the accounts of early writers induced abortion and infanticide are so closely associated that it is often difficult to separate them.

\section{Foetal Mortality}

Genera11y, mortality during the foetal period is divided into two broad age-ranges. Deaths prior to the 28 th week of gestation are termed 'abortions' (colloquially, 'miscarriages') and from the 28 th week to the end of pregnancy 'stillbirths'. Death arising from 'natural' causes is termed 'spontaneous' foetal mortality, while in weeks $0-27$ a distinction is made between 'spontaneous' and induced' abortions. Foetal mortality is most frequently and most easily induced during the first 12 weeks of gestation. In turn, induced abortions are divided into two categories - 'therapeutic' and 'illegal' abortions. In this section such detailed distinctions are not made, except for that between spontaneous and induced 
foetal mortality, because the data do not permit such fine distinctions to be drawn. But, it is as well to realise that these differentiations are based on empirical evidence which has indicated that causes and levels of foetal mortality vary considerably from period to period of gestation.

The study of foetal mortality is extremely problematical, the major difficulties being:

(1) To obtain a large and representative sample of pregnant women exposed to a variety of environmental and ante-natal conditions. Patients in obstetric or birth control clinics, the most commonly used sample groups, may not be representative of all classes of pregnant women.

(2) To obtain data relating to the first 12 weeks of gestation. Often a pregnancy is not diagnosed for a number of weeks, yet foetal mortality appears to be highest during this period, and thus, abortions may occur without either the pregnancy or the foetal loss being recognised.

(3) To build up histories of previous pregnancies in order to determine whether various patterns are repeated. Alternatively, some studies of causes of foetal loss have used this retrospective method, particularly when enquiring whether pregnant women have been exposed to the risk of infection from various diseases. This method suffers two disadvantages: interviewees may not be able to recall all events, while those events which are remembered may not have been clinically diagnosed. Thus, the interviewer often has to rely on the lay opinion of the interviewee.

(4) To determine the number of so-called illegals abortions. The distinction between therapeutic and illegal induced abortions varies from nation to nation, but it is obvious that women will be most reluctant to admit that they have had an abortion in societies in which abortions must be 
induced clandestinely, without legal and medical

authorisation, and at the risk of criminal proceedings

being undertaken if the act is discovered.

For these reasons data on foetal loss are, as yet,

fragmentary by comparison with many other demographic data,

even for those populations which have a long history of

accurate vital registration. The problem is, of course,

less acute for still-births, but the number of countries

having reliable still-birth registration data is still

restricted.

Sheps has reviewed the data on foetal mortality,

including the results of reliable studies, and comes to

this conclusion regarding spontaneous loss:

It is likely that the true incidence of fetal loss is considerably greater than is indicated by most data. As in other animals, a sizeable proportion of fertilized human ova are probably expelled before the existence of pregnancy is suspected and many shortly thereafter. A large part of early recognizable abortion is probably not included in reported data. Undoubtedly, there are in addition many cases which never receive medical care. In contrast, most pregnancies that end in a live birth eventually become known.

The resulting deficiency in reported data was estimated by French and Bierman in a study in

Kauai, Hawail. Despite a relatively successful attempt to learn of all pregnancies as early as possible, only half the subjects came under observation as early as the 12 th week of gestation. After excluding patients who may have come to their attention because of symptoms related to fetal death, the authors constructed a life-table in which a woman was entered at the first report of her pregnancy and withdrawn at its termination. They estimated a total fetal loss of $23.7 \%$ with a modal value in the earliest period [i.e. 4-7 weeks]. The more usual calculations, namely dividing all the known fetal deaths by all pregnancies, would have given a fetal death rate of $11.7 \%$ with a modal value at 12-15 weeks. Erhardt, from life-tables for New York cases, estimated a total loss of $29.5 \%$ and a distribution very similar to that [of French and Bierman]. It is possible that even these estimates are $10 \mathrm{w}$.

In populations such as the above, with

relatively good health status, $70-80 \%$ of early

abortions are believed to involve abnormalities of the conceptus, which are unlikely to be prevented 
by measures now available. Evidence that fetal

deaths increase with poverty, with untreated diseases such as syphilis or diabetes, and with poor obstetric care suggests that populations subject to poorer health conditions may have a higher incidence of fetal death which might be reduced by improved economic conditions and public health programs. Such a reduction would probably apply to fetal deaths occurring relatively late in pregnancy more than to early deaths.

From this evidence Sheps concludes that the probability of spontaneous foetal death is $124-30$ per cent' of all

pregnancies, but 'For populations living under poor health conditions this probability may be of greater magnitude, such as 35 per cent or perhaps even as high as 50 per cent?.158

The procedure here is to take shep's review as a checklist. By determining which of the specified causes of spontaneous foetal loss may have contributed to pregnancy wastage among Maoris of the period 1769-1921, some estimate may be made of possible levels of foetal mortality. Major causes may have been as follows:

(1) It must be assumed that abnormalities of the conceptus occurred as frequently among Maoris as among other populations.

(2) As suggested by the evidence in Section 4 of the present chapter, syphilis was widespread during this period and may have been an important cause of foetal mortality among Maoris during late prenancy ( $20+$ weeks of gestation). Diabetes was not reported among Maoris of this period. Although Sheps does not specify other diseases, there is some evidence to suggest that, as the U.N. has reported, Any acute contagious disease occurring in a pregnant woman may cause the death and expulsion of the foetus. Many such cases were observed during the influenza pandemic of

pp.112 \& 114. Sheps, Minde1 C (1964): 'Pregnancy Wastage as a Factor in the Analysis of Fertility Data', Demography, vol.1, no.1. pp.118-18. 
$1918-191.159$

It is not known whether the 1918 pandemic

had this effect among Maoris.

Foetal mortality from acute or chronic diseases may not be restricted to the late foetal period. This is evidencedby reference to rubella, which has been oneof the more frequently analysed causes of foetal and infant loss, and malformation resulting from infection of the foetus during pregnancy.

A rubella epidemic brokeout during the course of a recent, carefully controlled United Kingdom study of the relationship between general morbidity and foetal loss. Pregnant women in the large, random sample were closely examined during and after pregnancy, so that results previously obtained by retrospective deduction could be verified clinically. A higher percentage of abortions (excluding therapeutic and illegal abortions), still births, deaths of children aged 1 ess than 2 years, and malformations were recorded among thosecases in which the mother had contracted rubella in the first 12 weeks of pregnancy, than among those pregnant women contracting rubella subsequently or not at all. For other virus infections contracted during pregnancy the eivdence was not as clear. 160

It is suggested that Maori foetal mortality during the period 1769-1921 resulting from syphilis and other chronic and acute disorders would have been at higher levels than that reviewed by Sheps for twentieth century American populations.

(3) Unsatisfactory obstetrical practices would definitely have been a factor. It is probable that until

vo1.1, P.16. U.N. (1954): Foetal, Infant and Early Childhood Mortality, Pop. Studies, no.13, N.Y. 2 vols. 160

Anon. [Leading Article] (1960): 'Virus Infections during pregnancy', Lancet, vol.II, July-Dec. pp.800-01. 
recently few, if any, Maori women were attended by a medical practitioner, midwife or nurse during the ante-natal period and at parturition.

(4) The evidence presented above in Sections $3 \& 4$ of the present chapter suggests that morbidity levels were fairly high and that the 'health status' of Maoris in this period would have been inferior to that of the American populations discussed by Sheps.

(5) It is probable that socio-economic conditions would have been conducive to higher foetal mortality rates than in present day Kauai or New York.

The main inference to be drawn from this review is that spontaneous foetal mortality would have been in excess of the level of 24-30 per cent of all pregnancies given by Sheps for populations with 'good health status'. Probably, the level did not reach the suggested maximum of 50 per cent. When fertility is analysed various levels from 30 per cent to 50 per cent will be postulated in order to test the possible effects of foetal mortality on fertility levels. These levels will include a small allowance for induced foetal mortality.

\section{Infant Mortality}

The first references to infant mortality, other than infanticide, were made only after colonisation in the 1840 s. One of the earliest writers to mention infant mortality was George Clarke (Sen.), who stated that its prevalence in Taranaki was due to poor child rearing practices and late weaning; while Molesworth, quoting Dr Fitzgerald, reported 'great' infant mortality. Taylor noted high levels of infant mortality and pointed out that, until infants could eat potatoes, breast-feeding was their only sustenance. ${ }^{161}$ 
The indefatigable quantifier, Thomson, gives some idea of the severity of infant mortality at the midpoint of the nineteenth century:

It is among infants that inattention to the sick... is most injurious. Thus, Dr Rees, Colonial Surgeon at Wanganui, ascertained that out of 433 children born alive 229 died before their mothers; that out for 124 either had no children or 1dren had died. Mr Fenton discovered that out of 289 mothers in the Waikato district in 1858 , our of ost all their offspring from disease; and our of 18 children born in 1844 [in the Waikato], only 2 were alive in 1858 '.

Elsewhere, he cites poor food, which produced bowel complaints, and fever as the major causes of infant mortality, but also mentions 'croup', which was discussed above (Section 4, Two surveys of Morbidity) and 'worms'.162

In 1868, one official suggested that the few Maori children to be found in his district was an indication that the Maoris were not increasing in number:

I do not think the Natives in the Tauranga district are on the increase; comparatively few children are to be found amongst them. Many of the principal men are childless; in other cases whole families numbering 8 and 10 have been swept away. The principal causes are scrofula, pulmonary diseases, and fever:.163

In 1874 Bush, who was stationed at Raglan, reported that there were 'no infectious diseases among them'. Yet, over the previous 12 months there had been 38 births as against 40 deaths, 22 of the deceased being infants. The following year the ratio was 23 births to 26 deaths, of which 13 occurred among the adult population and 13 among infants. It appears that by infants' he meant both infants and children. ${ }^{164}$ Normally, the majority of deaths in

162

Thomson (1859): Vol.II, p.285; and, (1854-55): p.523 163

164 A.J.H.R. (1868): A-4, p.11.

A.J.H.R. (1874): G-2, pp.10-12; and, (1875): G-1, p.10. 
childhood occur during the first year or so of 1 ife, and thus, these data probably apply, in the main, to infants (in the strict sense of that word). Even if it is presumed that 10 of the 35 infant deaths' during this 24 month period occurred to children aged 1 or more years, the infant mortality rate for the district would have been 410 deaths per 1,000 live births. This rate is extremely high, particularly if, as Bush claimed, there had been no epidemics during the period concerned. Probably, the data are neither reliable nor representative, while the number concerned is very small. However, the rate of the Maori population as a whole could well have been at the level of 200-300 per 1,000, This presumes that the rate for the whole population in the 1870 s was $\frac{1}{2}-\frac{3}{4}$ that of Raglan. A level of 200-300 has been recorded since 1915 for a number of populations for which such data are available. Moreover, even a rate of 400 is not an unheard of phenomenon. 165 In 1878 , high levels of infant mortality were reported in the Hokianga, Waikato and East Coast districts. 166 However, this was probably a result of the widespread whooping-cough epidemic discussed above.

\footnotetext{
$\overline{165}$

of those populations for which there are data relating to the period 1915-44 at 1 east 6 had rates in excess of 200 per 1,000 live births: Mexico (most recently during the quinquennium 1920-24); Barbados (1935-39); Chile (1935-39); India (1915-19); Malta and Gozo (a11 quinquennia 1915-19 to 1940-44); Singapore (1920-24, then again during the war years); Romania (1920-24). See U.N. (1954): Vo1.I, Table II; a1so, pp.66-67. U.N. (1953): The Determinants and Consequences of Population Trends, Pop. Studies no.17, New York. They state that in mid-eighteenth century Stockholm the infant death rate was 400 , while during World War II a rate of 748 was recorded in Leningrad. These are unusual conditions; urban infant mortality rates, so they claim, usually exceeded rural until recently, and wartime Leningrad cannot be compared with nineteenth century New Zealand. 166

A.J.H.R. (1878): G-2, Pp.2, $4 \& 6$.
} 
In 1881 severe infant mortality, noted for Thames district, was caused by 'want of proper care and nourishment ... while, in 1884, a similar factor was noted in the

\section{Waikato:}

Death has also been busy amongst the children,... I am of the opinion that a good deal of it is caused by want of nourishment, as the scanty food upon which the natives usually subsist is not at all good for the rearing of children, so that, when through want of nourishment they once fall ill, their speedy death may, in most cases, be looked upon as a matter of course. Only the naturally strong and robust can stand the ordeal that the ordinary Native child has to pass through from the time of its birth until it is about twelve years old.167

In the $1890 \mathrm{~s}$, Ngata was certain that infant mortality was a severe problem, its causes being improper food, exposure, want of ordinary care and cleanliness'. Dr Bell noted the 1 ack of care of female infants (however, he also stated that infanticide was uncommon or had disappeared; see Fn. 17\%), and mentioned that 'Purulent Opthalmia is common in children!. 168

In 1901, the Taranaki census enumerator made this comment: lobservation, experience and reference to the detailed [census] returns point to a single conclusion i.e. that the rate of infant mortality is very high. Many cases are recorded in which whole families of children have died off'. In 1906, in the Kaipara area, the enumerator stated that The birth rate throughout the district is high, but,... the infant mortality is equally high,... In 1911 in the Bay of Plenty region, it was reported that 'a very small percentage of the infants

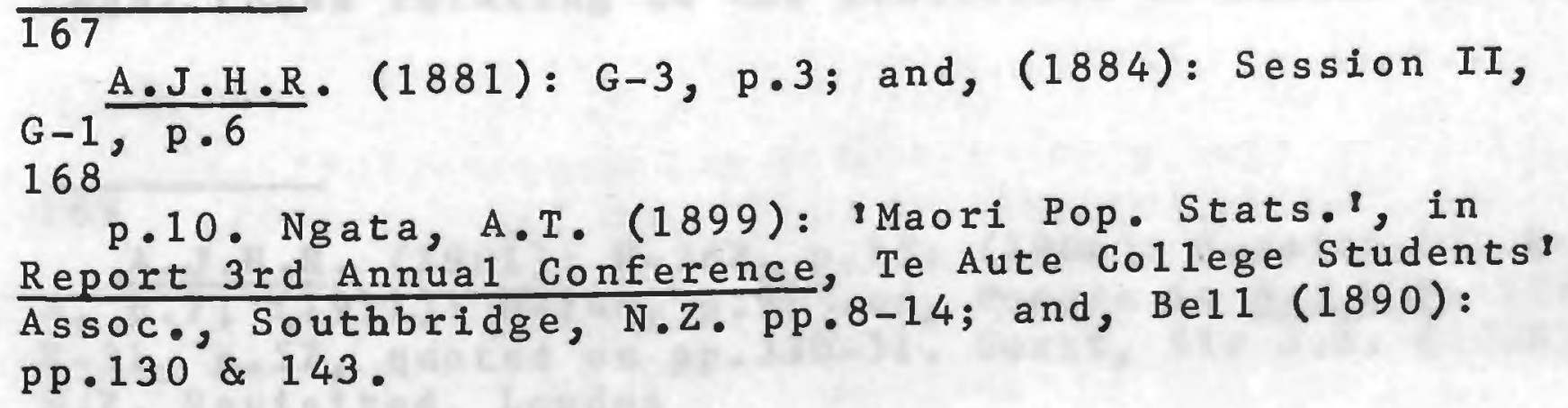
Assoc., Soutbbridge, N.Z. pp.8-14; and, Bel1 (1890): pp. $130 \& 143$. 
reach womanhood or manhood, and the preventible epidemics of typhoid and enteric fevers and measles, which break out periodically, sweep off both children and adults in large numbers'. Pomare reported that the causes of infant mortality operating at this time were: 'first and greatest, ignorance concerning the bringing-up of babies; second, unsuitable food; third, bad clothing; fourth, bad ventilation; fifth, improper nursing and non-attendance of qualified physicians when sick; sixth, tohunga-ism and superstition; seventh, prejudice' ${ }^{169}$

It is difficult to determine what levels of infant mortality are implied in the comments noted here. 400 infant deaths per 1,000 live births would seem rather too high an estimate except, perhaps, during years in which there were severe and wide-spread epidemics. In other years, rates would probably have exceeded 150 , but it is unlikely that a rate much in excess of 300 per 1,000 would have been reached.

\section{Induced Abortion and Infanticide}

A number of questions must be askedabout these practices. Most important1y, is there evidence to suggest that Maoris practised abortion and infanticide? If so, were they resorted to cladestinely and in defiance of societal norms, or were they accepted practices, even if not openly advocated by Maori society? Obviously, the distinction between therapeutic and illegal induced abortion does not apply in a society where there is no medical profession or legal codes relating to the protection of foetal and infant

\footnotetext{
169 A.J.H.R. (1901): H-26B, P.15; (1906): Session II, H-26 A, p.7; (1911): H-14A, p.9; and, Pomare in A.J.H.R. (1904): H-31, p.57, quoted on pp.330-31. Gorst, Sir J.E. (1908): N.Z. Revisited, London
} 
Iife; the distinction made here is between covert and overt practices. Thus, it must be asked whether these practices could occur during the course of any pregnancy and during the early life of any child, or were they restricted to certain classes of pregnancy and groups of children? Does the evidence suggest that these practices were resorted to frequently or infrequently? It might be noted that most of the evidence quoted here refers to the early period of contact from 1769-1840. Consequently, it must be ascertained whether these practices were a characteristic of the whole period 1769-1921.

There are numerous reports that Maoris induced foetal mortality and committed infanticide; but, there are fewer reports which indicate the exact nature of these practices. The records suggest that Maoris could induce abortion or stillbirth by rather gruesome methods, such as exerting pressure on the stomach of a pregnant woman; that the most frequently used methods were to damage the head of the foetus as it was being expelled (was this foetal mortality or f(inanticide?) and to strangle new born infants; and, perhaps, that some live-born infants were purposely neglected. In this last regard, it was also claimed that female infants were neglected more frequently than males. 170 In order to determine whether these acts were practiced openly or clandestinely, and for which classes of pregnancies or infants, it is necessary to review some of the possible causes. 'Nayti', a Maori who appeared as a witness before the House of Lords Committee in 1837-38, was the only

$\overline{170}$

Anon. Polynesians and N.Z. (1850): p.461; p.75. Biggs, Bruce (1960): Maori Marriage, Wellington; p.50. Tregear, Edward (1904): The Maori Race, Wanganui, N.Z.; and, Fenton, F.D. (1860): iobservations on the State of the Aboriginal Maori Inhabitants of N.Z.', J.S.S.L., vol.23. pp.508-41. 
observer to claim that infanticide was employed when families were already very large. It is worthwhile quoting his evidence to the committee:

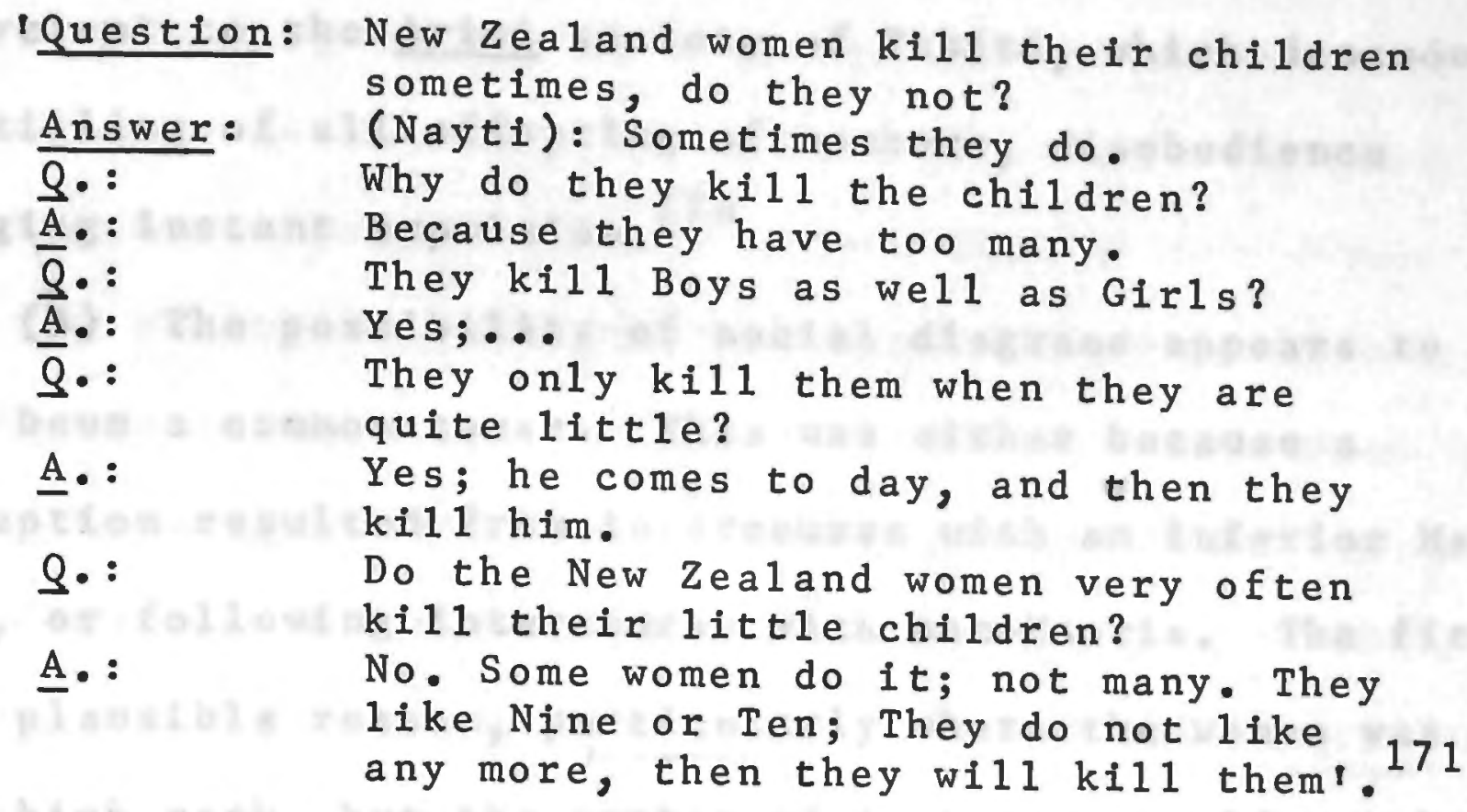

Other reported reasons for inducing abortions or committing infanticide can be listed briefly. They are:

(1) Hardship, resulting from the threat of starvation or some other type of duress, is cited. Usually these were circumstances affecting an entire social group, rather than the individual nuclear families. The most frequently reported instance is the killing, and, perhaps, eating of infants during sieges. 172

(2) Pre-marital sexual intercourse appears to have been a prevailing custom, marriage being contracted either after long periods of cohabitation, or when the woman conceived. It is claimed that some unmarried women killed their offspring to 'avoid the trouble of bringing them up...' Wright asserts that young women at the Bay [of Islands] were generally too busy entertaining whalers to bother raising families... 173 However, he then qualifies this

$\overline{171}$

172

P.P. $(1837-38): X X I, P .113$;

e.g. Biggs (1960): p.75; and, p.413. Best, Elsdon (1924): The Maori, vol.V., Memoirs of the Polynesian Society, Wellington.

173

Wright (1959): p.74. 
statement by referring to many reported cases where this situation did not hold true. Certainly, as contemporary observers noted, there were no sexually amoral sub-groups equivalent to the Arioi society of Tahiti, which demanded the killing of all offspring of members, disobedience bringing instant expulsion. 174

(3) The possibility of social disgrace appears to have been a common cause. This was either because a conception resulted from intercourse with an inferior Maori male, or following intercourse with non-Maoris. The first is a plausible reason, particularly where the woman was of very high rank, but the number of instances could not have been very frequent, because high ranking females 'at risk' would have been few in number. The second is stated by some writers, but is disputed by others. For Maoris, there were often advantages to be gained by permitting intercourse between their women and non-Maoris, while it seems that many women regarded with pride their ex-nuptially conceived half-caste children. Moreover, cases of infanticide and induced abortion resulting from this cause would have been restricted to areas of contact. 175

(4) Jealousy, rage and other motives seemed to have caused some women to kill their offspring. For example, there is some evidence that wives in polygamous households polygamy appears generally to have been restricted to chief's households - occasionally murdered children out of revenge when their husband returned with an additional wife. 176 However, these instances must have been relatively rare.

174 Anon. Polynesians and N.Z.' (1850): p.461. The author uses the spelling Areoi. 175

Wright (1959): pp.73ө75 discusses this evidence in some degree of detail. 176

Biggs $(1960): p .75$ 
(5) Finally, early writers often stated that a preference for male children caused Maori women to kill female infants. One writer claimed that it was a general custom, but Biggs notes that this notion 'is soon refuted... by reference to genealogical tables, though it may have occurred on occasion. 177

The practice of infanticide appears to have been restricted to the early years. Most observations span the period up until about $1840,{ }^{178}$ while there are virtually no references to infanticide after the $1850 \mathrm{~s}$. In 1858 Fenton, in the notes to his census, claims that neither infanticide nor induced abortion was common among Maoris, but that infanticide had been a frequent occurrence until 1835. He had met with 'many instances of women who have destroyed from six, and even seven children, offspring of themselves, and mostly females. Wright notes that the spread of Christianity brought about a decline of this practice, while Thomson states that 'they in former times occasionally destroyed their offspring; but among the present generation, from the sinfulness of child-murder in the eyes of the Christians, the love New Zealand women bear towards their children, and the intense desire they have for them, they are rarely destroyed directly;...' And, by 1890 Bell could claim 'I have never seen or heard of a case at the present day? 179

\section{7} 178

Biggs (1960): p.75

eg. Earle (1909); p.194 (Earle had visited N.Z. in 1827); Polack (1840): Vo1.II, p.91; Martin (1845): pp.302-03; Fox (1851): p.55; Colenso (1868): p.417; George Clark (Jun.) in P.P. (1844): XIII, Appendix, p.351, who noted that infanticide has occurred among several Wellington 'tribes? "till within the last two to three years". 179

Wright (1959): p.169; Thomson (1859): vol.II, p.287, and Bel1 (1890): p.127. 
Induced abortion was less frequently and specifically discussed by early writers, although it is certain that it occurred. Moreover, some cases may have been included under headings such as infanticide, 'child-murder', etc. After 1850 , there are only two references to induced abortion. In 1850 , one writer had noted the decline in infanticide, but was sure that ivoluntary abortion... still continues 180 And, Mr Heaphy, one of Fenton's enumerators, said in 1858: Abortion produced by artifical means, appears to be far from uncommon. The lack of references since 1860 is not prima facie evidence that Maoris did not induce abortions in the period from then until 1921, but it suggests that the practice was not common enough or sufficiently overt to come to the notice of district officials.

Therefore, $1840-60$ appears to be a critical period in this study of induced abortion and infanticide. It separates an early period when relatively speaking, these practices were common, from subsequent decades in which they were infrequent. Even in the period of early contact it is doubtful whether these practices were employed very frequently. For example, one early writer specifically stated that they were 1 ess widespread than elsewhere in Polynesia. 181 The study made above of the major reasons for infanticide and induced abortion suggests that this writer was correct. Few of the reasons would be sufficient cause for it to be concluded that these practices were common occurrences. Jealousy, disgrace and other motives would have been restricted to a few women at any one time, while the number of sieges during which it was necessary to kill infants must also have been 1 imited. 
However, 'Nayti's' statement implies that infanticide (and abortion?) were practiced openly and wilfully to limit the sizes of Maori families. It could be inferred from his evidence that there was some upward Malthusian limit to the size of the Maori population which Maoris recognised and kept below by a regime of infanticide and induced abortion among women with numerous offspring. Such does not seem the case. The quoted evidence gives no indication whether 'Nayti' was concerned with children ever-born, or children still alive. Presumably, he meant children still alive, but, even if he meant children ever-born, the number of females reaching parity 9 or 10 in any one year would have been sma11. Moreover, there is no indication that these practices were ordained and that this requirement was enforced. Desire to limit family size appears to have been merely a whim of some females. Thus, 'Nayti's' evidence is not an indication that these methods were widely used to limit the size of Maori families.

Another consideration is that most observers have commented on the fact that Maoris appeared to desire children. Moreover, they were very fond of their offspring, and even tolerated annoying acts by children without disciplining them. 182

In general, infanticide and induced abortion, particularly the former, appear to have been less widespread than it might be implied from early accounts. In fact, Biggs suggests that infanticide 'was the outcome of particular circumstances... and not a general custom ${ }^{183}$

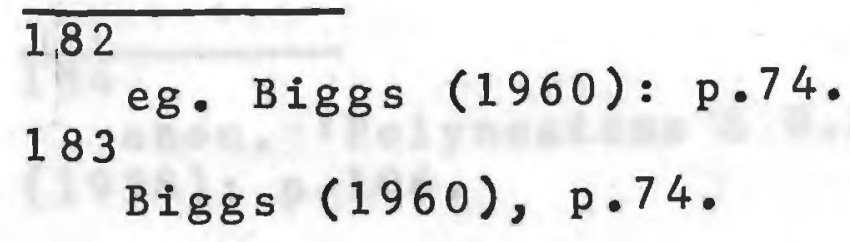


Thus, it is probable that early writers greatly exaggerated the effect of infanticide (and abortion), for many even stated that it was a major cause of depopulation. But, infanticide was the only reported cause of infant mortality in the period prior to 1840 , and it is improbable that infant mortality resulting from other causes was at a lower level in this period than subsequently. The tendency of earlier observers to emphasize induced abortion and infanticide may have resulted from the fact that, to many non-Maoris, they were alien and rather abhorent institutions. Of course, this would apply more to infanticide which was probably an extreme event in Europe. Such an emphasis in their accounts could cause a researcher to exaggerate both the importance of infanticide in the early period, and the decline in these practices during the 1840s. This is not to imply that there was no decline, but merely that its significance should not be over-rated. Consequently, these practices probably had far less effect on rates of foetal and infant mortality than most other causes, particularly after 1850.

\section{Preventive Measures}

Comprehensive measures were taken to improve Maori health only in the last thirteen years of the period 1769-1913. Prior to this there were a few spasmodic attempts. Thus, Sir George Grey founded four small hospitals at Wellington, Auckland, Wanganui, and New Plymouth, although this gesture to the Maoris was opposed by non-Maori settlers. ${ }^{184}$ Thomson, who tabulated data on the Maori hospital patients, outlined a plan for the prevention of disease among Maoris, and 
claimed that some two-thirds of the Maoris had been vaccinated by 1859.185 In the $1840 \mathrm{~s}$, there had been medical officers of health who entered Maori pa, and in the $1830 \mathrm{~s}$, there had been the mission surgeons. Another early effort noted explicitly in primary sources was 'a sanitary mission' for the government in the Thames and Waikato districts in 1862.186

In this period Smallpox Vaccination was the most widespread preventive measure. Vaccination was commenced in the Opotiki district in 1873, during which campaign 1,025 Maoris were vaccinated, and in the Wairoa district in 1874 when several hundred were vaccinated. Again, in 1881 , the under-secretary of Native Affairs proposed a vaccination campaign in a circular letter to district officers, IIn view of the spread of smallpox in a neighbouring colony... 187 The response to this call was noted in the reports of district officers in 1882. Difficulties were experienced in a number of districts, while in others some success was achieved. 188

From the reports of district officials it is apparent that the government paid some private medical practitioners for attendances on Maori patients. Moreover, some district officials may have been medically qualified. For example, in 1901 the census report refers to the fact that there had been no epidemics among Maoris since 1896 , but there had

\section{5} 186

Thomson (1859): vol.I, p.212.

187 Southern Cross (1862): Dec.30th., p.4.

A.J.H.R. (1873): G-1, p.11, in response to an outbreak in Auckland; (1874): G-2, p.22; and, Native Office IUnderSec.) Circular 1etter, Wellington. Aug.27th., 1881. Mss. A uck.Pub.Lib.

188

A.J.H.R. (1882): G-1, passim.; and, (1883): G-1A, p.7. 
been'outbreaks' of typhosd and in

been outbreaks of typhoid and influenza. It further notes that, IIn all cases of serious outbreak that have been

reported, the government has promptly sent medical assistance... 189 However, this system was not very comprehensive. Also, it is probable that the important barrier - reluctance on the part of the Maoris to accept medical advice - was seldom breached prior to 1900.

In 1900, the Department of Public Health was formed by the Public Health Act and Maui Pomare, the first Maori to graduate in medicine, was appointed in charge of Maori health. 190 In this same year, Dr Koch's views on tuberculosis made their impact upon New Zealand, and the control of tuberculosis became a major part of the Health Department's programme during its infancy. 191

In 1902, Pomare's first report was presented. As for the remainder of this period, he concentrated on the education of Maoris towards achieving higher standars of hygiene, the implementation of sanitation measures, and vaccination programmes. Appalled at the standard of hygiene in the 124 pa he visited, he gave 106 lectures in his first year, mainly on sanitation and the improvement of hygiene. By 1904, a vaccination campaign was well under way, and almost 6,000 vaccinations were carried out by public vaccinators, probably between 1901 and 1905.192 The main work at the local level, such as the control of village sanitation, was being done by village councils formed under the Maori Councils Act, 1900 , In 1905, Te Rangihiroa was

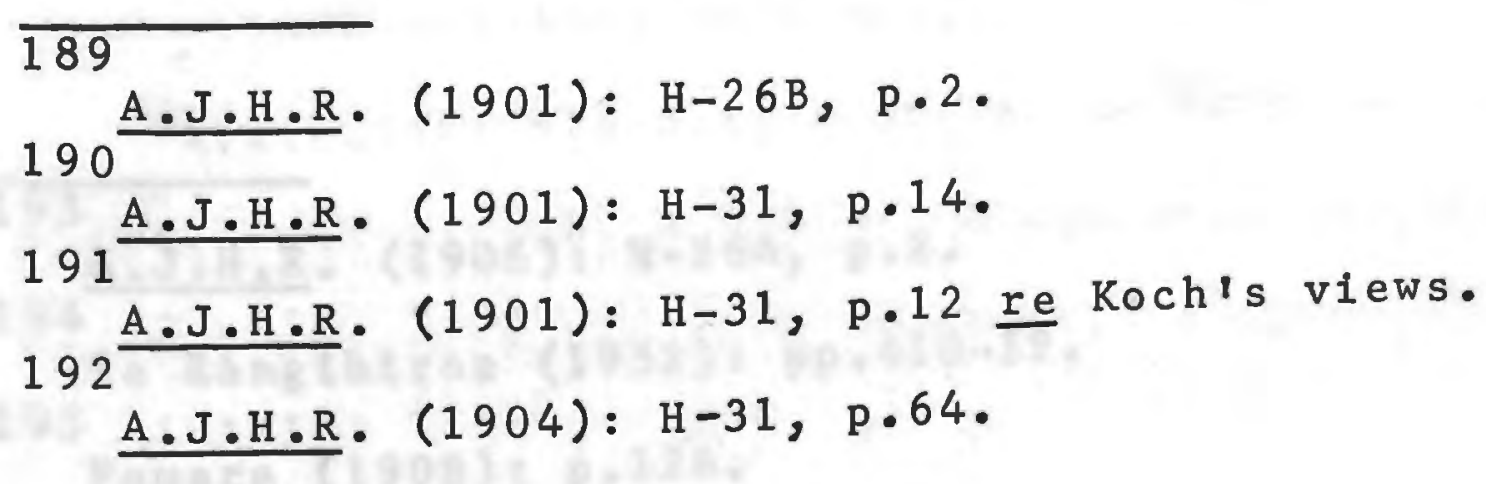


appointed under Pomare. By 1906, the census enumerators could state that there had been a marked improvement in Maori health since 1901.193

The programmes of education and sanitation were perhaps of greater significance than the other health measures. In the field of education, it was important that these practitioners were Maori, and were well-versed in Maori traditions. Thus, they were able to win Maoris over to health and sanitation measures. For example, Te

Rangihiroa describes a case when he drew on Ngata Ruanui tribal traditions, in order to counter objections by elders of this tribe to the building of latrines. 194

Their measures were often severe in the extreme. Pomare's special interest was the condemning and destruction of sub-standard whare (houses). By 1908, 1,057 had been destroyed and 1,183 new ones built, plus 839 latrines. 195

It is true that these events are seen through the eyes of the participants. Moreover, much has been written about the 'Maori Renaissance', and often the role of these reformers has been over-stated. But, in the $1890 \mathrm{~s}$, there was a tremendous fervour generated by the Te Aute College Studens' Association. Its members, including Pomare and Te Rangihiroa, achieved professional training and travelled all over New Zealand preaching health reform and other matters to their people. Above all, theirs was the first concerted effort to improve Maori health. Thus, the period probably saw improvements in Maori health resulting directly from the work of these young men. Much of the success must

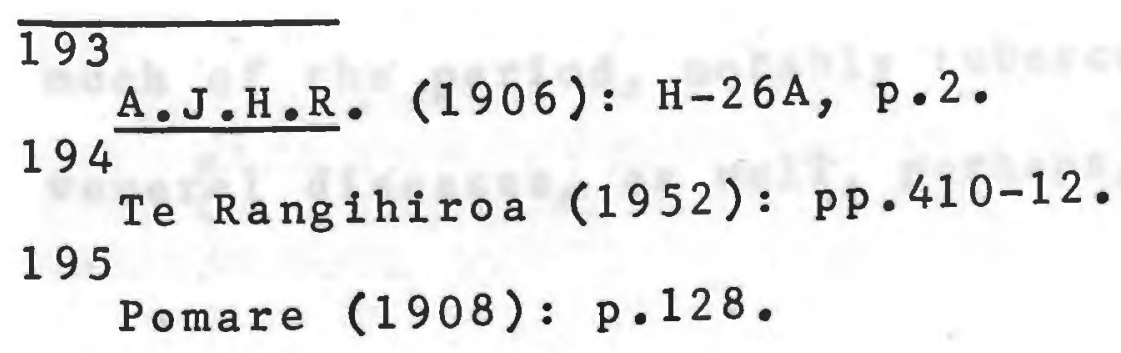


be attributed to their enthusiasm; through their efforts Maori general standards of health were probably better in 1921 than they had been since first contact with non-Maoris.

\section{Reconstruction and Interpretation}

From the evidence discussed above no incontrovertible conclusions can be made. Often it cannot even be proved directly that mortality occurred at all, or that it reached any given level. The researcher is left with the problem of inferring trends from a few critical pieces of direct proof, plus an abundance of generalised circumstantial evidence, little of which has any standing in its own right. However, on the side of the student is the increasing knowledge of population history, which proves beyond reasonable doubt that few nineteenth century populations had life-expectations at birth in excess of 50 years (see Table 8.4). Non-Maoris were among those few populations, but it is not likely that Maori levels of life-expectation were as high as the nonMaori (see Section 8). Thus, unless it can be otherwise shown, the researcher must assume that life-expectation was below 50 years at birth. The problem then becomes one of selecting some general figure from the widest possible range of 20-49 years.

The records reviewed in the earlier sections of this chapter can be summarised as follows:

(1) The evidence itself is vague, fragmentary and is seldom directly relevant to the study of mortality per se. There is an emphasis on epidemics, and comparatively little data on non-epidemic morbidity.

(2) Certain diseases appear to have been prevalent for much of the period, notably tuberculosis, typhoid, and the veneral diseases, as well, perhaps, as dysentery, diarrhoea 
and respiratory diseases other than tuberculosis. of these disorders, venereal diseases would not have caused the deaths of many adults.

(3) Observers often commented that tuberculosis, typhoid and other prevalent diseases caused 'high' rates of morbidity or mortality. During typhoid epidemics in small areas there were sometimes reports of the number of cases or deaths and the eye-witnesses were obviously concerned at the severity of these outbreaks.

(4) In addition, early writers expressed surprise at the level of mortality various prevalent diseases appeared to cause among Maoris. It is true that these observers had few objective criteria on which to base such a claim. However, it could be assumed that they were led to this conclusion by comparing Maori mortality with their experience of levels of mortality among the non-Maoris of New Zealand and Europe. Thus, Maori mortality levels from prevalent diseases were probably in excess of those of the British and New Zealand Non-Maori population.

(5) For the period 1914-21, it is possible to calculate from the registration/crude death rates for years in which there were not epidemics. For example, in 1917, the year before the great influenza pandemic, the rate was 15.5 per 1,000 as against 40 in 1918. It is difficult to estimate the crude death rate in normal years prior to 1913 , but four interesting clues are available.

Firstly, when Fenton took his census in 1857-58 he obtained detailed data on 1,369 Maoris in the Waikato whom whom the missionaries had previously enumerated in 1844.196 from data published in Fenton (1860): p.517; and, A.J.H.R. $(1874): G-2 c$, p.6; (1878): G-1, p.8 (1880): G-4, p.2; and, $(1881): G-3, \mathrm{p} .9$. 
From the mission records he could also calculate the number of out- and in-migrants and the number of deaths occurring in the intercensal period, but only among those persons whom the missionaries had enumerated. From other data he had obtained on Maori children ever-born (unfortunately, relating only to 13 women), from data on Saxony and from 'Mr Rickman's' tables of 1831 (England and Wales), he showed that only about 50 per cent of births could be expected to survive to age-group 0-14, and thus, that persons enumerated at ages 0-14 in 1958 were probably the survivors of only half the births of the period 1845-58. Consequently, the total deaths in the period 1844-58 equalled 50 per cent of the births in the period who had failed to survive to 1858 , plus the recorded deaths from 1844-58 occurring among persons enumerated in 1844 .

Fenton calculated a denominator by a procedure which is not, as he himself admitted, very satisfactory, but is expedient. He merely found the mean of the two enumerated populations (i.e. $\frac{\mathrm{P} 1844+\mathrm{P} 1858}{2}$ ). Then Fenton could estimate that the srelative annual number of deaths [in the period 1844-58 is] one in $22.14^{\circ}$ of the population. If these data hold true for all of New Zealand until 1857-58, the annual number of deaths at the time of Fenton's census would have been 2,540 , and the crude death rate would be 45.3 per 1,000 . However, there were several epidemics in the period 1844-58, notably measles in 1854 , and thus this rate may be an overestimate of the 'normal' crude death rate.

Secondly, McKay, the South Island census Commissioner, had obtained data on the number of births and deaths in the Provinces of Otago, Marlborough and Nelson for the 6 year period up until the 1874 census. The Maori population of these three provinces was only 1,211 at that census and 
thus the births and deaths comprised a very small total - 236 births, and 234 deaths. Assuming from these figures that the population was almost stationary, the average annual crude birth and death rates may be calculated with the 1874 figure as thedenominator. The rates were 32.4 per 1,000 (births), and 32.2 (deaths). It might be noted that McKay considered that the data, particularly those relating to infant deaths, were unreliable. Thus, both rates may be under-estimates. It is also possible that the actual rate of natural increase is the reverse of that shown here, for the death rate may have exceeded the birthrate. Even so, it is probable that the population of these provinces was almost stationary in the early 1870 s.

This crude death rate may not apply to North Island sections of the Maori population in the early 1870 s, because many of the South Island Maoris had probably achieved better environmental conditions than those obtained by most North Island groups. Moreover the South Island had not been affected by the war of 1860-72. However, it is likely that this rate does apply to Canterbury and Westland; the remaining South Is 1 and Provinces.

This rate pertains to a period when, by and large, epidemics were not widespread and severe, and may thus represent mortality levels in 'normal' periods more accurately than those calculated from Fenton's figures (above) or Bush's data (below). By contrast, during the widespread measles epidemic of 1878-81 the death rate for 534 Canterbury Maoris rose to 73 per 1,000 , which supports the suggestion that the rate of 32.2 for the period $1868-74$ was for a 'normal' period.

Thirdly, Bush, the official at Raglan who collected data on births and deaths, reported in 1878 'that during the past five years the deaths in this district averaged in the 
proportion of ten to eight births, which proves that the Maori is slowly decreasing in numbers'. By comparison, he continued, 'the deaths since my last report [1877] have nearly doubled the births.' During the year 1877-78 a whoopingcough epidemic had spread to Raglan. Even if a fair margin of error is allowed when this statistical evidence is interpreted, it would seem either that this epidemic gave rise to higher than 'normal' mortality, or that the birth rate was abnormally low in 1877-78. The first is the more plausible explanation, but two qualifications are necessary:

(a) Because of high foetal and maternal mortality, and dissolution of marriages, there may be a temporary diminution of the crude birth rate during and after an epidemic.

(b) In the five year period to which Bush referred an epidemic of measles had occurred in this area. However, in the neighbouring Kawhia district, it was reported that no deaths had occurred (see above, Section 3, Epidemics 1873-1911), and thus measles mortality may have been lower in this region than els ewhere.

If it is presumed that the crude birthrate in the Raglan district was between 30 and 40 per 1,000 at this time (Chapter 5, Section 4) the annual crude death rate during the 'normal' quinquennium may have been at the level of $38-50$ per 1,000, while during the whooping cough epidemic it may have risen to between 60 and 80 per 1,000. This 'normal' level of 38-50 per 1,000 is weighted, of course, by the abnormally high mortality occurring in the last year of the quinquennium, and thus may be an overestimate. However, rates as high as 40 per 1,000 are not an impossibility. For example, in the South Pacific in the 1 ate nineteenth century 
the 'normal' crude death rate of a number of the population may have been as high as this. Moreover, in the early nineteenth century the death rate for Eastern Europe may have been 38 per 1,000 . Finally, even today there may be populations with rates in excess of 40.197

Fourthly, data on births and deaths were collected for the Mongonui (Mangonui) district of North Auckland in 1878 and 1879 , while the census of 1878 recorded the numbers in each 'tribe' by 'place of residence'. The average annual crude death rate (1878-79) of the615 Aupouri, Rarawa and Ngapuhi tribesmen recorded as residing at Mongonui (1878 census) is 90.3. A whooping cough epidemic was reported for the neighbouring Hokianga district in 1877-78 (see Section 3, Epidemics 1873-1911), but no epidemic was reported in Mongonui in 1878-79. Consequently, a crude death rate of 90 is probably too high. It is apparent that this overestimate results from the fact that the population enumerated as residents of Mongonui come from the restricted area adjacent to Mongonui Harbour, while the births and deaths refer to the population of much of northern-most North Auckland. In 1878, Ahipara with a population of 998 was the only other place of residence recorded for this area. The totals for the two districts were combined, and with this denominator the crude death rate drops to 30.8 per 1,000 , while the crude birth rate is 35.2 . It is possible that some births and deaths went unreported, but it is also probable that these rates approximate Inormal levels during that period in Northland.

Among North Island Maoris conditions were most settled in Northland. The wars of the isixties had left the region almost untouched; 1 and purchasing was no 1 onger of great

Dr N. McArthur, (Personal Communication); and U.N. (1953): pp. $48 \& 51$. 
significance, and the region was isolated from contact both with Auckland city, which could be reached only by boat, and with the areas containing other large Maori populations. Moreover, as northern Northland's Maori population had been in contact with non-Maoris and had been subjected to frequent epidemics (etc), it is likely that levels of immunity to disease were higher among the Maoris of this region than elsewhere. Consequently, it can be argued that the Mongonui rates represent a favourable and perhaps a typical extreme. Death rates may have been lower and birth rates may have been higher than in many other regions.

The four estimated crude death rates discussed above cannot be accepted as entirely reliable. Nevertheless, it is reasonable to assume that rates estimated from Fenton's and Bush's data have a range of error of (I) 10 per 1,000 deaths. The estimates for the South Island and Mongonui are probably closer to the actual situation, and ( \pm ) 5 points per 1,000 might be allowed for possible inaccuracies. The 1917 crude death rate may also be inaccurate, and perhaps (I) 5 points per 1,000 should be allowed as a margin of error. Even after such 1 iberal allowances are made for error and the effect of epidemic mortality, these calculations still suggest that there was a considerable decline in mortality between 1858-78 and 1917. The possible maximum and minimum declines (per 1,000) can be tabulated as follows:

\section{Regions with 'high' mortality}

$$
\begin{array}{ll}
\text { Maximum decline from } 60-10 \\
\text { Minimum decline from } 28-20
\end{array}
$$

\section{Regions with 1 low' mortality}

Maximum decline from $37-10$
Minimum decline from $25-20$


Probably, a decline of about $15-25$ points (from a maximum of 32-42 to a minimum of 17 per 1,000) would not be an unacceptable estimate of the improvement in mortality Indicated by these data.

The emphasis so far has been on so-called 'normal' levels of mortality. However, were there any years, 1917 included, which were free from at least minor regional epidemics?

(6) At irregular intervals there were the more severe nation-wide epidemics which spread throughout much of the Maori population of certain ages. The most frequest widespread epidemics were of measles, whooping cough and influenza. By contrast, typhoid, the other common but severe epidemic disease, was restricted to particular regions.

(7) These widespread epidemics appear to have caused a higher level of mortality than would have occurred under 'normal' circumstances. For example, during 1877-78 whooping cough in Raglan caused a crude death rate of from 60-80 per 1,000 as against 38-50 per 1,000 during the quinquennium 1873-78. While the rate for Canterbury in 1878-81 was 73 per 1,000, and was probably double the 'normal' rate for the South Island in the $1870 \mathrm{~s}$ (see summary note (5), above). During the 1918 influenza pandemic the epidemic crude death rate was 22.6 per 1,000 , and epidemic deaths had constituted more than 50 per cent of the total crude death rate of 40.0 per 1,000 for the year as a whole. In turn, the 1918 figure was very much higher than the crude death rate of 1917 ( 40.0 as against 15.5 per 5,000).

(8) The only data on other epidemics which can be submitted to this type of analysis refer to smallpox (1913) and measles (1854). In 1913, the number of deaths was very 
low, probably because many Maoris had already been vaccinated, and also because steps were taken to limit its spread immediately news came to the authorities that the epidemic had broken out.

In 1854, measles deaths in the North Island, in which the overwhelming majority of Maoris lived, were estimated to have caused a crude death rate of 57-67 per 1,000. The reliability of this estimate is very much in doubt, and conclusions must be extremely tentative. However, if the death rate referred only to deaths occurring at the time of the epidemic, the total crude death rate for that year, judging from the experience of 1918, may have been in excess of 70 or 80 per 1,000. As the Raglan and Canterbury data of the late 1870 s suggest, such a high crude death rate is not an impossibility. Moreover the outbreak of 1854 appears to have been the first epidemic of measles in the North Island, and thus affected all age-groups. The quoted epidemic crude death rate assumes only that 5-8 per cent of the population died either directly or indirectly from measles. In Tonga, Samoa and Tahiti initial measles epidemics probably gave rise to a similar level of mortality. By contrast, in Fiji the death rate during the first measles epidemic was far higher, but this was caused by a peculiar series of circumstances which would not have applied in New Zealand in the $1850 \mathrm{~s} .198$ High epidemic crude death rates among the Maoris resulted from their extreme susceptibility to infection during outbreaks. In 1918, this was true for the Maori population in general. Moreover, even the more closely controlled army camp population had higher incidence

Dr N. McArthur (Personal Communication). The King's son had returned from Australia, contracting measles during the voyage. Chiefs of every district assembled to greet him. Later, they returned to their own districts, whereupon further meetings were held, and so on. 
and case fatality rates than non-Maoris of the same agegroup and under the same conditions of congregation and medical care.

(9) From the age-specific death rates calculated for the 1918 pandemic it was shown that, in addition to mortality of adults, the pandemic caused the dissolution of marriages and, thus, a temporary reduction of fertility. It is suggested that this was an accompaniment of earlier epidemics. Another result would have been the depletion of certain cohorts.

(10) Foetal and infant mortality rates appear to have been high throughout the period. More than 30 per cent of conceptions may have resulted in spontaneous foetal loss, but the level of induced foetal mortality cannot be estimated. There may have been fewer induced abortions after 1850 than earlier.

Infant mortality may have been at the level of 200-300 per 1,000 live births. One cause of infant mortality infanticide - appears to have declined in significance during the 1840s, and may not at any time have been as important as early observers believed,

(11) Warfare was the direct or indirect cause of much mortality. It appears that inter-tribal warfare in the 1820 s and 1830 s resulted in more deaths than the wars of the $1840 \mathrm{~s}$ and the $1860 \mathrm{~s}$.

(12) In this survey no account has been taken of famine or temporary food shortages. Some observers did mention this factor, but the evidence is too fragmentary to obtain a reasonable picture. In times of war there was sometimes a shortage of food (see above section 3, Epidemics and Wars, 1840-59). Widespread epidemics could have had the same effect by temporarily reducing the number of persons able to work in gardens. Moreover, the 
Maoris relied on a few basic root crops - in earlier times

kumara, etc.; 1ater the potato. These were seasonal and

it was necessary to store a section of the year's crop. A poor harvest, resulting either from crop failure or the dispersal of workers to other activities at harvest time, could have had disastrous consequences. For example, in the $1870 \mathrm{~s}$ and $1880 \mathrm{~s}$ 'most tribes produced little more food than was necessary for their immediate needs. A shortage of food just before a harvest was not an uncommon feature in many a hapu.: As recently as 1906, their major crop (the potato) was infected by blight in every region, and in some areas there was considerable distress and privation. 199

Taking all these factors into account it might be expected that reports of mortality from all causes would have been more systematic and more frequent than is shown by the evidence quoted here. However, it is evident that the reporters were interested in all aspects of Maori life and emphasized only those which seemed of significance at the time they wrote. Moreover, in these accounts there are often tantalizing but useless pieces of information, such as a remark tossed out by Major Mair in 1874: There has been a good deal of sickness prevalent, but nothing to call for special remark'. 200 Unfortunately, all the necessary details are left out, and thus nothing can be inferred from such a comment.

\section{9}

P.355. Hargreaves, R.P. (1960): 'Maori Agriculture after the Wars, $1871-86^{\prime}$, J.P.S., vol.69, no.4, Dec. PP. 354-67; and, A.J.H.R. (1906): Section II, H-26A, PP.2430. 200

A.J.H.R. (1874): G-2, p.9. 
Factors related to the high mortality of Maoris: an evaluation of the views of earlier observers.

Many of the stated underlying or direct causes of high mortality appear to have been based on logical criteria. Examples are factors such as the adoption of non-Maori clothing, which, so it was claimed, was more difficult to keep free of vermin and dirt than Maori garments; poor sanitation and housing; low levels of personal hygiene; unsatisfactory diet; and the claim, in 1858, that 'medical aid is declined by them... Other conclusions seem less logical or of less importance. Amongst these were 1 ack of exercise (because warfare had ceased, the missionaries had banned various indigenous dances and the Maoris had taken up horse-riding); cannibalism; ${ }^{201}$ addiction to lardent spirits'; the consumption of Kaanga Kopiro (maize soaked in a stream until it is rotten); makutu (superstition); the influence of tohunga (1iterally - 'wise men'); 'accidents by water'; and their 'uncleaness, inwardly and outwardly, in diet, dress and habitation, in body and mind, in all their thoughts, words and actions' (Italics in original statement by Rev. C.H. Snackenberg, Census enumerator, 1857-58). It might be noted that in the early period

\section{1}

Cannibalism usually occurred during war when prisoners were killed and eaten, generally at the actual battlefield. Maoris claimed that they enjoyed human flesh and that they obtained revenge against their enemies in this way. However, Vayda (1960): pp.69-72 points out that war parties 1 ived off the 1 and and often were short of supplies. Thus, ihuman flesh served as nutriment. The fact made cannibalism a useful practice in war'. Four points should be noted: (1) Prisoners would have been killed anyway, regardless of age, sex, rank or any other distinctions. (Vayda: pp.91-92). (2) Sometimes, prisoners would be enslaved and occasionally these people would later be eaten. (3) Maoris did not go to war with the intention of capturing people to eat; cannibalism was a side effect of war and not its raison s $^{\text {? }}$ etre. (4) In early accounts it is often implied that it was the actual eating of flesh which weakend the Maoris physiologically, and thus resulted in a population decrease. 
Maoris do not seem to have over-indulged in liquor, and that the effects of this practice, if any, would not have become important until later. 202

Frequently, it was stated that a cause of high mortality was the inferior physique of Maoris. Early writers mentioned that their 'constitutions' were 'rotten', and suggested reasons such as in-breeding' 'during the twenty generations that the Maoris have lived in this country...', 'racial inferiority', and that the Maoris have ifed in- and-in [see fn.201] as well as bred in- and -in, for generations'. Somewhat more refined views were put forward by two later observers. One stated, rather paradoxically, Physically the natives are a fine athletic race of people,... but possessing no stamina to support them in sickness'. The other noted: 'the fact that the death rate is higher among the young than the old... would seem to indicate that the older Natives retained more vitality than the rising generation appear to possess'. 203 The second observer, writing in 1896 , does not appear to be aware of the fact that commentators 40 years earlier had noted a lack of 'vitality' among the very group which he termed 'older Natives'. Moreover, these earlier writers had been extremely perplexed at the apparent susceptibility of Maoris of all ages to 'childhood ailments'.

Today, more is known about the behaviour of acute and chronic diseases, and thus the apparent susceptibility of the Maoris to infection can be viewed from a different perspective. Because of their isolation until the time of contact in the 1 ate 18 th century, the Maoris were a virgin

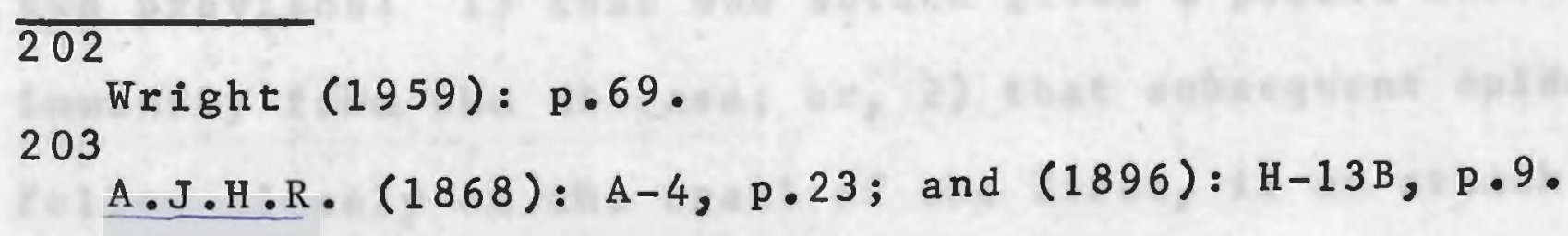


population having no immunity to a wide variety of diseases prevalent among the European non-Maoris who entered New Zealand. At first introduction to such a population acute disorders may follow a more virulent path than among groups having some degree of inherited or acquired immunity. Moreover, diseaseswhich are normally chronic in character may assume an acute form in these circumstances, as was discussed in the case of tuberculosis (Section 2). This virulence was enhanced, so it seems, by such factors as the breakdown of precontact modes of village sanitation and a change of habitat. Moreover, until the early 1900s, no comprehensive attempt was made to improve the standards of Maori hygiene and diet, or to accord them medical care, and so, with a few exceptions, disease went unchecked. Therefore, any decline in the effect of introduced diseases must have arisen spontaneously, either by the acquisition of immunity to these diseases, or by the possible changes in the virulence of various organisms. Probably, the more significant cause was the development of levels of immunity. This can be illustrated most clearly by reference to those acute infectious diseases which have distinct regimes of Infection and immunity.

When an initial epidemic strikes a population, incidence rates are high for all age-groups because nobody has immunity to the disease. Thus, in the 1854 North Island epidemic of measles, persons of all ages died.

During subsequent epidemics, persons who have survived an initial epidemic will have immunity from attack, with two provisos: 1) that one attack gives a person life-long immunity from the disease; or, 2) that subsequent epidemics follow closely on the trail of the first, if an attack of the disease provides only temporary immunity. Consequently, 
infants and young children are the only persons with no immunity to subsequent epidemics of most of the so-called childhood ailments which reached New Zealand. For example, persons under 21 years would have been the only victims of the 1875 measles epidemics, older persons having survived the epidemic of 1854. Again, children aged 0-7 years would have been the only persons at risk in the 1882 measles epidemic on the Hauraki P1ains, etc. etc. 204 By the end of the century, when documentation would have been more complete, there is little mention of widespread mortality among adults during epidemics of these diseases. Probably, by this stage, a 11 persons but infants and young children had gained immunity to measles, mumps and whooping cough, which had become childhood ailments, as they were to non-Maoris. From this reconstruction it seems that Maoris gained their immunity to acute infectious disease by suffering repeated epidemics. Two recent observers have attributed increases in levels of immunity to intermarriage with Europeans, which, so they imply, bred a new group of part-Maoris, each of whom had inherited his European parent's immunity to various diseases. 205 However, even if it were possible to show that part-Maoris were 1 ess susceptible to various diseases than Maoris, an argument in favour of inherited immunity could not be proven, because a number of other factors could not be isolated. Part-Maoris were most likely to live near non-Maori settlements and to have suffered various diseases. In the process, the survivors would have gained immunity. Again,

\section{4}

Burnet (1953): p.208 discusses a similar effect in Melbourne in the late nineteenth century. 205

pp.176 and 178-79. Price, A. Grenfell (1949): White Settlers and Native Peoples, Melbourne; and p.382. Duff, Roger (1940): 'South Island Maoris', in Sutherland, I.L.G. (ed): The Maori People Today, Wellington. pp.374-98. 
the style of living of part-Maoris would resemble that of non-Maoris and, presumably, the majority of non-Maoris lived in more hygienic conditions than did Maoris. Finally, it is impossible today to distinguish scientifically between 'ful1-blood' and 'mixed-blood' Maoris. From this distance it would be even more impossible to make such a distinction about nineteenth century Maoris.

Arguments about 'ethnic inferiority', and about the inability of primitive groups to withstand icivilized? diseases, can also be readily countered. In 1846 , in the isolated, Danish-owned, European Faroe Islands, a measles epidemic attacked all those persons born since the previous epidemic in 1781. In 1875, another epidemic infected those who had not gained immunity from the 1846 epidemic. In the 1846 epidemic, 6,000 of the 7,782 inhabitants of these islands came down with measles. Moreover, a leading contemporary immunologist confesses that 'we have as yet no clues as to how genetic factors can influence the resistance of the body to diseaser. 206

\section{An Estimate of Life-expectation}

An extremely crude estimate can be made of the level of Maori mortality in the late nineteenth century. Unfortunately, such an estimate cannot be made by reference to the data on non-Maoris which, it can be presumed, are fairly reliable. The reason is simple. At this period, non-Maoris enjoyed lower levels of mortality than most, or a11, other populations. For example, by 1881-91, every non-Maori age-group of both sexes had lower mortality rates thatheir counterparts in New South Wales, Victoria and

Burnet (1953): pp.199\& 230; and, Winslow (1944): pp. 267-71. 
Eng 1 and $(1871-80) .207$ The patterns of non-Maori lifeexpectation followed the trends noted by stolnitz, when referring to, what he termed, the 'West'. 208 That is, the most rapid declines in mortality occurred between 1880 and 1920. But even at the turn of the century non-Maori 1ifeexpectation at birth was comparatively high - 59 years (males) and 61 (females).

There is no likelihood that nineteenth century Maoris had levels of 1 ife-expectation at all akin to those of nonMaoris. To achieve such high levels, they had very great obstacles to overcome. The non-Maoris'style of living, attitudes to medical care and facility for obtaining reasonable attention were in advance of the Maoris'. By contrast, the Maoris resided in the more isolated sections of New Zealand. They were disorganised as a result of culture-contact, land alienation and wars, and they had a distrust of non-Maori New Zealanders. Until 1900, there were no qualified medical practitioners from their own ranks who could win their confidence and, thereby, bring about a general improvement in public health. Therefore, there were tremendous differences between Maori and nonMaori death rates. For example, in the 1870 s when the Maori crude death rate was perhaps as high as 40 per 1,000 , the non-Maori varied only from 11.0-15.9. To estimate Maori life-expectation another course must be followed.

\section{7}

pp.661-662. Adams, C.E. (1898.a): A Comparison of the general Mortality in N.Z., in Vict., \& N.S.W., and in England, T.N.Z.I., vol.31. pp.661-66. 208

cf.pp.29-33. Stolnitz, George J. (1955.a.): 'A Century of International Trends, ' Pop.Stud.', vol.ix, Ju1y. pp.24-55; with p.660. Adams, C.E. (1898.b.): 'A Comparison of N.Z. Mortality Trends During the Periods 1874-81\& \& 1881-913, T.N.Z.I., vo1.31. pp.659-60; and, Year Book (1915): p.193, BMortality Tables'. 
In Chapter Five on fertility in this period, the child-woman ratio for Maoris in 1901 will be compared with ratios estimated from various birth rates and levels of mortality. The expected $\mathrm{P}_{0-4}$ at the 1901 census can be estimated by applying various survival ratios, based on different mortality levels, to expected births of the quinquennium 1896-1901. There, it is presumed that the birth rate in the 1 ate nineteenth century was about $35-40$ per 1,000 .

Survival ratios calculated from the 1926 life-table, which is the first constructed for Maoris (see Table 8.4), cannot be used to determine the expected survivors at 1901 of births in the quinquennium 1896-1901. The number of expected survivors would be far higher than the enumerated $\mathrm{P}_{0-4^{\circ}}$ In the early $1900 \mathrm{~s}$, there were the campaigns to improve Maori hygiene, sanitation and general health, which were discussed above (Section 6). Thus, life-expectation must have risen quite sharply in the period from 1901-26, by which date it had reached the 1 evel of 45 years at birth.

In Chapter Five, Section 4 , it is concluded that, if the birth rate were $35-40$ per 1,000 , the infant mortality rate at the turn of the century must have been about 200 per 1,000 live-births, in order to account for the low number of survivors enumerated at the 1901 census. In the U.N. Model life-tables, the levels of life-expectation at birth associated with infant mortality rates of 200-250 per 1,000 range from about 30.0-37.5 years. These levels are not inconceivably low. For example, as late as 1919-22, life-expectation at birth in Chile was 30.9 years (males) and 32.3 (females). In India, in 1881, levels were even 
1 ower, being 23.7 years (males) and 25.6 years (females). 209 In normal years in the nineteenth century, Maori mortality would not have been as high as that of India, for diseases such as malaria, cholera and bubonic plague were not found in New Zealand, while they are important causes of death in India. Thus, about 1900 , it seems that Maori lifeexpectation at birth could have been relatively higher than the level figures given above for Chile; or, approximately 35 years. During the wars and nation-wide epidemics of the nineteenth century, life-expectation may have been at much lower levels. By contrast, in 1913, Maori lifeexpectation should have been much higher than in 1900 as a result of the public health campaigns of the previous decade. A level somewhere between that calculated for 1926 and that estimated for 1901 seems possible; that is, about 40 years 1 ife-expectation at birth. 


\section{CHAPTER FIVE}

\section{Fertility of Maoris Until 1921}

\section{Introduction}

Until the early 1900 s it was almost invariably assumed that the Maori birthrate was 'low'. Observers did not try to define what they meant by a 'high' or 'low' birthrate, but, after this basic assumption had been accepted without question, they proceeded to give their reasons for this phenomenon. The arguments relating to this subject are often long and tendentious, but they contain few data on which to base a study of fertility in the period. This results from two factors: (1) As already implied, these writers seldom collected facts on the number of births occurring to a given number of females, or within a population of some stated size. (2) More importantly, whenever they presented numerical data, and when discussing fertility in general, their accounts are difficult to follow because there is no clear indication of the demographic process under consideration. When fertility was discussed in these accounts four terms were used frequently, and sometimes interchangeably. They are: 'birthrate', 'few children', 'sterility' and 'lack of reproductive power'. From the contexts of a number of accounts it is apparent that the writers may be referring to one or more of the following factors: fecundity, which has recently been defined by the U.N. as The capacity of a man, a woman or a couple to participate in reproduction (i.e. the production of a live child)...'; fertility ('actual reproductive performance - whether applied to an individual or group'. Here used to mean live-births per woman of reproductive age); completed fertility (the number of livebirths occurring to a woman throughout the span of her 
reproductive life, usually taken as the period from 15 to 49 years of age); the crude birth rate ('The fraction, the numerator of which is the total number of births in a population during a given period, and the denominator is the total number of person - years lived by the population during that period'. Only 'live-births' are included here); and the replacement of the adult population (the proportion of the conceptions in any period surviving pregnancy, infancy and childhood. Here abbreviated to 'replacement'. The N.R.R. is a refined index of the replacement of females of reproductive age, but such a measure cannot be calculated here). For example, early observers often noted that there were few children in a particular locality. This was accepted as direct proof of the 'sterility' of Maori women, yet no account was taken of infant and early childhood mortality. Such evidence is inadmissable as proof that Maoris had a llow birthrate', or that 'the race is sterile'.1

Most of the other comments made in Chapter 3, Section 5, on the subject of the quality of the data - for example, that there was no systematic geographical coverage, that details are vague and that these authors concentrated on bizarre aspects of Maori life - apply to the data on fertility.

Previous commentators accepted that fertility was low and accounted for this phenomenon by the discussion of three possible causes:

(1) The earliest views related to the llack of reproductive power of the race', the 'sterility' of Maori women and the

$\overline{1}$

Definitions quoted or adapted from U.N. (1958): Multilingual Demographic Dictionary: English Edition, Pop. Studies no.29, New York. The following definition of live-birth was adopted by the Third World Health Assembly in 1950 (see, vol.I, P.4.U.N. Foetal, Infant and Childhood Mortality, Pop. Studies no.13, New York): 'Live birth is the complete expulsion or extraction from its mother a product of conception, irrespective of the duration of pregnancy, which after such separation, breaths or shows any other evidence of life,...' 
'lack of vigour of Maoris'. It is not possible to determine what these commentators intended to imply by such statements. Three examples might be quoted. Thomson and colenso reported that 'sterility is a powerful cause of the decay of the natives... In 1878 , a Raglan official noted that they are decreasing in number, one great cause of which is the sterility of their women'. In 1901, a Taranaki official commented that the sterility in males was very marked, and quoted the conjugal history of one thrice-married woman to prove his point. Probably, these observers are referring to low levels of replacement, and may not mean sterility (vis a vis fecundity), in the sense in which the term is used today. 'Sterility' was attributed to a wide variety of causes including the vegetable diet of the Maoris; the fact that infanticide and abortion permitted licentiousness, which, in turn, destroyed fecundity; and, because the major effect of high morbidity was to limit the capacity of females to reproduce.

Licentiousness recurred in another, and more frequent1y stated guise - sexual relations with non-Maoris. Writers were more or less evenly divided on the effects of miscegenation. One group accepted the theory of the Australian explorer Count Strzlecki that once a 'Native' woman had had intercourse with a foreigner she could not conceive when she renewed sexual relations with members of her own tracet. This factor was seen as a major cause of depopulation. A variation on this theme was that IIn all [cases of mixed marriages] the union is usually prolific, but unions between pure Maoris are rarely so... [for there is a] want of fecundity amongst the females in cases where they cohabit with or are married to males of their own race;...' Another group, including Thomson and Fenton, claimed that Strzlecki was wrong, while Fenton went as far as to state 
that, in 1858, miscegenation was most uncommon. He knew of on 1 y 23 interracial 'marriages' in Auckland, the major town of the period.

The only comment that can be made is that miscegenation may have had an indirect effect, in the sense that it might have aided the spread of venereal diseases. However, in general the argument of early writers does not appear to be particularly valid. 2

(2) Another early view was that levels of fertility were affected by the masculinity of the sex-ratio. Fenton stated that there was a natural law that where there was no emigration or immigration females should exceed males, even though male births might exceed female. Thus, the Maori population 'displays a remarkably abnormal condition'. The authors quoted above (fn.2) and others asserted that high masculinity produced low fertility, and one writer even suggested that a 'population consisting of 100 males and 80 females will be fruitful, not as might be supposed in the proportion of 80 , but only 60 pairs.' This viewpoint persisted at least until the 1920 s when Te Rangihiroa reiterated it, and Pitt-Rivers formalised it into a general theory to account for declines in fertility. 3

From the data presented by early writers on sex-ratios, it is obvious that males did outnumber females. This imbalance was attributed to factors such as female

2

e.g. see anon. (1850): 'Polynesians and N.Z.', Edin. Rev•, vo1.XCI, Pp.443-71; vol.II, Pp.266-8, Thomson, A.S. (1859): The Story of N.Z., London. 2 vols; Colenso, William (1868) IOn the Maori Races of N.Z.', T.N.Z.I., vol.I. Pp.339-424; A.J.H.R. $(1874): G-2 C, p .6 ;(1 \overline{878): G}-1, p .7 ;$ and, $(1901):$ H-26, P. 15; and, P.417. Fenton, F.D. (1860): robservations on the State of the Aboriginal Maori Inhabitants of N.Z.', $\frac{\mathrm{J}}{3} \cdot \mathrm{S} . \mathrm{S} . \mathrm{L} \cdot, \mathrm{vo1.23,} \mathrm{PP} \cdot 508-41$.

Te Rangihoroa (1924): The Passing of the Maori', T.N.Z.I., vo1.55, Pp.362-75; and Pitt-Rivers, George Henry Lane-Fox (1927): The C1ash of Cultures and the Contact of Races, London. 
infanticide and the 'drudgery imposed on their women'. It was even postulated that, as the Maoris had migrated from Hawaiki, they had retained the imbalance of sexes which characterised immigrant groups. However, there is no necessity to search so widely for causes. The sex-ratio at birth plus maternal mortality are probably sufficient causes for this imbalance. Moreover, female life-expectation at birth was below the male until very recently (see Table 8.4). It is possible that a surplus of males would have affected the birth rate, but only if high masculinity rates were an indication that the proportion of the total population exposed to the risk of pregnancy (females aged 15-49) was particularly low. By contrast, it is possible that fertility would be enhanced because, as McArthur has noted:

If there are more males of marriageable age in a population than there are females, it is likely that more of the females will marry at younger ages than would be the case if numbers of eligible males and females were equal. If girls marry younger, then it is likely that more of them will start reproducing earlier. 4

(3) From the early 1850s, both in New Zealand and the Pacific, English and French writers had put forward the view that, in Fox's words, there was a 'depression of spirits and energy which,... ensues upon his [the native's] contact with civilized men. ${ }^{5}$

With the development of psychology in the early twentieth century this view was formalised. Psychological causes were attributed to population decline, and, most

\section{4}

p.394. McArthur, Dr N. (1961): Pop. and Social Change: Prospect for Polynesia', J.P.S., vol.70, no.4, Dec. pp.393400 .

5

PP.49-60 Fox, William (1851): The Six Colonies of N.Z., London. cf. p.685 Leborgne, Dr. (1872): 'Sur La Depopulation des Iles Gambier,' Bul1. de 1 a Societe d'Anthropologie de Paris, 18 th July. p p.682-87; and, C1avel (1884): ILa Depopulation aux Iles Marquises', Bull. de la Societe d' Anthrop. de Paris, 16 th June. pp.490-500. 
importantly, to the 'low' fertility of Pacific peoples. It was stressed that social disorganisation following contact caused the Maoris, and others, to lose the desire to 1 ive. This led to a 'loss of reproductive urges', which, in turn, allowed mortality to take a greater toll than in a population whose 'orientation was to increase'. There was seldom any indication of the means by which these populations achieved the necessary family limitation, or, in lieu of family limitation, the processes by which 'depression' or 'insouciance of the native mind' could affect fertility. However, one observer claimed that 'Native' women could will themselves to prevent pregnancies, although indulging in a normal sexual 1 ife and not practicing contraception. Thus, upon contact with an alien and 'superior' culture Maoris and otherscommitted 'racial suicide' until some event, or else intermarriage, reversed the trend. 6

It is possible that psychological factors may affect the fertility of individuals. However, it is naive to assume that what is true for individuals may hold true for the group. It is difficult to accept any of these three viewpoints as serious contributions to the study of population. More importantly, there was no attempt to test the basic assumption that fertility was low. Yet, a remarkable feature has been the persistance of the psychological viewpoint. For example, as recently as 1959 Firth accepted that to the 'mental attitudel of the Maoris could 'be largely attributed their 1 ack of prosperity and decrease in numbers [in the nineteenth century]: 7

See Pitt-Rivers (1927); Chapt.III. Roberts, S.H. (1927): Pop. Problems of the Pacific, London. These books were inspired by Rivers, W.H.R. (1922): The Psychological Factor', in Rivers, W.H.R.(ed): Essays on the Depop. of Melanesia, Cambridge. gP. 84-113.

p.456. Firth, Raymond (1959): The Economics of the N.Z. Maori, We11ington. 
For the remainder of this chapter the concern will be with two questions:

(1) What were the factors affecting levels of fertility?

(2) What were the likely levels of fertility?

\section{Factors affecting the level of Maori Fertility in the} Period 1769-1840.

During the early period of contact fertility does not appear to have been considered directly by eye-witness observers. However, when some subsequent writers have noted aspects of fertility, it is implied that these factors extended back beyond 1840 .

In accounts written prior to 1840 and up until the $1860 \mathrm{~s}$ there is some discussion of factors which, so the writers considered, impeded population growth in the period 1769-1840. Among these are a number which, had they been significant, may have affected replacement. These were the spread of venereal diseases, infanticide and induced abortion, all of which were discussed in Chapter Four; and, polygamy, the 'degraded status of the women', 'drudgery imposed on the females' prostitution, and sexual intercourse at young ages. The venereal diseases and induced abortion could have affected fertility levels by causing foetal mortality and by reducing conception rates (venereal diseases only). In Chapter 4 (Section 4) it was shown that venereal diseases became widespread in this period, but that induced abortions (section 5) were probably of marginal significance. Polygamy may also have had some effect. It could be postulated the wives in polygamous households may have been less exposed to the risk of pregnancy than if they had been wives in monogamous unions. However, polygamy appears to have been restricted mainly to chiefs and generally occurred for three reasons: (1) When a first wife was barren, the husband would sometimes 
remarry, often at his first wife's insistence. Thus desire for children was a motive of some importance. (2) A man might 'marry for love after a first marriage de convenance.' (3) But, the main function of polygamy was economic and political, for the combined economic advantage of having several wives [to work in the fields, etc.] gave a chief the comparative wealth that was essential to the maintenance of his position. 8 In the 1830 s and 1840 s polygamy probably declined under the influence of missionaries. Throughout the period it probably had little effect on fertility, and certainly would have been of virtually no significance after about 1840 .

Prostitution could have had two indirect effects upon fertility. Firstly, women engaged in this occupation may have been unwilling to bear or to raise children, and thus may have resorted more frequently to infanticide and induced abortion. Secondly, prostitutes would have had the greatest chance of being infected by venereal diseases, and must also have been agents in their spread.

There was no cause for prostitution to exist among Maoris until European contact, for pre-marital intercourse was more or less an accepted mode of behaviour in all groups except those of highest status. Even after contact it is doubtful whether women made it a full-time calling, even in coastal locations. The so-called 'prostitutes' probably included both women interested in material rewards, and women who were merely promiscuous on some occasions, but who sought no rewards.

The 'drudgery of the females' may have had the effect of exposing some of the women to the risk of aborting

8 pp.57-59. Biggs, Bruce (1960): Maori Marriage, Wellington 
spontaneously, Furthermore, it may have increased the risks of maternal mortality and of deaths among women 15 to 49 . Indirectly, both fertility and the birthrate may have been lowered, but it is doubtful if this particular factor was as important as disease and 1 ack of adequate obstetrical care. When an adolescent female conceives there is a greater likelihood of foetal, neonatal or maternal mortality than at most subsequent ages. In turn, injury to the mother may impair her health and reduce the number of live-births she might have in the future. Finally, if abortion (induced or spontaneous), or still-birth occurs during a first pregnancy, there is more likelihood of abortion or still-birth occurring during subsequent pregnancies than if the first pregnancy terminates with the delivery of a live-birth. Consequently, conception at young ages may indirectly have caused a reduction in fertility. However, there is frequently a period of sterility between puberty and about 19 or 20 years of age, and thus many women engaging in early sexual intercourse may not have conceived. 9

Infanticide, were it widespread, would affect replacement, but not fertility. It was argued in chapter 4, Section 5 that this practice was not as ubiquitous as early observers claimed.

With the exception of venereal diseases and, possibly, induced abortion and infanticide, few of these factors discussed above would have been of more than marginal importance as causes of 'low' levels of fertility or repladement in the period 1769-1840. No further comment can be made about this period as there are no data. However, some of the factors affecting subsequent levels of fertility,

9 passim. Montagu, M.F. Ashley (1946) Adolescent Sterility, Springfield, I11.; and, Sutherland, I an (1949): Still-births, Their Epidemiology and Social Significance, London. 
to be discussed in Section 3 , probably influenced trends prior to 1840 , and thus the levels of fertility in the years of early contact may have approximated those about 1840-60.

3. Factors affecting the levels of Maori Fertility, 1840-1921

The concern of this section is to consider a variety of factors which might affect fertility. The significance of these factors is gauged by reference to any available evidence.

\section{Factors favouring High Levels}

Probably, contraception by 'modern' or 'traditional' methods was not practiced. If any methods had been used they would have included coitus interruptus and, taboos against intercourse during lactation. Maoris understood the relationship between sexual intercourse and conception, which is proved, so Te Rangihiora claims, by the fact that Maoris could practice coitus interruptus. But, Biggs was certain that this method was not used by Maoris until the $1920 \mathrm{~s} .10$ Even if Te Rangihiroa were correct he makes no suggestion that Maoris used coitus interruptus at all frequently, but merely offers the assertion that it was practiced as proof of the Maoris' knowledge of the physiology of sex.

Almost all women participated in conjugal unions at some time during their reproductive period. Probably, the majority were exposed to the risk of conception at a very early age. Generally, early exposure, say from 17 to 19 years, gives rise to a higher completed fertility than later exposure, but it also has some disadvantages (section 2). Early marriage was accompanied by early pregnancy; in fact, pregnancy was often the reason for marriage. Although the arranged marriage was the culturally approved avenue to matrimony...' pregnancy

10 pp.363-64. Te Rangihiroa (1952): The Coming of the Maori, Welington; and, Biggs (1960): p.21. 
could precipitate marriage, and may also have been one means of forcing of consent when families disapproved of an affair. ${ }^{11}$

The dissolving of a marriage by the death of a spouse probably had a minimal effect. Traditionally, 'remarriage was expected of widows, and in the case of a widower he had some claim upon his wife's family to supply him with another mate 12

\section{Factors not favouring High Levels}

Fertility may have been reduced by a number of factors, to be discussed below. In turn, the lowering of fertility may have affected the birthrate. But, the birthrate also could have been influenced by changes in the age/sex structure of the population; notably by increases and decreases in the proportion of the total who were females exposed to the risk of child-bearing, and particularly those aged 20-34 years. If cohorts at these ages are reduced because of such causes as differential cohort mortality, there will be a reduction in the birthrate. Thus, while factors such as the use of contraception and foetal mortality directly affect levels of fertility and the birthrate, other factors may have no noticeable effect on fertility, but may still reduce the birthrate. Finally, high replacement levels are not guaranteed just because fertility and the birthrate are high. Infant and childhood mortality may reduce the size of birth cohorts. In this section factors affecting fertility per se will be discussed; then situations in which the birthrate, but not fertility, may have been reduced, will be considered. This then leads to an analysis of factors affecting replacement.

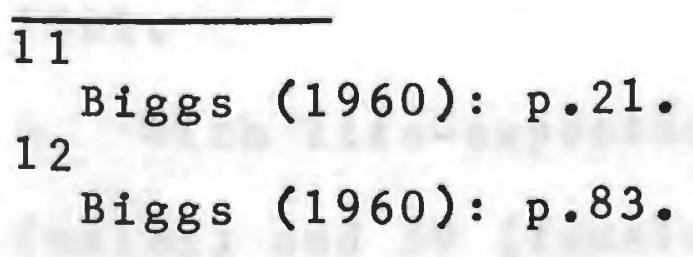


It is probable that venereal diseases were widespread at least until the early 1900 s and therefore gonorrhoea may have reduced conception rates (see Chapter 4, section 3, Venereal Diseases). But a more important factor affecting fertility is the level of spontaneous and induced foetal mortality, which numbers syphilis among its causes (Chapter 4, section 5, Foetal mortality).

As already suggested, spontaneous foetal mortality may have accounted for the 1 oss of between $25 \%$ and $45 \%$ of all conceptions. The percentage of conceptions resulting in induced abortions cannot be estimated, but it is probable that the induced foetal mortality was an infrequent phenomenon (then and today), possibly occurring in the case of $5 \%$ of pregnancies. This means that total foetal mortality may have been at the 1 evel of $30 \%$ to $50 \%$ of a 11 conceptions.

What effect would such levels of foetal loss have had on fertility and the birthrate? This can be estimated for 1901.

To make such an estimate it is necessary to estimate possible conception rates. This can be done for 1956, for which year a General Fertility Rate (G.F.R.) can be calculated. The 1956 G.F.R. was 202 (G.F.R. $=\frac{B}{F 15-49} \times \frac{1,000}{1}$ ). To facilitate the following calculations the G.F.R. (1956) was taken as 200 .

The following facts are known about 1956:

1. The data are relatively reliable.

2. The percentage $\frac{F 15-49}{m+f}$ was almost the same as in 1901. 3. Fertility was unrestricted socially; the enforcement of pre-marital chastity, and the practice of contraception and induced abortion was probably as infrequent in 1956 as in 1901.

4. With life-expectation at birth at the level of 57 years (males) and 59 (females) the 'health status' of the Maoris 
in 1956 was far better than in 1901, and probably approached that of Kauai, Hawail.

5. Levels of spontaneous foetal loss would probably have been in the range suggested by sheps for populations with a 'good health status.' Therefore, allowing for extremes and for a level of induced $10 s$ of 5 per cent, total foetal mortality in 1956 might have ranged from an extreme minimum of 25 per cent to an extreme maximum of 40 per cent of all conceptions.

Four conception rates in 1956 were then calculated by assuming 1 evels of total foetal mortality of $25,30,35$ and 40 per cent. These rates were calculated in the following manner:

Conception rate per 1,000 women $15-49=$ G.F.R. $\mathbf{x}$ $\left(\frac{100}{100 \text {-foetal 1oss }}\right)$. The four levels of foetal 1 oss gave conception rates of $267,286,308$ and 333 per 1,000 . According to the hypotheses outlined above, these conception rates represent the maximum limits of fecundity among Maoris in conditions of unrestricted fertility.

It was then assumed that the estimated conception rates for 1956 applied to 1901. Unfortunately, no estimate can be made of the possible effects of gonorrhoea which was probably more frequent in 1901 than in 1956. As gonorrhoea 1 imits conceptions, 1956 rates might have been higher than those of 1901 .

For 1901 it was assumed that total foetal mortality exceeded the level of 1956. Thus, G.F.R.s were calculated on the basis that $30,35,40,45$ and 50 per cent of possible conceptions resulted in foetal loss. The estimated G.F.R.s are presented in Table 5.1 .

By multiplying these estimated G.F.Rs by the number of women aged 15-49 in 1901 an estimated number of births was obtained. The possible crude birth rates for various 
Table 5.1: Estimated General Fertility and Crude Birth Rates in 1901, Assuming Various Conception and Foetal Mortality Rates.

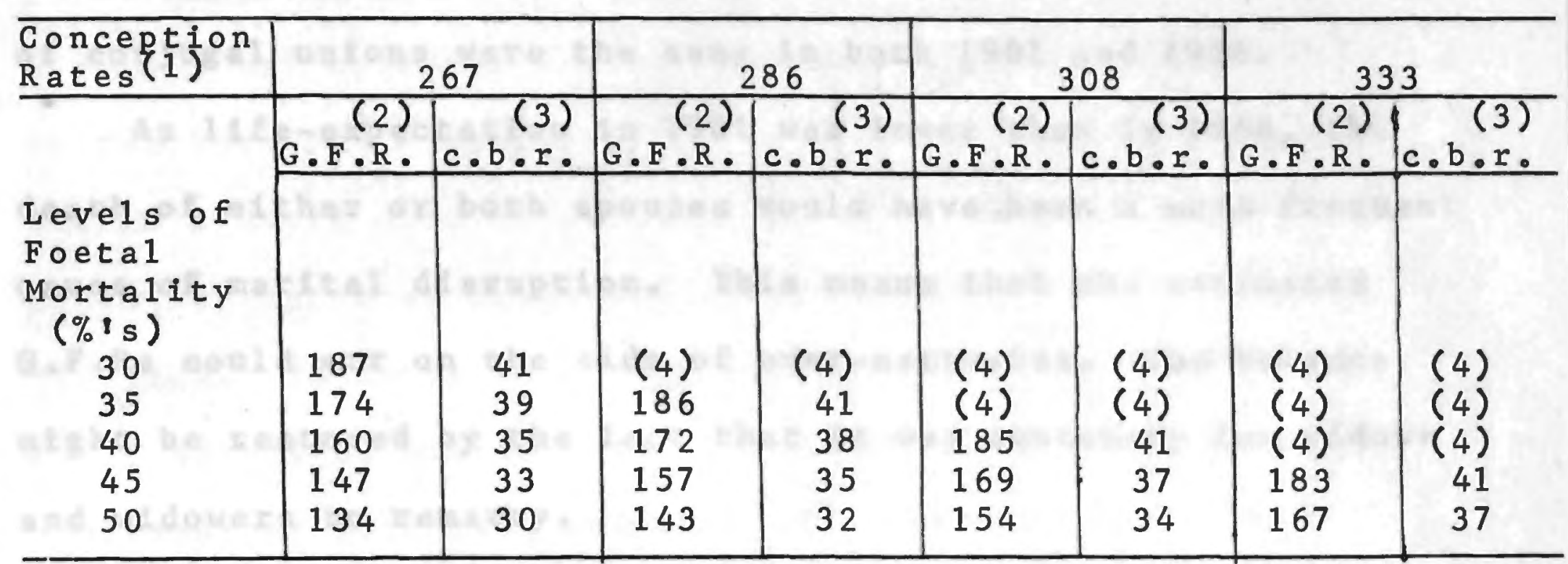

$$
\begin{aligned}
& \text { Notes: (1) Conception Rate }=\frac{\text { Gonceptions }}{\text { Females } 15-49} \times \frac{1,000}{1} \\
& \text { (2) G.F.R. } \\
& =\frac{\mathrm{B}}{\mathrm{f} 15-49} \times \frac{1,000}{1} \\
& \text { (3) } c \cdot b \cdot r \text {. } \\
& =\frac{\text { B }}{\text { Tota1 Population, } 1901} \times \frac{1,000}{1} \\
& \text { (4) The G.F.Rs and c.b.r's are equal to, or are }
\end{aligned}
$$

combinations of conception and foetal mortality rates can then be calculated on the basis: $\frac{\text { Estimated births }}{1901 \text { Population }}$. The results of these calculations are also presented in Table 5.1. The estimated crude birth rates range from 30-41 per 1,000 of the population in 1901 .

There is no method by which the validity of these estimates may be gauged. However, judging from the study of Kauai (Chapter 4, Section 5) it is probable that foetal mortality in 1956 was about the 30 or 35 per cent level. For 1901,35 to 45 per cent seems a reasonable estimate of foetal loss, with the sole proviso that foetal mortality would have been higher than in 1956. Under these conditions, a crude birthrate of between 35 and 41 per 1,000 might be expected for this time. 
The use of the G.F.R. in these calculations has permitted the births to be applied to the population at risk. However, this method assumes that patterns of survival and stability of conjugal unions were the same in both 1901 and 1956.

As 1 ife-expectation in 1901 was lower than in 1956, the death of either or both spouses would have been a more frequent cause of marital disruption. This means that the estimated G.F.Rs could err on the side of over-estimates. The balance might be restored by the fact that it was customary for widows and widowers to remarry.

Disruptions resulting from the instability of conjugal unions could also affect fertility levels, particularly if there were long durations between unions. There is no evidence to suggest that marriages and unions were any less stable in 1901 than in 1956; in fact, on a priori grounds it could be argued that unions were more stable in 1901 because most of the Maoris 1ived in small, rural, tight1y-knit communities, and thus their actions were subject to community approval and disapprova1. By contrast, there was a considerable degree of geographical mobility in 1956, particularly among persons aged 15-29, and thus unions may have been more exposed to the risk of temporary or permanent separation.

Nevertheless, in the period until 1921, the instability of unions was probably of considerable importance, for a number of writers noted the 'irregular marital habits' of the Maoris. However, Fenton implied that this had no effect on fertility for the most commonly actuating motive for the dissolution of marriages or unions is the failure of issue. The desire of children is great among Maori women?.13

\section{3}

p.519. Fenton, F.D. (1860): lobservations on the state of the Aboriginal Maori Inhabitants of N.Z.', J.S.S.L., vol.23. 
Perhaps the birthrates given above do err slightly on

the side of being over-estimates because of the two patterns of dissolution which have been noted. By contrast, early marriage may have acted as a counterbalance to this effect. At the turn of the century, it is probable that women married within a short time of reaching puberty, whereas today migration to urban areas and other factors tend to delay marriage. There is no direct evidence for this assertion, but a survey by McCreary has shown that a contrast exists in contemporary patterns, and this difference may have some bearing on the question. In the remote rural community of Ruatahuna over half of the women aged 15-19 were married, as against 14 per cent for the Maori population as a whole in 1956. 14 Probably, Ruatahuna is one of the few contemporary Maori communities to retain the isolation and style of living which must have characterised a large proportion of the Maori population about 1900.

In summary, it has been shown that foetal mortality may have reduced fertility and that in 1901 the resulting birth rates could have been of the order of 35-41 per 1,000. Although differential patterns of marital dissolution may bias these estimates the effect is probably minimal and may be counterbalanced by differences in age at marriage.

At various periods during the nineteenth century the size of some birth cohorts was depleted either because of ageselective mortality affecting the cohort at some period in its life, or because their parents, in turn, belonged to cohorts which had been diminished or which had achieved lower than normal levels of fertility. In view of the lack of adequate data, it is impossible to make any but the most speculative

\footnotetext{
14 p.4. McCreary, J.R. (1961): 'Ruatahuna: A Maori Community', N.Z. Geog. Soc. Record, no.32, July-Dec. pp.3-4.
} 
assessments of this factor. For example, it could be argued that the birth rate of the period 1840-60 may have been reduced by the fact that women at reproductive ages belonged to birth-cohorts which had been smaller than normal, or which were depleted during the wars and epidemics of the period $1810-30$

Finally, it can be argued that replacement was greatly reduced during this period because of high infant and childhood mortality rates. Obviously this would have been significant in the period 1840-1921.

In general, such social factors as age at marriage tended to favour high fertility, but offsetting these were high levels of general morbidity and of foetal mortality. For all of the period the birth rate should have been below that of today (about 45 per 1,000), but not at extremely 1 ow 1 evels. It is now necessary to study the available data to check the validity of this assertion.

\section{Levels of Fertility}

$$
\text { Direct evidence on levels of fertility is extremely }
$$

limited. The most systematic data are found in the censuses from 1886 onwards, and from these data child/woman ratios can be calculated.

Prior to 1886 , crude birth rates can be calculated for three regions:

(1) Fenton estimated that the population aged 0-14 in the Waikato in 1858 consisted of the survivors of 50 per cent of the births of the period 1845-58. This assumption was based on criteria which have been noted already (Chapter 4, Section 7 , Note 5).

Fenton concludes that the irelative annual number of births' among the Maoris in the period 1845-58 was 'one in 33.56'. On this basis and with the Maori population as 
enumerated in his census as the denominator, the crude birth rate for the population would have been 29.8 per $1,000 .^{15}$

(2) In 1874, in the South Island Provinces of Otago, Marlborough and Nelson the birthrate per 1,000 was 32.4 .

(3) In 1878-79, the crude birthrate in northern North Auckland was at the level of $35.2 .^{16}$

Fenton's data refer to a 14 year period in which morbidity and epidemic mortality was extremely high, while the cohorts exposed to the risk of pregnancy may have been abnormally depleted. Thus, it is possible that his rate represents the minimum level reached in the period 1769-1921, except in extremely abnormal years. It is interesting that the three rates presented above suggest that there was an increase in the crude birthrate between 1858 and 1879 .

\section{Child - Woman Ratios, 1886-1921}

The most systematic series of rates from which inferences may be drawn about changes in fertility and replacement are the child-woman ratios which can be calculated from age/sex data collected at each census, except that of 1911, in the period 1886-1921. The major problem is that it is difficult to separate the effects of changes in fertility from the effects of changes in the levels of infant and childhood mortality, and in standards of census enumeration and agereporting.

An attempt was made to overcome the problem of agereporting inaccuracies by the following procedure:

15

Fenton (1860). For discussion of Fenton's data, see Chapter 4, Section 7 , Note (5). 16

A detailed discussion of the data on which these two rates are based is given in Chapter 4, Section 7 , Note (5). 
(1) At most censuses data were published for each county, showing the numbers whose ages were 'not specified', or 'partly not specified' (i.e. reported as being above or below 15 years, but no further details given). Moreover, inspection of the raw data often revealed irregularities, which could not be accepted as the consequences of normal patterns of population growth. For example, in some regions there would be some hundreds of children 0-4, but either no women 15-49, or perhaps 5 or 10 at each age-group. Even allowing for migration, this seemed peculiar. Thus, the data relating to certain regions (made up of groups of adjacent counties) were suspect.

Moreover, until 1901 a similar range of data was published on tribes by county. These data on tribes were also inspected.

The data for some regions were subtracted from the National totals. These were for those regions which data on tribes and counties apparently were deficient, or which contained marked irregularities.

(2) To provide a check on this qualitative assessment another set of child-woman ratios was calculated. The assumption was made that there were no regional differences in the accuracy of age-reporting. Thus, for New Zealand as a whole ages 'not specified' and 'partly not specified' were distributed pro rata, and child-woman ratios were calculated from these adjusted data.

Except for 1916 the two sets of ratios are relatively close. The 1916 result is not unexpected for it was stated above (Chapter 3, Section 4) that under-enumeration was marked for certain regions, and that in 1911 and 1916 there was heaping at ages 40-49. Unfortunately, the publication of unspecified ages was restricted to the total 
'not specified' (i.e. there was no breakdown into 0-14, 15-44, 45+). A pro rata redistribution of these categories would, of course, not reduce the heaping.

In 1911, there were only 37 males and 20 females

reported as having ages 'not specified'. No persons were

reported as being of 'partly not specified ages'. The

regional data were not sufficiently irregular to suggest

that any region should be subtracted from the National

figure. Consequently, only one ratio was calculated for

this year.

Child-woman ratios are presented in Table 5.2. In general, the early ratios are lower than the more recent. Infant mortality and age-reporting inaccuracies, particularly the under-enumeration of children aged 0-4, were probably more severe in the early period.

The low ratio in 1886 may result from the fact that age-reporting was markedly inaccurate at this census, by comparison with the censuses of the period 1891-1901. The lower ratio in 1896 probably was caused by the influenza epidemics of the early 1890s, during which mortality was age-selective. That is,

1. At ages $0-4$ death rates were high.

2. At ages 15-44 death rates were 1 ower.

Consequently, there was a lower number of young children in 1896 than if there had been no epidemic, but not a correspondingly lower number of women. The net result is that the 1896 ratios are lower than if normal conditions had prevailed.

There was an increase in the ratios between 1896 and 1911. In 1916, a number of regions had to be excluded from the calculations because of known refusals to permit enumeration, particularly of males and females aged 15-49. 
Table 5.2 : Child-Woman Ratios,

\begin{tabular}{c|c|c}
\hline Census of: & \multicolumn{2}{|c}{ child-woman ratios: } \\
& $(2)^{(3)}$ \\
\hline 1886 & 491 & 478 \\
1891 & 531 & 523 \\
1896 & 462 & 480 \\
1901 & 572 & 567 \\
1906 & (nodata) & $($ no data) \\
1911 & $615(4)$ & $615(4)$ \\
1916 & 740 & 675 \\
1921 & 590 & 595 \\
\hline
\end{tabular}

Notes: (1) $\frac{\text { Children aged } 0-4}{\text { Females aged } 15-49} \times \frac{1,000}{1}$

(2) Poorly enumerated regions are excluded from the National totals.

(3) Data from all regions are included, but ages not specified have been distributed pro rata.

(4) In 1911, no data were published on ages not specified (etc) either for counties or for New Zealand as a whole.

Table 5.3 : Expected Child-Woman Ratios, 1901.

Ratios calculated from the following levels of crude birth rates and 1 ife-expectation:

\begin{tabular}{|c|c|c|c|c|c|c|c|c|}
\hline $\begin{array}{c}\text { Crude Birth } \\
\text { per } \\
1,000\end{array}$ & $\begin{array}{r}\text { Leve } 1 \\
22.5\end{array}$ & $\begin{array}{l}\text { of } 1 \\
25.0\end{array}$ & $\begin{array}{l}\text { if e-e } \\
\text { (U.N. } \\
27.5\end{array}$ & $\begin{array}{l}\text { xpect } \\
\text { Mode } \\
30.0\end{array}$ & $\begin{array}{l}\text { ation } \\
1 \text { Lif } \\
32.5\end{array}$ & $\begin{array}{r}\text { at b } \\
e-T a b \\
35.0\end{array}$ & $\begin{array}{l}\text { les ) } \\
37.5\end{array}$ & $\begin{array}{l}\text { in yea } \\
40.0\end{array}$ \\
\hline 25 & 364 & 379 & 392 & 404 & 415 & 425 & 435 & 445 \\
\hline 30 & 436 & 454 & 470 & 484 & 497 & 510 & 522 & 533 \\
\hline 35 & 524 & 457 & 563 & 582 & 600 & 614 & 628 & 641 \\
\hline 40 & 578 & 607 & 628 & 647 & 666 & 680 & 699 & 711 \\
\hline 45 & 657 & 683 & 704 & 729 & 747 & 766 & 784 & 798 \\
\hline 50 & 730 & 761 & 786 & 811 & 832 & 851 & 874 & 891 \\
\hline
\end{tabular}

This ratio is higher than the ratio calculated from data adjusted for not specified ages, and both ratios are higher than those of 1911 and 1921 .

In 1918 the excessive mortality during the influenza pandemic dissolved many marriages and thus reduced fertility in subsequent years. In addition there was the 
direct, but lower mortality of infants. These two factors readily account for the lower ratio in 1921.

These ratios show a steady improvement over recent years. Without vital data it is virtually impossible to determine accurately whether this change resulted from an increased birthrate, declining levels of infant and early child mortality, or improving standards of census enumeration. The relevance of this comment may be illustrated by reference to the more recent decade of 1945-56. During this decade infant mortality declined, while the birthrate remained stationary. Because of the declines in infant mortality, the child-woman ratio increased from 747-861. From the above remarks it is apparent that these child-woman ratios do not measure fertility alone, but that they are also affected by infant and early childhood mortality and census under-enumeration. The effects of various levels of birth rates and mortality can be inferred by comparing 'expected' child-woman ratios with these calculated from census data. This is done here for 1901.

Births were estimated for the period 1896-1901.17 Survival ratios calculated from U.N. model life-tables were employed to survive these estimated births to ages $0-4$. 'Expected' child-woman ratios could then be calculated by taking the estimated survivors aged $0-4$ as the numerator and the enumerated females aged 15-49 (1901 census) as the denominator.

17

Under normal circumstances these would have been calculated as follows:

$$
\left.B=5 \times \text { (c.b.r. } X \frac{P_{1896}+P_{1901}}{2}\right) \text {. }
$$

However, only 1901 was used because of the peculiar effects of the influenza epidemics of the early $1890 \mathrm{~s}$, plus the under-enumeration in certain regions in 1896. 
A wide variety of combinations of birthrates and mortality levels were experimented with, from a birthrate of 25 per 1,000 to one of 50; from a life expectation of 22. 5 years at birth to 40 years. These 'expected r ratios were then compared to that at the 1901 census which was 567 .

The 'expected' ratios are presented in Table 5.3. Those closest to 567 had been calculated from birthrates of 30,35 and 40 per 1,000 . As was noted above, birthrates as high as this were recorded for earlier periods, while rates of 35-40 were shown to result when various levels of foetal mortality were applied to assumed conception rates.

The U.N. model life-tables are based on the assumption that there is a direct relationship between levels of infant and general mortality. The levels of infant mortality associated with the levels of life-expectation used here approximate the 1 imits suggested for the 1870 s in Chapter Four, Section 7, Note 10 ; i.e. from 186-298 (rates of 200300 were postulated for the $1870 \mathrm{~s}$ ). However, by the end of the century, lower levels could be expected - from 186-245. These rates are associated with levels of 1 ife-expectation at birth ranging from 30-40 years. Thus, it appears that the 'expected' ratios derived from levels of life-expectation below 30 years are not directly comparable with the 1901 ratio. So far no allowance has been made for the accuracy of the 1901 data from which the ratio of 567 was calculated. Yet, in chapter III, Section 4, it was shown that the reporting of ages $0-4$ in 1901 was most unsatisfactory. 5,399 persons aged $0-4$ were enumerated in 1901 , but in 1911 this cohort had grown by 569 persons and numbered 5,968. If it is assumed that the enumeration in 1911 was correct, which is unlikely, the difference of 569 implies a level of underenumeration in excess of 10 per cent in 1901 , and if some 
account could be taken of intercensal mortality the level might even have been as high as 15 per cent. There may also have been under-enumeration at ages 15-49 in 1901, but, as the study of decennial age-groups revealed, it is likely that under-enumeration at ages $0-4$ was considerably in excess of that at ages 10-19, and may have been greater than at ages 20-49. If this excess is assumed to be 10 per cent $^{18}$ the 1901 child-woman ratio increases to 624 which compares favourably with 'expected' rates calculated from birth rates of 35-40 per 1,000 and from levels of 1 ifeexpectation at $30-40$ years.

The allowance made here for under-enumeration is not unreasonable. This is evidenced by the fact that high child-woman ratios were recorded for those regions which had a long history or relatively reliable enumeration stretching back to Fenton's census. They were: Northern North Auckland (753); Southern North Auckland (631); Manawatu-Horowhenua (641); and the South Island (720). The mean of these four regional child-woman ratios is 686 . This mean ratio is closest to the 'expected' ratio associated with 1 evels of 1 ife-expectation of 35.0 to 37.5 years and a birthrate of 40 .

The exact levels of birthrates, life-expectation and under-enumeration will never be known. However, the estimates made here support several conclusions:

1. In part, child-woman ratios at the turn of the century were lowbecause of the inaccuracy of the basic data.

2. The birth rate was about the 1 evel of $35-40$ per 1,000 . This is feasible, for it is reasonable to expect that the

\section{8}

This assumes that there was under-enumeration at ages 10-14 (1911), which was as high, proportionately, as that at ages 15-49 (1901). 
rate in 1901 would have been in excess of the rate of 35 per 1,000 notes above for Mongonui in the 1 ate 1870 s. Therefore, low child-woman ratios were not related to extremely low birthrates.

3. Life-expectation was between 32.5 and 40 years at birth. A higher rather than a lower value is suggested. This is because higher life-expectation values are associated with infant mortality rates in the range of 186-229 per 1,000 1ive-births. This would be a reasonable 1 evel to expect, by comparison with postulated rates somewhere in the range of 200-300 earlier in the nineteenth century. Nevertheless, at the turn of the century, low child-woman ratios were still related to high levels of infant mortality.

\section{Conclusion}

This study of fertility has been very brief for empirical evidence on the subject is fragmentary. From the study of factors which may have affected fertility, and from a short analysis of crude birth rates and child-woman ratios, the following conclusions may be made:

(1) Conception rates may have been restricted because of the effect of gonorrhoea. This factor would have varied in significance from decade to decade.

(2) Fertility may have been restricted by such causes as foetal mortality, but not because of social factors.

(3) The birth rate was affected both by changes in fertility and in the age/sex structure.

(4) These two factors brought about a birth rate perhaps as 10 as 30 per 1,000 at mid-century, but there was a gradual improvement to $35-40$ by 1901 . However, even a 
birth rate of 30 per 1,000 is not exceedingly $10 \mathrm{w}$; in fact it exceeds that for the non-Maori population at every year since 1890 .

Between 1873 and 1889 non-Maori birth rates had reached as high as 41.7 per 1,000 . It is true that the non-Maori sex-ratio in the 1870 s and 1880 s was weighted towards males because it was an immigrant population, but it was also 'young', it had a relatively 'good health status' and fertility was relatively unrestricted. Thus, the Maori birth rate in the nineteenth century was $3 / 4$ to $7 / 8$ of the 1 evel of the non-Maori during the period 187389 and the Maori rate was higher in subsequent years. Yet, the non-Maori birth rate was favourably affected by a variety of factors and at its peak reached levels which are approximately $4 / 5$ of the 1 evels reached by some present-day high fertility populations (i.e. about 50 per $1,000)$

In the twentieth century, the birth rates of some populations, including the non-Maori, have reached genuinely low levels (i.e. below 20 per 1,000 ). With such evidence before them recent writers might have been expected to be rather critical of the comments of their predecessors on the levels of Maori birth rates prior to 1922. Instead, some of these recent commentators have assumed that psychological factors restricted fertility to the same degree as contraception, induced abortion and late marriage do among other populations. To pursue this argument they had to accept the assertion of earlier writers that the birth rate was low.

It has been shown here that this basic assumption of early writers was not entirely correct. The rate was lower in the period of 1840-90 than 1ater, but not extremely low (i.e. not as 10 w as 15 per 1,000). 
(5) Replacement was at low levels, even after the birth rate had increased to a 1 evel of $35-40$ per 1,000 .

(6) The fragmentary data presented here suggest that the birth rate increased gradually and that replacement also increased. Prior to 1886 replacement may have been at lower levels than for the period covered by child-woman ratios. Both of these assertions can be supported very tentatively by some data on adults and minors collected at various dates between 1840 and 1921. From these data the following ratio can be calculated: $\frac{\text { males }+ \text { females aged } 0-14^{19}}{\text { females } 15+}$

These ratios are presented in Table 5.4. Like all other types of child-woman ratios, this measure is affected by under-enumeration. However, these ratios support a conclusion that declines in childhood mortality and increases in fertility occurred over a very long period. Table $5.4: \frac{\text { Children aged } 0-14 \text { per } 1,000 \text { females aged } 15+}{\text { years.(I) }}$

\begin{tabular}{|c|c|c|c|}
\hline Year & Ratio & Region & Primary Sources \\
\hline 1843 & 616 & $\begin{array}{l}\text { Horowhenua, Manawatu, } \\
\text { Wanganui, Taranaki }\end{array}$ & Mission 'censuses (2) \\
\hline 1847 & 714 & Wellington-Hutt & $\begin{array}{l}\text { Taken from official } \\
\text { records ( } 2 \text { ) }\end{array}$ \\
\hline 1850 & $\begin{array}{l}667 \\
(4)\end{array}$ & $\begin{array}{l}\text { Wellington, Horowhenua, } \\
\text { Manawatu, Rangitikei } \\
\text { Wairarapa }\end{array}$ & Ditto $(3)$ \\
\hline 1851 & $\begin{array}{l}580 \\
(5) \\
718\end{array}$ & Bay of Islands & $\begin{array}{l}\text { Return submitted by } \\
\text { Government official }\end{array}$ \\
\hline 1858 & 989 & $\begin{array}{l}\text { Northland, Waikato } \\
\text { Coromandel (no data on } \\
\text { remainder of Auckland } \\
\text { Province) }\end{array}$ & Fenton's Census \\
\hline 1858 & 691 & Taranaki & Ditto \\
\hline $\begin{array}{l}1858 \\
1858\end{array}$ & $\begin{array}{l}852 \\
646\end{array}$ & $\begin{array}{l}\text { Wellington Province } \\
\text { (Includes Hawkes Bay) } \\
\text { South Island }\end{array}$ & $\begin{array}{l}\text { Ditto } \\
\text { Ditto }\end{array}$ \\
\hline 0 & $s$ & $\frac{\text { Children }}{\text { female adults }}$, or $\frac{m+f}{f l}$ & $0-13$ \\
\hline
\end{tabular}




\begin{tabular}{l|c|c|c}
\hline Year & Ratio & Region & Primary Sources \\
\hline Table & 5.4. Contd. & A11 N.Z. & Census \\
1874 & 1,158 & & Ditto \\
1878 & & & Ditto \\
1881 & & Ditto & Ditto \\
1886 & 1,079 & Ditto & Ditto \\
1891 & 1,180 & Ditto & Ditto \\
1896 & 1,252 & Ditto & Ditto \\
1901 & 1,291 & Ditto & Ditto \\
1911 & 1,486 & Ditto & Ditto \\
1916 & 1,517 & Ditto & Ditto \\
1921 & 1,480 & & \\
\hline
\end{tabular}

Notes: (1) Sometimes $\frac{\text { non-adults }}{\text { female adults }}$ and $\frac{\text { children } 0-13}{\text { females } 14+}$

(2) Source: pp.449 and 451. anon. (1850): Polynesians \& $\mathrm{N}_{\text {.Z.' }}$ ', Edin. Rev., vo1.91. pp.443-71.

(3) Source: Vol.II., pp.334-35\&337. Thomson, A.S. (1859): The Story of N.Z., London

(4) $\frac{\text { Children }}{\text { Women }}$

(5) Children ever-married women

(6) Covers period of several years, but census completed in 1858 . 


\section{The Patterns of Growth of the Maori Population, 1769-1921}

\section{Introduction.}

From the 1830 s at least, and perhaps earlier, non-Maori writers agreed on at least one detail; i.e. that the Maori population was decreasing. Occasionally, an observer reported a temporary increase in some district, but it was not until the end of the century that authors began to note an increase in the Maori population in general. As recently as 1907 Walsh asserted that the increase in the period 1901-06 had probably been due to improved census methods, and so would prove to be temporary. But in 1891, Sir James Carrol1, the Maori M.P., had been somewhat more perceptive; I I am forced to the conclusion that it is a mistaken theory that the Native race will rapidly decrease'. In some districts 'a steady increase is perceptible' 1

Archdeacon Walsh was perhaps the last of a large number of eye-witnesses who reported specific or general causes for the decrease of the Mari population. If these writers were to be categorised, Walsh's account would exemplify the views of the humanitarian and sympathetic, but rather pessimistic group:

Doubly deimated by the guns of Hongi, of Te Rauparaha, and Waharoa; worn out with the agonising effort to secure a supply of weapons and amunition; their vitality sapped by the liquor traffic and the wholesale debauch of the mothers of the race; utterly wearied by ten year's war [against the government, 1860-72], and its disastrous consequences; discouraged by

$\overline{1}$

A.J.H.R. (1891): G-1, P.xxix, of Rees, Carrol1, McKay Commission ('Report of the Commission... into... Native Land Laws ${ }^{\text {) }}$. It is apparent that Carroll had not seen the 1891 census result which showed a slight increase over 1886. 
the injustice of the 1 and 1 aws; and disheartened by an ever-growing race prejudice, the Maoris of today are but a dying remnant of the once vigorous and populous tribes. 2

These 'humanitarians' felt that non-Maori contact was the crucial factor. The Rev. Colenso summarised their views: 'Cook found the New Zealanders healthy, happy, and contented in the midst of all their wars and poverty; are they so now? ${ }^{3}$

There were other settlers who were less altruistic, and who implied that Maoris stood in the way of organised development of the Colony. Few public figures advocated the extermination of Maoris, but a number probably subscribed to the view of Dr Featherston, Superintendent of Wellington Province, who stated in 1856, The Maoris are dying out and nothing can save them. Our plain duty as good compassionate colonists, is to smooth their dying pillow. Then history will have nothing to reproach us with's. But such an assertion was not without its critics. Thus, the Rev. Buller pointed out, IIt is a popular opinion that they are dying out. With many, I fear, the "wish is father of the thought",,$^{4}$

Another group of colonists believed that the decrease had commenced prior to non-Maori contact. Thus, the Rev. Wohlers, who referred to the 'grovelling animalism' of the Maoris, summarily stated: II can positively say that the coming of the Europeans has nothing to do with the dying

2

p.173. Walsh, Archdeacon (1907): 'The Passing of the Maori: An Inquiry into the Principal Causes of the Decay of the Race', T.N.Z.I., vo1.40, Pp.154-75. 3

The italics are Colenso's. p.419. Colenso, William (1868): The Maori Races (sic) of N.Z.', T.N.Z.I., vol.1., p p. 339-424.

4

Featherston quoted p.57. Bu1ler, Walter (1884). 'The Decrease of the Maori Race', N.Z. Journ. of Science, vol.2, pp.55-59; and, p.164. Buller, Rev. James (1878): Forty Years in N.Z..., London. 
out of the Maoris... The Maoris, as a race, had outlived

their time. 1 Dr A.K. Newman expressed a somewhat similar vi ewpoint:

I hope I have made it clear that the Maoris were

a disappearing race before we came here; that such a disappearance arises from an excessive mortality being largely due to the change from miserable, lofty, dry, well-aired villages, to that this change has caused an immense increase in the number of deaths from phthisis and other diseases of the chest, and rheumatism that this change has acted very severely upon the children; the other great cause being the large amount of absolute sterility and the small reproductive powers of the race. I believe that to these two things is due the rapid decrease of the race; a lessening in number hastened somewhat, though only in small degree, by imported European diseases, [he argues that syphilis is uncommon, 1 ues venerea universal but mild, and that

rheumatism and scrofula were indigenous]; and that the only one imported vice, viz. alcoholism, has in the least helped to hasten the disappearance of the race.

Taking all these things into consideration, the disappearance of the race is scarcely subject for much regret. They are dying out in a quick, easy way, and are being supplanted by a superior race.5

The reported causes for the decrease of the Maori population have been discussed above under the headings of mortality and fertility, but there was one other relevant general view which must be noted briefly. As early as 1850 , influenced apparently by Grey's advocacy of a policy of 'amalgamation' (probably Grey meant 'assimilation'), one writer quoted the missionary Lawry:

The preservation of any one of the families of the extensive Polynesian nation in their (sic) distinct and present form, seems to me unlikely... I am of the opinion... that the tide of emigration will, sooner or later, flow to their shores, and that a fine new race of civilized mixed people will cover this part of the earth... In many parts of New Zealand the natives are melting away; but

p.134. Wohlers, Rev. J.F.H. (1881): IOn the Conversion \& Civilization of the Maoris of the South Is. of N.Z.', T.N.Z.I., vo1.14. pp.123-34; and; pp.475-77, Newman, A.K. (1881): 'A Study of the Causes leading to the Extinction of the Maori,' T.N.Z.I., vol.14, pp.459-77. 
they are not 1 ost, they are merging into another and a better class. In this process there lacketh not sin; but Providence will overrule even this, and bring forth an order of things, which shall be better for the world, better for the Church, and better for the new race.16

In 1921, Te Rangihiroa took up this theme. He was certain that intermarriage was occurring at a rapid rate, and that the proportion of Maoris with non-Maori ancestry was far in excess of the percentages reported in the census. 7

Grey's policy of 'amalgamation' was never put into effect, and there were no government supported programmes of integration or assimilation (nor of segregation). Nevertheless, miscegenation and intermarriage were reported so frequently that they must have occurred. Moreover, there is no reason to suspect that Te Rangihiroa's genealogical evidence relating to 1919 and the early 1920 s is unreliable. If anything, it is possible that the degree of non-Maori 'blood' may have been understated either purposely or unconsciously. Only 50 per cent of the Maori soldiers and school children in his two samples were 'ful1' Maoris. Earlier writers often considered that, by this process, the Maoris would disappear both as a racially and a culturally distinct minority. By contrast, Te Rangihiroa could show that, although they were no longer biologically 'pure', the Maoris were an independent, viable, cultural minority.

It is impossible to prove empirically that some partMaoris moved away from the Maori population, and that they were almost (but not completely) assimilated by the nonMaori population. Observation suggests that this phenomenon

\section{$\overline{6}$}

p.471. Anon. (1850): 'Polynesians and N.Z.', Edin. Rev•, vo1.91. p p.443-71.

Te Rangihiroa (1924): 'The Passing of the Maori,' T.N.Z.I. vol.55, pp.362-75. See Chapter 2, Section 4 which presents Te Rangihiroa's data. 
did occur. Moreover, such an observation is possible only because the assimilation by choice, was not complete in every case. For example, there is often some contact between the Maori and the non-Maori descendants of early intermarriages.

In general, it is probable that the majority of the offspring of these early intermarriages remained within the Maori population. Because of the high masculinity ratio of the immigrant non-Maori population, there was a tendency for some surplus non-Maori males to take Maori wives, and for such marriages to be matrilocal. Consequently, the children mixed with their mother's people and eventually became Maoris who married other 'ful1' or 'part' Maoris. However, this was not a universal result. Variations depended on the personalities of the fathers and mothers, the patterns of education of the children, whether or not the original marriage was matrilocal, and so on. Moreover, the first generation's marriage patterns may have been of some importance.

In spite of some loss by assimilation, it is apparent that a great number of the descendants of mixed marriages elected to be known as Maoris. Obviously, if intermarriage and assimilation had been a predominant pattern the Maori population would have 'disappeared', as was prophesied earlier. Instead, as Te Rangihiroa noted, a new, viable, cultural group developed incorporating all persons who claimed to be Maori, whatever their exact biological composition.

The remainder of this chapter is concerned directly with the patterns of growth. By drawing on the evidence presented in Chapters 3,4 and 5 the following questions will be asked: 
(1) When did a decline of population commence and when was the decline arrested?

(2) In any period what were the feasible rates of decline or increase?

(3) In retrospect, what was the possible size of the Maori population at various dates between 1769 and 1921?

\section{Growth Patterns: $1769-1840$}

This is the most difficult period about which to draw conclusions. In fact, conclusions can be made only by reference to Fenton's census of 1858 , for this is the first relatively reliable indication of the size of the Maori population.

In the last three chapters a number of points have been discussed, and these may be summarised:

(1) Cook's estimate of the population in 1769 was merely a guess. Consequently, the argument in this section will not revolve around whether or not cook was right.

(2) Dieffenbach's estimate was as good as any of its period, but cannot be accepted uncritically.

(3) Cook's men probably introduced the venereal diseases, which may have increased foetal mortality rates as well as decreasing conception rates. Thus, the crude birth rate probably declined from 1769.

(4) Throughout the period 1769-1840, it is doubtful if the crude birth rate dropped below about 30 per 1,000. This is the figure calculated from Fenton's data for 1844-58, when a number of factors operated against high birthrates.

(5) Apparently, a number of acute infectious diseases were introduced about 1780 , and perhaps earlier. From 1780 there are vague reports of very widespread mortality. Other 
epidemics occurred at intervals, while by the $1820 \mathrm{~s}$ and 1830 s venereal diseases were widespread, at least in areas of contact.

(6) In the $1820 \mathrm{~s}$ and $1830 \mathrm{~s}$ warfare was widespread. The most conservative estimate of mortality directly and indirectly associated with this warfare is 30,000 to 40,000 deaths.

To these relatively verifiable considerations may be added these surmises:

(1) There is no reason to believe that the Maori population was declining before European contact. Apparently, few common epidemic diseases were indigenous, sanitation was carefully controlled, the population was isolated, and, although there were villages, there were no really large settlements. Moreover, even assuming that the 'great fleet' of Maori mythology consisted of more than 10 or 20 canoes carrying a maximum of 50 or 100 people, the growth rate must have been at a level of 0.5 to 1.0 per cent per annum to allow for the distribution of population reported in the early nineteenth century. If 2,000 people had arrived in 1350, the date taken from Maori mythology, a growth rate of 1 per cent per annum could have brought about a population numbering almost 250,000 in 1960 . However, there are many imponderables in such a surmise. For example, settlement may have occurred before 1350; no one will ever know the size of the 'great fleet'; and it is impossible to guess the growth rate.

(2) If the population was increasing in 1769 , this must have been maintained after contact, at least until the epidemics of 1780-1900 effected some changes; there was no cause sufficient to change a pattern of increase to one of decrease immediately contact had been established. 
Moreover, it is probable that the birth rate declined, but that throughout the period 1769-1840 it never dropped much below 30 per 1,000 , or perhaps 25 per 1,000 in extreme years. Thus, to postulate a decline of population it must be shown that the death rate was in excess of 30 per 1,000 in all years; to postulate a rapid decline it must have reached 40 per 1,000 in most years, and exceeded this figure in other years.

(3) From evidence relating to subsequent periods it appears that in periods of high mortality, such as occurred during the period 1780-1840, there was a decline in population. Moreover, such a decline was reported by early observers, and thus it is probable that a decline characterised most of the years from 1780-1840.

The actual rate of decline would have varied from year to year, while some account must be made of the first 10 or so years when an increase was probably still occurring. It is not unreasonable to accept a birthrate of 30 and a death rate of at least 35 per 1,000 in most of the years. But, during epidemics and the wars of the $1820 \mathrm{~s}$ and $1830 \mathrm{~s}$, the death rate could have risen as high as that calculated for the 1854 measles epidemic or the 1877-78 whooping cough epidemic; i.e. between 50 and 70 per 1,000. Under these circumstances an overall decline of between 5 and 10 per 1,000 is possible throughout the entire period.

The estimates of the 1840 population are not very reliable, but let it be assumed that the possible range was from 50,000 to 150,000 in 1840. Then for 1769 take another range from 75,000 to 300,000 . If it is assumed that the decline was between 0.5 per cent and 1.0 per cent per annum, the minimum and maximum numbers in 1769 from which populations in the 1840 range could be derived are as follows (in multiples of 25,000): 


\begin{tabular}{lrrrrr}
\hline Year & \multicolumn{5}{c}{ Population numbering: } \\
\hline 1840 & 50,000 & 75,000 & 100,000 & 125,000 & 150,000 \\
1769 (min. size) & 75,000 & 100,000 & 150,000 & 175,000 & 200,000 \\
1769 (max. size) & 100,000 & 150,000 & 200,000 & 250,000 & 300,000 \\
\hline
\end{tabular}

For example, on these assumptions Dieffenbach's estimated population of almost 115,000 could have been derived from a 1769 population of more than 150,000-200,000.

It is now necessary to turn to the period 1840-58 to determine the reliability of Dieffenbach's and other estimates of about 1840 .

\section{3. $1840-58$}

For the 18 year period under review, a decline of almost 4 per cent per annum from 114,890 to 56,049 is on record; i.e. from Dieffenbach's estimate to Fenton's census. Superficially, this hardly seems possible. If a crude birth rate of 30 per 1,000 is accepted a decline of this magnitude would imply an average annual crude death rate of about 70 per 1,000. Such a high rate may have occurred in 1854 , but there is no evidence to suggest that the 1854 rate was equalled in all other years of the period $1840-58$.

For the Waikato, Fenton's data on births and deaths show an annual rate of decrease of almost 16 per 1,000 during the period 1844-58. These are the most carefully compiled data available for this period, for Fenton made allowance for migration, and tried to maintain a close check on accuracy. More importantly, these data span years of severe epidemics as well as 'normal' years. Assuming that Fenton's Waikato rates are approximately correct and apply to New Zealand as a whole, two possible conclusions can be made: 
(1) that Dieffenbach's estimate is too high. Considering the method he employed to take this 'census', such an error is highly possible.

(2) that Fenton severely under-enumerated sections of the Maori population. As was suggested in Chapter III, Section 3 it is probable that such under-enumeration occurred.

To obtain a rate of decrease for New Zealand equivalent to the Waikato rate reported by Fenton, it is necessary to postulate 1840 and 1858 populations rather different from those recorded. Moreover, a greater margin of error must be allowed for in Dieffenbach's estimate than in Fenton's census. For example, if the population was 90,000 in 1840 and 65,000 in 1858 , the rate of decrease would have been 1.9 per cent per annum; if it were 85,000 in 1840 and 63,000 in 1858 the annual rate of decline would be 1.7 per cent, and so on. From these calculations it seems unlikely that the 1840 population could have been in excess of 90,000 , while the 1858 population was probably in the range 56,000-65,000. As a comparison, Pearce's detailed ammendments to Fenton's census give a population of 59,700 in 1858 .

\section{4. $\quad \underline{1858-74}$}

In 1874 a population of 47,330 was enumerated, probably with about the same degree of reliability as Fenton's census. If 65,000 is taken as the actual size of the Maori population in 1858, then the decline in the intercensal period $1858-74$ was about 2.1 per cent per annum. This appears to be too high, implying an annual average crude death rate of over 50 per 1,000. Yet, in the $1860 \mathrm{~s}$ the following annual rates of decrease have been calculated for two small regions: 
(1)

Bay of Islands, $1864-68 \ldots . .2$ per cent (calculated by the district official)

(2) Wairarapa, $1865-68 \ldots \ldots \ldots .2 .7$ per cent.

of these two regions Wairarapa was probably the more turbulent during the period, but a decline of 2.7 per cent per annum implies a very high death rate, and so the data are of doubtful validity. ${ }^{9}$

By contrast, McKay's South Island data on births and deaths for the period $1868-74$ show a very slight annual rate of natural increase of 0.02 per cent. However, the South Island was in a very favourable position at this time.

When these regional variations are taken into account it is probable that a decrease occurred - this was, after al1, a period of war - and that the rate was between 1 per cent and 2 per cent per annum. For example, Pearce gives an amended 1874 population of 49,700 . If the 1858 population had been 63,000 , the annual rate of decrease would have been 1.4 per cent, which seems entirely feasible.

\section{5. $1874-1921$}

From 1874 on the intercensal rates of increase and decrease appear to be feasible. The average annual rates of growth are:

$\overline{9}$

These rates are drawn (or calculated from) A.J.H.R. (1868): A-4, pp.6-8 \& 35. Rates could also be calculated for the Chatham Is. the population of which declined from $573(1863)$ to $306(1868)$. Obviously, these data are extremely incorrect, or else migration - in this case the return of prisoners of war to the mainland - has occurred in the period. 


\begin{tabular}{|c|c|}
\hline $\begin{array}{cc}\begin{array}{c}\text { Intercensal } \\
\text { Period }\end{array} & \begin{array}{c}\text { Rate }(\% \\
\text { per annum }\end{array} \\
\end{array}$ & Comments \\
\hline $\begin{array}{rr}1874-78 & -1.0 \\
1878-81 & 0.4 \\
1881-86 & -1.0 \\
1886-91 & 0.1 \\
1891-96 & -1.0 \\
1896-01 & 1.6 \\
1901-06 & 2.0 \\
1906-11 & 1.0 \\
1911-16 & 0.1 \\
1916-21 & 1.6\end{array}$ & $\begin{array}{l}\text { Measles (1875) and Whooping Cough } \\
\text { (1877-78) epidemics. } \\
\text { Whooping cough (1878-79). } \\
\text { Influenza etc. early } 1890 \text { s. Under- } \\
\text { enumeration } 1896 \text {. } \\
\text { No age data were collected in } 1906 . \\
\text { This may have made enumeration } \\
\text { simpler. } \\
\text { Under-enumeration and troops over- } \\
\text { seas } 1916 \text {. } \\
\text { Influenza Pandemic. }\end{array}$ \\
\hline
\end{tabular}

Vacillating rates of decrease and increase recurred until 1896. These vacillations resulted as frequently from varying standards of census enumeration as from intercensal epidemics, etc. For example, in the period 1877-78 falling into the intercensal quinquennium 1874-78, death rates may have reached as high as 60 or 70 per 1,000 , and thus a decrease occurred. However, the period 1881-86 is somewhat perplexing, for a study of mortality in the intercensal period 1886-91 gives no reason for a decline as high as -1.0 per cent. Perhaps the birth rate was lower than normal in this quinquennium as a result of the dissolutions of some marriages because of the death of either or both spouses aged less than 30 years during the whooping-cough epidemic of the late 1870s. It is certain that the death rate was high enough at this time to have had such an effect.

From 1896 onwards there has always been an increase, but this has varied. A notable cause of a lower rate of increase was the poor enumeration and the absence of troops in 1916. If the 1916 census had been more reliable the rate of increase in the intercensal period 1916-21 would 
have been lower than that recorded. This would have resulted from the severe influenza mortality in 1918-19.

\section{Summary}

(1) The Maori population was increasing until 1769.

(2) A decrease commenced sometime after non-Maori contact. The suggested date is 1780-1800.

(3) The population in 1840 may have been considerably below that estimated by eye-witnesses. A figure of 80,000-90,000 is a reasonable 1 imit, as against over 110,000 suggested by Dieffenbach.

(4) Taking this amended estimate for 1840 , and assuming a decrease of between 0.5 per cent and 1.0 per cent per annum for the entire period 1769-1840, the population in 1769 would have been in the range $125,000-175,000$.

(5) The recorded decline between 1840 and Fenton's census of 1858 is far too high. It is suggested that Dieffenbach's estimate is too high, and that under-enumeration occurred in 1857-58. An amended annual rate of decrease of 1.7 per cent to 1.9 per cent has been suggested here.

(6) During the period 1858-74 a severe decline of about 1. 4 per cent per annum occurred. This was a continuation of the severe declines of the period 1840-58.

(7) From 1874-1896 vacillating patterns of decreases and increases occurred as a result of intercensal vital events. However, the picture is obscured by variations in the standards of census enumeration.

(8) Since 1896 the population has increased, although the rate of increase has varied considerably.

(9) Two periods of severe decline may be noted:

(a) From 1820-1840 it is probable that the wars gave 
rise to severe population decline and to the depletion of various cohorts.

(b) From 1840-1870 the birth rate probably reached a record low level of about 30 , or 1 ess, per 1,000 . This was caused by factors such as high foetal mortality, but also, as Borrie has suggested, as a result of the depletion of various birth-cohorts during the period $1820-39.10$ At the same time mortality was extremely high.

(10) The fact that rates of decrease began to diminish from 1874 , and that variations in the growth rate resulted from abnormal levels of mortality, 11 suggests that the postMaori war period was one in which the Maoris began to gain adequate levels of immunity to acute infectious diseases, and in which the pattern was being set for the increase which has occurred since 1896. That is, all persons but infants had gained immunity from common infectious diseases by about 1880. Moreover, it is suggested that birth rates, and infant and childhood death rates began to even out. Thus, the late nineteenth century saw changes in the structure of birth cohorts, which were to be of significance in the total age-structure throughout the twenthieth century.

By 1921, the increase of the Maori population was assured. Replacement levels had so increased that even such an event as the influenza pandemic could not bring about a decrease of population.

10

pp.249-50. Borrie, W.D. (1959): The Maori Population: A Microcosm of the New World', in Freeman, J.D. \& Geddes, W.R. (eds.): Anthrop. in the South Seas., New Plymouth, N.Z. p p. 247-62.

11

That is genuine variations; not those resulting merely from differential standards of enumeration. 


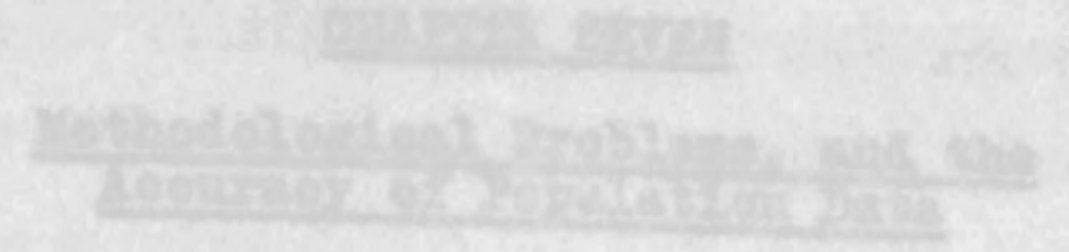

2. Introduction

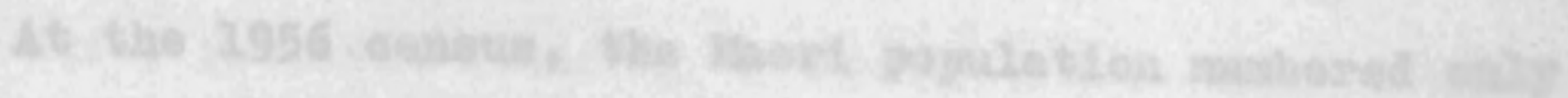

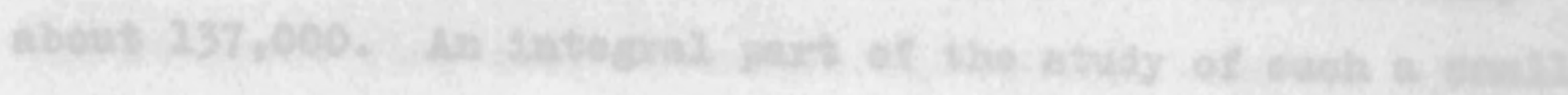

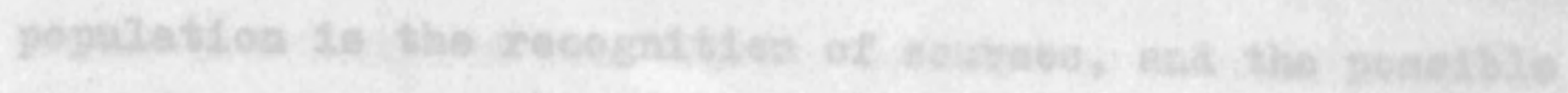

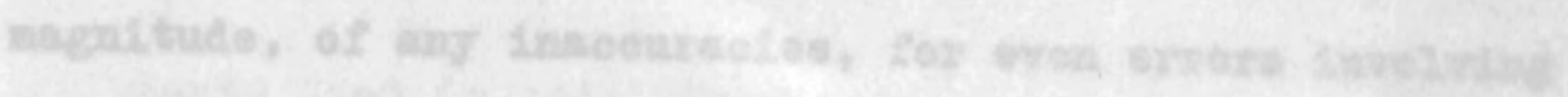

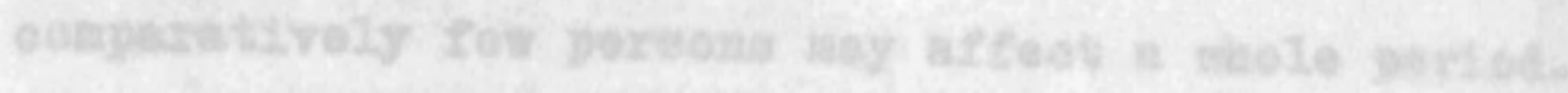

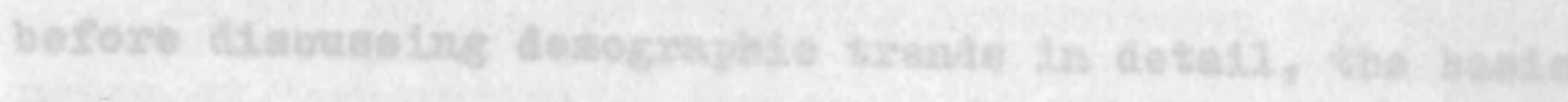

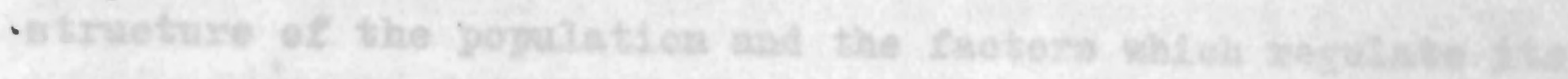

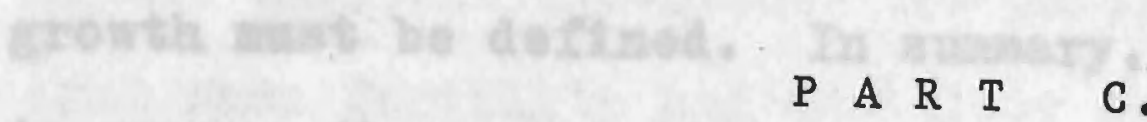

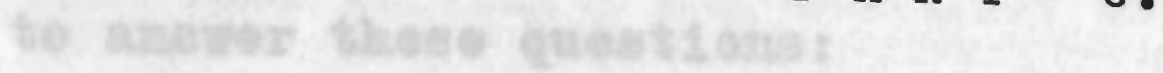

(a) 1050 Whathand $1922-$ Present

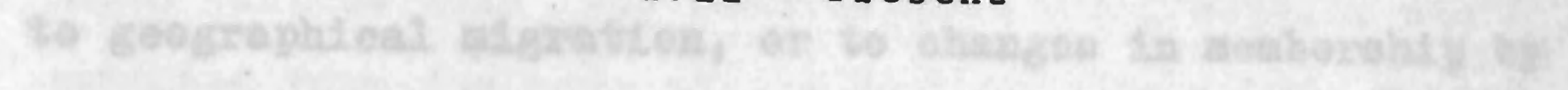
cetheocy-jumping otowt

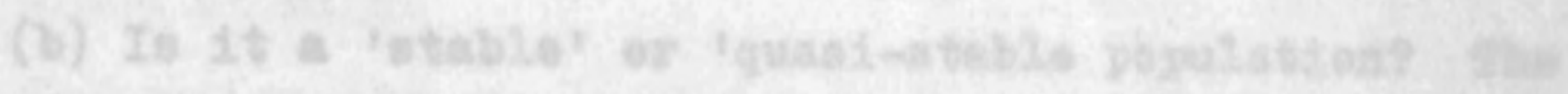

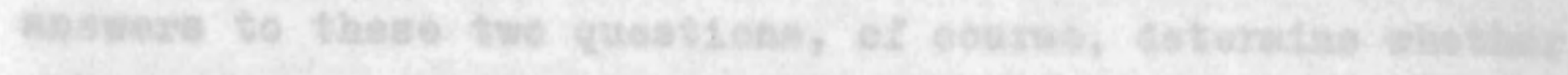

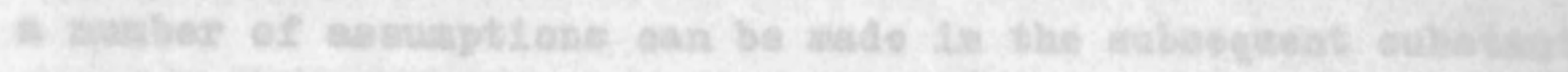

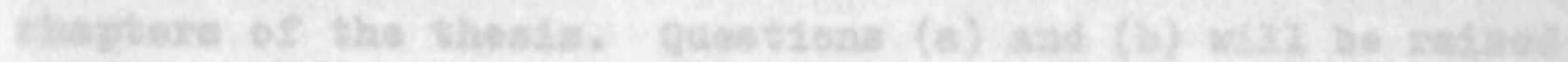

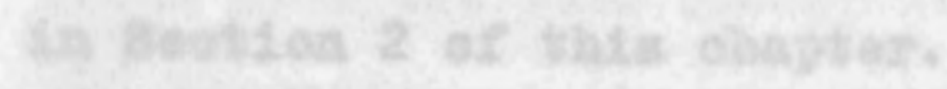

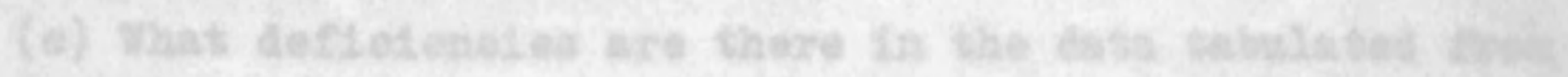

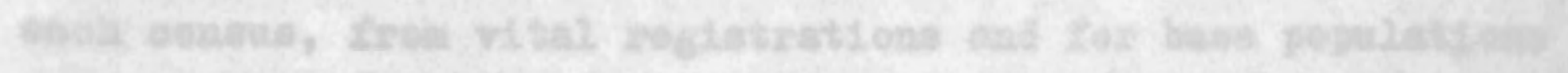

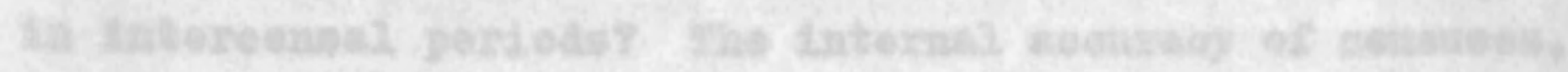

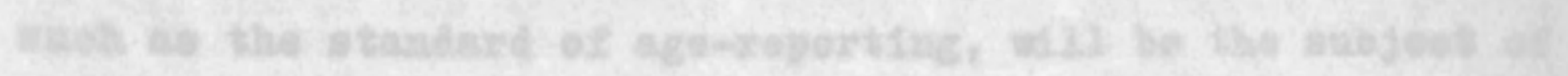

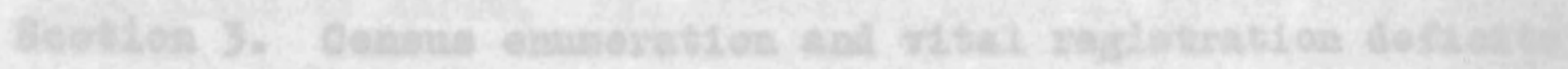

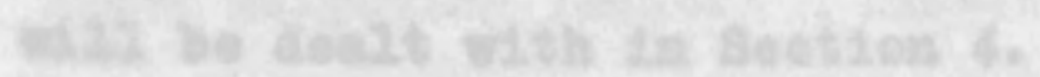

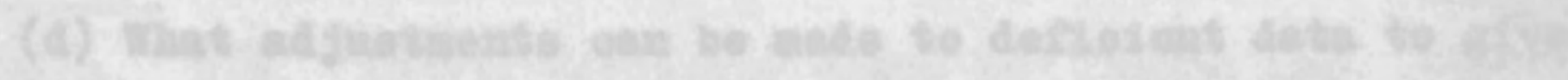

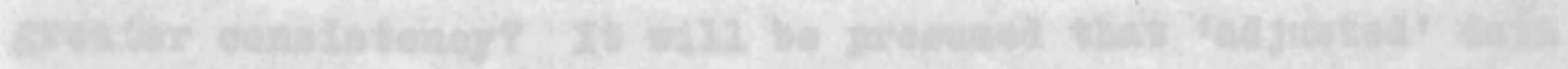

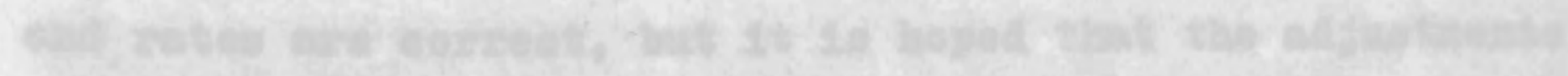


PART $C$

\section{CHAPTER SEVEN}

Methodological Problems, and the

Accuracy of Population Data

\section{Introduction}

At the 1956 census, the Maori population numbered only about 137,000. An integral part of the study of such a small population is the recognition of sources, and the possible magnitude, of any inaccuracies, for even errors involving comparatively few persons may affect a whole period. Moreover, before discussing demographic trends in detail, the basic structure of the population and the factors which regulate its growth must be defined. In summary, this chapter will attempt to answer these questions:

(a) Is the Maori population 'closed', or is it subject to geographical migration, or to changes in membership by category-jumping etc.?

(b) Is It a 'stable' or 'quasi-stable population? The answers to these two questions, of course, determine whether a number of assumptions can be made in the subsequent substantive chapters of the thesis. Questions (a) and (b) will be raised in Section 2 of this chapter.

(c) What deficiencies are there in the data tabulated from each census, from vital registrations and for base populations in intercensal periods? The internal accuracy of censuses, such as the standard of age-reporting, will be the subject of Section 3. Census enumeration and vital registration deficits will be dealt with in Section 4 .

(d) What adjustments can be made to deficient data to give greater consistency? It will be presumed that 'adjusted' data and rates are correct, but it is hoped that the adjustments give greater consistency. These adjustments will be discussed, for each intercensal period, in Section 4. 
(d) What adjustments can be made to deficient data to give greater consiatency? It will be presumed that 'adjusted' data and rates are correct, but it is hoped that the adjustments give greater consistency. These adjustments will be discussed, for each intercensal period, in section 4.

Other problems relating to specific data will be raised in the relevant chapters. However, the special problems of lifetable construction will be the subject of Section 5 .

\section{Tests Used in this Chapter}

In section 3, age-reporting inaccuracies are teated by means of 'age-ratios'. The ratio of one age-group to the mean of the adjacent age-groups was computed. This test assumes that when fertility and mortality have changed consistently, or remained constant, and when a population is 'closed', the ratio will be 1:l. For quinquennial age-groups, a score is computed from the mean of the deviation from 100, summed regardless of sign.

Sex-ratios are computed for each quinquennial age-group, the deviation of each ratio from the preceding ratio summed, and the mean deviation determined. This sex-ratio score is based upon the same assumptions about mortality, fertility and migration as the age-ratio score.

These two tests are described in a U.N. paper. ${ }^{1}$ This article then suggests the computation of a 'joint' score, which is the sum of the age-ratio scores, plus the sex-ratio score multiplied by three. The sex-ratio score is given this arbitrary weighting because a number of studies of age-reporting

1 passim. U.N. (1952): "Accuracy Tests for Census AgeDistributions in Five-Year \& Ten-Year Age-Groups", Pop.Bull., Oct. pp.59-79. In this U.N. paper the Miori Population is one of a number checked with similar societies. In this case, the Maoris (1945), Gilbert \& Fllice Is. (1947) and Cook Is. (1945) are compared (p. 79). These checks show that the adjustments that are made to allow for the size of population are valid. 
inaccuracies have shown that more reliance should be placed on sex-ratio scores than on those based on age-ratios. The latter are affected more by abnormal population trends.

In Section 3, life-table survival ratios are used to 'age' cohorts from census to census (1946-61). A study of the differences between 'expected' and enumerated $n^{P} x$ indicates the changing accuracy of the enumeration of various cohorts. This procedure will be termed 'a survival-ratio test'.

Also in Section 3, digit preference tests have been made along the lines suggested by Myers. ${ }^{2}$

In Section 4, balancing equations for the total population are employed, working back from the most recent census ( $t$ ) to the previous one $(t-n)$, to test the accuracy of census and registration data. These equations are calculated from census and vital data and, as there is no geographical migration (see Section 2), they take the form: $P_{t-n}=P_{t}-B+D$. The major basic problems were to make allowance for the timing of various censuses, and to incorporate some measure of category-jumping, changes in definition, etc.

For every intercensal period where balancing equations show that there are deficiencies in either enumeration or registration, an attempt is made to evaluate the causes and make the necessary adjustments. These will be described further for each relevant case.

Some tests could not be employed in this chapter. Firstly, those involving the use of very refined data could not be made, because the range of published data on Maoris is comparatively narrow.

Secondly, published vital and census data are the major sources of demographic materials on the Maoris. Thus, no

\footnotetext{
2 Myers, Robert J. (1951): "Errors \& Bias in the Reporting of Ages in Census Data", in Jaffe, A.J.: Handbook of Statistical Methods for Demographers, Washington, pp.115-25.
} 
comparison could be made with data collected independently. However, field studies and reports are referred to in the descriptive sections of the thesis.

\section{Besic structure of the Maori Population: A 'Closed' Population}

The growth and structure of a 'closed' population depends entirely on levels of natural increase. By contrast, international migration has a considerable effect on the growth and structure of an 'open' population. However, geographical migration is not the only such process to affect growth and structure. In a plural society there may be inter-ethnic 'migration'; i.e. movement from one census population to another. In this section the concerm is not with natural increase, but with these two 'migratory' processes - geographical migration and crossing from one census population to another.

The Maori population has always been virtually closed to geographical migration. The departure overseas of a small but increasing number of Maoris each year is not quite $b_{a}$ lanced by the return of other Maoris. However, the average annual excess of departures over arrivals is very slight. ${ }^{3}$ During both World Wars and after 1945, some Maoris went overseas on

3 During each of the three quinquennia beginning 3 lst March 1945, the total number of arrivals and departures (excluding troops)were: Quinquennia Arrivals Departures

\begin{tabular}{rrrrrrr} 
& m & \multicolumn{1}{c}{$\boldsymbol{f}$} & m & $\boldsymbol{f}$ & \multicolumn{2}{c}{ Depertures } \\
\hline $1945 / 46-49 / 50$ & 50 & 33 & 62 & 41 & 12 & $\mathbf{f}$ \\
$1950 / 51-54 / 55$ & 112 & 75 & 137 & 134 & 25 & 59 \\
$1955 / 56-59 / 60$ & 261 & 225 & 359 & 398 & 98 & 175
\end{tabular}

There are annual fluctuations, but the maximum average annual excess is only 35 (for females, quinquennium of 1955/56-59/60). Quinquennial data are used here because, with such small numbers, the annual figures may be affected by quite peculiar factors, e.g. The departure of a concert party or sports team, and its re-entry the following registration year. 
active service. Since 1945, New Zealand troops have served in Japan, Korea and Malaya. These people were almost entirely males in the age-group 20-44 years. For the computation of intercensal populations this created special problems, which will be discussed in section 4.

The only other calculations affected were the age-specific death rates for the period 1944-46, when the largest number were overseas. As troops overseas were not included in the census of 1945, it was decided to exclude the deaths of returning troops from deaths at quinquennial age-groups from september 1945 (the date of the 1945 census), until December 1946, by which time, it was presumed, all troops would have returned. However, investigations revealed that such an adjustment would not be much greater than two deaths per quinquennial age-group for the whole period 1944-46. Thus, age-specific mortality rates for the three year period 1944-46, averaged around the 1945 census, were not greatly affected by the return, in 1946, of troops not recorded in the census, but whose deaths were included in the vital registration data.

\section{Inter-ethnic 'migration'}

If the terminology of students of geographical migration were adopted here, two categories of inter-ethnic 'migrants' could be nominated: 'active migrants' (those persons who consciously decide to change their ethnic allegiances), and 'passive migrants' (those dependents, predominantly children, who are carried across ethnic boundaries as a result of the 'active' migration of the members of their family who are in a position of authority. In a sense, the offspring of mixedmarriages are 'passive migrants', in that they may be expected to adopt membership of the ethnic group into which their less dominant parent has married.) 
The process of inter-ethnic 'migration' may take two forms. It may be clandestine, such as the reputed 'passing' of Negroes in the United States. These persons sever all connections with the group from which they have 'passed'. Alternatively, this 'migration' may be overt, either as a result of the process of socially and legally sanctioned ethnic intermarriages, or else merely because individuals desire to change their ethnic group. Overt movement is probably the more common process in New Zealand. Moreover, because this process is largely voluntary and is not resisted by the ethnic group into which the 'migrants' are moving, few successful 'migrants' find cause to break their links with their former ethnic group. This is a characteristic of both 'active' and 'passive' 'migrants'.

This analysis has been directed towards movement from ethnic groups. Although the census definition is based entirely on the biological concept 'degree of Maori blood', the Maori census population (i.e. persons 'half or more Maori') is probably akin to the Maori ethnic or cultural group (Chapter 2, Section 4).

Because of the permissive attitude towards inter-racial marriage and inter-ethnic 'migration' the Maori census population may be affected in two ways by this movement:

1. 'Active' migrants may category-jump from the Maori census population at one census to the non-Maori census population at a subsequent census, or vice versa. There may also be such changes between the census and vital registration.

2. Reporting of 'degree of Maori blood' may indicate an individual's ethnic affiliation, but not his correct biological status; that is, people will report on what they 'feel' they are, and not what they are in actual fact (See Chapter 2, Section 4). 
Census of:

\begin{tabular}{|c|c|c|c|c|c|}
\hline Component $(1)$ & 1926 & 1936 & 1945 & 1951 & 1956 \\
\hline 'Full' Maoris & 45,429 & 55,915 & 61,440 & 76,918 & 88,440 \\
\hline$\frac{3}{4}$ Maori - $\frac{1}{4}$ European & 6,632 & 11,397 & 18,956 & 15,201 & 18,624 \\
\hline$\frac{1}{2}$ Maori - $\frac{1}{2}$ European & 11,609 & 15,014 & 18,348 & 23,183 & 28,492 \\
\hline Other Polynesian - Maori & 39 & 102 & 263 & $374^{(2}$ & $775^{(2}$ \\
\hline Other Ethnic - Maori & 18 & 114 & 485 & 745 & $820^{(3}$ \\
\hline$\frac{7}{4}$ Maori - $\frac{3}{4}$ European & 6,053 & 11,508 & 16,902 & 18,842 & $\begin{array}{r}199(4 \\
25,108\end{array}$ \\
\hline $\begin{array}{l}\text { Totals : Maori - } \\
\text { descent Population }\end{array}$ & 69,780 & 95,040 & 116,394 & 134,842 & 162,458 \\
\hline
\end{tabular}

Notes: (1) The census groups these components by $\frac{1}{4}$ 's; e.g. There is no attempt to provide data on persons $\frac{7}{8}$ Maori i European, etc. There is no attempt to take the tabulations beyond the $\frac{3}{4}$ Buropean - $\frac{1}{4}$ Maori group, and thus there are no data on $\frac{1}{6}$ and one-sixteenth Maoris, etc.

(2) Included in the Maori census population 'regardless of degree of Maori blood'.

(3) Included in the Maori census population if 'half or more Maori'.

(4) Excluded from the Maori census population if 'less than half-Maori'.

The horizontal line divides the Maori census population from the non-Maori census population (above the line Maori, below non-Maori). 
By this reasoning persons who are included in the nonMaori census population and who report some 'degree of Maori blood' may be implying that they have changed their ethnic affiliation, but do not wish to repudiate completely their association with Maoris. By comparison, clandestine 'passers' may not give an indication that they have any 'degree of Maori blood', in spite of assurances that census questionnaires are confidential. Thus, 'passers' would be lost into the nonMaori population, but it is doubtful whether many persons who know they are of Maori descent would take this step unless their 'degree of Maori blood' was very slight (1/8, 1/16, etc.). Moreover, in such cases inter-ethnic movements probably occurred prior to 1926 and are not the concern of the present argument.

Over and above these considerations are the changes in definition which were outlined in Chapter 2, Section 2. By these changes, the components of the Maori census population have changed in number during the period 1926-56.

The census contains data on all components of what may be termed here the Maori-descent population. The descent population is composed of persons of 'full' or 'part' Maori blood included in either the Maori or the non-Maori census populations.

Table 7.1 gives the numbers included in the Maori census and descent populations at each census from 1926 to 1956. It can be seen that the major effects of administrative changes came in the period since Forld War II. These changes will be taken into account in the balancing equations to be presented below (Section 4 ).

The next question to be raised is the composition of the so-called 'full-blood' Maori population, which constitutes the major proportion of the Maori census population. On this question must hinge both much of the subsequent argument and the argument raised above that persons may report incorrectly 
their biological status. This question can be investigated only by an indirect method; i.e. by making assumptions about marriage patterns.

There are no data on marital status by 'degree of Maori blood', but it is assumed here that within the Maori census population choice is random, that fertility patterns are the same for all categories of marital status by 'degree of Maori blood', and that the percentages of the Maori census population belonging to each 'degree of Maori blood' group apply to Maori census marital status groups. For example, if $\frac{1}{4}$ of the Maori census population is 'half-Maori', it is assumed that $\frac{1}{4}$ of the married 'Maoris' are 'half-Maori'.

Te Rangihiroa's samples taken about 1920, and discussed in Chapter 2, Section 4, showed that about $50 \%$ of Maoris were part-Maori. If the conditions outlined above held true, $75 \%$ of their off-spring would be part-Maori, as would 15/16 of their grand-children. Thus, allowing about 30 years per generation, only $1 / 16$ of the present birth-cohorts would be 'full-Maori', and only $\frac{1}{4}$ of their parents would fall into this category. The resulting level of between $6 \%$ and $25 \%$ ' fullMaori' is a far lower proportion than was recorded at the 1956 census $(62 \%)$.

Te Rangihiroa's samples may be unrepresentative, and may include persons in the Maori-descent population, but not in the Maori census population. However, at the 1926 census $71 \%$ of the Maori census population was recorded as 'full-Maori'. Applying the same conditions as above, the result is $50 \%$ 'part-Maori' after one generation, and 75\% 'part-Maori' after two generations.

In other words, if the assumptions made here are at all valid, the census category 'full-Maori' is grossly overenumerated. 
From this evidence it appears that a substantial proportion of 'full-Maoris' have only sentimental and not biological reasons for reporting themselves as 'full'. Furthermore, it might be assumed that they represent the 'hard-core' of the ethnic group; the proportion of the Maoridescent population which is determined to retain ethnic allegiances. To achieve this aim, they neglect to report any nonMaori ancestry, although, of course, this may often arise through ignorance.

By this reasoning, persons who report themselves as $\frac{3}{4}$ or $\frac{1}{2}$ Maori are moving away from the 'hard-core', in the sense that they are 'part-Maoris' who are prepared to acknowledge their non-Maori ancestry. Finally, it can also be argued that quarter-Maoris are those who have moved, but retain some allegiance. This is entirely permissible in the social climate in which inter-ethnic migration and intermarriage occur.

Changes in the composition of the Maori-descent population might reflect these patterns of movement and give some indication of category jumping. For example, any unduly large growth or decline of the quarter-Maori population could indicate a movement away from the Maori census population.

In lieu of detailed data tracing individuals from census to census, this type of check is the only available test of inter-censal category-jumping. However, some allowance for differential rates of natural increase must be built into this test. Thus, the enumerated components of the descent population, termed 'observed' populations were compared with 'expected' populations and the residuals were accredited to intercensal inter-ethnic movements. This method is based on the same assumptions as those used by students of geographical migration when they estimate migration by means of a residual method. However, because of the lack of vital data on components, the 'expected' populations were calculated on the basis: 


$$
\text { Expected } \mathrm{P}^{t+n}=\text { Observed } \mathrm{P}^{t}(1+r)^{\mathrm{n}}
$$

where $r=$ the Maori census population's annual intercensal rate of growth.

The use of the value ' $r$ ' for each component assumes that rates of natural increase are the same. 1961 is the only period for which rates of natural increase can be calculated for components of the Maori census population. Even then, no rates can be computed for the components of the descent population included in the non-Maori census population.

For components of the Maori census population the rates of natural increase (per 1000) in 1960-62 were:

\begin{tabular}{|c|c|c|c|}
\hline $\begin{array}{l}\text { Component } \\
\text { Population } \\
\text { (1961 census) }^{1}\end{array}$ & $\begin{array}{l}\text { Birth Rate } \\
\text { (Annual Av.B. for } \\
\text { period 1960-62 }\end{array}$ & $\begin{array}{l}\text { Death Rate } \\
\text { (Annual Av.D. } \\
\text { for period } \\
1960-62 \text { ) }\end{array}$ & $\begin{array}{l}\text { Rate of } \\
\text { Natural } \\
\text { Increase }\end{array}$ \\
\hline $\begin{array}{l}\text { Full } \\
\text { Mixed }\left(\frac{1}{2}+\frac{3}{4}\right)\end{array}$ & $\begin{array}{l}33.7 \\
65.3\end{array}$ & $\begin{array}{l}8.4 \\
7.0\end{array}$ & $\begin{array}{l}25.3 \\
58.3\end{array}$ \\
\hline
\end{tabular}

Note: (1) These data were obtained from Census (1961): vol.7, ('Race'). Vol.8 ('Maori Census ') is yet to be published.

Superficially, these figures show that 'mixed-bloods' are increasing at a far more rapid rate than 'full-bloods'. The deaths at older ages, at least, probably relate to persons likely to be recorded in the relevant census component. Thus, the crude death rate shown here is probably a reliable indication of trends.

By contrast, there is an obvious logical fallacy in the calculation of the birth rate. The numerator in the crude birth rate for 'mixed-bloods' includes the births of all marriages in which one or both parents are of 'mixed-blood', while the denominator includes only those persons who recorded themselves as 'mixed-bloods' in the census. Thus, both the crude birth rate, and the rate of natural increase of 'mixed bloods' appear to be inflated. 
It is impossible to make allowance here for every such possible contingency. For example, a 'mixed-blood' birth may result from the marriage of a 'full-Maori' to a 'full nonMaori', or from the marriage of a Maori census 'mixed-blood' to a quarter-Maori, and so on. Moreover, correct enumeration in the census may be accompanied by incorrect vital registration, and vice versa. However, the inflation of the 'mixedbloods' crude birth rate can be analysed.

In 1961, 'mixed-bloods' constituted $38 \%$ of the Maori census population of each sex. Provided that the selection of marriage partners is random, it is probable that $47 \%$ of marriages 4 will be between 'full' and 'mixed-bloods', and thus that their off-spring will be 'mixed-bloods'. Therefore, if birth rates are calculated by using two new denominators relating to the population exposed to risk of procreating 'full' and 'mixed-blood' infants, a completely different perspective is given to the question of differential rates of natural increase:

\begin{tabular}{lccc} 
& $\begin{array}{c}\text { Crude Birth } \\
\text { Rate }\end{array}$ & $\begin{array}{c}\text { Crude Death } \\
\text { Rate }\end{array}$ & $\begin{array}{c}\text { Rate of Natural } \\
\text { Increase }\end{array}$ \\
\cline { 2 - 4 } 'Full' & $53.8^{1}$ & $8.4^{2}$ & 45.4 \\
'Mixed' & $39.7^{1}$ & $7.0^{2}$ & 32.7
\end{tabular}

Notes: (I) Numerator = Census component's births Denominator $=$ Population to which births relate

(2) Numerator = Census component's deaths Denominator $=$ Census component

\footnotetext{
I.e. The probability that a 'full' male marries a 'mixed' female: $\frac{62}{100} \times \frac{38}{100}=23.6 \%$ The probability that a 'full' female marries a 'mixed' male: $\frac{62}{100} \times \frac{38}{100}=\frac{23.6 \%}{47.2 \%}$

The probability that both spouses are 'mixed'

Total marriages from which all births will be 'mixed':

$$
\begin{aligned}
\frac{38}{100} \times \frac{38}{100} & =14.4 \% \\
& =61.6 \%
\end{aligned}
$$
}




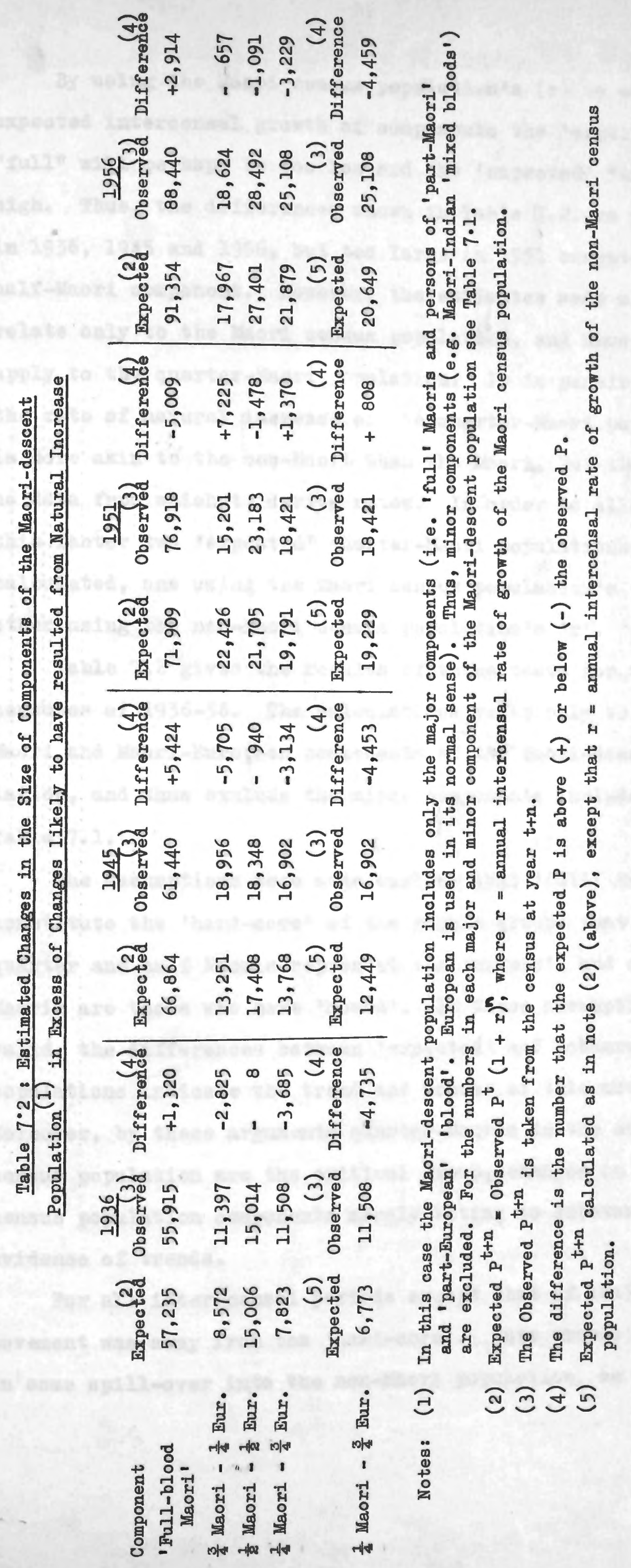


By using the Maori census population's ( $r$ ) to estimated expected intercensal growth of components the 'expected' "full" will perhaps be too low and the 'expected' "mixed" too high. Thus, the differences shown in Table 7.2.are too small in 1936, 1945 and 1956, but too large in 1951 except for the half-Maori component. However, the estimates made above relate only to the Maori census population, and thus may not apply to the quarter-Maori population. It is possible that the rate of natural increase of the quarter-Maori population is more akin to the non-Maori than the Maori, but there are no data from which to derive rates. In order to allow for this factor two 'expected' quarter-Maori populations were calculated, one using the Maori census population's ' $r$ ', the other using the non-Maori census population's ' $r$ '.

Table 7.2 gives the results of these tests for the censuses of 1936-56. The calculations refer only to the 'full' Maori and Maori-European components of the Maori-descent population, and thus exclude the minor components included in Table 7.1 .

The assumptions were made earlier that 'full' Maoris constitute the 'hard-core' of the ethnic group; that threequarter and half Maoris represent the 'movers', and quarterMaoris are those who have 'moved'. If these assumptions are valid, the differences between 'expected' and 'observed' populations indicate the trend and volume of this movement. Moreover, by these arguments quarter-Maoris in the non-Maori census population are the critical group, changes in the Maori census population components merely acting as substantiating evidence of trends.

For all inter-censal periods except that of 1945-51 the movement was away from the 'hard-core'. This probably resulted in some spill-over into the non-Maori population, as is 
suggested by the increasesin the quarter-Maori population which were in excess of the increases to be expected from natural causes. Thus, in these periods there appears to be intercensal category-jumping from the Maori to the non-Maori census. This is not proof that all excess increases in the quarter-Maori population were a result of category-jumping from the Maori census population. Probably, the major part of the excess was, but some allowance must be made for those nonMaori persons of Maori descent who report their quarter-Maori 'blood' for the first time. However, these cases would be counterbalanced by those persons who 'passed' completely from the Maori census without trace.

The intercensal period 1945-51 is somewhat different. The outward movement seems to have been reversed. QuarterMaoris or previous category-jumpers appear to have moved back into the half-Maori component, while three-quarter Maoris may have moved into the 'full' component. A possible cause for this reversal may lie in the increase in ethnic awareness following the return of the Maori batallion during this period. This may have engendered a feeling of pride in things Maori, and have caused some category-jumpers and even some quarterMaoris to identify themselves with the Maori census population.

Apart from this one period of reversal, the trend appears to be away from the Maori population. This conclusion must be accepted tentatively, in view of the unsatisfactory nature of the data on which these estimates are based. Nevertheless, there is no evidence to suggest that category-jumping does not occur. In fact, in a plural society with permissive attitudes, it is logical to assume that inter-ethnic 'migration' will be quite common and that, in general, the movement will be towards the larger and more dominant group. This argument is supported by these estimates. It might also be noted that there is no official attempt to combat category-jumping, 


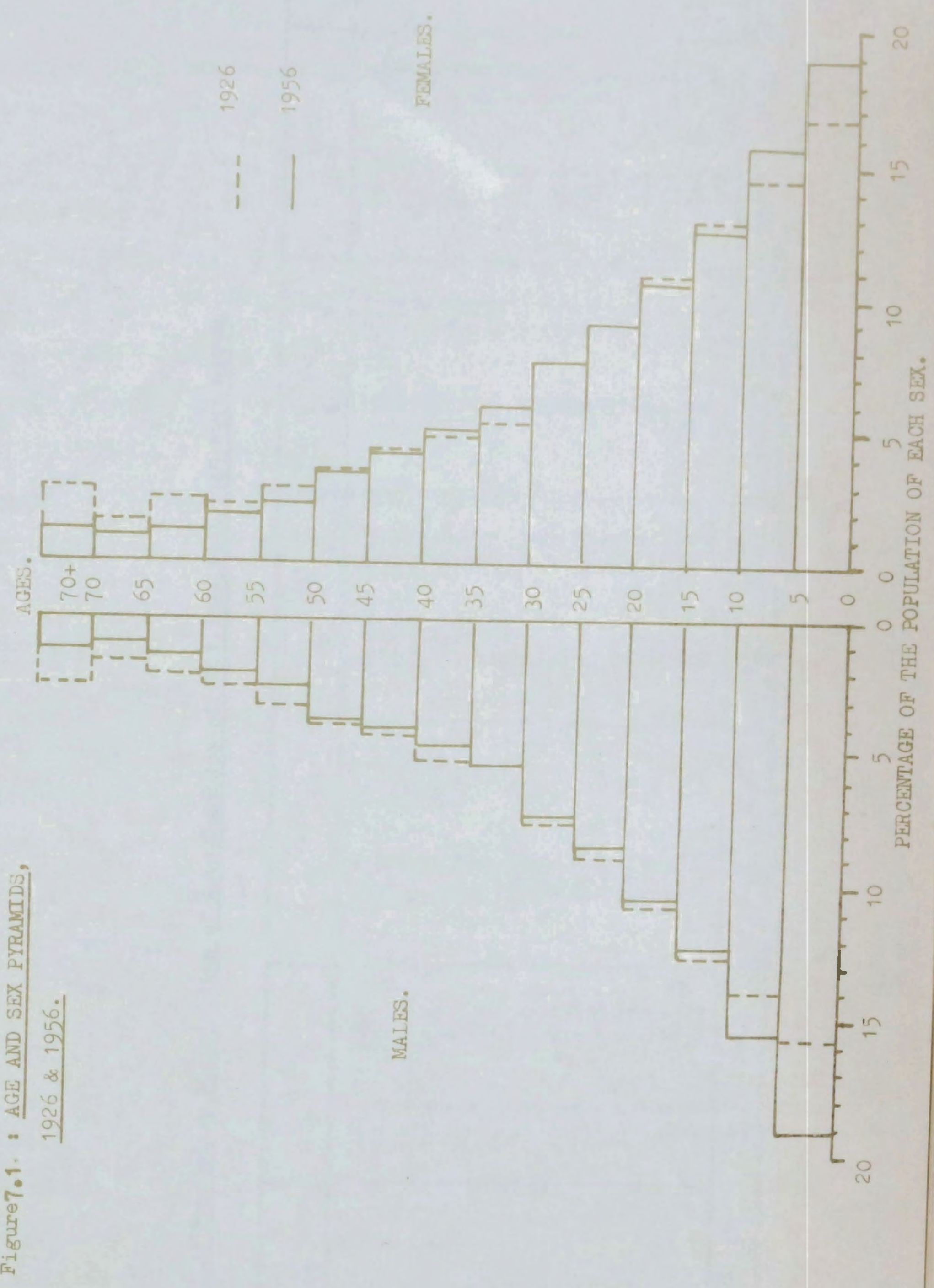




\begin{tabular}{|c|c|}
\hline 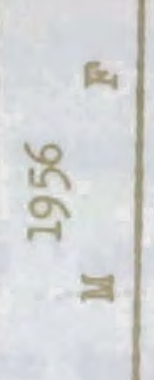 & 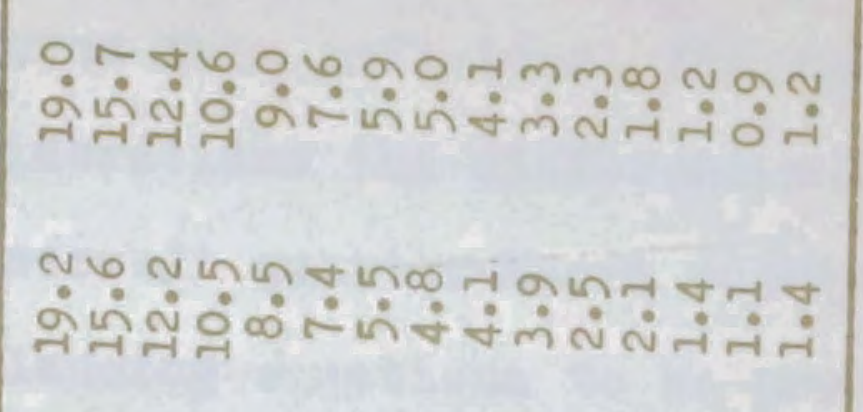 \\
\hline 䒿 & 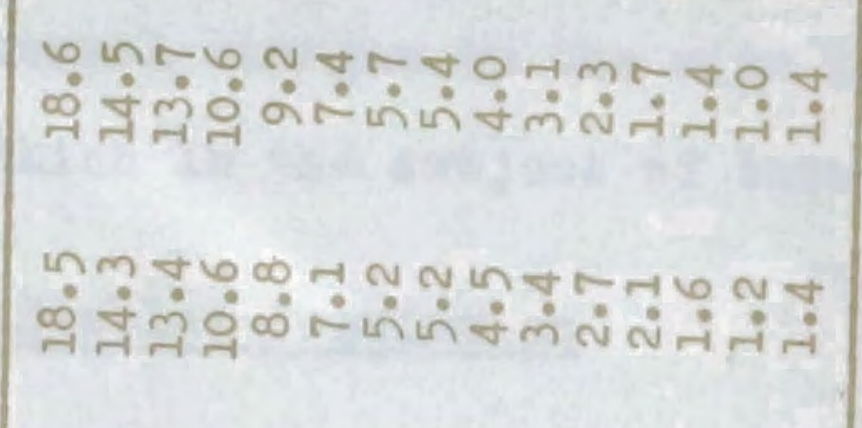 \\
\hline$\stackrel{\infty}{2}$ & 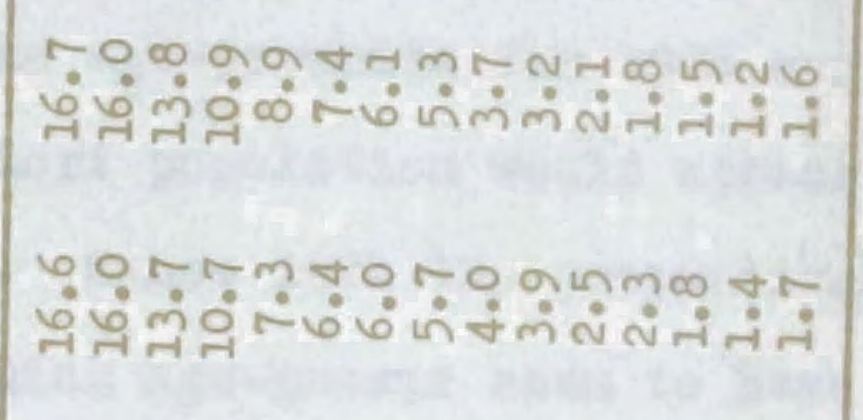 \\
\hline$\underset{\pi}{\stackrel{\infty}{\infty}}$ & 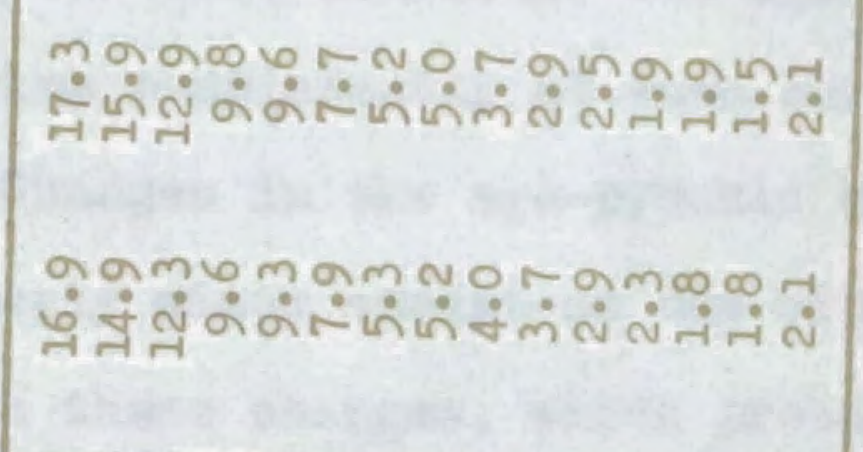 \\
\hline$\stackrel{2}{\circ}$ & 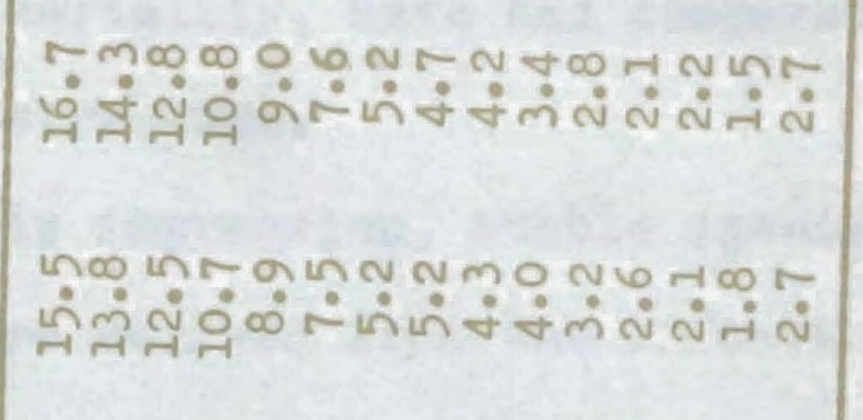 \\
\hline$=$ & 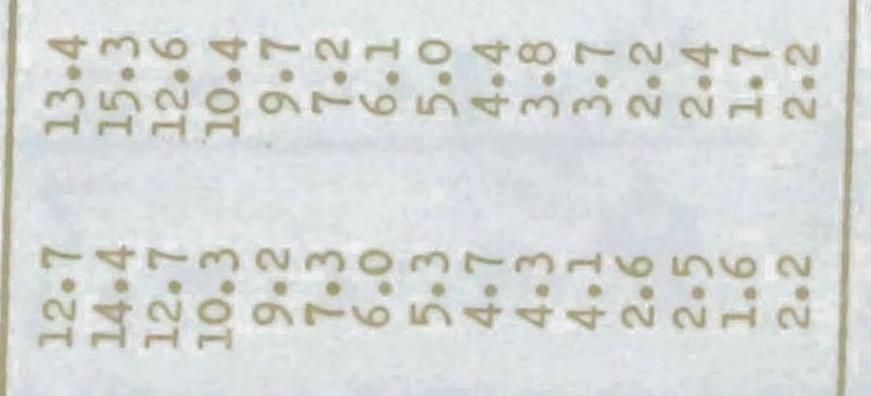 \\
\hline & 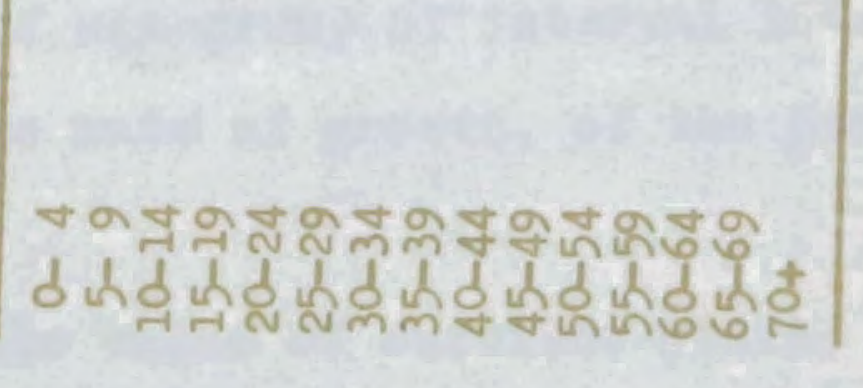 \\
\hline
\end{tabular}


although, presumably, census officials check internal inconsistencies in the returns from individual families.

In view of these considerations the differences between the 'expected' and the 'observed' quarter-Maori population will be employed in the balancing-equations to be presented in Section 4. This will permit an analysis of the effects of category-jumping on intercensal changes in the size of the Maori census population, which is the subject of this thesis.

\section{A 'Quasi-Stable' Population}

Table 7.3 presents the percentage age-distributions since 1921. Figure 7.1 shows the age-pyramids for 1926 and 1956. Superficially, the Maori population would appear to be a 'quasi-stable' population. Since 1921 the proportionate distributions of quinquennial age-groups seem to have been roughly similar. At each of these censuses, the age-pyramids are broadly based, narrowing consistently at each consecutive quinquennial age-group. Changes in the age-pyramid between 1926 and 1956 were relatively minor except at the oldest and youngest age-groups. Even these changes, which probably result from decreases in mortality, have had comparatively little effect on the age-structure.

In order to verify this impression, stable age-distributions, for males and females, were derived from the life-tables for 1955-57 by the formula:

$$
n^{P} x=\frac{e^{-r\left(x+\frac{n}{2}\right) \cdot \frac{n^{I_{1}}}{I_{0}}}}{\sum_{e^{-r}\left(x+\frac{n}{2}\right) \cdot \frac{n^{I_{x}}}{I_{0}}}} x N
$$

where, ${ }_{n}{ }^{x}=$ the number of males or females in the stable population of age-group of interval $x$ to $x+n$;

$r=$ the geometric rate of growth, of the period 1951-56;

$n^{I_{x}}=$ the life-table value of survivor-years, 1955-57 table;

and, $\mathbb{N}$ = the total mid-year population, 1956. 
The results, given in Table 7.4, show that the Maori midyear population is relatively close to the stable, if agegroup $70+$ is ignored. The most significant difference occurs at ages 10-14.

Table 7.4 : Stable and Mid-year Populations at 1956. Numbers at each age

\begin{tabular}{lrrrr} 
Age-Groups & $\begin{array}{c}\text { Males } \\
(1)\end{array}$ & $\begin{array}{c}\text { Males } \\
(2)\end{array}$ & $\begin{array}{c}\text { Females } \\
(1)\end{array}$ & $\begin{array}{c}\text { Females } \\
(2)\end{array}$ \\
\hline $0-4$ & 13,556 & 13,318 & 12,806 & 12,644 \\
$5-9$ & 10,992 & 10,962 & 10,610 & 10,457 \\
$10-14$ & 8,604 & 9,114 & 8,354 & 8,713 \\
$15-19$ & 7,390 & 7,575 & 7,169 & 7,247 \\
$20-24$ & 5,993 & 6,282 & 6,081 & 6,030 \\
$25-29$ & 5,191 & 5,176 & 5,125 & 4,996 \\
$30-34$ & 3,879 & 4,256 & 3,988 & 4,138 \\
$35-39$ & 3,354 & 3,474 & 3,384 & 3,396 \\
$40-44$ & 2,884 & 2,829 & 2,791 & 2,754 \\
$45-49$ & 2,727 & 2,269 & 2,218 & 2,175 \\
$50-54$ & 1,783 & 1,766 & 1,541 & 1,667 \\
$55-59$ & 1,476 & 1,351 & 1,214 & 1,259 \\
$60-64$ & 992 & 933 & 806 & 864 \\
$65-69$ & 752 & 600 & 612 & 561 \\
$70+$ & 991 & 660 & 844 & 642 \\
Totals: & 70,564 & 70,565 & 67,543 & 67,543
\end{tabular}

Notes: (1) Mid-year population aged from census, April 1956.

(2) Stable population derived from the life-table for 1955-57.

In theory, a 'stable' population isfone which has had constant levels of mortality and fertility for a period exceeding the life-span of the oldest person; that is, for 60 or more years. However, in practice, changes in levels of mortality alone have comparatively little effect on a stable agedistribution, or even on what Coale has termed a "transitory age-distribution". An exception is a change in the pattern of infant and early childhood mortality, which acts on the agestructure in approximately the same manner as do changes in fertility. 5 For Maoris, it appears that infant mortality

5 pp.89-92, 95, 101 \& 113. Coale, Ansley J. (1956): "The Effects of Changes in Mortality \& Fertility on Age-Composition", M.M.F.Q., vol.XXXIV, no.1, pp.79-114. 

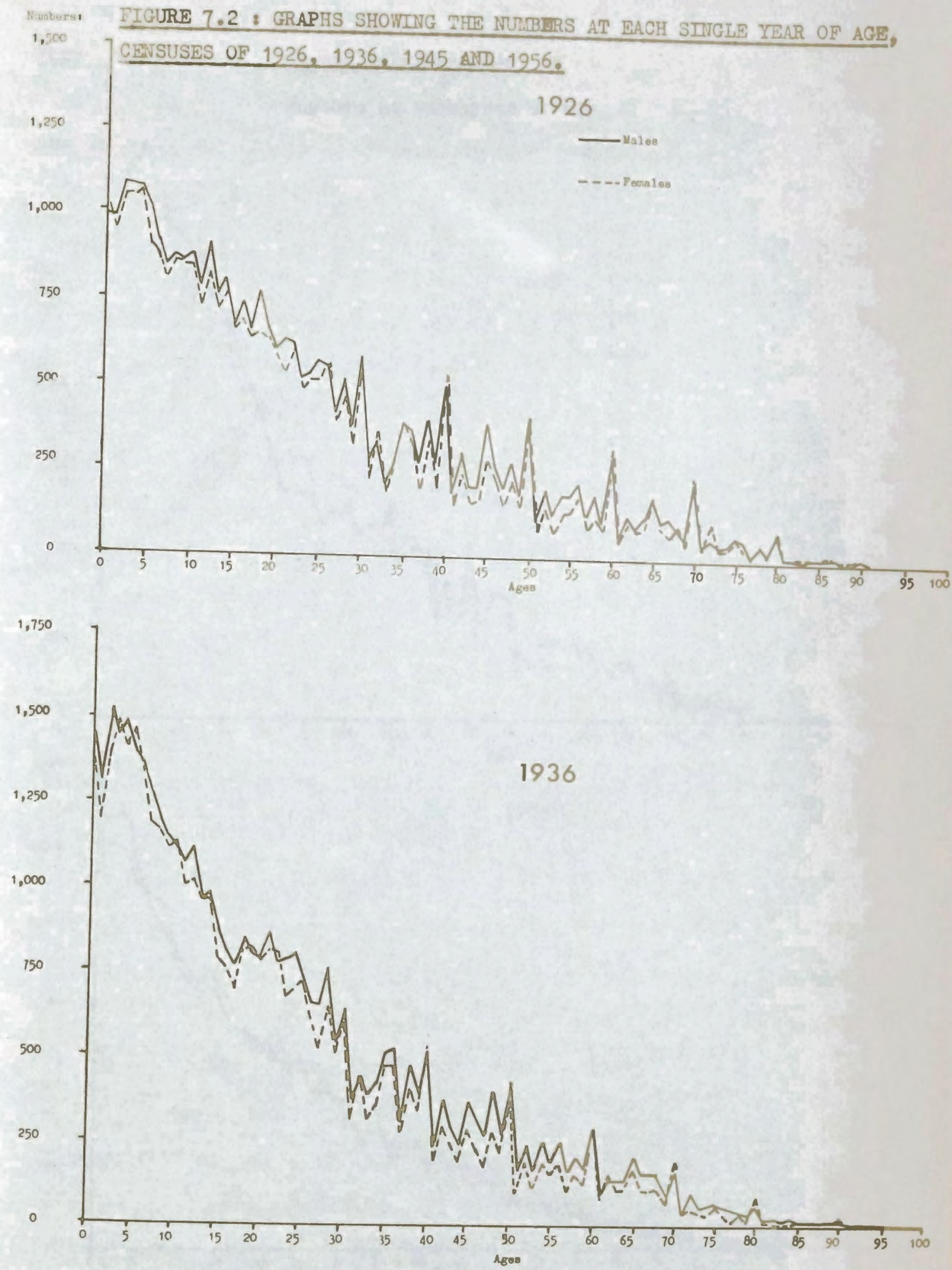


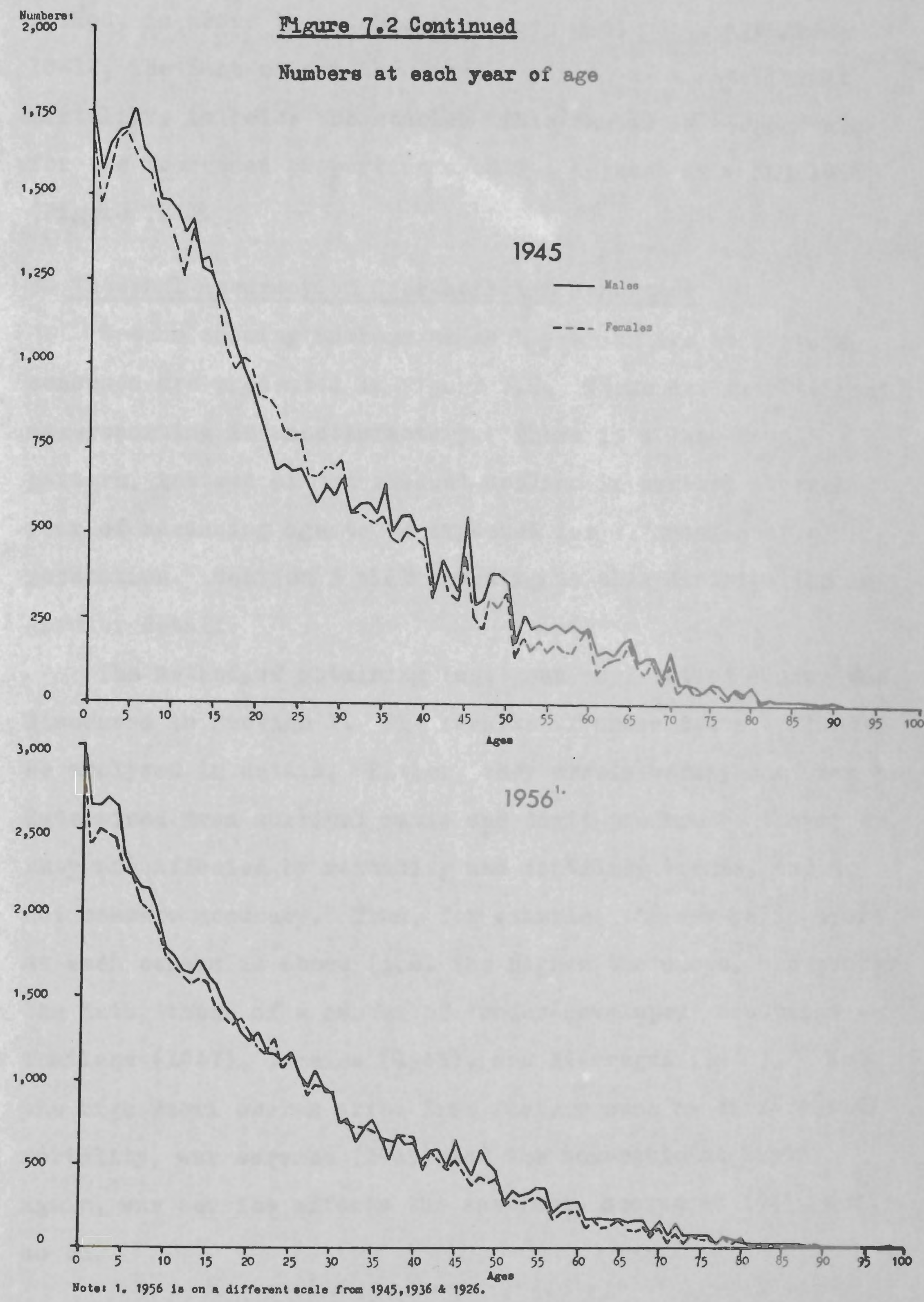


declined after World War II. About 1945, there was a sudden increase in the proportions of children surviving infancy. This was followed by a period when mortality rates consistently declined. Thus, age-group 0-4 at 1956, born in the latter period, is above the stable age-group 0-4, while age-group 10-14, the last cohort born in the period of higher infant mortality, is below the stable. This factor is responsible for the increased proportion aged 0-4 between 1926 and 1956 (Figure 7.1).

\section{Internal Accuracy of Censuses: Age Reporting}

Graphs showing numbers at each year of age at certain censuses are presented in Figure 7.2. These demonstrate that age-reporting is unsatisfactory. There is a 'saw-tooth' pattern, instead of the gradual decline in numbers at each year of advancing age to be expected for a 'quasi-stable' population. Section 3 will investigate this distribution in greater detail.

The method of obtaining 'age' and 'sex-ratio' scores was discussed in Section 1. The results of these tests will not be analysed in detail. Either, they merely verify what can be determined from survival ratio and digit-preference tests; or, they are affected by mortality and fertility trends, and do not measure accuracy. Thus, for example, the sex-ratio score at each census is above (i.e. the higher the score, the poorer the data) those of a number of 'under-developed' countries -Thailand (1947), Jamaica. (1943), and Nicaragua (1940). 6 Yet, the high Maori scores arise from factors such as differential mortality, war service (1945) and the sex-ratio at birth. Again, war service affects the age-ratio scores at 1945, and so on.

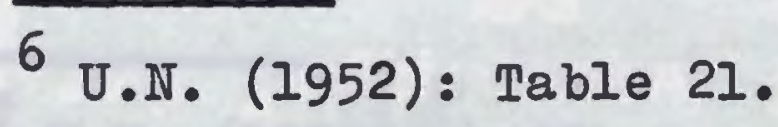


The age-ratio scores for each sex are added to the sexratio score multiplied by three to give joint scores, which are given in Table 7.5. The joint scores can be looked at in two ways:

If we wish to describe the general usefulness or reliability, of the several age-distributions for purposes of statistical manipulation, we shall have to regard the joint scores obtained without adjustment for smallness.... If, on the other hand, we merely wish to determine the degree of accuracy with which the ages have been recorded, we must consider the scores which remain scores, after reduction for smallness. 7

Table 7.5: Age Ratio, Sex Ratio and Joint Scores ${ }^{1}$

\begin{tabular}{|c|c|c|c|c|c|}
\hline Census & Age : & 0 Score & Sex Ratio Score & Joil & Score \\
\hline \multirow[b]{2}{*}{$\begin{array}{l}1956 \\
1951 \\
1945 \\
1936 \\
1926\end{array}$} & Male & Female & \multirow[b]{2}{*}{$\begin{array}{r}4.4 \\
4.9 \\
7.0 \\
8.8 \\
8.0\end{array}$} & $\underline{2}$ & 3 \\
\hline & $\begin{array}{l}6.7 \\
5.0 \\
8.3 \\
9.3 \\
5.6\end{array}$ & $\begin{array}{l}4.0 \\
6.4 \\
5.8 \\
9.0 \\
6.9\end{array}$ & & $\begin{array}{l}23.7 \\
26.0 \\
35.0 \\
44.6 \\
36.5\end{array}$ & $\begin{array}{l}17.7 \\
17.0 \\
27.0 \\
35.6 \\
25.5\end{array}$ \\
\hline
\end{tabular}

Notes: 1. No attempt has been made in this table to distribute the small number of persons with ages not stated. The percentages in this cat egory were:

\begin{tabular}{lrrrrr} 
& 1956 & 1951 & 1945 & 1936 & 1926 \\
\cline { 2 - 6 } Males & 0.1 & 0.2 & 0.6 & 0.2 & 0.6 \\
Females & 0.2 & 0.2 & 0.6 & 0.3 & 0.5 \\
\cline { 2 - 5 }
\end{tabular}

2. Joint score

3. Joint score adjusted for the size of the population.

The writers of this U.N. article argue that chance factors are more likely to affect the regularity of the age-distribution of a small population. For computations such as life-table construction, it is important to know whether the age-distribution is satisfactory or not, regardless of whether the cause of irregularities is the poor reporting of ages at the census, or chance. Thus, the unadjusted joint score must be used as an index of the reliability of the age-distributions of populations

7 U.N. (1952): p.77. 
of all sizes, if statistical manipulations are to be undertaken. By contrast, the adjusted joint scores are merely an index by which the general accuracy of age-reporting can be readily compared with that of other populations. The adjustments for size are based on a constant, which is a function of the reciprocal of the square root of the size of population. This constant has been derived by an analysis of the relationship between unadjusted joint scores and size of population for counties in Ontario, Canada, and the districts of certain West Indian territories. Joint scores should be interpreted as follows:

\begin{tabular}{|c|c|c|c|}
\hline 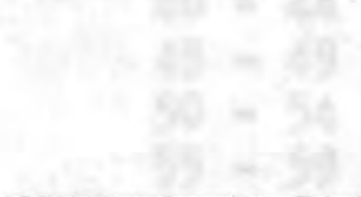 & $\begin{array}{l}\text { In the lst case } \\
\text { (unadjusted) }\end{array}$ & $y$ & $\begin{array}{l}\text { In the 2nd case } \\
\text { (adjusted for } \\
\text { smallness) }\end{array}$ \\
\hline Score & \multicolumn{3}{|c|}{ Value of census enumerations } \\
\hline $\begin{array}{l}0-19 \\
20-39\end{array}$ & $\begin{array}{l}\text { 'reasonably reli } \\
\text { 'fairly unreliak }\end{array}$ & ole & $\begin{array}{c}\text { 'at least tolerably } \\
\text { accurate' } \\
\text { 'markedly inaccurate' }\end{array}$ \\
\hline $40+$ & 'quite unreliab] & & 'greatly in error' \\
\hline
\end{tabular}

Thus, in the first case, all Maori scores, which are shown in Table 7.5, place the Maori age data in the category of 'fairly unreliable'; 1936 is 'quite unreliable'. In the second case, 1951 and 1956 are 'at least tolerably accurate'; the remainder 'markedly inaccurate'. Howner, these censuses cannot be condemned quite as simply as this, for these high scores result, in part, from known causes. Moreover, these data are not so poor as to preclude analysis of general demographic trends. What the test does show is that the quality of age-reporting has improved in recent years, with the exception of 1926.

The major remaining problems are the small difference between 1926 and 1945, and the fact that 1926 has a lower score than 1936. In the first case, the cause seems to lie, in part, in the special effect of men overseas in 1945, as well, possibly, 
Table 7.6 : Survival Ratio Tests: Difference Between

Expected $n^{P} x$ and Enumerated $n^{P} x$

Note: The differences are the numbers by which the Expected ${ }_{n} P_{x}$ are above $(+)$, or below $(-)$ the Enumerated ${ }_{n} P_{x}$.

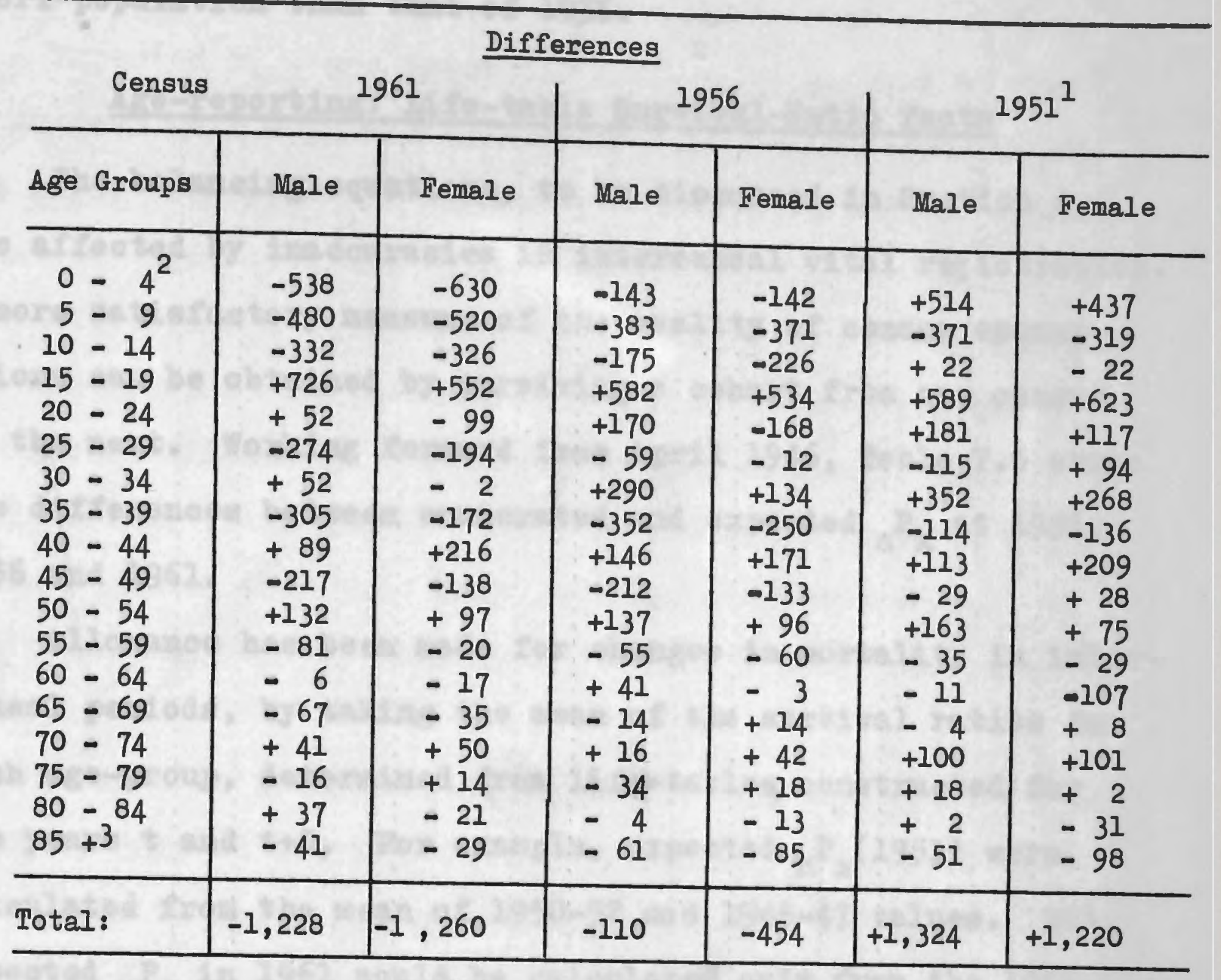

Notes: 1. When aging $n^{P} x$ at Sept. 1945 to April 1946, it was presumed that $70 \%$ of the troops overseas at 1945 had returned by April 1946. This meant that at April 1946 there were 186 males aged 20-24; 145 aged 25-29; 39 aged 30-34; 24 aged 35-39; and 6 aged 40-44 still overseas. The return of these men after April 1946 would have had the effect of increasing the expected $\mathrm{n}^{\mathrm{P}} \mathrm{x}$ at 1951 , and thus altering the pattern of differences slightly. However, there were other men overseas on active service in 1951, mainly 20-24 to 30-34, which would partly restore the balance. Therefore, the pattern of difference shown here for ages 25-29 to 45-49 at 1951 would be affected only a little by the return of troops between April 1946 and 1951.

2. Expected $P_{0-4}=B^{t-(t-4)} \times \frac{I_{0-4}}{5 \cdot I_{0}}$

3. It was presumed that all persons aged $85+$ years died between one census and the next. 
in the rapid changes in mortality at that time. In the second case, no definite answer can be given. Perhaps the 1926 census was a qualitatively better enumeration of the Maori population than that of 1936.

\section{Age-reporting: Iife-table Survival-Ratio Tests}

The balancing equations, to be discussed in section 4, are affected by inaccuracies in intercensal vital registration. A more satisfactory measure of the quality of census enumerations can be obtained by surviving a cohort from one census to the next. Working forward from April 1946, Table 7.6 shows the differences between enumerated and expected $n^{P}$ at 1951 , 1956 and 1961.

Allowance has been made for changes in mortality in intercensal periods, by taking the mean of the survival ratios for each age-group, determined from life-tables constructed for the years $t$ and $t+5$. For example, expected $n^{P} x^{(1951)}$ were calculated from the mean of 1950-52 and 1945-47 values. But, expected $n^{P} x$ in 1961 could be calculated only from the 1955-57 values, as there is no life-table for 1960-62.

A further problem was the uneven period from September 1945 to April 1951. This was overcome by aging each $P_{x}^{1945}$ to April 1946.

Finally, the life tables for 1950-52 and 1955-57 were constructed from smoothed data (see Section 5). The effect of this smoothing is to reduce the variations in the expected ${ }_{n}{ }^{P} x^{\prime}$ and thus in the differences between expected and enumerated $n^{P} x^{\circ}$

In 1951, at ages 0-4, the expected ${ }_{n}{ }^{P} x$ is larger than the enumerated. The expected $\mathrm{P}_{0-4}$ is obtained by surviving births in the previous quinquennium in the census. Thus, the discrepancy may be caused by the improved birth registration in the previous quinquennium, over and above a sudden improvement at 1946, compared with some under-enumeration of age-group 0-4 at the 1951 census. In 1956 there is less difference 
between the expected and the enumerated $\mathrm{P}_{0-4^{\circ}}$ In 1961, the substantial difference at age-group 0-4 may be caused, in part, by the use of the 1956 survival ratio for this quinquennium. 8

Expected $P_{5-9}$ are below the enumerated at each of these censuses. This suggests that under-enumeration of ages $0-4$, the group 'survived' to ages 5-9, occurred at each of the censuses 1945, 1951 and 1956. Another consistent feature is that expected $\mathrm{P}_{15-19}$ are above the enumerated at each census. The age-group 15-19, the school leavers, is probably one of the most difficult to enumerate, as many Maoris of these ages migrate from their homes. Thus, as age-group 10-14 in their parents' homes they have been reliably enumerated. But, by the following census, when 15-19, they are away from parental control.

It is also possible that Maoris of this age-group commonly category-jump to the non-Maori population. However, it is impossible to test this assertion because (a) category-jumpers would be few in number even by comparison with minor enumeration errors in the non-Maori population at this age-group; (b) any test of this type would require, in addition to census data, figures on non-Maori geographical migrants by single years of age.

Persons in age-group 20-24 are also highly mobile, but as each expected $\mathrm{P}_{20-24}$ has been survived from an underenumerated $\mathrm{P}_{15-19}$, deficits are not as marked. Moreover, digitpreference may play some part at ages 20-24. From 20 years to about 60 years, the expected populations with digits $0-4$ (i.e. $20-24,30-34$, etc.) are often above the enumerated, while expected age-groups with digits 5-9 (i.e. 25-29, 35-39, etc.) are below the enumerated. This distinct pattern results from digit-preference and will be discussed below.

8 There was an improvement in infant mortality in this quinquennium. See Vit.Stats.(1961): p.45. 


\section{Exaggeration of Ages}

Persons in age-groups over 70 are liable to exaggerate their ages. No conclusive test can be made other than verification by comparing census returns at one date, with those of another. The Census Department has not done this for Maoris. However, the number of Maori centenarians recorded at each census is so high that there must be some exaggeration. This fact, brought out in Table 7.7, probably holds true for other older age-groups.

Table 7.7: Maori Centenarians, 1926-1956

\begin{tabular}{|c|c|c|c|c|c|}
\hline Th of Mnomi nomi & 1926 & 1936 & 1945 & 1951 & 1956 \\
\hline No. of Maori Centenarians & 28 & 30 & 22 & 20 & 13 \\
\hline No. of Non-Maori Centenarians & 12 & 8 & 8 & 19 & 22 \\
\hline $\begin{array}{l}\text { No. of times the Non-Maori } \\
\text { population out-numbered the } \\
\text { Maori }\end{array}$ & $20 x$ & $18 x$ & $16 x$ & $16 x$ & $15 x$ \\
\hline
\end{tabular}

Source: Census (1926): vol.XIV, p.6; (1936): vol.III, p.IV; (1945): vol.III, p.iii; (1951): vol.VI, p.9;

(1956): vol.VIII, p.12.

\section{Digit-Preference}

Table 7.8: Preferences for Each Unit Digit of $\mathrm{Age}^{\mathrm{l}}$ Recorded by Miles and Females, 1945, 1951 and 1956

Census of:-

$1945 \quad 1951 \quad 1956$

\begin{tabular}{crrrrrr}
\hline $\begin{array}{c}\text { Unit Digit } \\
\text { of Age }\end{array}$ & Males & Females & Males & Females & Males & Females \\
\hline 0 & 10.83 & 11.30 & 11.16 & 11.51 & 10.42 & 10.75 \\
1 & 8.40 & 8.59 & 9.21 & 8.90 & 9.05 & 8.83 \\
2 & 9.27 & 9.76 & 9.87 & 9.58 & 9.55 & 9.62 \\
3 & 9.49 & 9.46 & 9.34 & 9.37 & 9.40 & 10.08 \\
4 & 9.65 & 9.89 & 9.58 & 9.84 & 9.80 & 9.84 \\
5 & 11.43 & 10.97 & 10.37 & 10.29 & 11.09 & 10.71 \\
6 & 9.70 & 9.43 & 10.09 & 10.26 & 10.35 & 10.11 \\
7 & 9.93 & 9.29 & 9.59 & 9.14 & 9.31 & 9.19 \\
8 & 10.85 & 10.57 & 10.45 & 10.92 & 10.83 & 10.36 \\
9 & 10.46 & 10.76 & 10.42 & 10.21 & 10.20 & 10.51 \\
\hline Total & 100.01 & 100.02 & 100.00 & 100.02 & 100.00 & 100.00 \\
$0-4$ & 47.64 & 49.00 & 49.16 & 49.20 & 48.22 & 49.12 \\
$5-9$ & 52.37 & 51.02 & 50.84 & 50.82 & 51.78 & 50.88 \\
\hline Index & 7.13 & 7.18 & 4.98 & 6.36 & 5.78 & 5.04 \\
\hline
\end{tabular}

(Notes overleaf) 
Table 7.8 (cont'd)

Notes: 1. For method used see Muers, Robert J. (1951): "Errors \& Bias in the Reporting of Ages in Census Data", in Jaffe, A.J.: Handbook of Statistical Methods for Demographers, Washington. pp.115-25. The age ranges used here are from 13 to 62 and from 23 to 72 .

2. Deviations from $10 \%$ summed regardless of sign.

Table 7.8 gives the results of digit-preference tests, which are summarised as follows:

(1) Digits $0,5,6,8$ and 9 are preferred digits, while 1,2 , 3,4 and 7 are avoided.

(2) The greater preference for digits $5-9$ (i.e. 15, 25, 35... $65 ; 16,26,36 \ldots 66$; etc.) than for digits $0-4$ (i.e. 20, $30,40 \ldots 70 ; 21,31,41 \ldots .71$; etc.) affects the

distribution of quinquennial age-groups, as was shown above.

(3) The effect on quinquennial age-groups was most marked for males in 1945 and 1956. In 1945, the cause is both digitpreference and the absence of troops overseas. There would have been more men absent aged 20-24 than 25-29; more 30-34 than 35-39, etc. (see note 1, Table 7.6). The cause in 1956 is unknown.

(4) For both sexes, 1945 has the highest index of deviation, so that digit preference was probably the most extreme at that census.

\section{Mid-Year Populations}

Censuses were held either in March/April or september. For many purposes, it was necessary to obtain a mid-year population and age-distribution in census years. This was done by 'aging' the census population to June 30th, after the few cases of unspecified ages (see Table 7.5 , note 1 ) had been distributed on a pro rata basis. Wherever the published mean annual intercensal populations seemed to be deficient, this mid-year population provided a basis from which intercensal total mid- 
year populations were calculated by the formula:

$$
P_{t+n}=P_{t}(1+r)^{n}
$$

where, $P_{t}=$ the mid-year population derived from

a census in the year $t$;

and, $r=$ the geometric rate of growth

4. Anomalies in Intercensal Periods: Notification and Registration of Vital Events

The combining of the Maori and non-Maori registers as from 1962 was discussed in Chapter 2, Section 3. But earlier, certain other administrative and external factors, to be discussed here, affected the implementation of reasonable standards of registration.

(1) Birth notification, as well as registration, is a standard procedure:

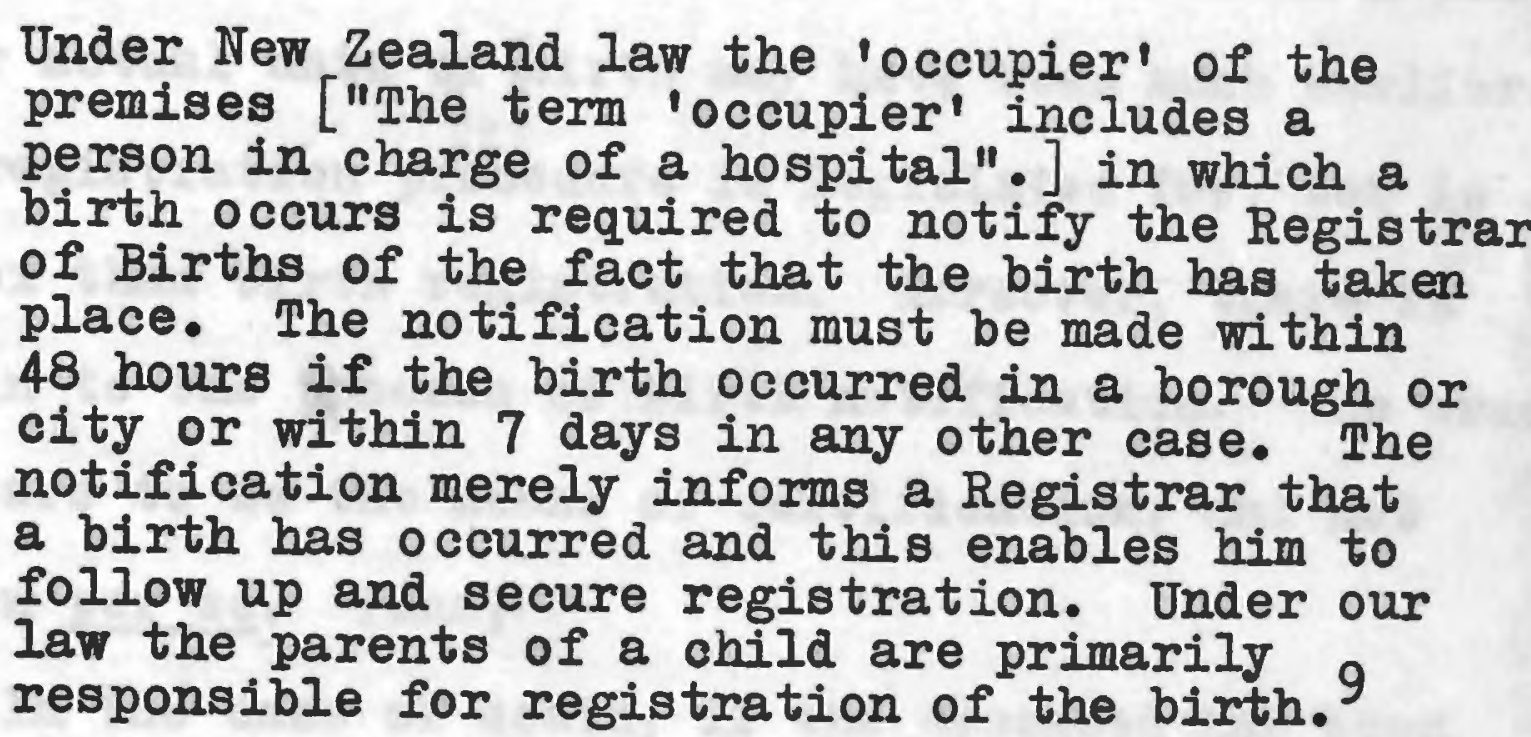

When the 'occupier' is merely a householder, it is possible that notification will be haphazard and therefore it may not always be possible for registrars to secure registration. By contrast, hospitals could be expected to adhere closely to this law. Therefore, increases in hospitalization of maternity cases would probably have brought about an improvement in birth registration.

Foster has calculated, from the birth registration records, that only $16.8 \%$ of Maori live-births occurred in hospitals in the first quarter of 1937. By the first quarter of 1947 this had risen to $49.8 \%$, and by $1960,91.5 \%$ of Maori live-births

9 Registrar-General (Personal Communication) 
occurred in hospitals. 10

In attempting to secure the registration of notified births the registrar probably secures the registration of previously unreported neonatal infant deaths. Thus, the increase in hospitalization of maternity cases has probably resulted incidentally in an improvement in the standards of registration of neonatal infant deaths.

(2) In 1946 the means test was abolished for family benefit payments. Maori families were not excluded prior to this date, but, like non-Maoris, had had to undergo a test to determine their level of income or wealth. 11

To obtain a family benefit evidence of birth registration had to be supplied. Thus, persons up to 16 years of age were registered as births of 1946 although, as is shown in Table 7.11, their actual date of birth may have been much earlier. (3) Death registration procedure is legislated for, but is more complex than birth registration. Moreover, there is nothing akin to the process of birth notification. The crucial factor appears to be the means of certification, and not registration per se. Thus,

In the case of death, if the deceased had been attended during his last illness by a registered medical practitioner, that practitioner is required to issue a medical certificate of causes of death and make it available to the Funeral Director. The practitioner must not, however, issue a medical certificate in a case where he considers that there are suspicious circumstances surrounding the death or where he believes that death was due to violence or unnatural causes. In a case where (a) the deceased had not been attended by a registered medical practitioner or (b) he had died under suspicious circums tances or (c) death was due to violence or unnatural causes, the death must be brought to notice of the Coroner, who is

10 p.12. Foster, F.H. (1962): Maori patients in Mental Hospitals, N.Z. Dept. of Health, Special Report, No.8, Wellington.

11

Year Book (1947-49): p.458. The earlier act came into force in 1938. See N.Z. Govt. (1938): Social Security, Wellington. 
required to determine whether it is a case where he should hold an inquest or not. In certain cases the Coroner must hold an inquest - in others he can order a post-mortem examination or make enquiries with a view to determining the cause of death and if it were established that death was from natural causes he may decide not to hold an inquest. Where the Coroner holds an inquest he becomes responsible under our law for informing the Registrar of his finding and of the other particulars required to be registered. In all other cases the responsibility for registration of a death devolves upon the Funeral Director. No responsibility rests with a relative or next of kin. In most cases, of course, the Funeral Director would obtain the personal details from a relative or next of kin. If a death is reported to the Coroner and he decides not to hold an inquest he must inform the Registrar of the cause of death as disclosed by post-mortem registration or by the enquiries

If attendance by medical practitioners is uncommon a death may go unregistered, unless it is brought to the notice of a coroner. As recently as 1959 the Medical Statistician reported, with respect to Maori deaths, that: "Death certificates are not required by law to be submitted by a medical practitioner, though nowadays an increasing percentage is vouched for either by a medical practitioner or by a coroner". 13 The increase in the certification of Maori deaths by practitioners is shown in Table 9.1. In earlier periods almost $50 \%$ of deaths were not certified either by a practitioner or by a coroner (Chapter 9, Section 2), and yet registration was somehow secured. The obvious questions are these: how many uncertified deaths were not eventually registered? Were all certified deaths eventually registered?

Certification by a medical practitioner is not a guarantee that registration will occur. It is probable that responsible practitioners, many of whom would have been government employees in the earlier periods, would take steps to see that registration was completed. However, this is not their legal responsibility, the responsibility lies with funeral directors.

\footnotetext{
12 Regiatrar General (Personal Communication)

13
} 
Yet, it is probable that until recently a considerable proportion of Maori burials would have occurred at tangi in the deceased's home community and without the employing of a funeral director. From these comments it appears that death registration procedure was more haphazard than for birth registration. Recently, these factors have probably declined in importance, but earlier they may have impeded the collection of adequate death statistics.

(4) New Maori death registration procedures were introduced in 1935. These include the shortening of the statutory maximum period between death and registration of the death, from 2 months to 7 days (South Island), and to 14 days (North Island) 14

$\frac{\text { A Survey of Published Vital }}{\text { Rates }}$

Table 7.9 presents published crude death and birth rates. These rates are adjusted neither for census under-enumeration nor for vital under-registration. Before discussing intercensal periods in detail it is worthwhile to survey these vital rates to note whether there are any periods in which vital data appear to be unsatisfactory.

A number of tentative conclusionsmay be made:

(1) Generally, crude death rates were lower in the period 1926-34 than in the period 1935-42. Since 1942 they have declined, but this decline probably arose from declines in mortality rather than in standards of death registration.

1935 was the year in which new administrative procedures were introduced and this may have led to improved standards of registration. Moreover, there were no changes in age-structure sufficient to affect the death rate in any significant way. Thus, it appears that $c$ rude death rates in the period 1926-34 may require further examination.

14 A.J.H.R. (1935): H-3l, p.6. 
Table 7.9: Published Vital Rates (Both Sexes), 1926-56

Rates per 1,000 of the mean annual population

\section{Year}

\section{Crude birth rate $\quad$ Crude death rate}

$\begin{array}{lll}1926 & 25.3 & 11.0 \\ 1927 & 23.2 & 15.9 \\ 1928 & 28.4 & 16.9 \\ 1929 & 33.6 & 13.3 \\ 1930 & 31.6 & 13.6 \\ 1931 & 33.7 & 14.2 \\ 1932 & 39.3 & 16.2 \\ 1933 & 41.2 & 15.3 \\ 1934 & 38.1 & 16.4 \\ 1935 & 40.4 & 18.0 \\ 1936 & 43.8 & 19.3 \\ 1937 & 46.6 & 18.3 \\ 1938 & 43.4 & 24.3 \\ 1939 & 46.2 & 19.9 \\ 1940 & 46.9 & 17.5 \\ 1941 & 44.8 & 20.6 \\ 1942 & 45.8 & 18.3 \\ 1943 & 45.8 & 17.3 \\ 1944 & 45.3 & 17.0 \\ 1945 & 46.1 & 16.2 \\ 1946 & 56.8 & 16.0 \\ 1947 & 47.5 & 14.6 \\ 1948 & 46.0 & 13.7 \\ 1949 & 44.5 & 14.2 \\ 1950 & 45.1 & 12.1 \\ 1951 & 45.0 & 11.4 \\ 1952 & 45.4 & 12.3 \\ 1953 & 44.5 & 10.8 \\ 1954 & 44.4 & 9.4 \\ 1955 & 43.6 & 9.6 \\ 1956 & 44.6 & 9.4\end{array}$


(2) For males, the absence of troops during World War II must be taken into account. The published rates use deaths occurring in New Zealand as a numerator, whereas the denominator, the mean annual population, has not been adjusted for the absence of troops overseas. Thus, the male crude death rate of this period may be higher than the published data suggest.

(3) It has been shown that the population is 'quasi-stable'. Thus, throughout the period crude birth rates should approximate those of the period about 1956. Yet, in eight of the ten years in the period 1926-35 the rates do not exceed 40 per 1,000, which is just above the level estimated for 1900 . Thus, birth rates in the period 1926-35 may require some adjusting.

(4) Since 1936 birth rates have always been above 40 per 1,000 .

(5) In 1946, the rate is extremely high, which coincides with the late registration resulting from changes in the administration of family benefits. However, this was also the period during which Maori troops returmed from the war. It is necessary to examine the significance of each of these factors.

In the next section balancing equations are presented. These are based on vital and census data plus the estimates of category-jumping made above. Where a severe imbalance is shown for an intercensal period, the quality of vital registrations may be only one factor. However, this brief survey has pointed to periods in which this factor may be of some importance. 


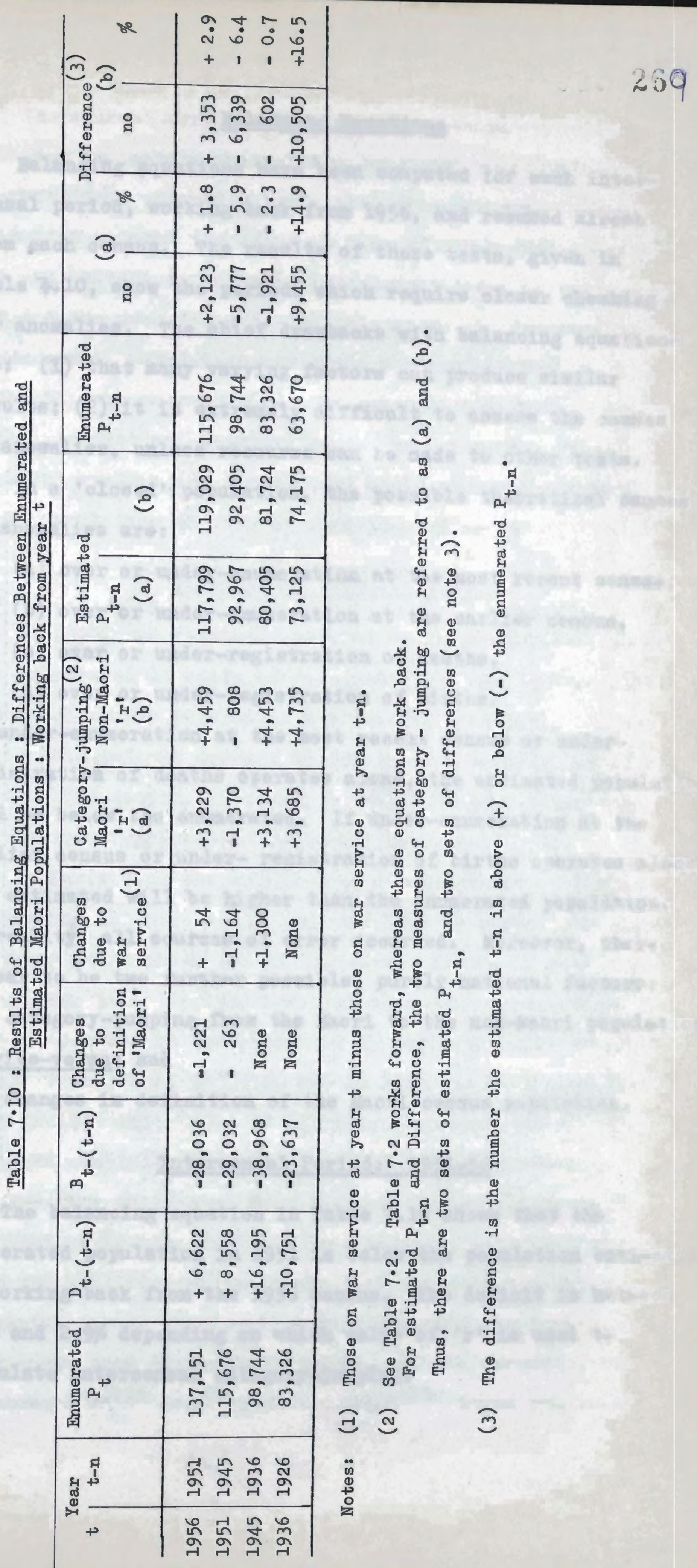




\section{Balancing Equations}

Balancing equations have been computed for each intercensal period, working back from 1956, and resumed afresh from each census. The results of these tests, given in Table 7.10 , show the periods which require closer checking for anomalies. The chief drawbacks with balancing equations are: (1) that many varying factors can produce similar results; (2) it is extremely difficult to assess the causes of anomalies, unless recourse can be made to other tests.

In a 'closed' population, the possible theoretical causes of anomalies are:

(a) over or under-enumeration at the most recent census,

(b) over or under-enumeration at the earlier census,

(c) over or under-registration of deaths,

(d) over or under-registration of births.

If under-enumeration at the most recent census or underregistration of deaths operates alone, the estimated population will be below the enumerated. If under-enumeration at the earlier census or under- registration of births operates alone, the estimated will be higher than the enumerated population. In reality, all sources of error occurred. Moreover, there appear to be two further possible, purely national factors: (1) category-jumping from the Maori to the non-Maori population, or vice-verse; and

(2) changes in definition of the Maori census population.

\section{Intercensal Period: 1951-56}

The balancing equation in Table 7.10 shows that the enumerated population in 1951 is below the population estimated by working back from the 1956 census. The deficit is between 1.8\% and $2.9 \%$ depending on which value of ' $r$ ' is used to calculate intercensal category-jumping. 
The bulk of the deficit arises from category-jumping, and thus it appears that vital registration was fairly satisfactory. Provided that category-jumping was not a selective process (in terms of age and other characteristics) the only marked deficits in intercensal rates in this period would occur near the end. At this stage the denominator (mean annual population aged from a census at $t-n$ ) would refer to some Maoris whose vital events, presumably, were now being recorded in non-Maori registers. However, it is doubtful whether the denominator would exceed the actual Maori population at risk by more than $2 \%$ to $3 \%$.

\section{Intercensal Period: 1945-51}

At 1945, the estimated population is considerably below the enumerated in spite of some category-jumping back into the Maori census population between 1945 and 1951. On the whole this deficit appears to result from under-enumeration at the 1951 census. However, a factor of some importance is the over-registration of births in 1946.

In Table 7.11 the actual date of occurrence of births registered in 1936, 1941, 1946 and 1951 is shown. In each of these years about $10 \%$ of registered births in year $t$ occurred in year t-l. In 1936 and 1941 over 12\% of registered births occurred in the years $t-2$ or earlier. This factor had almost disappeared in 1951, but in 1946 was more significant than in 1936 and 1941. If all late registrations in 1936 and 1941 are combined and termed 'normal late registrations', (\%), and are then subtracted from the late registrations in 1946, the residue is the 'abnormal late registration' resulting from the abolition of the means test for family benefit payments. After this residue is subtracted the crude birth rate drops from 57 per 1,000 to 49, and the excess of the Enumerated $\mathrm{P}^{1945}$ over the Estimated $\mathrm{P}^{1945}$ drops from the 
range 5,777 to 6,339 , down to the range 5,206 to 5,768 .

A second factor of importance in this period was the return of troops in 1945-46. They were not enumerated in 1945 but were in 1951, which causes an inconsistently high annual intercensal rate of growth $(r)$.

Table 7.11: Date of Occurrence of Births (Both Sexes) Registered in 1936, 1941, 1946 and 1951

\begin{tabular}{|c|c|c|c|c|c|c|c|c|}
\hline \multirow{3}{*}{$\begin{array}{r}\text { Year of } \\
\text { occurrence }\end{array}$} & \multicolumn{8}{|c|}{ Date of Registration ( $=$ year $t$ ) } \\
\hline & \multicolumn{2}{|c|}{1936} & \multicolumn{2}{|c|}{1941} & \multicolumn{2}{|c|}{1946} & \multicolumn{2}{|c|}{1951} \\
\hline & (I) & (2) & (1) & (2) & (1) & (2) & $(1)$ & (2) \\
\hline $\begin{array}{l}t \\
t-1 \\
t-2 \text { to } t-10 \\
t-11 \text { to } t-19 \\
t-20 \text { to } t-n\end{array}$ & $\begin{array}{r}2,713 \\
418 \\
363 \\
123 \\
13\end{array}$ & $\begin{array}{r}74 \cdot 4 \\
11.5 \\
10.0 \\
3.4 \\
0.4\end{array}$ & $\begin{array}{r}3,168 \\
428 \\
322 \\
179 \\
37\end{array}$ & $\begin{array}{c}76.6 \\
10.4 \\
7.8 \\
4.3\end{array}$ & $\begin{array}{r}3,796 \\
533 \\
636 \\
750 \\
61\end{array}$ & $\begin{array}{r}65.6 \\
9.2 \\
11.0 \\
13.0 \\
1.1\end{array}$ & $\begin{array}{r}4,598 \\
530 \\
11 \\
36 \\
63\end{array}$ & $\begin{array}{r}87.8 \\
10.1 \\
0.2 \\
0.7 \\
1.2\end{array}$ \\
\hline tals $t$ & 30 & 99.7 & 4,134 & 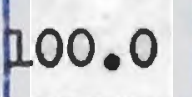 & 5,776 & 99.9 & 5,238 & 100 \\
\hline
\end{tabular}

Notes: (1) Numbers. (2) \%'s. (3) In 1946 includes births occurring between 1927 and 1935. (4) Largely registrations by persons wishing to receive old age pensions.

Source: Unpublished data from Department of Statistics (personal communication).

\section{Intercensal Period: 1936-45}

Once allowance is made for category-jumping, there is a very small difference between the estimated and enumerated $\mathrm{P}^{1936}$. The remaining difference is more than accounted for by the combined effect of two factors:

(1) There was under-enumeration at ages 0-9 in 1945.

(2) There was an improvement in birth registration in the period 1936-45, probably in response to the increasing hospitalization of maternity cases.

These two arguments can be supported as follows: 'Expected' $P_{0-4}^{1945}$ and $P_{5-9}^{1945}$ can be estimated by surviving births of the previous two quinquennia through to the 1945 census. 
These expected $\mathrm{P}_{0-4}$ and $\mathrm{P}_{5-9}$ exceed the enumerated, as is shown in the following table:

Differences between Expected $(1)$ \& Enumerated
$\mathrm{P}_{0-4}$ and $P_{5-9}$ at the 1945 census.

$\begin{array}{lcr} & \frac{P_{0-4}}{P_{0}} & \frac{P_{5-9}}{+277} \\ \text { Females } & +1,661 & +253\end{array}$

Note: (1) Survival ratios were derived only from life-tables for 1944-46. However, lifeexpectation at ages $0-9$ were very similar in 1945 and 1936. (See Table 8.6).

The other factor of importance was the movement overseas of troops during the war. This had two effects on trends: (1) $r^{1936-45}$ is inconsistently low because of the absence in 1945 of men enumerated in 1936. Thus, $r_{(m)}$ was calculated including troops overseas in 1945.

(2) Published mean annual populations take no account of this movement. Thus, mid-year populations (male) were calculated for war years by determining $r^{1936-45}$ as discussed above. Then mid-year populations were calculated for the period 1936-40; to the year in which the first large group of Maori troops left. Finally, $r_{(m)}$ was calculated for the period 1941-45, excluding troops at both periods.

A new series of male crude death rates were calculated using these mid-year populations as a denominator. However, this adjustment has only a slight effect on the rates:

Male Crude Death Rates, 1941-45

Year

1941

1942

1943

1944

1945
Published Rate

21.7

19.4

17.5

17.1

16.9
Adjusted Rate

22.1

19.8

18.0

17.6

17.3 


\section{Intercensal Period: 1926-36}

The balancing equation shows a deficit of $15.5 \%$ for the 1926 census, $^{15} i, e$, the enumerated population is below the estimated by this amount. The causes appear to be as follows: (a) births are under-registered; (b) deaths are underregistered, but the under-registration of births is greater, proportionately, than that of deaths; (c) the 1926 census is under-enumerated; (d) some persons enumerated in the 1926 Maori census population were recorded as non-Maoris in 1936.

In this section, under-registration of births will be estimated and adjustments will be made. Then the underregistration of deaths will be calculated. Moreover, it will be shown that the 1926 census is deficient, and the necessary adjustments will be made.

Registered births were compared, at each calendar year, with births estimated by reverse survival ratios from the relevant $P_{X}$ at the 1936 census. This comparison was considered valid only in those years where the difference was greater than 10\%, in this case between 1926 and 1931. The reasons for this are:

(a) There was poor enumeration of ages 0-2 at the 1936 census, which can be seen by inspecting the published data on single years of age (Figure 7.2 ).

(b) The life-table values $I_{0}, I_{1-4}$ and $I_{5-9}$ were the only sources available from which survival ratios could be estimated; the publication of deaths by grouped ages precludes the construction of 'complete' tables until 1951.

The adjustments to births made on this basis are compared with published data in the following table:

\footnotetext{
15

14.9\% using Mrori ' $r$ ' when estimating categoryjumping, and 16.5 using non-Maori ' $r$ '.
} 
Published Data

Year Mean Births $\frac{\text { Annua }}{\text { P. }}$

\section{6}

1927

1928

1929

1930

1931

1932

1933

1934

1935
61,842

65,125

66,399

67,934

69,841

71,665

73,626

75,910

78,239

80,559
1,536

1,495

1,845

2,216

2,124

2,312

2,745

2,948

2,981

3,251

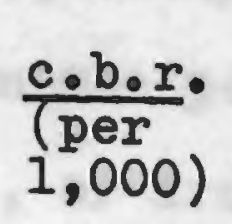

25.3

23.2

28.4

33.6

31,6

33.7

39.3

41.2

38.1

40.4
Adjusted Data

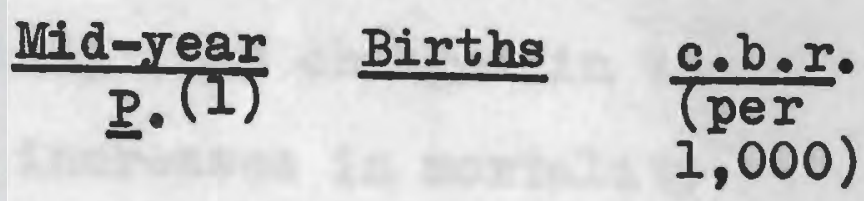

70,171

71,345

72,539

73,753

74,987

76,242

77,518

78,816

79,535

81,476

2,283

2,389

2,482

2,662

2,865

2,844

2,836

2,925

3,031

3,274
32.4

33.5

34.3

36.1

38.2

37.3

36.6

37.2

38.1

40.3

Note: (1) Allowing 10\% under-enumeration in 1926

For descriptive purposes it appears that the adjusted rates give a more consistent picture than the published rates. However, the adjustments are not entirely satisfactory; the adjusted rates are probably still too low.

When deaths were adjusted, the adjusted births given here were used. In this light two further considerations must be noted. Firstly, because of possible digit-preference, this procedure tends to exaggerate deficits at certain years corresponding to such ages as 5 and 6 at the 1936 census. Secondly, it is apparent that birth registration improved during the $1930 \mathrm{~s}$, if the published rate can be taken as a gauge. In 1935, new administrative procedures for vital registration were brought into being, but were of greater importance to death registration. However, improved registration of infant deaths could have had the effect of ensuring that the births of infants, who subsequently died, were registered when their deaths were recorded.

If the estimated births (see above), determined from this test, are taken as a truer indication of trends in the period 1926-36, then the $15.5 \%$ deficit in the balancing equation is reduced to $6.1 \%$. However, this adjustment is not sufficient, for it has been shown that published death rates were lower 
in this period than subsequently. This could arise either from poor registration in the period, from changes in the age-structure about 1935, or from increases in mortality about 1935. The following reasons suggest that the lower death rates, from 1926 to 1935, resulted from poor registration: (a) The age-structure was relatively similar in the decades 1926-35 and 1936-45. Thus there is little difference between standardised and crude death rates at 1926, 1936, and 1945 as is shown in the accompanying table: $\frac{\text { Death Rates } 1926,1936 \text { and } 1945 \text { Standardised to the }}{1956 \text { Population (Direct Standardisation) }}$

Males

Females

Years crude d.r. Standardised d.r. Crude d.r. Standardised

$\begin{array}{lllll}1926 & 14.6 & 14.1 & 14.5 & 14.0 \\ 1936 & 18.6 & 18.2 & 18.2 & 17.6 \\ 1945 & 17.0 & 17.4 & 16.5 & 16.5\end{array}$

(b) All the evidence points to crude death rates as high in the earlier decade as the one following. Rather, there is no evidence to support an increase in mortality in 'normal' years after 1935 (i.e. years in which there were no widespread epidemics). (c) As noted above,/death registration procedures were introduced in 1935.

Thus, deaths should be adjusted to allow for under-registration, and the following method was used:

(1) The mid-year population in each year was found by the formula given in Section 3. (2) Deaths can then be obtained quite simply:

$$
D_{t}=\left\{\frac{\left[P_{t-1}+\frac{B_{t-1}+B_{t}}{2}\right]-\left[P_{t-1}(I+r)\right]}{2}\right\}+\left\{\frac{\left(P_{t}+\frac{\left.B_{t}+B_{t+1}\right]}{2}\right]-\left[P_{t}(I+r)\right]}{2}\right\}
$$

where, $D_{t}$ are the estimated deaths in cal endar year $t$;

$P_{t}$ is the estimated mid-year population in calendar year $t$.

$B_{t}$ are the adjusted births (see above) in calendar year $t_{s}$ 
The higher death rates, once this adjustment had been made, are shown in the following table:

\begin{tabular}{|c|c|c|c|c|c|c|c|c|}
\hline \multirow[t]{2}{*}{ Year . } & \multicolumn{2}{|c|}{ Deaths } & \multicolumn{2}{|c|}{$\begin{array}{l}\text { Death rates } \\
(\text { per } 1,000)\end{array}$} & \multicolumn{4}{|c|}{$\frac{\text { Adjusted Data }}{\text { Deaths } \mid \begin{array}{l}\text { Death rates }(1) \\
(\text { per } 1,000)\end{array}}$} \\
\hline & 宜 & $f$ & m & $f$ & m & $f$ & m & $f$ \\
\hline $\begin{array}{l}1926 \\
1927 \\
1928 \\
1929 \\
1930 \\
1931 \\
1932 \\
1933 \\
1934\end{array}$ & $\begin{array}{l}469 \\
546 \\
585 \\
504 \\
493 \\
528 \\
619 \\
613 \\
660\end{array}$ & $\begin{array}{l}450 \\
487 \\
539 \\
402 \\
453 \\
487 \\
573 \\
548 \\
623\end{array}$ & $\begin{array}{l}14.7 \\
16.1 \\
17.2 \\
14.6 \\
14.1 \\
14.8 \\
17.0 \\
16.5 \\
17.3\end{array}$ & $\begin{array}{l}15.6 \\
15.8 \\
17.3 \\
12.8 \\
14.1 \\
14.8 \\
17.1 \\
16.0 \\
17.7\end{array}$ & $\begin{array}{l}615 \\
623 \\
676 \\
730 \\
772 \\
788 \\
800 \\
850 \\
937\end{array}$ & $\begin{array}{l}588 \\
581 \\
625 \\
715 \\
795 \\
795 \\
774 \\
773 \\
801\end{array}$ & $\begin{array}{l}16.8 \\
16.7 \\
17.9 \\
19.0 \\
19.7 \\
19.8 \\
19.8 \\
20.7 \\
22.5\end{array}$ & $\begin{array}{l}17.5 \\
17.0 \\
18.0 \\
20.3 \\
22.2 \\
21.8 \\
20.9 \\
20.5 \\
20.9\end{array}$ \\
\hline
\end{tabular}

Notes: (1) The denominators are the published mean and estimated mid-year populations given in the table in the text in which published and adjusted births are shown.

One further problem was the geometric rate of growth $(r)$, which was used for the adjustment to the deaths. This rate depends, of course, on the veracity of the census enumerations. In Table, it can be seen that the 1926-36 growth rate is inconsistent, unless the 1926 census is adjusted for underenumeration.

If it is assumed that death rates in the period 1936-41 (excepting 1938, when there was an epidemic) ${ }^{16}$ were similar to those in the period 1926-35, a factor is obtained: $\frac{\text { av. crude death rate } 1936-37 \text { and } 1939-45}{\text { av. crude death rate } 1926-35}$, which can be used to adjust the deaths in the 1926-36 balancing equation. The result of this new equation is that under-enumeration is $10 \%, 17$ and the growth rate is lowered accordingly. This was

\footnotetext{
16 There was an epidemic of smaller magnitude in 1941. As there was also at least one epidemic in the decade 1926-35, inclusion of 1941 data in this factor seems fair.

17 The percentage was 9.5 or 11.1 depending on the value of ' $r$ ' which was used to measure category-jumping. Although their mean is $10.3 \%$, for facility of calculation this figure was rounded to $10 \%$.
} 
the growth rate used to adjust for the under-registration of deaths, and when mid-year populations were estimated for this intercensal period and for 1925. In the latter case, the mid-year $P$ was determined by the formula: $P_{1925}=P_{1926^{\circ}} \frac{1}{1+r}$. It was necessary to determine $\mathrm{P}_{1925}$ when making adjustments to births and deaths for the period 1926-35.

\section{Iife-Table Construction}

Two sets of life-tables are used in this thesis:

(1) 'Abridged' tables were constructed by the writer for the periods 1925-27, 1935-37 and 1944-46. (2) Government

'complete' tables were available for 1950-52 and 1955-57. This section is concerned with the construction of lifetables by the present writer.

Obviously, accuracy in the construction of life-tables is as affected by poor data as are other computations. But there are several special problems:

(a) Iife-tables were based upon average $D_{x}$ (deaths at age $x$ ) for a 3-year period around June 30 th in a census year. (b) In general, standard procedures for the construction of 'abridged' tables were followed, ${ }^{18}$ although it was not possible to obtain greater detail than $D_{0}, D_{1-4}, D_{5-9}, \ldots$ $D_{85+^{*}}$

18 For most values construction has followed the methods described by Glass for abridged tables. pp.374-83. Glass,D.V. (1940): Pop.Policies \& Movement in Europe. Oxford. In particular,

$$
\begin{aligned}
& { }^{p_{x}}=\frac{n^{P}-5 / 2 D_{x}}{{ }^{P}+5 / 2 D_{x}} \\
& P_{0}=\frac{\text { births - deaths } 0-11 \text { months }}{\text { births }} \\
& p_{1-4}=\frac{P_{1-4}-2 D_{x}}{P_{1-4}+2 D_{x}}
\end{aligned}
$$

Deaths at age $x$ and births were averaged for the 3-year period around June 30 th in a census year. A mid-year population was aged from a census to June $30 \mathrm{th}$. Thus, the life-table for 1945 uses the average annual number of deaths for the period 1944-46.

The official tables for 1950-52 and 1955-57 describe the methods employed in their construction. See census (1951): 
(c) Approximations had to be made for $I_{x}$ values at the youngest age groups. Thus, $I_{0}=.25 I_{0}+.75 I_{1} ; I_{1-4}=2\left(I_{1}+I_{5}\right)$; and, $5^{I_{x}}=2.5\left(I_{x}+I_{x+5}\right)$.

(d) In order to allow for poor data, three tables were constructed for 1926. Firstly, one was constructed using published data. In the second case, estimated births were used; numbers at each age were increased to allow for $10 \%$ under-enumeration; and deaths at each age were increased by $32 \%$ (males) and $42 \%$ (females). This last adjustment was the average percentage difference bwteen published and estimated deaths for the period 1926-30. In the third case, for females only, it was assumed that deaths at age 0 were underregistered by $72 \%$, an arbitrary number $30 \%$ greater than that used for all ages. Other data were the same as for the first estimated table. The results for $\varepsilon_{0}$ are shown here:

(1) Using published data

(2) Correcting for under-enumeration and under-registration

(3) As in (2), but allowing $72 \%$ under-registration of $\mathrm{D}_{0}$

\begin{tabular}{|c|c|}
\hline Males & Females \\
\hline 49.4 & 49.6 \\
46.6 & 44.7 \\
- & 43.5 \\
\hline
\end{tabular}

Even allowing for a considerable degree of under-registration, results do not vary greatly from those obtained from published data.

(e) When ${ }_{n} p_{x}$ columns were graphed, it was ascertained that little extra value would be added to the study if death rates at older ages were smoothed. Inconsistencies occur in the

fn.18 (cont'd)

Appendix B, pp.12-14; and, (1956): Appendix B, pp.22-23. The only other official ife-table value for Maoris was that presented to the Dominion Population Committee. This was an \& for both sexes of 46.2 years, and appears to have been derlved from a table constructed for 1936. See "Report of the Dom.Pop.Committee", A.J.H.R. (1946): I-17, pp.18 \& 126. 
abridged tables constructed for earlier periods, but these tables will be used for general descriptive purposes only. The exceptions to this are the use of survival ratios for younger ages in the 1926-36 and 1936-45 intercensal periods, and for the entire population from 1946 to 1951.

During the construction of the two most recent tables, which are the government 'complete' tables for 1950-52 and 1955-57, and which are used for survival-ratios for recent periods, both age and age at death data were smoothed. These two tables can be considered the most reliable, both in terms of the method of construction and the data available.

\section{Conclusion}

The Maori census population is 'quasi-stable' and is 'closed' to geographical migration. However, it is 'open' to inter-ethnic 'migration', which takes the form of categoryjumping from the Maori to the non-Maori census population, and vice versa. Category-jumping could be a random process (in terms of age-selectivity), for it has not had the effect of moving the population away from its 'quasi-stable' structure. Although 'active migration' may occur mainly at ages 15t, such a movement, even if age-selective, would have the same effect as changes in mortality. Changes in mortality have little effect on 'quasi-stable' age-distributions except at very young ages. Moreover, some 'active' migrants may carry 'passive' migrants aged 0-14 with them.

The tests relating to intermal accuracy and underenumeration have revealed that age-reporting was unsatisfactory until the Second World War. Even at the two most recent censuses age-reporting anomalies occurred. However, in general, there was probably an improvement at the more recent censuses with 1956 standing out as perhaps the most satisfactory. Nevertheless, when the censuses are compared in terms of their relative qualities a complex patterm is derived. Relatively, 
under-enumeration was more marked in 1951 and 1926 than in 1956, 1945 and 1936. Although the 1936 and 1945 censuses appear to be fairly complete enumerations, their agedistributions are not as satisfactory as at 1956, 1951 and 1926.

It was necessary to adjust the vital data of the period 1926-35. Since 1935, vital registration appears to have improved, but an adjustment had to be made to births in 1946 to counteract abnormally high levels of late registration in that year.

The adjustments to births and deaths in the period 1926-35 give higher and more consistent crude rates for the period than are shown by published data. Nevertheless, the adjustments have probably not counteracted all under-registration, for the adjusted rates still fall below the rates calculated from published data for a number of subsequent years. 


\section{CHAPTER EIGHT}

Maori Mortality Trends Since 1922: Part I,

\section{General Trends}

\section{Introduction}

Rapid declines in mortality provide the essential explanation of the contemporary expansion of population growth in 'under-developed'areas. In many South American, Asian and even African countries the declines in this century have been much more rapid than the mortality transition of nineteenth century Europe. New Zealand is one of the few countries where the nineteenth century European-type trends and the twentieth century contemporary-type trends in mortality have occurred within a single nation-state. Here is a country with high per capita incomes, in wich live both a majority population mainly of European origin with levels of mortality which are amongst the lowest in the world, and at the same time and closely associated with this majority population, an ethnic minority whose mortality experience bears a closer resemblance to that of the populations of the world's 'underdeveloped' areas. Thus, New Zealand provides almost a unique opportunity of examining the reaction of a population of high fertility and high mortality to direct contact with a population with a high degree of rational control over fertility and very low levels of mortality.

In many respects the environments to which both Maoris and non-Maoris have been exposed are similar. There have been no political upheavals in the period. In theory, both groups have participated in periods of economic growth. Similarly, the depression of the 1930s affected both Maoris and nonMaoris. Involvement in the two wars was not restricted to non-Maoris. Zew Zealand has experienced few of the major 'apocalyptic' epidemic diseases. Social welfare, public 
health and hygiene legislation applies to both groups.

Social services, private and public, are freely available to

Maori and non-Maori. Presumably, there should be no

differences in mortality. But, in practice, these differences are marked, and result from a host of minor environmental

factors.

In another sense, New Zealand is a good subject, for some mortality data are of a high standard, in terms of both accuracy and scope. By comparison with high mortality populations elsewhere, this is true for Maori mortality data, for Stolnitz has shown that one of the factor closely correlated with high mortality is inaccuracy of mortality data, which characterises his 'Latin America - Africa - Asia' region of 'under-developed' nations.' But, Maori mortality data are not entirely satisfactory when compared with those available for non-Maoris.

The questions to be asked here are: 1) What were the trends of Maori mortality in the period, and when did improvements, if any, take place? 2) What factors brought about improvements? 3) Were Maori trends different from non-Maori and, if so, why?

\section{Accuracy of Data}

This topic has been covered in Chapter Seven, but several features should be noted. (a) 1921 is an approximate dividing line in this thesis, but in studying mortality during the last few decades there are sufficient comparable data to take the study back to 1920-22 (See Chapter Two, Section 6). (b) Improvements in vital registration did not take place until the mid-1930s, and it was even later that their coverage

1 pp.45-47. Stolnitz, George J. (1955.a.): "A Century of International Mortality Trends: Part I ", Pop.Stud., vol.IX, no.1, July. pp.24-55. 


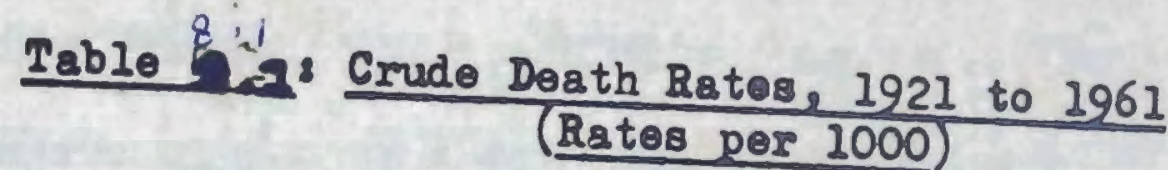

\begin{tabular}{|c|c|c|c|c|}
\hline \multirow{2}{*}{ Year } & \multicolumn{2}{|c|}{ Males } & \multicolumn{2}{|c|}{ Females } \\
\hline & (1) & (2) & (1) & (2) \\
\hline 1922 & $\begin{array}{l}16.6 \\
16.9\end{array}$ & - & 15.3 & - \\
\hline 1923 & 14.9 & - & $\begin{array}{l}17.5 \\
13.5\end{array}$ & - \\
\hline 1924 & 14.3 & - & 14.4 & $\overline{-}$ \\
\hline $\begin{array}{l}1925 \\
1926\end{array}$ & 15.1 & - & 14.7 & - \\
\hline 1927 & $\begin{array}{l}14.7 \\
16.1\end{array}$ & 16.8 & 15.6 & 17.5 \\
\hline 1928 & 17.2 & 16.7 & 15.8 & 17.0 \\
\hline 1929 & 14.6 & $\begin{array}{l}17.9 \\
19.0\end{array}$ & 17.3 & 18.0 \\
\hline 1930 & 14.1 & 19.7 & 12.8 & 20.3 \\
\hline 1931 & 14.8 & 19.8 & 14.1 & 22.2 \\
\hline 1932 & 17.0 & 19.8 & 14.8 & 21.8 \\
\hline 1933 & 16.5 & 20.7 & 17.1 & 20.9 \\
\hline 1934 & 17.3 & 22.5 & $\begin{array}{l}16.0 \\
17.7\end{array}$ & 20.5 \\
\hline 1935 & 19.2 & - & $\begin{array}{l}17.7 \\
19.4\end{array}$ & 20.9 \\
\hline 1936 & 19.6 & - & $\begin{array}{l}19.4 \\
19.0\end{array}$ & - \\
\hline 1937 & 18.8 & - & $\begin{array}{l}19.0 \\
17.8\end{array}$ & $\overline{-}$ \\
\hline 1938 & 24.5 & - & 24.2 & $\overline{-}$ \\
\hline 1939 & 20.9 & - & 18.9 & $\overline{-}$ \\
\hline 1940 & 18.0 & - & 17.0 & - \\
\hline 1941 & 21.7 & $22.1(3)$ & 19.5 & - \\
\hline $\begin{array}{l}1942 \\
1943\end{array}$ & 19.4 & $19.8(3)$ & 17.2 & - \\
\hline $\begin{array}{l}1943 \\
1944\end{array}$ & 17.5 & $18.0(3)$ & 17.1 & - \\
\hline $\begin{array}{l}1944 \\
1945\end{array}$ & 17.1 & $17.6(3)$ & 16.8 & - \\
\hline $\begin{array}{l}1943 \\
1946\end{array}$ & $\begin{array}{l}16.9 \\
16.0\end{array}$ & $17 \cdot 3(3)$ & 15.5 & - \\
\hline 1947 & 14.7 & - & 16.0 & $\overline{-}$ \\
\hline 1948 & 14.3 & - & $14 \cdot 5$ & - \\
\hline 1949 & 14.0 & - & $\begin{array}{l}13.0 \\
14.3\end{array}$ & - \\
\hline 1950 & 12.6 & - & 11.5 & - \\
\hline 1951 & 12.4 & - & 10.3 & - \\
\hline 1952 & 13.0 & - & 11.6 & - \\
\hline $\begin{array}{l}1953 \\
1954\end{array}$ & 12.0 & - & 9.7 & - \\
\hline $\begin{array}{l}1954 \\
1955\end{array}$ & 10.4 & - & 8.4 & - \\
\hline 1956 & $\begin{array}{l}10.2 \\
10.0\end{array}$ & - & 8.9 & - \\
\hline 1957 & 11.0 & $\bar{z}$ & 8.7 & - \\
\hline 1958 & 9.6 & - & $\begin{array}{l}9.2 \\
7.7\end{array}$ & $\overline{-}$ \\
\hline 1959 & 9.1 & - & 7.9 & - \\
\hline $\begin{array}{l}1960 \\
1961\end{array}$ & 9.5 & - & 7.6 & - \\
\hline & 9.3 & - & $7 \cdot 2$ & - \\
\hline
\end{tabular}

Notes: (1) Published Deaths

Fublished Mean Population. Prior to 1926, vital registrations employed a different definition of Maori from that used in the census.

(2) Deaths adjusted for under-registration Mid-year population adjusted for under-onumeration eto.

(3) Published Doaths

Mid-year Population adjusted for under-enumeration otc. The adjustments to wartime male populations are the value of this measure. 
was close to complete. (c) vital registration data on age at death, and the census figures for the number at each agegroup probably have deficiencies, particularly before the mid-1930s. This affects the calculation of age-specific rates right through the period, and also the life-tables constructed by the writer for 1926, 1936 and 1945. When the 1951 and 1956 government tables were constructed both $\mathrm{Dx}$ and $\mathrm{nPx}$ were smoothed. (d) Generally, chapters eight to eleven on mortality since 1913 deal with the period 1925 to the present, as no attempt was made to adjust data prior to this. Any brief excursions into the period prior to 1925 presume that the data are most unreliable. Moreover, denominators are different from those of the period since 1925, for there was a major change in the census definition of Maori in the intercensal period 1921-26.

\section{Crude Death Rates}

This analysis of crude death rates, from data presented in Table 8.1 , is more securely based than many, because cross-cultural comparisons are not being made. Furthermore, variations in age-structure were not large enough to affect the crude rates. The published rates are lower at the earlier and most recent periods, than in the middle decade (1936-46), but the earlier published rates are probably too low because of deficiencies in the death registration data. However, when rates are calculated on the basis of deaths sdjusted for under registration mid-year population adjusted for under-enumeration (See Chapter Seven, Section 4), Maori crude death rates are high from 1926 to 1946, by comparison with subsequent periods. The relative consistency in the rates, once the latter adjustments have been made, should be borne in mind when crude death rates by cause are given below (Chapter 9). 
Figure 8.1 : DEATH KATES FROM ALI CAUSES, FOR QUIN UENNIAL AGE GROUPS, 1936-1956. (Semi-logarithmic scale.)

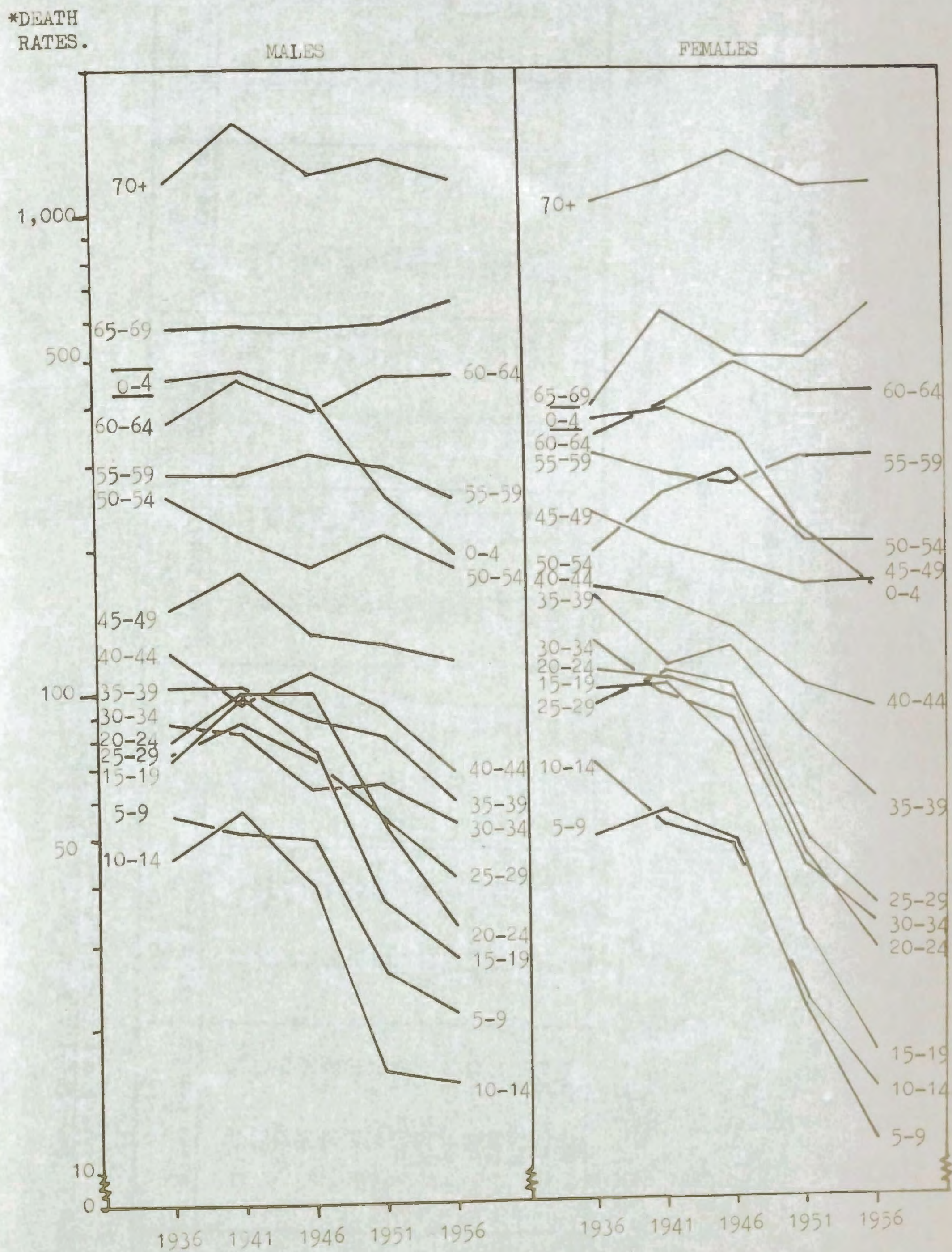

YEARS. 


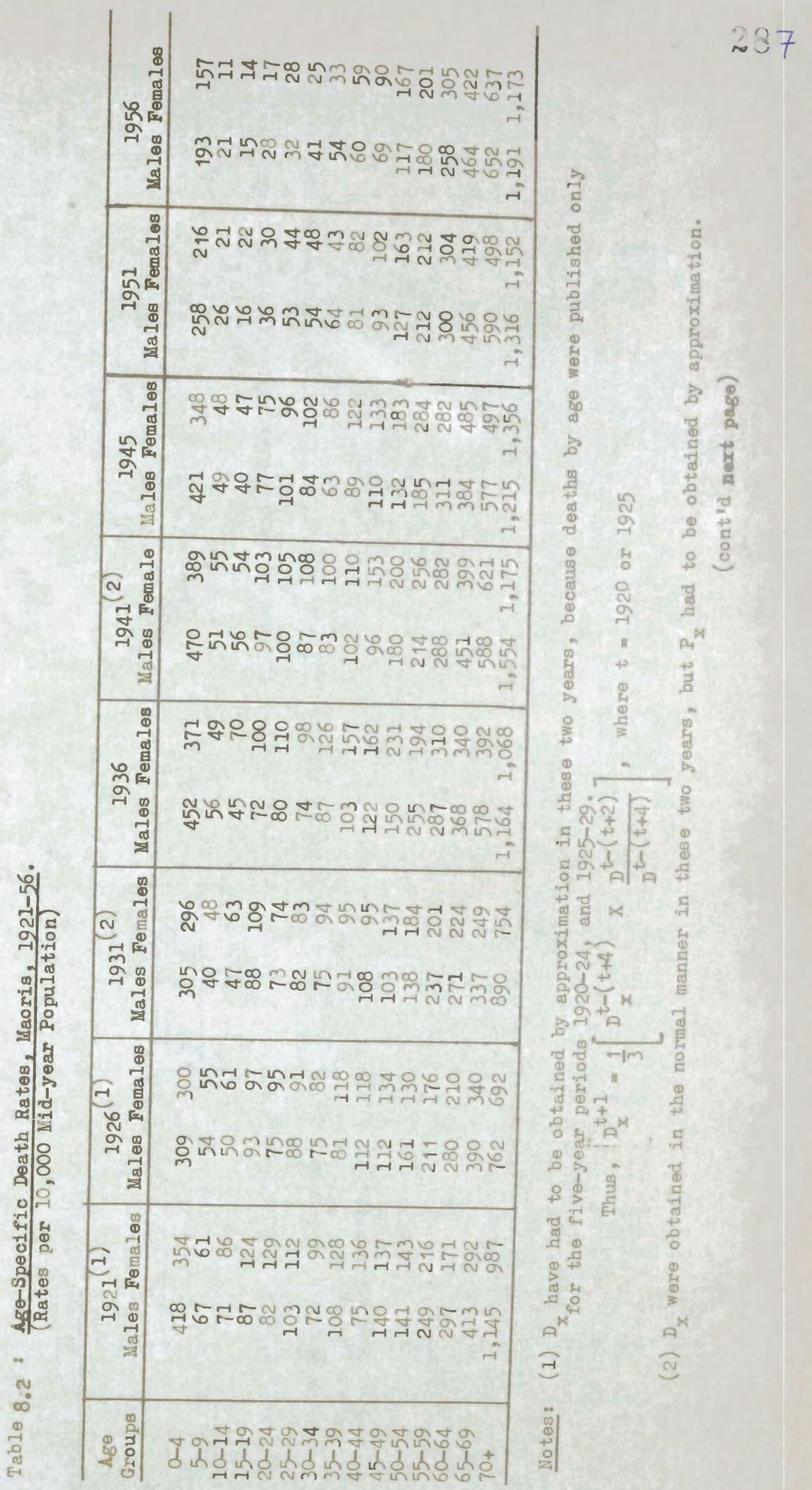




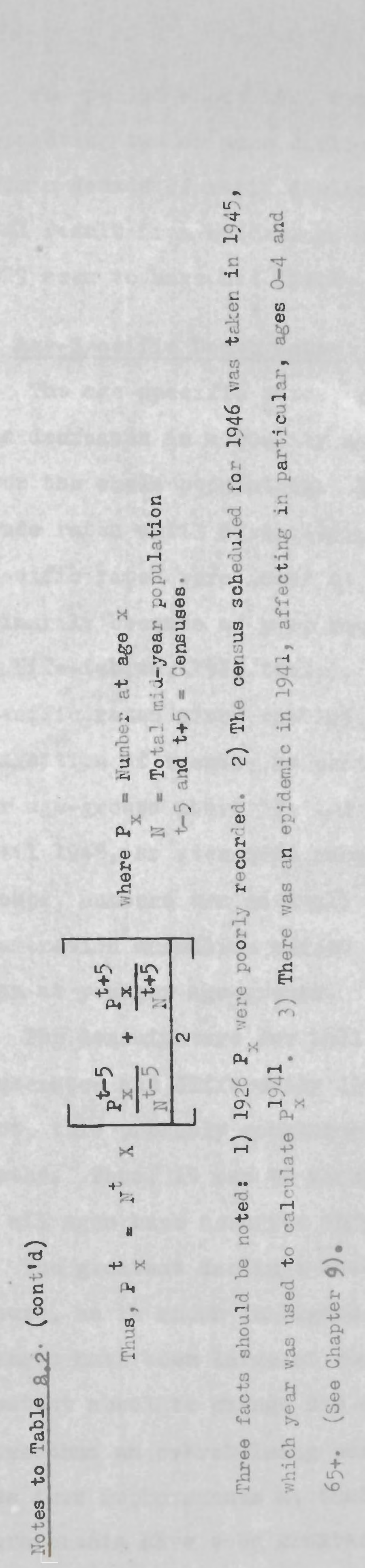


The period about 1945 would appear to be crucial, separating two or more earlier decades of high mortality from a decade of rapid decline. Higher rates in 1938 and 1941 result from epidemics, but other epidemics in 1927 and 1929 seem to have had little effect on the rates.

\section{Age-Specific Death Rates}

The age-specific rates, given in Table 8.2 , reveal that the decreases in mortality noted above did not occur evenly over the whole population. In view of the lack of change in crude rates until after 1945, it can be assumed that agespecific rates were lower at 1926 and 1931 than at 1936, primarily because of poor registration (see below, Section 5, Iife-tab;es, 1926 table). For younger age-groups, agespecific rates since the 1935 census probably give a fair indication of trends, as changes seem to be consistent. But, for age-groups above 55, the rates appear to be inconsistent until 1945, or even more recent years. At these older agegroups, numbers are so small that any registration or enumeration anomalies affect the results to a greater degree than at younger age-groups.

The denominators for 1921 are derived from a poorly enumerated and differently defined Maori population. In part, this probably counteracts the poor registration of deaths. Thus, it can be assumed that significant improvements at all ages have occurred only at recent dates.

The greatest declines have occurred at the younger agegroups, as is shown in Figure 8.2. Proportionately, these changes have been large at most age-groups below 40, but the greatest absolute change has occurred at ages 0-4. Table 8.3. shows that an overwhelming percentage of the total change had come from improvements at that age-group. Relatively, improvements have been greater for females than males at every 


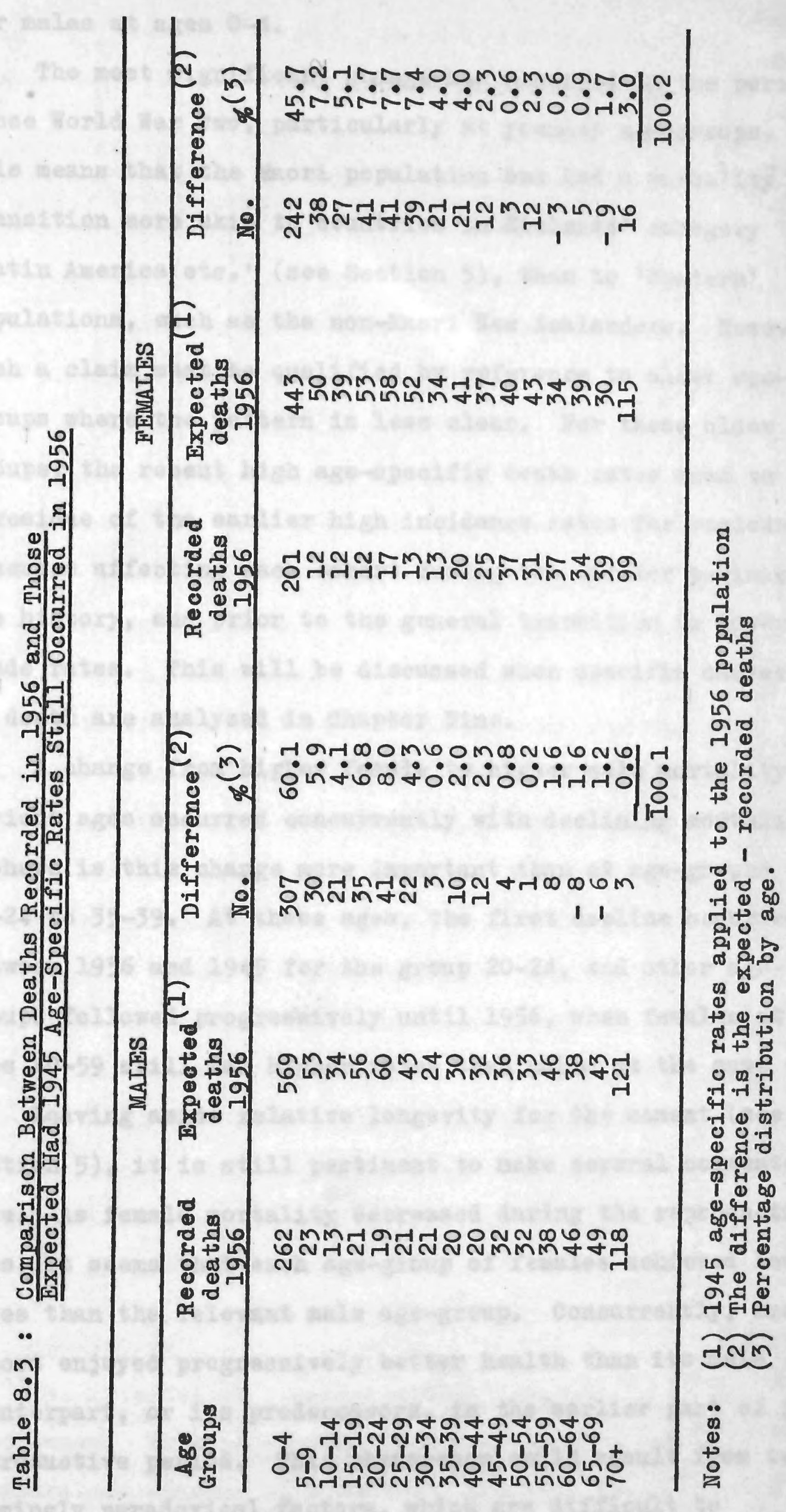


age-group between 5-9 and 35-39, and above 65. By contrast, improvements in female mortality have been less marked than for males at ages $0-4$.

The most significant change has occurred in the period since World War Two, particularly at younger age-groups. This means that the Maori population has had a mortality transition more akin to countries in Stolnitz' category 'Latin America etc.' (see Section 5), than to 'Western' populations, such as the non-Maori New Zealanders. However, such a claim must be qualified by reference to older agegroups where the pattern is less clear. For these older agegroups, the recent high age-specific death rates seem to be a residue of the earlier high incidence rates for various diseases affecting each cohort during the earlier periods of its history, and prior to the general transition to lower crude rates. This will be discussed when specific causes of death are analysed in Chapter Nine.

A change from higher female to higher male mortality at various ages occurred concurrently with declining mortality. Nowhere is this change more important than at age-groups 20-24 to 35-39. At these ages, the first decline occurred between 1936 and 1945 for the group 20-24, and other agegroups followed progressively until 1956, when females at ages 40-59 still had higher rates than males at the same ages. Leaving aside relative longevity for the moment (see Section 5), it is still pertinent to make several comments here. As female mortality decreased during the reproductive ages, it seems that each age-group of females achieved lower rates than the relevant male age-group. Concurrently, each cohort enjoyed progressively better health than its male counterpart, or its predecessors, in the earlier part of its reproductive period. This phenomenon could result from two seemingly paradoxical factors, which are difficult to segregate. 
Firstly, it seems likely that male Maoris had lower 292 age-specific death rates at many ages until after World War II. This will be raised again in section 5, but as lower female mortality at most ages is one characteristic of low mortality populations, the change from lower male to lower female mortality at certain age-groups can be interpreted as a further index of declining mortality.

Conversely, as was shown in Table 4.3, during the 1918 influenza pandemic there were higher death rates among males than among females from ages 15 to 44. The male survivors of this epidemic belonging to these cohorts in which there had been marked sex-differentials in influenza mortality subsequently may have been less susceptible to various diseases than females. Thus, even as recently as 1956, the surviving members of this cohort of males had lower rates than females of the same age.

It is likely that both these factors have operated, although it is impossible to analyse with any degree of confidence their relative importance. However, a study of the decline in the age-specific rates of certain causes of death (see Chapter Nine), in particular tuberculosis, suggests that the first of these two factors was of greater significance. There were lower male than female tuberculosis age-specific death rates at ages 15-39 in 1945 (see Table 9.9). These cohorts would have been younger than seventeen years in 1918, or even unborm, and thus would have been below the ages at which mortality was extremely high and at which sex-differentials were marked.

\section{Iife-tables}

The life-tables provide further information on points of importance. This is because they are the best summary and standardised measure of mortality, and thus international comparisons can be made. 
Table 8.4: Life-Expectations at Various Ages; the Maori, Non-Maori and Other Pcoulations

(1)

1. Males

Maori (1925-27 Maori (1925-27)

Maori (1935-37)

Maori 1944-46

Maori (1950-52

Maori (1955-57)

Jamaica (1950-52)

Ceylon (1954)

Japan (1959)
N.Z. non-Maori (1880-92)

N.Z. non-Maori 1901-05

N.Z. non-Maori (1921-22)

N.Z. non-Maori (1934-38

N.Z. non-Maori (1950-52)

N.2. non-Maori (1955-57)

Sweden (1901-1910)

Sweden (1957) (a)

\begin{tabular}{cccc}
$8_{0}$ & $\AA_{15}$ & $\AA_{45}$ & $\AA_{60}$ \\
\hline 47 & 44 & 25 & 15 \\
49 & 47 & 27 & 17 \\
46 & 44 & 23 & 14 \\
49 & 44 & 23 & 14 \\
54 & 46 & 23 & 13 \\
57 & 49 & 23 & 13 \\
56 & 50 & - & 14 \\
60 & 56 & - & 17 \\
65 & 54 & - & 15
\end{tabular}

$\left\{\begin{array}{l}c \\ c \\ c \\ c \\ c \\ c \\ d \\ d\end{array}\right\}$

54

59

63

65

68

69

55

71

$\begin{array}{lll}49 & 25 & 15 \\ 51 & 26 & 15 \\ 53 & 27 & 16 \\ 54 & 28 & 16 \\ 56 & 28 & 17 \\ 56 & 29 & 17 \\ 50 & - & 16 \\ 61 & - & 19\end{array}$

\section{Females}

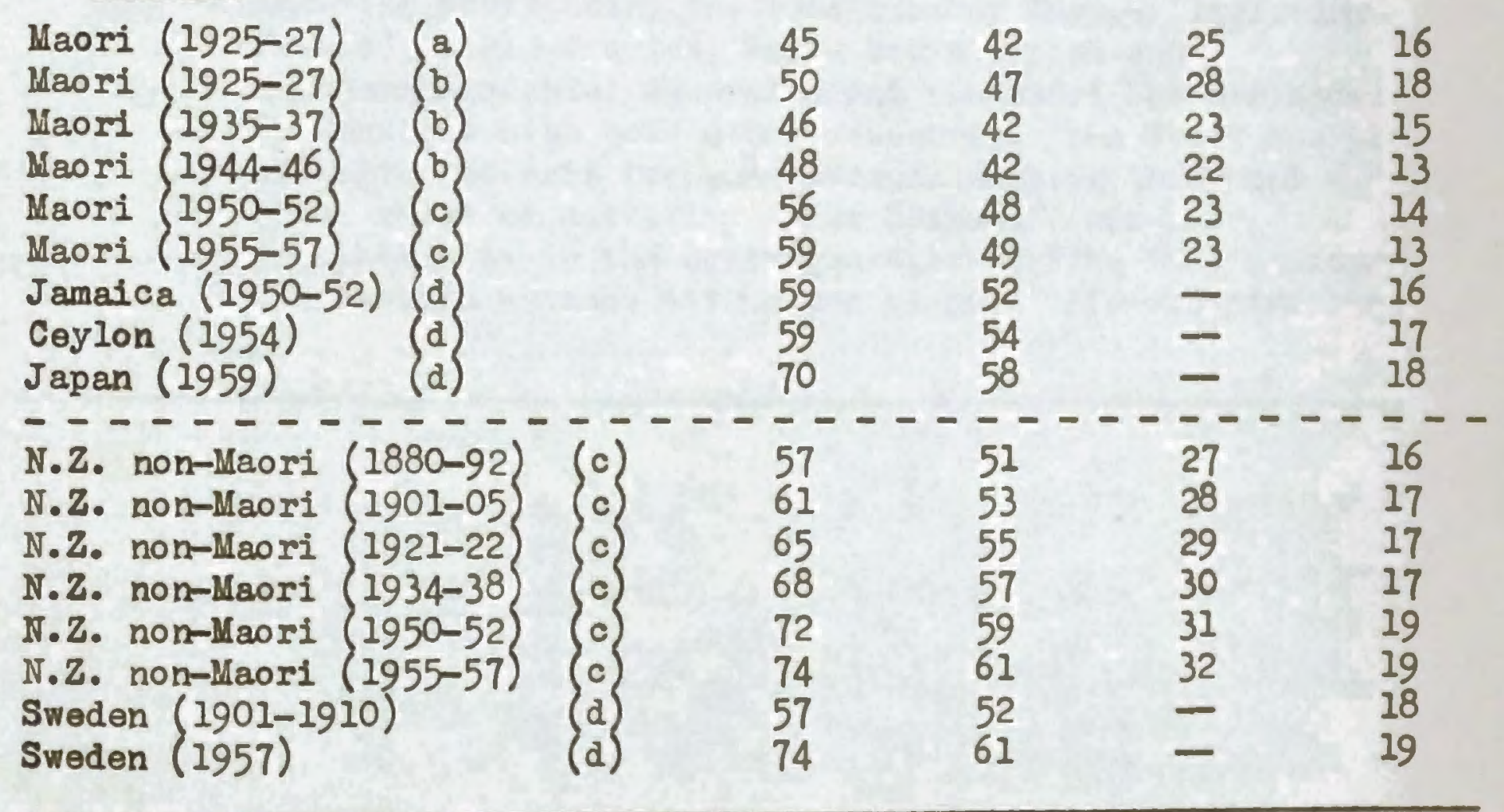

\section{Both Sexes}

'Latin America-Africa-Asia'

Median (1940s)

Japan (1950)

(e)

46

57

44

23
$50 \quad 26$

13 
Table 8.4 (Continued)

Minimum, 'The West', (1940s) (e)

Sweden (1840)

Sweden (1880)

Sweden (1920)

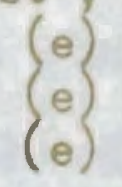

\begin{tabular}{cccc}
$\AA_{0}$ & $\AA_{15}$ & $\AA_{45}$ & $\AA_{60}$ \\
\hline 62 & 54 & 27 & 16 \\
45 & 45 & 22 & -- \\
48 & 48 & 25 & -- \\
65 & 55 & 28 & --
\end{tabular}

Sources: (a) Table constructed by the present writer, allowing for under-enumeration and underregistration (see Chapter Three).

(b) Constructed by the present writer.

(c) Census (1951) \& (1956): Appendix B.

(d) Demog. Year Book (1957) \& (1960).

(e) pp. $30 \& 49$. Stolnitz, George J. (1955.a.): "A Century of International Mortality Trendss Part I", Pop. Stud., vol. IX, July. pp.24-55.

Note: (1) Stolnitz' categories are very handy and will be retained here. His other two groups ares "non-Western Europe", being the Balkan, Slavic, Mediterranean and East Central European countries plus Malta and Finland; and "the West" being the remainder of Europe (including France), Anglo-America, White South Africa and Southern Rhodesia, Australia and non-Maori New Zealand. By contrast with both other categories "the West" has had accurate data for long periods showing lower and lower rates of mortality. New Zealand's non-Maori population is in the upper quartile of "the West", among the Western nations having the highest life-expectations. 
Stolnitz has noted that changes in life-expectation in the 'West' commenced about 1840. But, these changes did not become rapid until the last quarter of the nineteenth century, when 'As a rule..., the increases... were more than $50 \%$ higher than those in the preceding thirty years... ${ }^{2}$ They were undoubtedly greater than at any other previous period in world history. However, it is unlikely that the 'West's' great transition can be repeated, as future improvements in 'Western' life-expectation can only be minor, and will be brought about mainly by decrease in the mortality at neonatal infant ages, and at old age. The improvement in the life-expectation of non-Maoris follow those of the remainder of the 'West', as is shown in Table 8.4 .

By contrast, the major changes in 'Latin America-AfricaAsia' only commenced after World War II. Until about 1945 , most of 'Iatin America etc.' had life expectations below those of the 'West' about 1900 (i.e. 40 years). However, Stolnitz notes that any changes in the mortality patterns of 'Iatin America etc.' have occurred at a far more rapid rate than in the 'West'. 3 It can be seen from Table 8.4 . that Maori life-expectation follows the trends of 'Latin America etc.'. Iife-expectation is similar to that of populations with life-expectations in the top quartile of lifeexpectations found in countries of that region in the $1940 \mathrm{~s}$ and again in the 1950s; i.e. Maori life-expectation is at a similar level to the highest values found in 'Latin America etc.'. Thus, the post-war period, particularly 1945-51,

2 Stolnitz (1955.a.): p.31.

3 p.31. Stolnitz, George J. (1955.b.): "Comparis on between some Recent Mortality Trends in Underdeveloped Areas \& Historical Trends in the West", Trends \& Differentials in Mortality, Annual Conference, Milbank Memorial Fund, New York. pp. 26-34. 


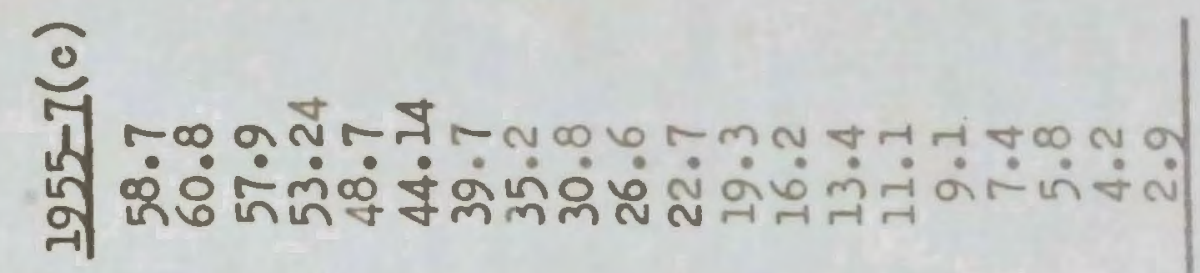

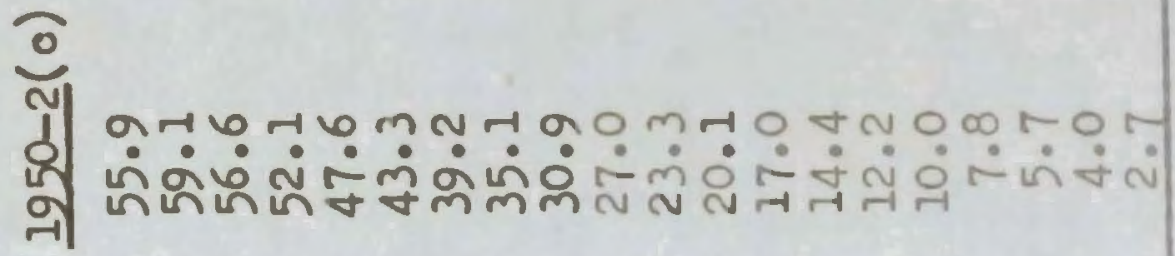

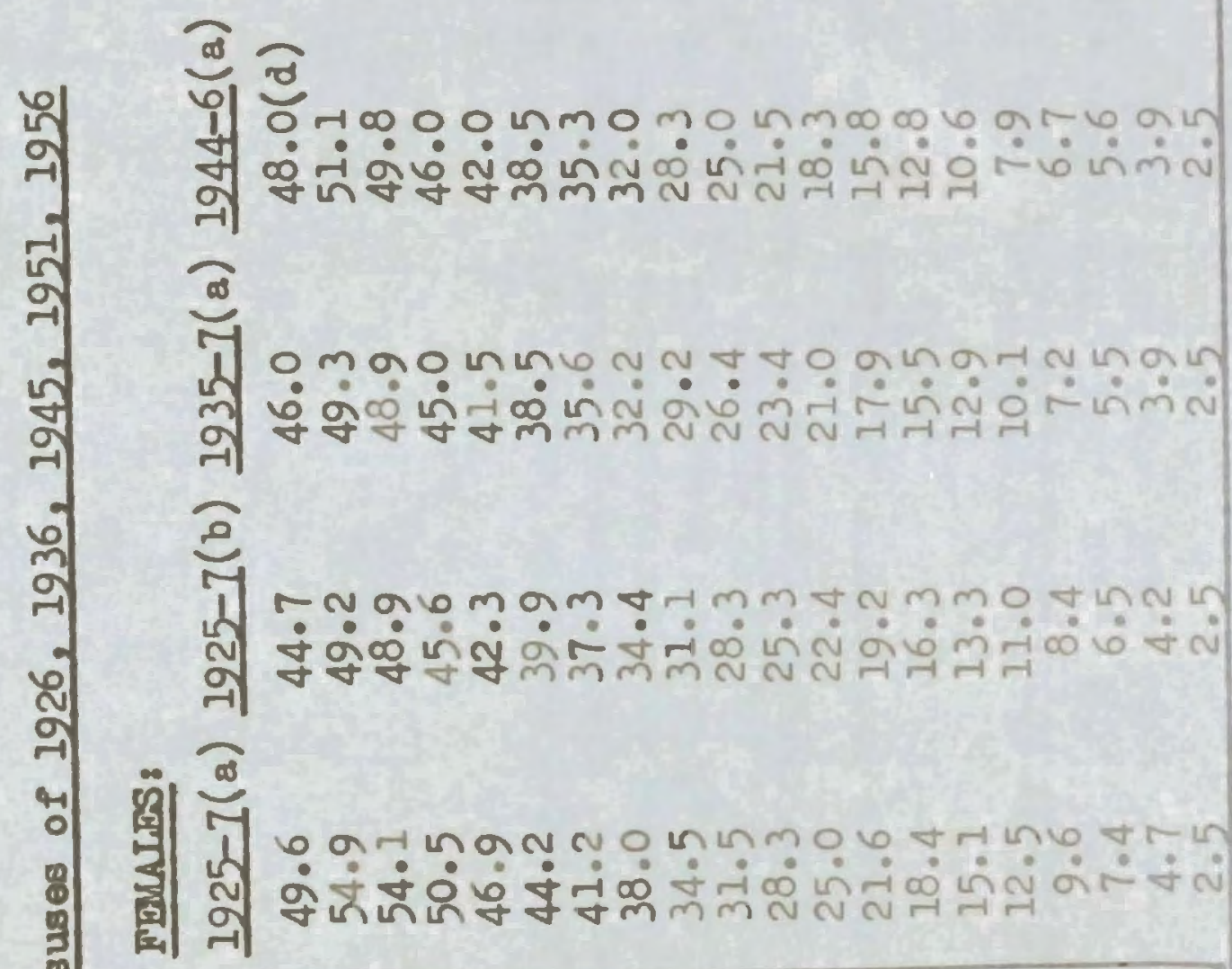

ว

ฟัل

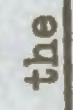

워

ํㅝำ

Hน.

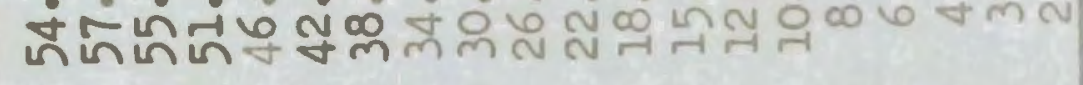

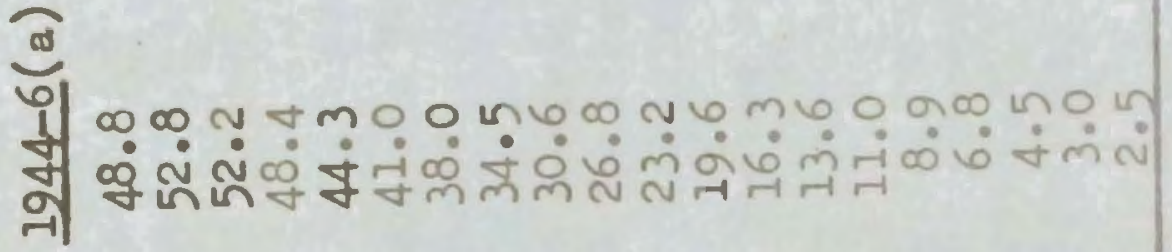

(

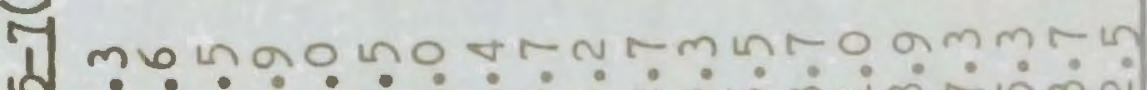

ને

2

तो

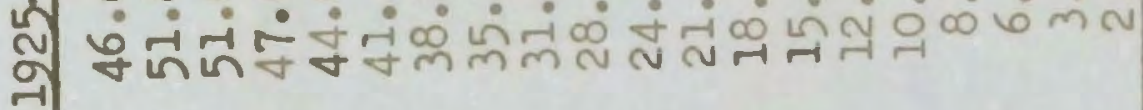

ํㅕㅇ

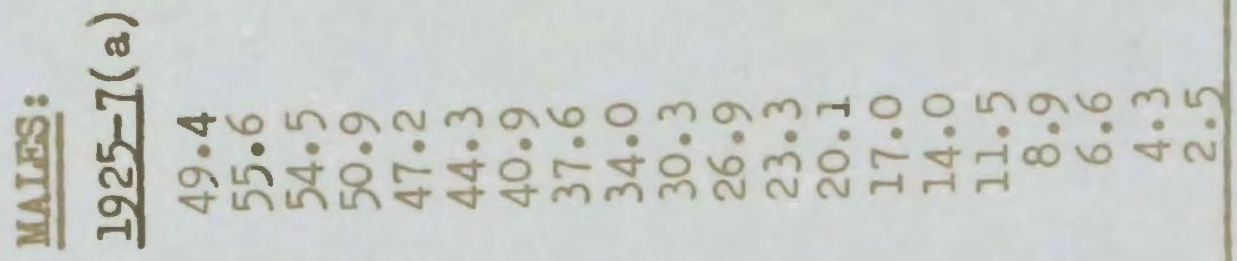

党

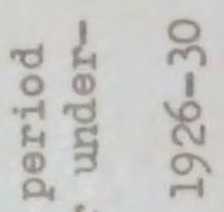

द्व

iे क्ष

䨌学 章

눙 क्ष

요

80

4 


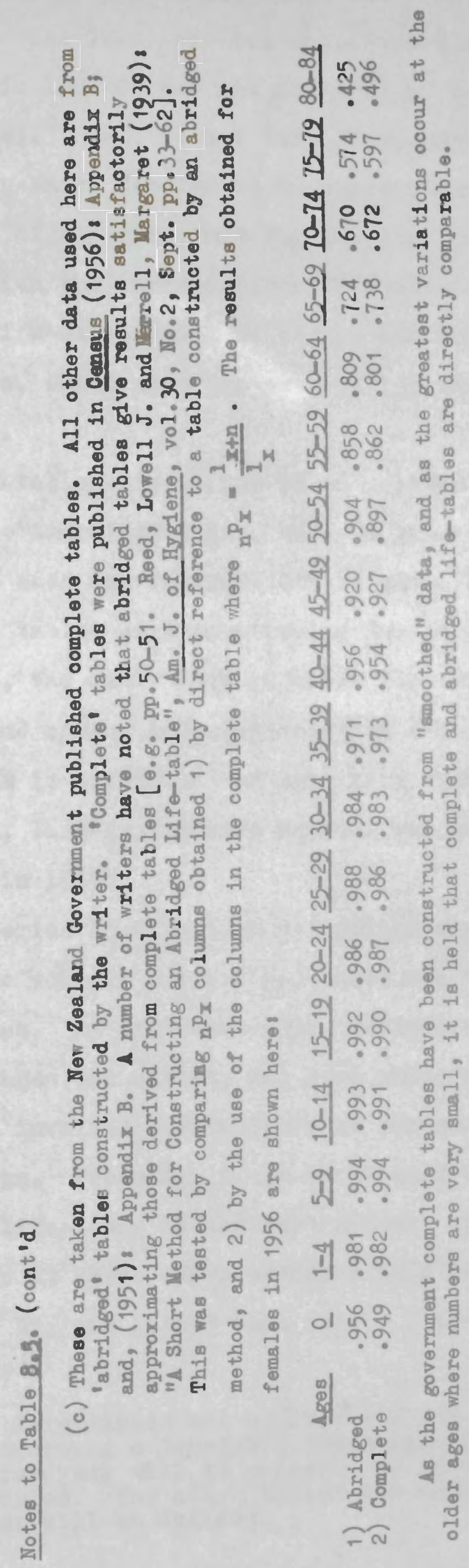


stands out as the period during which the most rapid changes have occurred. The level of life-expectation at birth reached by non-Maoris in 1901-05 was not achieved by Maoris until 1956 (Table 8.4).4 Yet, it had taken from $1890-92$ until 1921-22 for non-Maori females to increase their lifeexpectation by eight years, and for males to gain nine years. Compare this with the increasesfrom 48 years to 59 years in Maori female life-expectation at birth, and from 49 to 57 for Maori males, which were achieved during the eleven year period 1945-56.

When life-tables are looked at in greater detail, as in Table 8.5, some anomalies arise, but, in general, lifeexpectation at each age remained stable until 1945, then improved. Two tables were constructed for 1926, one employing published data, the other data adjusted for vital underregistration and census under-enumeration (see Chapter 7 , Section 5). It is sufficient to note here that, even by using published data, life-expectation at 1926 was at roughly the same level as in 1945.

For the period 1926 to 1945 two points stand out. Firstly, at the younger age-groups, there are improvements in life-expectation. At the older ages, decreases occur. In both cases changes are slight, and poor enumeration and other factors may be involved particularly at the smaller-sized older age-groups. Secondly, if it is assumed that the adjusted 1926 life-table is the more correct of the two for that date, then at these three censuses male life-expectation, at all ages to 35, was higher than female life-expectation.

\footnotetext{
4 As all Maori life-tables are constructed for a 3-year period averaged around a June 30 th population in a census year, the central year will be referred to instead of the whole 3-year period. For other tables the whole period to which they refer will be defined.
} 
Moreover, this is true for all ages to 75 in the 1945 table. This feature also occurs in the post-war period, and thus there is greater male longevity at ages 25-49 in 1956, but in 1951 this phenomenon is not found at any age-group.

Generally speaking, the Maori crude death rates (section 3), show that male mortality exceeded female, which would seem to run contrary to the patterns at certain ages shown on the 1926, 1936, 1945 and 1956 life-tables. However, lifetables are a far better measure of mortality. Moreover, the evidence from Maori life-tables is in accord with Stolnitz' finding that 'On a world-wide basis the occurrence of higher male longevity hasprobably not been unusual at any time during the last century and may have been rather frequent before $1900^{\prime} .5$

It was noted that 1951 did not have the same pattern. This seems to be due to differential rates in the improvement of male and female life-expectation at various ages. In general, improvements for males were more evenly spread over the whole period 1945-56 than was the case for females. The period 1945-51 saw far greater improvements in the lifeexpectation of females at ages 15 to 49 than for males. From 1951-56, there was even a slight decrease in life-expectation for females at ages 35 to 74 . But, the census notes, 'Owing to the relatively small size of the Maori population their age-specific mortality rates show minor fluctuations of a random nature and it is probable that most of these decreases in female life-expectancy are not indicative of a significant trend'. 6 In the period 1951-56, male life-expectation

5 p.24. Stolnitz, George J. (1956): "A Century of International Mortality Trends: Part II", Pop.Stud., vol.X, July. pp.17-42.

6 Census (1956): Appendix B, p.7. 


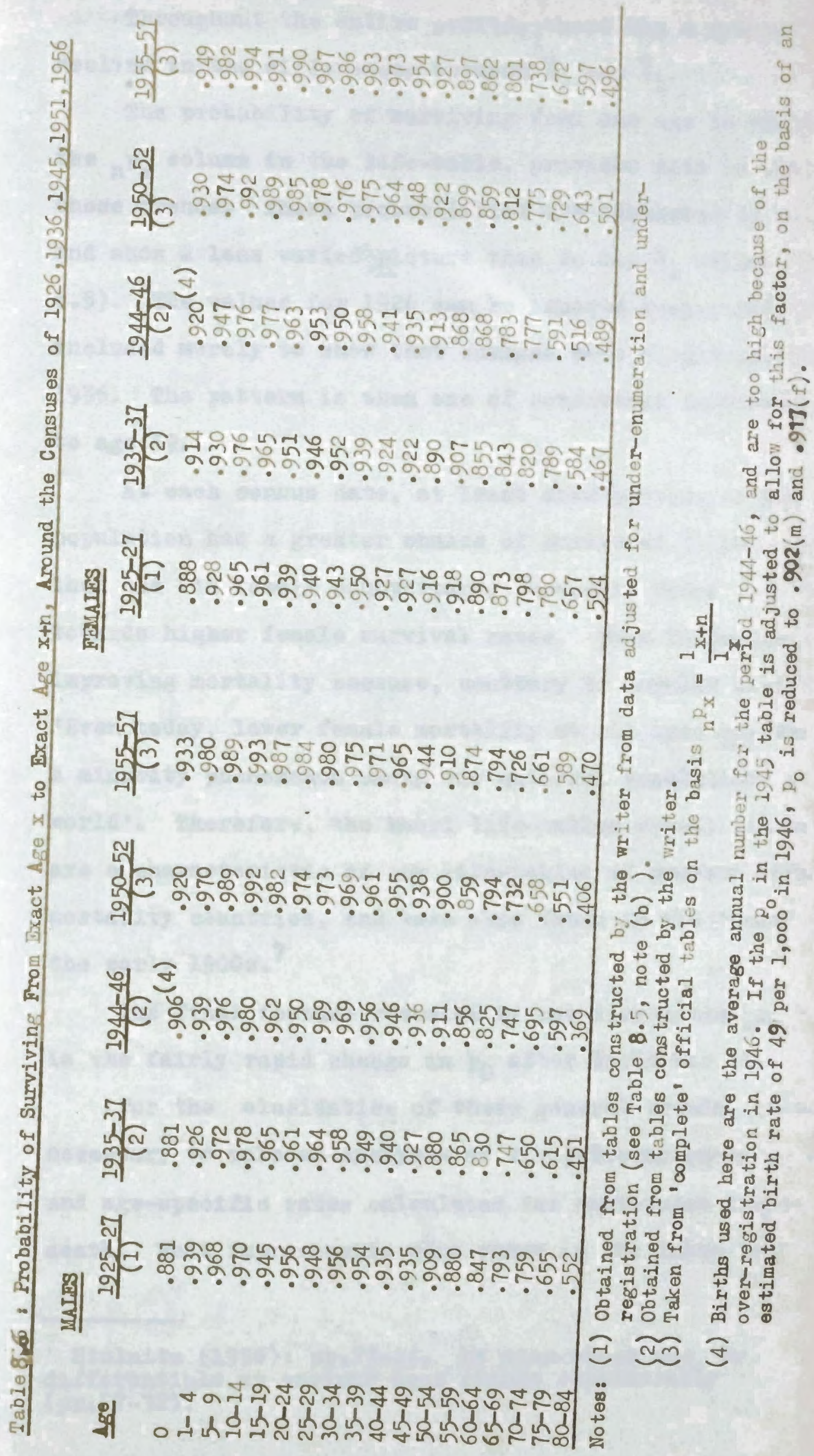


improved at every age, and allowed males to regain their higher longevity at ages 25 to 50 .

Throughout the entire period, there was a gradual decline in the differences between $\varepsilon_{0}$ and $\&_{1}$.

The probability of surviving from one age to another, the ${ }_{n} \mathrm{p}_{x}$ column in the life-table, provides data to analyse these trends. These probabilities are tabulated in Table 8.6, and show a less varied picture than do the $e_{\bar{x}}$ values (Table 8.5). The values for 1926 can be ignored temporarily, being included merely to show that changes were slight prior to 1936. The pattern is then one of consistent improvement up to age 59 .

At each census date, at least some portion of the male population had a greater chance of surviving to the next age than did its female counterpart. However, there is a trend towards higher female survival rates. This is indicative of improving mortality because, contrary to popular belief, 'Even today, lower female mortality at all ages may well be a minority phenomenon among the national populations of the world'. Therefore, the Maori life-tables reveal trends which are a characteristic of the life-tables of present high mortality countries, and were also found in the 'West' until the early 1900s. 7

The final feature revealed by the life-table ${ }_{n} p_{x}$ columns is the fairly rapid change in $p_{0}$ after World War II.

For the elucidation of these general trends, it is necessary to make an analysis of the patterns shown by crude and age-specific rates calculated for particular causes of death. What improvements were there in the death rate of

7 Stolnitz (1956): pp.23-24. He also shows how the differentials at various ages change considerably (pp.27-32). 
major causes, particularly between 1945 and 1956? In what way did these major causes give rise to differential mortality according to age and sex? Two age-groups stand out as requiring particular consideration: the age-group 15-49, and infancy. The latter is so crucial that its mortality trends will be studied in a separate chapter, after changes in the patterms of death by cause are analysed in the next chapter. 


\section{CHAPTER NINE}

\section{$\frac{\text { Maori Mortality Trends Since 1922: Part II, }}{\text { Deaths by Cause }}$}

\section{Introduction}

To analyse deaths by cause, this scheme will be followed:

(a) In Section 2, the accuracy of data will be investigated.

(b) In Section 3, 16 significant diseases or groups of causes will be studied in detail.

(c) Section 4 will summarise major trends in the period by analysing all the causes of death combined into larger groups.

Throughout this chapter wider age-groups will be used than is customary. For most diseases, the numbers dying are so small that to study deaths/cause/quinquennial age-groups would introduce problems regarding the validity of results, which would unnecessarily complicate the analysis. An exception to this is the analysis of tuberculosis, which has been a major cause of death for much of the period. Rates for deaths/cause/age for all periods, except 1956 (see Note to Table 9.8), are for a three year period averaged around a census. Where deaths from specific diseases or forms of injury seem related to a specific cause, this will be noted here, but more general relationships will be discussed in Chapter Eleven.

\section{Accuracy of the Certification of Causes of Death}

In a detailed study of deaths by cause it is not sufficient to check registration alone, for there may be inaccuracies in the certification of the cause of death, as well as in the registration. The accuracy of certification of those Maori deaths actually registered can be tested in two ways:

1. It can be established whether the persons certifying the causes of deaths were qualified to do so. 
2. The relative importance of 'ill-defined' causes of death can be analysed.

As recently as 1959, the Medical Statistician noted, with regard to Maori deaths, that: "Death certificates are not required by law to be submitted by a medical practitioner, though nowadays an increasing percentage is vouched for either by a medical practitioner or by a coroner". ${ }^{I}$ For each year since 1926, the type of certification of the causes of registered Maori deaths had been tabulated under three headings:
1) Certified by a medical practitioner;
2) Certified by

a coroner;

3) Not certified, or certification not stated. Edson, for the period 1925-40, calculated the percentage of Maori deaths "satisfactorily certified", by combining categories 1 and 2, and dividing them by all deaths. This percentage increased, with slight fluctuations, from 51 in 1925, to 77 in 1940, but the percentages varied from disease to disease. ${ }^{2}$ Deaths certified by a coroner have been ignored here for the following reasons: 1) The number of deaths certified by coroners is not extremely high. 2) Accidents, homicide and suicide constitute a varying, but considerable proportion of these certifications. Thus, to determine the character of certification, the following ratio was used:

\section{$\frac{\text { deaths not certified, or certification not stated. }}{100 \text { deaths certified by a medical practitioner }}$}

Table 9.1 shows that the type of certification has improved right through the period, but it is only since 1945 that certification of causes by a medical practitioner has become almost a standard procedure. In the 1920s, by contrast, causes were often obtained second-hand from relatives or witnesses, so that the certification of cause of death would

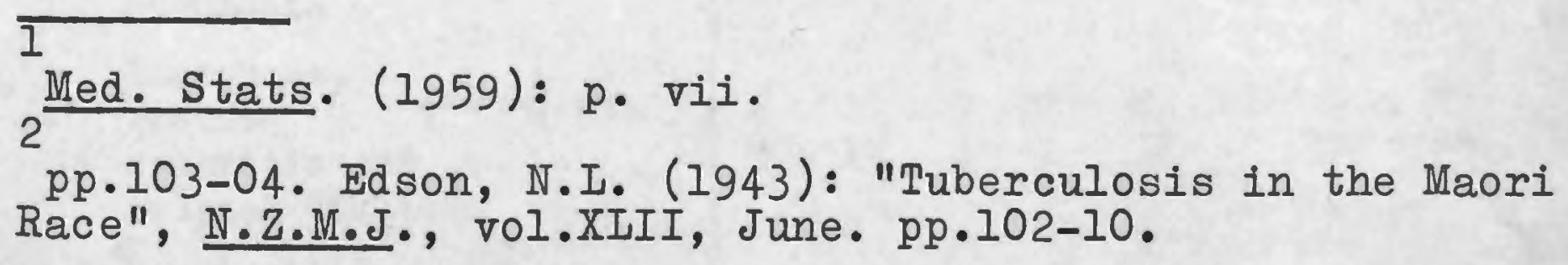


Table 9.1 : Type of Certiflcation of Causes of Death, $1925-56$ (all causes)

Ratio of deaths not certified

Deaths certified by a medical practitioner

\begin{tabular}{|c|c|c|c|c|c|}
\hline & Male & Pemale & & Male & Perale \\
\hline 1925 & & $117\}$ & 1941 & 30 & 32 \\
\hline 1926 & & 110 & 1942 & 25 & 27 \\
\hline 1927 & & Both & 1943 & 23 & 30 \\
\hline 1928 & & Sexes & 1944 & 17 & 21 \\
\hline 1929 & & $62)$ & 1945 & 14 & 17 \\
\hline 1930 & 80 & 75 & 1946 & 14 & 15 \\
\hline 1931 & 90 & 95 & 1947 & 9 & 9 \\
\hline 1932 & 100 & 85 & 1948 & 7 & 7 \\
\hline 1933 & 86 & 70 & 1949 & 8 & 8 \\
\hline 1934 & 69 & 73 & 1950 & 9 & 8 \\
\hline 1935 & 66 & 62 & 1951 & 9 & 8 \\
\hline 1936 & 60 & 53 & 1952 & 9 & 6 \\
\hline 1937 & 49 & 53 & 1953 & 5 & 5 \\
\hline 1938 & 50 & 48 & 1954 & 6 & 9 \\
\hline 1939 & 42 & 44 & 1955 & 0 & 0 \\
\hline 1940 & 35 & 33 & 1956 & 0 & 0 \\
\hline
\end{tabular}

Table 9.2: Certification of Certain Causes of Death at Census Years

\begin{tabular}{|c|c|c|c|c|c|c|c|c|c|c|c|c|c|}
\hline \multirow[b]{2}{*}{ Influenza } & \multicolumn{3}{|c|}{$\begin{array}{l}1926 \\
\text { Both Sexes } \\
\text { 1) }(2) \text { (3) }\end{array}$} & \multicolumn{3}{|c|}{1936} & (3) & (1) & \multicolumn{2}{|c|}{1945} & \multicolumn{3}{|c|}{1951} \\
\hline & 14 & 1 & 29 & $\mathrm{~m}$ & $\begin{array}{r}8 \\
12\end{array}$ & $\begin{array}{l}2 \\
1\end{array}$ & $\begin{array}{l}9 \\
6\end{array}$ & $\begin{array}{r}13 \\
6\end{array}$ & - & $\begin{array}{l}1 \\
-\end{array}$ & $\begin{array}{l}8 \\
4\end{array}$ & $\begin{array}{l}1 \\
-\end{array}$ & - \\
\hline Typhoid & 19 & - & 4 & m & $\begin{array}{l}12 \\
12\end{array}$ & - & 2 & $\begin{array}{l}4 \\
3\end{array}$ & - & - & 2 & - & - \\
\hline Tuberculosis & 127 & 9 & $75^{\circ}$ & m & $\begin{array}{r}95 \\
122\end{array}$ & $\begin{array}{l}9 \\
6\end{array}$ & $\begin{array}{l}44 \\
53\end{array}$ & $\begin{array}{l}167 \\
175\end{array}$ & $\begin{array}{l}8 \\
7\end{array}$ & $\begin{array}{r}9 \\
11\end{array}$ & $\begin{array}{l}92 \\
61\end{array}$ & $\begin{array}{l}4 \\
3\end{array}$ & $\begin{array}{l}4 \\
4\end{array}$ \\
\hline $\begin{array}{l}\text { Whooping } \\
\text { Cough }\end{array}$ & 3 & 1 & $\begin{array}{c}8 \\
(1926)\end{array}$ & $m$ & 11 & - & 21 & 3 & - & - & 2 & - & - \\
\hline & 15 & 2 & $\begin{array}{c}36 \\
(1927)\end{array}$ & $f$ & 9 & - & 15 & 4 & - & 1 & 1 & - & 1 \\
\hline Cancer & 26 & 2 & 11 & m & $\begin{array}{l}18 \\
23\end{array}$ & $\overline{1}$ & $\begin{array}{l}1 \\
4\end{array}$ & $\begin{array}{l}20 \\
30\end{array}$ & $\overline{1}$ & $\begin{array}{l}1 \\
4\end{array}$ & $\begin{array}{l}40 \\
33\end{array}$ & 1 & $\begin{array}{l}3 \\
2\end{array}$ \\
\hline $\begin{array}{l}\text { Diseases of } \\
\text { the circula- } \\
\text { tory system }\end{array}$ & 26 & 4 & 12 & m & $\begin{array}{l}40 \\
44\end{array}$ & $\begin{array}{l}8 \\
3\end{array}$ & $\begin{array}{r}9 \\
1.5\end{array}$ & $\begin{array}{l}127 \\
104\end{array}$ & $\begin{array}{l}5 \\
9\end{array}$ & $\begin{array}{l}16 \\
14\end{array}$ & $\begin{array}{l}149 \\
146\end{array}$ & $\begin{array}{l}15 \\
11\end{array}$ & $\begin{array}{r}11 \\
5\end{array}$ \\
\hline $\begin{array}{l}\text { Bronchitis, } \\
\text { Broncba- } \\
\text { pneumonia an } \\
\text { pneumonia }\end{array}$ & 48 & 6 & 66 & 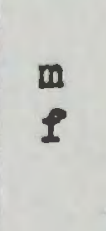 & $\begin{array}{l}125 \\
116\end{array}$ & $\begin{array}{l}14 \\
13\end{array}$ & $\begin{array}{l}56 \\
45\end{array}$ & $\begin{array}{r}110 \\
95\end{array}$ & $\begin{array}{l}9 \\
7\end{array}$ & $\begin{array}{l}10 \\
11\end{array}$ & $\begin{array}{l}75 \\
68\end{array}$ & $\begin{array}{l}18 \\
12\end{array}$ & $\begin{array}{l}4 \\
2\end{array}$ \\
\hline $\begin{array}{l}\text { Diarrhoea, } \\
\text { gastro- } \\
\text { entaritis an } \\
\text { related dise }\end{array}$ & $d^{10}$ & 4 & 16 & $\begin{array}{l}m \\
f\end{array}$ & $\begin{array}{l}16 \\
19\end{array}$ & $\begin{array}{l}5 \\
4\end{array}$ & $\begin{array}{r}10 \\
4\end{array}$ & $\begin{array}{l}55 \\
31\end{array}$ & $\begin{array}{l}3 \\
7\end{array}$ & $\begin{array}{r}8 \\
10\end{array}$ & $\begin{array}{l}23 \\
19\end{array}$ & $\begin{array}{l}1 \\
3\end{array}$ & $\begin{array}{l}1 \\
1\end{array}$ \\
\hline $\begin{array}{l}\text { Diserses of } \\
\text { pregnancy } \\
\text { and childbir }\end{array}$ & th & 1 & 4 & 1 & 14 & 1 & 5 & 7 & 1. & 1 & 3 & 2 & - \\
\hline
\end{tabular}




\section{Table 22 (cont'd)}

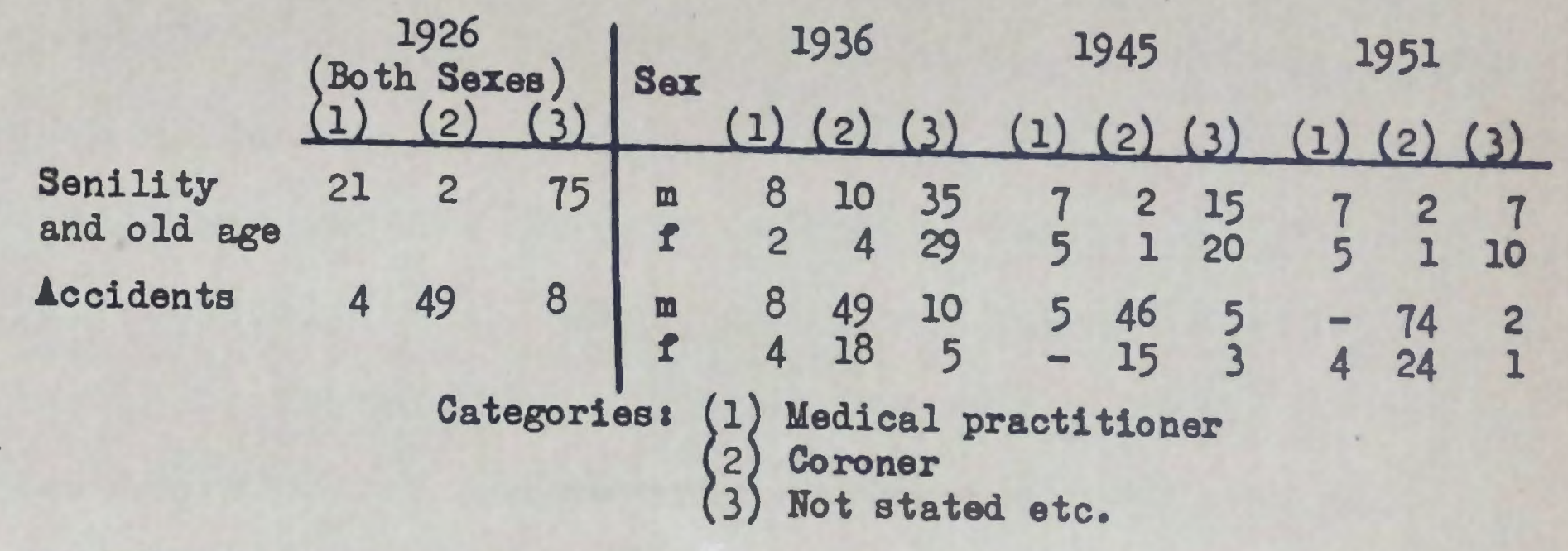

Table $2.3: \frac{\text { Crude Doath Rates: Ill-Defined Causes of Daath. }}{\text { (Rates per } 100,000 \text { of the mid-year population) }}$

\begin{tabular}{|c|c|c|c|c|c|}
\hline Year & Males & Females & Yoar & Males & Females \\
\hline 1926 & 21 & 26 & 1943 & 46 & 85 \\
\hline 1927 & 29 & 32 & 1944 & 10 & 15 \\
\hline $\begin{array}{l}1928 \\
1920\end{array}$ & 31 & 56 & 1945 & 12 & 15 \\
\hline $\begin{array}{l}1929 \\
1930\end{array}$ & & 58 & 1946 & 4 & 4 \\
\hline $\begin{array}{l}1930 \\
1931\end{array}$ & 27 & 15 & 1947 & 19 & 12 \\
\hline $\begin{array}{l}1931 \\
1932\end{array}$ & 100 & 55 & 1948 & 5 & 17 \\
\hline $\begin{array}{l}1932 \\
1933\end{array}$ & 31 & 70 & 1949 & 18 & 15 \\
\hline $\begin{array}{l}1933 \\
1934\end{array}$ & 40 & 35 & 1950 & 14 & 4 \\
\hline $\begin{array}{l}1934 \\
1935\end{array}$ & 27 & 40 & 1951 & 18 & 16 \\
\hline $\begin{array}{l}1935 \\
1936\end{array}$ & 36 & 49 & 1952 & 10 & 7 \\
\hline $\begin{array}{l}1930 \\
1937\end{array}$ & 23 & 35 & 1953 & 5 & 10 \\
\hline 1938 & $\begin{array}{l}43 \\
74\end{array}$ & $\begin{array}{l}49 \\
60\end{array}$ & 1954 & 5 & 19 \\
\hline 1939 & 38 & 47 & $\begin{array}{l}1955 \\
1956\end{array}$ & $\bar{l}$ & 3 \\
\hline 1940 & 39 & 39 & 1957 & 1 & - \\
\hline 1941 & 60 & 52 & 1958 & - & 1 \\
\hline 1942 & 15 & 22 & 1959 & - & 3 \\
\hline
\end{tabular}


have been most unreliable.

Table 9.2 shows the mode of certification for selected causes at census years. Numbers are so small that only the raw data are shown. Certain causes of death tended to be more frequently certified by a medical practitioner, particularly after 1936, for example, typhoid, cancer, diseases of the circulatory system and puerperal diseases. By contrast, accidents were certified predominantly by coroners, while disproportionately "unstated or not certified" were the diseases "taken to be common among Maoris" ---tuberculosis and other infectious diseases, 'bronchitis (etc.)' and 'diarrhoea (etc.)'. A decline in ' senility' occurred as definition became more accurate, and as increasing proportions of deaths were certified by medical practitioners.

The second factor is the importance of ill-defined causes of death, the rates for which are given in Table 9.3. The male crude death rate for ill-defined causes dropped, with fluctuations, to zero in 1955. For females fluctuations were far greater, but since 1947 the rate has not been above 16/100.000. The 1ll-defined causes form a comparatively small proportion of the total death rate (cf. Table 8.1). For example, the highest male rate, in 1931, reached only 6.8 percent of the total crude death rate. However, this is not very satisfactory as a measure, because many genuinely ill-defined causes are classified elsewhere. Edson combined ill-defined causes with 'convulsions' (under 5 years of age), senility, cold, cough, chest trouble, and stomach and internal trouble, to give the rates for "unsatisfactorily defined causes of dea.th". The percentage so defined declined in more recent years, as is shown in Table 9.4 . 
Table 9.4 : Unsatisfactorily Defined Causes of Death

$1920 \quad \underline{1920-24} \underline{1925-29} \underline{1930-34} \underline{1935-39} \underline{1940}$

Total unsatisfactorily defined

$5.1 \quad 3.6$

2.1

1.9

1.61 .5

Total a.11 causes $18.3 \quad 16.4$ $15.6 \quad 15.4$ $20.0 \quad 17.5$

Percentage unsatisfactorily defined 27 22 14 12 $8 \quad 8$

Source: p.104. Edson, N.I. (1943): "Tuberculosis in the Maori Race", N.Z.M.J., vol.XIII, June. pp.102-10.

There are few data on which to base a check on the standard of certification of causes by age, but Table 9.5 shows the age-specific rates for ill-defined causes. It seems that the

$\frac{\text { Table } 9.5}{\text { Age-Specific Death-Rates: Ill-defined Causes of }}$

Age

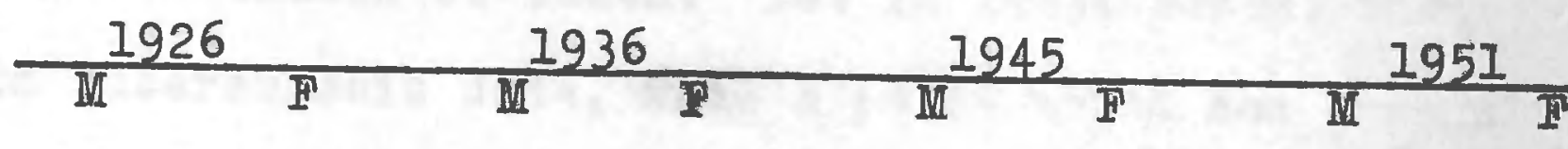

$0-4$

$5-14$

$15-24$

25-44

$45-64$

$65+$

\begin{tabular}{rrrrrrrr}
\hline 6 & 6 & 8 & 9 & 2 & 2 & 4 & 2 \\
1 & 1 & 2 & 2 & 1 & 1 & 1 & - \\
1 & 2 & 1 & 1 & - & - & 1 & - \\
2 & 2 & 2 & 2 & 1 & 1 & 1 & 1 \\
6 & 8 & 9 & 11 & 2 & 2 & 2 & 2 \\
- & - & 7 & 14 & 7 & 7 & 13 & 7
\end{tabular}

Notes: In 1956 there was one ill-defined death only per sex, thus 1956 is not shown on the table.

In this and all subsequent tables showing deaths/ cause/age, 1926 and 1921 figures, if used, have had to be obtained by approximation because the only data available were deaths by cause for each year 1920-24 and 1925-1929 and deaths/cause/age for the whole period. For example $D_{x}$ for the 3-year period around the 1926 census were found by multiplying the $D_{x}$ for the whole period by the factor:

Deaths 1925-1927. The product was then divided by 3 to give the average annual $D_{X}$ in the period 1925-1927. 
major improvements have occurred recently, and that higher rates occurred at ages where higher death rates were found for all causes. For ages $65+$ some ill-defined deaths may have been attributed to senility.

To test the accuracy of mortality data in further detail, it would be most valuable if there were comparable data from independent sources. However, four observers have stated that the statutory notification of cases of Maoris suffering from various diseases is inaccurate. ${ }^{3}$ This leaves field surveys. and hospital records, but the latter are liable to be unsatisfactory. 4 Thus, there are no supplementary data, other than those obtained in field surveys.

From the above analysis, it seems certain that death registration, when it occurred, was unsatisfactory until the 1940s, with regard to both the standard of certification and the definition of causes of death. Yet in 1943, Edson, when referring to tuberculosis data, made a point which has general application here: "When all the difficulties are assessed, it becomes clear that tuberculosis statistics of the Maori are not so incomplete as to defy an elementary analysis, especially if emphasis be placed on the last ten years". 5

Other than improved certification and definition, there were probably improvements in diagnostic techniques in the period. However, these are very difficult to assess, and refer to specific diseases, some of which may not be studied in detail such as poliomyelitis. Of the diseases to be examined here, possible improvements occurred in the diagnosis of cancer in its various forms, and in differentiating between bronchitis and pneumonia.

\section{3}

A.J.H.R. (1934): H-3I, p.15; Edson (1943): p.110; p.3.Rose, R.J. (1960): Maori-European Standards of Health, N.Z.Dept. of Health, Special Report No.1, Wellington; and, pp.232-33. Turbott, H.B. (1940): "Health \& Social Welfare", in Sutherland, I.I.G. (ed.): The Maori People Today, Wellington. pp.229-68.

${ }^{4}$ Rose (1960): p.4. 5

Edson (1943): p.104. 
Table 2.6 : Crude Death Rates: Certain Infectious Diseases

(Rates per 100,000 of the mid-year population)

\begin{tabular}{|c|c|c|c|c|c|c|c|c|}
\hline Year & Measles & $\begin{array}{l}\text { les } \\
\text { Females }\end{array}$ & \multicolumn{2}{|c|}{$\begin{array}{l}\text { Whooping Cough } \\
\text { Males Females }\end{array}$} & \multicolumn{2}{|c|}{$\begin{array}{l}\text { Typhoid } \\
\text { Males Females }\end{array}$} & \multicolumn{2}{|c|}{$\begin{array}{l}\text { Tuberculosis } \\
\text { (all forms) } \\
\text { Males Females }\end{array}$} \\
\hline 1926 & 9 & 10 & 15 & 23 & 42 & 30 & 264 & 404 \\
\hline 1027 & 26 & 22 & 76 & 86 & 38 & 38 & 336 & 406 \\
\hline 1928 & 9 & 12 & 6 & 6 & 37 & 62 & 339 & 373 \\
\hline 1929 & - & - & 8 & 15 & 39 & 18 & 314 & 361 \\
\hline 1930 & - & 3 & 5 & 9 & 14 & 21 & 309 & 342 \\
\hline 1931 & - & - & 8 & 17 & 21 & 17 & 293 & 402 \\
\hline 1932 & - & - & 72 & 95 & 10 & 17 & 342 & 442 \\
\hline 1933 & 20 & 16 & 28 & 16 & 18 & 11 & 306 & 373 \\
\hline 1934 & 17 & 16 & 32 & 37 & 17 & 8 & 337 & 417 \\
\hline 1935 & - & 3 & 64 & 78 & 24 & 23 & 333 & 419 \\
\hline 1936 & 2 & - & 74 & 60 & 32 & 30 & 343 & 456 \\
\hline 1937 & 2 & 2 & 14 & 5 & 23 & 25 & 315 & 409 \\
\hline 1938 & 247 & 246 & 11 & 27 & 29 & 27 & 386 & 470 \\
\hline 1939 & 51 & 38 & 4 & 2 & 24 & 12 & 411 & 486 \\
\hline 1940 & - & - & 2 & - & 15 & 12 & 396 & 449 \\
\hline 1941 & - & 2 & 103 & 122 & 6 & 9 & 417 & 477 \\
\hline 1942 & 21 & 11 & 48 & 31 & 13 & 9 & 417 & 483 \\
\hline 1943 & 10 & 15 & - & - & 10 & 9 & 360 & 399 \\
\hline 1944 & - & - & 51 & 47 & 8 & 11 & 346 & 448 \\
\hline 1945 & 4 & 4 & 6 & 10 & 8 & 6 & 369 & 401 \\
\hline 1946 & 25 & 28 & - & - & 6 & 8 & 348 & 437 \\
\hline 1947 & - & 2 & 13 & 16 & 8 & 16 & 304 & 372 \\
\hline 1948 & - & 4 & 33 & 19 & 2 & 6 & 234 & 285 \\
\hline 1949 & 23 & 30 & 20 & 37 & 2 & 6 & 210 & 281 \\
\hline 1950 & - & - & - & 13 & 7 & 2 & 210 & 239 \\
\hline 1951 & - & - & 3 & 4 & 3 & - & 167 & 120 \\
\hline 1952 & 13 & 12 & 5 & 14 & - & - & 120 & 128 \\
\hline 1953 & 8 & 2 & 8 & 8 & 2 & 3 & 102 & 89 \\
\hline 1954 & 11 & 5 & 3 & 5 & 2 & 2 & 76 & 80 \\
\hline 1955 & 3 & 8 & 3 & 5 & - & 3 & 67 & 44 \\
\hline 1956 & 6 & 3 & 9 & 3 & - & - & 51 & 64 \\
\hline 1957 & - & 1 & 1 & - & 1 & 3 & 57 & 40 \\
\hline 1958 & 1 & 1 & 1 & 1 & 1 & - & 48 & 36 \\
\hline 1959 & 5 & 5 & 5 & 3 & 1 & - & & 22 \\
\hline
\end{tabular}

Table $91: \frac{1938: \text { Age-Specific Death Rates for Certain }}{\text { Diseases (Rates per 10,000 mid-year population }}(1)$ )

Cause of Males Age Groups Females Neasles, 13272 - 26117124 - 3 \begin{tabular}{|llllll|llllll} 
Bronchitis, & 11 & 5 & 13 & 37 & 156 & 222 & 9 & 5 & 13 & 39 & 140
\end{tabular} pneumonia,

pneumonia

(Diarrhoea 74 - -2 - 70 - 1 (and related (diseases

\begin{tabular}{lllllll|l|llllll} 
Influenza & 17 & 4 & 2 & 3 & 6 & $23^{(2)}$ & 21 & 2 & 4 & 7 & 8 & 7 \\
\hline
\end{tabular}

Notes: (1) Each $P^{1938}$ was found by distributing the 1938 mid-year population by the 1936 census age distribution.

(2) This age-group is very small, a rate of $23 / 10,000$ being derived from 4 deaths only. 
Changes in the classification of diseases have also led to some difficulties. For this reason, some specific diseases, or else blocks of causes were adhered to, rather than a detailed analysis of each and every cause. Moreover, while a check has been kept on changes in classification, some small error may have been introduced. New Zealand has followed the International Statistical Classification of Injury and Death throughout much of the period, and the published data give sufficient information for amended classifications to be compared with the earlier ones.

\section{A Study of Certain Causes of Death}

\section{Measles}

The crude rates for this disease, given in Table 9.6, have fluctuated in importance during the period, but, in general, they seem to have declined in recent years. In 1938 there was a major epidemic, the high rates in the following year being, perhaps, a result of late registrations of deaths occurring during this outbreak. Measles was not alone in causing high rates in these two years, for abnormally high mortality occurred for certain respiratory diseases and for diarrhoea. Such a relationship is common, cross-infection and the subsequent development of other diseases, including bronchitis, having been demonstrated by experiences in 'open-wards'. Moreover, the reported complications of measles include enteritis and respiratory diseases. 6 In many cases measles may be the primary cause of death, but that which is registered may be one of its sequelae.

The age-specific rates for measles and its sequelae in 1938 are given in Table 9.7. During the 1938 epidemic the highest measles death rates occurred among young children, as might be expected, and this was generally true for the other Control of the Communicable Diseases, Iondon. 
diseases. Also, the high rates at ages $65+$ for bronchitis (etc.) appear to be a little higher than normal (cf.Table 9.13).

\section{Whooping Cough}

This disease is a more important cause of death than measles. It has the same characteristic of fluctuating, but generally declining rates, which is shown in Table 9.6. Female rates are higher than males for much of the period, which is a normal feature of the disease. ${ }^{7}$ In 1941, the most severe epidemic occurred, accompanied by somewhat higher rates for dysentery, and bronchitis and pneumonia, which are recognised sequelae of whooping cough, while the second biggest epidemic, in 1927, was accompanied by a higher than normal measles crude death rate. Throughout the period, young children had the highest whooping cough death rates, but Table 9.8 shows that, as the crude rate declined, so did the death rates for ages $0-4$.

Table 9.8 : Age-specific Death Rates: Whooping Cough (Rates per 10,000 mid-year population)

\begin{tabular}{lcccccccccc} 
Ages & 1926 & 1936 & 1945 & 1951 & $1956^{(1)} 1926$ & 1936 & 1945 & 1951 & $1955^{()}$ \\
\hline $0-4$ & 21 & 25 & 11 & 2 & 2 & 22 & 26 & 11 & 6 & 1 \\
$5-14$ & - & - & - & - & - & - & - & - & - & - \\
$15-24$ & - & - & - & - & - & - & - & - & - & - \\
$25-44$ & - & - & - & - & - & - & - & - & - & - \\
$45-64$ & 1 & - & - & - & - & - & - & - & - & - \\
$65+$ & - & - & - & - & - & - & - & - & - & -
\end{tabular}

Note: (1) In this and most subsequent tables on agespecific rates by cause of death, rates are derived, for 1956, from Appendix. Rose, R.J. (1920): Maori-European Standards of Health, N.Z. Dept. of Health, Special Report No.1, Wellington. $\mathrm{He}$ used deaths for a 5-year period averaged around the 1956 census (i.e. 1954-58), whereas here a 3-year period is used, but the results should still be comparable. A five year period probably allows greater smoothing of random and other fluctuations, but has more chance of being affected by sudden important changes in mortality. Throughout Chapter Nine the agegroupings used by Rose have been continued here to give comparability.

\footnotetext{
7 A characteristic of whooping cough is the low masculinity of death rates. This is also true for its frequent sequel, bronchiectasis, which includes chronic bronchitis. Because of the grouping of bronchitis, broncho-pneumonia and pneumonia used here, this factor is obscured. For comments on whooping cough see pp.178-80. Lancaster, H.0. (1952.a): "The Mortality in Aust.
from Acute Infective Diseases"
} 
Typhoid

Crude death rates, shown in Table 9.6, are the only rates given here for this disease. Its decline has been relatively steady, but most marked since 1940. Formerly, it was a disease which caused considerable concern, but it can be overcome by fairly simple preventive measures, particularly by improved sanitation, by the provision of clean water supplies, and by innoculation. For example, deaths from typhoid in Hawkes Bay, in 1933, were traced to polluted shell-fish, so the taking of this Maori delicacy from certain areas was prohibited. ${ }^{8}$ Turbott shows that, in the mid-1930s, rates were higher in South Auckland than on the East coast, and that this could be due to innoculation campaigns in the latter area. ${ }^{9}$

The earlier typhoid epidemics were severe, but always seem to have been limited to certain districts (see chapter 4, section 3). Outbreaks in the 1930s were smaller than this and more spasmodic, 10 and, since then, have almost disappeared.

\section{Dysentery}

The most important epidemic of this disease occurred in January-May 1929, in the Auckland and Taupo regions, resulting in a male crude death rate of 44 , and a female rate of $52 / 100,000$. A smaller epidmeic coincided with the whooping cough epidemic in 1941, and gave rise to rates of 24 for males, and 32 for females.

\section{8}

A.J.H.R. (1933): H=31, pp 45=46.

9

A.J.H.R. (1937): H=3l, p.2

II A.J.H.R. (1936): H-3I, p.2.

A.J.H.R. (1930): H-31, pp.87-89, which notes 48 deaths, while the annual vital statistics notes only 33. As Dr E.P. Erihana, the Director of Maori Hygiene, made his report from personal supervision of preventive measures in the field, his figure is probably the more accurate, although the vital statistics figure is used here. 
The annual incidence of this disease may have been more widespread than the death rates suggest. ${ }^{12}$

\section{Diphtheria}

1945 was the only year in which this disease reached important levels, with rates of 24 for males, and 19/100,000 for females. Rates appear to have been low for the other populations of Australasia in most years from 1920 to the present. However, the reasons suggested by Lancaster for this phenomenon in Australia --- improved Hygiene, improved nutrition and a decline in the probability of younger children being infected by their older siblings, which was a result of the reduction in the size of families -.- would be of limited importance for Maoris, particularly in earlier years. ${ }^{13}$

\section{Venereal Diseases}

Venereal diseases do not cause high mortality, but can affect fertility. ${ }^{14}$ Erihana and Te Rangihiroa felt that these diseases were not very prevalent among Maoris. ${ }^{15}$ yet Turbott noted high incidence rates for Gonorrhoea at one pa, and for syphilis at another. ${ }^{16}$ Because of the use of anti-biotics, incidence rates may have declined since World War II, but this is purely speculation.

\section{2 \\ Turbott (1940): p.232} 13

P.276. Iancaster, H.0. (1952.b): "The Mortality in Aust. from Measles, Scarlatine \& Diphtheria", M.J.A. Aug 23rd. pp.272-76. He notes that immunization could be a factor, except that the relative decline of diphtheria was no greater than for those diseases for which there was no specific prophylaxis (measles and whooping cough). For N.Z. see A.J.H.R. (1947):H-3I, pp.4-6 where an increase, which proved to be temporary, is discussed and Rose (1960): p.15. Paul (1952): pp.69-70, states that immunization first occurred in New York in 1920. 14

See under heading Venereal Diseases, Section 4, chapter 4. 15 p.295 Erihana, E.P. (1931: "The Maori \& Hygiene", in Jackson, P.M. (ed.): Maori \& Education, Wellington. pp.282-308; and A.J.H.R.

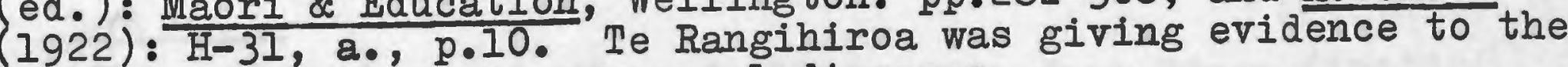
Committee investigating menereal diseases. 16 Turbott (1940): pp.232-33; and, p.30. Scrimgeour, C.G. et al. (1942): The Shadow over N.Z.: Venereal Disease, Wellington. 


\section{Tuberculosis}

At earlier stages in the period 1913 to the present, the Maoris had an "alarmingly high tuberculosis death rate ...", which, in 1943, was "one of the highest of known contemporary racial $=[$ i.e. total population, vis a vis those of certain cities, etc. 7 mortalities from that cause". 17 Recently, however, the dedline in the Maori tuberculosis death rates, crude and age-specific, has been one of the more spectacular achievements of New Zealand's public health services (see also Section 4).

Edson showed that the crude and standardised (to the 1936 population) rates for respiratory tuberculosis remained fairly stable throughout the two decades he studied (1920-40), which is probably an indication that registration of this type of tuberculosis was relatively reliable. By contrast, an increase in the rates for non-respitatory forms was more "apparent than real...", for it was probably caused by improving registration.

Crude rates calculated for the present study are for 'all forms", and are presented in Table 9.6. They remain relatively stable until the 1940s, but display greater fluctuations than do the respiratory rates calculated by Edson.

Since Edson wrote his paper the crude rates have declined rapidly. Until 1950, female crude rates were higher than the male for every year, but in the period 1951-59, male rates were higher in six of the nine years.

For this group of diseases, rates have been calculated for quinquennial age-groups for each census year from 1921 to 1956, and for two intercensal years, 1931 and 1941. Then an analysis is made of these age-specific rates, presented in Table 9.9, the relative inaccuracy of the earlier data obscures some of the results. Until, and even including 1936, age-reporting 17This quotation and those following are from Edson (1943): pp.105-07. 
was probably unsatisfactory in the vital statistics, while, in Chapter seven, Section 3, it was shown that census agereporting was most unreliable in this early period. Moreover, there was under-registration of deaths, and incorrect certification of many deaths as due to 'senility'. It seems unlikely that the incidence and fatality rates of tuberculosis would have been lower in these earlier years than later, so that lower death rates in the 1920s and 1930s probably result from unsatisfactory data.

The rates for a number of age-groups at 1921 are higher than at 1926. This could result from two causes:

1. Under-registration and census under-enumeration were equally poor at both periods, in which case there must have been a decline in tuberculosis in the period 1921-26.

2. The numerator for the 1921 rates referred to all persons "half or more Maori", while the denominators for the calculation of age-specific death rates excluded that section of the Maori population composed of "half-castes living as Europeans". This is the more likely cause of the differences between 1921 and 1926, and thus there would appear to have been no significant decline in this period.

Age-specific death rates have been calculated for the inter-censal years 1931 and 1941, and the numerators have been obtained in the manner described in Section 1 of this chapter. The denominators --- the numbers at each quinquennial age-group--have been calculated by multiplying the mean of the percentage at each age-group at the adjacent censuses, by the total mid-year population. Thus, in 1931 the mean for each age at 1926 and 1936 was used, while in 1941 the mean of 1936 and 1945 was employed. The 1931 data are subject to all the unsatisfactory characteristics noted above, but the mid-year population has not been adjusted for under-enumeration at the 1926 census, for to do so, without adjusting for the under-registration of tuberculosis 
Fieure 9.1: TUBERCULOSIS AGE SPECIFIC D ATH RATES, 1941 \& 1956.

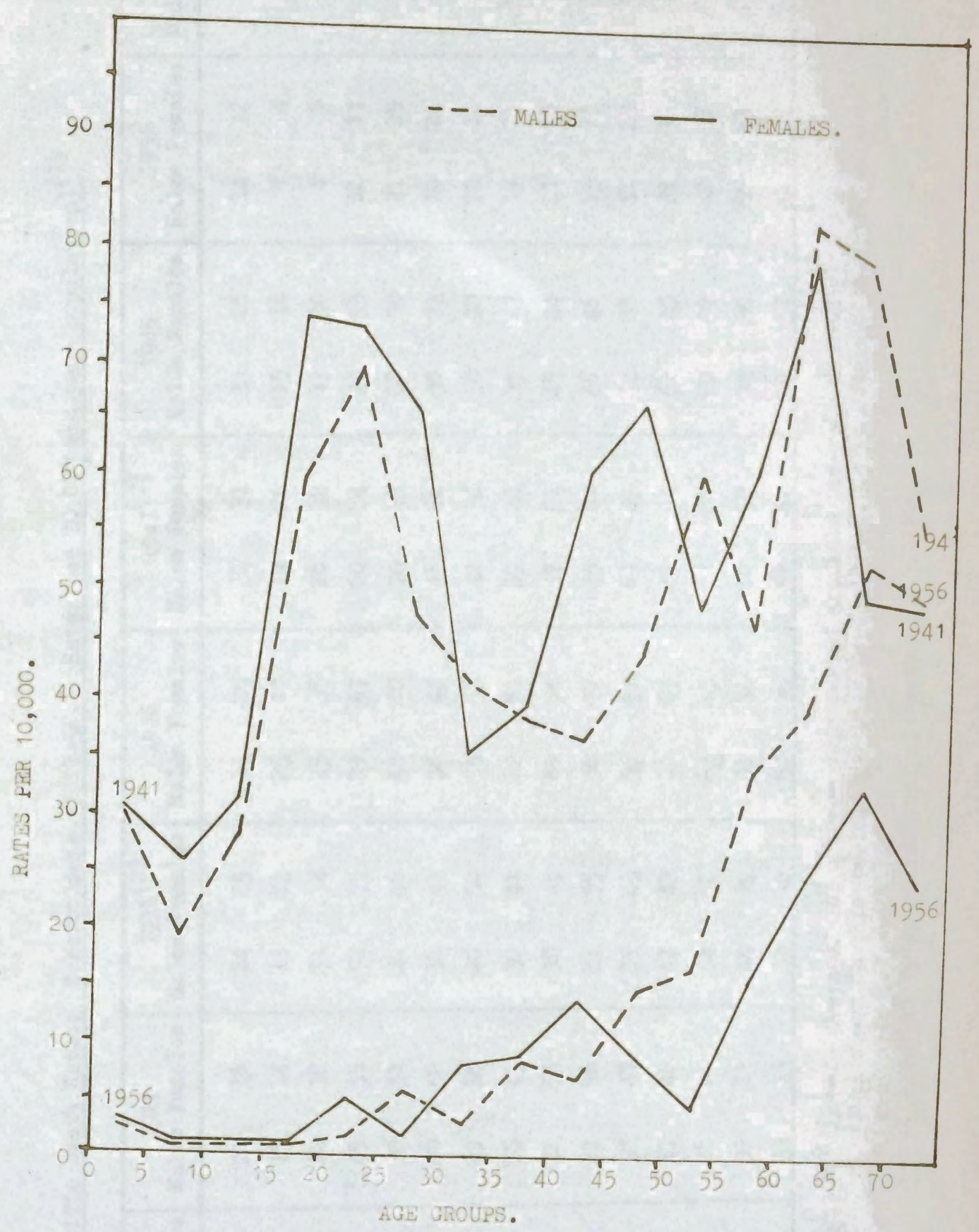




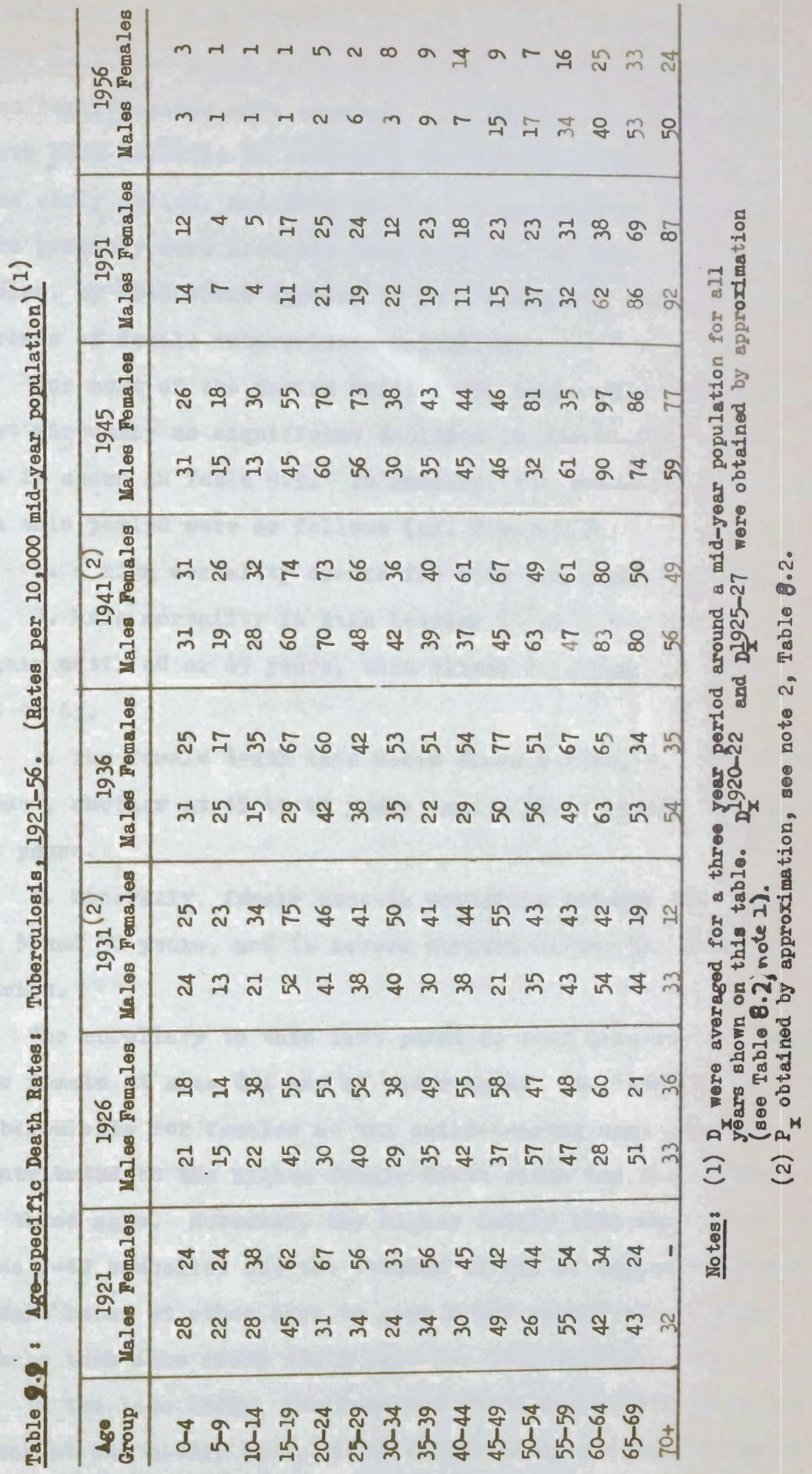


deaths, would give very low rates. In 1941, no adjustments were made, but death registration was probably more complete and certification more accurate. In Fig.9.1 the 1941 rates have been selected to exemplify age-specific death rates in the early period, and this is for two reasons: 1) The data are probably more accurate than earlier. 2) As will be shown below, by 1945 there appears to be a change in the age-specific trends of female tuberculosis mortality.

For most of the period until 1945, there were fluctuations but virtually no significant declines in age-specific rates, as is shown in Table 9.9. In summary, the trends for "all forms" in this period were as follows (cf. Fig.9.1.):

1. A high mortality occurs for both sexes at most ages.

2. Male mortality is high between 15 and 25 years, drops again until 40 or 45 years, then climbs to a peak at about 60 or 65 .

3. The female death rate shows three maxims, one at 15 to 19 years, another at 45 to 49 years, and a third between 55 and 64 years.

4. Generally, female exceeds mortality between the ages of 5 and 50 years, and is severe throughout the child-bearing period.

The corollary to this last point is that male rates exceeded the female at ages $0-4$ and at older ages. The severity of tuberculosis for females at the child-bearing ages probably contributed to the higher female death rates for all causes at these ages. Moreover, the higher female than male rates at ages 5-49 cancelled out the reverse effect of higher male than female rates at other ages to give a net result of a higher female than male crude death rate for tuberculosis.

In the late 1940s, for females, there was a decline in the rates at the middle ages, while the older ages began to displace the reproductive ages as the period when rates were highest. 
By 1951 male rates had declined, but there were much the same peaks as before, while for females, there was a marked continuation of the trend for peaks to shift from middle, and even young adult age-groups to old age. By 1956, for both sexes, maximum rates occurred only at older ages. Today, rates at these ages are higher for males, which is the cause of the change from higher female to higher male crude rates within the general framework of the decline in tuberculosis mortality. However, the profile of the distribution of female age-specific rates, shown in Fig. 9.1, still retained slightly, at 1956, the 'maxima' at ages 20-24 and, more importantly, at the end of the reproductive period. This latter peak is undoubtedly a cause of the greater female mortality from all causes of these ages. The possibility that there is undue strain placed on the constitution of Maori females because of frequent pregnancies will be discussed later when referring to degenerative diseases.

For tuberculosis it is instructive to make an analysis of the trends of birth cohorts, for this group of diseases has this unique combinations of characteristics:

1. Rates are very high.

2. Mortality is spread right through all age-groups. By comparison the group of respiratory diseases 'bronchitis (etc.)' (see below) has very high rates, but is clearly restricted to ages 0-4 and to old age, while throughout the periods, the degenerative diseases (see below) have been significant only at older ages.

3. For respiratory forms of tuberculosis, registration appears to have been relatively full for much of the period.

Obviously, the reliability of the analysis is dependent upon the general accuracy of date as well as the factor of mis-certification of deaths at older age-groups. However, this latter factor is not as significant as it might have been, for the emphasis here is to see the effect of earlier tuberculosis death rates on cohorts currently reaching older 
ages. The available data span the trends of cohorts only from 1921 to 1956, so that much of the analysis must be based on presumptions about earlier age-specific rates for the older cohorts, and about future trends for the younger cohorts. As the census scheduled for April 1946 was taken in September 1945 instead, the 1945 age-specific rates are used as if they had been derived from April 1946. Probably this has only the slightest effect on the results.

Fig. 9.2 shows the trends for each cohort, which are derived from the age-specific rates given in Table 9.9. Two comments can be made:

1. 1. The trends for older cohorts, if synthesised, would probably resemble the 1941 age-specific rates shown in Fig.9.1.

2. Since 1945, most male and almost every female cohort has had a remarkable decline in mortality, regardless of the age the cohort has reached, and regardless of the level of rates reached earlier in the cohort's history. For both sexes, the one exception is the birth-cohort of 1877-81, which was at age $70+$ in 1951, but even its neighbour, the cohort of 1882-86, showed a spectacular decline between 1951 and 1956. For males, slight increases occurred between 1951 and 1956 for the cohorts of 1892-96, 1902-06 and 1907-11.

In view of the quality of the date and the short time span involved, conclusions must be very tentative. Two points may be noted. The shift of high Maori tuberculosis mortality rates from a wide range of ages to old age alone is but a further example of the trend, noted by other observers, of "the residual effect of high infection rates in the past as evidenced by a high mortality rate of the same cohort at other ages." Thus today, highest Maori rates are found at ages $60+$ while, in general, each cohort had a lower death rate in 1956 than its immediately senior cohort.

The rationale, on which can be based a conclusion drawn from a cohort analysis of tuberculosis, has been defined by springett, 


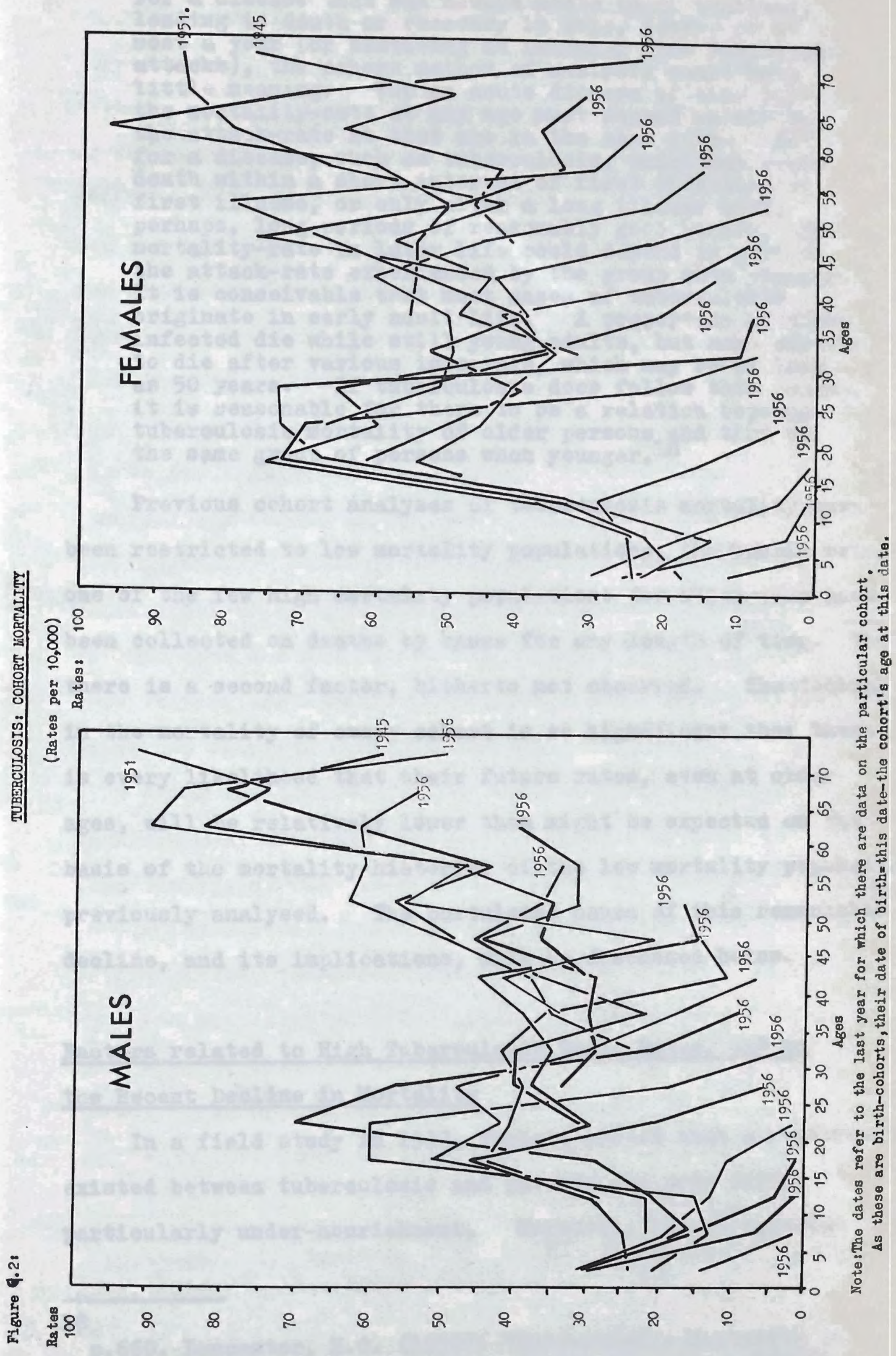


who is one of the observers noted immediately above:

For a disease that was always acute (e.g. measles), leading to death or recovery in days, weeks, or at most a year (or bestowing an immunity from subsequent attacks), the cohort method of analysis could have little meaning. For an acute disease of this type the mortality-rate at any age must depend mainly on the attack-rate at that age in the same year. But for a disease, such as tuberculosis, which may cause death within a short interval of first infection or first illness, or only after a long illness with, perhaps, long periods of reasonably good health, the mortality-rate in later life could depend in part on the attack-rate experienced by the group when younger. It is conceivable that most cases of tuberculosis originate in early adult life. A proportion of those infected die while still young adults, but some survive to die after various intervals, which may be as long as 50 years. If tuberculosis does follow this course, it is reasonable for there to be a relation between tuberculosis mortality of older persons and that of the same group of persons when younger. 18

Previous cohort analyses of tuberculosis mortality have been restricted to low mortality populations, the Maoris being one of the few high mortality populations for which data have been collected on deaths by cause for any length of time. Thus, there is a second factor, hitherto not observed. The decline in the mortality of every cohort is so significant that there is every likelihood that their future rates, even at older ages, will be relatively lower than might be expected on the basis of the mortality histories of the low mortality populations previously analysed. The postulated cause of this remarkable decline, and its implications, will be discussed below.

Factors related to High Tuberculosis Death Rates, and to

\section{the Recent Decline in Mortality}

In a field study in 1933, Turbott showed that a relationship existed between tuberculosis and poverty and poor diet, particularly under-nourishment. Moreover, it was apparent that

\section{8}

p.660. Iancaster, H.0. (1950): "Tuberculosis Mortality in Aust., 1908-45, M.J.A., May 20th. pp.655-62; and, p.524-25 Springett, V.H. (1952): "An Interpretation of Statistical Trends in Tuberculosis", Lancet, March 15th \& 22nd. pp.521-25 \& 575-79. 
"contact must be a potent factor in the spread of tuberculosis...", including attendances at gatherings, visiting and movement to other areas. Finally, "The history of treatment of this tuberculosis makes sad reading...60.8 per cent (of those found by the survey to be sufferers) had no institutional or practitioner's treatment whatsoever. Failure to seek aid was the trouble, the facilities being adequate if utilized". Turbott was unable to find a close relationship between overcrowding and insanitary dwellings, lack of personal hygiene, and the widespread incidence of tuberculosis. ${ }^{19}$

Edson, in his 1943 survey noted above, declined to give the causes for high tuberculosis death rates, but stated "that tuberculosis cannot be reduced to negligible proportions in New Zealand until a solution of the Maori problem is in sight". By Maori problem" he undoubtedly meant various environmental factors. In this case the solving of the "Maori problem", if indeed it has been solved, has caused only a part of the decline in tuberculosis, which has occurred since he wrote.

Among the 'environmental' factors which might have aided the decline, are improving diet and a decrease in poverty. More importantly, as will be discussed later in this chapter and also in Chapter Eleven, there has been an increase in the effectiveness of preventive, diagnostic and curative measures. For example, improved notification rates indicate that, today, many sufferers are being located and treated at early stages. 20 Thus, the trends shown by the cohort analysis result from causes which are different from those which brought about the tuberculosis

19

pp.45-48 \& 63. Turbott, H.B. (1935): Tuberculosis in the Maori: East Coast of N.Z., Wellington.

20

p.5. Robb, Douglas (1960): "Maori \& European: Differential Incidence of Surgical \& Other Diseases", N.Z.M.J., vol.59, No. 334, June. pp.271-79. 
mortality declines in low mortality populations. For example, McKeown and Record show that declines in tuberculosis in England and Wales were relatively 'gradual', and were caused, to a considerable degree, by 'environmental' (vis a vis 'curative') factors, most particularly improving diet. ${ }^{21}$ By contrast, the Maoris, like many other high mortality populations, have had a rapid transition to lower mortality, which has been caused by new curative and preventive measures introduced since the war. It is postulated that the new methods of diagnosing and treating tuberculosis are more likely to bring about a 'complete' cure while the traditional declines in the incidence of tuberculosis, which resulted from changes in diet or other environmental factors, may not have been as thorough. Thus, when cohorts experiencing the traditional type of decline reached older ages there seems to have been a recrudescence of the disease. By contrast, there is every likelihood that, in future, older Maoris will have lower tuberculosis mortality rates than might be expected on the basis of the experiences of low mortality populations. In the future, such a trend may be exhibited by other high mortality populations for this and other causes of death.

21

p.116. McKeown, Thomas \& Record, R.G. (1962): "Reasons for the Decline in Mortality in England \& Wales During the Nineteenth Century", Pop.Stud., vol.XVI, No. 2, Nov. pp.94-122. They note that increased consumption of milk may have assisted in the decline (p.114) "(a) by causing more early deaths from the bovine form of the disease; and (b) by affording some degree of protection to those who survived early infection". Thus (p.115), "some part of the reduction... may have been associated with the consumption of infected milk". Turbott (1935) found that milk was not "widely incorported in Maori diet...", and $50 \%$ of the milk used was boiled. Moreover, only one sample of cow's milk, out of 110 taken from 1,005 cows in the district, was found to be infected, and tests of 515 individual cows in 15 herds found that only 27 were infected (pp.59-60). Turbott concludes ( $p .64)$ : "Bovine tuberculosis was held to be a negligible factor at present in the incidence of tuberculosis". When tuberculosis declined in the post-war period, the effect of diet would have been, therefore, more in terms of improving nutrition. Presumably, most milk consumed would be pasteurised or from uninfected herds. Frequent checks for bovine tuberculosis are made on the herds of dairy factory suppliers and tow milk suppliers. 
Table 9.10: $\frac{\text { Crude Death Rates: Certaln Respiratory Diseases }}{\text { (Rates per 100,000 mid-year population) }}$

326

\begin{tabular}{|c|c|c|c|c|}
\hline \multirow[t]{2}{*}{ Yoar } & \multicolumn{2}{|c|}{ Influenza } & \multicolumn{2}{|c|}{$\begin{array}{l}\text { Bronohitis, Bronoo- } \\
\text { pnoumonia and pnoumoni }\end{array}$} \\
\hline & Males & Females & Males & Femalos \\
\hline 1926 & 57 & 82 & 237 & \\
\hline 1927 & 67 & 38 & 278 & 278 \\
\hline 1928 & 117 & 103 & 342 & 252 \\
\hline 1929 & 61 & 58 & 295 & 158 \\
\hline 1930 & 32 & 35 & 246 & 204 \\
\hline 1931 & 71 & 40 & 174 & 221 \\
\hline 1932 & 46 & 31 & 290 & 249 \\
\hline 1933 & 28 & 22 & 291 & 275 \\
\hline 1934 & 64 & 53 & 352 & 321 \\
\hline 1935 & 55 & 47 & 376 & 382 \\
\hline 1936 & 44 & 48 & 452 & 438 \\
\hline 1937 & 37 & 44 & 496 & 387 \\
\hline 1938 & 67 & 72 & 587 & 536 \\
\hline 1939 & $\begin{array}{l}80 \\
50\end{array}$ & 66 & 504 & 373 \\
\hline $\begin{array}{l}1940 \\
1941\end{array}$ & $\begin{array}{l}50 \\
34\end{array}$ & 35 & 333 & 287 \\
\hline $\begin{array}{l}1941 \\
1942\end{array}$ & $\begin{array}{l}34 \\
63\end{array}$ & $\begin{array}{l}29 \\
32\end{array}$ & 468 & 355 \\
\hline 1943 & 31 & $\begin{array}{l}33 \\
26\end{array}$ & $\begin{array}{l}408 \\
344\end{array}$ & $\begin{array}{l}321 \\
310\end{array}$ \\
\hline 1944 & 41 & 19 & 346 & $\begin{array}{l}349 \\
278\end{array}$ \\
\hline 1945 & 28 & 15 & 259 & 235 \\
\hline 1946 & 41 & 32 & 321 & 279 \\
\hline 1947 & 19 & 10 & 259 & 195 \\
\hline 1948 & 18 & 23 & 256 & 190 \\
\hline 1949 & 5 & 17 & 256 & 250 \\
\hline 1950 & 14 & 22 & 174 & 165 \\
\hline 1951 & 15 & 9 & 162 & 145 \\
\hline 1952 & 21 & 15 & 225 & 192 \\
\hline 1953 & 8 & 2 & 155 & 156 \\
\hline 1954 & 5 & 5 & 158 & 107 \\
\hline 1955 & 4 & 3 & 151 & 150 \\
\hline 1956 & 3 & 6 & 156 & 138 \\
\hline 1957 & 33 & 40 & 160 & 134 \\
\hline 1958 & 5 & 4 & 136 & 98 \\
\hline 1959 & 10 & 11 & 162 & 147 \\
\hline
\end{tabular}

Table 2012: Age-specific Death Ratess Influenza Rates per 10,000 mid-year population)

\begin{tabular}{|c|c|c|c|c|c|c|c|c|c|c|}
\hline \multirow[b]{2}{*}{ Ages } & \multicolumn{5}{|c|}{ Mates } & \multicolumn{5}{|c|}{ FonuLEs } \\
\hline & 1926 & 1936 & 1945 & 1951 & 1956 & 1926 & 1936 & 1945 & 1951 & 1956 \\
\hline $0-4$ & 14 & 14 & 14 & 6 & 4 & 17 & 12 & 9 & 6 & 3 \\
\hline $5-14$ & 2 & 3 & 3 & - & . & 2 & 3 & 1 & - & - \\
\hline $15-24$ & 2 & 1 & 1 & - & - & 2 & 1 & - & - & - \\
\hline $25-44$ & 3 & 2 & - & - & - & 2 & 2 & - & - & - \\
\hline $45-64$ & 5 & 4 & 2 & - & 1 & 3 & 3 & 2 & 2 & 3 \\
\hline & 20 & 7 & 20 & 13 & 7 & 10 & 28 & 15 & 24 & 12 \\
\hline
\end{tabular}


A considerable amount of space has been expended on this one cause of death. This has been necessary, for it will be show in Section 4 that the decline in tuberculosis has been responsible for a very significant proportion of the total decrease in mortality in the post-war period.

\section{Influenza}

This respiratory disease is included with the acute infectious diseases in the summary to this chapter (see Section 4). As is show in Table 9.10, crude rates have declined, particularly since 1945, but with considerable fluctuations. High male rates occur more frequently than do high female rates. The age-specific rates, given in Table 9.11, show the same downward trend. Mortality is concentrated at the very youngest and the very oldest ages, but, while declines have occurred at both age-groups, they have, perhaps, been less significant at ages 65+. There may have been an epidemic of influenza in 1928.

\section{Bronchitis, Broncho-Pneumonia and Pneumonia}

Because there are problems in the diagnosis of these diseases, they have been grouped together. Combined, they are a most significant cause of mortality, having higher rates than tuberculosis. Although the rates have declined by half since the late 1940s, unlike tuberculosis these diseases still remain a major cause of death. The crude rates, given in Table 9.10, do not include some cases of 'bronchitis (etc.)' at the neonatal ages.

The age-specific rates, presented in Table 9.12, show that peaks occur at the youngest and oldest ages, while declines have been most marked at the youngest age-groups. In general, female rates are lower than the male. 
Table 9.12 : Age-specific Death Rates: Bronchitis, Bronchopneumonia and Pneumonia.

(Rates per 10,000 mid-year population)

\begin{tabular}{|c|c|c|c|c|c|c|c|c|c|c|}
\hline Ages & 1926 & 7036 & & & & & & EWM & & \\
\hline $0-1$ & 80 & +200 & 1742 & 1971 & 193 & 1926 & 1936 & 1945 & 1951 & 1956 \\
\hline $\begin{array}{c}0-4 \\
5-14 \\
15-24 \\
25-44 \\
45-64 \\
65+\end{array}$ & $\begin{array}{r}82 \\
6 \\
6 \\
9 \\
24 \\
71\end{array}$ & $\begin{array}{r}173 \\
7 \\
7 \\
13 \\
39 \\
132\end{array}$ & $\begin{array}{r}156 \\
2 \\
4 \\
5 \\
13 \\
66\end{array}$ & $\begin{array}{r}75 \\
1 \\
- \\
3 \\
14 \\
96\end{array}$ & $\begin{array}{r}52 \\
1 \\
1 \\
3 \\
12 \\
100\end{array}$ & $\begin{array}{r}91 \\
6 \\
7 \\
6 \\
15 \\
41\end{array}$ & $\begin{array}{r}150 \\
9 \\
6 \\
17 \\
25 \\
111\end{array}$ & $\begin{array}{r}121 \\
6 \\
2 \\
5 \\
17 \\
66\end{array}$ & $\begin{array}{r}71 \\
2 \\
1 \\
2 \\
10 \\
79\end{array}$ & $\begin{array}{r}45 \\
1 \\
-2 \\
2 \\
15 \\
87\end{array}$ \\
\hline
\end{tabular}

Although these diseases are frequently cited as causes of high mortality, particularly among infants, they have seldom been studied in detail, but both Turbott's and Prior's surveys revealed the frequency of chronic bronchitis, which Prior related to continual cigarette smoking. 22

\section{Diarrhoea and Related Diseases.}

This group includes those diseases generally coded as diarrhoea, but at various times as gastro-enteritis, enteritis, colitis, and gastritis. Usually, deaths at neonatal ages are excluded from published data.

Crude death rates, given in Table 9.13, have tended to decline, with fluctuations, but this is more marked for females than for males.

\section{2}

Turbott (1935): pp.17-18, who notes that the prevalence of these diseases had often been attributed to asthma, or (by nonMaori neighbours) to tuberculosis; and, p.11. Prior, Ian (1962): "A Health Survey in a Rural Maori Community, With Particular Emphasis on the Cardiovascular, Nutritional \& Metabolic Findings", N.Z.M.J., vol.61, No. 359, July. pp.1-16 (reprint). The effect of smoking is noted in Stuart-Harris, C.H. (1963): "The Epidemiology of Chronic Bronchitis", N.Z.M.J., vol.62, No. 365, Jan.pp.35-39. 
Table 9.13 : Crude Death Rates: Diarrhoea and Related Diseases (Rates per 100,000 mid-year population)

\begin{tabular}{lccccc} 
Year & \multicolumn{2}{c}{ Rates } & Year & \multicolumn{2}{c}{ Rates } \\
\hline 1926 & Males & Females & & Males & Females \\
1927 & 42 & 52 & 1943 & 70 & 67 \\
1928 & 67 & 67 & 1944 & 79 & 81 \\
1929 & 48 & 59 & 1945 & 132 & 100 \\
1930 & 22 & 55 & 1946 & 91 & 91 \\
1931 & 57 & 47 & 1947 & 72 & 65 \\
1932 & 42 & 26 & 1948 & 51 & 50 \\
1933 & 46 & 42 & 1949 & 71 & 58 \\
1934 & 30 & 27 & 1950 & 45 & 42 \\
1935 & 44 & 27 & 1951 & 42 & 41 \\
1936 & 81 & 59 & 1952 & 78 & 48 \\
1937 & 72 & 68 & 1953 & 50 & 43 \\
1938 & 57 & 57 & 1954 & 35 & 42 \\
1939 & 126 & 125 & 1955 & 64 & 29 \\
1940 & 93 & 61 & 1956 & 31 & 24 \\
1941 & 63 & 67 & 1957 & 38 & 37 \\
1942 & 86 & 63 & 1958 & 29 & 27 \\
\hline
\end{tabular}

Moreover, crude rates are still high, and male rates are generally higher than females. Higher death rates in 1938-39 may have been associated with the measles epidemic of 1938 (see above), and the higher rates in 1945-46 arise probably from an epidemic, but no more is known. The age-specific rates, in Table 9.14, show that mortality is concentrated at the youngest ages, where recent declines have been most marked.

Table 9.14 : Age-specific Death Rates: Diarrhoea and Related Diseases (Rates per 10,000 of the mid-year Population).

\begin{tabular}{ccccccccccc} 
Ages & \multicolumn{1}{c}{ MALES } & \multicolumn{1}{c}{ FEMALES } \\
& 1926 & 1936 & $1945^{1}$ & 1951 & 1956 & 1926 & 1936 & $1945^{1}$ & 1951 & 1956 \\
\hline $0-4$ & 26 & 42 & 53 & 28 & 20 & 24 & 32 & 47 & 23 & 16 \\
$5-14$ & 1 & - & 2 & 1 & - & 2 & 2 & 1 & 1 & - \\
$15-24$ & 1 & - & - & - & - & 1 & - & - & - & - \\
$24-44$ & - & - & 1 & 1 & - & 1 & - & - & - & - \\
$45-64$ & - & - & 2 & - & - & - & - & - & - & 1 \\
$65+$ & 2 & - & 13 & - & 6 & - & - & 15 & - & 5
\end{tabular}

Note: 1. The 1945 rates, although averaged for the period 1944-1946 include abnormally high crude death-rates for the two years 1945 and 1946 (See Table 9.13). 
Table 9.15: Crude Death Rates: Certain Degenerative Diseases

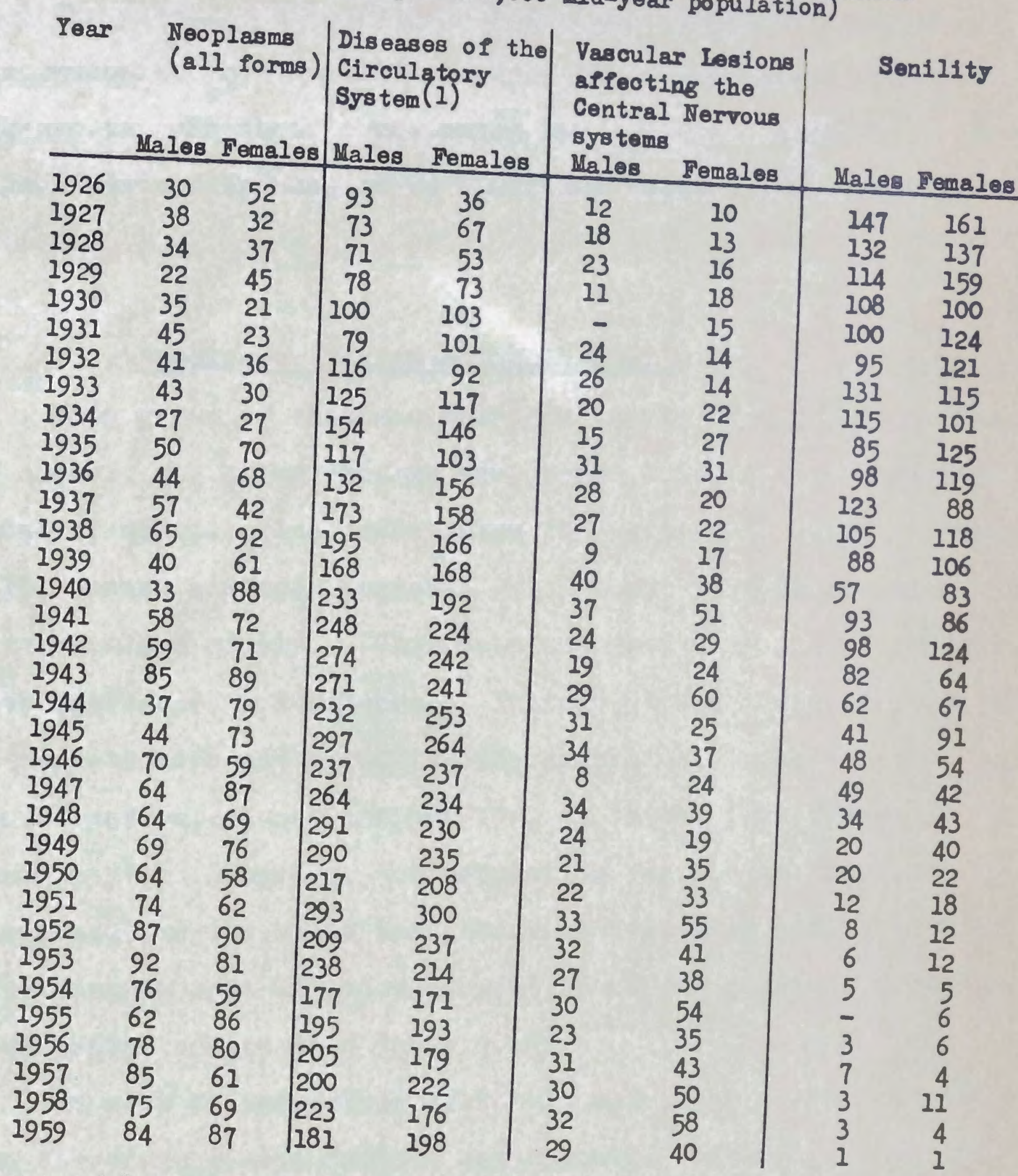

Note: (1) $\Delta t$ earlier periods rheumatic fever was olassified in a group of general and rheumatic diseases, but recently has been included here. Pollowing earlier procedure 'Diseases of the Ciroulatory System' in this table include rheumatic heart-disease, but exclude rheumatic fever. The numbers involved are small so that the possible error introduced must be slight.

Table 9.16: Age-specific Death Rates: Neoplasms (Rates per 10,000 mid-year population)

\begin{tabular}{|c|c|c|c|c|c|c|c|c|c|c|}
\hline \multirow[b]{2}{*}{ Ages } & \multicolumn{5}{|c|}{ MALES } & \multicolumn{5}{|c|}{ FMaAdas } \\
\hline & 1926 & 1936 & 1945 & 1951 & 1256 & 1926 & 1936 & 1945 & 1951 & 1956 \\
\hline & 1 & 1 & 1 & - & 2 & - & 1 & 1 & 2 & 2 \\
\hline $5-14$ & $\overline{-}$ & - & 1 & 1 & 1 & - & - & - & 1 & 1 \\
\hline $15-24$ & 1 & - & 1 & 2 & 1 & 1 & 1 & 1 & 1 & 1 \\
\hline $25-44$ & 2 & 2 & 4 & 4 & 4 & 4 & 3 & 6 & 6 & 6 \\
\hline $45-64$ & 13 & 26 & 23 & 36 & 30 & 18 & 44 & 39 & 35 & 36 \\
\hline & 31 & 42 & 39 & 90 & 59 & 28 & 42 & 44 & 65 & 87 \\
\hline
\end{tabular}




\section{Degenerative Diseases}

The diseases discussed above, with the exception of tuberculosis, have tended to affect the youngest and oldest age-groups, and their crude rates have declined recently. The degenerative diseases, to be discussed below, have different trends.

\section{Neoplasms (Benign and Malignant)}

This group of diseases consists mainly of the various forms of cancer, the group 'benign neoplasms' being a very insignificant cause of death. The crude rates for neoplasms, given in Table 9.15, showed a steady increase until about 1950, since when they have remained stable. This does not mean that these diseases have increased in incidence. Instead, there is the probability of registration and certification anomalies, including the certification, at earlier periods, of deaths from cancer as 'senility'. Secondly, the population exposed to risk has increased, in the sense that there is a greater chance today of surviving to ages 45 and above, at which the greatest mortality from cancer occurs (see Table 9.16).

It must be reiterated that this age-group is very small, and therefore random factors may operate. Thirdly, there is the possibility of mis-diagnosis where cancer is a secondary cause, particularly in the case of lung cancer. For example, in 1960, Rose noted that an investigation of medical certificates showed "a number of cases where malignancy had developed in a longstanding tuberculosis infection of the lung". 23

One of the immediate causes of high death rates is that Maoris do not come forward for medical treatment until the disease is very advanced. 24 Generally, females have higher rates than do males.

\footnotetext{
23

Rose (1960): p.20.

24

Rose (1960): p.18.
} 
The age-specific rates, given in Table 9.16 show the same trend, although the rates for males aged 65+ in 1956 are surprisingly low. Mortality from cancer is concentrated at the older age-groups.

\section{Diseases of the Circulatory System}

The points to be noted for these diseases are similar to those discussed above for neoplasms. Moreover, it seems that either deaths from these causes were not recorded, or were recorded wrongly until about 1940. However, the crude rates, shown in Table 9.15, indicate two differences. Firstly, there is a slight recent decline, and, secondly, male rates are usually higher than female.

Age-specific rates are shown in Table 9.17. Mortality in 1956 was lower than in earlier years, while throughout the period the major age-groups affected were the older ages. A possible factor causing high rates at these ages is "that heart damage is sustained during attacks from the many forms of infection contracted in childhood". 25 Turbott and Robb have noted a relationship between these diseases and the high incidence of rheumatic fever, while Prior has discussed the effect of chronic bronchitis. 26

Table 9.17 : Age-specific Death Rates: Diseases of the $\frac{\text { Circulatory System }}{\text { (Rates per 10,000 mid-year population) }}$

\begin{tabular}{|c|c|c|c|c|c|c|c|c|c|c|}
\hline Ages & 1926 & 1936 & $\begin{array}{r}\text { MALES } \\
1945\end{array}$ & 1951 & 1956 & 1926 & 1936 & $\begin{array}{c}\text { EMALES } \\
1945 \\
\end{array}$ & 1951 & 1956 \\
\hline $\begin{array}{c}0-4 \\
5-14 \\
15-24 \\
25-44 \\
45-64 \\
65+\end{array}$ & $\begin{array}{r}1 \\
1 \\
2 \\
4 \\
23 \\
67\end{array}$ & $\begin{array}{r}4 \\
\overline{1} \\
6 \\
39 \\
222\end{array}$ & $\begin{array}{r}2 \\
3 \\
6 \\
9 \\
78 \\
433\end{array}$ & $\begin{array}{r}\overline{2} \\
3 \\
11 \\
84 \\
448\end{array}$ & $\begin{array}{r}1 \\
2 \\
3 \\
9 \\
70 \\
388\end{array}$ & $\begin{array}{r}1 \\
1 \\
3 \\
3 \\
13 \\
48\end{array}$ & $\begin{array}{r}1 \\
2 \\
4 \\
9 \\
55 \\
146\end{array}$ & $\begin{array}{r}2 \\
3 \\
3 \\
12 \\
105 \\
418\end{array}$ & $\begin{array}{r}1 \\
4 \\
4 \\
13 \\
91 \\
425\end{array}$ & $\begin{array}{r}2 \overline{2} \\
2 \\
10 \\
77 \\
381\end{array}$ \\
\hline
\end{tabular}

25

Rose (1960): p.33.

26

Turbott (1935:p.15; Robb (1960):p.6; and, Prior (1962): p.15. 
Rose felt that high mortality from heart diseases among Maoris may be related to overweight, particularly in women. 27 Prior's survey shows that "Excess weight and obesity are common in both sexes, but are of greater extent in women up to the age of fifty". For women "Multiple pregnancies may be a contributing factor if only through obesity". 28 Here, Prior refers to the number of times a Maori woman may conceive during her reproduction period, rather than the frequency of Multiple births, such as twins or triplets, at any one confinement.

\section{Vascular Lesions Affecting the Central Nervous}

This group includes 'apoplexy' (at earlier dates) cerebral haemorrhage, embolism and thrombosis; and subarachnoid haemorrhage. The comments about the two previous groups of diseases generally apply here. Thus, in Table 9.15 highest rates occur recently while, since 1940, the female crude rates have usually been higher than the male. The age-specific rates in Table 9.18 show that these diseases affect the two oldest age-groups, and that, recently, the gap ibetween males and females has been substantial.

Table 9.18: Age-specific Death Rates: Vascular Lesions Affecting the Central Nervous System (Rates per 10,000 mid-year population)

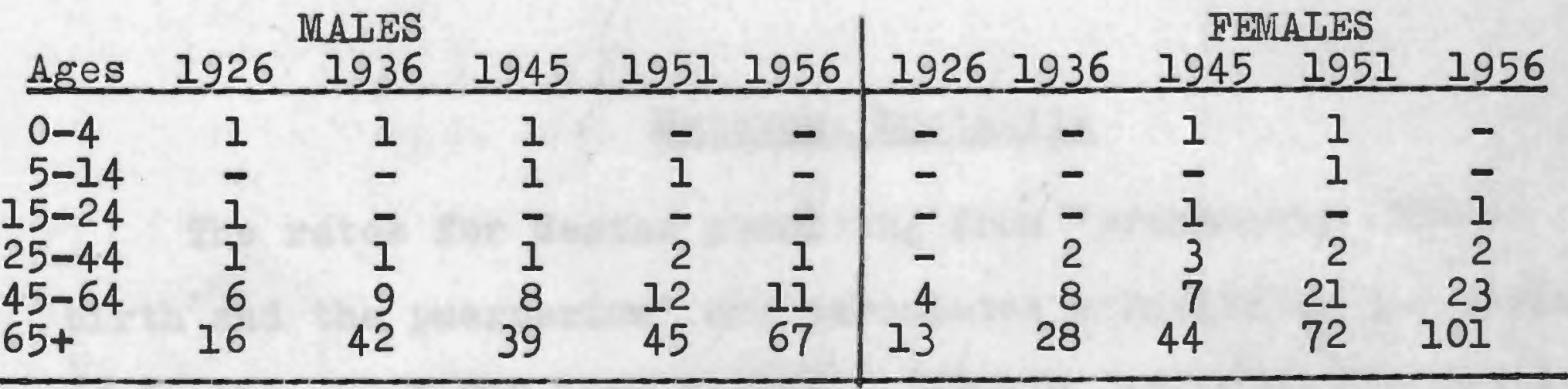

\footnotetext{
27 28

Rose (1960): p.22

Prior (1962): p.15
} 


\section{Senility}

This so-called 'cause of death', the crude rates of which are tabulated in Table 9.15, results from poor certification. Thus, as the crude rates of the three degenerative diseases discussed above have increased, largely because of improved registration and certification, so have the rates for senility decreased to almost negligible proportions. 'Abnormally' high rates in 1941 may have resulted from the poor certification of some of the diseases which were the sequelae of the whooping cough epidemic in that year.

The age-specific rates in Table 9.19 illustrate the decline even more emphatically. Senility, almost alone among the causes of death discussed here, had age-specific rates in 1926 which were similar to those in 1936.

\section{Table 9.19: $\frac{\text { Age-specific Death Rates: Senility }}{\text { (Rates per 10,000 mid-year population) }}$}

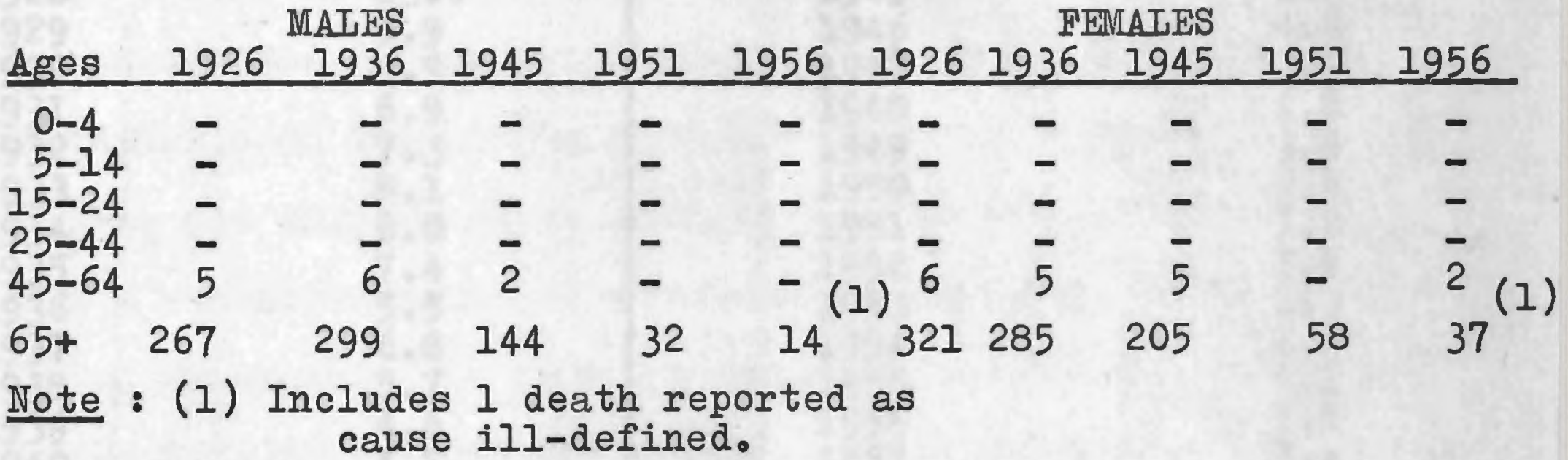

\section{Maternal Mortality}

The rates for deaths resulting from 'pregnancy, childbirth and the puerperium' are calculated normally on the basis of deaths per 1,000 live births. Ideally, age-specific rates should be determined on the basis of deaths per 1,000 births to mothers of a given age, for the exposure to risk factor here is rather the number of pregnancies, than the number of persons at each age. As there are do data on births by age of women, no calculation of age-specific rates can be made. 
Moreover, there are no data on deaths by parity, so this factor cannot be analysed.

The maternal mortality rates, given in Table 9.20, have show a steady decline since the early 1940s. Several points arise from this. Firstly, this decline would cause part of the decrease in deaths at the reproductive ages. Secondly, maternal mortality is only one cause of death resulting from pregnancy for other diseases may be more virulent than normal at this time. Thirdly, frequent pregnancies may result, indirectly, in a greater chance of mortality from other causes at this and other ages (See above, Diseases of the Circulatory System).

Table 9.20 : Crude Death Rates: Maternal Mortality (Rates per 1,000 live births)

\begin{tabular}{|c|c|c|c|}
\hline Year & Rates & Year & Rates \\
\hline $\begin{array}{l}1926 \\
1927 \\
1928 \\
1929 \\
1930 \\
1931 \\
1932 \\
1933 \\
1934 \\
1935 \\
1936 \\
1937 \\
1938 \\
1939 \\
1940 \\
1941 \\
1942\end{array}$ & $\begin{array}{l}9.8 \\
8.7 \\
13.6 \\
5.9 \\
9.9 \\
6.9 \\
7.3 \\
8.1 \\
6.0 \\
7.4 \\
5.5 \\
6.8 \\
5.7 \\
4.6 \\
4.7 \\
4.6 \\
4.6\end{array}$ & $\begin{array}{l}1943 \\
1944 \\
1945 \\
1946 \\
1947 \\
1948 \\
1949 \\
1950 \\
1951 \\
1952 \\
1953 \\
1954 \\
1955 \\
1956 \\
1957 \\
1959 \\
1959\end{array}$ & $\begin{array}{l}2.2 \\
3.3 \\
1.9 \\
4.0 \\
2.2 \\
1.8 \\
3.5 \\
2.4 \\
1.0 \\
2.6 \\
1.3 \\
1.6 \\
2.1 \\
1.8 \\
1.4 \\
1.3 \\
1.3\end{array}$ \\
\hline
\end{tabular}

The decline in maternal mortality seems to be associated with the increased hospitalisation of Maori maternity cases (see Chapter 7, Section 4). Because of the increase in hospitalisation, some of the major problems of Maori confinements may have been overcome. In 1938, the Committee on Maternal Services had noted that these were the inability of friends and relatives attending confinements to deal with complications, unhygienic living conditions and poor diet. 29 But even in 1960, with fuller

29 \& Broughton, I.W. (1942): Some Psychological Aspects of the Maori, Dunedin, Mss.Pub.Lib. 
hospitalisation, inadequate ante-natal care remained an important problem. 30

\section{Accidents, Homicide and Suicide}

of all aspects of Maori mortality, these causes are perhaps the most accurately recorded, for throughout the period they were certified by coroners. The crude rates, given in Table 9.21 , show two characteristics. Firstly, they have remained, with some fluctuations, at a fairly stable level. Secondly, male rates are approximately two to three times those of females.

The age-specific rates are given in Table 9.22. The causes can only be understood by referring to Rose's study of the type of accident involved, and the comparisons he makes with non-Maoris for accidents, homicide and suicide. For most ages and for each sex, Maori motor-vehicle accident death rates are much higher than the non-Maori. Rose attributes this to isolated residence, and the subsequent dependence on motor-vehicles, many of which are unsafe, and which must be used on poor roads. For 'other' (vis a vis motor-vehicle) accidents at ages 0-4, Maori rates far exceed non-Maori, the causes being, Rose suggests, less direct supervision of children by parents (older siblings often being entrusted with the care of infants), and poorly constructed houses and equipment. At the working ages high male 'other' accident rates must arise from the types of occupations favoured by Maoris, for example, farming, construction, labouring and forestry. At age-group 65+, where falls are the most common cause of accidental death, the non-Maori rates are similar to the Maori.

Suicide and homicide are very insignificant causes of death, but Rose's analysis is worth repeating here. In 1956, Male age-

30

p.2.Moore, Rina (1960): Maori Health 1960, Paper presented Conference of Maori Leaders, Marton, 12th Nov. (cyclostyled). 
Table 9.21 : Crude Death Rates: All Accidents, Suicide and Self-Inflicted Injury, and Homicide (Rates per 100,000 mid-year population)

\begin{tabular}{lcc|ccc} 
Year & Males & Females & Year & Males & Females \\
\hline 1926 & 132 & 56 & 1943 & 108 & 61 \\
1927 & 126 & 38 & 1944 & 120 & 32 \\
1928 & 148 & 50 & 1945 & 112 & 37 \\
1929 & 72 & 24 & 1946 & 132 & 51 \\
1930 & 119 & 65 & 1947 & 126 & 67 \\
1931 & 121 & 69 & 1948 & 132 & 46 \\
1932 & 147 & 78 & 1949 & 140 & 52 \\
1933 & 115 & 60 & 1950 & 154 & 40 \\
1934 & 139 & 66 & 1951 & 127 & 51 \\
1935 & 119 & 85 & 1952 & 152 & 49 \\
1936 & 155 & 68 & 1953 & 164 & 46 \\
1937 & 135 & 59 & 1954 & 167 & 56 \\
1938 & 124 & 51 & 1956 & 163 & 52 \\
1939 & 157 & 68 & 1957 & 133 & 55 \\
1940 & 148 & 67 & 1958 & 139 & 46 \\
1941 & 152 & 48 & 1959 & 134 & 45 \\
1942 & 145 & 49 & &
\end{tabular}

Table 9.22 : Age-specific Death Rates: All Types of Accidents, Suicide and Self-Inflicted Injury, and Homicide (Rates per 10,000 mid-year population)

\begin{tabular}{lrrrrr|rrrrr} 
& \multicolumn{1}{c}{ MALES } & \multicolumn{7}{c|}{ FEMALES } \\
\hline Ages & 1926 & 1936 & 1945 & 1951 & 1956 & 1926 & 1936 & 1945 & 1951 & 1956 \\
\hline $0-4$ & 12 & 15 & 13 & 15 & 16 & 12 & 19 & 10 & 11 & 12 \\
$5-14$ & 8 & 4 & 8 & 5 & 7 & 4 & 4 & 3 & 3 & 3 \\
$15-24$ & 18 & 15 & 16 & 17 & 17 & 7 & 5 & 3 & 3 & 5 \\
$25-44$ & 13 & 17 & 13 & 20 & 20 & 2 & 1 & 1 & 2 & 3 \\
$45-64$ & 18 & 19 & 11 & 20 & 21 & 2 & 8 & 2 & 6 & 4 \\
$65+$ & 25 & 35 & 26 & 26 & 19 & 13 & 14 & 15 & 7 & 12 \\
\hline
\end{tabular}

specific rates for suicide were similar for Maoris and non-Maoris. With only one suicidal death in five years the Maori female rate was much below the non-Maori at all age-groups. Maori homicide rates (standardised to the non-Maori population) are far higher than the non-Maori crude rate. Maori age-specific rates are highest for males at age-group 25-44, and for females at 15-44. 31

\section{Deaths by Cause: Summary and Conclusions}

From the data presented above, the following facts emerge: (i) For the causes of death analysed above, data from 1926 to the

31 The data in the last two paragraphs are taken from Rose (1960): pp. 3 \& 30-32。 
mid-1930s are deficient, but for the degenerative diseases these deficits extend to a later period.

(ii) Epidemic, other infectious and respiratory diseases, such as measles, tuberculosis and bronchitis, declined in significance in the period.

(iii) The degenerative diseases discussed above, such as cancer, remained at approximately the same levels throughout the period, as did death rates from accidents and violence.

(iv) Declines occurred for the infectious and respiratory diseases to which infants and young children are most susceptible.

( $v)$ The decline of tuberculosis was a most important cause of a decrease in mortality at ages 15-44.

A number of causes of death have not yet been included in this review. To summarise the overall trends the rates for groups of causes will be analysed, first for the total population, and then by grouped ages. This will be done for the three year periods averaged around the 1936, 1945 and 1956 mid-year populations, including every cause of death, the rates being shown in Table 9.23. 1936 data would seem to apply to 1926, for the evidence suggests that registration was poor in the earlier of these last two years, so that lower rates resulted from this cause and not from lower mortality.

In general, the declines from 1936 to 1945 are relatively small, but are probably a reasonable indication of trends in the period. Most noteworthy are the decreases in infectious and respiratory diseases. By contrast, the increases for tuberculosis and for degenerative diseases probably result from improved death registrations, while it is likely that higher rates from diarrhoea arise from an epidemic about 1945. Higher female than male rates for 'other' causes (see Note (e), Table 9.23) at both years arise from the inclusion of maternal mortality in this category. 
Table 9.23 : Crude Death Rates: Grouped Causes of Death (Rates per 100,000 mid-year population)

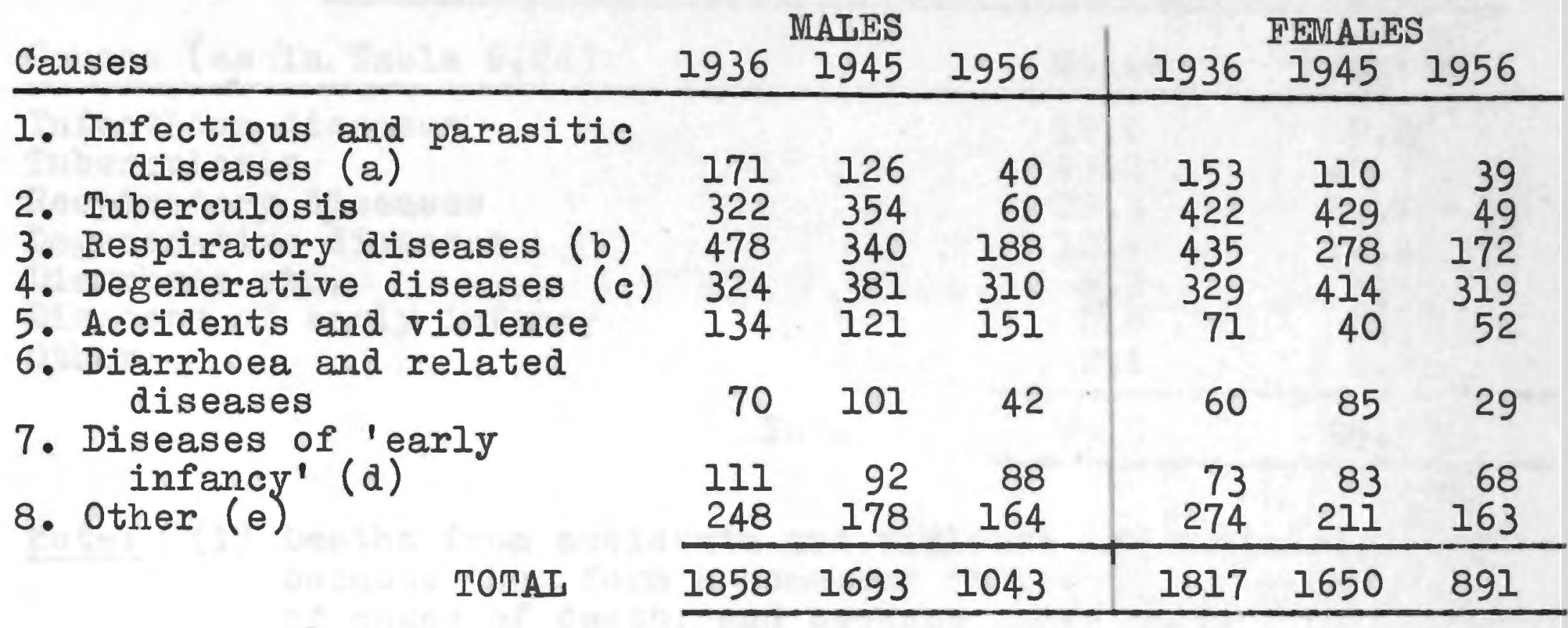

Notes: (a)All 'Infectious and parasitic diseases' (International Iist) except tuberculosis. Includes influenza as well.

(b)All diseases of the respiratory system (International List), except influenza.

(c)Diseases of all parts of the cardiovascular system except rheumatic fever (330-334, 410-468 International List); malignant and benign neoplasms (140-239 International List); and senility.

(d)This group of causes will be analysed below in Chapter Ten.

(e)Includes: Rheumatic diseases (including rheumatic fever); remaining diseases of the digestive system; congenital malformations; 'symptoms' and other ill-defined causes; diseases of the genito-urinary system; remaining diseases of the nervous system and sense organs; diseases of the blood-forming organs; allergic, endocrine, metabolic and nutritional diseases; and, for females, maternal mortality.

From 1945 to 1956 the decline was rapid, but an overwhelming proportion of the decrease came from a few causes, most notably tuberculosis, as can be seen in Table 9.24. The proportion of the decline in this period coming from degenerative diseases may seem surprising when it is recalled that earlier it was argued that there was a greater chance of surviving to ages 45 and above, and thus, of being exposed to the risk of dying from cancer and diseases of the circulatory system. However, crude rates for diseases of the circulatory system declined, while crude rates for senility dropped to almost negligible proportions. 
Table 9.24: 1945-1956: The Percentage of the Decline in the Total Crude Death Rate Arising from Declines in the Crude Death Rates of Various Groups of Diseases)

Causes (as in Table 6.24)

\begin{tabular}{ccc} 
& Males & Females \\
\hline & 12.6 & 9.2 \\
& 43.2 & 49.3 \\
22.3 & 13.7 \\
10.4 & 12.3 \\
& 8.7 & 7.3 \\
& 0.6 & 1.9 \\
TOTAI & 2.1 & 6.2 \\
\cline { 2 - 3 } & 99.9 & 99.9 \\
\hline
\end{tabular}

Note: (1) Deaths from accidents and violence are excluded, because they form a somewhat different category of cause of death, and because their rates increased in the period. (See Table 9.23).

It is necessary to extend this analysis to age-specific death rates, as is done in Table 9.25, to find the real areas in which the decline occurred. For ages 0-4, the significant decrease after 1945 came from the lower mortality from tuberculosis, other infectious diseases and respiratory diseases. At ages 15-44, declines were most marked for tuberculosis, while decreases for this cause plus respiratory and infectious diseases occurred for almost all ages 5-64. Moreover, some decreases in the death rates from respiratory, infectious and 'other' causes had occurred between 1936 and 1945 for ages 5-64.

For females, the importance of the decline of tuberculosis at the reproductive ages cannot be over-emphasized. Furthermore, 'other' causes for females include maternal mortality, so the rates at ages 15-44 differ considerably, and decline more noticeably than those for males.

The results of this analysis correspond to those of other studies, which show the importance of declines in the death rates of diarrhoea, respiratory and infectious diseases, and the comparative stability of rates from degenerative diseases. The net result is that the proportion of mortality which is derived from degenerative diseases increases, while the proportion arising 


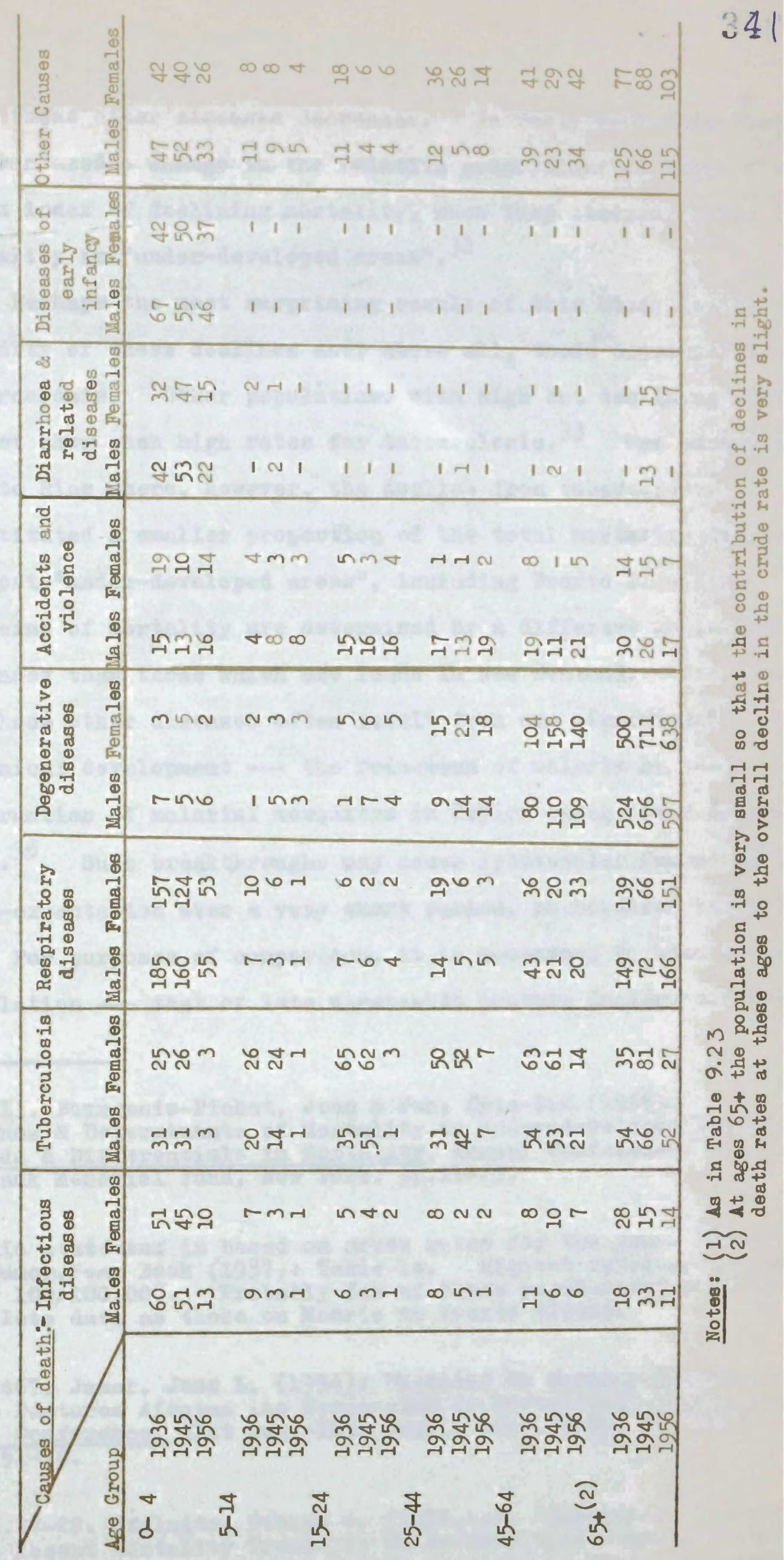


from these other diseases decreases. In fact, Bourgeois-Pichat and Pan used a change in the relative proportions of these diseases as an index of declining mortality, when they studied trends in mortality in "under-developed areas". 32

Perhaps the most surprising result of this study is the rapidity of these declines and, above all, those occurring for tuberculosis. Other populations with high but declining mortality do not show such high rates for tuberculosis. 33 One exception is Puerto Rico where, however, the decline from tuberculosis constituted a smaller proportion of the total mortality decrease. 34 In most "under-developed areas", including Puerto Rico, the patterns of mortality are determined by a different series of diseases than those which are found in New Zealand. The decrease in these other diseases often result from one significant technical development -- the reduction of malaria by the destruction of malarial mosquitos in Ceylon being the classical case. 35 Such breakthroughs may cause spectacular increases in life-expectation over a very short period, as occurred in Ceylon.

For purposes of comparison, it is necessary to turn to another population --- that of late nineteenth century England and Wales ---

32

p.13. Bourgeois-Pichat, Jean \& Pan, Chia-lin (1955):

"Trends \& Determinants of Mortality in Under-developed Areas", Trends \& Differentials in Mortality, Annual Conference, Milbank Memorial Fund, New York. pp.11-25.

33

This statement is based on crude rates for the years 1952-55 in Demog. Year Book (1957): Table 14. Highest rates are seldom over 100/100,000. Probably few of these populations have as complete data as those on Maoris or Puerto Ricans.

34

p.467. Janer, Jose I. (1954): "Medidas de Salud y Saveamiento como Factores Afectan las Tendencias de Mortalidad", Proc. World Pop. Conference, 3lst Aug.-lOth Sept., Rome. U.N., New York. pp.451-70.

pp.27-28. Stolnitz, George J. (1955.b.): "Comparison between some Recent Mortality Trends in Under-Developed Areas \& Historical Trends in the West", Trends \& Differentials in Mortality, Annual Conference, Milbank Memorial Fund, New York. pp.26-34. 
where the decline in tuberculosis constituted $47.2 \%$ of the total decrease. 36 But, the decline of the Maori tuberculosis death rate has been more rapid and has reached lower levels over a shorter period than did the decrease in England and Wales in the late nineteenth century. Thus, the causes of the decline suggested for England and Wales may not apply to Maoris.

The Maoris fall between two worlds. The rate of their mortality decline is similar to that of "Latin America, etc.", but the death rates have become lower for the same diseases which decreased in incidence during "the West's" great mortality transition. In Chapter Eleven below, a more explicit analysis will be made of the possible causes of the post-war decline. Firstly, however, infant mortality must be studied in greater detail, as this is an area of mortality analysis which has special problems. 


\section{CHAPTER TEN}

\section{Mortality Trends Since 1922: Part III, \\ Infant Mortality}

Table 8.6, showing the life-table ${ }_{n} p_{x}$ values, illustrates that, of the ages 0-4 which hitherto have been taken as a block, age 0 has the lowest survival rates. Thus, mortality at age 0 requires detailed study. This chapter will look firstly at the accuracy of data relating to infant deaths; secondly, at infant death rates throughout the period; thirdly, at death rates by age for each quinquennium in the period; fourthly, deaths by cause, and deaths/age/cause at each quinquennium; and, finally, will attempt to show some factors related to infant mortality.

\section{Accuracy of Data}

Adjustments to births alone (Chapter 7, Section 4) have the effect of reducing infant death rates. This is because, in the period 1925-34, both infant deaths and births, the numerator and denominator of the infant death rate, were probably under-registered. As in the case of death registration for the total population, improvements in the registration of infant deaths seem to have occurred about 1934-35. Again, the over-reporting of births in 1946 gave rise to infant death rates which are lower than might be expected.

For each quinquennium the problem raised by the underregistration of births and total infant deaths, $\mathrm{w}_{\mathrm{a}} \mathrm{s}$ overcome by taking the $q_{0}$ of the relevant life-tables as an expected total infant death rate. These are compared in Section 3 with rates derived for each quinquennium from published data. Obviously, the life-table $q_{0}$ 's are also affected by poor registration. Thus, these expected rates are of greatest use in the decade 1926-35 for which there is a life-table adjusted for under-registration (1926 table). 
The low infant mortality rates resulting from overregistration of births in 1946 can be adjusted. The estimated birth rate for that year is 49 per 1,000, as against a published rate of 57 . On the basis of this estimate the number of births is reduced. Thus, the infant mortality rate is increased to 90.5 (males) and 74.6 (females) per 1,000 live-births, as against the published rates of 81.5 (m) and $67.2(\mathrm{f})$ (see Table 10.3).

\section{Registration At Infant Age-groups}

It has been stated already (Chapter 7, Section 4) that the notification of births is a statutory procedure in New Zealand, and that this method permits birth registration to be secured. With the increased hospitalisation of Maori maternity cases this procedure has probably become more effective. Furthermore, in securing birth registration the registration of previously unrecorded infant deaths is probably also achieved. This is most important in the case of neonatal deaths, for some post-neonatal deaths may occur after birth registration has been completed.

In earlier quinquennia during the period 1925-59 infant death registration was probably incomplete, for which adjustments have been made as was noted above. This is also probably true for each of the component infant age-groups. Moreover, death registration at younger infant ages probably improved particularly in the two most recent quinquennia when hospitalisation of maternity cases became an almost universal practice.

Normally, the number of deaths at each day of age are highest at these youngest ages. The rates decline sharply with each increasing day of age, particularly at month 0 . From month 1 the decline is less sharp, but continues to reach a minimum at 9-11 months. (See non-Maoris, 
Table 10.1). Thus, it is probable that marked underregistration of deaths at any particular infant age-group will cause this distribution to become uneven. However, it is very difficult to separate under-registration from late registration. Obviously, the distribution will also be altered if, for example, neonatal deaths are not registered until after the 27 th day, and if the age at time of death is incorrectly stated.

For Maoris, data are available on the number of deaths at each of the following infant age-groups: day 0 ; day 1 , days 2-6; days 7-13; days 14-20; days 21-27; month 1 ; month 2; months 3-5; months 6-8; and months 9-11. If the average number of deaths per day of age is calculated the distributions should indicate any possible under or late registration. For example, to find the average, the deaths recorded for day 0 are divided by 1 ; the deaths at months 9-11 are divided by 84; etc.

For post-neonatal age-groups, the calendar month of death could not be determined, and thus a 28 day month was used throughout to calculate the number of deaths per day of age. This tends to inflate the average at post-neonatal ages, and thus to exaggerate any possible deficits occurring prior to the 28 th day of age.

Because the absolute number of deaths at any Maori infant age-group is so few, the total deaths per quinquennia were used. Moreover, in general this analysis must rely heavily on absolute numbers. If any attempt were made to standardise the quinquennia by calculating average rates at each day of age per 1,000 live births, it would not be certain whether anomalies in early years, particularly prior to 1936, resulted from incorrect birth or death registration.

The results are shown in Table 10.1 and Figure 10.1. Data on non-Maoris are included for two quinquennia. It is 


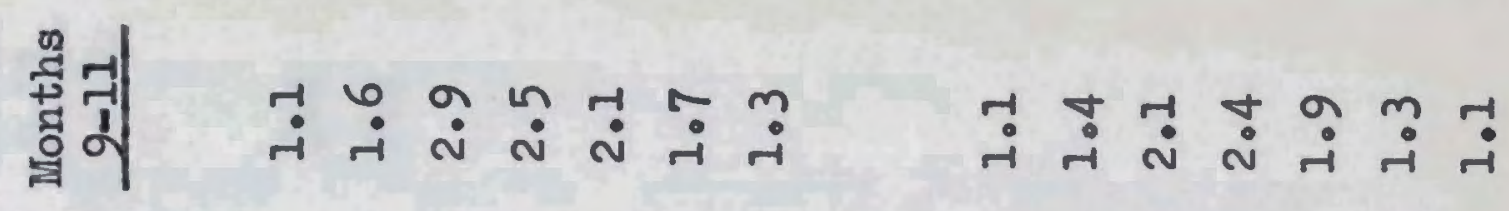

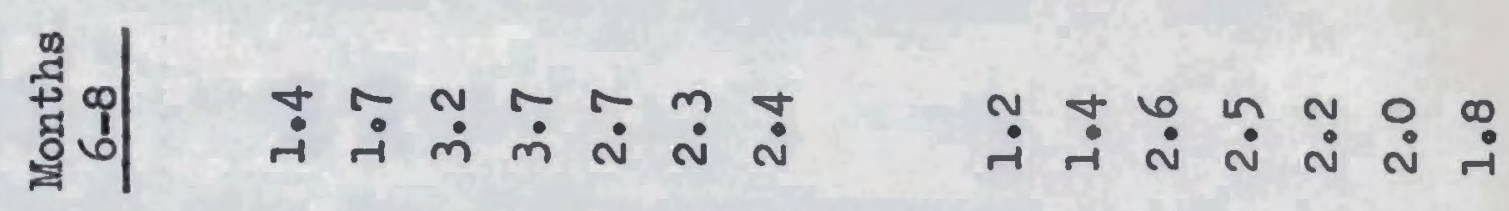

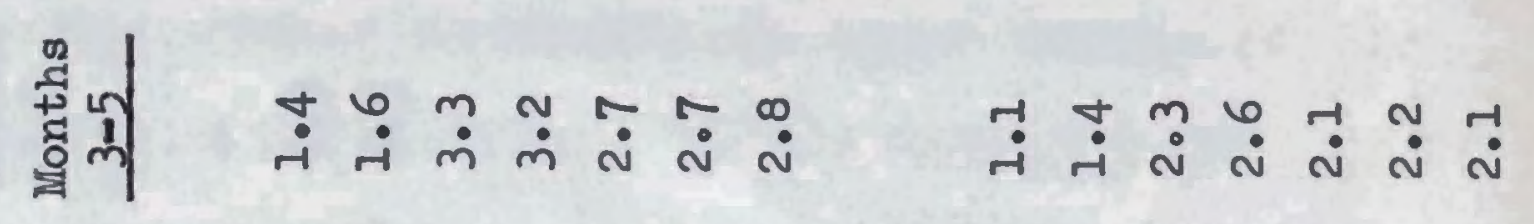

की

题

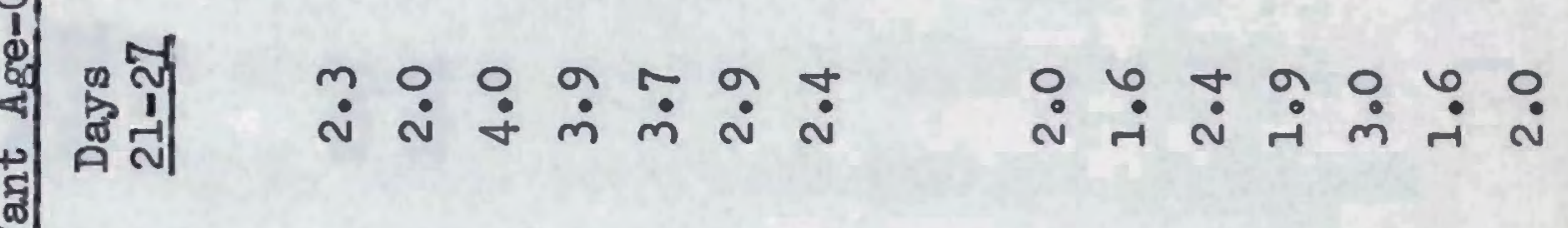

苞

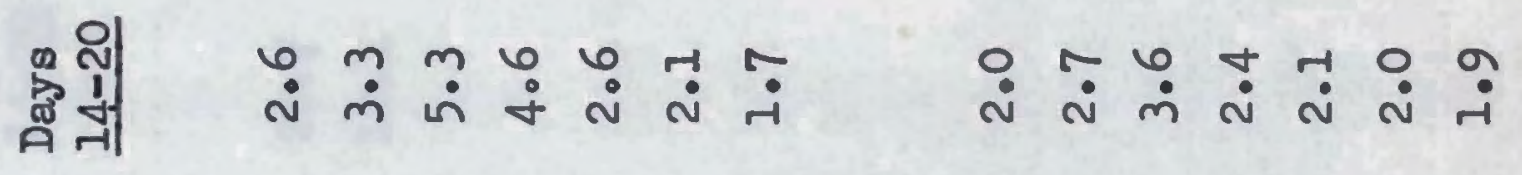

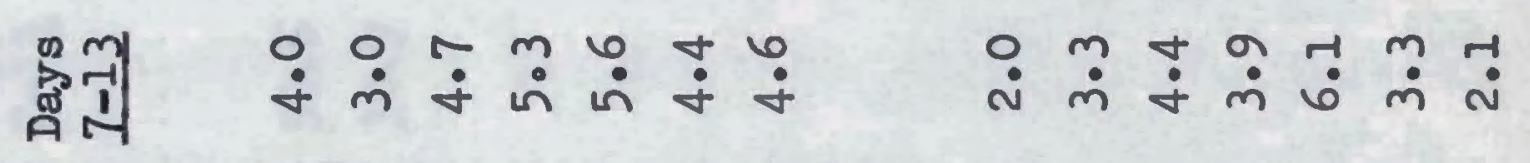

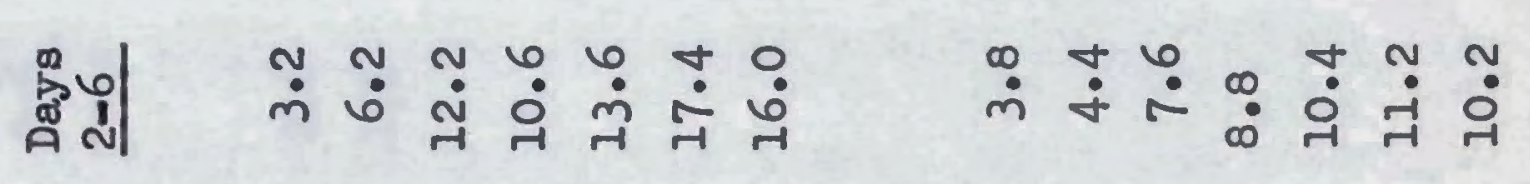

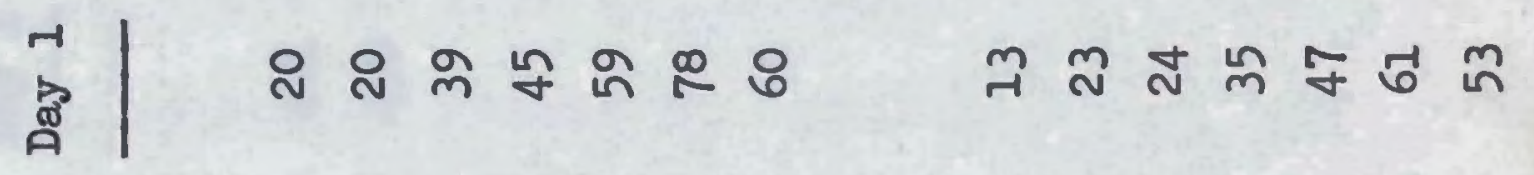

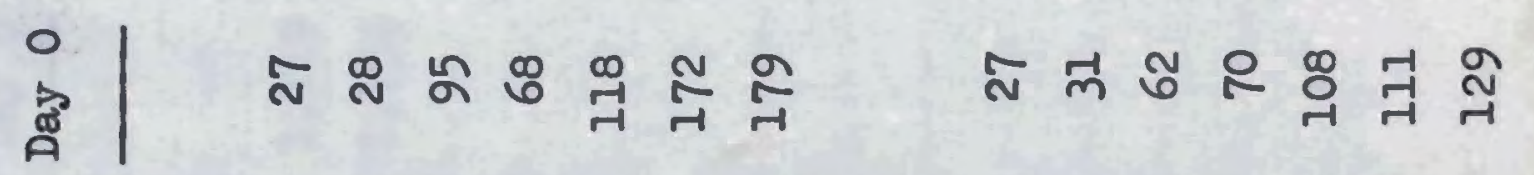

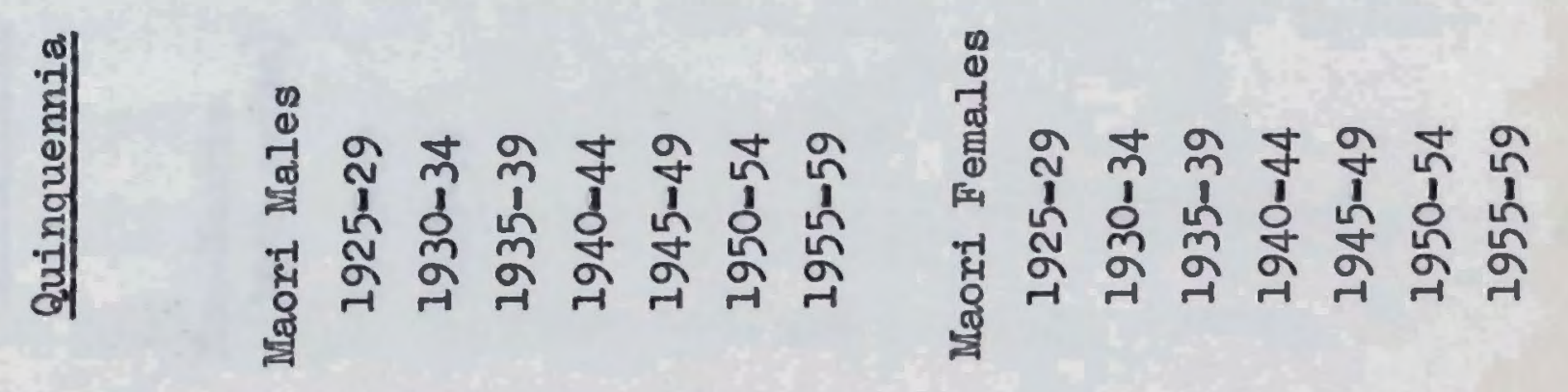




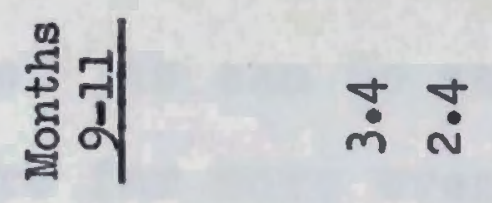

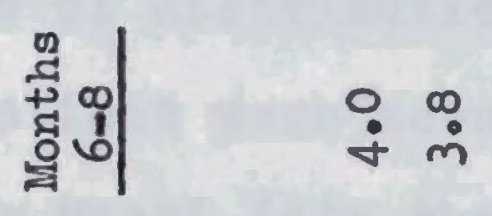

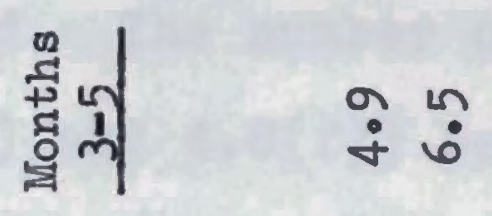

$$
\begin{aligned}
& \text { 莸川 }
\end{aligned}
$$

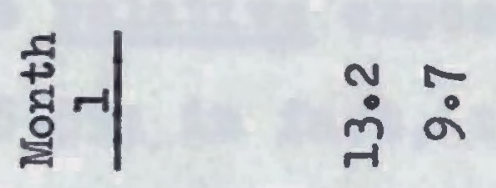

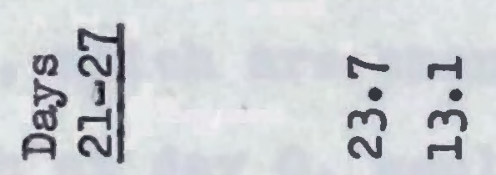

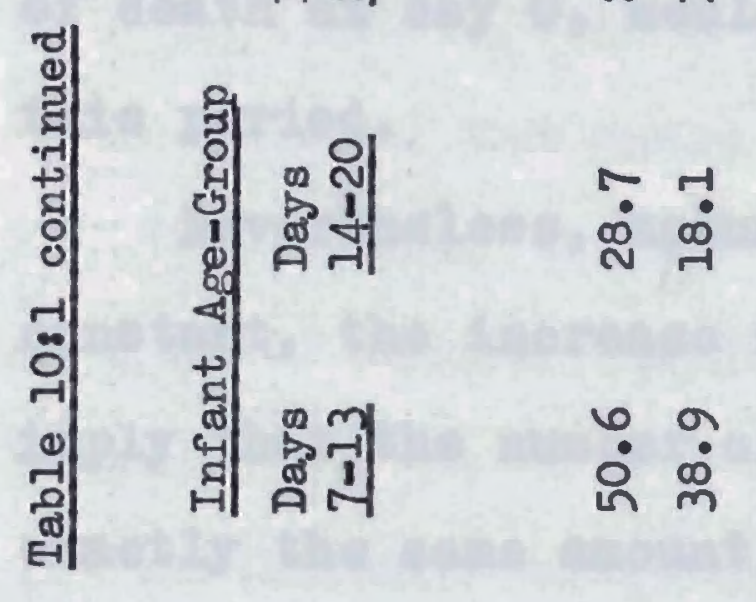

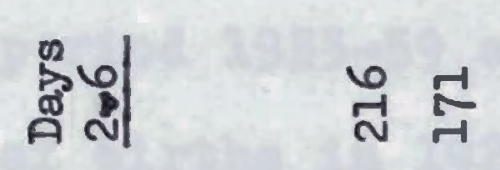

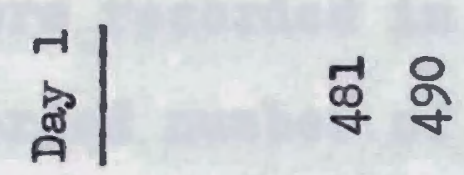

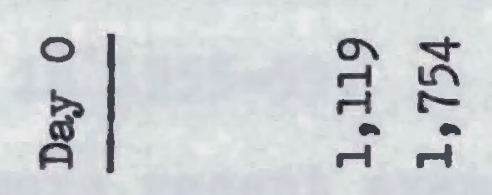

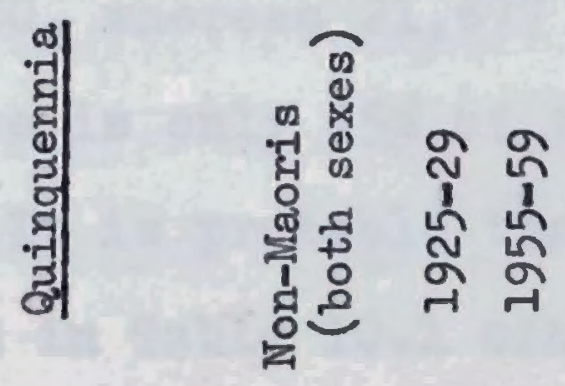


fair to assume that the non-Maori registration was reasonably accurate. As can be seen in Table 10.1, their two distributions are far more even, and probably represent approximately the type of distribution which would occur if Maori

registrations were accurate.

For Maori data the following defioits appear to have occurred. The number of deaths at day 0 increased 5.75 times (6.7 (m) and 4.8(f)) between 1925-29 and 1955-59. It is true that the number of births exposed to the risk of death at day 0 also increased, and that by using absolute numbers this factor cannot be tested directly. However, it is improbable that the relative exposure to risk increased between 1925-29 and 1955-59; in fact, the contrary is probably true. With increasing hospitalization some of the hazards of the birth process, which are among the most easily preventable causes of death at day 0 , would have been reduced significantly in this period.

Nevertheless, assuming that exposure to risk remained constant, the increase in the number of deaths at day 0 would imply that the number of births also would have increased by exactly the same amount; by 5.75 times. Instead, if births of the period 1955-59 are divided by 5.75 to give an estimated number of births in 1925-29, the result is 5.720 , whereas 8,808 were recorded in that quinquennium. In other words, the recorded number of deaths at age 0 in 1925-29 was only $65 \%$ of the expected number, assuming that exposure to risk was the same as in 1955-59.

A more recent example can be taken, based on the same assumptions. Thus, the estimated births in 1940-44 were 14,150, whereas 21,677 were recorded. Again the recorded figure is only $65 \%$ of the expected.

It is probable that at other ages and other quinquennia given in Table 10.1 similar deficits occur. Using the non- 
Maori distributions as a guide, but without analysing the Maori distributions in detail, further anomalies can be noted:

1. In 1925-29, numbers at all semanatal ages appear to be too low. For females there are also deficits at days 7-13 and 14-20; at months 1 and 2 and, perhaps, months 3-5. 2. In 1930-34, there are deficits at all neonatal ages except, possibly, 14-20 days; and at month 1 . 3. In 1935-39, 7-13 days (males), 21-27 days (females) and 1-2 months (both sexes) appear to be unsatisfactory; as well as 3-5 months (females).

4. In 1940-44, in addition to the figures already quoted, the female data show anomalies at ages 7-27 days, and months 1-2; while those for males are lower than might be expected at ages 7-13 days to 3-5 months.

5. In 1945-49, there are deficits in the data for both sexes at 14-20 days and again at month 1 , and at month 2 (females). 6. In 1950-54, there are deficits at ages 14-20 days, and at 1 and 2 months (males); and from 14 days to 2 months (females).

7. In 1955-59, there are deficits at ages 14-20 days and at months 1 and 2 (both sexes). In addition, 20-27 days (both sexes), are probably too low.

These comments are only impressionistic, but they do suggest two tentative conclusions. Firstly, poor registration appears to have occurred in both the neonatal and post-neonatal periods. Secondly, after an allowance is made for an increase in the number exposed to risk, it can be seen that in the semanatal period there has been an improvement in death registration in recent quinquennia.

Figure 10.1 compares the average death rate (per 100,000 live-births) of Maoris with that of non-Maoris at each day of 
FIGURE 10.1: NIAORI \& NON-M OORI POPULATIONS 1955-59:THE AVERAGE NUMBER OF DEATHS AT EACH DAY OF AGE PER INRANT AGE-GROUP, PER 100,000 LIVE-BIRTHS.

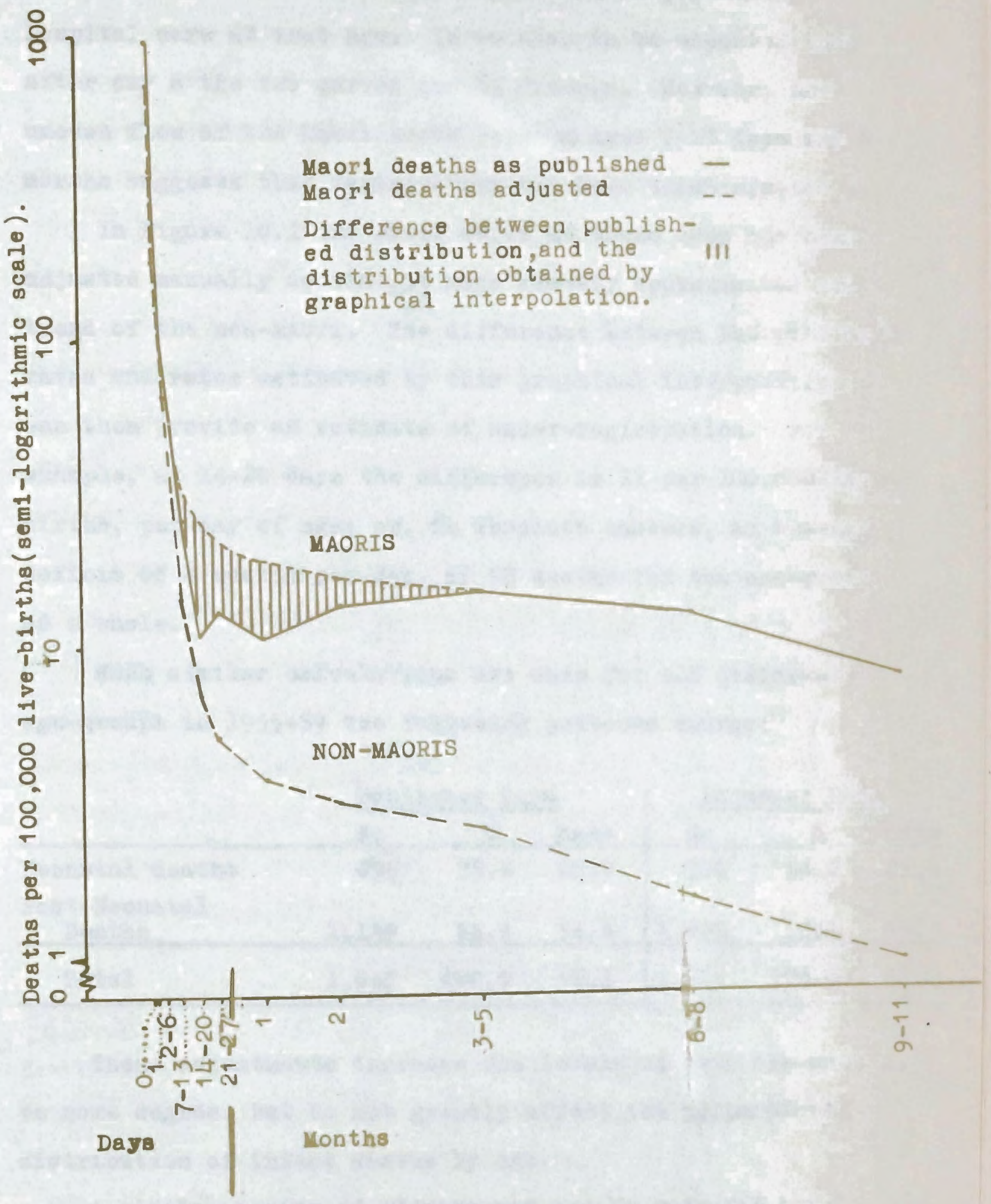

Infant age-groups 
age in the quinquennium 1955-59. It is presumed that the non-Maori data are reliable and that differences between the type of curve they display and the type shown by Maoris is indicative of poor Maori registration. The close proximity of the two curves until day 6 is feasible, as both groups of infants would receive similar conditions of post-natal hospital care at that age. It is also to be expected that after day 6 the two curves should diverge. However, the uneven flow of the Maori curve between ages 7-13 days and 2 months suggests that registration has been unsatisfactory.

In Figure 10.1 the Maori curve at these ages has been adjusted manually so that it more closely approximates the trend of the non-Maori. The difference between the published rates and rates estimated by this graphical interpolation can then provide an estimate of under-registration. For example, at 14-20 days the difference is 12 per 100,000 livebirths, per day of age; or, in absolute numbers, an average deficit of 4 deaths per day, or 28 deaths for the age-group as a whole.

When similar calculations are made for all deficient age-groups in 1955-59 the following patterns emerge:

\begin{tabular}{cccc|ccc} 
& \multicolumn{3}{c}{ Published Data } & \multicolumn{3}{c}{ Adjusted Data } \\
\cline { 2 - 7 } & No & $\%$ & Rate & No & $\%$ & Rate \\
\hline $\begin{array}{l}\text { Neonatal deaths } \\
\begin{array}{c}\text { Post-Neonatal } \\
\text { Deaths }\end{array}\end{array}$ & 655 & 35.6 & 20.2 & 726 & 36.2 & 22.3 \\
\hline Total & 1,188 & 64.4 & 36.4 & 1,289 & 63.8 & 39.5 \\
\hline
\end{tabular}

These adjustments increase the levels at both age-groups, to some degree, but do not greatly affect the proportional distribution of infant deaths by age.

A similar series of adjustments may be made for any previous quinquennium. 1940-44 can be taken as an example. However, it has been shown already that day 0 was poorly 
recorded in that quinquennium. Because the distribution declines so steeply at young ages it is difficult to interpolate day 0 manually. By means of a comparison with 1955-59 it was estimated that recorded deaths at day 0 in 1940-44 were only $65 \%$ of the expected (see above). This estimate does not seriously affect the results shown in the table below, so that the adjustments to be made there are not an artifact of estimated under-registration at only one day of age. If recorded deaths per day 0 are used when adjusting the infant death rates the resulting adjusted neonatal death rate is 32.7 per 1,000 live-births, whereas by using the expected deaths at day 0 the rate is increased to 35.3

It might be noted that it was necessary to use rates rather than absolute numbers here, for by standardising the Maori and non-Maori distributions, the making of comparisons could be facilitated. However, earlier in this section an objection was raised to standardisation of this type, i.e. that some anomalies (higher rates in early quinqunnia than subsequently) might result more from deficient birth than from deficient death registration. By 1940-44 birth registration appeared to have improved and thus this objection was no longer quite so important. Moreover, this factor is not relevant within any distribution, because the same denominator - recorded live births - is used for every age-group.

The results for 1940-44 are given in the following table:

\begin{tabular}{cccc|cccc} 
& \multicolumn{3}{c|}{ Published Data } & \multicolumn{3}{c}{ Adjusted Data } \\
\cline { 2 - 8 } & No. & $\%$ & Rate & No. & $\%$ & Rate \\
\hline $\begin{array}{l}\text { Neonatal deaths } \\
\begin{array}{l}\text { Post-neonatal } \\
\text { deaths }\end{array}\end{array}$ & 468 & 21.4 & 21.6 & 782 & 27.9 & 35.3 \\
\hline Total & 1.705 & 78.6 & 78.7 & 2,013 & 72.1 & 93.2 \\
\hline
\end{tabular}

The adjustments significantly increase rates at both infant age-groups, and affect patterns to some degree. This is because the published neonatal infant death rate is only $58 \%$ 
of the adjusted, whereas the published post-neonatal rate is 84\% of the adjusted. Another important point is that the adjusted total infant mortality rate presented here is in excess of the published total infant death rate, and even the expected total infant death rates based on life-tables (Table 10.4).

The published data indicate that between 1940-44 and 1955-59 there was a decline in the post-neonatal and total rates, but almost no decline for neonatal rates. By contrast, the adjusted rates show a major decline for all three categories - neonatal, post-neonatal and total. The decline of the adjusted neonatal rate is important, for its suggests that the published rate of the quinquennium $1940-44$ is too low because of poor registration. However, in 1940-44 poor registration occurred at both infant age-groups, which is indicated by the fact that the percentage distribution of infant deaths in that period changed comparatively little after adjustments had been made for deficient registration.

The analysis of these two periods permits three related conclusions to be stated:

(1) Poor registration of infant deaths will clearly affect levels of neonatal and post-neonatal mortality; but it does not seriously skew the patterm.

(2) This is because it is probable that deficits occur more through under-registration at particular ages, than because of mis-registration, such as the late registration of neonatal deaths as post-neonatal. Thus, even in 1955-59 the recorded total infant death rate may not be entirely reliable; the published rate for that quinquennium is 57 per 1,000, whereas the rate estimated here is 62 .

(3) There has been an improvement in registration at all ages, at least since the quinquennium 1940-44. Thus the difference between published and adjusted rates was much smaller by 1955-59 than it had been at the earlier period. 
The certification of causes of infant deaths was unsatisfactory at the early period, as it was for deaths at all ages. The crude infant death rate for ill-defined and not-stated causes, presented in Table 10.2, increased between 1925-29 and 1930-34, then declined consistently. Probably, the early change was more because of an increase in the registration of deaths than because of declining standards of certification.

Table 10.2 : Infant Death Rates: Ill-Defined and Not-stated Causes of Death (Rates per 1,000 live-births as published)

\begin{tabular}{lcc|ccc} 
Quinquennia & Males & Females & Quinquennia & Males & Females \\
\hline $1925-1929$ & 1.3 & 1.4 & $1945-49$ & 1.0 & 0.7 \\
$1930-1934$ & 2.4 & 3.0 & $1950-1954$ & 0.4 & 0.3 \\
$1935-1939$ & 2.4 & 2.5 & $1955-1959$ & - & 0.1 \\
$1940-1944$ & 1.8 & 2.1 & & & \\
\hline
\end{tabular}

However, these ill-defined rates are somewhat misleading as another, blanket category -- 'diseases of early infancy -includes some 'ill-defined diseases peculiar to early infancy', 'immaturity unqualified', and 'immaturity unqualified with mention of any other subsidiary condition'. For semanatal and neonatal ages, this category of causes of death remained significant throughout the period, but for the post-neonatal ages, death rates from this group of causes declined and virtually disappeared (see below, Table 10.7). This shows that, in all probability, certification had improved at postneonatal ages. Moreover, for semanatal and neonatal deaths, the definition of causes included in the group 'diseases of early infancy' seemed to improve, probably as a result of the increased hospitalization of Maori confinements. There was a greater likelihood of trained personnel being present to record neonatal deaths correctly. 
Certain types of analysis were not undertaken. (1) No attempt to determine the 'true' infant death rate could be made, as this requires data on deaths by calendar year of births, ${ }^{1}$ which are not available for Maoris. (2) The separation of 'exogenous' from 'endogenous' causes of death, as defined by Bourgeois-Pichat, could not be carried out, as certification is not satisfactory enough. Moreover, by implication, changes in the patterns of, say, infectious and respiratory diseases are changes in exogenous causes. This leaves only the 'diseases of early infancy' and 'remaining causes' (as defined here; see below Section 4). It was considered undesirable, in view of the poor certification and registration, to analyse separately exogenous neonatal causes, even 'birth injuries', although this cause constitutes a significant group of deaths. Furthermore, Iogan shows that the exogenous infant death rate virtually measures the same factors as the post-neonatal rate. ${ }^{2}$ (3) Still-births were not recorded until 1942 and, in view of the normal difficulties associated with the obtaining of these data, it was decided that neither still-birth nor peri-natal death rates would be analysed in detail. It would be impossible, particularly in view of the recency of increased hospitalisation of Maori confinements, to make any analysis of still-births comparable to that made for non-Maori New Zealanders by Sutherland. 3

\section{Vol.I, pp.10-1I, U.N. (1954): Foetal, Infant \& Early} Childhood Mortality, New York. 2 vols.

2 P.1. Bourgeois-Pichat, J. (1952): "An Analysis of Infant Mortality", Pop.Bull., No.2, 0ct. pp.1-14. "Endogenous causes are those which were inherited from [the] parents at conception or acquired from [the] mother during gestation or delivery". "Exogenous causes are those extant in the environment in which the child lives". Cf. pp.53-4. Iogan, W.P.D. (1953): "The Measurement of Infant Mortality", Pop.Bull., No.3, Oct. pp. 30-55. Iogan also notes that the implication that 'endogenous' causes are unpreventible is becoming less true today.

3 Passim. Sutherland, Ian (1949): Stillbirths, Their Epidemiology and Social Significance, London. 
During the period there may have been changes in the diagnosis of various causes of death, but this factor cannot be analysed. The U.N. has noted that 'The ideal of universal clarity and consistency in medical classification of causes of death, even within the boundaries of the same country, is yet to be attained...'.4

\section{Infant Death Rates for All Causes of Death}

Table 10.3 gives the infant death rates for the quinquennium 1925-29, then for each year thereafter. Birth and infant death registration anomalies are more likely to affect these annual rates than the rates for quinquennia (see section 3). However, annual rates have the advantage of showing up any abnormal mortality trends. Thus, the measles epidemic of 1938 and the whooping cough epidemic of 1941 gave rise to high total rates (for the definition of infant age-groups see Notes to Table 10.3), while outbreaks of both these diseases in 1927 had the same result (see Note 5, Table 10.3). 1927, 1938 and 1941 appear to be the only years with extremely high mortality but, while post-neonatal rates are affected by the epidemics of 1938 and 1941 (data on infant deaths by age are not available for 1927), there is no apparent increase in neonatal or semanatal death rates in these two years.

Other features are, firstly, that male rates are almost always higher than female. Secondly, total and post-neonatal rates decline slowly in the 1940s, then decrease pidly after this. Assuming that the adjustments made in Section 1 are reliable, it would appear that a decrease occurred in neonatal rates, but at a somewhat later period than with post-neonatal rates. Published semanatal mortality rates increased, with fluctuations, until about 1950, then declined. As was

4 U.N. (1954): vol.I, p.42. 
Table 10.3 \& Infant Death Rates \& 1925-1929 to 1959

(Rates per 1,000 live births. All rates are computed from published data).

\begin{tabular}{|c|c|c|c|c|c|c|c|c|}
\hline Year & & (1) & Seman & al (2) & & ${ }_{21}(3)$ & Post & nata \\
\hline & Males & males & & Females & IIal & & \% & $\mathrm{mals}$ \\
\hline $\begin{array}{l}1925-9(5) \\
1930 \\
1931 \\
1932 \\
1933 \\
1934 \\
1935 \\
1936 \\
1937 \\
1938 \\
1939 \\
1940 \\
1941 \\
1942 \\
1943 \\
1944 \\
1945 \\
1946 \\
1947 \\
1948 \\
1949 \\
1950 \\
1951 \\
1952 \\
1953 \\
1954 \\
1955 \\
1956 \\
1957 \\
1958 \\
1959\end{array}$ & $\begin{array}{r}119.48 \\
85.09 \\
101.61 \\
96.17 \\
100.91 \\
95.18 \\
120.52 \\
126.38 \\
100.00 \\
160.39 \\
133.52 \\
87.05 \\
136.36 \\
108.01 \\
97.04 \\
112.97 \\
92.51 \\
81.48 \\
76.74 \\
84.20 \\
90.84 \\
72.14 \\
75.38 \\
87.54 \\
84.26 \\
67.48 \\
73.40 \\
60.01 \\
65.11 \\
57.45 \\
61.00\end{array}$ & $\begin{array}{r}107.52 \\
91.84 \\
89.30 \\
94.71 \\
83.57 \\
91.81 \\
95.84 \\
93.51 \\
83.73 \\
145.38 \\
94.44 \\
87.40 \\
112.74 \\
87.29 \\
82.37 \\
90.83 \\
85.14 \\
67.17 \\
69.47 \\
68.44 \\
80.60 \\
67.23 \\
60.19 \\
81.06 \\
60.87 \\
49.17 \\
51.01 \\
48.51 \\
50.62 \\
51.22 \\
47.43\end{array}$ & $\begin{array}{r}13.7 \\
14.3 \\
9.3 \\
13.0 \\
12.4 \\
10.2 \\
16.5 \\
20.4 \\
18.9 \\
18.1 \\
25.5 \\
18.9 \\
18.1 \\
13.5 \\
12.8 \\
11.2 \\
17.6 \\
15.0 \\
15.3 \\
21.6 \\
23.1 \\
26.1 \\
22.9 \\
23.1 \\
27.0 \\
21.1 \\
19.4 \\
20.1 \\
20.1 \\
20.5 \\
16.3\end{array}$ & $\begin{array}{r}14.0 \\
14.8 \\
7.1 \\
12.5 \\
12.7 \\
12.1 \\
9.4 \\
11.0 \\
12.1 \\
18.8 \\
17.4 \\
18.1 \\
17.7 \\
10.9 \\
13.3 \\
11.5 \\
19.1 \\
9.4 \\
20.8 \\
22.4 \\
14.1 \\
21.6 \\
16.1 \\
20.0 \\
15.9 \\
14.5 \\
13.8 \\
14.9 \\
13.6 \\
16.5 \\
13.9\end{array}$ & $\begin{array}{l}27.2 \\
22.9 \\
15.2 \\
21.0 \\
26.7 \\
15.9 \\
27.3 \\
28.1 \\
25.2 \\
30.9 \\
38.0 \\
26.2 \\
27.8 \\
21.2 \\
19.0 \\
23.2 \\
25.5 \\
21.3 \\
22.4 \\
28.6 \\
26.7 \\
31.1 \\
29.1 \\
27.3 \\
32.2 \\
24.2 \\
22.1 \\
22.3 \\
24.3 \\
24.0 \\
21.8\end{array}$ & $\begin{array}{l}24.0 \\
26.0 \\
14.1 \\
23.5 \\
19.1 \\
18.5 \\
20.8 \\
16.5 \\
17.8 \\
29.6 \\
25.5 \\
21.5 \\
25.8 \\
17.6 \\
18.9 \\
15.1 \\
26.6 \\
15.2 \\
28.6 \\
29.2 \\
18.7 \\
25.6 \\
20.5 \\
24.2 \\
20.8 \\
15.5 \\
15.2 \\
17.5 \\
16.4 \\
20.0 \\
16.5\end{array}$ & $\begin{array}{r}92.3 \\
62.1 \\
86.4 \\
75.2 \\
74.2 \\
79.3 \\
93.2 \\
98.2 \\
74.8 \\
129.4 \\
95.5 \\
60.9 \\
108.5 \\
86.9 \\
78.1 \\
89.8 \\
67.0 \\
60.2 \\
54.3 \\
55.6 \\
64.1 \\
41.1 \\
46.2 \\
60.2 \\
52.0 \\
43.3 \\
51.3 \\
37.7 \\
40.8 \\
33.5 \\
39.2\end{array}$ & $\begin{array}{r}83.6 \\
65.9 \\
75.2 \\
71.2 \\
64.4 \\
73.3 \\
75.1 \\
77.0 \\
65.9 \\
115.7 \\
68.9 \\
65.9 \\
87.0 \\
69.7 \\
63.5 \\
75.7 \\
58.5 \\
52.0 \\
40.9 \\
39.3 \\
61.9 \\
41.6 \\
39.7 \\
56.9 \\
40.1 \\
33.6 \\
35.8 \\
31.1 \\
34.3 \\
31.2 \\
30.9\end{array}$ \\
\hline
\end{tabular}

Notes: (1) 'Total' refers to all infants 0 - 11 months.

2) 'Semanatal' refers to the period $0-6$ days.

(3) 'Neonatal' refers to the period $0-27$ days, and thus includes semanatal infant deaths.

(4) 'Post-neonatal' refers to ages 28 days - 11 months.

(5) Deaths by sex are not available for single years in this period. Total death rates for both sexes were:

$\begin{array}{llllll}\text { Using published data } & \frac{1925}{107.2} & \frac{1926}{117.2} & \frac{1927}{157.9} & \frac{1928}{118.2} & \frac{1929}{78.5}\end{array}$


shown above the increase until 1950 was the result of unsatisfactory registration in earlier years, and thus was not an indication that semanatal mortality increased.

Finally, by the end of the period, neonatal rates made up a larger proportion of the total rates than earlier but, as will be discussed below, a lower proportion than might be expected.

\section{Infant Death Rates for All Causes of Death at Each Quinquennium}

Both 'published' and 'expected' total rates for quinquennia are given in Table 10.4 , and by comparing these two sets of rates a more consistent pattern emerges.

$\frac{\text { Table } 10.4}{: \text { Infant Death Rates for Various Quinquennia }}$

\begin{tabular}{|c|c|c|c|c|}
\hline \multirow[t]{2}{*}{ Quinquennia } & \multicolumn{2}{|c|}{$\begin{array}{l}\text { Rates based on } \\
\text { published data }\end{array}$} & \multicolumn{2}{|c|}{$\begin{array}{l}\text { Expected rates } \\
\text { (I) }\end{array}$} \\
\hline & Males & Females & Males & Femeles \\
\hline $\begin{array}{l}1925-1929 \\
1930-1934 \\
1935-1939 \\
1940-1944\end{array}$ & $\begin{array}{r}119.5 \\
96.3 \\
128.1 \\
108.1\end{array}$ & $\begin{array}{r}107.5 \\
90.2 \\
102.2 \\
91.8\end{array}$ & $\begin{array}{l}118.7 \\
119.0 \\
111.0\end{array}$ & $\begin{array}{r}118.7 \\
102.3 \\
86.5\end{array}$ \\
\hline $\begin{array}{l}1945-1949 \\
1950-1954 \\
1955-1959\end{array}$ & $\begin{array}{l}84 \cdot 9 \\
77.4 \\
63.1\end{array}$ & $\begin{array}{l}73.8^{(2)} \\
63.5 \\
49.7\end{array}$ & $\begin{array}{l}92.5 \\
73.4 \\
66.9\end{array}$ & $\begin{array}{l}78 \cdot 5 \\
60.7 \\
50.9\end{array}$ \\
\hline
\end{tabular}

\section{Published Rates : Infant Age-groups}

SEMANATAI RATES

1925-1929

1930-1934

1935-1939

1940-1944

1945-1949

1950-1954

1955-1959

$\begin{array}{ll}13.7 & 14.0 \\ 11.8 & 11.9 \\ 20.0 & 13.9 \\ 14.8 & 14.2 \\ 18.4 & 16.9 \\ 24.0 & 17.5 \\ 19.2 & 14.6\end{array}$

NEONATAI RATES

$\begin{array}{ll}27.2 & 24.0 \\ 20.4 & 20.2 \\ 30.1 & 22.1 \\ 23.4 & 19.6 \\ 24.8 & 23.4 \\ 28.7 & 21.2 \\ 22.9 & 17.2\end{array}$

POST-NEONATAI RATES

$1925-1929$

$1930-1934$

1935-1939

1940-1944

1945-1949

1950.1954

1955-1959

Notes: (1) Based on $q_{0}$ from the relevant life-table.

1925-1929 is taken from the adjusted 1926 table. 1930-1934 is taken from the average of the 1936 and adjusted 1926 tables.

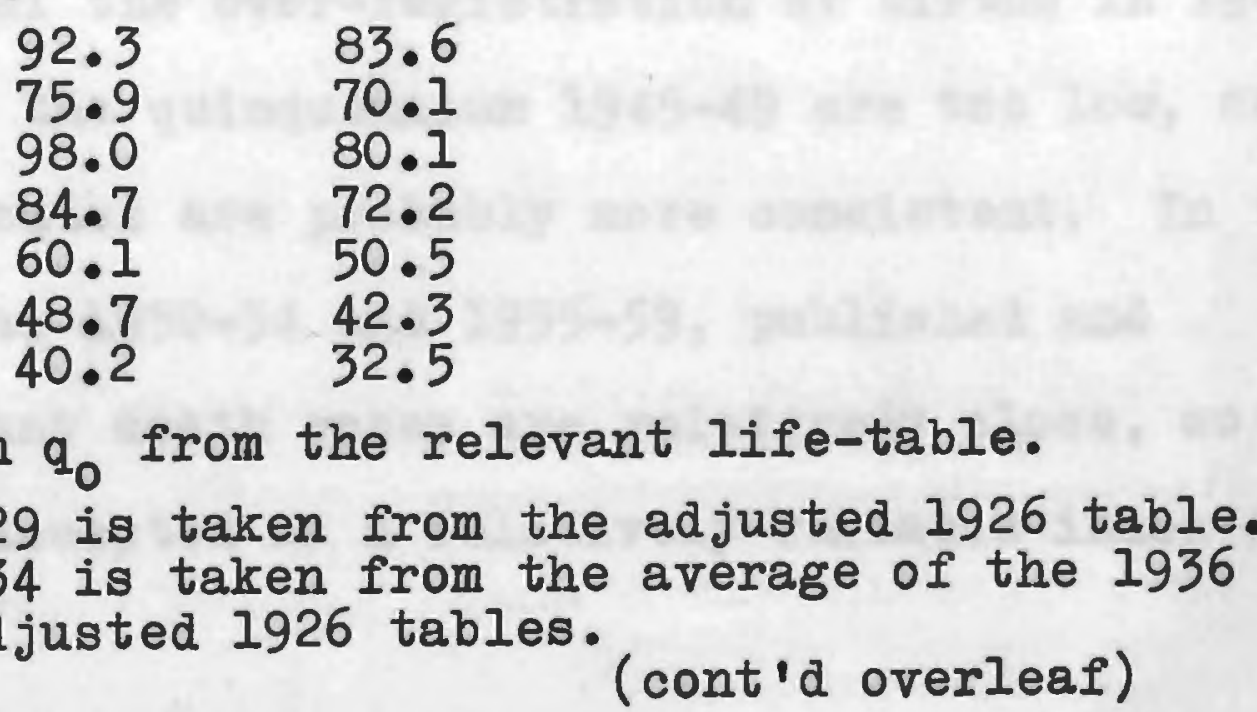

92.3

84.7

60.1

(cont'd overleaf) 
Notes to Table 10.4 (cont'd)

1935-1944 is taken from the average of the 1936 and 1945 tables. $p(1945)$ is adjusted to allow for over-reglstration in 1945 (see Note 4, Table 8.6).

1945-1949 is taken from the average of the 1945 and 1951 tables. The same adjustment to $p_{0}$ has been made for this quinquennium.

1951-1954 is taken from the average of the 1951 and 1956 tables.

1955-1959 is taken from the 1956 table.

(2) No adjustment was made here for over-registration of births in 1946.

In the quinquennium 1925-29 under-registration of births seems to have cancelled out under-registration of infant deaths, and thus the expected and published rates are similar. However, it was shown earlier that there was severe underregistration of deaths at day 0 . This appears to be characteristic of other ages. Thus, it is possible that both expected and published rates may be too low in this period (cf. adjusted total rates for 1940-44 in Section 1 above). In the quinquennium 1930-34 birth registration improved, apparently at a more rapid rate than death registration, for the published infant death rate is much lower than the expected. For the decade 1925-34 expected rates give a more consistent, and possibly more reliable, idea of levels of infant mortality. Certainly, the expected rates for this decade are in accord with the published rates for 1935-36 when there were improvements in death registration.

It was shown earlier that probably both the published and expected total rates were too low for the quinquennium 1940-44. Because of the over-registration of births in 1946, published rates in the quinquennium 1945-49 are too low, and thus the expected rates are probably more consistent. In the last two quinqunnia, 1950-54 and 1955-59, published and expected total infant death rates are relatively close, so the former can be accepted as a relatively reliable index of 
infant mortality in the decade. Moreover, in 1955-59

although the published rate is below the rate obtained from the adjusted data, the difference is not too extreme.

The post-neonatal rates for quinquennia follow approximately the same trends as the total rates. Postneonatal rates declined after 1945, while from this time their proportionate importance also decreased,as is shown in Table 10.5 .

Table 10.5 $: \frac{\text { Post-Neonatal Deaths as a Percentage }}{\frac{\text { of Total Infant Deaths }}{\text { (Deaths as published) }}}$

\begin{tabular}{|c|c|c|c|c|c|}
\hline Quinguenni & Males & Females & Quinquennia & Males & Females \\
\hline $\begin{array}{l}1925-1929 \\
1930-1934 \\
1935-1939\end{array}$ & $\begin{array}{l}77.3 \\
78.8 \\
76.5\end{array}$ & $\begin{array}{l}77.7 \\
77.7 \\
78.3\end{array}$ & $\begin{array}{l}1940-1944 \\
1945-1949 \\
1950-1954 \\
1955-1959\end{array}$ & $\begin{array}{l}78.3 \\
70.8 \\
62.8 \\
63.8\end{array}$ & $\begin{array}{l}78.8 \\
68.4 \\
66.6 \\
65.5\end{array}$ \\
\hline
\end{tabular}

The decrease in the proportionate importance of postneonatal infant death rates arises, of course, from the increased significance of neonatal death rates, which will be discussed below. It has been shown above that neonatal rates were markedly inaccurate probably until 1945-1949 or even 1950-54. This accounts for their increase about this time, which coincides with the increased hospitalisation of maternity cases. Subsequently, in a decade when the rates can be taken as relatively reliable, there has been a decline.

The relative significance of post-neonatal and neonatal infant death rates is of considerable importance as an index of infant mortality trends. However, Maori patterns of infant mortality are somewhat different from those experienced normally, so the relationship between these two age-specific rates is also unusual, and requires special comment.

When total infant mortality declines the most important decreases usually occur at the post-neonatal ages, while 
decreases at neonatal ages are less significant. In low mortality populations, although neonatal mortality rates may be very low, deaths at the post-neonatal ages are so uncommon that neonatal deaths constitute an overwhelmingly high proportion of the total infant deaths - $70 \%$ in the case of the non-Maoris in the quinquennium 1955-59. Thus, an increase in the proportion of total infant mortality derived from neonatal deaths can be taken as an index of declining infant mortality for most populations. In the case of the Maoris, infant mortality has declined and the greatest decreases have occurred at post-neonatal ages. However, neonatal infant mortality has also declined in thelast few quinquennia, from over 30 per 1000 live-births in 1940-44 to just in excess of 20 in 1955-59. The latter rate is at such a relatively low level that less than $40 \%$ of the total infant deaths occur within the first 28 days of life. As was shown in Section 1, this figure is not an artifact of registration deficits. The quoted percentage is extremely low and contrasts markedly with the experience both of low mortality populations and of high mortality populations. In the mid-1950s, other populations having data as reliable as those available for Maoris and with similar levels of total infant mortality had considerably higher levels of neonatal infant mortalitty. Their rates are as follows: ${ }^{5}$

\begin{tabular}{lcc} 
Population & $\begin{array}{c}\text { Total Infant } \\
\text { Death Rates }\end{array}$ & $\begin{array}{c}\text { Neonatal } \\
\text { Death Rat }\end{array}$ \\
\hline Maoris (1955-56 & 58.5 & 19.4 \\
Hungary (1955-56 & 59.4 & 31.4 \\
Italy (1954-56) & 52.0 & 26.6
\end{tabular}

Note: In this period no other population with comparable rates had as reliable data. For Puerto Rico, where data were reported to be incomplete, the rates were: Total - 56.7; Neonatal - 26.1.

5 Demog. Year Book (1957): Table 13. 
It is obvious that the assumption that declines in total infant mortality are inversely correlated with increases in the percentage importance of neonatal mortality does not apply to the Maoris.

Recent data from Czechoslovakia appear to provide an explanation for this phenomenon. In Czechoslavakia the neonatal rate is 12.7 , while the total infant death rate is 22.7 instead of the 16 or 17 to be expected as a normal accompaniment of such a low neonatal rate. The low neonatal rate results, it is claimed, from the availability of free maternity care. ${ }^{6}$ Thus, it is suggested that the almost universal hospitalisation of Maori maternity cases has brought about the present low neonatal rates, whereas unsuitable environmental conditions cause high post-neonatal rates once the mother and child return from hospital. Another factor here may be that ante-natal care has improved and thus, for example, the iron stores built up by mothers on the advice of their doctors may be retained by neonates. This has been postulated as a cause of the lower anaemia rates found among Maori infants aged $0-5$ months, than at ages $6-23$ months. 7

Finally in this commentary on Table 10.4, reference must be made to semanatal deaths, which are probably quite accurately recorded now. Their rates show a slight decline in the most recent quinquennium, in which period they constituted over $80 \%$ of neonatal deaths. Prior to this registration may not have been as satisfactory, and thus the decline may have been occurring for a longer period than one quinquennium.

\footnotetext{
6 P.153. Srb, Vladmir (1962): "Population Policy in Czechoslovakia", Pop.Stud., vol.XVI, no.2, Nov. pp.147-59. 7 Pp. 22 \& 27. Neave, M. et al. (1963): "The Prevalence of Anaemia in Two Maori Communities", N.Z.M.J., vol.62, no.365, Jan. pp.20-28; See also Akel, R.N. et al. (1963): "Anaemia in Maori \& European Infants on Admission to Hospital: A Co-operative Survey from Six N.Z. Hospitals", N.Z.M.J., vol.62, no.365, Jan. pp.29-33.
} 


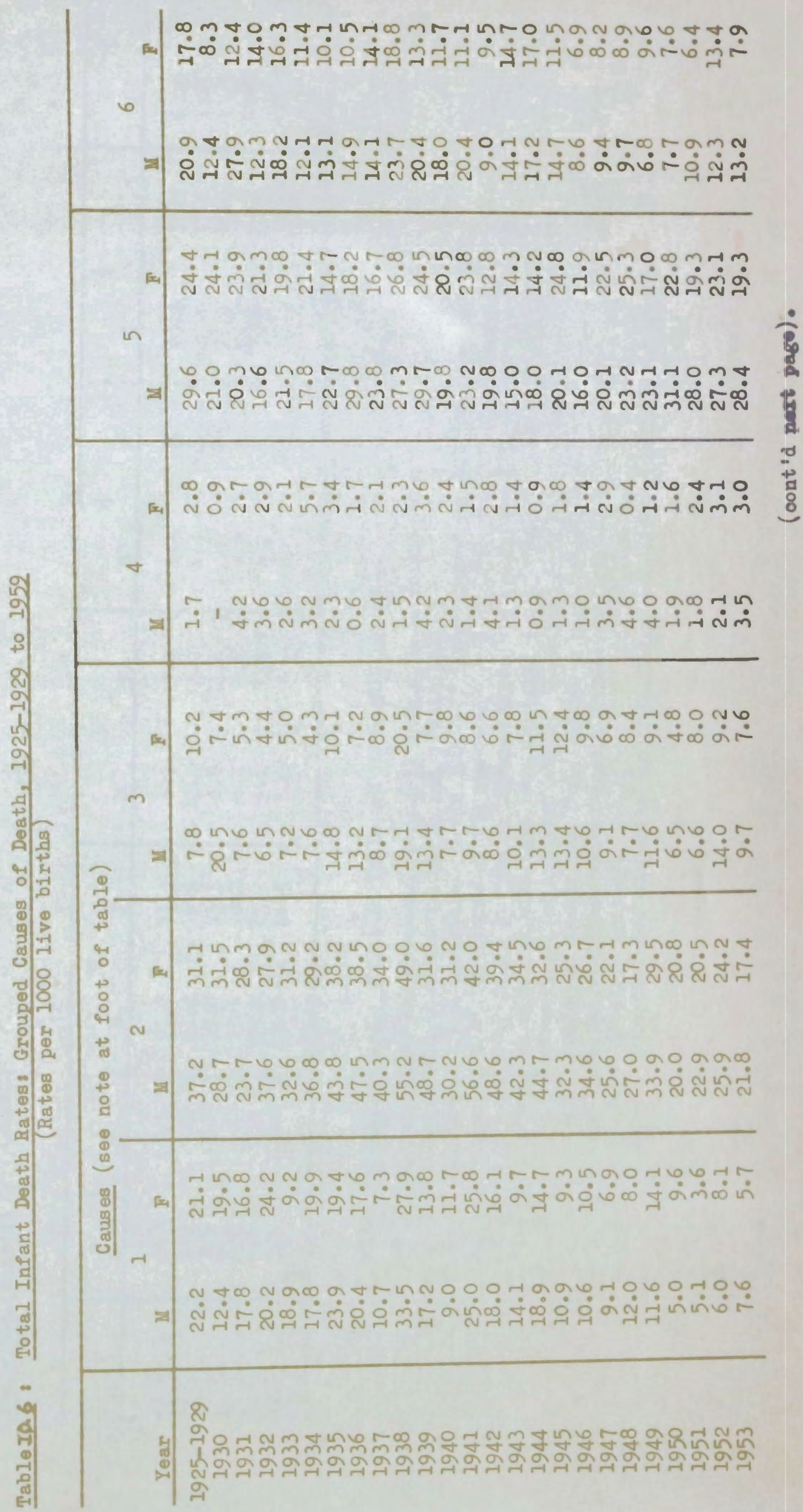




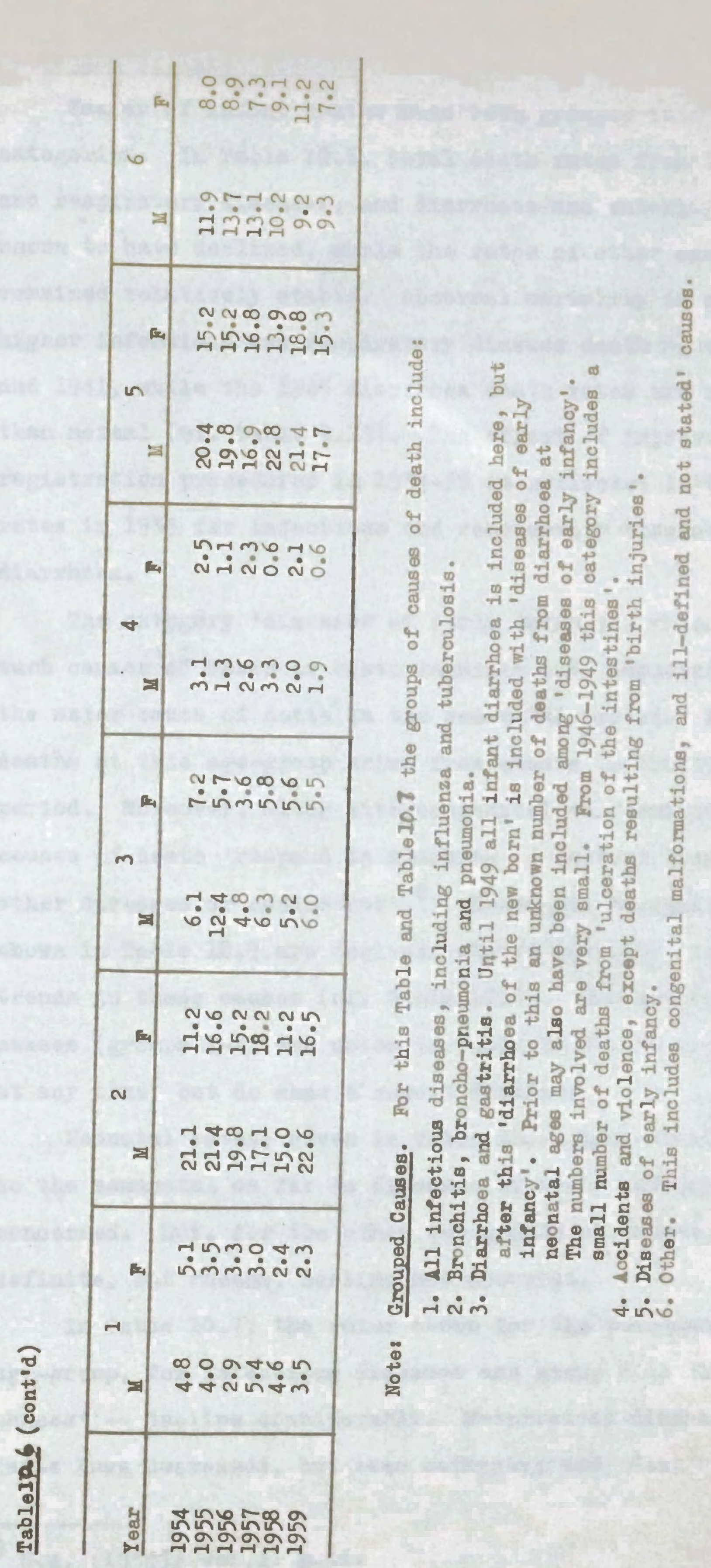

365 


\section{Causes of Infant Deaths}

Causes of infant deaths have been grouped into six categories. In Table 10.6 , total death rates from infectious and respiratory diseases, and diarrhoea and enteritis are shown to have declined, while the rates of other causes have remained relatively stable. Abnormal mortality is shown by higher infectious and respiratory disease death rates in 1938 and 1941, while the 1945 diarrhoea death rates are higher than normal (cf. Table 9.13). The effect of improved registration procedures in 1934-35 is reflected in the increased rates in 1935 for infectious and respiratory diseases, and diarrhoea.

The category 'diseases of early infancy', which includes such causes of death as birth injuries and immaturity, is the major cause of death in the semanatal period. Many of the deaths at this age-group arise from causes in the foetal period. Moreover, along with congenital malformations, these causes of death 'respond to measures of control less than any other diseases or conditions'.8 Semanatal mortality trends, shown in Table 10.7 are derived, almost entirely, from the trends in these causes (cf. Table 10.4). The remaining causes (groups 1-4; see notes to Table 10.6) are not important at any time, but do show a recent decline.

Neonatal rates, given in Table 10.7, have similar trends to the semanatal as far as diseases of early infancy are concerned. But, for the other two groups of causes, a more definite, but recent, decline has occurred.

In Table 10.7, the rates shown for the post-neonatal age-group, for infectious diseases and group 6 -- 'other causes' -- decline considerably. Respiratory disease death rates have decreased, but less markedly; and, diarrhoea seems

8 U.N. (1954): vol.I, p.46. 
Table107 $: \frac{\text { Infant Death Rates: Grouped Causes of Death }}{\text { Por Various Infant Afe-Groups }}$

A. Semanatal Deaths Males

\begin{tabular}{l|ccc||ccc} 
Quinquennia & causes & cause & cause & causes & cause & cause \\
& $1-4$ & 5 & 6 & $1-4$ & 5 & 6 \\
\hline $1925-1929$ & 0.7 & 12.0 & 1.1 & 0.2 & 13.1 & 0.7 \\
$1930-1934$ & 0.3 & 10.9 & 0.6 & 0.9 & 9.7 & 1.3 \\
$1935-1939$ & 0.6 & 16.4 & 3.0 & 0.6 & 12.2 & 1.1 \\
$1940-1944$ & 0.3 & 11.9 & 2.7 & 0.5 & 11.6 & 2.1 \\
$1945-1949$ & 0.9 & 16.0 & 1.5 & 0.7 & 14.4 & 1.8 \\
$1950-1954$ & 0.5 & 21.4 & 2.1 & 0.2 & 15.8 & 1.5 \\
$1955-1959$ & 0.2 & 16.6 & 2.4 & 0.1 & 13.4 & 1.1 \\
\hline
\end{tabular}

B. Neonatal Deaths

\begin{tabular}{l|lll||lll}
$1925-1929$ & 4.1 & 18.7 & 4.4 & 2.8 & 19.2 & 1.9 \\
$1930-1934$ & 2.5 & 15.5 & 2.4 & 2.5 & 14.4 & 3.3 \\
$1935-1939$ & 3.2 & 21.9 & 5.0 & 2.8 & 16.3 & 2.9 \\
$1940-1944$ & 2.8 & 15.6 & 5.0 & 2.2 & 14.4 & 3.1 \\
$1945-1949$ & 3.1 & 18.3 & 3.4 & 2.8 & 18.0 & 2.5 \\
$1950-1954$ & 1.4 & 24.2 & 3.1 & 1.1 & 18.1 & 2.1 \\
$1955-1959$ & 0.7 & 18.8 & 3.4 & 0.1 & 15.3 & 1.7 \\
\hline
\end{tabular}

\section{Post-neonatal Deaths}

\begin{tabular}{l|r|r|r|r|r|r||r|r|r|r|r|r} 
Quinquennia & \multicolumn{1}{c|}{ Causes } & \multicolumn{1}{c|}{ Males } \\
\hline $1925-1929$ & 20.2 & 35.3 & 1.8 & 1.5 & 10.9 & 16.5 & 20.2 & 29.4 & 8.8 & 2.6 & 6.6 & 15.9 \\
$1930-1934$ & 16.7 & 31.1 & 7.1 & 2.7 & 4.5 & 13.8 & 17.1 & 28.2 & 5.0 & 2.3 & 7.7 & 9.7 \\
$1935-1939$ & 19.8 & 45.2 & 13.3 & 1.9 & 5.3 & 12.3 & 16.6 & 36.3 & 10.4 & 2.0 & 4.4 & 10.5 \\
$1940-1944$ & 15.6 & 43.2 & 9.5 & 1.8 & 3.9 & 10.7 & 14.7 & 34.6 & 8.6 & 1.6 & 2.9 & 9.8 \\
$1945-1949$ & 9.9 & 28.8 & 10.1 & 2.3 & 2.3 & 6.7 & 9.1 & 22.5 & 8.8 & 1.3 & 2.5 & 6.4 \\
$1950-1954$ & 5.2 & 22.0 & 8.6 & 1.9 & 2.7 & 8.2 & 5.8 & 18.5 & 7.4 & 2.2 & 1.8 & 6.6 \\
$1955-1959$ & 3.7 & 19.2 & 6.8 & 1.9 & 1.0 & 7.6 & 2.9 & 15.4 & 5.2 & 1.2 & 0.7 & 7.0 \\
\hline
\end{tabular}

Notes: Causes of death are grouped as follows (see notes to Table10.6 for fuller details).

1. Infeotious diseases.

2. Respiratory diseases.

3. Diarrhoea.

4. Accidents and violence.

5. Diseases of early infancy.

6. Other (mainly congenital malformations).

At the Semanatal and Neonatal ago-groups, causes I- 4 are further grouped together. 
to be declining after fluctuating. Accident and violence death rates have fluctuated for males, but declined for females. Improved certification would seem to be the cause for the consistent decline of diseases of early infancy at these ages.

Thus, semanatal and neonatal death $r$ ates have increased because of improved registration, then declined more recently. For post-neonates, death rates from 'exogenous' causes, for example infectious diseases, have declined, the exception being male accident and violence rates. Improved certification, rather than improved health, has withered away post-neonatal death rates from 'diseases of early infancy'.

While these declines are to be welcomed, the continuation of high infant death rates from certain causes shows that Maori infant mortality is still a severe problem. For example, the Maori post-neonatal death te from respiratory diseases alone is almost equal to the non-Maori total infant death rate from all causes.

\section{Some Factors Related to Maori Infant Mortality}

Biological factors, such as 'number and spacing of births, age of mother, multiple births and prematurity' are related to differential infant mortality. ${ }^{9}$ In this regard, Gardiner has shown that Maori infants have a large number of siblings, alive and dead, than non-Maoris. In his study, to which frequent reference will be made, Gardiner determined the circumstances of death and the home environment of all Maori infants dying in 1954, in five hospital districts (Group A). The control groups were a sample of 1 in every 13 Maori births in these same districts (Group B), and 1 in every 60 non-Maori births in two districts (Group C). Throughout Gardiner's results, the Maori Group A tends to have the least favourable

9 U.N. (1954): vol.II, p.I2. 
environmental and other conditions; the non-Maori Group $C$ has the most favourable; while Group $B$ is intermediate but, generally, closer to A than to C. 10

Gardiner shows that Maoris received less ante-natal and post-natal care than did non-Maoris. Moreover, while only $0.8 \%$ of non-Maori births took place at home, this figure rose to $23.9 \%$ and $14.8 \%$ for Groups $A$ and $B$ respectively. Since 1954, the situation has obviously improved (see Maternal Mortality, Chapter Nine). However, reluctance to take children to pre-school clinics must have some effect on the health of post-neonates. 11

The U.N. has analysed the role of diet and its importance in the development of normal children. They note that, unless particular care is taken, artificial feeding is not as satisfactory, in terms of food value and hygiene, as breastfeeding. 12 The Maoris in Gardiner's survey breast-fed far less frequently than the non-Maoris; $60.6 \%$ were artificially fed in Group A, as against $17.8 \%$ in Group C. Non-Maori artificial feeding was more 'satisfactory' than Maori, particularly Maoris in Group A.

Low levels of dietary iron resulting from inferior diet, particularly protein intake, are seen by Neave, Prior and Toms as a cause of the high anaemia rates among Maori children at ages six months to two years. They state, that once feeding has stopped, less than half a pint of milk will be drunk daily. 13

\footnotetext{
10 P. 324. Gardiner, Cedric E. (1959): "Maori Infant Mortality", N.Z.M.J., vol.IVIII, no.325, June. pp.321-40.

11 A.J.H.R. (196I): H-3I, p.18; and, p.15I. Pearson, Bill (1962): "N.Z. Since the War: 7. The Maori People", Landfall, vol.16, no.2, June. pp.148-80.

12 U.N. (1954): vol.II, pp.18-20.

13 Neave et al (1963): pp.26-27.
} 
It is generally realised that socio-economic factors, such as social class, may have some relationship with infant mortality. Moreover, evidence from England and Wales, and the United States shows a definite relationship between levels of neonatal mortality and income and social class. The United States study illustrated that 'racial' differences disappeared when socio-economic factors were held constant. For upper income levels, rates were similar, but, below a critical level, neonatal mortality correlated inversely with family income. 14 This seems to be caused by a reluctance or inability to seek medical advice, by poor environmental conditions and by other factors. For Maoris, Gardiner has not distinguished neonates from post-neonates, nor does he attempt to show a relationship with income or other social class variables. Instead, he showsa direct relationship between infant mortality and certain environmental factors. Thus, the differences between Maori and non-Maori are very wide for most of the following environmental conditions occurrence of tuberculosis among other members of the household; site, construction, floor space, number of occupants, condition of repair, cleanliness, amenities and sanitation of dwellings; and, urban or rural occurrence of the birth. In Gardiner's survey, 30\% of the sample births (Group B) had occurred in urban areas, as against $22 \%$ of the sample deaths (Group A). Urban or rural residence is analysed also by Rose, who found that urban rates were higher for neonatal mortality, a point he could not account for, ${ }^{15}$ but were considerably

14 Pp.524-26. Willie, Charles V.\& Rothney, William B. (1962): "Racial, Ethnic \& Income Factors in the Epidemiology of Neonatal Mortality", Amer. Sociol.Rev. vol.27, no.4, Aug. pp.522-6. See also p.209. Logan, W.P.D.(1954): "Social Class Variations in Mortality", Proc.World.Pop.Conference, Rome, vol.I, pp. 185-213. 15 If Maori birth and death statistics are compiled in the same manner and with the same accuracy as are the non-Maori, there is no possibility that the denominator and numerator are 
lower for post-neonatal mortality. Rose also noted that, of the urban areas, Wellington-Hutt had the lowest post-neonatal rates. 16 This concurs with the findings of a study on anaemia. There, the least difference in severity between Maori and nonMaori occurred in Wellington children and contrasted with results from five other hospitals (including a small sample from the Hutt). 17

In Australia, Lancaster has noted that the decline in the size of the Australian family has led to a decrease in the frequency of the introduction of infections by older siblings. This has been a significant factor in the decline of the death rate from acute infective diseases. ${ }^{18}$ Maori families are larger than non-Maori (see above). Thus, it is likely that Maori infants are exposed more frequently to the risk of infection from older siblings than are non-Maori infants. A decline in the size of Maori families could lead to some decrease in Maori infant mortality.

It has been shown that Maori infant mortality is declining, and for reasons which are characteristic of decreases elsewhere. But, there may be a purely national factor. Hospitalisation of confinements is so common that neonatal death rates are lower than is to be expected in a population whose postneonatal rates are declining, but which are still at fairly

15 (cont'd)

determined by different criteria. In both cases, for nonNaoris, place of normal residence is the criterion by which the allottment of statistics is determined. Thus, the difference could not be caused by the sending of sick neonates, who later die, to the city for specialist attention. However, as it is possible that a higher percentage of urban births occur in hospital than do rural, there is thus a greater chance that urban neonatal deaths will be registered correctly. 16 Rose (in press)

17 Akel et al. (1963): p.33.

18 P.177. Iancaster, H.0. (1952.a.): "The Mortality in Aust. from Acute Infective Diseases", M.J.A., Feb. 9th. pp.175-80. 


\section{2}

high levels. This means that neonatal rates still constitute not more than $30-40 \%$ of total rates, as against the $50 \%$ or more to be expected for a population with comparatively low neonatal mortality rates.

Deaths from certain 'exogenous' causes have declined in importance. Yet, even today, many environmental and biological factors may cause high infant mortality among Maoris. Urbanisation could be a factor which will bring Maoris into environments which are conducive to improvements in postneonatal infant health. 


\section{CHAPTER ELEVEN}

Maori Mortality Trends Since 1922: Part IV, Causes and Trends in Maori and Non-Maori Mortality

\section{Differentials}

\section{The Extent of Differences}

Iife-expectation data in Table 8.4 showed that Maori mortality is considerably higher than non-Maori, the latter population having one of the highest standards of health in the world. This difference extends to virtually every agegroup and every aspect of mortality.

It must be presumed that Maori still-birth data have become reasonably reliable only in the last decade since the hospitalisation of maternity cases became a standard practice. In this decade, Maori still-birth rates have been higher than the non-Maori in almost every year. These data, presented in Table 11.1, do not include deaths occurring prior to the $28 \mathrm{th}$ week of gestation.

Table 11.1 : Still-birth ${ }^{(1)}$ Rates, Maoris and Non-Maoris, 1942-1959 (Rates per 1000 live births)

\begin{tabular}{ccc|ccc}
\hline Year & Maoris & Non-Maoris & Year & Maoris & Non-Maoris \\
\hline 1942 & 12.3 & 25.9 & 1951 & 20.6 & 17.7 \\
1943 & 17.7 & 26.3 & 1952 & 19.8 & 17.9 \\
1944 & 16.3 & 23.3 & 1953 & 21.6 & 18.8 \\
1945 & 22.1 & 22.8 & 1954 & 19.1 & 17.7 \\
1946 & 13.8 & 21.8 & 1955 & 16.1 & 15.7 \\
1947 & 18.7 & 19.9 & 1956 & 19.7 & 16.7 \\
1948 & 18.0 & 18.5 & 1957 & 15.2 & 15.8 \\
1949 & 19.5 & 17.8 & 1958 & 16.2 & 15.0 \\
1950 & 20.3 & 19.2 & 1959 & 18.9 & 14.5
\end{tabular}

Source: Vit.Stats. (1959): Tables 1 \& 55.

Note: (1) The definition of still-birth is the standard one. See Vit. Stats. (1959): p.6.

Non-Maori infant death rates are given in Table 11.2. Total infant death rates were at the same level as the present Maori rates in the quinquennium 1911-15. Yet, non-Maori neonatal rates reached the present Maori levels only in the 1940s. Thus, 
for much of the period the decline in non-Maori infant mortality has resulted from decreases in post-neonatal infant mortality. Since 1911-15, over 50\% of non-Maori infant deaths have occurred to neonates. This, it might be added, is the normal pattern of distribution by age of infant mortality, and contrasts markedly with the Maori pattern in the quinquennium 1955-59.

Table 11.2 : (Rates per 1000 live births)

\begin{tabular}{llll} 
Period & $\begin{array}{l}\text { Neo-Natal } \\
\text { death rate }\end{array}$ & $\begin{array}{l}\text { Post } \\
\text { Neo-Natal } \\
\text { death rate }\end{array}$ & $\begin{array}{l}\text { Total } \\
\text { Infant } \\
\text { death rate }\end{array}$ \\
\hline
\end{tabular}

$\begin{array}{llll}1946-50 & 17.31 & 6.61 & 23.92 \\ 1941-45 & 20.01 & 9.52 & 29.53 \\ 1936-40 & 22.51 & 9.32 & 31.83 \\ 1931-35 & 22.34 & 9.54 & 31.88 \\ 1926-30 & 24.82 & 11.88 & 36.70 \\ 1921-25 & 27.48 & 15.27 & 42.75 \\ 1916-20 & 28.16 & 20.46 & 48.62 \\ 1911-15 & 29.28 & 24.35 & 53.63 \\ 1906-10 & 30.28 & 39.34 & 69.62 \\ 1901-05 & 30.64 & 44.13 & 74.77\end{array}$

Source: Med.Stats. (1951): p.viii

At each major age-group at 1954-58, shown in Table 11.3, Maori death rates far exceeded non-Maori. For example, at ages 15-24 the Maori female rate is 4.0 times the non-Maori. The low non-Maori death rates have resulted from declines at most ages, but particularly among infants and children.

Table 11.3 $: \frac{\text { Age-specific Death Rates, Maoris and Non-Maoris, }}{1954-1958 .}$ (Rates per 10,000)

\begin{tabular}{|c|c|c|c|c|c|c|}
\hline Ages & Maoris & Non-Maoris & $\begin{array}{l}\text { Maori Rate } \\
\text { Non-Maori } \\
\text { Rate }\end{array}$ & Maoris & Non-Ma & $\begin{array}{c}\text { Maori Rate } \\
\text { Non-Maori } \\
\text { Rate }\end{array}$ \\
\hline $\begin{array}{l}0-4 \\
5-14 \\
15-24 \\
25-44 \\
45-64 \\
65+\end{array}$ & $\begin{array}{r}188.7 \\
17.6 \\
30.8 \\
52.9 \\
216.4 \\
920.9\end{array}$ & $\begin{array}{r}60.0 \\
5.1 \\
14.9 \\
19.4 \\
115.3 \\
716.0\end{array}$ & $\begin{array}{l}3.1 \\
3.5 \\
2.1 \\
2.7 \\
1.9 \\
1.3\end{array}$ & $\begin{array}{c}158.2 \\
13.6 \\
21.5 \\
43.8 \\
224.1 \\
878.4\end{array}$ & $\begin{array}{r}46.3 \\
3.8 \\
5.3 \\
13.1 \\
74.3 \\
543.6\end{array}$ & $\begin{array}{l}3.4 \\
3.6 \\
4.0 \\
3.3 \\
3.0 \\
1.6\end{array}$ \\
\hline
\end{tabular}

Source: p.11. Rose, R.J.: Maori-European Standards of Health, N.Z.Dept. of Health, Special Report No.1, Wellington 
Standardisation of Maori death rates to the non-Maori

population in the period 1954-58 showed that:

In addition to the group of epidemic and

infectious diseases as well as a.ll the acute types of respiratory and gastro-intestinal diseases the Maori is much more susceptible than the European [non-Maori] to death from every one of the so-called degenerative conditions such as cancer, diabetes, cerebral vascular lesions, heart diseases and chronic forms of nephritis. 1

The favourable position of the non-Maoris has been brought about particularly by the decline in the death rates from tuberculosis, other infectious, respiratory, gastric and intestinal diseases, accidents and maternal mortality. These patterns of decline vary, of course, from age-group to age-group. ${ }^{2}$ In general, the decreases followed patterns described elsewhere in the 'West' and so, presumably had resulted from improved sanitation, public health, nutrition, and living conditions. Recently, these factors have been accompanied by high standards of medical care and, particularly since World War II, by effective curative and prophylactic measures. Thus, the patterns and causes described for the decline in Australian mortality probably apply, in substance, to the non-Maoris. 3

It is obvious from these brief remarks that there must be a number of important factors which have given rise to lower standards of health for Maoris, and which acted as obstacles

1 P.33. Rose, R.J. (1960): Maori-European Standards of Health, N.Z. Dept. of Health, Special Report, No.1, Wellington.

2 The major part of this analysis is a summary of Med.Stats. (1951): pp.viii-xiv. See also Deem, Helen (1947): "Infant Loss in N.Z.", N.Z.M.J., vol.XIVI, Dec. pp.475-85; Lessof, Elizabeth (1949): "Mortality in N.Z. and England and Wales", Pop.Stud., vol.3, June. pp.76-99; Edson, N.I. (1942):

"Tuberculosis Mortality in N.Z. with Special Reference to Women of the Child-Bearing Ages", N.Z.M.J., vol.XII, April. pp.51-62; and, pp.24-29. U.N. (1962): "The Situation \& Recent Trends of Mortality in the World", Pop.Bull., No.6, pp.3-145.

3 passim. Lancaster, H.0. (1963): "Vital Statistics as Human Ecology", Aust. J. of Science, vol.25, no.11, May. pp.445-53. 
to improvements in Maori mortality levels, virtually until after World War II.

\section{Some Factors which may be Related to Differences between Maori and non-Maori Trends}

The data on these relationships are rather sketchy, so that little of a definite nature can be said. This section will work from possible biological factors, through sanitation, to social and economic characteristics, and will reject those factors which seem least probable. But, this does not mean that the more likely factors have a proven relationship to mortality among Maoris. 4

\section{Genetical Factors}

These factors and their relationship to general Maori mortality could be studied only if, on the one hand, medical science and the data at its disposal could segregate influences from diet, hygiene and other factors; and if, on the other hand, it was certain that the deaths recorded as 'Maori' occurred only to people who were Maori in a biological sense. Neither of these conditions is easy to fulfil. At present, the researcher studies a population 'culturally' Maori, and perhaps Maori in a biological sense, but certainly not 'pure'. A feeling of 'belonging' is the real basis for a person to claim that he is Maori.

However, two facts should be noted. Firstly, if adequate case histories, including details of family records, could be assembled for individuals, it might be shown that combinations of certain traits gave rise to a disposition towards various specific diseases in individuals possessing these traits through inheritance. Secondly, Robb has suggested that the susceptibility of Maoris to a few specific diseases may be

4 See also Turbott, H.B. (1940): "Health \& Social Welfare", in Sutherland, I.I.G. (ed.): the Maori People Today, Wellington. 
genetically determined. But, he adds 'In none of these have convincing relationships been established'. Nevertheless, using recent haematological evidence, Robb shows that persons of blood group A 'run more risk than those of other groups of suffering from ... carsinoma of the stomach, diabetes mellitus, pernicious anaemia, and carcinoma of the female genitalia'. Maoris 'are high in group $A^{\prime}$ and seem to have higher (standardised) death rates than non-Maoris for the disease groups into which these four conditions fall. There may also be genetic factors operating in the low incidence of rheumatoid arthritis among Maoris. 5

Lennane et al. note that gout may be 'at least partially genetically determined,...' However, tests undertaken by these authors suggest that the probable recent increase in the incidence of gout among Maoris may be adequately explained by marked economic and dietary changes 'without postulating any alteration in the necessary genetical constitution'. 6

At present, it must be accepted that environmental and other factors are of greater importance than genetical characteristics as causes of high mortality for all but a few diseases. 7

5 pp.8-9 (reprint). Robb, Douglas (1960): "Maori \& European Differential Incidence of Surgical \& Other Diseases", N.Z.M.J., vol.59, no.334, June. pp.271-79; and, p.12 (reprint). $\frac{\text { Prior, }}{4}$ Ian (1962): "A Health Survey in a Rural Maori Community, with Particular Emphasis on Cardiovascular, Nutritional \& Metabolic Findings", N.Z.M.J., vol.61, no.359, July. pp.1-16. He found a high rate of diabetes among the Maoris he surveyed and said that genetic factors, particularly "inter-marriage" (endogamy?), could be important.

6

p.124. Iennane, G.A.Q. et al. (1960): "Gout in the Maori", Annals of the Rheumatic Diseases, vol.19, June. pp.120-25.

7 cf. Rose (1960): pp.2-3 who reaches a similar conclusion. He uses evidence from military records to show that, given similar conditions, Maori and non-Maori standards of health can be much the same. 


\section{Physique and Other Physiological and Morbid Factors}

In 1940, Turbott stated that Maori children had better average physique and fewer deformities than non-Maoris. These results were derived, mainly, from samples of school children, so could perhaps be biased by the non-attendance of children of poorer physique, and the fact that mortality is lowest at school-ages. 8 Moreover, personal observation of a Maori by the present author suggests that absenteeism from school is common for specific causes, or because the children are 'sick' or 'weak'.

It was noted earlier when discussing diseases of the circulatory system that Prior found a considerable degree of obesity among Maori adults. Excluding pregnant women, he used such anthropometric observations as height and relative weight, skin fold measurements and mid-arm circumference, and compared his findings with the Actuarial Society of America Tables (1912). He felt that, for both sexes, excessive caloric intake was of prime importance while, for women, multiple pregnancies have an adverse effect. ${ }^{9}$

There is ample evidence of other morbid and physiological conditions which cause discomfort, at least, and may have a debilitating effect. Firstly, anaemia is extremely frequent and 'must be a major contributing cause of morbidity and mortality, particularly in the younger age-groups'. 10 Secondly, hypertention is common, especially among women. ${ }^{11}$ Thirdly, dental health is considered to be unsatisfactory. ${ }^{12}$ Fourthly,

$\overline{8 \text { Turbott }}$ (1940): p.234.

9 Prior (1962): p. 5 .

10 p.33. Akel, R.N. et al. (1963): "Anaemia in Maori \& European Infants on Admission to Hospital: A Co-operative Survey from Six N.Z. Hospitals", N.Z.M.J., vol.62, no.365, Jan. pp.29-33.

11 Prior (1962): p.10.

12 Turbott (1940): p.235; and, Prior (1962): pp.13-14. 
investigators have pointed to the high incidence of skin diseases and other infections, particularly among children. For example, a study in 1953 found that 22\% of children examined had impetigo, $13 \%$ had scabies, $9 \%$ infected wounds, etc. ${ }^{13}$ These researchers noted the 'inadequate facilities for maintaining adequate standards of cleanliness...', while Turbott found that towels were not provided for individuals in $70 \%$ of the homes he surveyed. ${ }^{14}$ Recently, researchers have pointed out that the frequency of infections is related to the high incidence of anaemia, already noted, among Maori children. ${ }^{15}$

\section{Diet and Nutrition}

It has been shown that there is a relationship between diet and various causes of death, as well as infant mortality in general. Thus, diet must be an important factor. Turbott noted the following pattern of diet for East Coast Maoris in 1933: breakfast -- potato or kumara (sweet potato); bread and tea; meat sometimes. Midday -- tea and bread; corn (maize) in season. Dinner -- potato or kumara; meat; vegetables infrequently; puwha (sow thistle) perhaps twice a week; tea and bread. Normally, milk was drunk in tea only. Turbott says 'This diet, mainly carbohydrates has enough factors to maintain nutrition, but is probably deficient in building up disease resistance. 16

13 p.6. McArthy, D.D. \& Marples, M.J. (1953): Report on a Short Medical Expedition to Northland..., Dunedin (cyclostyled); see also Turbott (1940): p.234.

14 p. 45. Turbott, H.B. (1935): Tuberculosis in the Maori: East Coast of N.Z., Wellington.

15 p.27. Neave, M. et al. (1963): "The Prevalence of Anaemia in Two Maori Communities", N.Z.M.J., vol.62, no.365, Jan. pp.20-28; and, Akel et al. (1963): p.33. 16 Turbott (1935): p.47. 
A study of the remote and isolated village of Maungapohatu, in 1937, showed a similar patterm. In 1945, Maori diet, which was shown by a survey to be deficient in milk, cheese, eggs, fruit and vegetables, and whole cereals, was stated to be inferior to that of non-Maori families on the basic wage. 17 Prior, in his recent survey, shows that caloric intake is high 'particularly from carbohydrate sources such as potatoes, bread and sugar and to a lesser extent of fat from meat, bacon and butter...'.18 In general, diet patterns seem to have been similar 'qualitatively' throughout the period, while 'By European standards the total quantity of food consumed would be considered generous'.19

\section{Housing}

The standard of housing has been shown to be related to levels of infant mortality. The 1926 census drew attention to the fact that while only $1.2 \%$ of non-Maori dwellings were huts and tents, $28.7 \%$ of Maori dwellings came into this category. Moreover, with 5.7 persons per dwelling, as against 4.3 for non-Maoris, the situation was even more unsatisfactory. Taking as his criteria more than two persons per room, and less than 300 cubic feet per person, Turbott, in 1933, found that $58 \%$ of the 323 families he studied lived in overcrowded conditions, while $36 \%$ of these families lived in imperfectly constructed dwellings. 20 By 1956, the situation had improved as far as types of dwellings were concerned, but Maoris were

17 A.J.H.R. (1937): H-31, p.64; and, p.97. Molaughlin, E.C.G. \& Wilson, I. (1945): "N.Z. Dietary Studies, III", N.Z.M.J., vol.XIIV, April. pp.93-98. Similar assessments are made on pp.94-95. Beaglehole, Ernest \& Beaglehole, Pearl (1946): Some Modern Maoris, Christchurch; and, pp.99-100, Hawthorn, H.B. (1944): "The Maoris: A Study in Acculturation", Amer. Anthropologist, New Series, vol.46, no.2 (Memoir).

18 Prior (1962): p.15.

19 Iennane et al. (1960): p.121.

20 Turbott (1935): pp.43-44. 
still at a disadvantage in terms of the number of occupants per dwelling and the provision of amenities.

\section{Sanitation}

This is related to the incidence of gastro-intestinal and infectious diseases. In particular, water supplies should be clean and toilets efficient. Turbott's survey showed that $61 \%$ of the houses had pit-privies and $33 \%$ no privy accommodation at all. 21 In 1942, Bennett and Broughton stated that a South Auckland survey had found that $80 \%$ of Maori dwellings had unsatisfactory water supplies and that $62 \%$ lacked suitable privy accommodation. 22 Even in 1956, a large proportion of Maori dwellings did not have suitable amenities (Table 13.12).

\section{Social Factors and Attitudes}

The following factors could have some bearing on differential mortality, although relationships are often not very direct. Maori educational attainments are lower than non-Maori. There are few Maori medical practitioners. Hui, and other large scale meetings are still common and, on these occasions, visitors sleep in the local meeting-houses. Moreover, there is a reluctance to seek medical attention, as was mentioned in the case of cancer. Blake-Palmer noted that child-rearing practices are different, and that there is a tendency to seek advice or treatment from tohunga, rather than medical practitioners. This may act as a catharsis or may be harmless, but sometimes it is not. ${ }^{23}$ Today, it seems, tohunga are becoming uncommon in Northland and on the East Coast. ${ }^{24}$

\footnotetext{
21 Turbott (1935): p. 44 .
}

22 pp.47 \& 49. Bennet, H.R. \& Broughton, I.W. (1942): Some Psychological Aspects of the Maori, Dunedin, Mss. Pub. Iib. 23 p.403. Blake-Palmer, G. ) 1956): "Maori Attitudes to Sickness", M.J.A., Sept. 15th. pp.401-05.

24 p.151. Pearson, Bill (1962): "N.2. Since the War: 7. The Maori People", Landfall, vol.16, no.2, June. pp.148-80. 
Finally, rural or urban residence seems an important factor, at least in the case of infant mortality. In $1956,24 \%$ of Maoris lived in urban areas, as compared with $65 \%$ of nonMaoris.

\section{Economic Factors}

Chapter 13, Section 8 shows that Maoris are in an unfavourable economic position. This factor may well have some bearing on mortality levels. Its most important effect would be on the opportunities Maoris have to maintain adequate standards of diet, housing and hygiene. Medical care is free under the social security scheme, so that adequate attention is not precluded because of the economic position of the Maoris.

In summary, therefore, it has been shown that Maoris are at a disadvantage, as indicated by certain physiological, social and economic variables, and that their diet patterns and home environments are not as satisfactory as those of non-Maoris. If these factors do have a bearing on mortality, then this chapter has noted some of the causes of lower Maori life-expectation and their poorer standards of health. The over-whelming importance, in such a case, of environmental factors outweighs the possible effects of genetical factors. However, these environmental factors are probably interrelated, so that it is difficult to assign their specific roles as causes of mortality.

\section{Factors causing a Decline in Maori Mortality, 1945 to the Present}

Throughout, this study has stressed the rapidity of postwar improvements in Maori mortality. The possible causes seem fourfold:

(I) Some biological factors could have operated to bring about the change. For example, there could have been a 
reduction in the virulence of important organisms causing disease, or else Maoris could have changed their degree of natural immunity against major diseases. There is no evidence to support such an argument, particularly as the time span was too short for factors such as heredity to have operated. Moreover, although immunity to epidemic mortality may be agespecific and dependent on the course of previous epidemics, the frequency of very minor epidemics suggests that each Maori age-group should have gained immunity from infection at an early age. For example, the wide-spread 1938 epidemic of measles would have given immunity to any persons born prior to that date who had not already gained immunity. In fact, the age-specific rates suggest that all but infants already had immunity to this disease at that time (Table 9.7).

(2) Curative measures may have been increased and made more efficient. This seems to be the major cause of mortality declines in 'Latin America - Africa - Asia', as against improvements in diet and living standards which operated, at least in the early stages, to bring about a mortality decline in the 'West'. 25 This cause is a strong possibility for Maoris too, for it is in the post-war period that antibiotics and other health measures have been widely used. Moreover, for Maoris, almost half the mortality decline has come from a decrease in the death rate of tuberculosis. Thus, it is not surprising that efficient measures to locate and combat tuberculosis have been introduced only since the war, and must have affected Maori and non-Maori alike. About 1945, a Division of Tuberculosis was formed and plans laid to fight the disease, including the improvement of institutional and

25 pp.33-34. Stolnitz, George J. (1955.b.): "Comparison Between Some Recent Mortality Trends in Underdeveloped Countries and Historic Trends in the West", Trends \& Differentials in Mortal ity, Annual Conference, Milbank Memorial Fund, New York, pp.26-34. 
domiciliary treatment, the provision of housing for sufferers, the initiation of mass surveys and the education of the public. 26 In 1949, BCG vaccine was introduced and mobile $\mathrm{X}$-ray units began operating in a number of districts. 27 By 1953, vaccination programmes had so advanced that it was estimated that by December 1954 all persons in age-groups and occupation-groups most at risk would have been vaccinated. 28 By 1958, 10\% of the whole population, Maori and non-Maori, was being X-rayed annually. ${ }^{29}$ Health measures affecting measures affecting other diseases were introduced as, for example, the new series of regulations in 1948-49 governing eating houses, quarantine procedures and infectious diseases. 30 These and other measures could have brought about, for example, declines in gastro-intestinal diseases.

The sheer importance of tuberculosis, the apparent relationship between its decline and the introduction of efficient preventive and curative measures and the steps taken to combat other diseases, suggest that, as in 'Latin America etc.', the recent rapid declines in Maori mortality result in no small part from public health measures. In other words, if no environmental, dietary or natural biological changes had occurred during the period, mortality still would have declined.

(3) Improvements in diet and nutrition could have brought about changes. The data presented above (Section 2) are not sufficiently comprehensive to determine whether diet patterns

\footnotetext{
26 A.J.H.R. (1945): H-31, p.18.

27 A.J.H.R. (1949): H-31, p.46. A major factor in the decline of tuberculosis has been the effectiveness of vaccination and new drugs'. See U.N. (1962): p.16.

28 A.J.H.R. (1953): H-31, p.63.

29 A.J.H.R. (1959): H-3I, p.102.

30 A.J.H.R. (1949): H-3I, pp.24-25.
} 
changed. Prosperity and the shift of residence to urban areas might have had some effect. There is no evidence of the effect of a dietary change important enough to have decreased tuberculosis rates in the same manner shown to have occurred in England and Wales (Chapter 9, Section 3).

(4) Finally, if it is accepted that socio-economic factors affect mortality, then changes in these could have brought about an improvement in the death rate. If the possession of household amenities is any index of sanitation and the general state of dwellings, then the effect of any improvements in housing could have been quite considerable in the period.

Perhaps the most significant change of environment in this period has resulted from the considerable increase in the proportion of the Maori population residing in urban areas. Persons of age-group 15-44 are the largest migrating group, 31 but this is a low-mortality age-group. Moreover, the child-woman ratio for urban areas in 1956 was far below that of rural areas (see Table 12.9). This means that crude death rates, if available, could not be used to measure rural-urban differences in mortality, as the age-structures are so different. However, post-neonatal ratesare available, and urban rates are below levels outside. The reverse is true for neonatal rates, but environmental conditions, the main concern of this paragraph, are less likely to be of significance at neonatal ages, while the higher Maori urban neonatal rates may even result from better urban than rural standards of registration (see footnote 17, Chapter Ten). The causes of the lower urban post-neonatal infant death rates

31 pp.37 \& 40. Maxwell, Gabrielle M. (1961): "Some Demographic Indications of Population Movement among N.Z. Maoris", J.P.S., vol.70, no.1, Mar. pp.31-42. 
may be the different living conditions in urban areas, as suggested by a study by the present writer of Auckland urban area, 32 which contained half the Maoris residing in urban areas in 1956. In Auckland, Maoris had first moved into innercity slum areas. Iatterly, there has been a shift to the outer-suburbs most particularly for families with young children. The majority of outer-suburban Maori families in 'lower-middle grade' suburbs composed of 'new single-unit' dwellings. It is suggested that the majority of urban infants live under better conditions than any other group of Maori children.

The Maori mortality decline since 1945 has been partly the result of improvements in environment and socio-economic conditions. However, unlike the classical mortality of the 'West' in the nineteenth century, curative and preventive measures have also played a considerable, and probably the leading, role.

\section{Conclusion}

Today, Maori life-expectation is closer to the nonMaori than at any time since 1926, for mortality has declined rapidly since 1945. Maori mortality still remains at fairly high levels, while non-Maori life-expectation is almost the highest recorded anywhere. The Maori of today, in terms of health, are an under-privileged people and, if any severe criticism were to be made of the efficacy of New Zealand's much lauded welfare measures, it would be here in the field of Maori health.

If, as the evidence suggests, mortality differentials are brought about primarily by environmental rather than genetical factors, the problem of mortality differentials

32 Pool, Ian (1961): "Maoris in Auckland; A Population Study", J.P.S., vol.70, no.1, Mar. pp.43-66. 
between Maoris and non-Maoris may be considered in the same light as are social class and regional differences elsewhere. Thus, public health measures should be combined with attempts to improve the general environments of Maoris. In particular, Maoris should be made more aware of the range and availability of the health services wich are the birthright of all citizens. Such an awareness is being aroused particularly by the activities of government departments and influential Maori organisations.

The interest of the state in this aspect of Maori welfare, and the machinery at its disposal by which Maori health standards can be improved, suggest that the Maori mortality transition will continue, and that differentials between Maori and non-Maori will diminish. The implications of possible future mortality trends and the effects of past trends on the growth of the Maori population will be discussed in subsequent chapters after an analysis has been made of fertility trends.

The trends reviewed here may have a more general interest as the Maori population is but one of a number of high mortality populations undergoing a mortality transition at present. Often there are few reliable data available for the study of the mortality trends of high mortality populations, particularly on causes of death, but (ehe Maoris are relatively well placed in this regard. It would be unrealistic to claim that the Maori mortality transition is a detailed replica of the transitions of those other larger and more diversified high mortality populations. Nevertheless, the trends reviewed in the last four chapters may throw some light on various aspects of the mortality transitions of other high mortality populations, for it is apparent that the general pattern of the Maori mortality decline bears some 
resemblance to the patterns of mortality decreases in latin America and Asia, and even possibly Africa. Thus, it is of value to summarise the most important conclusions which are:

1. There has been a rapid decline in Maori mortality since World War II, particularly at the younger age-groups. This type of trend is perhaps the most important characteristic of high mortality populations, and as such has been frequently noted in the demographic literature. This type of decline results from decreases in infections, respiratory and intestinal diseases.

2. The decrease in Maori mortality rates has occurred most markedly for a few causes of death, of which tuberculosis is the outstanding example. This emphasis has also been frequently noted for other high mortality populations, but in these other cases the greatest declines occurred in the rates of acute infectious diseases and most importantly for the 'pestilential' diseases such as yellow fever. Maori and non-Maori New Zealanders have both been fortunate that the great pestilential diseases do not appear to have reached twentieth century New Zealanders. By contrast, tuberculosis may be an important cause of death in other high mortality populations, but hitherto it has been overshadowed by, for example, malaria or cholera. Now that the 'pestilences' have been eradicated these other high mortality populations could have a further 'Maori-type' mortality decline largely as a result of decreases in such diseases as tuberculosis.

3. The Maori mortality transition results, very considerably, from improved curative and prophylactic measures. Improvements in environmental conditions have not been as significant factors in the Maori mortality decline as they were in the "West's" mortality transition. For Maoris, the effect of high standards of medical care has been noted as a determinant of the decline of tuberculosis and of the relatively low 
neonatal infant death rates, whereas the high post-neonatal infant death rates point to deficiencies in Maori living conditions. New curative and prophylactic measures, introduced since World War II, have been seen as the major determinants of the mortality declines recorded for other high mortality populations.

4. In the past, high mortality rates were not restricted to the infectious, respiratory and intestinal diseases, but also occurred for degenerative and other diseases. Even today, the Maoris have higher age-specific death rates than non-Maoris for almost every disease. The fact that age-specific death rates from degenerative diseases may be greater in high than in low mortality populations has often been overlooked, either because mortality from infectious, respiratory and other intestinal diseases forms such an important component of the death rates of high mortality populations or because the data on mortality do not permit the calculation of age-specific rates.

5. There has been little improvement in the death rates of a number of these degenerative diseases, and thus they constitute a proportionately more important component of the Maori crude death rate than at earlier periods. However, there has been no increase in the age-specific rates of any of the degenerative diseases studied here, after account is taken of the poor quality of data at earlier periods.

6. Highest rates for degenerative diseases occur at older age-groups. The differentials between Maoris and nonMaoris at these ages may result from the fact that the Maori cohorts have been subjected to high incidence rates for a wide range of diseases at earlier periods in their lives. For example, high incidence rates in the infectious diseases of childhood may sustain heart damage which leads to various forms of heart disease at older ages. As incidence rates for 
infectious disease have declined at younger ages, so too could declines in degenerative diseases occur when these younger cohorts reach older ages.

7. For tuberculosis, high rates are found today mainly at older ages. It has been shown that this trend results from the residual effect of the high tuberculosis infection rates occurring when the present older cohorts were at younger ages. Recently, the diagnosis and cure of tuberculosis has become much more effective than formerly, so that when cohorts at present middle-aged reach older ages there is every likelihood of a declinein tuberculosis age-specific death rates. It is suggested that the earlier experiences of 'Western' populations are not completely applicable to an understanding of present Maori tuberculosis trends as 'Western' declines largely resulted from improved environmental conditions, and thus the residual effect of earlier high incidence rates would have been more pronounced. This is but a further proof of the differences between the determinants of mortality declines in the 'West' and in the contemporary high mortality populations.

The Maori population has certain advantages which set it apart from other high mortality populations. Most importantly, New Zealand has standards of medical care which, if availed upon, are probably better than in most other countries. Herein lies the most paradoxical feature of Maori mortality trends, for the Maoris should have very low mortality. Perhaps the non-Maori majority has not been aware until recently of the considerable disadvantages suffered by Maoris, perhaps the Maoris have not availed themselves of the opportunity provided by the State for medical care, or perhaps the sheer isolation, geographically and socially, of the Maori population is the basic cause of this disparity in standards of health. For example, the few data on rural-urban differentials suggest that urbanisation may be one factor effecting improvements 
in Maori health. Certainly, the differentials in New Zealand show that despite the interest of a state in social welfare certain sections of the community can still be underprivileged in terms of health.

The differentials in mortality seem to have continued because low mortality is not only achieved by advances in medical technology, but also by improvements in environmental conditions. For example, the decline of Mori tuberculosis death rates and the achievement of low Maori neonatal infant death rates are commendable features of New Zealand's postwar record of public health, and result from the introduction of only the most advanced type of medical care. Yet, Maori post-neonatal infant mortality rates, which can be drastically reduced by fairly simple preventive measures, remain at high levels. The replacement of substandard housing and the provision of better household sanitation and water supplies, are costly measures, but so too has been the provision of adequately equipped and staffed matermity hospitals, or mobile X-ray units. This is a problem to be faced by the populations of the newly-developing nations, where declines in mortality have been achieved at a fairly low cost by the use of anti-biotics and other relatively cheap measures. But, unlike the Maoris, they are not minority populations residing in a nation which has a high per capita income and a comprehensive social security scheme financed from taxation and general revenue. 


\section{CHAPTER TWELVE}

\section{Maori Fertility since 1922}

\section{Introduction}

Since the mid-1930s, the Maori crude birth rate has been over 40 per 1,000 of the mean annual population. The crude birth rate is a most unsatisfactory measure, but rates of this magnitude show that fertility is at high levels. A more exact picture of Maori fertility cannot be obtained as the necessary data, even births by age of mother, are not collected and agespecific fertility rates have had to be estimated. The study of observed levels of fertility, carried out in Section 2, is restricted therefore to an analysis of birth rates, general fertility rates and child-woman ratios. Within this narrow framework, the aim is to determine whether Maori fertility had been at similarly high levels prior to the mid-1930s. Moreover, the uniformity of the subsequent birth rates may, by the nature of crude birth rates, hide real changes in fertility. The only other collection of data on fertility was at the 1945 census, when the total numbers of children over-born to currently married women at each quinquennial age-group were published. These data have proved on investigation to be most unsatisfactory which will be discussed below.

The accuracy of data has been alalysed in Chapter seven. Birth registration was poor until the mid-1930s and even until 1946, in which year there was a rush of late registrations of births from as far back as the early 1930s. Since then, registration has probably improved. Secondly, for the period 1926-35, an attempt was made to determine the under-registration of births, and the published data were altered accordingly. Thirdly, the accuracy of censuses improved towards the present, 
with some probable under-enumeration at most censuses, particularly of infants and of age-group 15-24. In 1945, among recent censuses, the under-enumeration at ages 0-4 ma\& have considerable effect on child-woman ratios. The main denominator used here, females at reproductive ages, is such a wide agegroup that digit preference anomalies, and even underenumeration, jave less effect that they would have had if quinquennial age-groups were used.

Differential fertility has been studied, in recent periods, by the use of child-woman ratios calculated from data grouped, from adjacent counties, into regions. Although an attempt has been made to maintain consistency, county boundaries have changed and this had precluded complete uniformity.

The analysis of rural-urban differentials, including 1956 and 1961 when general fertility rates can be calculated as well, runs into the problem that the raw census data are not categorised in a completely satisfactory manner. For example, child-woman ratios can be computed recently for urban areas, which include the cities and their rural-urban fringes; for boroughs and cities, which include some administrative units already included in urban areas; and, for counties, which include, without any means of segregation, the portions of counties falling into the rural-urban fringes of urban areas (for details of residential breakdowns in N.Z. Statistics, see Appendix B). However, this does not preclude the analysis of rural-urban differentials (see Section 4). Therefore, this study of fertility is based on trends of child-woman ratios; general fertility rates; and crude birth rates. Relevant data on factors which could affect fertility are sparse and data on nuptiality are not entirely satisfactory. These will be analysed below in Section 3 . 


\begin{tabular}{ll} 
Year \\
\hline 1926 \\
1927 \\
1928 \\
1929 \\
1930 \\
1931 \\
1932 \\
1933 \\
1934 \\
1935 \\
1936 \\
1937 \\
1938 \\
1939 \\
1940 \\
1941 \\
1942 \\
1943 \\
1944 \\
1945 \\
1946 \\
1947 \\
1948 \\
1949 \\
1950 \\
1951 \\
1952 \\
1953 \\
1954 \\
1955 \\
1956 \\
1957 \\
1958 \\
1959 \\
1960 \\
1961
\end{tabular}

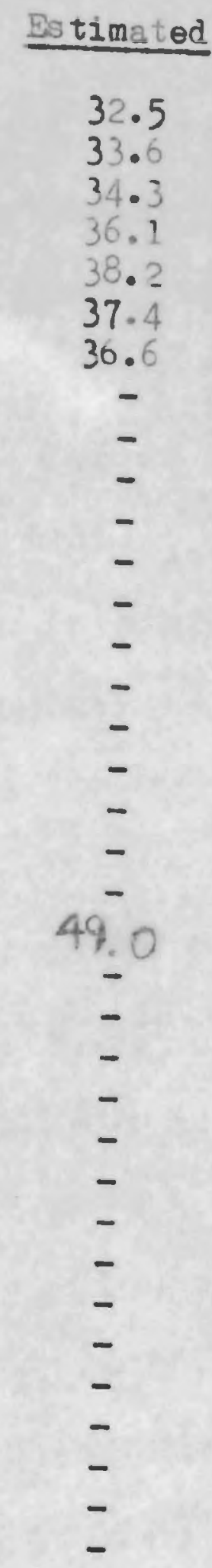

Published (2)

1926

1928

1929

1930

1932

1933

1934

1935

1936

1938

1939

1940

1941

1942

1944

1945

1946

947

1948

950

1951

1952

1953

1954

1956

1957

1958

1960

Notea: (1) Estimated Bixthis

Batimated mid-year population

(See Chapt.7, Section 4).

(2) Published rates. In addition to clearly deficient birth rogiatration, the mean annual population is belor the estimated mid-year population employed in (1). This accounts for the discrepanoy in 19323i.e.that the est.1s below the pub.

(3) Possibly some deaths of very young infants were reglstered neither as births mor deaths birth was registered.

(4) There was considerable late registration in this 1946. The estimated rate in this year is:

\section{Estimatod B}

\section{Publishod mean amusl $\bar{P}$.}




\section{Ievels of Fertility}

The crude birth rates, given in Table 12.1 have been high throughout the period since 1936. There were no important changes in age-structure during the period, such as an increase in the proportion of the total population who were females at reproductive ages. This figure varied only from 21.1 per cent (1936), to 22.4 percent (1945) in the whole period. As noted above, births were poorly recorded at 1946 and prior to the mid-1930s. For these years, estimates have been made of the degree of over or underregistration.

The Maori crude birth rate is comparable with those recorded for high fertility populations elsewhere. Examples are Taiwan (until recently) and the Hutterites of the United States. However, the Maori rates have never reached as high levels as those recorded for the Cocos-Keeling Islands. ${ }^{1}$

Even after allowance is made for over-registration in 1946, the crude birth rate is still in excess of that in adjacent years. It is probable that the return of troops about this time affected the rates by allowing the resumption of normal marital patterns temporarily interrupted by the war.

General fertility rates, presented in Table 12.2 are also uniformly high, being over 200 per 1,000 for each census since 1936. The rates at 1926 are low, even when estimates are made of the under-registration of births and the under-enumeration of women at the census. The 1945 rates show the effect of the higher birth rate in 1946.

\footnotetext{
p.178 Lorimer, Frank (1954): Culture \& Human Fertility, J.N.E.S.C.0., Paris; p.222. Freedman, R. et al. (1963): "Fertility Trends in Taiwan: Tradition and Change", Pop.Stud, vol.XVI, No.3 Mar. pp.219-36; p.15. Eaton, Joseph W' \& Mayer, Albert J. (1954): Man's Capacity to Reproduce: The Demography of a Unique Pop, Glencoe, Ill.; and, p.102. Smith T.E. (1960): "Cocos-Keeling Is: A Demographic Laboratory", Pop.Stud., vol. XIV, No.2, Nov. pp.94-130.
} 
Table 12.2. : General Fertility Rates, 1926-1961

(Births per 1000 women 15-49, and 15-44; Mid-Year populations at census years and births averaged for a three-year period around the census )

Year $\frac{\text { G.F.R. }}{\frac{B}{15-49}} \frac{\text { G.R.F. }}{\frac{B}{\text { T }_{15-44}}}$

\begin{tabular}{lll}
\hline $1926(1)$ & 116 & 125 \\
$1926(2)$ & 159 & 172 \\
1936 & 207 & 222 \\
$1945(3)$ & 218 & 234 \\
1951 & 205 & 220 \\
1956 & 202 & 217 \\
$1961(4)$ & 205 & 221
\end{tabular}

Notes: $\quad$ (1) Using published data.

(2) Using data adjusted for under-enumeration and under-registration

(3) Taking 1946 births as $49 / 1,000$

(4) Mean population 1961, in Pop.Mig. \& Bldg.Stats $(1961-62):$ p.23. Births for 1961 only.

Table 12.3 : Child-Woman Ratios, 1926-56

\begin{tabular}{ccc} 
& Children 0-4 & Children 0-4 \\
Year & $(1)$ & \\
\cline { 2 - 3 } 1926 & 768 & 830 \\
1936 & 809 & 868 \\
1945 & 747 & 803 \\
1951 & 840 & 904 \\
1956 & 861 & 927
\end{tabular}

(1) Ages not specified distributed pro rata. 
Child-woman ratios show a steady increase towards the most recent years. The exception is 1945, which has the lowest ratio of the group.

During the 1918 influenza mortality was low among females below 15 years of age, while higher mortality rates occurred for females at the reproductive ages. This pandemic's mortality patterns are reflected in 1936 by the high proportion of females at reproductive ages aged 20-29, and by a high child-woman ratio.

The lower ratio in 1945 could have resulted from high infant mortality rates during a diarrhoea epidemic that year, from the 1941 whooping-cough epidemic, or from underenumeration of children aged 0-4. Thus, it does not measure a change in fertility levels.

Important decreases in infant mortality since the war have increased the child-woman ratios. This has not been accompanied by increases in fertility, in so far as the crude birth rate can be taken as a guide.

The final measure obtainable from published data is the number of children ever-born alive to currently married women at the 1945 census (see Table 12.4). These data have a number of faults. Firstly they refer only to the currently married. Secondly, at each five-year age-group, about 25 per cent of the women who had recorded themselves as currently married did not reply to the question on the number of children they had born. It cannot be presumed that their pattern of fertility was the same as the respondents', but, for the purpose of analysing these data, non-respondents have been substracted from the married woman. Thirdly, there is no way of determining the proportion of unregistered marriages (see below, section 3 ), nor is it certain that children born illegitimately have been included. It is

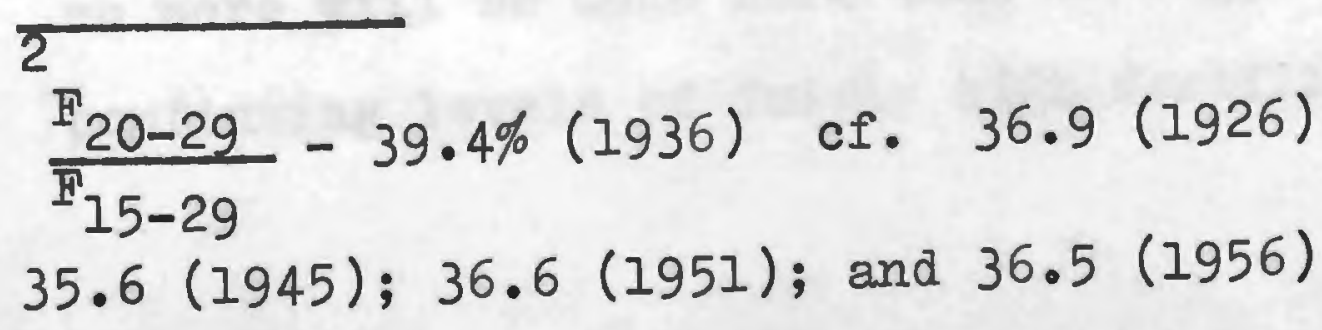


obvious that these data can be used only as stating the

levels of fertility of those women who claimed to be 'married' at the time of the census. Directly, they may give some idea of the patterns of fertility of 'married' women who had completed their child-bearing at the 1945 census. Table 12.4: $\frac{\text { Children Ever-Born Alive to Currently }}{\text { Married Women, 1945. }}$

Age of Women Years in which childbearing was completed (approximate)
Average Number of Iivebirths.

To currentzy-married women
$15-79$

20-24

$25-29$

$30-34$

$35-39$

40-44

$45-49$

$50-54$

$55-59$

60-64

65-69

$70-74$

$75+$

$\begin{array}{cl}\overline{-} & 0.68 \\ \overline{-} & 1.83 \\ \bar{z} & 3.53 \\ \overline{-}(1) & 4.84 \\ \overline{-} & 6.03 \\ 1941-45 & 6.79 \\ 1936-40 & 6.55(6.94)^{(2)} \\ 1931-35 & 6.98 \\ 1926-30 & 6.72 \\ 1921-25 & 6.68 \\ \text { up to } 1921 & 6.98 \\ \end{array}$

Notes: (I) Although some births may occur to women aged 40-49, the numbers will be few, and the average figure shown here can be taken as the approximate level of their completed fertility.

(2) There appears to be no cause for the lower reported completed fertility of this cohort unless it is the fact that it was commencing child-bearing at the 1918 epidemic (i.e. it would then be about 19-23 years). The figure in brackets was obtained by graphical interpolation.

Table 12.4 shows that, for successive cohorts of currently married women who had completed their childbearing at the 1945 census (i.e. the women aged from 40-44 to $75+)$, the number of children born alive had remained at similar levels. Problems of recall among older women may have contributed to the lower levels at ages 60-64, 70-74 and 75+. Comparisons with other surveys are difficult to make because of the poor quality of these data, and thus no more will be done here than to suggest that these data show continuing levels of fairly high fertility since about 1910. 
In 1956, 'substitute' total fertility rates can be

estimated by applying Western Samoan, American Samoan and Fijian age-specific fertility rates to Maori women at each age-group. The results are shown in Table 12.5. Trom these 'substitute' rates, net reproduction rates were computed, and were compared with the replacement index calculated on the basis:

Child-woman ratio from enumerated data child-woman ratio from stationary population' which gives an approximate estimate of the N.R.R. Results for all three 'substitute' patterns of fertility were relatively close to the replacement index. As Western Samoan marriage patterns were similar to the Maori, ${ }^{3}$ their pattern of fertility was selected for use on earlier Maori populations.

The comparisons made with other populations, in Table 12.5, show that age-specific fertility rates for Maoris are very high. At older ages, the Hutterites have peculiarly high levels of fertility, so their rates are not strictly comparable.

3

The percentage never-married at each age-group of Maori and Western Samoan females in 1956 was as follows:

\section{Age-group}

15-19

$20-24$

25-29

30-34

$35-39$

40-44

45-49
Meoris

85.9
38.9
15.1
9.1
6.1
4.8
5.4

Western Samoans

82.9
37.3
16.2
9.8
5.6
3.4
3.8


Table 12.5: Maori Estimated Age-Specific Fertility Rates 1956, Compared with Rates for the Hutterites (per 1,000 females at each age-group).

\begin{tabular}{l|rrr|c}
\hline \multirow{2}{*}{$\begin{array}{l}\text { Age } \\
\text { Group }\end{array}$} & \multicolumn{3}{|c}{ Maoris, 1956} & Hutterites \\
& & & & \\
& $(1)$ & $(2)$ & $(3)$ & $(4)$ \\
\hline $15-19$ & 41.1 & 65.7 & 48.0 & 12.0 \\
$20-24$ & 312.1 & 338.4 & 319.0 & 230.0 \\
$25-29$ & 402.7 & 351.8 & 390.0 & 382.7 \\
$30-34$ & 251.5 & 254.0 & 245.0 & 391.1 \\
$35-39$ & 208.3 & 175.2 & 210.1 & 344.6 \\
$40-44$ & 64.5 & 76.0 & 66.3 & 208.3 \\
$45-49$ & 24.3 & 23.0 & 19.8 & 42.1 \\
\hline Total & 6.5 & 6.4 & 6.5 & 8.1 \\
Fertility & 6.5 & \\
Rate(5) & & & \\
\hline N.R.R. & 2.84 & 2.79 & 2.82 & \\
\hline
\end{tabular}

Maoris: Replacement Index - 2.71

Notes: (1) Using American Samoan rates

(2) Using Fijian rates (i.e. indigenes).

(3) Using Western Samoan rates.

The age-specific rates of each of these 'substitute' populations have been applied to the Maori females at each age-group to determine expected births at each age-group. These expected births are summed and the factor actual births is obtained. expected births

Estimated age-specific rates are calculated by multiplying the age-specific rate of the 'substitute' population by this factor.

The rates for these Pacific populations were obtained from Dr N. McArthur (personal communication), to whom grateful acknowledgement is made.

(4) Source: p.16. Eaton, Joseph W. \& Mayer, Albert J. (1954): Man's Capacity to Reproduce: The Demography of a Unique Pop., Glencoe, III.

(5) $\sum\left(\frac{B}{F_{x}}\right) \times 5$. As is customary, this rate is here per female, instead of per 1,000 females. In a 'stable' population the total fertility rate should also measure 'completed family size'. 
By applying the estimated age-specific rates to the mid-year population at each quinquennial age-group, estimated general fertility rates and net reproduction rates were obtained for 1945 and for 1936. These are presented in Table 12.6. They are close to the observed general fertility rates, to the replacement indices and to a 1936 net reproduction rate calculated, by some indirect methods, for the Maoris by Glass. 4 These estimated rates show that, in all probability, the Maoris had had high age-specific fertility rates at least from 1936, if not earlier.

Table 12.6: Estimated Net-Reproduction and Estimated General Fertility Rates compared with Replacement Indices and General Fertility Rates calculated from Published Data, 1936 and 1945

\begin{tabular}{llccc}
\hline Year & N.R.R. & $\begin{array}{c}\text { Replacement } \\
\text { Index }\end{array}$ & $\begin{array}{c}\text { Estimated } \\
\text { G.F.R. }\end{array}$ & $\begin{array}{l}\text { G.F.R. calculated } \\
\text { from published } \\
\text { data (Taken from } \\
\text { Table }\end{array}$ \\
\hline 1936 & 2.12 .2 above) \\
1945 & $2.39^{(2)}$ & 2.09 & 208 & 207 \\
\hline
\end{tabular}

Notes: (1) Calculated by applying the estimated 1956 age-specific rates to the 1945 and 1936 female age-distributions. Survivor-years were those from life-tables computed by the writer.

(2) An N.R.R. for 1936 of 2.24 is given on p.69. Glass, D.V. (1945): "The Maori Pop.", Eugenics Rev., vol.37, April 1945-Jan.1946. pp.67-70.

Estimated and observed data point to one conclusion --Maori fertility has been at high levels, at least since 1926. What are the factors which are related to these high levels of fertility?

\section{Factors Related to High Levels of Fertility}

The high current crude birth rates suggest that the Maoris are just as fecund as any other ethnic group; that is, 
natural sterility is anfrequent among Maoris as among any other population. However, there is a direct link between the incidence of venereal diseases, and the prevalence of sterility and high still-birth rates. As was discussed in chapter section 5 , levels of general morbidity may be related to levels of foetal loss. These factors were probably of significance during the nineteenth century, but during the twentieth century their importance may have declined. Furthermore had venereal diseases been at all common in the twentieth century, there would have been a decrease in their effect with the improved diagnostic and curative measures introduced since World War II.

Induced abortion was known to the Maoris, and appears to have been practiced in the ninteenth century. Redently, there is little evidence from anthropological studies of birth-control by this method, although the Beagleholes noted its occurrence in a community they studied in the early 1940s. 5

The effect of other 'traditional' methods of family limitation, such as taboos on intercourse during lactation and coitus interruptus, cannot be gauged. The only reference to these methods is that Biggs cited that coitus interruptus was advocated in the 1920 s by some older men to younger men. 6 'Modern' methods of contraception do not seem to be used, although Maoris have heard of them, are sometimes interested in them, but do not possess detailed knowledge. At a recent, fairly sophisticated conference of young Maoris, discussion of family planning was "clearly an embarrassment to some women delegates."7

Б.p.80 Beaglehole, Ernest \& Beaglehole, Pearl (1946): Some Modern Maoris, Wellington. 6 .

p.21 Biggs, Bruce (1960): Maori Marriage, Wellington p.152. Pearson, Bill (1962): "N.Z. Since the War: 7. The Maori People", Landfall, vol.16, no.2, June. pp.148-80. See also Beaglehole \& Beaglehole (1946): pp. 78-80 who note religious influences (there are quite a number of Catholics in the district they studied), ignorance and (important in the 1940s) the "high cost... in relation to the usual plane 
However, current evidence suggests that there has been a slight change of attitude, and that there is a potential for radical reforms, at least among younger women. In 1962, at a conference organised by the Auckland University Council for Adult Education, lectures were given on the subject of birth control by medical practitioners and others. It is most significant that this conference took place on the East Coast, a region in which a number of modern rural reforms have been initiated. Dr. Joan Metge, an anthropologist who was present, felt that there was considerable interest in the lectures and the subsequent discussions, and that this could lead to an increase in the practice of contraception. Furthermore, Dr. Metge has gained the impression from her field work that there has been an increase in the use of contraception among Maoris in the Auckland urban area. 8

Evidence collected by anthropologists shows that Maoris have an ambivalent attitude towards desired family size. Briefly, it is that Maori women see a need to limit their families, particularly in order to provide equal opportunities for each child. Maori families are more often likely to be poor than are non-Maori. However, desired family size bears little relationship to the actual size, extra children being accepted with a feeling of inevitability. Moreover, there are very strong motivations to have children, and even a large family. Childless married women are held in some degree of pity, and sometimes contempt, while women with large families appear to be held in high regard, particularly if none of their children has died. It is felt 7 (Cont'd) of Maori living..." as factors which inhibited the use of contraceptives; p.50 Hawthorn, H.B.(1944): "The Maori: A Study in Acculturation", Amer. Anthropologist, New Series, vol.46, No.2 (Memoir); and, Ritchie, Jane (1957): Childhood in Rakau: The First Years of Iife, Vic.Univ.Dept. of Psychology Publications No. 10, Years of Life, Dr A.J. Metge, who worked in a rural community near Hawthorn's, reports that, while roughly the same situation occurs there today as described by Hawthorn or Ritchie, younger women are interested in birth-control methods. However, in 1955, there was no apparent change in the size of families (Personal Communication). 8

Dr.A. Joan Metge (Personal Communication). The lectures and discussions are contained in "Data Papers \& Conference Agenda", Tairawhiti Regional Maori Leadership Conference, Ruatoria, 19th22nd 0ct.1962; and, Report of Regional Maori Leadership Conference Ruatoria, 19th-22nd 0ct. 1962, Auckland (Cyclostyled). 
that children cement a marriage, and for a woman to avoid pregnancy would be an act of selfishness towards her husband. 9 In cases of economic hardship children may be adopted by relatives. More commonly, adoption is desired by grandparents, or childless relatives, who request, or even demand, that parents relinquish one or more of their children. Where desertion takes place, or where a child is 'illegitimate' - in the sense that it was conceived as a result of a temporary union - and the father is unknown or unwilling to assume responsibility for it, the child will be adopted. Most importantly, no stigma seems to be attached to such a child today. ${ }^{10}$ It is usual for adopted children to know their biological parents, and they may visit them quite frequently. Often, arrangements for adoptions are made shortly after parturition, now most commonly after the mother returns from hospital. ${ }^{11}$ Previously, adoptions were not legally binding, but today they are frequently undertaken as full legal measures in order to give the guardians the right to collect the child's family benefit payments. Therefore, Maoris do not appear to have a strong desire to limit their families, nor in general, do they undertake measures of family limitation at present.

It must be noted here that this reluctance to practice contraception does not seem to stem from religious prohibitions, at least for the majority of Maoris. As is shown in Appendix A, Maori religious adherence differs in many respects from non-Maori. But the proportion belonging to the Catholic faith is similar for

9 Beaglehole \& Beaglehole (1946): pp.80 \& 87; Hawthorn (1944): p.50; and, Ritchie, Jane (1957): pp.41-43.

10 Beaglehole \& Beaglehole (1946): p.52. Biggs (1960): p.21, notes that, traditionally, there was a stigma attached to this status.

11

Ritchie, Jane (1957): p.61; and, Beaglehole \& Beaglehole (1946): pp.90-9l who discuss the frequent reluctance of parents to give up a child for adoption. 
both groups. It seems that Maori religions, such as Ringatu and Ratana, as well as the Church of Latter Day Saints (Mormons), whose New Zealand membership is chiefly Maori, do not specifically prohibit contraception.

Small families may be associated, at least in the minds of older Maoris, with the earlier period of population decline and of relative poverty, and thus there is some feeling that family limitation "might not in the long run prove to be of benefit to the race". 12 But this view may soon disappear. The older cohorts, composed of persons who can remember (or who pretend to remember) conditions at the end of the nineteenth century, are rapidly diminishing. They are being replaced by younger cohorts of persons who recognise that child-bearing and raising are far more efficient today -- there is less foetal, infant or childhood loss of life.

Early marriage of females appears to be a consistent pattern throughout the period for which there are census data on marriage (see below). Thus, celibacy is almost certainly not resorted to for purposes of family limitation. 13

Early marriage, with no family limitations, gives rise to a higher general fertility than marriage at older ages. However, between puberty and late adolescence --- about 19 or 20 years of age --- there is frequently a period of low fertility, even in societies where adolescent marriages or pre-marital intercourse

\section{2 "Data Paper \& Conference Agenda", Tairawhiti Regional Maori Leadership Conference (1962): Te Araroa Health Report.}

13

cf. Lorimer (1954): p.107. 
Tablal2.7 : Proportions in Various Marital-status Groupe, 1926-1956 (fomales on 17)

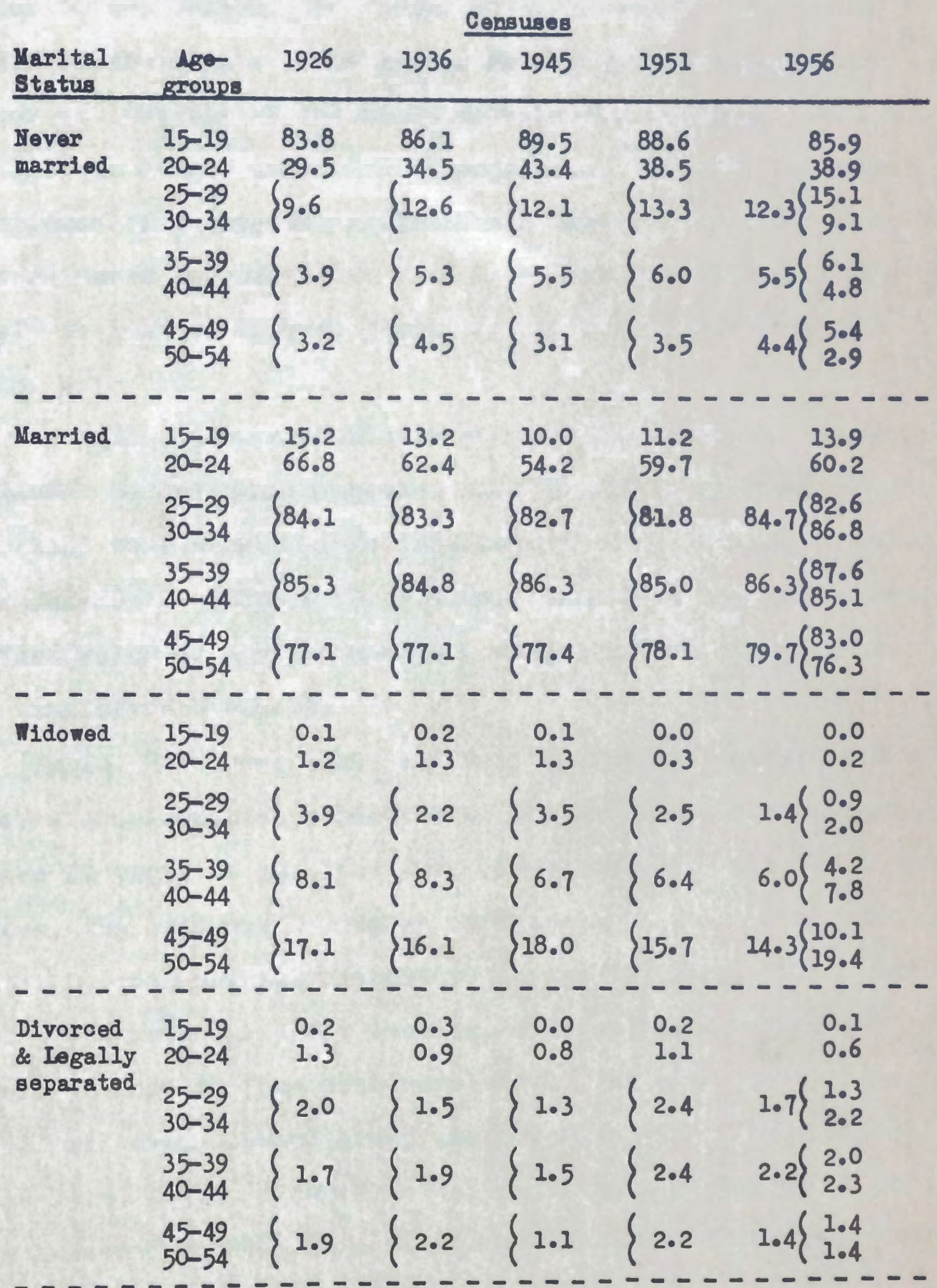

Note: 1. This table does not show a small percentage of not spectifled cases. 
are common. Furthermore, if conception occurs during late adolescence, there is a greater likelihood of injury or death, either to the mother, the foetus or the neonate. In turn, injury to the mother could impair her health and reduce the number of live births she might have in the future. When a still-birth occurs at the first pregnancy, there is a greater likelihood of subsequent still-births than if the first pregnancy is terminated successfully. 14 Thus, the age at marriage most likely to lead to maximum fertility is from about 19-20 to 24-25.

In Table 12.7, census data on marital status are presented. It cannot be determined whether women reporting themselves as 'married' were spouses in a 'registered' or a 'conjugal' union (see Chapter 2, Section 5). Thus, these data have to be adopted at face value as a measure of the number of 'marital unions' at the time of each census.

Table 12.7 shows that, at every census for which there are data, a considerable proportion of the Maori women were married before 20 years of age, and over 50\% by age 24. At the 1956 census, the only one for which data are available on marital status by quinquennial age-groups beyond 25 years, $90 \%$ of women aged 30-34 were currently married, widowed, or divorced or legally separated (the ever-marrieds). At ages 35-44 and 45-54 this ever-married group was more than 95\% of the total. Table 12.8, which is based on the registration records of the only period for which data on age at the time of marriage are available, shows the same tendency.

\section{4} passim.Montagu, M.F. Ashley (1946): Adolescent Sterility, Springfield, Ill.; and, Sutherland, Ian (1949): Still-births, Their Epidemilogy \& Social Significance, Iondon. 
Table 12.8 : The Numbers and Proportions of Females Marrying at Various Ages, and the Median Age at Marriage for Males and Females, 1948-1951(1)

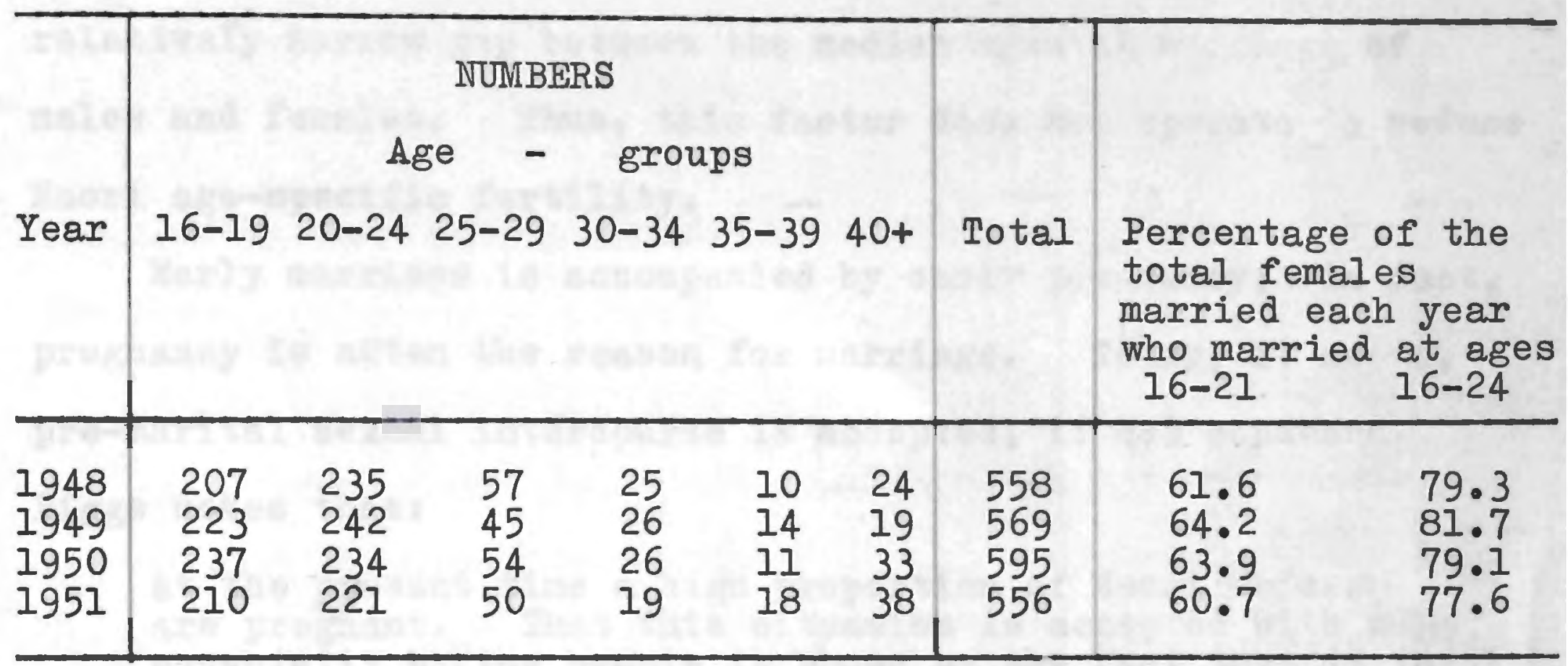

Median age at marriage : Males 23.77 - Females: 21.00.

Note: (I) These are the only years for which vital registration data on age at marriage and similar details are available. As many 'marriages' contracted in each of these years would be de facto (see Chapter 2, Section 5), the data in Table 12.8 cover only an unknown proportion of 'total marriages' and may or may not be representative.

In 1945 and 1951, the proportions never-married at younger ages were higher than at other censuses (Table 12.7). This was probably brought about by marriages being delayed because of the war or because of the migration of females to urban areas.

If there were a considerable gap between the median ages of males and females at marriage, the effect of the early age at marriage of females would be nullified to some extent. Caldwell has shown that, for rapidly growing stable populations with high mortality and which practice monogamy, the continuation of wide average age-differentials between husbands and wives leads eventually to an unbalanced sex-ratio at marriage ages. That is, there will be more females at age-group $x-n$ than available males at the age-group $x$, into which it is customary for females to marry. Unless a change in the marriage pattern occurs, there 
will be an increase in spinsterhood and a decline in age-specific fertility. 15 Table 12.8 shows that, for Maoris, there is a relatively narrow gap between the median ages at marriage of males and females. Thus, this factor does not operate to reduce Maori age-specific fertility.

Early marriage is accompanied by early pregnancy; in fact, pregnancy is often the reason for marriage. Today, it seems, pre-marital sexual intercourse is accepted, if not condoned. Biggs notes that:

at the present time a high proportion of Maori brides are pregnant. That this situation is accepted with some equanimity by the people is shown by the fact that it is not generally mentioned as an undesirable feature of Maori life. A number of social and economic factors operate here but the acceptance of the situation in spite of strong moral sanctions of christianity and European society in general suggests a carry over from the past.16

For those who are not pregnant, the absence of contraception and strong motivations to limit family size would ensure that a short period elapses between marriage and conception, for all but the unfecund.

The legal, but not the de facto dissolution of marriage is not particularly important until later in the reproductive period, as is shown in Table 12.7. Recently, there has been a decline in the proportion at each age-group who are widows, but at every census widows have been an important marital status group only at the older ages.

It has been noted already (Chapter 2, Section 5) that the census category 'married' probably includes both de facto and 'registered' marriages. But, what about the categories 'legally separated' and 'divorced'? The proportion of Maoris aged 16+

15

Caldwell, J.C. (1963): "Fertility Decline \& Female Chances of Marriage in Malaya", Popstud., vol.XVII, No. 1, July. pp.20-32. 16 Biggs (1960): p.2l. 
years in 1956 belonging to these categories was below that of non-Maoris, as is shown in the following table:

The percentage of Maoris and non-Maoris aged $16+$ in 1956 who were divorced or legally-separated

Males

Maoris

Non-Maoris

\section{1}

1.9
Females

1.2

2.1

It is probably that, whereas the group 'married' includes de facto unione, the group 'divorced' or 'legally separated' includes only those persons whose de jure status has been correctly recorded. Thus, census fligures probably underestimate the instability of Maori marriages. 17 Their comments refer to all relatively long-term unions and thus probably cover dissolutions of both de facto and registered unions. Moreover, it is likely that field observations will uncover facts, which have not been recorded in the census.

If Maori unions are unstable, levels of fertility could be affected as has been shown for Jamaica. There, the period spent between unions at the most fecund age-groups lowered agespecific fertility. 18 However, for Maoris this does not seem as significant a factor for three reasons:

(a) First marriage, whether registered or de facto, is an important event in contemporary Maori society. Certain aspects of the wedding ceremony and reception, as commonly practiced by European ${ }^{19}$ New Zealanders, have achieved an important role in

17 17 p.168 Metge, A. Joan (1957): "Marriage in modern Maori society",
Man Vol. IVII, Article 212, Nov. pp.166-70; Beaglehole \& Beaglehole (1946): p.54.

18

Blake, Judith (1955): "Family Instability \& Reproductive Behaviour in Jamaica", 19

Used here to refer to non-Maoris of European descent, mainly, of course, of British descent. Thus, most social customs of Europeans New Zealanders are close to British models. 
Maori weddings, which do, however, have some differences. One difference, for example, is the tomo or betrothal ceremony, when the woman's kin are visited by the man's for a 'conference', during which the woman's kin may pretend to be against the match. The extended family usually assists in the arrangements and financing of the wedding, not just the bride's parents. Today, weddings may be contracted among kinsfolk and within limits previously prohibited, such as between first cousins; alternativelj exogamous marriages are becoming more common, particularly in urban areas. Such breaks with traditional prohibitions are not illegal, so that couples who do not marry with the approval of kinsmen may contract a legal marriage. "A marriage once legally established secures acceptance from kin, if not their blessing". 20 Thus, with the social significance of wedding ceremonies, and the occasional use of registered marriages as a lever to force acceptance of a disapproved union, legal first marriage has become relatively common. Moreover, registered marriage must give some stability to the union for a reasonable time, and this is likely to coincide with the most fecund portion of a woman's reproductive life. As was shown above, the majority of registered marriages occur between late adolescence and 25 years of age. (b) The Maori community has accepted marital instability, but places some sanctions on second unions particularly if one spouse is already a partner in a registered marriage. The sanctions take the form of disapproving of those which are temporary, or which "offend the Maori sense of propriety"。2I

(c) The parenthood and rearing of 'illegitimate' children may not bar a woman from a subsequent marriage or union. 22

20

Metge (1957): p.167. For details of tomo and marriage ceremonies etc. see p.3. Metge, A. Joan (n.d.): "The Nature and Functions of the Hui...", Maori Society Today, Lecture 5, Council of Adult Education, Auckland Univ. (Cyclostyled). Bisgs (1960): p.26 gives figures on exogamy and endogamy from a sample survey he took on the East Coast.

21 
In strictly legal terms illegitimacy appears to be

very frequent. This can be estimated as follows :

(1) Prior to 1962 Maori births were not included in the figures on ex-nuptial births.

(2) Since January 1962, the marital status of both Maori and non-Maori mothers of live-born infants at time of tegistration has been recorded.

(3) Since this date ex-nuptial births have risen very suddenly.

(4) Thus, if the average annual number of ex-nuptial births in the last 2 years prior to this change (1960-61) are substracted from the average annual number in 1962-1963 the difference should, in theory, approximate the number of Maori ex-nuptial births.

(5) The estimated annual number of Maori ex-nuptial births was divided by the total average annual number of Maori live-births of the period 1960-63. The proportion born ex-nuptially was estimated to be 30.4 per cent.

It is obvious that a strictly legal definition has little meaning in Maori communities. Maoris must have a somewhat different concept of illegitimate births;probably, they differentiate between the offspring of temporary long term unions. They probably comment most adversely about births occurring prior to first marriage. Thus paragraph (c) above refers to the offspring of temporary unions.

The high fertility, which has been a characteristic of the Maori population for at least the period since 1926, results, undoubtedly, from the social factors and the methods of family formation discussed above. Almost every factor operates towards high nuptial and ex-nuptial fertility, the exception being a recent trend of urbanisation. This last factor will be discussed in the next section. 


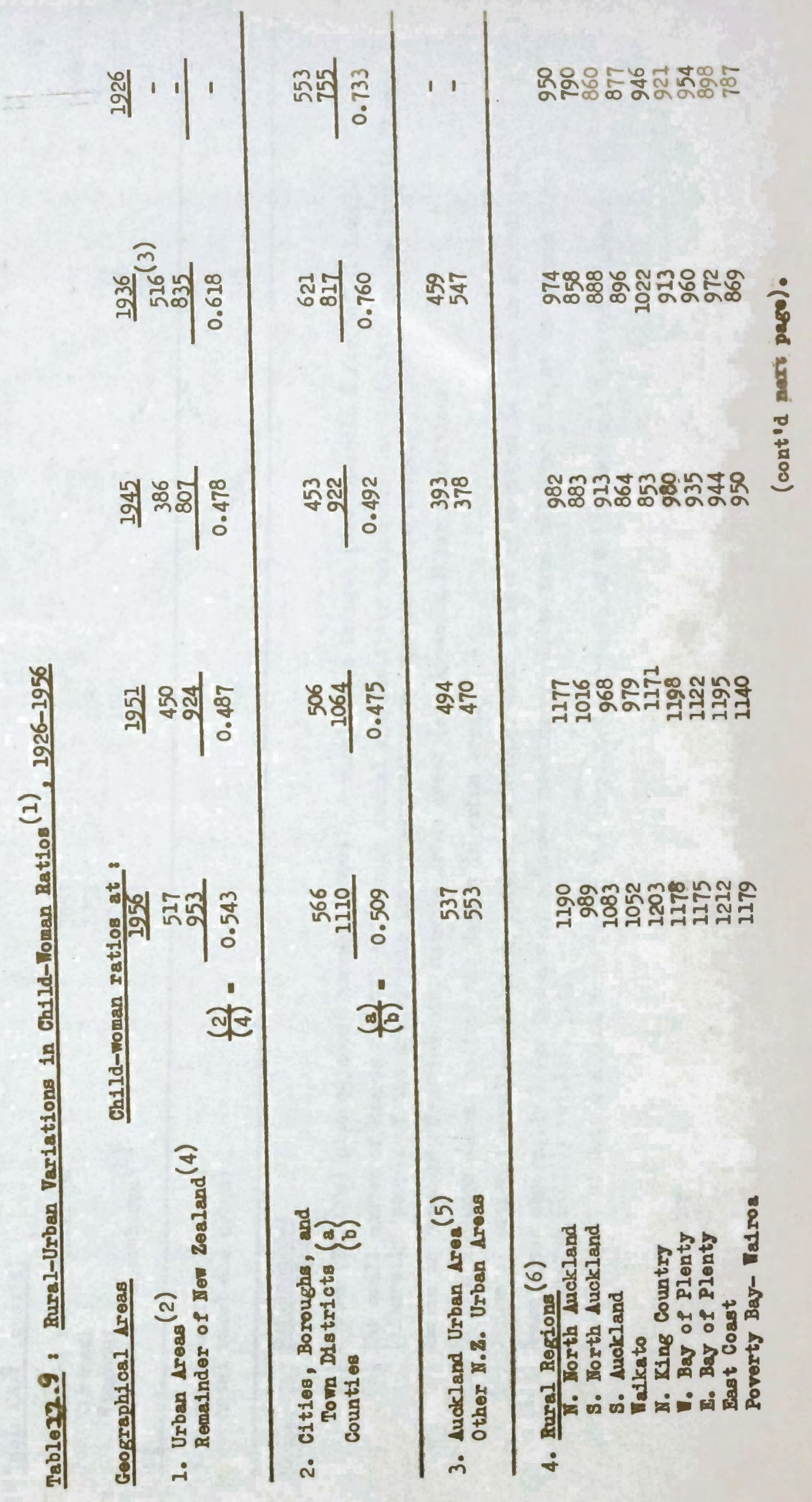





\section{Differential Fertility}

The child-woman ratios in Table 12.9 show that urban fertility is at lower levels than that for every rural region. Unfortunately, it is impossible to obtain a continuum from completely rural areas to the largest urban areas. The areal breakdown of New Zealand census data (etc.) is discussed in Appendix B. In Section 1 of Table 12.9 the 'urban areas' defined there are contrasted with a category the (Remainder of New Zealand). In Section 2 of Table 12.9, the boroughs, cities and town districts, already included in the 'urban areas', are added to other boroughs (etc.) and are contrasted with 'counties'. The Category 'counties' includes the portions of rural-urban fringe counties which were included in the 'urban areas' tabulated in Section 1 of Table 12.9. Thus, the categories are not mutually exclusive. However, the urban areas in Section 1 of Table 12.9, have lower child-woman ratios than the broader urban category 'boroughs and cities, etc.' used in Section 2. This suggests that, were a more satisfactory breakdown available, the following differences would occur: (I) The highest child-woman ratios would characterise the fully rural counties. (2) There would be intermediate values for the boroughs and town districts.

(3) The lowest child-woman ratios would occur for the population of the urban areas.

Prior to the 1939-45 war, the disparity between rural and urban ratios was not as large as at the 1945 and 1951 censuses. Prior to the war, the tangata whenua (literally, 'people of the area') made up a larger proportion of the few Maoris in urban areas and boroughs at that time than they do now. In the latter period large numbers of single women have entered urban areas in search of work. ${ }^{23}$ The fertility patterns of the tangata whenua would more likely have resembled rural

\section{3}

The following data are from passim. Pool, Ian (1961): "Maoris in Auckland: A pop.Study", J.P.S., vol.70,No.1, March. pp.43-66. 
fertility patterns than would those of migrants.

By 1956, the gap between the rural and the urban childwoman ratios had diminished, although there was still a considerable difference between their general fertility rates which are show in Table 12.10.a.

Table 12.10 : Rural-Urban Variations in General Fertility Rates Table 12.10a.: 1956

$$
\begin{aligned}
& \text { Urban areas (2) } \\
& \text { Remeinder of N.Z. : } \begin{array}{l}
131.6 \\
244.9
\end{array} \\
& \text { - - - - - - - - - - - - - - }
\end{aligned}
$$

Notes: (1) Births averaged for a 3-years period around the census. Females aged 15-44 at the census.

(2) For definitions of these categories see notes(2) and (4) to Table 92.9 ; and Appendix $B$.

Table $12.10 b: 1961$ (1)

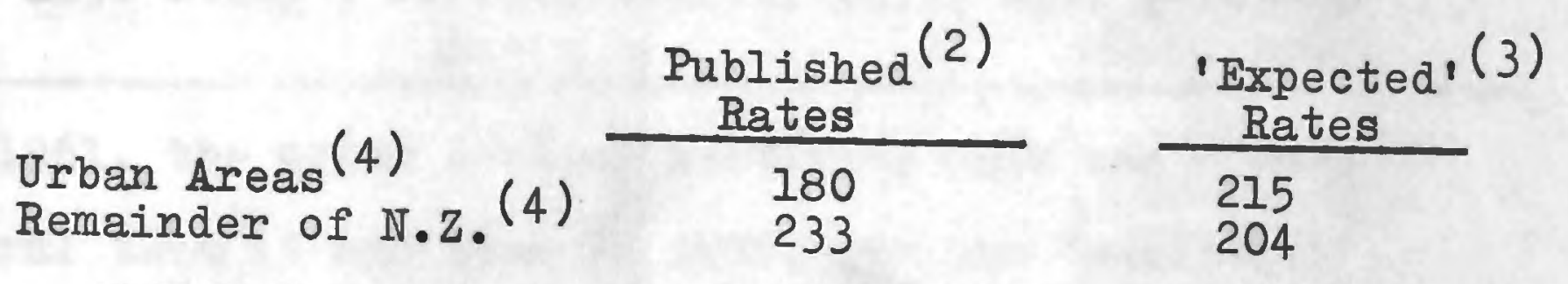

$--------------$

Notes: (1) $\mathrm{B}^{1961}$ only. Females aged $15-49$ at the census.

(2) $\frac{B^{1961}}{1961}$

$\mathrm{F}_{15-49}$

(3) Calculated by applying estimated age-specific rates ( Table 12.5) to the females at quinquennial age-groups to give expected births. G.F.R. was then calculated as shown in note 2 .

(4) See notes (2) and (4), Table 12.9

In 1956 for Auckland in particular, it seemed that migrants were marrying other migrants and were settling in the urban sreas. Families were moving to the outer suburbs from the central city, where they were being displaced by younger in-migrants. Consequently, as is shown in Table 12.11, outer suburban child-woman ratios in Auckland were higher, at the 1956 census, than those for the inner city. It is in the outer suburbs that urban ratios most closely approximate rural ratios, and least resemble non-Maori urban ratios. 
Table 12.11 : Child Woman Ratios, Auckland Urban Area, 1956

Section of the Urban Area

Ratio

Inner City

Non-Maori

336

Maori

Inner Suburbs

Non-Maori

Maori

Outer Suburbs

Non-Maori

Maori

Rural-Urban Fringe Counties

Non-Maori

Maori

Total Auckland Urban Area

Non-Mari

Maori

Source: pp. 51 \& 64. Pool, Ian (1961): "Maoris in Auck.: A Pop. Study", J.P.S., vol.70, No.1, Mar. pp.43-66

By 1961, the urban general fertility rate was closer to the rural than it had been in 1956, but the 'expected' rate, based on national estimated age-specific rates and presented in Table 12.10b., was above the 'published'. By contrast, the rural 'expected' rate was below the 'published'.

Urbanisation is increasing at a rapid rate, which is shown, for example, by an increase in the proportion of Maori females aged 15-44 residing in urban areas from 15.5 percent (1945) to 23.0 percent (1956). The maintenance of rural-urban differences in child-woman ratios could thus be crucial in reducing Maori fertility. This will depend on the level of outer suburban fertility, for it is here that a growing population of the young Maori families live.

The rural-urban differences in both the child-woman ratios and the general fertility rates seem to result from differential marriage rates. Unfortunately, the only data on rural-urban differences in the proportions belonging to various maritalstatus groups aged $15+$ are not very recent. Because of the areal breakdown that was used, the data on marital status at 1936 and 1945 
given in Table 12.12, have more application to the problem than those of 1926. However, the proportions never-married in urban areas may have been lower in 1936 than more recently, because of the greater importance in 1936 of tangata whenua whose age-sex structure would more closely resemble that of rural Maoris than of migrants. As was shown in Table 12.7, the proportion of women who were never-married was higher in 1945 than more recently, for the younger age-groups. This proportion would probably have been highest in the urban areas. Thus, 1945 data for urban areas give proportions for never-married females which may be higher than at recent periods.

Table 12.12 : Rural-Urban Variations in Marital Status, Females, 1926-1945 (Age-group 15+).

\begin{tabular}{|c|c|c|c|c|}
\hline Year & $\begin{array}{l}\text { Never- } \\
\text { Married }\end{array}$ & Married & $\begin{array}{l}\text { Iegally Widowed } \\
\text { separated } \\
\text { and } \\
\text { divorced }\end{array}$ & $\begin{array}{l}\text { Not } \\
\text { specified }\end{array}$ \\
\hline
\end{tabular}

\section{6}

Boroughs

$\begin{array}{lrrrrrr}\text { cities(etc)(1) } & 30.9 & 54.4 & 1.7 & 11.8 & 0.9 & 99.7 \\ \text { Counties (2) } & 19.9 & 66.3 & 1.3 & 11.6 & 0.9 & 100.0\end{array}$

\section{6}

$\begin{array}{lllllll}\text { Urban areas(3) } & 29.2 & 57.8 & 2.3 & 10.4 & 0.3 & 100.0\end{array}$

Remainder of

$\begin{array}{lllllll}\text { N.Z. (4) } & 23.3 & 64.1 & 1.3 & 10.5 & 0.5 & 99.7\end{array}$

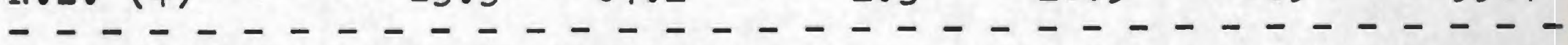

\section{5}

$\begin{array}{lllllll}\text { Urban areas(3) } & 39.8 & 49.7 & 2.3 & 8.1 & 0.1 & 100.0\end{array}$ $\begin{array}{lllllll}\text { Remainder of } & & & & & \\ \text { N.Z. (4) } & 24.7 & 64.2 & 0.7 & 10.0 & 0.2 & 99.8\end{array}$

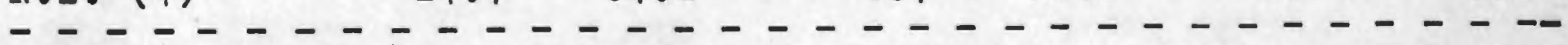

Notes: (1) N.Z. minus Counties, thus wider in scope than urban areas.

(2) Counties only thus narrower in scope than (4).

3) See note (2), Table 12.9

(4) N.Z. minus urban areas. See note (4), Table 12.9 


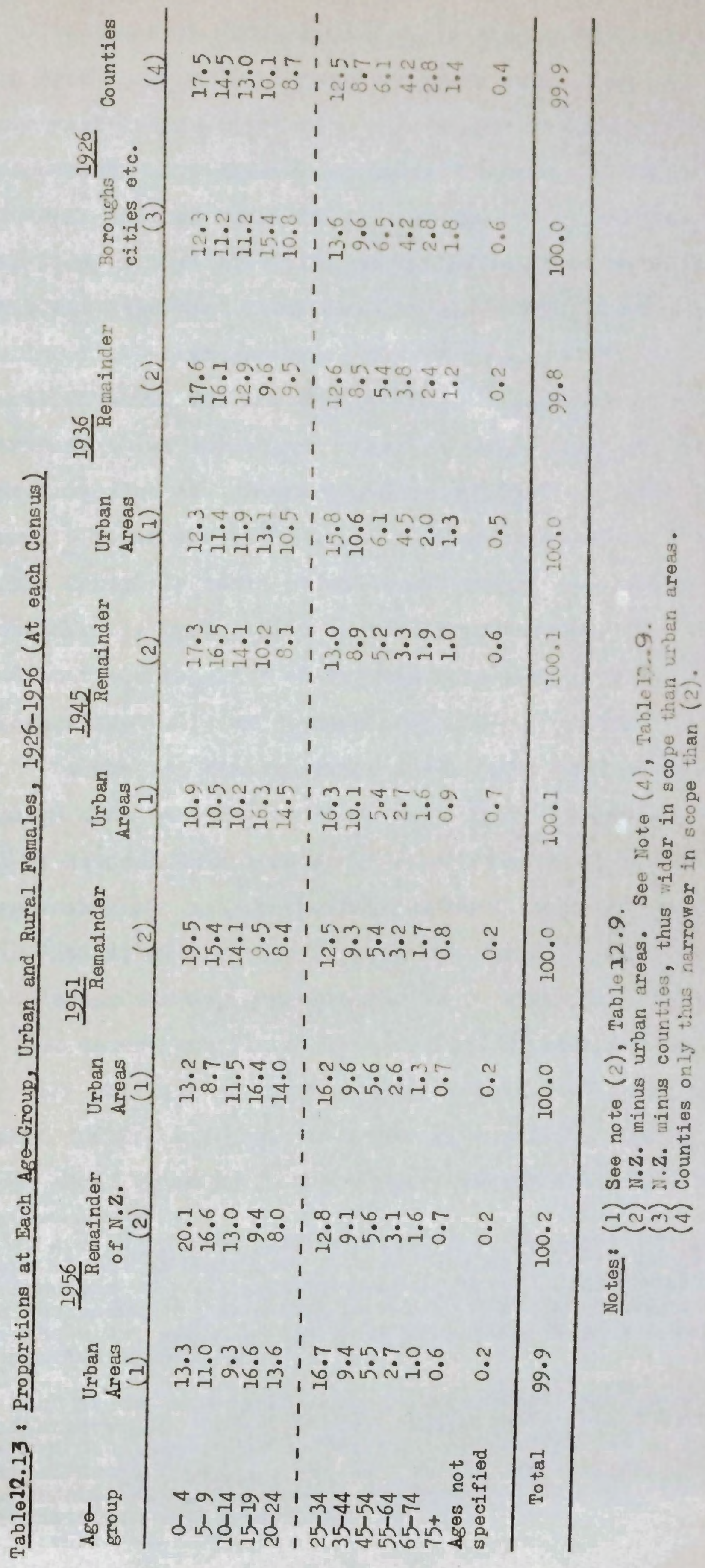

419 
Table 12.13 shows that a greater proportion of urban females are aged 15-24 than is found in rural areas. At this age never-married females are a more important marital status group, proportionately, than older ages. Thus, a higher proportion of urban than of rural females belong to an age-group at which marriage is less likely to be the dominant pattern. This does not mean that urban females aged 15-24 remain un-exposed to the risk of pregnancy. Instead,it is likely that some unmarried women, who conceive in urban areas, return to give birth to their children in rural areas, where opportunities for adoptions and assistance would be greater. In this case, rural G.F.R.s and child-woman ratios would be inflated, while urban fertility would be under-estimated. However, there is a considerable probability that this pattern may be changing, and that the majority of infants conceived in urban areas, whether nuptially or ex-nuptially, are born there. 24

Because of Western experience, urbanisation is often looked upon as a factor which will cause a lowering of fertility. 25 It is assumed that this decline is effected by the increased accessibility to agencies interested in programmes of family limitation, by a change in both the standard and style of living with urbanisation, and by a desire to limit families because cities do not provide as satisfactory an environment in which to rear children as rural areas. Indeed, the only low rates for Maori fertility appear to be among Maoris in urban areas. Yet, this could prove to be a temporary factor resulting from the

${ }^{24}$ Dr A.J. Metge, the anthropologist who has done much fieldwork in the Auckland urban area, feels that "In my experience, the number of girls who go home to have illegitimate babies is decreasing -- so often they have parents or close relations in the city, and more and more are going to city homes for unmarried mothers". 25

Here is one high growth population where rural-urban differences in fertility seem significant. See Robinson, Warren C. (1963): "Urbanisation \& Fertility: the Non-Western Experience", M.M.F.Q., vol.X工I, No.3, July, pp.291-308. This paper challenges the common assumption about the effect that urbanisation has on declines in fertility. 
higher proportions of single females aged 15-24 in the urban areas. Moreover, the experience from outer suburban suggests that among Maoris married and settled in urban areas, childwoman ratios are reaching levels not unlike those of rural Maoris. But conclusions are hard to draw, for the inner-outer suburban differentiation used here is based solely on the presumption that outer suburban Maoris are married and settled, while those of the inner city are single, recent migrants.

\section{5 . Conclusion}

Maoris accept high fertility and large families as inevitable. However, at present the whole fabric of Maori life is being altered by rural-urban migration, so that any long-term declines in fertility could well occur in urban areas, for the following reasons :

1. Urban Maori parents are in the early phases of family formation, and thus it is possible that completed fertility will be lower than that of rural Maoris.

2. It is in the urban areas that there is the greatest opportunity for married women to find work, and this may bring about a desire to limit the size of their families, or to complete child-bearing at an earlier age than would be the case in rural areas.

3. If migration is selective, the females entering urban areas may be those who wish to avoid early marriage. 4. The attraction of material gain which, initially, brought many of these young Maoris to the cities as migrants, could create a desire to limit the sizes of their families, so that a higher standard of living might be achieved.

5. It is in the outer suburbs and the rural-urban fringes that there is likely to be the most intimate contact between Maoris and non-Maoris of approximately equal status. These are new suburbs whose non-Maori populations are young and relatively 
homogeneous in terms of social class. It is true that the non-Maori child-woman ratios are high in these areas (see Table 12.11), but these non-Maoris are just commencing their married life. It is also true that non-Maori fertility has been relatively high over the last fifteen years, which has been

a result of changes in the age at marriage, proportions remaining single, etc. But, if past trends are followed, 26 there is a likelihood that the fertility of the younger marriage cohorts living in outer suburbs will decline once they reach higher marriage durations. The attitudes of Maori parents to family limitations may well be affected by the patterns of childbearing evident among their neighbours. However, in the balance, the Maori ethos is against family limitation at present. Nowhere should this be more true than in the isolated rural regions. Yet, the most recent evidence discussed above shows that there is a potential for change even there.

Overt government intervention is unlikely, for it could be misconstrued as prejudice. Any legislation advocating family limitation would obviously be directed more at the high fertility Maori population than at the low fertility non-Maori. Furthermore, New Zealand is a pro-natalist country; welfare legislation is very heavily weighted towards aiding parenthood.

The next decade is extremely crucial for Maoris in every sphere of their existence. In the case of fertility, declines could occur. The alternative is a continuation of the low standard of living engendered by the twin factors of employment disabilities and the necessity for each householder to provide for a large family.

\section{6}

See Jacoby, E.G. (1958): "A Fertility Analysis of N.Z. Enon-Maori/Marriage Cohorts", Pop.Stud. vol.12, No.I, July. pp.18-39; and, Jacoby, E.G. (1961): "Some Demographic Observations on First Order Births in the Light of the Cohort Approach", Econ.Record, Sept. pp.308-319. 
CHAPTER THIRTEEN

Social and Economic Factors Interrelated with Population Growth, 1926 to the Present

\section{Introduction}

The previous chapters have shown that Maori fertility has been at high levels throughout the last four decades. Since World War II mortality has declined rapidly.

After adjustments are made for under-enumeration, it appears that annual intercensal rates of growth have accelerated consistently since 1926. These rates are given in Table 13.1. In the most recent quinquennia they have reached almost the highest recorded levels for 'closed' populations. ${ }^{1}$ However, the Maori population is not 'closed' in the strict sense of the word, for there is movement to and from the non-Maori population. Thus, if it were not for a movement away from the Maori population in the quinquennium 1951-56 the rate of growth would have been even higher.

Table 13.1 : Annual Intercensal Rates of Growth (\%'s)

\begin{tabular}{l|cc|cc}
\hline \multirow{2}{*}{ Intercensal Period } & \multicolumn{2}{|c|}{ Males } & \multicolumn{2}{c}{ Females } \\
\cline { 2 - 5 } & $(1)$ & $(2)$ & $(1)$ & $(2)$ \\
\hline $1926-1936$ & 2.6 & $1.6(3)$ & 2.7 & $1.7(3)$ \\
$1936-1945$ & 1.6 & $2.0(4)$ & 2.2 & - \\
$1945-1951$ & 3.1 & $2.6(4)$ & 2.8 & - \\
$1951-1956$ & 3.4 & - & 3.6 & - \\
\hline
\end{tabular}

Notes: (1) Published rates

(2) Adjusted rates (see Chapter Three)

(3) Allowing for 10\% under-enumeration at 1926

(4) Including troops overseas.

The most significant factor has been that the Maori population doubled in the period 1926-56. If it is assumed

1 The rates for other populations are given in Appendix D. 
that the 1926 population was under-enumerated this increase is not quite as large -- from 70,000 to 137,000 -- but is still extremely high.

In this chapter an investigation will be made of the social and economic factors inter-related with this high population growth.

\section{Rural-urban migration and its Consequencies}

Throughout the period under review the Maori population was predominantly rural. A number of studies have analysed the problems of Maori mural life in this period. Their major findings are:

(1) The Maori rural population has been growing rapidly since 1926.

(2) The Maoris live in the more geographically isolated sections of the North Island, particularly the Auckland Province, away from major economic foci.

(3) Maoris have been predominantly engaged in rural occupations, mainly farming and farm labouring, for there are few other employment opportunities in these regions.

(4) There is under-employment and even unemployment in a number of these districts.

(5) Even when Maoris own and operate farms it is likely that, because of a number of factors such as the small size of their farms and their isolation, farm productivity and thus farm incomes will be low, by comparison with non-Maori farms.

(6) Rural standards of material comfort, including standards of housing, diet and clothing, are below the levels obtained by non-Maoris.

(7) For these reasons rural Maoris, including some landholders, have been forced to migrate permanently or seasonally, or to commute on a daily or weekly basis if some work is available in nearby areas (usually small towns). 


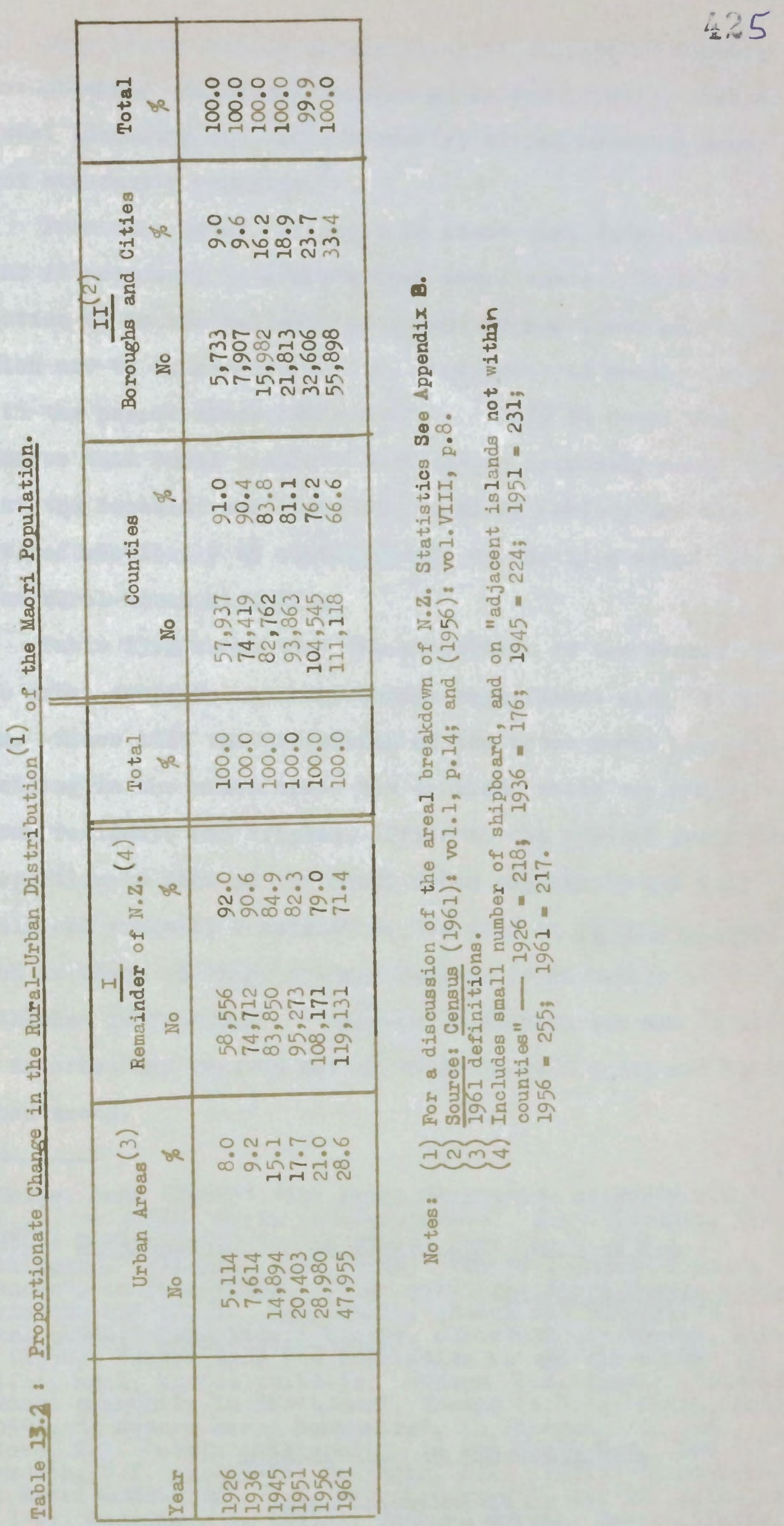


(8) Many Maoris unable or unwilling to migrate or commute have obtained additional sources of income locally, such as casual labouring and, more recently, social security unemployment and family benefits. 2

From this brief review it is clear that Maoris often find it necessary to migrate from rural areas. In this section it is the patterns of migration and their consequences which are to be considered. This analysis is mainly concerned with the period since 1945, for it is only in these two decades that rural problems have become extremely acute, and that the location and structure of Maori society has been altered drastically by social change of the type which results from rural-urban migration.

Table 13.2 shows that the proportion of the Maoris who are urban dwellers has only become significant since World War Two. Since 1945 the proportion of the total Maori population residing in the urban areas has doubled, while the number of urban residents has tripled. Prior to the war the number and proportionate size of the Maori urban population was very small and probably consisted in the main of tangata whenua, such as those of Okahu Bay and Mangere in Auckland; of Bethlehem in Tauranga; of Ngapuna, Whakarewarewa and Ohinemutu in Rotorua; and Porirua and Waiwhetu in Wellington and Hutt urban areas.

2 Metge, Joan (1952): "The Maori Population of North N.Z.", N.Z.G., vol.VIII, no.2, Oct. pp.104-24; p.43. Turbott, H.B. (1935): Tuberculosis in the Maori: East Coast of N.Z., Wellington, Belshaw, H.B. (1940): "Maori Economic Circumstances", in Sutherland, I.I.G. (ed): The Maori People Today, Christchurch; ch.II. Beaglehole, Ernest and Beaglehole, Pearl (1946): Some Modern Maoris, Christchurch: Frazer, Roger M. (1958): "Maori Iand and Population in the Far North", N.Z.G., vol.14, no.1, April. pp.19-31; Hohepa, P.W. (1961): 'Paerau: A Maori community in Northland', Thesis (A.U.); Booth, John (1959): "A Modern Maori Community", in Freeman, J.D. and Geddes, W.R. (eds): Anthropology in the South Seas, New Plymouth, N.Z. pp.235-45; McCreary, J.R. (196I): "Ruatahuna - A Maori Community", N.Z. Geog. Soc.Record, no. 32, July-Dec. pp.3-4; Rangihau, J. (1958): Ohakune Survey, Mao ri Affairs Dept. (cyclostyled). 
Table 13.3 shows the net increases and decreases for North Island and South Island regions in the intercensal period 1956-61. In the North Island a remarkably clear pattern seems to emerge, but a qualification is necessary. The published data on the numbers at each age-group for the counties from which the rural regions are formed are for decennial age-groups after 25 years of age, so that the type of analysis presented in Table 13.4 (below) cannot be undertaken here. An approximate idea of the volume of outmigration from rural regions can be obtained if it is assumed that the $20 \%$ rate of intercensal increase for the Maori population as a whole is the level of natural increase for these rural regions. Thus, any figure below $+20 \%$ indicates that out-migration may have occurred and has reduced the increase resulting from the surplus of births over deaths. This assumption is not entirely satisfactory because, even if age-specific fertility and mortality rates in rural areas are similar to those of the population as a whole, differing agestructures could result in differential crude birth and death rates, and thus in differential rates of natural increase. On the basis of this assumption it appears that the four rural regions in section 1 of Table 13.3, have lost a considerable proportion of their population by out-migration, for the reasons outlined above in section 2 of this chapter. These regions have lost population to other rural regions, and to cities, boroughs and town districts, including those close at hand, the figures for which are excluded from the rural regional totals. However, the new industries at Kawerau and Murupara may have reduced slightly the outward flow in the Eastern Bay of Plenty region, at least in Whakatane county in which these industries are located. There may even have been some in-migration to Whakatane from Opotiki county, also in this region, and elsewhere. Nevertheless, it must be noted 
Table 133 : Regional Differences in Increases and Decreases of the Maori Population, 1956-61 (Ranked according to \% gain or loss)

\begin{tabular}{|c|c|c|c|c|c|}
\hline Region & $1956^{\text {Numbe }}$ & | 1961 & $\begin{array}{l}\text { Differ } \\
\text { No. }\end{array}$ & ence & Maoris:- \\
\hline 1. Rural (North I.) & & & & & \\
\hline $\begin{array}{l}\text { N. North Auckland } \\
\text { East Coast } \\
\text { E.Bay of Plenty/2) } \\
\text { N.King Country } \\
\text { 2. Rural (Including rur }\end{array}$ & $\begin{array}{r}15,181 \\
8,692 \\
9,612 \\
7,044 \\
\end{array}$ & $\begin{array}{r}13,658 \\
8,513 \\
10,203 \\
8,189 \\
---1 \\
\end{array}$ & $\begin{array}{c}-1,523 \\
-\quad 179 \\
+\quad 591 \\
+1,145 \\
-0--\end{array}$ & $\begin{array}{l}-10.0 \\
-2.1 \\
+6.1 \\
+16.3[+4.9] \\
---0 .-\end{array}$ & $\begin{array}{r}.476 \\
.667 \\
.483 \\
.317 \\
-.-.-\end{array}$ \\
\hline $\begin{array}{l}\text { Wanganui (3) } \\
\text { Poverty Bay-Wairoa } \\
\text { Taranaki } \\
\text { W. Bay of Plenty (4) } \\
\text { Hawkes Bay-Wairarapa } \\
\text { Waikato } \\
\text { S. North Auckland } \\
\text { South Auck land (5) } \\
\text { Manawatu-Horowhenua } \\
\text { 3. Total North I. Rural }\end{array}$ & \begin{tabular}{|r}
4,867 \\
7,059 \\
4,234 \\
12,534 \\
6,154 \\
6,748 \\
6.411 \\
8,131 \\
3,427 \\
$(6)---1$ \\
100,134
\end{tabular} & $\left|\begin{array}{r}3,990 \\
7,047 \\
4,344 \\
13,558 \\
6,773 \\
7,622 \\
7,396 \\
9,925 \\
4,355 \\
----\mid \\
105,573\end{array}\right|$ & $\left|\begin{array}{r}-\quad 877 \\
-\quad 12 \\
+\quad 110 \\
+1,024 \\
+\quad 619 \\
+\quad 874 \\
+\quad 985 \\
+1,794 \\
+\quad 928 \\
---- \\
+5,439\end{array}\right|$ & $\mid \begin{array}{l}-18.0[-1.6] \\
-0.2 \\
+2.6 \\
+8.2 \\
+10.1 \\
+13.0 \\
+15.4 \\
+22.1 \\
+27.1 \\
------- \\
+5.4\end{array}$ & $\begin{array}{l}.173 \\
.419 \\
.104 \\
.286 \\
.127 \\
.146 \\
.085 \\
.102 \\
.055 \\
-.---- \\
.220\end{array}$ \\
\hline 4. South I. Rura] & 3,338 & 3,885 & +547 & +16.4 & .014 \\
\hline 5. South I. Urban ${ }^{(7)}$ & 1,907 & 3,246 & $+1,339$ & +70.2 & .007 \\
\hline 6. North I. Urban $(8)$ & 31,517 & 54,165 & $+22,648$ & +71.9 & .050 \\
\hline $\begin{array}{l}\text { 7. } \text { other (Shipboard } \\
\text { etc.) }\end{array}$ & 255 & 217 & -38 & - & .026 \\
\hline 8. New Zealand & 137,151 & 167,086 & 30,049 & +21.9 & .069 \\
\hline
\end{tabular}

Notes: (1) Figures in brackets [] refer to estimated changes.

(2) Taumarunui County absorbed Kaitieke County formerly in the Nanganui region.

(3) Kaitieke County lost to Taumarunui in the N. King Country region.

(4) The Maori population of Mangakino included in this region increased by 614 persons, 1956-61.

(5) Includes 845 Maoris in the rapidly growing township of Tokoroa.

(6) Includes 40 Haoris from town districts forming parts of counties and each containing less than 50 Maoris.

(7) \& (8) Includes cities, boroughs and independent town districts.

For a discussion of the areal breakdown of N.Z. Statistics see Appendix 8. The counties included in the various rural regions are tabulated in Appendix $C$. 
that Kawerau borough itself and Numpara Town district are excluded from the figure for the Eastern Bay of Plenty region. An administrative change has artificially raised the Northern King Country figures, the estimated increase being much smaller and indicating that out-migration has exceeded inmigration.

In the second section of Table 13.3 are the rural regions which include some rural urban fringes of cities, that is some of the counties in each region abutt cities and contain a 'suburban' population of commuters. The first five regions have probably lost some population by out-migration, but it is hard to determine whether the bulk of the migration has been to the nearby cities of Wanganui, Gisborne, New Plymouth, Rotorua, Tauranga, Napier and Hastings, and to boroughs close at hand, or whether most migrants left these areas altogether. Certainly, some out-migration would have been stemmed in the Poverty Bay-Wairoa, Western Bay of Plenty and Wanganui regions by the fact that Maoris commute daily to work in Gisborme, Tauranga and Rotorua, and Wanganui cities. But, the Wanganui and Poverty Bay-Wairoa figures are very low even after, in the case of Wanganui, adjustment is made for the loss of Kaitieke county to Taumarunui county in the Northern King Country region. A further factor in the Western Bay of Plenty has been the increase of the Maori population of Mangakino Public Works settlement, the Maori workers being drawn 'from almost every tribe in New Zealand, the largest groups being WaikatoManiapoto, Ngati Porou, and Ngapuhi, in that order...'.3 It is difficult to determine what has been the pattern in the Waikato where there are a variety of factors operating. For example, there has been an increase in the Maori population of Hamilton city's rural-urban fringes, there are some fairly long-established nucleated, Maori communities, such as Waahi pa on the outskirts of Huntly, and a factor of some importance Gerard and Ward, Marion W. (eds): N.Z's Industrial Potential, Auckland. pp.156-76. 
may even have been the establishment of a Mormon settlement and residential school near Hamilton, which has attracted Maoris from all over New Zealand. The most important nucleated settlement in the Waikato, Turangawaewae $\mathrm{Pa}$, which is the centre today of the King Movement, is in Ngaruawahia borough and thus is excluded from the rural Waikato region.

In all probability there have been significant increases resulting both from in-migration and natural increase in the last three rural regions in section 2 of Table 13.3, for those areas include rural-urban finges of Auckland, Wellington and Hutt cities and their neighbouring boroughs. There is a further factor in the case of South Auckland, where Maoris have been attracted to Tokoroa district in the Volcanic Plateau in which is located a pulp and paper mill, and to Pukekohe, 40 miles south of Auckland city where they work on market gardens. Despite the rapid growth of Whangarei urban area, the Naori population of adjacent Whangarei county has declined, and thus the growth of South North Auckland has resulted probably from the spread of suburban Auckland.

It is difficult to determine what has happened in the mural South Island but there has been a marked increase in the urban Maori population of this Island, undoubtedly because of in-migration probably from both the North Island and the rural South Island. Finally, but most importantly, natural increase and a very large volume of in-migration together have brought about the very rapid and very significant increase of Maoris in North Island cities, boroughs and independent town districts.

In summary Table 13.3 points to heavy losses of population in the more isolated rural regions where there are few opportunities for employment locally or by daily commuting and in which Maoris constitute a high proportion of the total population. By contrast, the cities, boroughs etc. and the 
rural-urban fringes, particularly of Auckland, Wellington and Hutt, have received migrants.

The data in Table 13.3 refer to counties, which have been contrasted with the administrative units of cities, boroughs etc., but there is a different areal breakdown in Table 13.4, which shows the age-distribution of migrants in 'urban areas', composed of cities and adjacent boroughs and rural-urban fringe sections of neighbouring counties. These migrants have moved out from the 'remainder of New Zealand', which includes all of the residual parts of the counties adjacent to cities, of the full counties and of the boroughs and town districts located outside the urban areas.

It is obvious from the previous discussion that urban areas attract a large proportion of the out-migrants from mural regions. By the use of census survival ratios a more detailed analysis can be made of this migration. Whangarei, Rotorua and Tauranga are excluded from the 'urban areas' and are included with the 'Remainder of New Zealand', because they were declared 'urban areas' only at the 1961 census and thus there are no comparable data for 1956. It is also unfortunate that the census survival ratio method measures only net intercensal migration, and in this case only from the 'Remainder of N.Z.' to 15 urban areas. Thus, migration from the country to townships and boroughs outside urban areas cannot be analysed, nor can migrations to 'rural' localities such as Mangakino, and finally no measurement can be made of the migrations of seasonal labour or of the movement to and from urban areas in intercensal years. 
Table 13.4 : Rural-Urban Migration 1956-61:

Estimated Number( (1) of Net In-Migrants

to Urban Areas (2) at Various Age-Groups

\begin{tabular}{crc} 
Age-group & Males & Females \\
\cline { 2 - 3 } $0-4(3)$ & 552 & 533 \\
$5-9$ & 641 & 760 \\
$10-14$ & 535 & 726 \\
$15-19$ & 1,346 & 1,453 \\
$20-24$ & 930 & 626 \\
$25-29$ & 333 & 317 \\
\hline $30-39(4)$ & 460 & 416 \\
$40-49$ & 258 & 295 \\
$50-59$ & 172 & 146 \\
$60-69$ & 46 & 66 \\
$70-79$ & 23 & 27 \\
$80+$ & 5 & -1
\end{tabular}

Net in-migrants $\quad 5,301 \quad 5,364$

Notes: (1) Estimated on the basis:

In-Migrants at age $\mathrm{x}=\left[(\right.$ urban $\left.) \mathrm{n}_{\mathrm{x}} \mathrm{P}^{1961}\right]-\left[(\right.$ urban $) \mathrm{P}_{\mathrm{x}-5}^{1956} \mathrm{x}$

$$
\left.\frac{(N \cdot Z)_{n} P_{x}^{1961}}{(N \cdot Z)_{n} P^{1956}}\right]
$$

where ${ }^{P} x=$ Population aged $x$ to $x+n$.

(2) At both dates excludes Whangarei, Tauranga and Rotorua, which were declared urban areas only at the 1961 census.

(3) In-migrants $_{0-4}=\frac{1}{2}$ (In-migrant) $\mathrm{F}_{15-49}^{1961} \times$ (urban)

$$
\frac{P_{0-4}^{1961}}{F_{15-49}^{1961}}
$$

and, male In-migrants ${ }_{0-4}=$ Total I-Mig I $_{-4} \mathrm{X}$ (N.Z.)

$$
\frac{B(m)}{B(m)+B(f)}
$$

(4) In 1956, there were no published data on quinquennial age-groups from 25 years on. Thus, decennial agegroups $25-34,35-44 \ldots 75+$ were brought forward to $30-39,40-49 . .80+$ at 1961 .

There are no questions on 'place of last residence' in the census and thus the only other way in which internal migration could have been estimated was by the use of lifetable survival ratios. In view of the unsatisfactory 
enumeration at ages 15-24, and the fact that no life-table was availble for 1961, it was preferable to use census survival ratios rather than life-table survival ratios. Assuming that age-reporting deficiencies were equally marked and that mortality was the same for both urban and rural populations, census survival ratios, based on the numbers recorded for each cohort of the Maori population as a whole at subsequent censuses, will be weighted by this factor of differing standards of cohort enumeration from census to census. Census survival ratios are calculated as follows:

$$
\frac{n^{P} x}{n^{P} x-5} \quad(N \cdot Z \cdot)
$$

This ratio is applied to the urban $n^{P_{x-5}^{t}}$ to determine an 'expected' urban population aged $x$ at year $t+5$. If age-group 10-14 (N.Z.) was accurately enumerated at the 1956 census, but if deficiencies then occurred at 1961 in the enumeration of this cohort at age-group 15-19, the survival ratio will be too low. This pattern of enumeration appears to have occurred. Thus, it is likely that too high an estimate of in-migrants, to urban areas, aged 15-19 will result, because in-migrants are assumed to be the residue after the expected $\mathrm{n}_{\mathrm{x}}^{t+5}$ is subtracted from the enumerated. However, the urban $\mathrm{P}_{15-19}$ is likely to be the most mobile and the most poorly enumerated section of the Maori $\mathrm{P}_{15-19}$, and thus this may counteract in part the over-estimate of in-migration resulting from the weighting of the survival ratio.

Probably, both the numerator and the denominator of the survival ratio $\frac{\mathrm{P}_{20-24}^{1961}}{\mathrm{P}_{15-19}^{1956}}\left(\mathrm{~N} . \mathrm{Z}_{\mathrm{.}}\right)$ are deficient, and thus there will not be an over-estimate of the number of in-migrants at age 20-24. Instead, there is likely to be an under-estimate because the urban $\mathrm{P}_{20-24}$ is also highly mobile and thus may be poorly enumerated. 
It is difficult to determine what is the effect of this method on the results for other age-groups, however a comment must be made about ages 0-4. To calculate the in-migrants at these ages it is assumed that the estimated in-migrant women in 1961 have lived in the urban areas and adopted urban fertility patterns for an average of 2.5 years per in-migrant woman, and that their urban offspring have been exposed to urban mortality risks. Thus, it would have been preferable to use the mean of the urban child-woman ratios for 1956 and 1961 to calculate in-migrants aged 0-4 at the 1961 census, in order to take account of changes in urban fertility and childhood mortality in the period 1956-61. However, agegroup 15-49 was available only for 1961, and thus the 1961 child-woman ratio was used here. It is difficult to determine what effect this has on the results.

If these assumptions are valid, then the following pattern characterises Maori rural-urban migration. Migrants to urban areas are, as is shown in Table 13.4, drawn very strongly from age-group 15-24, that is from school-leavers or from persons who have been employed elsewhere for short periods after leaving school and now are moving into urban areas. Females outnumber males, most noticeably at ages 15-19, and for them the migration may be of both the 'push-type' and the 'pulltype' -- 'push' in the sense that there are even fewer jobs in rural areas for females than males; 'pull' in the sense that the 'bright lights' of the city may be an attractive alternative to staying at home and marrying. For example, in the remote, rural village of Ruatahuna, McCreary found that over hallf of the women between 15 and 19 years were married, ${ }^{4}$ as against $14 \%$ for the Maori population as a whole

4 McCreary (1961): p.4. 
in 1956. For males, there are the altermatives of seeking local labouring jobs, moving to construction camps, engaging in seasonal work or migrating to the city. But, at age-group 20-24 male migrants outnumber female migrants, probably when they have ttried the other alternatives, found these to be unattractive, and have decided to opt for the city. At older ages there is less imbalance, so that family migration may be more important then. Generally, it appears that the migration has more of a 'push' form for males than for females, particularly for those males who must support a family .

The importance of this migration to urban areas can be judged from the fact that the 10,600 net in-migrants constituted over $6 \%$ of the total Maori population in 1961. It must be reiterated that these figures refer only to the net migration into urban areas for the intercensal period 1956-61. Under these circumstances the mobility of 15-24 year-old Maoris is astounding, for in 1961 these migrants constituted $18 \%$ of the total Maori population at ages $15-19$ and $11 \%$ of the total aged 20-24.

What of their contribution to the Maori urban population growth? These in-migrants contributed about $56 \%$ of the intercensal growth of the urban area Maori population, and constituted $22 \%$ of the Maori population of the urban areas in 1961. At the same census, the migrants made up $51 \%$ of the urban area population of ages $15-19$, and $27 \%$ of those aged 20-24. This change in geographical distribution has had three important consequences. Firstly, the Maori population is highly mobile, especially at ages 15-24, and will be for some time to come, probably at least until the Maori population's geographical distribution approximates that of the non-Maori. For Maoris this is not only a desirable alternative to remaining in rural regions, but is the only course open to 
them. Thus, in reference to Maoris and to New Zealand's overseas immigration, Woods made this highly relevant point:
We could be committing a supreme folly if
we pursued overseas immigration to the point of creating a racial problem of under-employed Maoris pent up in 'Maori' areas while immigrant labour filled the vacancies for labour in other areas. Maori migration to urban areas should already be flowing at a rate of possibly some 4,000 a year $[10,600$ in the quinquennium 1956-6i, see above ] and must continue to increase in volume year by year. It would appear imperative that overseas migration should not hinder or substitute for Maori migration. 5

Moreover, this may entail a high degree of 'job mobility' as well as geographical mobility. Each Maori migrant, unless he is particularly fortunate, may 'try his hand' at a number of occupations before opting for a particular job. However, this period of testing may consolidate the unfavourable stereotype already held by many non-Maoris that Maoris are 'shiftless'.

Secondly, it is obvious that this migration has had, and will continue to have, a considerable impact on the Maori population of urban areas, on the urban areas as a whole and on the Maori population as a whole. As far as its effect on Maori social structure is concerned, it is probably a truism to say that the personal and social problems resulting from this migration are very significant, and that Maori society has gone through a process of mutation.

As a result of this migration there have been a number of changes in the structure and distribution of Maori populations in urban areas, over and above the obvious large increase in numbers. For example, in Auckland urban area, which today contains the largest Maori population of any region rural or urban, the Maoris first moved into 'Inner

5 p.2. Woods, Noel S. (1960): "Immigration and the Labour Force", Industrial Development Conference, Background Paper 26, June, Wellington. 
City' areas, predominantly slums. Between 1951 and 1956 there was an increase of only $13.6 \%$ in this 'Inner City' area despite an increase of $49 \%$ in the size of the Maori population of the urban area as a whole, while the proportion of the total living in the 'inner City' declined from 43 to $32 \%$. The 'Inner Suburbs', lying around the 'Inner City' core, increased by some $27 \%$ in this period, but the major change occurred in the size of 'Outer Suburban' population which increased by 125\% (numerically, from 1,954 in 1951 to 4,392 in 1956), and replaced the 'Inner City' as the section of the urban area containing the largest proportion of the urban Maori population. It was to the 'Outer Suburbs' and the mural-urban fringes that non-Maoris moved in this intercensal period, so that the 'suburban drift' of the Maoris followed the firm precedent of the non-Maoris. Moreover, like the non-Meori 'suburbanites' these 'Outer Suburban' Maoris entered new lower-middle grade suburbs, in which there developed few marked residential concentrations of Maoris.

Within Auckland Urban area in 1956 there were marked differences in the age-structure of the Maori population. $56 \%$ of the Auckland 'Inner City' Maoris were aged 15-34 years in 1956, while in the 'Outer Suburbs' this proportion fell to 35\%. Age-group 0-14 constituted only $23 \%$ of the total 'Inner City' Maori population as against $47 \%$ of the Maoris of the 'Outer Suburbs'. At ages $35+$ there was little difference between the two extremes of 'Inner City' and 'Outer Suburbs', the age-group forming $21 \%$ of the population of the former area and $18 \%$ of the 'Outer Suburban' Maori population. The 'Inner Suburbs' fell between these two poles.

From these data it appeared that the 'Outer Suburban' population was composed of settled families and the 'Inner City' group of new single arrivals, which was further evidenced by the discrepancies in child-woman ratios. The place of the 
Maoris moving to the suburbs from the 'Inner City' had sometimes been taken by Maori in-migrants, but also by Pacific Island Polynesians -- Samoans, Cook Islanders, Niueans, etc. -- with whom Maoris compete for housing and jobs. 6

The major conclusions to be drawn from this study of Auckland are:

1. That the Maoris, for the first time, are becoming closely associated with non-Maoris. They are no longer purely an in-migrant group living precariously in inner city slums, but as family groups are to be found throughout the urban area sharing residential amenities with non-Maoris. Whether this implies a considerable degree of integration or merely token integration, and whether the provision of jobs and suburban homes can keep pace with the influx of Maoris into urban areas are questions for the future.

2. For their part it seems Maoris have been willing to forego the benefits of close association with other migrant kinsmen in 'Inner City' localities, to run the risk of discrimination and to adjust to perhaps the most alien style of non-Maori living, that of 'suburbia', in order to obtain for themselves and their families a better way of life. In fact, a Wellington sample survey shows:
quite unequivocally that three-quarters of the [Maori] mothers interviewed consider that it is more desriable for Maori families in the city to live scattered amongst non-Maori families... [and] that far from hankering after a closely-knit rural Maori community life, these city Maori are eager for fuller experience of city life, for self-improvement and increased knowledge of European life. They seek to attain the standards of the European and want nothing less than autonomy, equality and a chance to choose their own community of friends. 7

\footnotetext{
6 These data are from Pool, Ian (1961): "Maoris in Auckland": A. Pop. Study", J.P.S., vo1.70, no.1, Mar. pp.43-66.

7 pp.197 \& 199. Ritchie, Jane (1961): "Together or Apart:

A Note on Urban Maori Residential Preferences", J.P.S. , vol.70, (cont'd overleaf)
} 
The third consequence of rural-urban migration has been

a change in the occupational structure of the Maori work force, as is shown in Table 13.5. The major movement has been from agriculture, etc. (mainly farming) to manufacturing, construction and transport, etc.

Table 13.5 : Percentage of the Maori Work-Force Belonging to Each Industrial Division, 1945 and 1956

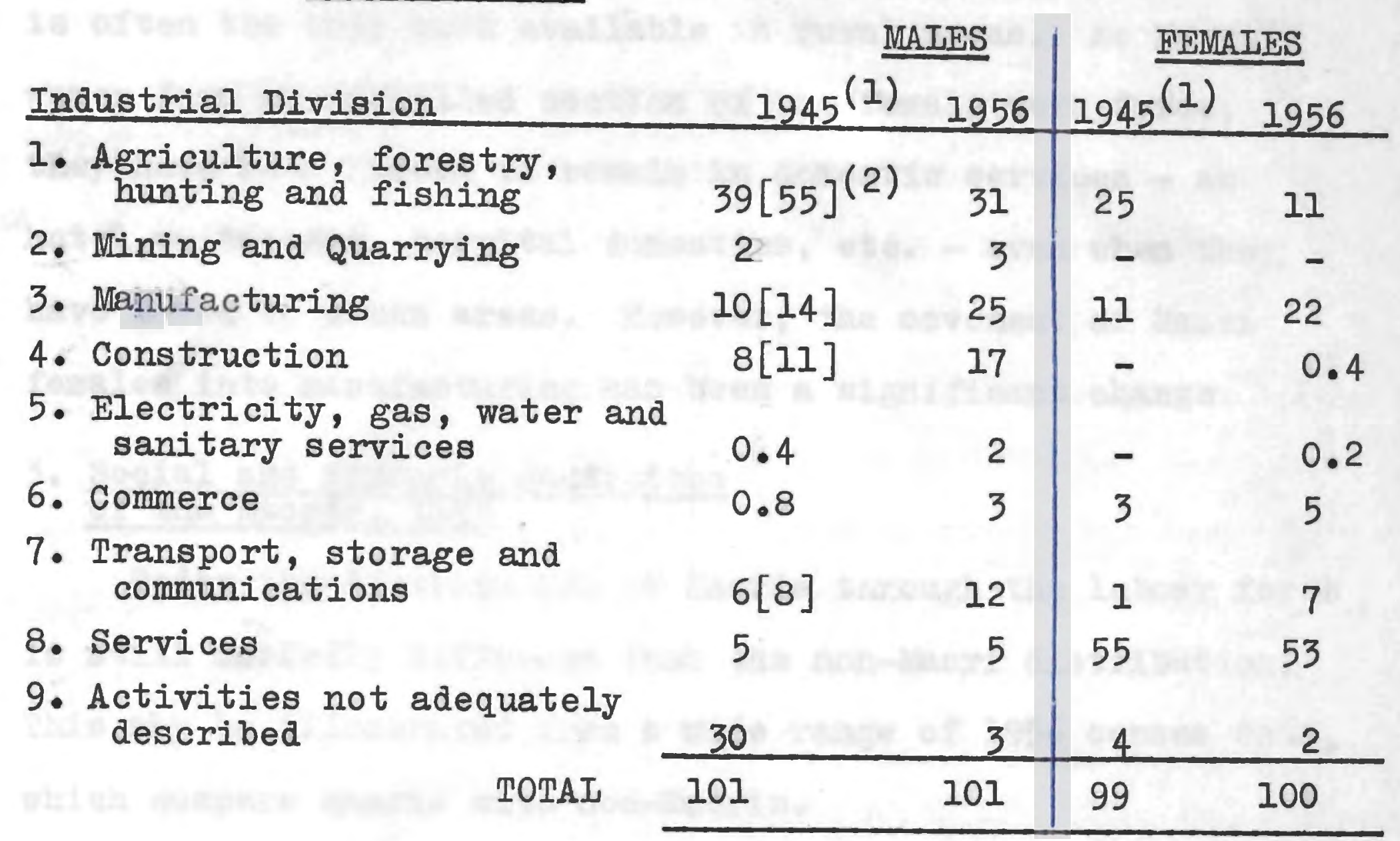

Notes: (1) In placing 1945 data in these divisions some decisions have had to be fairly arbitrary, thus the two years may not be completely comparable.

(2) Figures in brackets [] are adjusted percentages when labourers n.o.d. (see note 3) are distributed pro rata among Agriculture (etc.), Manufacturing, Construction, and Transport (etc.)

(3) Mainly 'Labourer not otherwise defined', which makes up 26 per cent of the total work-force.

Sources: For 1956, Census (1956): vol.VIII. p.19. The 1945 data were calculated from detailed tables giving raw data.

\section{f.n.7 (cont'd)}

no.2, June. pp.194-99. Although her sample was small ( $n=98)$, it was carefully stratified from 'scattered', 'semi-scattered' and 'old-community families', and a 'one-street community'. The last group was mainly composed of related families and was the only one in which the number opting for 'scattered living' approximated, but still exceeded the number desiring 'close living'. The overwhelming majority of the others opted for 'scattered living', as did $\frac{3}{4}$ of the whole sample. 
Two comments can be made here. Firstly, as will be shown below, the change in occupations has not led to a rise in occupational status for most Maoris. Secondly, the category 'Services', which is the major industry for females, includes both the professions and jobs such as waitressing and domestic service. These last two occupations have been the major standby for rural Maori females, largely because this is often the only work available in rural areas. As Maori women form an unskilled section of the female work force, they have been forced to remain in domestic services - as hotel waitresses, hospital domestics, etc. - even when they have moved to urban areas. However, the movement of Maori females into manufacturing has been a significant change.

3. Social and Economic Conditions of the Maoris, 1956

Today the distribution of Maoris through the labour force is still markedly different from the non-Maori distribution. This may be illustrated from a wide range of 1956 census data, which compare Maoris with non-Maoris.

Table 13.6 : Percentage of the Fmployed Maori and Non-Maori Populations in Various Industrial Divisions (1956)

\begin{tabular}{|c|c|c|c|c|}
\hline & & MALES & & MALES \\
\hline Industrial Division & Maori & Non-Maori & Maori & Non-Maori \\
\hline $\begin{array}{l}\text { Agriculture, Forestry, } \\
\text { Hunting and Fishing }\end{array}$ & 30.67 & 19.14 & 11.05 & 4.42 \\
\hline $\begin{array}{l}\text { Mining and Quarrying } \\
\text { Manufacturing } \\
\text { Construction } \\
\text { Electricity, Gas, Water and }\end{array}$ & $\begin{array}{r}2.71 \\
24.96 \\
17.34\end{array}$ & $\begin{array}{r}1.09 \\
24.04 \\
12.55\end{array}$ & $\begin{array}{r}0.05 \\
21.55 \\
0.44\end{array}$ & $\begin{array}{r}0.06 \\
22.55 \\
0.75\end{array}$ \\
\hline $\begin{array}{l}\text { Sanitary Services } \\
\text { Commerce }\end{array}$ & $\begin{array}{l}1.59 \\
2.55\end{array}$ & $\begin{array}{r}1.50 \\
16.13\end{array}$ & $\begin{array}{l}0.24 \\
4.81\end{array}$ & $\begin{array}{r}0.38 \\
26.08\end{array}$ \\
\hline $\begin{array}{l}\text { Transport, Storage and } \\
\text { Communications } \\
\text { Services } \\
\text { Activities not adequately }\end{array}$ & $\begin{array}{r}12.05 \\
5.31\end{array}$ & $\begin{array}{l}11.83 \\
13.33\end{array}$ & $\begin{array}{r}6.93 \\
53.03\end{array}$ & $\begin{array}{r}4 \cdot 96 \\
40.37\end{array}$ \\
\hline described & 2.82 & 0.39 & 1.90 & 0.43 \\
\hline TOTALS & 100.00 & 100.00 & 100.00 & 100.00 \\
\hline
\end{tabular}

Source: Census (1956): vol.VIII, pp.19-20. 
It is immediately obvious from Table 13.6, which is the corollary to Table 13.5, that Maori males by comparison with non-Maori males, are heavily over-represented in agriculture (etc.) and under-represented in commerce and services industries. The same differences of distribution apply to females, except that Service industries are important for both Maoris and non- Maoris. In this case, as was suggested above, an important distinction applies in the type of service industry to which they are attracted, or for which they have sufficient education or vocational training -- for Maoris, it is domestic work plus, to a limited degree, teaching and nursing; for non-Maoris, it is clerical work in government, commercial and professional offices, plus teaching and nursing. However, this difference may not greatly affect the relative income distributions because: (a) trainee nurses and teachers are on low salaries, and (b) the differences in salaries are not marked between the high and low status service industries into which females are attracted.

Farming in New Zealand is a skilled, highly capitalised, commercial proposition and the profit margins are generally stable because New Zealand farmers are protected against market fluctuations. Moreover, the predominant pastoral industries are even less susceptible than is arable farming to changes in what may be regarded as a climate unmarked by temperature extremes or by long and severe droughts. However, the concentration of Maoris in Agriculture etc., predominantly farming, is not an indication that Maoris are sharing equally in current levels of rural prosperity. Indeed, as has been shown above, the rural Maoris are in an unfavourable position. This is further evidenced when Maoris and non-Maoris in this industry are compared on the basis of their 'occupational status' -- whether they are employers, on their 'own account', 'wage and salary earners' etc. In all other industries this 
is not a satisfactory index, because an overwhelming proportion of workers, Maori and non-Maori, fall into the category of 'wage and salary earners'. However, for Agriculture etc. the differentials are extremely marked, as is shown in Table 13.7. $67 \%$ of Maoris in this industry are employees, while $60 \%$ of the non-Maoris are employers or are on their 'own account'.

By moving to urban areas Maoris have not attained occupational as well as geographical mobility. This is indicated in Table 13.8 on 'Occupations by division', which is the closest approximation in the New Zealand census to differentiation of occupations by 'social grade'. Congalton has shown that occupations are so graded by New Zealanders, and that occupation is as important an index of 'social class' there, as overseas. 8

Thus, these data on 'occupations by division' are important because they provide a crude index of the place of Maoris in New Zealand's 'social class' system, as judged by the one criterion of occupational grading. On this count Maoris would seem to fare badly for they are in those occupations which are of lowest 'prestige', most importantly in the category 'Craftsmen etc.', and are found least commonly, by comparison with non-Maoris, in occupations of a higher 'prestige' -- 'Professional etc.' and 'Managers etc.'. A number of the occupations in Table 13.8 provide no index of social grade whatsoever, most particularly 'Farmers etc.', which includes both employers and employees. In this case the differentials between Maori and non-Maori have already been examined. However, these data do confirm an earlier assertion that Maori women in 'Service industries' work predominantly as domestics etc., whereas non-Maori women in this industry are primarily in clerical occupations. The 
Table 13.7 : Percentage of Forkers in Agriculture, (1)

Forestry, Hunting and Fishing belonging to Various Status Groups, Laori and non-Maori, 1956

\begin{tabular}{|c|c|c|c|c|}
\hline \multirow[b]{2}{*}{ Occupational Status } & \multicolumn{2}{|c|}{ NALIES } & \multicolumn{2}{|c|}{ FEMLALES } \\
\hline & Maori & Non-Maori & Moori & Non-Maori \\
\hline $\begin{array}{l}\text { Pmployer } \\
\text { Own Account } \\
\text { Wages or Salary } \\
\text { Other (2) }\end{array}$ & $\begin{array}{r}6.40 \\
21.13 \\
67.48 \\
4.99 \\
\end{array}$ & $\begin{array}{r}25.66 \\
34.56 \\
38.61 \\
1.17 \\
\end{array}$ & $\begin{array}{r}6.54 \\
17 \cdot 36 \\
69.35 \\
6.75 \\
\end{array}$ & $\begin{array}{r}26.76 \\
24.66 \\
45.29 \\
3.29 \\
\end{array}$ \\
\hline TOTALS & 100.00 & 100.00 & 100.00 & 100.00 \\
\hline
\end{tabular}

Notes: (1) The majority of workers in this industrial division are in agriculture.

(2) Includes "unemployed", "Relative Assisting", etc.

Source: Census (1956): vol.vIII, pp.21-22

Table 23.8 : Percentage of Haoris and Non-Maoris in Various Occupation Divisions (1956)

Professional, technical and related workers

Managers, administrators and related workers

Sales Norkers

Farmers, fishermen, forestry and related workers

Torkers in mining, quarrying and related occupations

Thorkers in transport and communications occupations

Craftsmen, production process workers and labourers

Entertainment, sport and recreation

Occupations unidentifiable or not specified

Armed Forces personnel

\begin{tabular}{|c|c|c|c|}
\hline , & is & ion- & Maoris \\
\hline $2: 12$ & Females & Males & Females \\
\hline 1.52 & 10.53 & 6.88 & 15.89 \\
\hline $\begin{array}{l}1.89 \\
0.74\end{array}$ & $\begin{array}{l}7.73 \\
2.86\end{array}$ & $\begin{array}{r}13.88 \\
6.87\end{array}$ & $\begin{array}{l}29.65 \\
13.62\end{array}$ \\
\hline .1 & 10.28 & 19.51 & 4.08 \\
\hline 2 & - & 0.78 & - \\
\hline 7 & 4.10 & 8.53 & 2.17 \\
\hline 47.4 & 21.09 & 37.61 & 17.79 \\
\hline 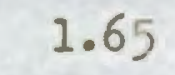 & 40.85 & 4.16 & 16.19 \\
\hline & $\begin{array}{r}1.75 \\
0.81 \\
\end{array}$ & $\begin{array}{l}0.25 \\
1.53 \\
\end{array}$ & $\begin{array}{l}0.28 \\
0.33 \\
\end{array}$ \\
\hline & 100.00 & 100.00 & 100.00 \\
\hline
\end{tabular}

Source: Census (1956): vol.VIII, p.23. 
category 'Entertainment etc.' in Table 13.8 includes domestic service, while the group 'Managers etc.' includes clerical workers. With this clarification of Table 13.8 it is apparent that the differentials noted above between Maori and non-Maori female employees in 'Service industries' are realistic.

When two populations are compared the 'social class' values of one may have little relevance for the other, whereas it is fair to assume that income is as important a determinant of the style and standards of living of Maoris as it is for non-Maoris. In Table 13.9 a return is made to data on occupations by industries, and the relative incomes of Maori and non-Maori workers are assessed. For both sexes and for every industry a higher proportion of the Maoris than the nonMaoris are in the lower income groups, and conversely, a lower proportion of Maoris are found in higher income groups. The second factor is most marked for agriculture (etc.), the industry in which the highest proportion of non-Maoris earn incomes in excess of EN.Z.1,000. To this obvious disability must be added the further factor, that in 1951 the average non-Maori married man with children supported 2.22 dependants, while his Maori counterpart supported 3.46. The lower incomes of Maoris may result in part from the fact that the Maori work force is younger than the non-Maori, as is shown in Table 13.10. A higher proportion of Maori than non-Maori workers are below 45 years, and the differential being most marked for the age-group 'below 20'. Thus, a smaller proportion of Maori than non-Maori workers may be eligible to receive adult award wages, although in a number of industries to which Maoris are attracted it is presumed that all job applicants are adults. For example, this is often the case on construction projects. However, in general, lower Maori incomes result from the fact that within the hierarchy of 


\begin{tabular}{|c|c|c|c|c|c|c|c|}
\hline \multirow{2}{*}{\multicolumn{2}{|c|}{ Industrial Division }} & \multicolumn{6}{|c|}{$\begin{array}{l}\text { Peroentage of those omployed in } \\
\text { each divis ion with the following } \\
\text { incomes (in } \mathbb{N} . \mathrm{C}^{\prime} \mathrm{C} \text { ) }\end{array}$} \\
\hline & & $\begin{array}{c}0 \\
-299 \\
\end{array}$ & $\begin{array}{r}300 \\
-699 \\
\end{array}$ & $\begin{array}{l}700 \\
-1099 \\
\end{array}$ & $\begin{array}{l}1100 \\
-1499 \\
\end{array}$ & $1500+$ & Totale \\
\hline \multicolumn{8}{|l|}{ Males } \\
\hline \multicolumn{2}{|c|}{$\begin{array}{l}\text { 1. Agriculture, Forestry } \\
\text { hunting and Non-Maorl } \\
\text { flshing }\end{array}$} & $\begin{array}{r}9 \\
23\end{array}$ & $\begin{array}{l}33 \\
57\end{array}$ & $\begin{array}{l}22 \\
12\end{array}$ & $\begin{array}{r}12 \\
4\end{array}$ & $\begin{array}{r}24 \\
4\end{array}$ & $\begin{array}{l}100 \\
100\end{array}$ \\
\hline $\begin{array}{l}\text { 2. Mining and } \\
\text { quarrying }\end{array}$ & $\begin{array}{l}\text { Non-Maori } \\
\text { Maori }\end{array}$ & 10 & $\begin{array}{l}34 \\
64\end{array}$ & $\begin{array}{l}53 \\
24\end{array}$ & $\begin{array}{l}6 \\
2\end{array}$ & $\begin{array}{l}3 \\
1\end{array}$ & $\begin{array}{r}99 \\
101\end{array}$ \\
\hline 3. Manufacturing & $\begin{array}{l}\text { Non-Mlaor1 } \\
\text { Maori }\end{array}$ & $\begin{array}{r}8 \\
14\end{array}$ & $\begin{array}{l}38 \\
60\end{array}$ & $\begin{array}{l}45 \\
25\end{array}$ & $\begin{array}{l}6 \\
1\end{array}$ & 3 & $\begin{array}{l}100 \\
100\end{array}$ \\
\hline 4. Construction & $\begin{array}{l}\text { Non-Mlaori } \\
\text { Maor1 }\end{array}$ & $\begin{array}{r}8 \\
13\end{array}$ & $\begin{array}{l}41 \\
64\end{array}$ & $\begin{array}{l}42 \\
21\end{array}$ & $\begin{array}{l}6 \\
1\end{array}$ & 4 & $\begin{array}{r}101 \\
99\end{array}$ \\
\hline $\begin{array}{l}\text { 5. Electricity, gas, } \\
\text { water and } \\
\text { sanitary } \\
\text { servicos }\end{array}$ & $\begin{array}{l}\text { Mon-Maori } \\
\text { Maori }\end{array}$ & $\begin{array}{l}4 \\
8\end{array}$ & $\begin{array}{l}40 \\
65\end{array}$ & $\begin{array}{l}51 \\
26\end{array}$ & $\begin{array}{l}5 \\
1\end{array}$ & $\begin{array}{l}2 \\
-\end{array}$ & $\begin{array}{l}102 \\
100\end{array}$ \\
\hline 6. Commerco & $\begin{array}{l}\text { Non-Maor1 } \\
\text { Maori }\end{array}$ & $\begin{array}{r}6 \\
19\end{array}$ & $\begin{array}{l}38 \\
62\end{array}$ & $\begin{array}{l}39 \\
16\end{array}$ & $\begin{array}{l}9 \\
2\end{array}$ & $\begin{array}{l}8 \\
1\end{array}$ & $\begin{array}{l}100 \\
100\end{array}$ \\
\hline $\begin{array}{l}\text { 7. Transport, } \\
\text { Storage and } \\
\text { Comminications }\end{array}$ & $\begin{array}{l}\text { Yon-M(aor1 } \\
\text { Kaori }\end{array}$ & $\begin{array}{l}5 \\
9\end{array}$ & $\begin{array}{l}36 \\
58\end{array}$ & $\begin{array}{l}50 \\
29\end{array}$ & $\begin{array}{l}6 \\
2\end{array}$ & $\begin{array}{l}3 \\
1\end{array}$ & $\begin{array}{r}100 \\
99\end{array}$ \\
\hline 8. Services & $\begin{array}{l}\text { Non-Maorl } \\
\text { Maor1 }\end{array}$ & $\begin{array}{r}7 \\
19\end{array}$ & $\begin{array}{l}34 \\
58\end{array}$ & $\begin{array}{l}41 \\
20\end{array}$ & $\begin{array}{l}9 \\
2\end{array}$ & $\begin{array}{l}9 \\
1\end{array}$ & $\begin{array}{l}100 \\
100\end{array}$ \\
\hline $\begin{array}{l}\text { 9. 1ctivities not } \\
\text { adequately } \\
\text { desoribed }\end{array}$ & $\begin{array}{l}\text { Mon-llaori } \\
\text { Maori }\end{array}$ & $\begin{array}{l}33 \\
58\end{array}$ & $\begin{array}{l}46 \\
36\end{array}$ & $\begin{array}{r}14 \\
5\end{array}$ & 3 & 3 & $\begin{array}{l}99 \\
99\end{array}$ \\
\hline TOTAL & $\begin{array}{l}\text { Non-Maor1 } \\
\text { Moor1 }\end{array}$ & $\begin{array}{r}7 \\
17 \\
\end{array}$ & $\begin{array}{l}37 \\
59 \\
\end{array}$ & $\begin{array}{l}39 \\
20 \\
\end{array}$ & $\begin{array}{l}8 \\
2 \\
\end{array}$ & $\begin{array}{l}9 \\
2 \\
\end{array}$ & $\begin{array}{l}100 \\
100\end{array}$ \\
\hline Females & & & & & & & \\
\hline $\begin{array}{l}\text { 1. Agricul ture, } \\
\text { (oto.) }\end{array}$ & $\begin{array}{l}\text { Mon-Maory } \\
\text { Maori }\end{array}$ & $\begin{array}{l}37 \\
66\end{array}$ & $\begin{array}{l}34 \\
25\end{array}$ & $\begin{array}{r}11 \\
4\end{array}$ & $\begin{array}{l}6 \\
1\end{array}$ & $\begin{array}{r}12 \\
3\end{array}$ & $\begin{array}{r}100 \\
99\end{array}$ \\
\hline 3. Manufacturing & $\begin{array}{l}\text { Noln-Meor1 } \\
\text { Maori }\end{array}$ & $\begin{array}{l}35 \\
45\end{array}$ & $\begin{array}{l}62 \\
54\end{array}$ & $\begin{array}{l}2 \\
1\end{array}$ & - & - & $\begin{array}{r}99 \\
100\end{array}$ \\
\hline 6. Commerce & $\begin{array}{l}\text { Mon-Maori } \\
\text { Maori }\end{array}$ & $\begin{array}{l}33 \\
52\end{array}$ & $\begin{array}{l}62 \\
47\end{array}$ & $\begin{array}{l}3 \\
1\end{array}$ & $\overline{-}$ & $\overline{-}$ & $\begin{array}{r}98 \\
100\end{array}$ \\
\hline 7. Transport (etc) & $\begin{array}{l}\text { Non-Maor1 } \\
\text { Maor1 }\end{array}$ & $\begin{array}{l}29 \\
41\end{array}$ & $\begin{array}{l}68 \\
58\end{array}$ & $\begin{array}{l}3 \\
1\end{array}$ & - & - & $\begin{array}{l}100 \\
100\end{array}$ \\
\hline 8. Services & $\begin{array}{l}\text { Non-Maori } \\
\text { Maori }\end{array}$ & $\begin{array}{l}40 \\
47\end{array}$ & $\begin{array}{l}52 \\
51\end{array}$ & $\begin{array}{l}6 \\
2\end{array}$ & 1 & $\overline{-}$ & $\begin{array}{r}99 \\
100\end{array}$ \\
\hline $\begin{array}{l}\text { 9. Activitios not } \\
\text { adequately } \\
\text { described }\end{array}$ & $\begin{array}{l}\text { Non-11aor1 } \\
\text { Kaor1 }\end{array}$ & $\begin{array}{l}61 \\
91\end{array}$ & $\begin{array}{r}35 \\
9\end{array}$ & $\begin{array}{l}3 \\
-\end{array}$ & 1 & - & $\begin{array}{l}100 \\
100\end{array}$ \\
\hline TOTAL & $\begin{array}{l}\text { Non-Mari } \\
\text { Maori }\end{array}$ & $\begin{array}{l}37 \\
49\end{array}$ & $\begin{array}{l}57 \\
48\end{array}$ & $\begin{array}{l}5 \\
2 \\
\end{array}$ & 1 & 1 & $\begin{array}{r}101 \\
99 \\
\end{array}$ \\
\hline
\end{tabular}

Source : Summarised from Census (1956): vol. VIII, pp.24-26. 
statuses found in every occupation, Maoris occupy the lower ranks. In agriculture this results from the fact that there is a shortage of Maori-held land, so rural Maoris are forced to work for wages, and farm labouring, shearing etc. are the only jobs available.

Table 13.10 : Proportion of the Work Force at Various Age-Groups, 1956

\begin{tabular}{|c|c|c|c|c|}
\hline \multirow[b]{2}{*}{ Age-group } & \multicolumn{2}{|c|}{ MAORIS } & \multicolumn{2}{|c|}{ NON-MAORIS } \\
\hline & $\mathrm{m}$ & $f$ & $\mathrm{~m}^{-}$ & $f$ \\
\hline $\begin{array}{l}\text { under } 20 \\
20-44 \\
45-64 \\
65+\end{array}$ & $\begin{array}{r}15.04 \\
65.27 \\
18.65 \\
1.04\end{array}$ & $\begin{array}{r}33.82 \\
56.33 \\
9.39 \\
0.46\end{array}$ & $\begin{array}{r}8.32 \\
57.62 \\
30.24 \\
3.82\end{array}$ & $\begin{array}{r}24.82 \\
50.74 \\
22.41 \\
2.03\end{array}$ \\
\hline TOTALS & 100.00 & 100.00 & 100.00 & 100.00 \\
\hline
\end{tabular}

Source: Census (1956): vol.vIII, p.27.

The lower status of Maori urban and rural non-farm workers arises because Maoris are an unskilled group, and this, in turn, results from their lower educational attainments. In Table 13.11 data are presented on the educational attainments of Maori and non-Maori school leavers in 1960. Not only do Maoris leave school earlier -- often at the statutory minimum of 15 years which usually falls during the second year of secondary school -- but the vast majority of the Maoris enter the labour force without School Certificate, which is increasingly taken as an 'employers' guide' at least in clerical and some skilled occupations. In the words of the recent Report of the Commission on Education in New Zealand:

No group in the community has given the Commission greater cause for thought and discussion than the Maori people... In providing true equality of educational opportunity for the Maori people of New Zealand, in aiding them by this means in their effort to reach equality of status in this community, we have before us a task of imperative priority. 9

A.J.H.R. (1962): E-2, p.15. 
Table 13.11 : Percentages of State Secondary School Leavers (1960): (a) By Years of Attendance at Secondary School; (b) By Attainments (I)

(a) Percentage of the Secondary School Leavers who had left School by the end of:

Their first year of Secondary School
" second "
" third " " " " "
" fourth " "
" fifth year or higher

Total

\begin{tabular}{rc} 
Maori & Non-Maori \\
\hline 19.1 & 7.0 \\
37.0 & 32.0 \\
27.5 & 32.7 \\
12.2 & 18.6 \\
4.2 & 9.7 \\
\hline 100.0 & 100.0 \\
\hline
\end{tabular}

(b) Percentage of Secondary School Leavers who had left School:

without School Certificate ${ }^{(2)}$ with School Certificate or Endorsed School Certificate with University Entrance or higher Total

\begin{tabular}{rr}
95.2 & 70.3 \\
3.3 & 17.9 \\
1.4 & 11.8 \\
\hline 99.9 & 100.0 \\
\hline
\end{tabular}

Notes: (1) Source: A.J.H.R. (1962): E-2, p.408, "Report of the Commission on Education in N.Z.".

(2) An examination sat at the end of third year Secondary School (at about $15 / 16$ years), which has become, so the Commission claims (p.402), New Zealand's "new cultural norm"; particularly, it is a minimum standard of education for many fields of employment.

Moreover, the Commissioners recognised the importance of demographic variables, such as the rapid growth of the Maori population and particularly of the numbers at school and school leaving ages, the urbanisation of the Maoris and their considerable degree of geographical concentration. 10

Another possible factor determining the entry of Maoris into lower-status jobs is that they may desire the work day company of other Maoris, or they may feel that there is a greater chance of being discriminated against if they enter jobs in which no other Maoris are employed. Although these factors may be of some significance, there is no way of

10 A.J.H.R. (1962): E-2, pp.408-14. 
determining their effect on choice of employment for the majority of Maoris, while by contrast, there is ample evidence that Maoris are entering the labour force untrained and ill-equipped.

There are few Maori students in tertiary educational institutions, although there have been increases in the numbers of Maori teacher trainees and university students in recent years. Among Maori children leaving school in 1961, only $2.7 \%$ of the males and $4.3 \%$ of the females wished to enter university, teachers' college or professional cadetships, while for non-Maris the proportions were $13.9 \%$ and $11.8 \%$ respectively. ${ }^{11}$ A factor here may be that Maori parents cannot afford to keep a child at school until he passes the University Entrance examination, or to assist him during an apprenticeship or university education. However, secondary and tertiary education are supported by the State, and there is a wide variety of scholarships. Moreover, Maoris can obtain some financial assistance from the Maori Purposes Fund, so for the determined parent and child the financial burden can be reduced and almost eliminated, unless the student is forced to study away from his home. Even in this case extramural and part-time university education is freely available in New Zealand, as are boarding and professional bursaries (teaching, engineering etc.). Thus, a more important factor may be that: 'Maori parents tend to adopt more permissive and laissez-faire attitudes than pakeha parents towards their children's vocational careers... [while Maori parents] are less capable of assisting with appropriate information, advice and guidance'. ${ }^{12}$ Whatever the reason, one thing is certain: namely, that Maori children are not achieving

12 pp.166-67 ff. Ausubel, David P. (1961): Maori Youth, Victoria University Publications in Psychology, no.14, Wellington. 
benefit from their period at school and thus the concentration of Maoris in unskilled employment is maintained.

In terms of occupations and incomes the Maoris are in an unfavourable position. This extends to their domestic living conditions.

Their standard of housing in both urban and rural areas has improved considerably since 1945, as is seen from the data on the provision of household amenities which are given in Table 13.12 .

\section{Table 13.12: The Percentages of Maori Households} Without Certain Amenities

\begin{tabular}{|c|c|c|c|c|c|}
\hline Households & $\begin{array}{l}\text { Piped } \\
\text { Water (1) }\end{array}$ & $\begin{array}{c}\text { Hot Water } \\
\text { Service }\end{array}$ & $\begin{array}{l}\text { Bath or } \\
\text { Shower (2) }\end{array}$ & $\begin{array}{l}\text { Flush } \\
\text { Toilet }\end{array}$ & $\begin{array}{l}\text { Electric } \\
\text { Light (3) }\end{array}$ \\
\hline $\begin{array}{l}1945 \\
1956\end{array}$ & $\begin{array}{l}72 \\
52[26]\end{array}$ & $\begin{array}{l}82 \\
54[1\end{array}$ & $\begin{array}{l}67 \\
44[10]\end{array}$ & $\begin{array}{l}92 \\
74[35\end{array}$ & no data \\
\hline
\end{tabular}

\section{Urban}

Households

1945

1956

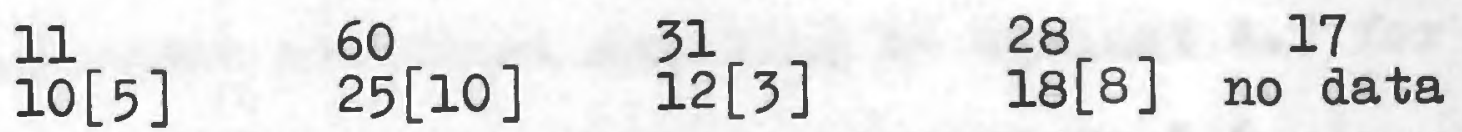

Total

Households

1945

1956

$\begin{array}{llll}67 & 80 & 63 & 87 \\ 48[13]^{4} & 50[10]^{4} & 40[4]^{4} & 67[17]^{4} \text { no data }\end{array}$

Notes: (1) In 1945 'Water laid on'.

(2) In 1945 'Bathroom'

(3) Data available only for 1945.

(4) Figures in brackets [] are for non-Maoris in 1956.

In both 1945 and 1956 urban Maori households were better equipped than rural. Thus, by migrating to urban, and particularly suburban areas Maoris have attained better housing standards.

The provision of these amenities is an important index of the standard of living as defined earlier. Table 13.12 shows that a very low proportion of total (rural and urban) nonMaori households are without these amenities, and thus they 
are necessities in the sense that they are the accepted prerequisites to a high standard of living among non-Maoris. The urban Maori households are closer to achieving this prerequisite than are rural Maori households, but for New Zealand as a whole Maori households are substandard by comparison with the non-Maori.

The possession of amenities such as refrigerators and washing machines is perhaps less of a necessity than the provision of flush toilets or baths, and ownership of these former articles is more dependent on the prevailing wealth of the householders. In this regard it is not surprising that $80 \%$ of Maori households in 1956 were without refrigerators and electric washing machines, whereas for non-Maoris the proportions were $44 \%$ and $41 \%$ respectively.

Finally, in 1956 the actual Maori dwellings were unsatisfactory by comparison with non-Maori houses. There was an average of 3.9 rooms per Maori dwelling as against 4.7 for non-Maori houses, while on the average there were 5.6 occupants per Maori house, but only 3.6 per non-Maori dwelling. These figures refer only to permanent private dwellings and exclude temporary dwellings, such as tents, shearers' quarters, musterers' huts etc., and institutions, yet $12.7 \%$ of Maori permanent dwellings were classified as 'huts' at the 1956 census, as against $2.1 \%$ for non-Maoris.

This chapter has analysed the present socio-economic situation of the Maori population. It has shown that an economically depressed population exists in a nation with a high standard of living, while earlier chapters showed that the Maoris are a population with high but rapidly declining mortality and high fertility. The two variables of a low standard of living and a high rate of natural increase are not unique to the Maoris, but the close juxtaposition of two populations with marked differential socio-economic and demographic trends is almost peculiar to New Zealand. Thus, the 
situation of the Maoris cannot be compared with that of other emergent populations who are not fortunate enough to live in a country with highly capitalised and soundly based secondary and tertiary industries, which can provide an alternative outlet to primary industry.

The rural location of the bulk of the Maori population has prevented them from obtaining a reasonable share of the nation's prosperity and thus it has been necessary for the Maoris to migrate to urban areas. The movement to urban areas has brought about some improvement in Maori housing conditions and has increased the degree of association between Maoris and non-Maoris. Association of this sort has two potential outcomes; it can lead to mutual understanding, or it can create friction, but so far it is difficult to judge its impact. More importantly, the shift from rural areas has not been accompanied by any marked diffusion of the Maoris through all strata of the urban work force. There has been no development of an urban Maori 'middle class' of professional, clerical and commercial workers. 13

In part, this results from the fact that a majority of Maori adolescents are leaving school so unequipped for the demands of urban industrial life that those who enter the cities, in addition to the increasing number who have been raised in the urban areas, eventually find their way to the most poorly paid occupations. However, their lack of adequate preparation cannot be viewed entirely in terms of their entry

13 The use of the term 'midale class' opens up an avenue which is paved with speculations and which cannot be entered into here. It is doubtful whether Maoris envisage their situation in social class terms, for they have a viable and relatively autonomous culture with its own status system which is not closely akin to that of non-Maori New Zealand. On the other hand, in certain contexts the situation of urban Maoris is that of a lower social class, an unskilled urban proletariat. Moreover, many aspects of Maori life which appear to be unique when Naoris are studied in isolation may in fact characterise most 'working class' New Zealand groups -- Maori and non-Maori. 
into the labour force, for they are also taking up a new way of life in a milieu which differs from their rural home environments. Thus, 'Here in the city a Maori frequently finds himself in a society but not wholly of it; socially awkward, lonely, frustrated, a marginal person on the fringe of two cultures but without status or hope in either'. ${ }^{14}$ Many of these young Maoris may fail to reach their goals, but the majority probably achieve some degree of adjustment to this alien environment and in doing this they are developing a new Maori way of life, an urban way of life. Because of the demographic trends of the last two decades this revolution is certain to gain momentum, but it is equally certain that even at present the Maori situation qualifies as one of New Zealand's major economic and social problems.

14 p.12. Morris, Albert (1955): "Some Aspects of Delinquency and Crime in N.Z.", J.P.S., vol.64, no.1, Mar. pp. $5=15$. 


\section{CHAPTER FOURTEEN}

\section{Projections of the Maori Population}

The main problem brought out by this survey is what to do with the increasing Maori population... The question of adjustment to changing conditions is not the problem of the Naori alone. The pakeha hasnot been able to adjust himself satisfactorily to the machine age, and Western civilization has to get its own house in order before it can offer any satisfactory solution.

p.16. Te Rangihiroa (1940): "Foreword" to Sutherland, I.I.G. (ed): The Maori People Today, Christchurch.

\section{Introduction}

The founders of the Young Maori Party would find it difficult to comprehend the increase of the Maori population since 1900 , to say nothing of the radical changes in the Maori way of life. Even since Te Rangihiroa made the statement quoted above, the Maori population has almost doubled its size.

Throughout the twentieth century Maori fertility has been at high levels, while mortality has declined, and thus growth has accelerated. The accelerated rapid growth has been accompanied by urbanisation and a change in the Maori industrial distribution, but not in the distribution of occupational statuses. Maoris still tend to be found predominantly in the lower status and income strata of the work force.

The present chapter utlises the data analysed in past chapters in order to project the Maori population to 1976. The concern is not with the socio-political implications of population growth, but purely with the demographic patterns. Three projections will be made in order to show these patterns. They are:

(1) Assuming mortality and fertility remain constant;

(2) Assuming a decline in mortality; 
(3) Assuming declines in both mortality and fertility.

2. Projections by Age of the Maori Population

from 1961-1976: No.1.

The projections shown in Table 14.1 are based on the following assumptions:

(1) That mortality will remain constant at the level of 1956. $1956 I_{X}$ values were used for the computation of survival ratios.

(2) That fertility will remain constant at the level of 1956. As there are no data from which age-specific fertility rates can be calculated, 1956 General Fertility rates were used here. The rate was 202.

The age-group 0-4 in 1966, 1971 and 1976 was obtained by applying the 1956 general fertility rates to the mean of the number of females at age-group $x$ at the censuses in the years $t$ and $t+5$.

$$
\begin{array}{ll}
\text { Thus, } & F_{15-49}=\frac{F_{15-49}^{t}+F_{15-49}^{t+5}}{2} \\
& B^{t-(t-4)}=5 X\left(G \cdot F \cdot R \cdot x F_{15-49}\right) \\
\text { and, } \quad P_{0-4}^{t+5}=B^{t(t+4)} \times \frac{I_{0-4}}{5 \cdot I_{0}}
\end{array}
$$

where, $F=$ females

$$
G \cdot F \cdot R \cdot=\frac{B^{1956}}{F_{15-49}^{1956}}
$$

$\frac{I_{0-4}}{5 \cdot I_{0}}=$ survival ratio for age-group 0-4 in the 1956

It is obvious that, after the total births had been obtained, it was necessary to divide them into male and female births, to which survival ratios for each sex were applied.

(3) That the sex-ratio at birth will remain constant. The mean ratio for the period 1957-61 was employed, and was 103.4 males per 100 females. 
(3) Assuming declines in both mortality and fertility.

\section{Projections by Age of the Maori Population from 1961-1976: No.1.}

The projections shown in Table 14.1 are based on the following assumptions:

(I) That mortality will remain constant at the level of 1956. $1956 \mathrm{I}_{\mathrm{X}}$ values were used for the computation of survival ratios.

(2) That fertility will remain constant at the level of 1956. As there are no data from which age-specific fertility rates can be calculated, 1956 General Fertility rates were used here. The rate was 202.

The age-group 0-4 in 1966, 1971 and 1976 was obtained by applying the 1956 general fertility rates to the mean of the number of females at age-group $x$ at the censuses in the years $t$ and $t+5$.

$$
\begin{aligned}
& \text { Thus, } F_{15-49}=\frac{F_{15-49}^{t}+F_{15-49}^{t+5}}{2} \\
& B^{t-(t-4)}=5 X\left(G \cdot F \cdot R \cdot x F_{15-49}\right) \\
& \text { and, } P_{0-4}^{t+5}=B^{t(t+4)} \times \frac{I_{0-4}}{5 \cdot I_{0}}
\end{aligned}
$$

where, $F=$ females

$$
G \cdot F \cdot R \cdot=\frac{B^{1956}}{F_{15-49}^{1956}}
$$

$\begin{aligned} \frac{I_{0}-4}{5 . I_{0}} & = \\ & \text { survival ratio for age-group } 0-4 \text { in the } 1956 \\ & \text { life-table. }\end{aligned}$

It is obvious that, after the total births had been obtained, it was necessary to divide them into male and female births, to which survival ratios for each sex were applied.

(3) That the sex-ratio at birth will remain constant. The mean ratio for the period 1957-61 was employed, and was 103.4 males per 100 females. 
The 1961 population was used as a base from which the projections were made. As was discussed in Chapter Seven, the accuracy of the age-distribution in 1961 was tested by surviving cohorts from the 1956 census to the 1961 census. This showed that the age-distribution at 1961 was irregular and thus it was smoothed by means of moving averages. For $\mathrm{P}_{0-4}^{1961}$ published data were used after it has been established that the published number was above the number estimated by surviving births from the previous quinquennium to 1961 , and below the number obtained from the smoothed age-distribution by graphical interpolation. $\mathrm{P}_{80-84}, \mathrm{P}_{85-89}$ and $\mathrm{P}_{90+}$ were used when smoothing of the 1961 population was undertaken, so that $\mathrm{P}_{80-84}$, after smoothing, did not have to be obtained by interpolation. $\mathrm{P}_{80-84}^{t}$ was brought to $\mathrm{P}_{85+}^{t+5}$ by multiplying $\mathrm{P}_{80-84}^{t}$ by the survival ratio $\frac{\mathrm{I}_{85-89}}{I_{80-84}}$. To overcome the methodological problem of the resultant population being $\mathrm{P}_{85-89}$ and not $\mathrm{P}_{85+}$, it was assumed that all persons $85+$ at the census in yeart died before the census in year $t+5$. After 1966 this means that there has been no allowance made for survival beyond 89 years, which thus affects the size of the $\mathrm{P}_{85+}$ at these years. However, the numbers are so small and the base population is so unsatisfactory at these older ages that such an approximation affects the total projection but slightly, and any error introduced may be derived more from the poor quality of the raw data than the method. There are two further methodological questions to be raised.

Firstly, the population is small and, as was shown in Chapter Seven, the raw data are not yet completely satisfactory, while the future fertility patterns have been derived from general fertility rates. Consequently, it was decided to project the population only as far forward as 1976.

Secondly, from graphical interpolation it appears that the probable under-enumeration at ages 15-19 and 20-24 in 1961 


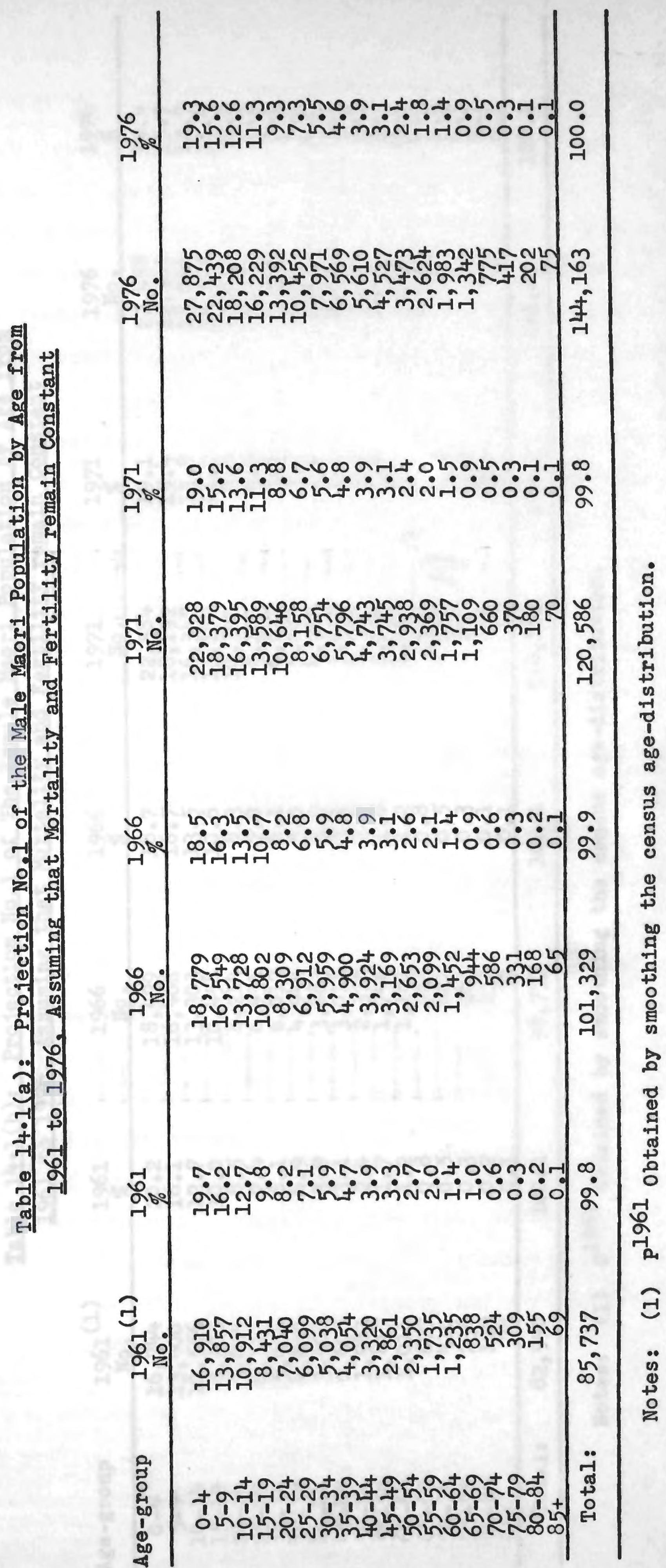




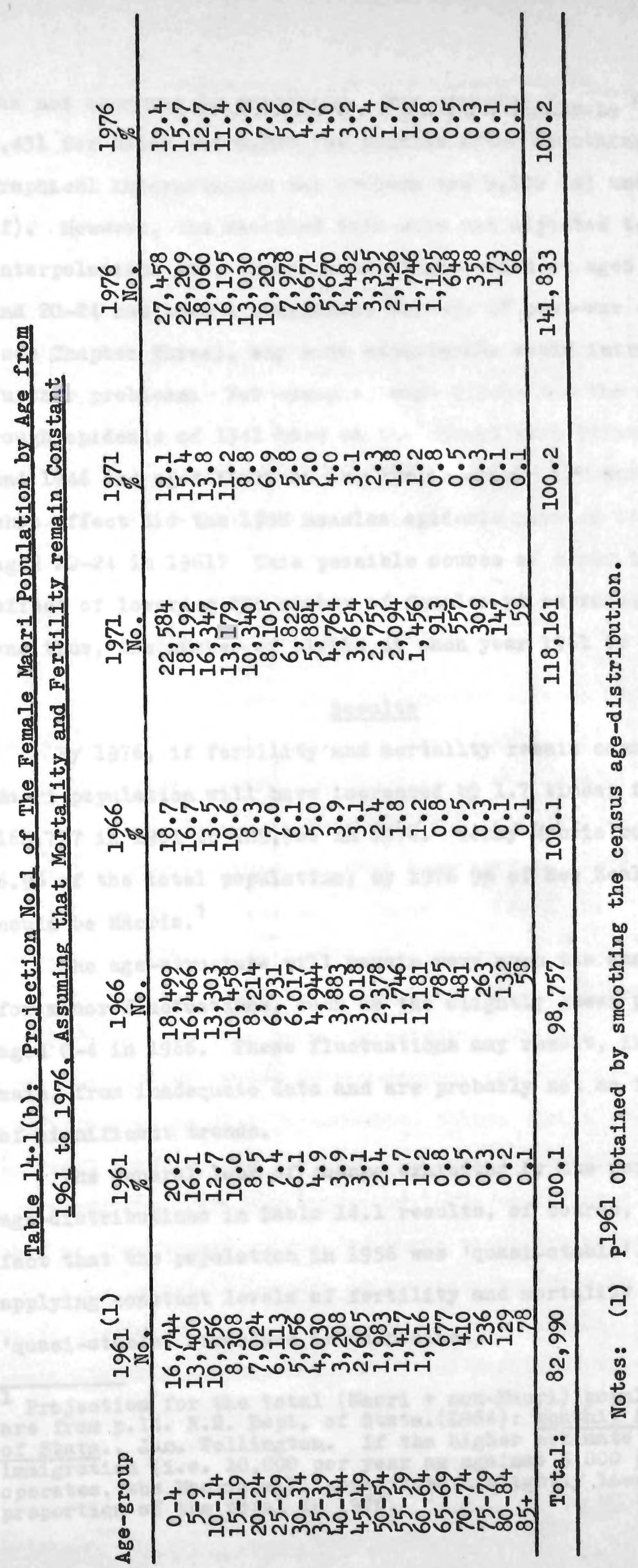


was not overcome by smoothing. For example, $P_{15-19}$ numbers 8,431 for males and 8,308 for females after smoothing, but by graphical interpolation the numbers are 9,100 (m) and 9,000 (f). However, the smoothed data were not adjusted to these interpolations for, though under-enumeration at ages 15-19 and 20-24 has been a consistent feature of post-war censuses (see Chapter Three), any such adjustments would introduce further problems. For example, what effect did the whooping cough epidemic of 1941 have on the cohort born between 1941 and 1946 and aged 15-19 at the 1961 census? Alternatively, what effect did the 1938 measles epidemic have on the cohort aged 20-24 in 1961? This possible source of error has the effect of lowering the number of females at reproductive ages, and thus, the number of births at each year 1961 to 1976.

\section{Results}

By 1976, if fertility and mortality remain constant, the Maori population will have increased by 1.7 times; from 168,727 in 1961 to 285,966 in 1976. Today Maoris constitute 6.9\% of the total population; by 1976 9\% of New Zealanders could be Maoris. ${ }^{1}$

The age-structure will remain very much the same except for minor fluctuations, such as the slightly lower percentage aged 0-4 in 1966. These fluctuations may result, in the main, from inadequate data and are probably not an indication of significant trends.

The general lack of change exhibited by the percentage age-distributions in Table 14.1 results, of course, from the fact that the population in 1956 was 'quasi-stable'. By applying constant levels of fertility and mortality this 'quasi-stable' structure is maintained.

TProjection for the total (Maori + non-Maori) population are from p.14. N.Z. Dept. of Stats. (I964): Monthly Abstract of stats., Jan. Wellington. If the higher estimate of net immigration (i.e. 10,000 per year as against 5,000 per year) operates, the Maoris will constitute a slightly lower proportion of the total in 1976. 


\section{Assumptions and Methods}

As it is now almost 1966 it was assumed that there woxld be no changes/until ifity or fertility 1966 in Table 14.1 have been used again to project forward to 1971 and 1976 in Table 14.2.

In the projection for 1971 and 1976, presented in Table 14.2, a new assumption was introduced: that mortality will decline rapidly between 1966 and 1976, but that fertility will remain constant at the level of 1956. It was assumed that life-expectation at birth would increase as follows:

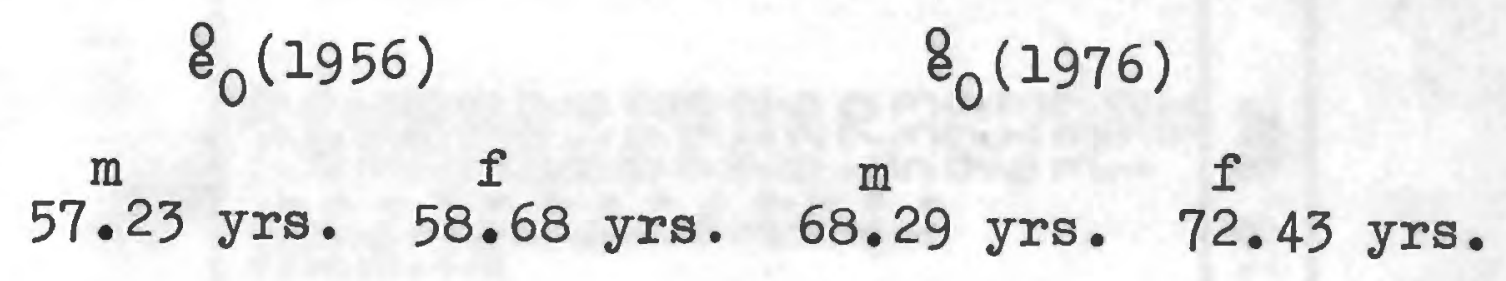

This assumption implies that differences between Maori and nonMaori mortality levels will decrease rapidly, and that by 1976 Maori life-expectation at birth will be the same as that of non-Maoris in 1950-52. It was further assumed that by 1971 Maori life-expectation will have increased to 62.76 years (males) and 65.43 (females). These are the levels in the 1921-22 non-Maori life-table.

At 1966 the survival ratios used in the projections were derived from the 1956 Maori life-table. In 1971 they came from the 1921-22 table for non-Maoris; and for 1976 they were obtained from the 1950-52 non-Maori table. To calculate survival between 1966 and 1971 the mean of the assumed values for these two years was taken; and between 1971 and 1976 the mean of the assumed values for these these two years was used. This procedure results in projections based on a very rapid decline in mortality during two quinquennia. How reasonable is this assumption? It is possible, indeed probable, that Maori mortality will decline rapidly in the next decade, 


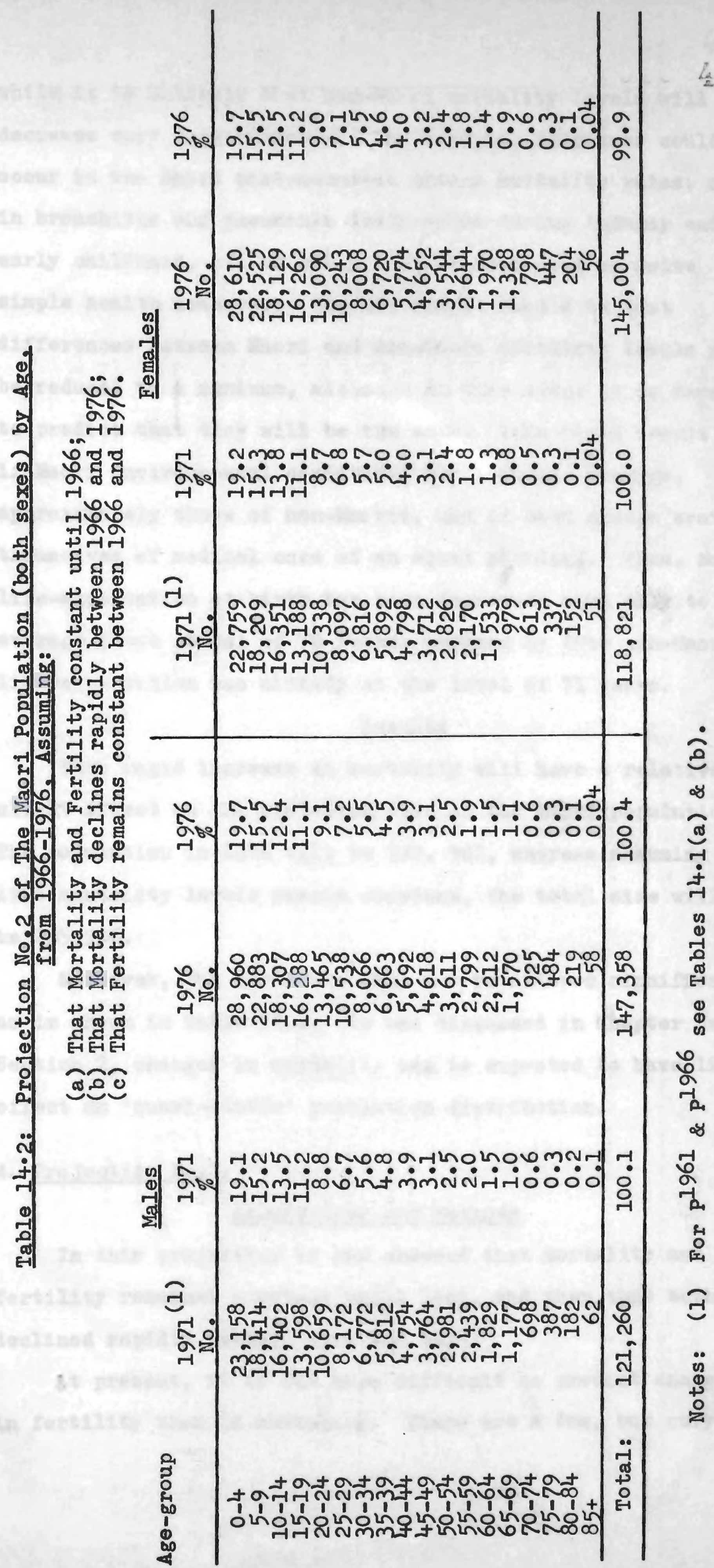


while it is unlikely that non-Maori mortality levels will decrease very significantly. For example, decreases could occur in the Maori post-neonatal infant mortality rates, or in bronchitis and pneumonia death-rates during infancy and early childhood, all of which could be achieved by quite simple health measures. The net result should be that differences between Maori and non-Maori mortality levels will be reduced to a minimum, although at this stage it is impossible to predict that they will be the same. This would result only if Maori environmental conditions were, on the average, approximately those of non-Maoris, and if both groups availed themselves of medical care of an equal standard. Thus, Maori life-expectation at birth has been increased here only to an average (both sexes) of 70 years, whereas by 1956 non-Maori life-expectation was al ready at the level of 71 years.

\section{Results}

This rapid increase in mortality will have a relatively slight effect on the projected size of the Maori population. The population in 1976 will be 292, 362, whereas assuming the 1956 mortality levels remain constant, the total size will be 285,996 .

Moreover, the structure will not be altered significantly, as is shown in Table 14.2. As was discussed in Chapter Seven, Section 2, changes in mortality can be expected to have little effect on 'quasi-stable' population distribution.

\section{Projection No.3.}

\section{Assumptions and Methods}

In this projection it was assumed that mortality and fertility remained constant until 1966, and then that both declined rapidly between 1966 and 1976.

At present, it is far more difficult to predict changes in fertility than in mortality. There are a few, but only a 


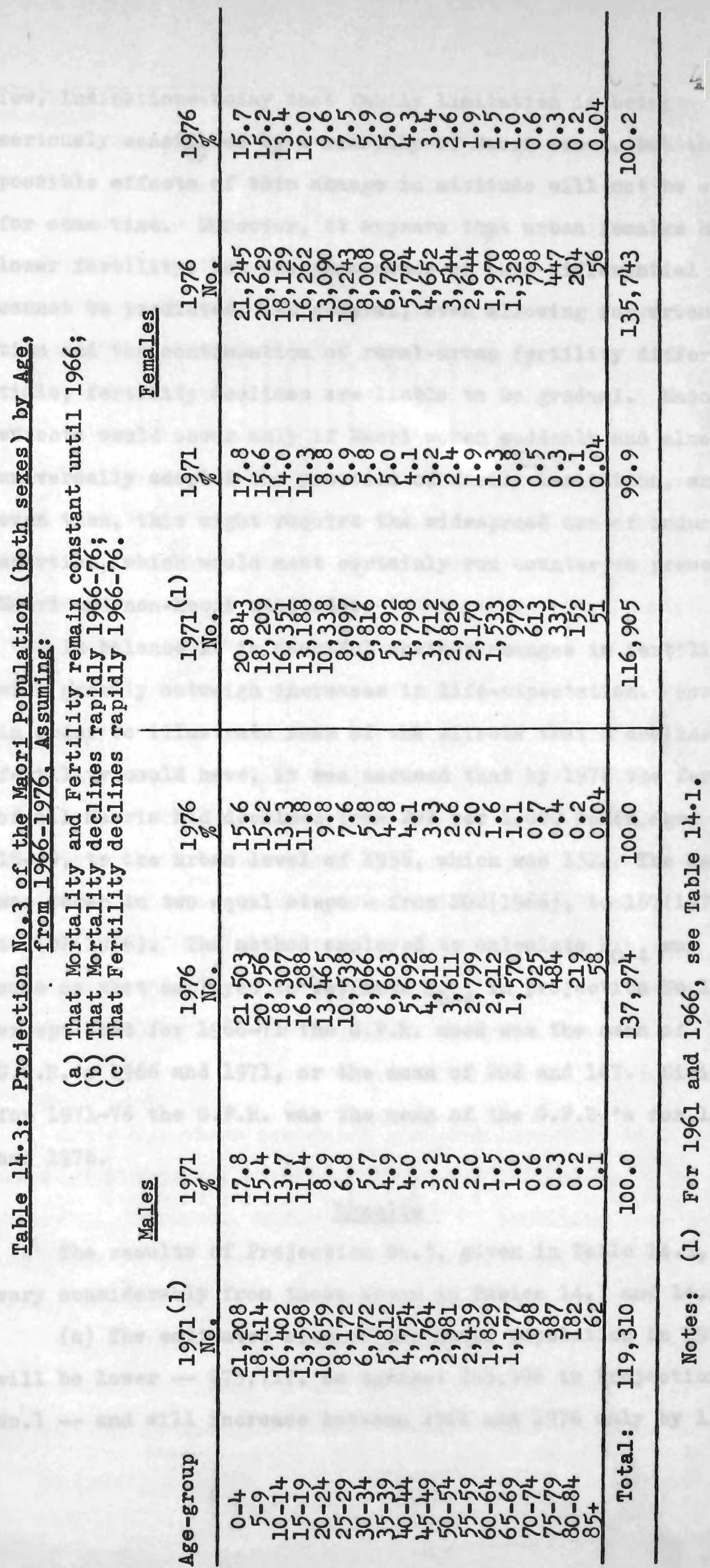


few, indications today that family limitation is being seriously considered by a minority of Maori women, but the possible effects of this change in attitude will not be seen for some time. Moreover, it appears that urban females have lower fertility, but the permanence of this differential cannot be predicted. In general, even allowing for urbanisation and the continuation of rural-urban fertility differentials, fertility declines are liable to be gradual. Major effects would occur only if Maori women suddenly and almost universally adopted the practice of family limitation, and even then, this might require the widespread use of induced abortion, which would most certainly mun counter to present Maori and non-Maori attitudes.

In balance it is doubtful whether changes in fertility will greatly outweigh increases in life-expectation. However, in order to illustrate some of the effects that a decline in fertility could have, it was assumed that by 1976 the fertility of all Maoris had declined from 202 per 1,000 women aged 15-49, to the urban level of 1956, which was 132. The decline was taken in two equal steps - from 202(1966), to 167(1971), to 132(1976). The method employed to calculate $\mathrm{P}_{0-4}$ was the same as that employed to estimate $\mathrm{P}_{0-4}$ in projection No.1, except that for 1966-71 the G.F.R. used was the mean of G.F.R.'s 1966 and 1971, or the mean of 202 and 167. Similarly, for 1971-76 the G.F.R. was the mean of the G.F.R.'s for 1971 and 1976.

\section{Results}

The results of Projection No.3, given in Table 14.3, vary considerably from those shown in Tables 14.1 and 14.2 .

(a) The estimated size of the Maori population in 1976 will be lower -- 273,717 , as against 285,996 in Projection No.1 -- and will increase between 1961 and 1976 only by 1.6 
times, as against 1.7 times in the other projections.

(b) The age-structure will be affected, as there will be fewer at younger ages, particularly at ages 0-4. At the same time the middle age-groups will form a proportionately larger section of the population than they do in the other projections. For example, the male work-force (males 15-64) in 1976 will constitute $53.4 \%$ of the male population by this projection, but only $50.6 \%$ and $50.3 \%$ of the population in the other projections.

Projection No. 3 has assumed an extremely radical change in fertility, but as yet there is no indication even of the potential for such change. Thus, Projection No.3 is probably too conservative an estimate of growth. Moreover, even allowing for this factor, the size of the estimated $\mathrm{P}^{1976}$ in Projection No.3 is over $95 \%$ of $\mathrm{P}^{1976}$ estimated by assuming that fertility and mortality will remain constant.

However, Projection No.3 does illustrate another point. If fertility declines during the period 1961-76, depleted cohorts will enter age-group 15-49 after 1976. If the low level of fertility of the period $1966-76$ is maintained there will be significant decreases in the rate of growth of the period 1976-91. In the long run, any declines in the rate of growth will come from decreases in fertility.

\section{Conclusion}

The projections presented here indicate that in 1976 a Maori population of between 270,000 and 295,000 is to be expected. Moreover, unless declines in fertility are marked and rapid in the next decade the age-structure will be relatively similar to the present distribution.

The socio-political implications of this rapid growth are outside the field of the present study. However, at present the geographical distribution of the Maori population 
is uneven. Since the war this imbalance has been reduced by rural-urban migration. Undoubtedly, in the future this movement will be maintained. Furthermore, it is probable that the volume of rural-urban migration will increase. For this population shift to be an effective instrument it is obvious that it must be accompanied by a diffusion of Maoris throughout the economy in order to overcome the present concentration of Maoris in the lowest strata.

If this occurs, Firth's concluding words would seem well-chosen:

We have watched with curious eyes his first
meeting with the pakeha, and have seen the tragedy
and the courage of that encounter - to turn and
bid him farewell at the last, not with the
mourner's cry, but with the augury of a more
lustrous future as a member of a community
wider and more strongly knit than his fathers
ever knew.

While voicing this optimism, heed must also be paid to Sutherland's plea: 'In the whole of recent history there could be no more significant time than this very present for any country to be sure of its attitude and policy towards a racial minority'. 3

\footnotetext{
2.p.494. Firth, Raymond (1959): Economics of the N.Z. Maori, Wellington.

3 p.441. Sutherland, I.I.G. (1940): "The Maori Situation", in Sutherland, I.I.G. (ed): The Maori People Today, Christchurch.
} 


\section{APPBWIX A}

Table Shoving the percentage Bolonging to Varlous IReligious

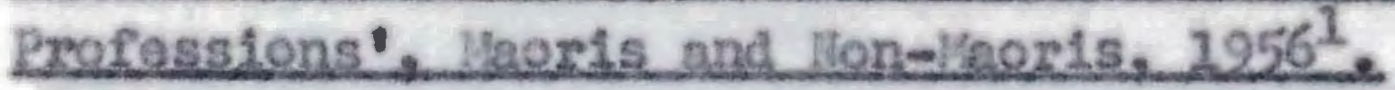

Holletous Profosstons: Maoris Mion- Maoris

Chuxeh of Bnglond $32.27 \quad 36.17$

Foman Cathol1e (Including Catholic Undefinod)

Ratana

Mothodist

Latter Day Saints (Mornons)

Ringatu

Presbyterian

Brothren

Jehovah's Witness

Seventh Day Adventist

Commonvealth Covenant Chureh

Hau Mau

Salvation Arny

Misstons

Iio Religion (so returned)

Al1 Other Donominations

object to steto 2

llot spacifled

$16.08 \quad 24.17$

$13.69 \quad .0 .04$

$7.65 \quad 7.43$

$7.17 \quad 0.36$

$3.66 \quad 0.00$

$2.23 \quad 23.61$

$0.58 \quad 1.06$

$0.35 \quad 0.17$

$0.34 \quad 0.33$

$0.22 \quad 0.02$

$0.16 \quad 0.00$

$0.10 \quad 0.69$

$0.07 \quad 0.02$

$0.48 \quad 0.59$

$1.20 \quad 7.15$

$12.42 \quad 7.68$

$1.33 \quad 0.71$

Totals: $\quad 100.00 \quad 100.00$

Notes: (1) Source: Census (1956): Vol. VIII, p.16.

(2) In the Hev Zealand census the question on

'roliglous profession' (in the sonse of 'profossing to belong to...') is not compulsory. Thls category includes those who rofuse to state their roligious denominations. 
Non-Vaoris, Crude and Infant Death Rates, and Numbers of Deaths from cortain. Infectious Disoases, $1872-1921^{2}$.

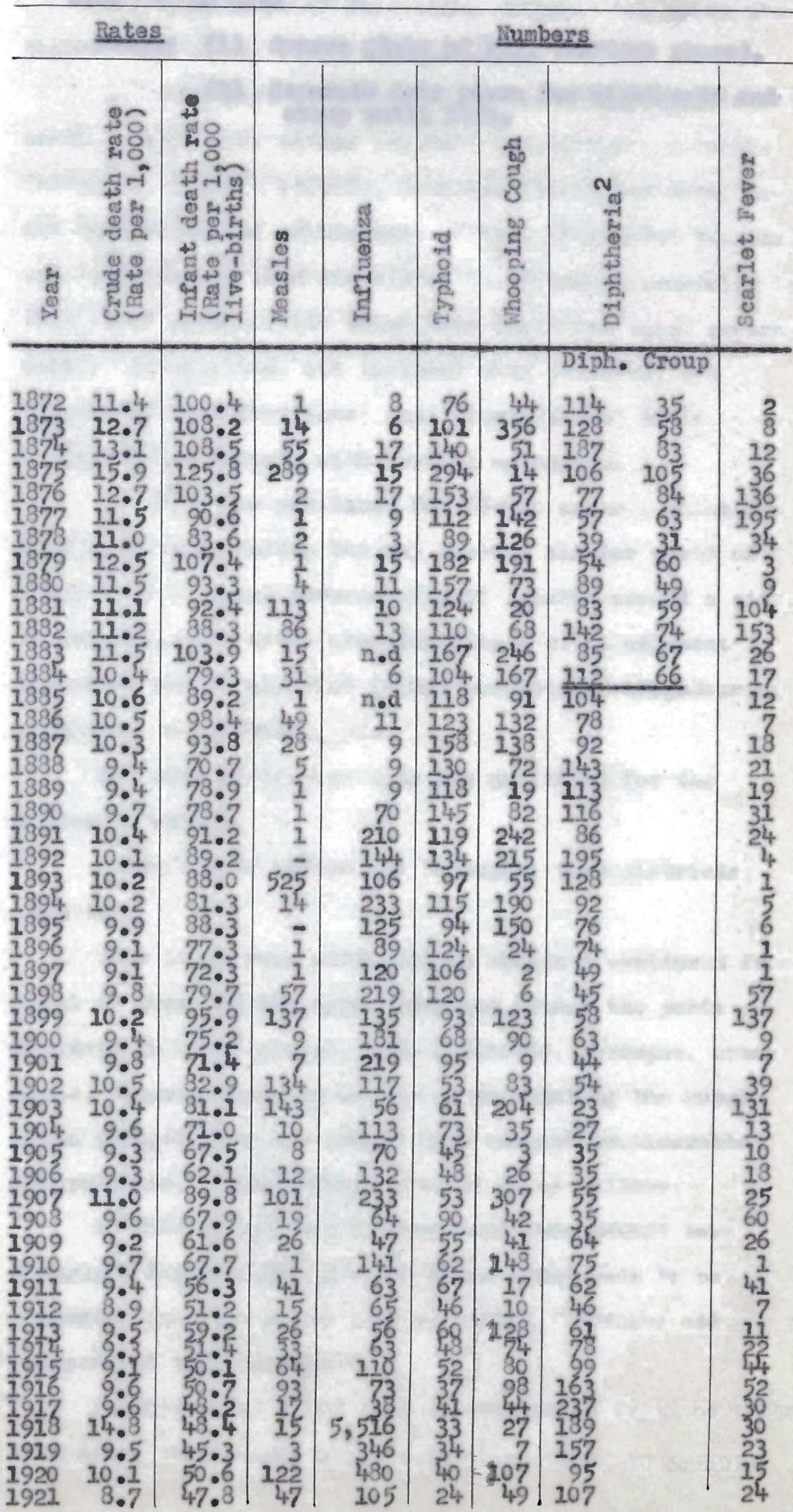




\section{Appendix B(1) Cont.2}

n.d. = no date

Notes: (1) Source Stats of N.2. (various years).

(2) Separate data given for diphtheria and eroup unt11 1884.

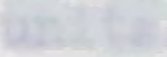

Crovanation

waronghe

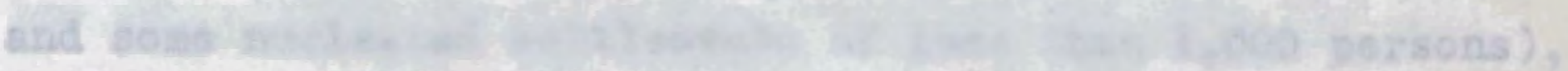

and timan ano

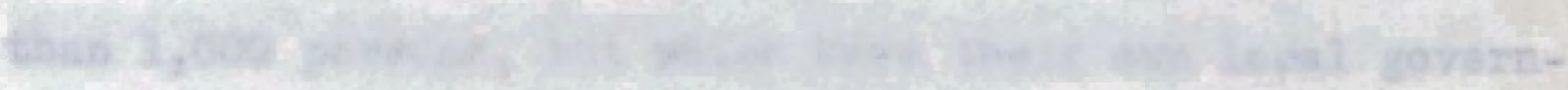

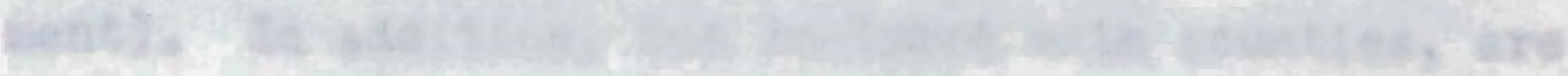

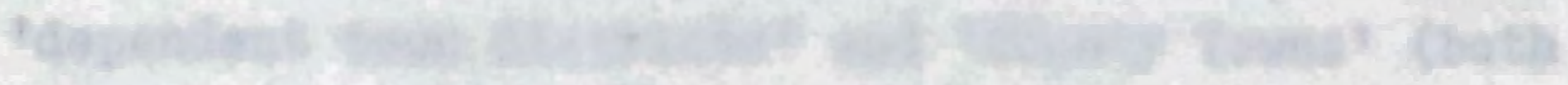

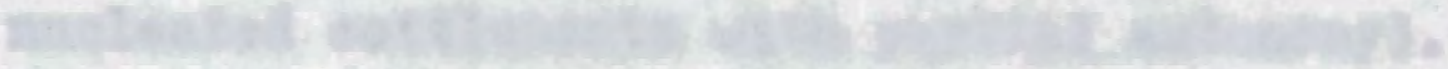

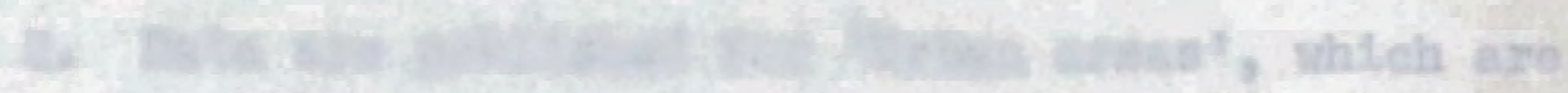

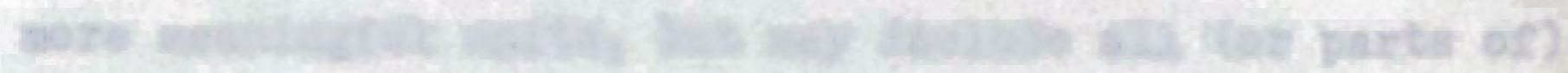

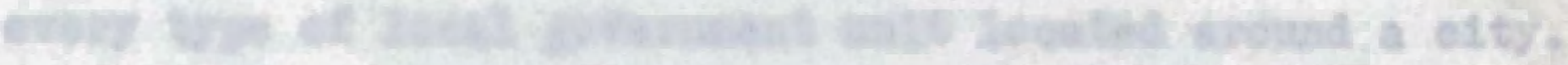

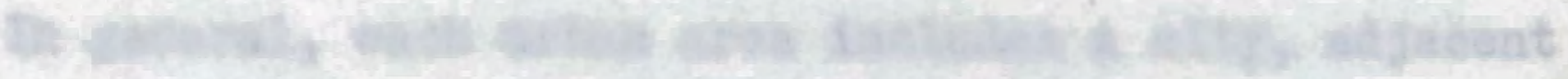

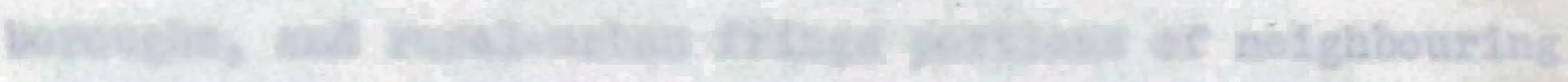

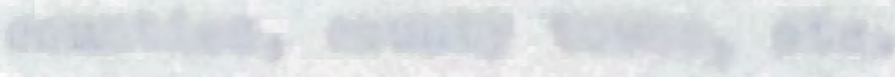

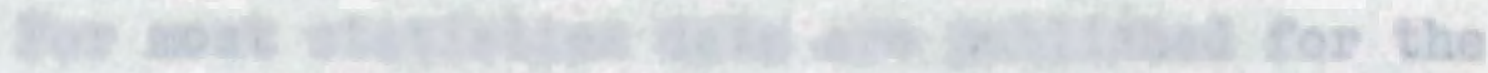

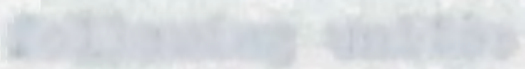

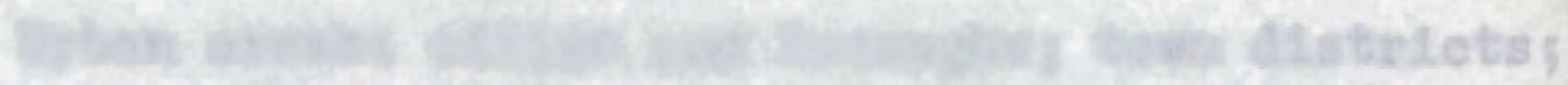

countiess

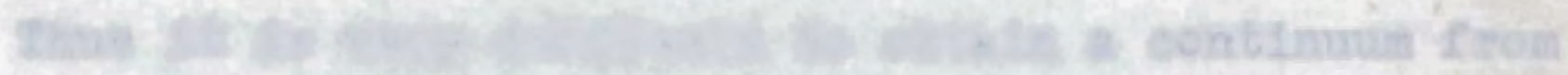

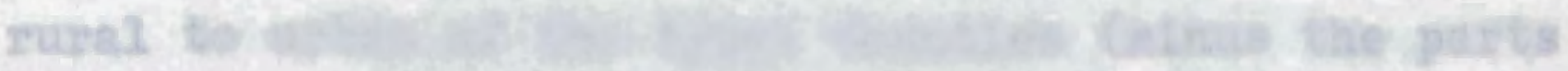

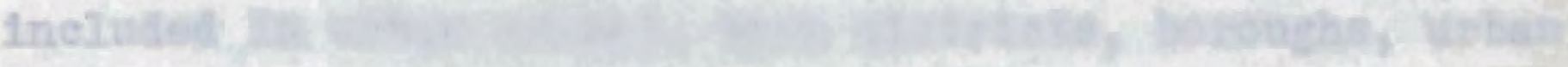

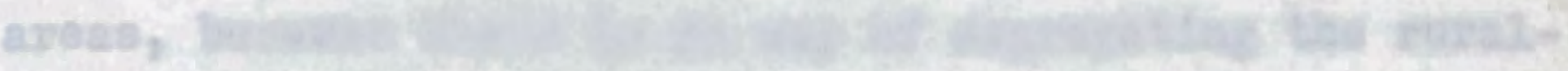

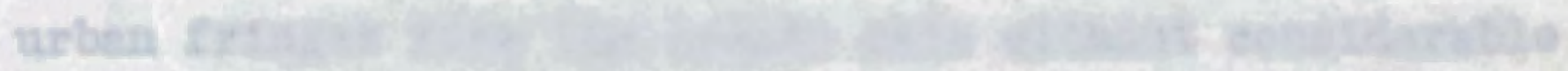

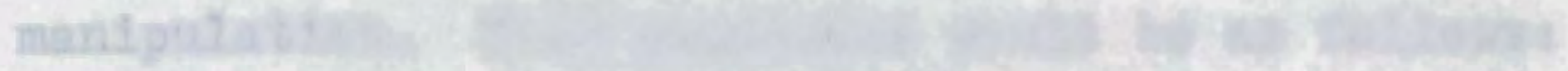

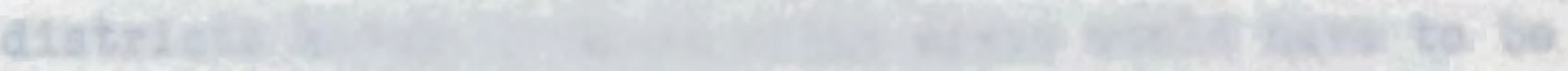

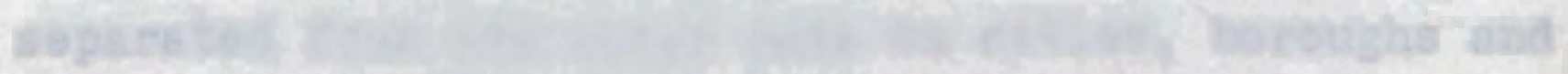
Indeganitar

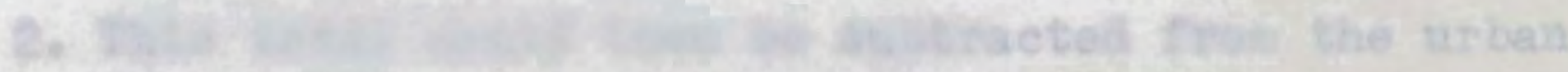


Note on the Areal Breakdown of New Zealand Census Statistics.

The Department of Statistics attempts two tasks when census results are published:

1. Data must be provided for local body administrative units. These are: Cities $(20,000+$ population $)$, boroughs (normally, 1,000 - 19,999), counties (including rural areas and some nucleated settlements of less than 1,000 persons), and 'independent town districts' (settlements generally less than 1,000 persons, but which have their own local government). In addition, but included with counties, are 'dependent town districts' and 'County Towns' (both nucleated settlements with partial autonomy).

2. Data are published for 'Urban areas', which are more meaningful units, but may include all (or parts of) every type of local government unit located around a city. In general, each urban area includes a city, adjacent boroughs, and rural-urban fringe portions of neighbouring counties, county towns, etc.

For most statistics data are published for the following units:

Urban areas; cities and boroughs; town districts; counties.

Thus it is very difficult to obtain a continuum from rural to urban of the type: Counties (minus the parts included in urban areas), town districts, boroughs, urban areas, because there is no way of segregating the ruralurban fringes from the county data without considerable manipulation. This procedure would be as follows:

1. Data on cities, boroughs and independent town districts known to be in urban areas would have to be separated from the other data on cities, boroughs and independent town districts.

2. This total could then be subtracted from the urban area data, the residue being data on portions of counties 
included in urban areas.

3. This residue could then be subtracted from the data on counties.

Instead of following this procedure, the date have been divided into two categories: 'Urban areas' and 'remainder of New Zealand'. Thus, the category 'remainder of New Zealand' includes all boroughs, counties, parts of counties, etc. outside the urban areas. Sometimes, however, the administrative units have been divided into two categorles: (1) Counties, and (2) Boroughs, cities, and independent town districts. Consequently, two types of overlapping rural-urban breakdowns have been used. 


\section{APPENDIX C}

Counties Included in Rural Regions, 1956

County boundary and name changes occurred at various times, and thus the area of these regions changed. However, in general, the area of the regions noted below did not alter greatly in the period 1926-61.

A further qualification is that the age data for six counties, having a total population of 176 Maoris, were not published separately as there were less than 50 Maoris present at the time of the census. This does not apply to the data on the total Maori population.

The criteria by which counties were grouped together to form regions were:

(a) Geographical contiguity;

(b) Some very general tribal association or interrelationship. Thus, Waikato region is mainly inhabited by Waikato and Ngati Maniapoto tribes which are closely related. Again, W. Bay of Plenty is mainly the domain of the tribes of the Arawa canoe - Arawa, around Rotorua, Ngati Tuwharetoa, around Taupo, and their kinsmen around Maketu;

(c) Some similarity in socio-economic conditions. Thus, East Coast is primarily a sheep-farming region, South Auckland intensive farming, etc.

(d) Sufficient numbers to allow reasonable conclusions to be drawn within the framework of the above mentioned criteria, which aim to provide some degree of homogeneity.

It must be noted that the only data available are for counties (see Appendix B), which are not homogeneous units. However, each of these regions displays certain trends corresponding to the criteria outlined earlier. 
Region

N.North Auckland:

S. North Auckland:

S. Auckland:

Waikato:

N.King Country:

W. Bay of Plenty:

E. Bay of Plenty:

East Coast:

Wairoa - Poverty Bar:

Hawkes Bay - Wairarapa: Hawkes Bay, Waipawa, Patangata,

Taranaki:

Wanganui:

Manàwatu-Horowhenua:

South Island Rural: Waipukurau, Dannevirke, Woodville, Pahiatua, Akitio, Eketahuna, Mauriceville, Castlepoint, Masterton, Wairarapa South, Featherston.

\section{Counties}

Mangonui, Whangaroa, Hokianga, Bay of Islands. Whangarei, Hobson, Otamatea, Rodney. Waitemata, Gt. Barrier Is. Manukau, Franklin, Coromandel, Thames. Hauraki Plains, Ohinemuri, Piako, Matamata. Waikato, Waipa, Raglan. Otorohanga, Waitomo, Taumaranui. Tauranga, Rotorua, Taupo. Whakatane, Opotiki. Matakaoa, Waiapu, Jawa, Waikohu. Cook, Wairoa. Clifton, Taranak1, Inglewood, Stratford, Egmont, Eltham, Ohura, Waimate West, Hawera, Patea. Kaitieke, Wanganul, Waimarino, Waitotara, Rangitikei. Hutt, Makara, Oroua, Manawatu, Kairanga, Horowhenua, Kiwitea, Pohangina.

All South Island counties. 


\section{APPENDIX D}

Highest Annual Rates of Increase in the Period 1953-56

These figures refer to all populations with growth rates estimated, or known to be in excess of $3.0 \%$. The data on a number of these populations are recognised to be markedly deficient, while in some cases gains may have occurred from migration, as surely must have been the case for the Bahamas (8.1), Israel (3.5) and Singapore (4.0). However, no attempt has been made here to be selective, merely to show populations with growth rates which are comparable to those of the Maoris.

AFRICA

Cape Verde Is. (3.3); Mauritius (3.3); Portuguese Guinea (3.4)

AMERICA

British Honduras (3.1); Costa Rica (3.9); Dominican Rep. (3.4); EI Salvador (3.4); Guadeloupe (3.1); Guatemala (3.1); Honduras (3.0); Nicaragua (3.4); Surinam (3.3); Trinidad \& Tobago (3.1); Venezuela (3.1).

ASIA

Brune 1 (5.9); Laos (3.2); Malaya (3.1); Syria (3.8); Taiwan $(3.8)$.

EUROPE

Albania (3.0)

OCEANIA

Aust. New Guinea, Trust Territory (3.7); Fiji (3.4); French Oceania (4.4); Hawail (3.7); Papua (4.4); U.S. Trust Territory of the Pacific (4.0); Western Samoa $(3.0)$.

Source: Demoge Year Book (1957): Table I. 


\section{BIBLIOGRAPHY}

\section{Sections of the Bibllography}

PART I : New Zealand (Material relating to N.Z.)

(1) Published N.Z. Official (including those

publications with the author's name stated, but published under the auspices of a Govt. Dept.)

(2) Published Non-N.Z. Official Books \& Articles

(3) Unpublished (including Govt., theses, and other)

(4) Newspapers

PART II: General (includes U.N. publications, articles, etc.)

Abbreviations: See Preface.

PART I: New Zealand

(1) Published N.Z. Official (AIl published in Wellington. A number are serial publications.)

Appendices to the Journals of the House of Representatives

Booth, J.M. \& Hunn, J.K. (1962): Integration of Maori \& Pakeha, Special Studies by Dept. of Maori Affairs.

Dept. of Health ${ }^{1}$, Med. Stats.

Dept. of Statistics, Census.

Monthly Abstract of Statistics.

Pop. Mig. \& Bldg. Stats.

Stats, of N.Z.

(1961): Statistical Publications, $1840-1960$.

Vit. Stats.

Foster, F.H. (1962): Maori Patients in Mental Hospitals, N.Z. Dept. of Health, Special Report no.8.

Hunn, J.K. (1961): Report on Dept. of Maori Affairs.

N.Z. Govt. (1938): Social Security (pamphlet published at the time of the introduction of Social security).

\section{N.Z. Official Year Book.}

Rose, R.J. (in Press): Infant \& Foetal Loss in N.Z., Dept. of Health, Special Report.

(1960): Maori-European Standards of Health, Dept. of Health, Special Report no. 1.

Turbott, H.B. (1935): Tuberculosis in the Maori: East Coast of N.Z.

1. This and other Govt. Depts. \& their publications have changed their names during the period. The most recent name 
Woods, Noel S. (1960): 'Immigration \& the Labour Force', Industrial Development Conference, Background Paper 26, June.

(2) Published Non-Official Books and Articles

Adams, C.E. (1898a.): 'A Comparison of the General Mortality in N.Z., in Vict. \& N.S.W., \& in England', T.N.Z.I., vol. 31. pp.661-66.

(1898b.): 'A Comparison of N.Z. Mortality Trends During the Periods 1874-81 \& 1881-91', T.N.Z.I., vol. 31. pp.659-60.

Akel, R.N. et. al. (1963): 'Anaemia in Maori \& Buropean Infants on Admission to Hospital: A Co-operative Survey from Six N.Z. Hospitals', N.Z.M.J., vol. 62, no.365, Jan. pp.29-33.

Alpers, Hon. O.T.J. (1931): 'The Young Haorl Party', in Jackson, P.M. (ed.): Vaor1 \& Educat1on, Wellington.

Anon. (1850): 'Polynesians \& N.Z.', Edinburgh Review, vol. XCI, $\mathrm{pp} .443-71$.

Ausubel, David P. (1960): The Fern \& the Tiki, Sydney. (1961): Maori Youth, Victoria Univ. Publications in Psychology, No.14., Wellington.

Bannister, Saxe (1838): 'Account of the...Pop. of N.Z.', J.S.S.I., vol. I. pp.362-76.

Beaglehole, Ernest \& Beaglehole, Pearl (1946): Some Modern Maoris, Christchurch.

Bell, Thos. W. (1890): 'Medical Notes on N.Z.', N.Z.M.J.2 vol. III (original series). pp.67-83 \& pp.129-145.

Belshaw, H.B. (1940): 'Maor1 Economic Circumstances', in Sutherland, I.I.G. (ed): The Maori People Today, Christchurch. pp.182-228.

Bennett, George (c.1832): 'The Practice of Medicine and Surgery etc. Among the New Zealanders \& Natives of some of the Polynesian Islands', Iondon Medical Gazette (Later Med. Times \& Gaz.) vol. 9, pp.434-38[1], \& $628-33[2]$.

Best, Elsdon (1924): The Maori, vol. V., Memolrs of the Polynesian Society, Wellington.

Biggs, Bruce (1960): Maori Marriage: An Essay in Reconstruction, Wellington.

Booth, John M. (1959): 'A Modern Maori Community', in Freeman, J.D. \& Geddes, W.R. (eds): Anthropologr in the South Seas, New Plymouth, N.Z. pp.235-45.

\& Hunn (1962): See Section (1) of Bibllography.

Borrie, W.D. (1959): 'The Maori Pop.: A Microcosm of the New World', in Freeman, J.D. \& Geddes, W.R. (eds): Anthropology in the South Seas, New PIymouth, N.Z. pp.247-62.

(196I): 'Some Economic \& Social Implications of Maor1 Pop. Growth in N.Z.', J.P.S., vol. 70, no.4. Dec. pp.410-18. 
Buller, Rev. James (1878): Forty Years in N.Z.: Including... an Account of Maoridom..., London.

Buller, Walter (1884): 'The Decrease of the Maor1 Race', N.Z. Journ. of Science, vol. 2, pp.55-59.

Colenso, William (1868): 'On the Maori Races [sic] of N.Z.', T.N.Z.I., vol.I. pp.339-424.

Condliffe, J.B. (1930): N.Z. in the Making, London.

Congalton, A.A. (1953): 'Social Grading of Occupations in N.Z.', Brit. Journ. of Sociol., vol.IV, pp.45-59.

Cowan, James (1956): The N.Z. Wars, Wellington. 2 vols.

Cruise, Maj. Richard A. (192I): Journal of a Ten Months Visit of H.M.S. Dromedary to Northern N.Z. in 1820, Auckland. (Published under the title: N.Z. One Hundred Years Ago)

Cumberland, K.B. (1949): 'Aotearoa Maor1: N.Z. about 1780', Geog. Rev., vol.39, no.3, July, pp.401-24.

Deem, Helen (1947): 'Infant Loss in N.Z.', N.Z.M.J., vol.xIVI, Dec. pp. $475-85$.

Dieffenbach, Ernest (1841): N.Z, and its Native Pop, London. (1843): Travels in N.Z., London, 2 vols.

Duff, Roger (1940): 'South Island Maoris', in Sutherland, I.I.G. (ed): The Maori People Today, Welíington. pp.374-98.

Earle, Augustus (1909): A Narrative of Nine Months Residence in N.Z., 1827, Wellington. Edson, N.I. (1943): 'Tuberculosis in the Maori Race', N.Z.M.J.,
vol. XIII, June. pp.102-10.

(1942): 'Tuberculosis Mortality in N.Z. with Special Reference to Women of the Child-bearing Ages', N.Z.M.J., vol. XII, April. pp.5I-62.

Erihana, E.P. (1931): 'The Maori \& Hygiene', in Jackson, P.M. (ed): Maori \& Education, Wellington. pp.208-308.

Fenton, F.D. (1859): Observations on the State of the Aboriginal Maori Inhabitants of N.Z., Auckland.

(1860): 'Observations on the State of the Aboriginal Maori Inhabitants of N.Z.', J.S.S.I., vol. XXIII, pp.508-4I. (It is difficult to determine whether this is Fenton's own abstract of Fenton (1859) (see above), or someone else's)

Firth, Raymond (1959): Economics of the N.Z. Maori, Wellington.

Forster, John Reinold (1778): Observations Made During a Voyage Round the World, 1272-25, Iondon.

Foster (1962): See Section (1) of bibliography.

Fox, William (1851): The Six Colonies of N.Z., London.

Frazer, Roger M. (1958): 'Maori Land \& Pop. in the Far North', N.Z.G., vol. 14, no.l, April. pp.19-3l.

Gardiner, Cedric E. (1959): 'Maori Infant Mortality', N.Z.M.J., vol. LVIII, no.325, June. pp.321-40. 
Geddes, W.R. (1961): 'Maor1 and Aborigine: A Comparison of Attitudes \& Policies', Aust. Journ, of Science, vol.24, no.5, Nov. pp.217-25.

Glass, D.V. (1945): 'The Maori Pop.', Eugenics Reve, vol. XXXVII, April 1945 - Jan. 1946. pp.67-70.

Goldle, W.H. (1904): 'Maori Medical Lore', T.N.Z.I., vol.37. pp.1-130.

Golson, J. (1961): 'The Polynesian Settlement of N.Z.', in Sinclair, Kelth (ed): Distance Looks Our Way: The Effects of Remoteness on N.2., [Auckland]. pp.15-26.

Gorst, J.E. (1959 Reprint): The Maori King, Hamilton, N.Z. (1908): N.Z. Revisited, London.

Hamlin, J. (1915): 'Estimate of the Maori Pop. of the North Island, circa $1840^{\prime}$, J.P.S., vol.24, June. pp.72-74. (This is an edited reprint of an article by Rev. Hamlin probably pblished in the Tasmanian Journal of Science, c.1842).

Hargreaves, R.P. (1960): 'Maori Agric. After the Wars $1871-86 i$, J.P.S., vol. 69 , no.4, Dec. pp.354-67.

Harre, John (1963): 'The Background to Race Relations in N.Z.', Race, vol. V, no.I, July. pp.3-25.

(1962): 'A Case of Racial Discrimination in N.Z.', J.P.S., vol.70, no.2, June. pp. 257-60.

Hawthorn, H.B. (1944): 'The Maoris: A Study in Acculturation', Amer. Anthropologist, New Series, vol. 46, no.2. (Memoir).

Hill, H. (1896): 'The Maoris Today \& Tomorrow, Part I', T.N.Z.I., vol. 29. pp.150-63.

(1902): 'The Maoris Today... Part II', T.N.Z.I., vol. 35, pp.169-86.

Hilliard, Noel (1960): Maor1 Girl, London (A Novel).

Hunn (1961): See section (1) of Bibliography.

Jackson, Keith (1962): 'The Electoral Framework', in Chapman, R.M. et ale: N.Z. Politics in Action: The 1960 General Election, London.

Jacoby, E.G. (1958): 'A Fertility Analysis of N.Z. [nonMaorif Marriage Cohorts', Pop. Stud., vol.12, no.l, July. pp.18-39.

(1961): 'Some Demographic Observations on First Order Births in the Light of the Cohort Approach', Econ. Record, vol.37, Sept. pp.308-19.

Lennane, G.A.Q. et al. (1960): 'Gout in the Maori', Annals of the Rheumatic Diseases, vol.19, no.2. pp.120-25.

Lessof, Elizabeth (1949): 'Mortality in N.Z. \& Fngland \& Wales', Pop. stud, vol.3, June. pp.76-99.

Lewthwaite, G.R. (1950): 'The Pop. of Aotearoa: Its Number and Distribution', N.Z.G., vol.VI, no.I, April. pp.35-52.

McCreary, J.R. (1961): 'Ruatahuna - A Maori Community', N.Z. Geog. Soc. Record, no.32, July - Dec. pp.3-4. 
McDonald, R.A. (1929): Te Hekenga: Reminiscences of Early Horowhenua, Palmerston Nth., N.Z.

MacMillan, David (1946): By-Ways of History \& Medicine, Christchurch.

McNab, R. (ed) (1908): Historical Records of N.Z., Volf, Wellington. 2 vols.

(1914): Historical Records of N.Z., Vol.II, Wellington. 2 vols.

Ma1r, G. (1923): Reminiscences \& Maori Stories, Auckland.

Maning, F.E. (1884): old N.Z, London.

Martin, S.M.D. (1845): N.Z., London.

Maxwell, Gabrielle M. (1961): 'Some Demographic Indications of Pop. Movement Among N.Z. Maoris', J.P.S., vol.70, no.1, Mar. pp.31-42.

Melvin, L.W. (1962): 'Te Waharoa of the Ngatihaua', J.P.S., vol. 71, no.4, Dec. pp.361-78.

Metge, A. Joan (1960): 'The Human Factor', in Ward, R. Gerard \& Ward, Marion W. (eds): N.Z.'s Industrial Potential, Auckland. pp.156-76.

(1952): 'The Maori Pop. of Northern N.Z.', N.Z.G., vol. VIII, Oct. pp.104-24.

(1960): 'The Maor1 Settlement of N.Z.', in McLintock, A.H. (ed): Descriptive Atlas of N.Z., Wellington. pp.1-3.

(1957): 'Marriage in Modern Maori Society', Man, vol.LVII, Article 212, Nov. pp.166-70.

(1964): A New Maori Migration, London.

Miller, John (1958): Early Victorian N.Z.: A Study in Racial Tension \& Social Attitudes, 1839-52, London.

Morris, Albert (1955): 'Some Aspects of Delinquency \& Crime in N.Z.', J.P.S., vol.64, no.1, Mar. pp.5-15.

Neave, M. et al. (1963): 'The Prevalence of Anaemia in Two Maori Communities', N.Z.M.J., vol.62, no.365, Jan. pp.20-28.

N.Z. Coy. (1844): Twelfth Report of the Directors, 26th April, London. (Published in P.P. (1844):XIII.)

Newman, A.K. (1882): 'Is N.Z. A Healthy Country?', T.N.Z.I., vol.15. pp.493-510.

(1881): 'A Study of the Causes Leading to the Extinction of the Maori', T.N.Z.I., vol.14. pp.459-77.

Ngata, A.T. (1899): 'Maori Pop. Statistics', Report of the Third Annual Conference. Te Aute College Students Assoc, Southbridge, N.Z. pp.8-14.

Nicholas, J.L. (1817): Narrative of a Voyage to N.Z.
Performed in the Years 1814 \& 1815, London. 2 vols. 
Oliver, W.H. (1960): The Story of N.Z, Iondon.

Parliamentary Papers (British, relating to N.Z.)

Pearson, Bill (1962): 'N.Z. Since the War: 7. The Maor1 People' Landfall: A N.Z. Quarterly, vol.16, no.2. pp. $148-80$.

Pift-Rivers, George Henry Lane-Fox (1927): The Clash of Cultures \& the Contact of Races, London.

Polack, J.S. (1840): Manners \& Customs of the New Zealanders, London. 2 vols.

Pomare, M. (1908): 'The Maor1', Aust. Med, Con., 8th Session, Oct. vol.II. pp.118-28.

Pool, Ian (1961): 'Maoris in Auckland: A Pop. Study', J.P.S., vol. 70, no.1, Mar. pp.43-66.

(1963): 'When is a Maori a 'Maori'? A Viewpoint on the Definitions of the Word Maori', J.P.S., vol.72, no.3, Sept. pp.206-10.

Price, A.Grenfell (1957): 'Moving Frontiers \& Changing Landscapes in the Pacific and its Continents', A.N.Z.A.A.S., 23rd Session, Jan., Dunedin. pp.96-103.

Melbourne.

(1949): White Settlers \& Native Peoples,

Prior, Ian (1962): 'A Health Survey of a Rural Maori Community, with particular Emphasis on Cardiovascular, Nutritional \& Metabolic Findings', N.Z.M.J., vol.61, no.359, July. pp.1-16 (reprint).

Ritchie, James E. (1963): The Making of a Maor1, Wellington.

Ritchie, Jane (1957): Childhood in Rakau: The First Years of Iffe, Vict. Univ. Dept. of Psychology, Publication no.10, Wellington.

(1961): 'Together or Apart: A Note on Urban Maori Residential Preferences', J.P.S., vol.70, no.2, June. pp.194-99.

Robb, Douglas (1960): 'Maori \& European: Differential Incidence of Surgical \& Other Diseases', N.Z.M.J., vol.59, no.334. pp.271-79.

Roberts, S.H. (1927): Pop. Problems of the Pacific, London.

Rose (In Press): See Section (1) of Bibliography. (1961): See Section (1) of Bibllography.

Scrimgeour, C.G. et al. (1942) The Shadow Over N.Z.: Venereal Disease, Welington.

Sinclair, Keith (1959): A History of NeZ, London. Wellington.

(1957): The Origins of the Maori Wars,

Skinner, H.D. (1933): 'The Maoris', in Cambridge History of the British Empire, vol. VII, Part II, Cambridge. pp.8-21. 
Smith, S. Percy (1910): The Moori Wars of the Nineteenth Century, Christchurch.

Sorrenson, M.P.K. (1956): 'Land Purchase Methods \& Their Effect on the Maori Pop. 1865-1901', J.P.S., vol.65, no.3, Sept. pp.183-99.

Sutherland, I.L.G. (1940): 'The Maori Situation', in Sutherland, I.I.G. (ed): The Maori People Today, Christchurch.

Sutherland, Ian (1949): Still-births, Their Epidemiology \& Social Significance, Iondon.

[Swainson, William] (1840) in Supplementary Information Relative to N.Z., Comprising Dispatches \& Journals of the Company's officers of the First Expedition, London. (Reviewed in N.Z. Journal (1841): vol.1)

(1859): N.Z. \& Its Colonization, London.

Taylor, Rev. Richard (1855): Te Ika a Maui, London.

Te Rangihiroa (Buck, P.H.) (1952): The Coming of the Maori, Wellington.

(1940): 'Foreword' to Sutherland, I.L.G. (ed): The Maori People Today, Christchurch.

(1924): 'The Passing of the Maori', T.N.Z.I., vol.55. pp.362-75.

Te Rangihiroa (Buck, P.H.) (1914): 'The Smallpox Epidemic Amongst the Maoris in the Northern District', Aust.Med.Con., 10th Session, Feb. pp.212-24.

Terry, Charles (1842): N.Z..... Its Advantages \& Prospects..., Iondon.

Thompson, R.H.T. (1961): 'Community Conflict in N.Z.: A Case Study', Race, Vol.3, no.1, Nov. pp.28-38.

(1953): 'Maori Affairs \& the N.Z. Press, Part I', J.P.S., vol.62, no.4, Dec. pp.366-83. (1954a): 'Maori Affairs... Part II', J.P.S., vol.63, no.1, Mar. pp.1-16.

$(1954 \mathrm{~b})$ : 'Maori Affairs... Part III', J.P.S., vol.63, no.3, pp.216-27.

(1955) 'Maori Affairs... Part IV', J.P.S., vol.64, no.1, Mar. pp.22-34.

(1963) Race Relations in N.Z., National Councll of Churches, Christchurch.

Thomson, A.S. (1854): 'Contribution to the Natural History of the N.Z. Race of Men...', J.S.S.I., vol. XVII, $\mathrm{pp} \cdot 27-33$.

(1854) (quoted 1854-55 in the footnotes): The customs \& Diseases of the New Zealanders', British \& Foreign Medico-Chirurgical Review, no. XXVI, April. pp.489-502. 
Thomson, A.S. (1854) (quoted 1854-55 in footnotes): The Customs...', Brit, \& For, Medico-Chir, Rer, no. XXVIII, oct. pp.461-70.

(1855) (quoted 1854-55 in footnotes): The Customs...', Brit. \& For. Medico-Chir, Rere, no. $\mathrm{XXX}$, April. pp.520-29.

(1859): The Story of N.Z, London. 2 vols.

Tregear, Edward (1904): The Maor1 Race, Wanganui, N.Z.

Turbott, H.B. (1940): 'Health \& Social Welfare', in Sutherland, I.L.G. (ed): The Maori People Today, Wellington.

(1935): See Section (1) of Bibliography.

Vaughan, G.M. \& Thompson, R.H.T. (196I): 'N.Z. Children's Attitudes towards Maoris', Journ, of Abnormal \&

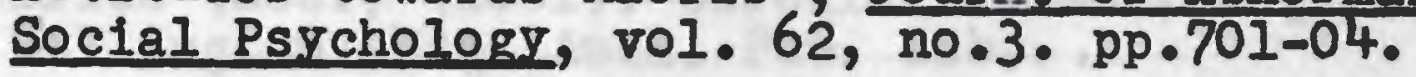

Vayda, A.P. (1960): Maori Warfare, Wellington.

Walsh, Archdeacon (1907): 'The Passing of the Maori: An Inquiry into the Principal Causes of the Decay of the Race', T.N.Z.I., vol.40. pp.154-75.

Williams, Rev. H.W. (1935): 'The Reaction of the Maoris to the Impact of Civilization', J.P.S., vol. 44 . pp.216-43.

Wilkes, C. (1845): Narrative of the U.S. Exploring Expedition During the years 1838 to 1842 , Philadelphia.

Wilson, D. Macdonald (1934): 'History of N.Z.: Notes of Medical Interest', N.Z.M.J., vol.33. pp.102-10 \& 205-16.

Wohlers, Rev. J.F.H. (1881): 'On the Conversion \& Civilization of the Maoris of the South Island of N.Z.', T.N.Z.I., vol.14, pp.123-34.

Woodbury, Robert M. (1926): 'Infant Mortality in N.Z.', in Infant Mortality \& Its Causes, Baltimore.

Woods (1960): See Section (1) of Bibliography.

Wright, Harrison M. (1959): N.Z. 1769-1840: Early Years of Contact, Cambridge, Mass.

(3) Unpublished

Bennett, H.R. \& Broughton, L.W. (1942): Some Psychological Aspects of the Mori, Dunedin. Mss. Pub. Lib.

'Data Papers \& Conference Agenda', Tairawhiti Regional Maori Leadership Conference, 19th - 22nd 0ct., 1962, Ruatoria. (Cyclostyled)

Durward, Elizabeth Wallace (1929): The Maori Pop, of Otage, Thesis $(0.0$.

Goldie, W.H. (1899): Polrnesian Medical Researches, M.D. Thesis (?), Edin. Mss. Auck. Pub. Lib. 
Grey N.Z. Mss 144, Alexander Turnbull Lib., Wellington.

Hohepa, P.W. (1961): Paerau: A Maori Community in Northland, Thesis (A.U.)

McCarthy, D.D. \& Marples, M.J. (1953): Report on a Short Medical Expedition to Northland...e, Medical School Lib., Dunedin (Cyclostyled).

Metge, A. Joan (1951): The Distribution \& Character of the Maori Pop. of the Auckland Province, Thesis (A.U.)

(n.d.): 'The Nature \& Functions of the Hui...', Maori Society Today, Lecture 5, Council of Adult Education, Auckland Univ. (Cyclostyled).

Moore, Rina (1960) Maori Health, 1960, Paper Presented at Conference of Maori Leaders, Marton, 12th Nov. (Cyclostyled).

Native Office (Sec.) (1881): Circular Letter, Aug. 27th. Wellington. Mss. Auck. Pub. Lib.

Pearce, Nancy G. (1952): The Size \& Location of the Maori Pop.e 1857-96, Thesis (V.U.)

Pitt-Rivers, G. [George Henry Lane-Fox] (Convenor) (1923): Report of the Research Committee on the Vital Statistics of Primitive Races, Wellington Meeting, A.N.Z.A.A.S., Typed Mss., Hocken Lib. Denedin.

Rangihau, J. (1958): Ohalsune Survey, Maori Affairs Depte

Report of Regional Maori Leadership Conference, 19th-22nd. Oct., 1962, Ruatoria (Cyclostyled).

Rutherford, D.W. (1940): The South Island Maori Pope, Thesis $\left(0 . U_{0}\right)$

Sorrenson, M.P.K. (1955): The Purchase of Maori Lands, Thesis (A.U.)

Vaughan, G.M. (1962): Ethnic Awareness \& Attitudes: A Developmental studp of Maori \& Pakeha Children in N.Z., Thesis (Ph.D) (V.U.)

(4) Newspapers

Southern Cross.

PART II: Generale

Anon. [Leading Article] (1960): 'Virus Infections During Pregnancy', Lancet, Vol.II, July-Dec. pp.800-0I.

Blake, Judith (1955): 'Family Instability \& Reproductive Behaviour in Jamaica', Current Research in Human Fertility, Milbank Memorial Fund, Annual Conference, New York. pp.24-41.

Bourgeois-Pichat, Jean (1952): 'An Analysis of Infant Mortality', Pop. Bulle, no.2, Oct. pp.1-14.

\& Pan, Chia-lin (1955): 'Trends \& Determinants of Mortality in Under-developed Areas', Trends \& Differentials in Mortality, Annual Conference, Milbank Memorial Fund, New York. pp.11-25. 
Burnet, Frank Macfarlane (1953): Natural History of Infectious Diseases, Cambridge.

Caldwell, J.C. (1963): 'Fertility Decline \& Female Chances of Marriage in Malaya', Pop. Stud., vol. XVII, no.I, July. pp.20-32.

Clavel (1884): 'La Depopulation aux Iles Marquises', Bulletins de la societe d'Anthropologie de Paris, 16th Juno. pp.490-500.

Coale, Ansley J. (1956): 'The Effects of Changes in Mortality \& Fertility on Age-Composition', M.M.F.Q., vol. XXXIV, no.1. pp.79-114.

Creighton, Charles (1894): A History of Epidemies in Britain, Cambridge. 2 vols.

Dublin, Louis I. et al. (1949): Length of Life, New York.

Eaton, Joseph W. \& Mayer, Albert J. (1954): Man's Capacity to Reproduce: The Demography of a Unique Pope, Glencoe, III.

Ellis, R.W.B. (1960): Health in Childhood, London.

Freedman, R. et, al. (1963): 'Fertility Trends in Taiwan: Tradition \& Change', Pop. Stud, vol. XVI, no.3, Mar. pp.219-36.

Horvath, R. (1962): 'Quelques Donnees Inconnues Sur la Mortalite de la Peste de Debrecen/1739-40/et celle du Cholera en Hongrie/1831, 1872-73/, Bull de L'Inst. Int. de Statse. vol. xxxix, No.4. pp.373-79.

Janer, Jose I. (1954): 'Medidas de Salud y Saveamiento como Factores Afectan las Tendencias de Mortalidad', Proc. World Pop. Conference, vol.1, 3lst Aust. loth Sept., Rome. pp.451-70.

Jupp, Kathleen M. (1956): Territory of W. Samoa: Report of the Pop. Census, Wellington, N.Z.

Lancaster, H.0. (1952a.): 'The Mortality in Aust. from Acute Infective Diseases', M.J.A., Feb. 9th. pp. $175-80$.

(1952b.): 'The Mortality in Aust. from Measles, Scarlatina \& Diphtheria', M.J.A., Aug. 23rd. pp.272-76.

(1950): 'Tuberculosis Mortality in Aust., 1908-45', M.J.A., May 20th. pp. 655-62.

(1963): 'Vital Statistics as Human Ecology', Aust. Journ. of science, vol. 25, no.1l, May. pp. 445-53.

Laurent, L.J. Maurice (195I): 'Whooping Cough', in Banks, H Stanley (ed): Modern Practice in Infectious Fevers, London. 2 vols. pp.250-85.

Leborgne, $\operatorname{Dr}$ (1872): 'Sur la Depopulation des Iles Gambier', Bulletins de la Societe d'Anthropologie de Paris, 18th July. pp.682-87.

Lessa, William A. \& Myers, George C. (1962): 'Pop. Dynamics of an Atoll Community', Pop.stud., vol.XV, no.3, Mar. pp.244-57. 
Lewthwaite, Gordon R. (1964): 'Man and Land in Early Tahiti', Pacific Viewpoint, vol.5, no.1, pp.11-34.

Logan, W.P.D. (1953): 'The Measurement of Infant Mortality', Pop. Bulle, no.3, oct. pp.30-55.

(1954): 'Social Class Variations in Mortality', Proce World Pop. Conference, vol.1, 3lst Aug.10th Sept., Rome. pp.185-213.

Lorimer, Frank (1954): Culture \& Human Fertility, U.N.E.S.C.O., Paris.

McArthur, Norma (1961): 'Pop. \& Social Change: Prospect for Polynesia', J.P.S., vol.70, no.4, Dec. pp.393-400.

McKeown, Thomas \& Record, R.G. (1962): 'Reasons for the Decline in Mortality in England \& Wales During the Nineteenth Century', Pop. Stud, vol. XVI, no.2 Nov. pp.94-122.

Ministry of Health (U.K.) (1920): 'Report on the Pandemic of Influenza, 1918-19', Reports on Public Health \& Medical Subjects, no.4, London.

Montagu, M.F. Ashley (1946): Adolescent Sterility, Springfield, Ill.

Myers, Robert J. (1951): 'Errors \& Bias in the Reporting of Ages in Census Data', in Jaffe, A.J.: Handbook of Statistical Methods for Demographers, Washington. pp.115-25.

Paul, Hugh (1952): The Control of Communicable Diseases, Iondon.

Rivers, W.H.R. (1922): 'The Psychological Factor', in Rivers, W.H.R. (ed): Essays on the Depopulation of Melanesia, Cambridge. pp.84-113.

Robinson, Warren C. (1963): 'Urbanisation \& Fertility: The Non-Western Experience', M.M.F.Q., vol.XII, no.3, July. pp.29I-308.

Sheps, Mindel C. (1964): 'Pregnancy Wastage as a Factor in the Analysis of Fertility Data', Demography, Vol.1, no.1, pp.111-18.

Smith, T.E. (1960): 'The Cocos-Keeling Islands: A Demographic Laboratory', Pop. Stud., vol. XIV, no.2, Nov. pp. 94-130.

Springett, $\nabla . H$. (1952): 'An Interpretation of Statistical Trends in Tuberculosis', Lancet, Mar. 15th. pp. 521-25.

(1952): 'An Interpretation of Statistical Trends in Tuberculosis', Lancet, Mar. 22nd. pp.575-79.

Srb, Vladimir (1962): 'Pop. Policy in Czechoslovakia', Pop. Stude, vol. XVI, no.2, Nov. pp.147-59.

Stolnitz, George J. (1955.a.): 'A Century of International Mortality Trends: Part I', Pop.stud., vol. IX, no.1, July. pp.24-55. 
Stolnitz, George J. (1956): 'A Century... Part II', Pop, Stud., vol. X, no.1, July. pp.17-42.

(1955b): 'Comparison between Some Recent Mortality Trends in Underdeveloped Countries \& Historic Trends in the West', Trends \& Differentials in Mortality, Annual Conference, Milbank Memorlal Fund, New York. pp.26-34.

Stuart-Harris, C.H. (1963): 'The Epidemiology of Chronic Bronchitis', N.Z.M.J., vol.62, no.365, Jan. pp.35-39.

(1953): Influenza, London.

Thompson, Theophilus (1852): Annals of Influenza in Gt. Brit. from 1510 to 1837 , London.

Thompson, William A.R. (1961): Black's Medical Dictionary,
London.

United Nations (1952): 'Accuracy Tests for Census AgeDistributions in Five-Year \& Ten-Year Age-Groups', Pop. Bulle, Oct. pp.59-79.

United Nations, Demog. Year Book, New York (Serial Publication)

(1953): The Determinants \& Consequences of Population Trends, Pop. Studies no.17, New York.

(1954): Foetal. Infant \& Early Childhood Mortality, Pop. Studies, no.13, New York. 2 vols. (1956): Methods for Pop. Projections by Sex \& Age, Pop. Studies, no.25. New York.

(1958): Multi-lingual Demographic Dictionary: English Edition, Pop. Studies, no.29, New York.

(1962): 'The Situation \& Recent Trends of Mortality in the World', Pop. Bulle, no.6, pp.3-145.

Van Rooyen, C.E. \& Rhodes, A.J. (1948): Virus Diseases of Man, New York.

Willie, Charles V. \& Rothney, William B. (1962): 'Racial, Ethnic \& Income Factors in the Epidemiology of Neonatal Mortality', Amer. Sociol. Rev., vol.27, no.4, Aug. pp.522-26.

Wilson, G.S. \& Miles, A.A. (1961): Topley \& Wilson's Principles of Bacteriology \& Immunity, London. 2 vols.

Winslow, Charles-Edward Amory (1944): The Conquest of Epidemic Diseases, Princeton. 